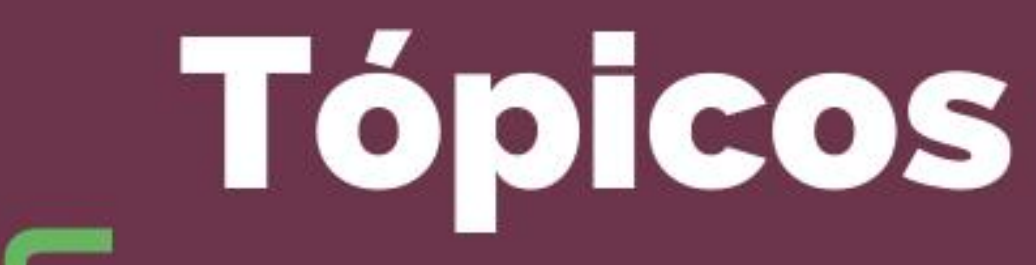

탐

$$
\text { Administraçāo }
$$
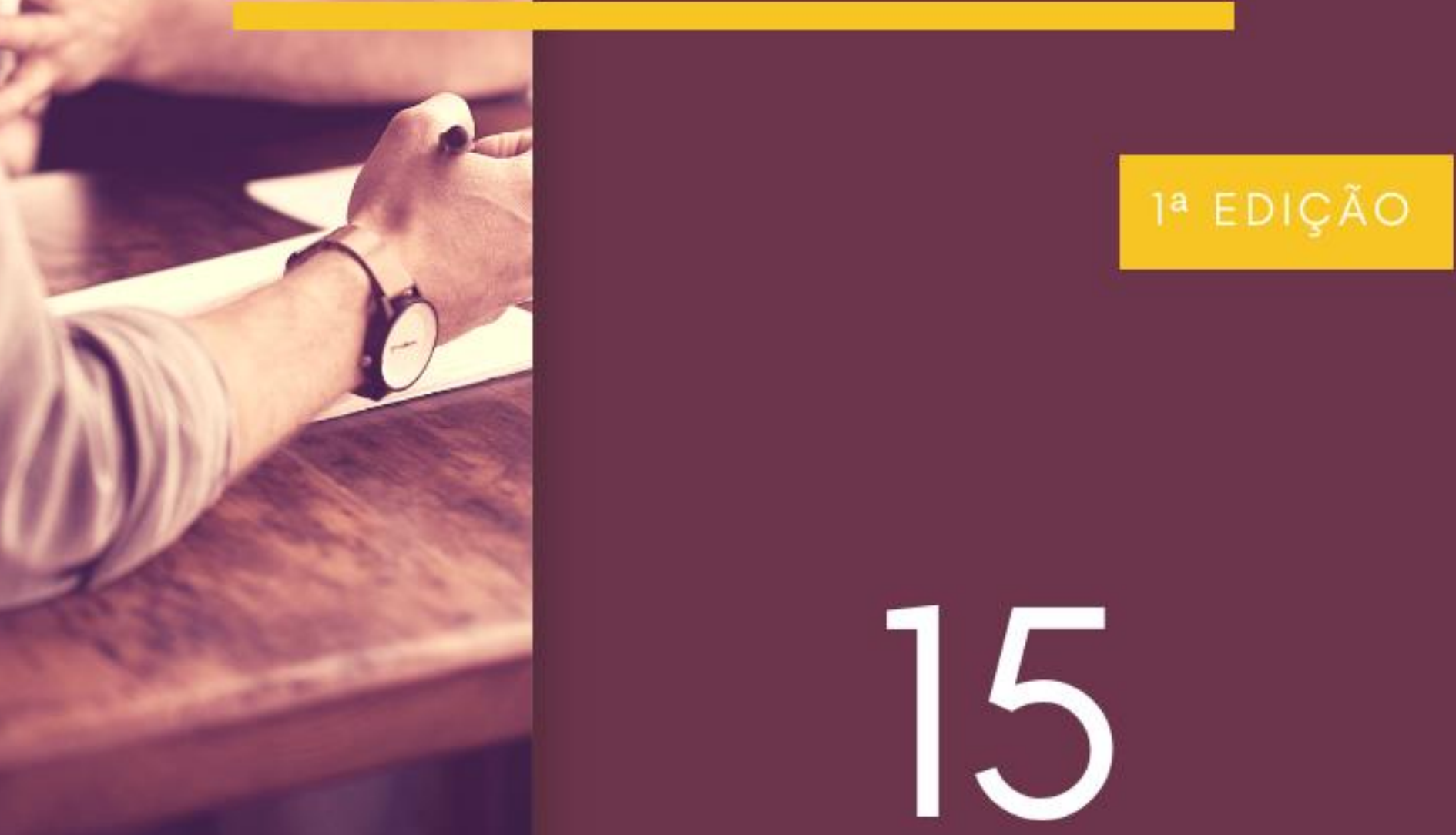

Editora Poisson

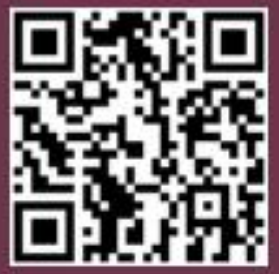


Editora Poisson

\title{
Tópicos em Administração Volume 15
}

\author{
1a Edição
}

Belo Horizonte

Poisson

2018 
Editor Chefe: Dr. Darly Fernando Andrade

Conselho Editorial

Dr. Antônio Artur de Souza - Universidade Federal de Minas Gerais

Dr. José Eduardo Ferreira Lopes - Universidade Federal de Uberlândia

Dr. Otaviano Francisco Neves - Pontifícia Universidade Católica de Minas Gerais

Dr. Luiz Cláudio de Lima - Universidade FUMEC

Dr. Nelson Ferreira Filho - Faculdades Kennedy

Ms. Valdiney Alves de Oliveira - Universidade Federal de Uberlândia

Dados Internacionais de Catalogação na Publicação (CIP) T674

Tópicos em Administração - Volume 15/

Organização Editora Poisson - Belo

Horizonte - MG: Poisson, 2018

$221 p$

Formato: PDF

ISBN : 978-85-7042-024-4

DOI : $10.5935 / 978-85-7042-024-4$

Modo de acesso: World Wide Web

Inclui bibliografia

1. Administração 2. Gestão. I. Título

CDD -658

O conteúdo dos artigos e seus dados em sua forma, correção e confiabilidade são de responsabilidade exclusiva dos seus respectivos autores.

www.poisson.com.br

contato@poisson.com.br 


\section{Sumário}

Capítulo 1: Ecologia industrial: estudo de multi casos em um arranjo produtivo da industrial têxtil.

Karina Maria Costa Bardi, Ana Paula Duarte

Capítulo 2: Lidera - um sistema voluntário de apoio ao desenvolvimento e avaliação da sustentabilidade de materiais e produtos da construção civil

Joao Luiz Rissardi, Vanessa do Rocio Nahhas Scandelari, Manuel Duarte Pinheiro

Capítulo 3: Aproveitamento de água de chuva em estabelecimento de pequeno porte situado em Niterói/RJ

Marcela Dutra Tenorio Campany

Capítulo 4: Gestão estratégica de sustentabilidade: conectando lucro com impactos socioambientais

Maria Christina Barbosa da Costa, Sonia Lopesda Silva

Capítulo 5: Despertar do consumo consciente na cidade do Rio de Janeiro .55

Yuri Pinheiro Santos, Regina Rianelli de Brito, Jesus Domech Moré, Jose Carlos Beker, Jorge Julio Landeiro de Vaz

Capítulo 6: Estratégias para a aplicação dos conceitos de sustentabilidade em universidades: o caso do telhado verde na Puc-SP

Tatiane de Oliveira Amancio, Igor Polezi Munhoz, Alessandra Cristina Santos Akkari,Neusa Maria Bastos Fernandes dos Santos

Capítulo 7: A revitalização urbana e a infraestrutura de transportes como formas de legado dos jogos Rio 2016

Ingrid Johnson, Paulo Roberto Rocha Aguiar

Capítulo 8: Produção e exportação de frutas tropicais: uma análise da região nordeste do Brasil

Richeliel Albert Rodrigues Silva, Genival Jardel Trajano Teixeira, Lúcia de Fátima Lúcio Gomes da Costa, Mônica Almeida Gavilan, Rodrigo Mackssuel Silva de Melo 


\section{Sumárīio}

Capítulo 9: Novas estratégias tecnológicas no setor de energia: um estudo patentário

Igor Polezi Munhoz, Alessandra Cristina Santos Akkari, Neusa Maria Bastos Fernandes dos Santos

Capítulo 10: Estratégias de carreira e identificação de valores em discentes do curso de engenharia

Neusa Maria Bastos Fernandes dos Santos, Igor Polezi Munhoz, Alessandra Cristina Santos Akkari,

Capítulo 11: Estratégias de transferência de Conhecimento em projetos: um estudo com gerentes de projetos

Neusa Maria Bastos Fernandes dos Santos, Nelson José Rosamilha

Capítulo 12: Utilização da técnica de modelagem Data Flow Diagramming (DFD) para melhoria no processo de aprovação de projetos estratégicos de grande porte.. 129

Roquemar de Lima Baldam, João Caldeira Lélis, Lourenço Costa, Thalmo de Paiva Coelho Junior, Leandro Colombi Resendo

Capítulo 13: As ferramentas de compartilhamento de conhecimento nos jogos rio 2016: um estudo de caso.

Raphael Alves Soares, Déborah Daniel Ferreira Coelho Soares, Leonardo Mangia Rodrigues

Capítulo 14: O processo de inovação disruptiva através do empreendedorismo 149 Alyne Madeira Kautnick

Capítulo 15: Contribuições da criatividade para a retenção de clientes em clínicas médicas 160

Joiceli Rossoni Lapolli, Paulo César Lapolli, Leandro Maciel Nascimento, Inara Antunes Vieira Willerding, Édis Mafra Lapolli

Capítulo 16: Governança de tecnologia da informação na Universidade Federal do Recôncavo da Bahia: um estudo da implementação dos mecanismos baseado habilitadores do Cobit 5 


\section{Sumárīo}

Capítulo 17: Classificação e análise das práticas de gestão de projetos sob a luz da gestão do conhecimento: estudo de caso de um projeto de implantação de ERP 182

Bernardo Almeida Mudjalieb, Jéssica Galdino de Freitas, Denise Terezinha Lisboa Bassani

Capítulo 18: Implementando a inovação - estratégias de integração dos processos e serviços de um atacado/ distribuidora 198

Darciane Alves Justino

Autores: 


\section{Gapítulo 1}

\section{ECOLOGIA INDUSTRIAL: ESTUDO DE MULTI CASOS EM UM ARRANJO PRODUTIVO DA INDUSTRIAL TEXXTIL}

\section{Karina Maria Costa Bardi}

\section{Ana Paula Duarte}

Resumo: O presente artigo tem por objetivo abordar a importância da sustentabilidade para o setor confeccionista, bem como, relatar os problemas causados pela geração de resíduos sólidos nas indústrias de confecções. Por meio de pesquisa de campo com 10 (dez) indústrias do ramo de confecções, utilizando aplicação de questionário, com perguntas semiestruturadas, aplicada por meio de entrevistas, no mês de julho de 2016, pode-se ter uma visão geral sobre a quantidade aproximada de resíduos gerados e o destino dado a eles. Conclui-se que o acelerado crescimento do setor de empresas no ramo têxtil na região produz um volume de resíduos considerável e especificamente, uma grande quantidade de cones sem perspectiva de reutilização. Percebe-se que há pouco interesse dos proprietários para a prática de produção mais limpa. Nesse sentido, o estudo propõe a implantação da ferramenta de produção mais limpa nas empresas no formato Cluster e a aplicação do Ecodsign para a criação de artesanatos com os cones, aumentando, assim, o ciclo de vida de alguns resíduos e de geração de renda, e, ainda assegurar melhor qualidade de vida e respeito ao ambiente. Estar localizado em um modelo cluster traz vantagens para as empresa, criando diferenciais de competitividade e possibilitando vantagens econômicas e ambientais.

Palavras-chave: ecologia industrial, resíduos têxteis e produção mais limpa. 


\section{INTRODUÇÃO}

O crescimento populacional e consequentemente, o alto ritmo de consumo que o mundo está vivendo, preocupa, pois, provoca consequências ao meio ambiente desde o esgotamento de seus recursos, até pela quantidade de resíduos gerados pelos processos de produção e consumo. Os problemas ambientais estão se agravando e várias atitudes e políticas foram desenvolvidas para resolver alguns problemas e mitigar outros. Nesse sentido surgiu a ideia de controlar atos e criar soluções possíveis para reduzir esse problema que se encontra um tanto avançado. Criou-se o conceito de sustentabilidade, que se resume basicamente em ações que não comprometam o futuro das novas gerações e visa usar recursos naturais de forma apropriada e otimizada sem agredir o meio ambiente.

Segundo Barata (2007) a constatação de que a capacidade assimilativa dos ecossistemas e da regeneração dos recursos naturais ocorria a taxas incompatíveis com 0 desgaste imposto à natureza, inspirou o surgimento de um novo conceito de desenvolvimento sustentável.

Ao considerar sustentabilidade e responsabilidade social percebe-se que houve um alerta na área de resíduos sólidos descartados. Sabe-se que uma das maiores preocupações com relação ao volume de resíduos gerados e descartados se dá pelo fato de que os aterros sanitários se esgotam mais rapidamente, além de aumentar consideravelmente a risco de contaminação ambiental. Atualmente políticas públicas federais procuram com uma vasta legislação ambiental e com políticas para educação ambiental conscientizar e minimizar o problema. Surgem, então, iniciativas de vários seguimentos da sociedade, a científica, empresariais, ONGs, entre outros, a ideia de dar vida útil a tais resíduos, reciclando ou até se tornando insumos para outros produtos serem fabricados. Dentro das empresas essa iniciativa foi encarada como um desafio, pelo fato de não poderem simplesmente pensar somente no lucro bruto, e ter que ser considerado o fator ambiental. Passaram a repensar seus processos já realizados, evitando desperdício de matéria prima e, buscando novas formas e melhorias nos processos produtivos, afim de gerar diminuição de custos e futuros lucros.
Um ramo de indústria que gera resíduos em grande volume é o seguimento têxtil. Quanto maior a produção destas empresas, maior a quantidade de resíduos têxteis gerada e, consequentemente, maior é o impacto ambiental causado por esses dejetos. Tais resíduos industriais, assim como resíduos oriundos de outras fontes, devem ser dispostos e tratados conforme legislação vigente, a fim de minimizar impactos ambientais (LIMA JUNIOR et all, 2010)

No Brasil, existem algumas cidades que que se tornaram famosas por concentrar várias empresas do mesmo segmento, os chamados arranjos produtivos locais (APLs).

O conceito de Arranjos Produtivos Locais (APLs) é definido por Cassiolato e Lastres (2003) como:

\begin{abstract}
Aglomerações territoriais de agentes econômicos, políticos e sociais - com foco em um conjunto específico de atividades econômicas - que apresentam vínculos mesmo que incipientes. Geralmente envolvem a participação e a interação de empresas - que podem ser desde produtoras de bens e serviços finais até fornecedoras de insumos e equipamentos, prestadoras de consultoria e serviços, comercializadoras, clientes, entre outros e suas variadas formas de representação e associação. Incluem também diversas outras instituições públicas e privadas voltadas para: formação e capacitação de recursos humanos (como escolas técnicas e universidades); pesquisa, desenvolvimento e engenharia; política, promoção e financiamento.
\end{abstract}

Existe uma dificuldade em mapear os APLs, pois não existe um padrão único de surgimento e desenvolvimento desses arranjos. Alguns estudos buscam identificar o tipo de relacionamento entre as empresas e instituições no seu entorno. A identificação da concentração de empresas em determinada localidade, e especialmente de um setor particular, seria uma alternativa para mapear o arranjo de APLs. (MASCENA et all, 2012).

Diferenças conceituais importantes são notadas entre o modelo de APLs e o de Cluster. Segundo Zaccarelli et al. (2008), cluster de negócios é defendido como entidades supra-empresariais que têm como característica principal a proximidade 
geográfica e compatibilidade de produtos. Sua performance competitiva de clusters de negócios, segundo Zaccarelli et al. (2008, p.73), é fundamentada da seguinte maneira: reduzida;

Concentração geográfica em área 2. Abrangência de negócios viáveis e relevantes;

3. Especialização das empresas;

4. Equilíbrio com ausência de posições privilegiadas;

5. Complementaridade por utilização de subprodutos;

6. Cooperação entre empresas;

7. Substituição seletiva de negócios;

8. Uniformidade de nível tecnológico;

9. Cultura da comunidade adaptada ao cluster,

10. Caráter evolucionário por introdução de (novas) tecnologias;

11. Estratégia de resultado orientada para o cluster.

Assim, os clusters se diferenciam dos APLs pela maior intensidade de vínculos entre as empresas e pela participação das empresas privadas que estão aglomeradas para 0 desenvolvimento do agrupamento, com menor envolvimento do governo. Para Kwasnicka (2006), a diferença principal entre APLs e cluster é que o primeiro engloba somente atividades produtivas, enquanto o segundo envolve outros tipos de atividades, como comércio e serviços, projetos e práticas ambientais.

Outro ponto a ser considerado é que no segmento do vestuário, um modelo de produção emergiu no final dos anos 1990, chamado de fast fashion ou moda rápida, identificado como um fenômeno de mudança cada vez mais acelerada na moda, e que foi sendo adotado por muitas marcas e redes de varejo. Apesar de ter intensificado os lucros das empresas, o fast fashion também trouxe consequências negativas, pois houve um significativo aumento no volume de roupas produzidas com características como: baixo preço e durabilidade reduzida, aumentando, assim, a demanda por materiais, água, energia, produtos químicos e consequentemente gerando um maior volume de resíduos (UNIETHOS, 2013).

A cidade de Juruaia é um exemplo de Arranjo Produtivo Local (APL). É uma das cidades responsáveis pela produção de lingeries, localizada no sudoeste de Minas Gerais. Possui pouco mais de nove mil habitantes e é considerada a capital mineira do lingerie e também o terceiro maior polo fabricante do país. O surgimento empresarial na cidade foi a vinte quatro anos com a abertura de duas empresas no ramo têxtil, que serviram de modelo para as futuras empresas. Atualmente, a economia da cidade gira em torno do lingerie contando com aproximadamente 200 confecções que geram milhares de empregos diretos $e$ indiretos. Juntamente com alto crescimento e desenvolvimento econômico da cidade, surgiram, também, o problema do descarte irregular e inadequado dos resíduos gerados. $\mathrm{Na}$ falta de infraestrutura adequada e de políticas ambientais, os resíduos são recolhidos pela coleta de lixo sem nenhuma separação para possível reciclagem, causando sérios problemas.

Além dos resíduos têxteis gerados pelo polo, outros resíduos são gerados e descartados no aterro, é o caso dos cones de polipropileno, que armazenam matéria prima, geralmente linhas de costura, utilizados na produção de lingerie. O polipropileno é um polímero termoplástico de pouca resistência, facilmente reciclável, e atualmente encontra-se em uma grande variedade de produtos.

Assim objetivo deste estudo foi abordar a importância da sustentabilidade para o setor confeccionista, bem como, relatar os problemas causados pela geração de resíduos sólidos nas confecções.

Se considerarmos a quantidade de empresas no ramo têxtil do município descrito e a perspectiva de crescimento do setor, o volume de cones de costura utilizados diariamente e por consequência a quantidade deste resíduo gerado diariamente, a pesquisa justifica-se por:

Se tratar de um tema de relevância ambiental e de sustentabilidade;

De oportunidade de estudar maneiras para implantar um sistema de PML;

Aumentar o ciclo de vida do objeto
estudado pela reciclagem e consequentemente a mitigação de problemas ambientais.

Além disso, a pesquisa justifica-se, pois, conforme objetivos citados é necessária uma medida corretiva, com uma certa urgência, devido ao fato de que o aterro da cidade, onde realiza-se o estudo de caso, encontra-se em fase de esgotamento. É preciso que as empresas do polo industrial se conscientizem 
sobre o papel que devem ter para se tornarem sustentáveis e ambientalmente corretas.

Diante do despreparo do município em relação a esse crescimento excessivo e procurando propor soluções, ao final do estudo, propõem-se a diminuição de considerável volume de resíduo polimérico, apenas com a utilização dos cones de forma simples, sem a necessidade de cada empresa realizar grandes mudanças em suas linhas de produção. A proposta prevê penas a separação do material para coleta seletiva para a produção de matérias dentro da proposta do ecodesign. Após a coleta os carretéis serão entregues a artesãs que darão novas formas a esse produto.

\section{REVISÃO BIBLIOGRÁFICA}

A sustentabilidade é o novo paradigma da sociedade contemporânea e contempla o planejamento estratégico de muitas organizações empresariais como forte diferencial competitivo em diversas áreas, atribuindo valor para toda a cadeia produtiva.

Para Kazazian (2005), o desenvolvimento sustentável concilia crescimento econômico com preservação do meio ambiente e traz melhorias nas condições sociais.

Para Manzini e Vezzoli (2005), uma proposta sustentável é compreendida como:

1. Centrada em recursos renováveis;

2. Por otimizar o emprego dos recursos não-renováveis, tais como ar, água, energia e território;

3. Não acumular resíduos que o ecossistema não seja capaz de reabsorver;

4. Fazer com que indivíduos e comunidades ricas permaneçam nos limites de seu espaço ambiental e que indivíduos e comunidades das sociedades pobres possam efetivamente gozar do espaço ambiental ao qual potencialmente têm direito.

Outro conceito importante é o de ecologia industrial que considera que todos os resíduos e materiais devam ser reciclados dentro de um sistema.

A ecologia industrial é a base para o desenvolvimento de sistemas industriais sustentáveis. Uma aplicação prática da ecologia industrial é a formação de arranjos industriais, onde uma unidade consome os resíduos de outra, gerando produtos e resíduos que serão utilizados alhures como matérias-primas.

A reciclagem de produtos poliméricos preocupa a sociedade mundial, quando se considera o crescimento populacional e consequentemente $\mathrm{o}$ crescente volume utilizado e todas as implicações ambientais inerentes ao descarte pós consumo.

Os hábitos do consumo da sociedade moderna, a definição de regulamentação específicas, a implantação de centros de pesquisa e o desenvolvimento de tecnologias, constituem pauta de ações específicas de setores governamentais e empresariais na reciclagem de embalagem. Segundo Adhikari e Maiti (2000), muitos fatores têm sido a causa desse problema, dentre eles a dificuldade da decomposição dos materiais poliméricos.

As formas de reaproveitamento são, evidentemente, pontos de fundamental importância para a minimização do problema, pois além de contribuírem para o prolongamento do ciclo de vida do produto, tendem a destinar somente o "resíduo último" ao aterro, o que já vem ocorrendo em países como Estados Unidos da América, Canadá e alguns país da Europa, (LIMA e ROMEIRO FILHO, 2001).

A reciclagem é o processo de reaproveitamento de resíduos, por meio de sua reinserção no ciclo produtivo, trazendo inúmeros benefícios para a sociedade e para o meio-ambiente. Existem vários tipos de processo de reciclagem, variando de acordo com o material a ser reaproveitado, dentre os quais se destacam: o de papel, de metal, de plástico, de vidro e de lixo orgânico.

Segundo Broega et all (2011), a prática de reciclagem dos resíduos têxteis, é quase inexistente no Brasil, devido à complexidade do processo, que é descrito por de acordo com o seguinte fluxo:

1. Coleta e transporte;

2. Identificação e separação;

3. Desmontagem e esmagamento;

4. Lavagem ou limpeza;

5. Pré-produção de matérias-primas secundárias.

Por isto, a reciclagem desses resíduos, tornase um dos principais desafios do setor têxtilconfeccionista, sendo que o descarte destes resíduos representa desperdício de recursos como água e energia, além do impacto ambiental negativo com o descarte 
inadequado (DE OLIVEIRA GUIMARÃES et al 2014).

Além dos processos industriais de reciclagem, muitos materiais podem ser reaproveitados no ambiente doméstico, geralmente, de forma simples e criativa pela técnica do artesanato. Os principais materiais utilizados na reciclagem artesanal são o papel, o plástico e o alumínio, por apresentarem métodos de remoção de impurezas, moldagem e recondicionamento menos complexos, sem a necessidade de processos industriais. Quando se fala em reciclagem como fonte de renda, em geral, associa-se à ideia dos catadores de materiais recicláveis. Contudo, a reciclagem artesanal traz além dos benefícios ao meio-ambiente, a possibilidade de uma fonte de renda alternativa através da venda de produtos feitos com materiais reaproveitados como por exemplo no ecodesign.

$\mathrm{O}$ termo ecodesign surge nos anos $90 \mathrm{com} 0$ intuito de reutilizar materiais antes já descartados, projetando novos produtos com pouco impacto no meio ambiente. Sem desconsiderar a qualidade e a durabilidade.

No ecodesign, o projetista seleciona e articula soluções de projeto segundo seu impacto no ciclo de vida do produto: fabricação, embalagem, uso, troca de peças e fim de vida (BORCHARDT, et all 2008).

O ecodesign é uma importante ferramenta que pode ser utilizada para implementar a prática da ecologia industrial. Ele é considerado uma ferramenta, que atua no processo de comunicação entre o designer, o empresário e a sustentabilidade ambiental. O ecodesign trata não somente da questão ecológica, mas também da parte social e ética, criando produtos que sejam ecologicamente corretos em todas as etapas do seu ciclo de vida, que engloba desde a extração da matéria prima até a sua disposição final, passando pela gestão dos seus resíduos, ou seja, quase sempre, envolvendo as fases de Projeto, Fabricação, Transporte, Instalação, Utilização e Gestão de resíduos.

Figura 1- Apresenta a Teia das Estratégias do ecodesign.

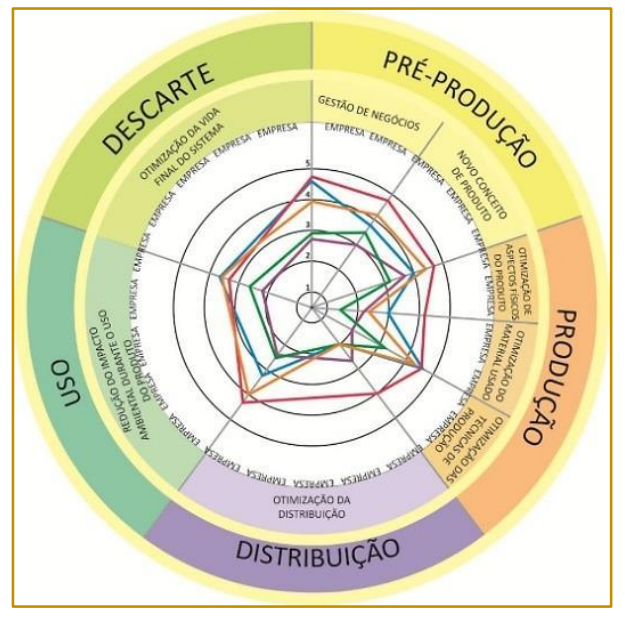

Fonte: VALPORTO, et all (2016)

\section{METOLOGIA}

A metodologia utilizada para o presente estudo foi primeiramente pesquisa bibliográfica e posteriormente estudo de múltiplos casos. A pesquisa bibliográfica abordou assuntos relacionados a geração de resíduos pelo setor industrial, à gestão ambiental, ecologia industrial, produção mais limpa, ecodesign e gestão de resíduos do processo de confecção de lingeries, especificamente em Juruaia. O estudo de caso foi conduzido por meio de entrevistas semiestruturadas, observação in loco (visitas às empresas). As entrevistas foram realizadas com proprietários ou funcionários das empresas visitadas com o auxílio de um roteiro previamente elaborado. A Figura 2 apresenta o questionário. 
Figura 2 - Quadro do questionário aplicado

Questionário utilizado na abordagem as empresas

1 - Qual é o número de funcionários de sua empresa?

( ) até vinte funcionários ( ) até 50 funcionários ( ) mais de 50 funcionários

2 - Qual é o seu conhecimento sobre práticas ambientais?

3 - Já viu algum artesanato feito com cone de costura? ( ) sim ( ) não

4 - Qual Seu interesse em participar de uma cooperativa de reciclagem desses cones?

( ) nenhuma ( ) pouca ( ) alguma ( ) muita

5 - A empresa conhece o processo de produção mais limpa? ( ) sim ( ) não

6 - Que tipo de resíduos são gerados em sua empresa?

( ) tecidos ( ) cone de costura, ( ) plásticos, ( ) pilhas e baterias ( ) papéis

7 - Quais são os principais produtos? Qual o ramo de atividade?

( ) Lingerie

( ) Moda praia

( ) Fittness

( ) Cuecas

( ) Meias

( ) Pijamas

( ) Moda sensual

( ) embalagens

8 - Existe alguma atividade que gere resíduos tóxicos? ( ) sim ( ) não

Se sim, quais?

( ) Silkscreen

( )Tingimentos

( ) Soldas metálicas

( ) Soldas plásticas

( ) Alvejamentos,

( ) Outros processos e tratamentos químicos

9 - A empresa já recebeu algum tipo de fiscalização ou comunicação oficial da prefeitura municipal, ou órgãos governamentais de fiscalização ambiental ou órgão competente?

( ) $\operatorname{sim}($ ) não

10 - Existe pesagem dos resíduos?

( ) $\operatorname{sim}($ ) não

11 - Se houver, são pesados separadamente por tipo de resíduos?

( ) $\operatorname{sim}($ ) não

12 - Quantos quilos ou quantidade de cones são gerados por semana?

13 - Qual atividade da empresa que mais gera resíduo? ( ) Têxteis ( ) outros

14 - Os funcionários da empresa foram treinados e capacitados quanto a geração de resíduo e aos procedimentos de produção mais limpa? ( ) sim ( ) não

15 - A empresa separa os cones de costura dos resíduos têxteis no momento em que são gerados? ( ) $\operatorname{sim}($ ) não

16 - Em quantas categorias eles são separados?

17 - A empresa separa os outros resíduos, como por exemplo, copos descartáveis, papeis, embalagens, resíduos têxteis e resíduos do processo de costura?

( ) $\operatorname{sim}($ ) não

18 - Que tipo de embalagem a empresa utiliza para armazenar os resíduos gerados?

( ) tambores ( ) saco plástico ( ) outros

19 - A empresa possui espaço físico suficiente para armazenagem de resíduos? ( ) sim ( ) não

20 - Quem realiza o transporte dos resíduos da empresa até o órgão receptor?

( ) prefeitura ( ) recicladores

21 - Existe algum artesão que recolhe os cones de costura? ( ) sim ( ) não

22 - O receptor de resíduos é uma empresa ( ) formal ou ( ) informal?

23 - Qual finalidade é dada aos resíduos de cone de costura ? ( ) Aterro ( ) reciclagem

24 - Algum funcionário da empresa já realizou algum tipo de auditoria no órgão receptor ou o vistoriou? ( ) sim ou ( ) não

25 - A empresa possui :

( ) plano de gerenciamento de resíduos Sólidos (PGRS) ou ( ) um plano de gerenciamento integrado de Resíduos? Por quem foi elaborado?

Fonte: 0 autor 


\section{RESULTADOS E DISCUSSÕES}

A análise de resíduos foi feita a partir de questionários, previamente elaborado, respondidos por empresários e funcionários das empresas.

A quantidade de funcionários foi pesquisada com o intuito de poder dimensionar o tamanho da empresa. Para esse caso, observou-se que as empresas podem ser classificadas em sua maioria (80\%), em pequena e média empresa. Algumas empresas da amostra pesquisada ficaram classificadas como microempresas.
Ao quantificar e qualificar os resíduos notouse que 33\% dos mesmos é de tecido, 30\% cone de costura, $20 \%$ papeis e $17 \%$ plásticos. Os cones de costura representam um volume considerável dentro do total amostral de resíduos. Neste caso, 80 \% das empresas responderam gerar em média 250 cones por semana. Os princip'ais produtos fabricados no APL são lingerie (42\%), seguido de $13 \%$ de pijamas e cuecas, e $12 \%$ fitness e moda praia. A Figura $3 \mathrm{~A}, \mathrm{~B}, \mathrm{C}$ e D.

Figura 3- Quantificação de funcionários e resíduos, identificação de produtos e resíduos.
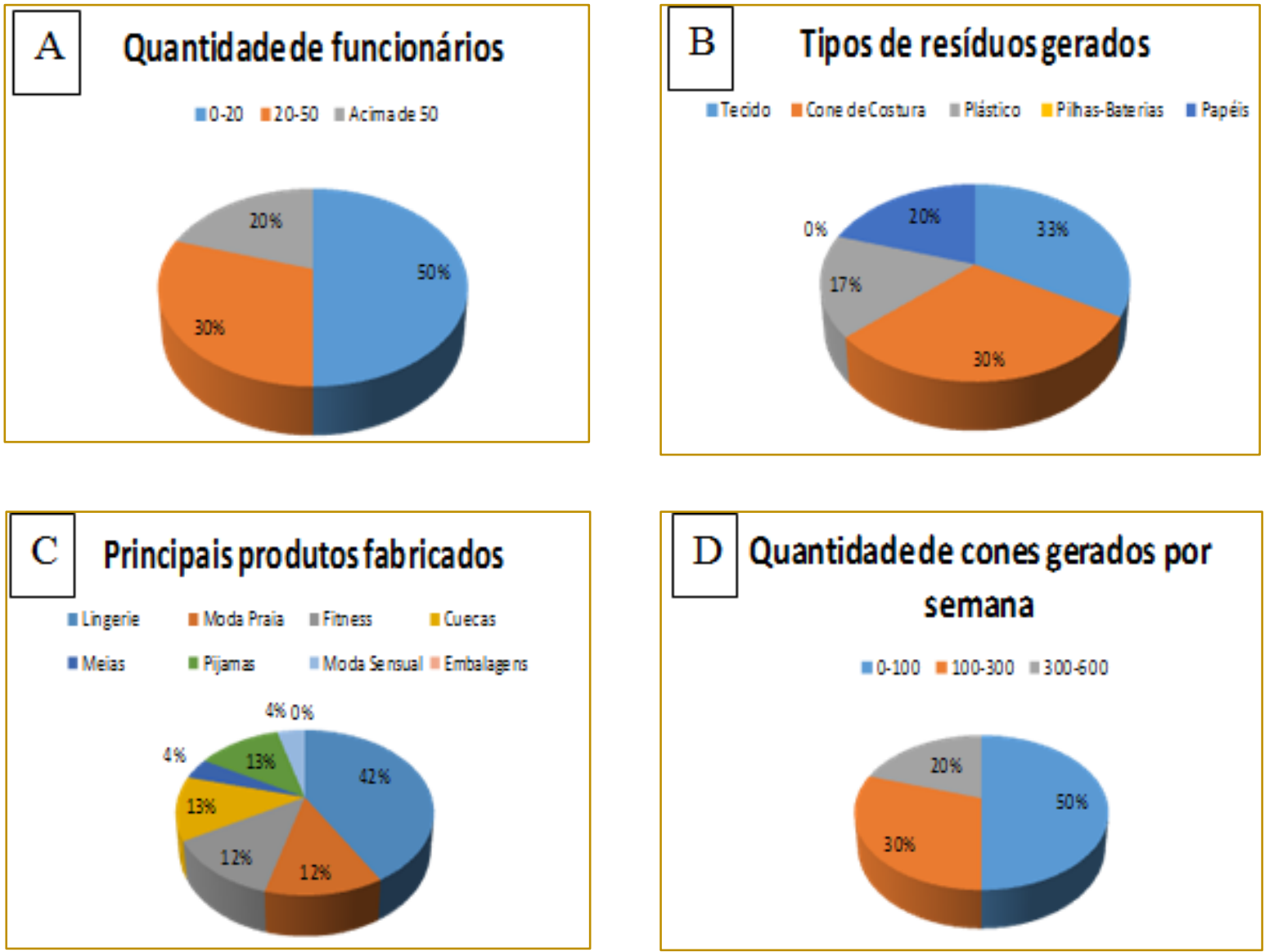

Fonte: o autor

Ao analisar o resultado das questões abaixo, observa-se que as empresas operam sem qualquer consciência ambiental, embora 50\% declararam conhecer a técnica de PML e $80 \%$ deles tenham declarado possuir pouco ou nenhum conhecimento sobre práticas ambientais.
Nota-se, também, que as empresas não possuem espaço físico suficientes para armazenagem e apenas 10\% delas pesam seus resíduos. Entretanto, as empresas que declararam pesá-los e separá-los, mostraramse desmotivadas devido ao fato de não haver políticas públicas ou privadas para os resíduos gerados neste segmento industrial em seu município, ou mesmo, na região. Os 
resíduos são coletados diariamente pela prefeitura de Juruaia e, os que foram separados são novamente misturados no momento da coleta de lixo urbano. A Figura 4 apresenta os resultados.

Figura 4- Conhecimento de práticas ambientais, espaço físico, produção mais limpa e pesagem para os resíduos
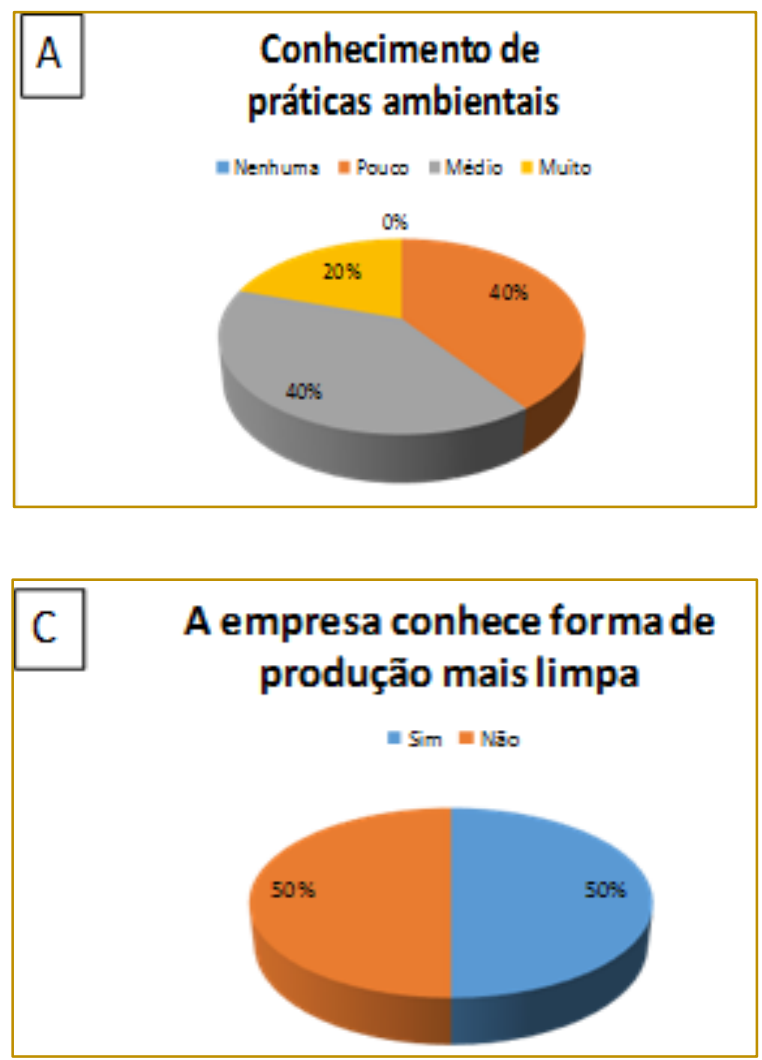
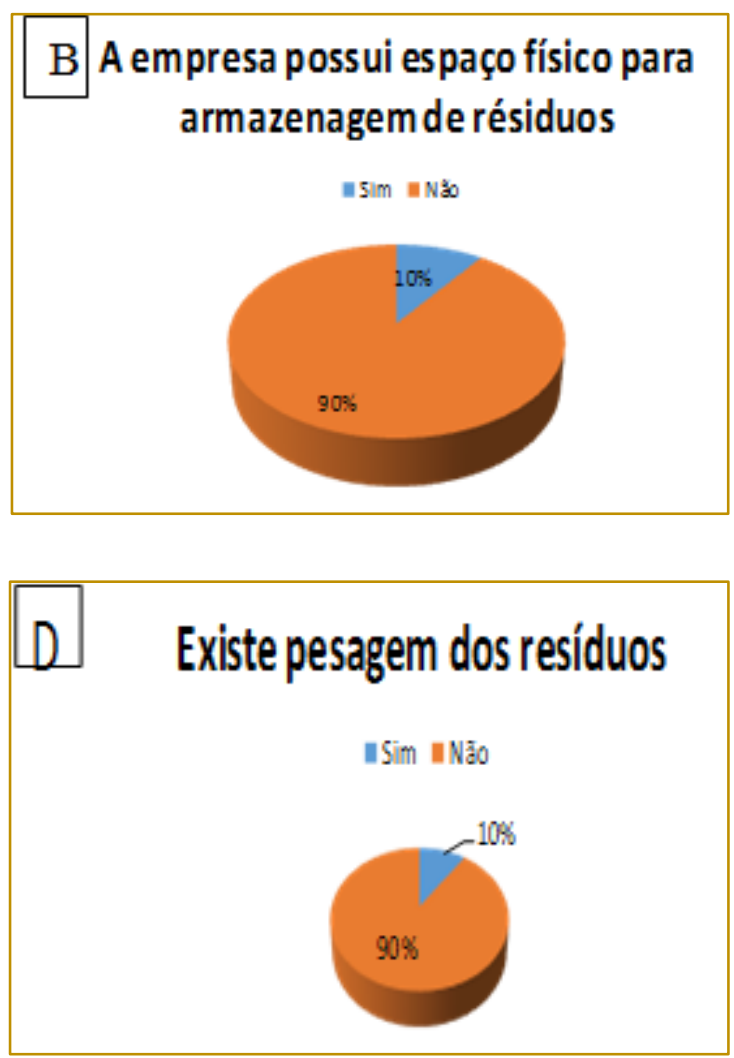

Fonte: o autor

Outro ponto evidenciado na pesquisa foi que algumas empresas possuem conhecimento sobre a possibilidade de transformar os cones em peças de artesanatos (Figura 5). Porém, percebe-se que não há interesse por parte dos empresários nesta prática; não existe preocupação com os resíduos gerados e muito menos intenção para treinar ou implantar técnicas de produção mais limpa.
Quando o enfoque da pergunta é alterado, e o entrevistado é estimulado com alguma solução para o problema, nota-se que uma parcela dos entrevistados se interessa pela a ideia de cooperativa para reciclar cones (Figura 5B). Entretanto, observou-se que tais questionamentos provocaram um certo desconforto por parte dos empresários e, a resposta positiva possa ter sido no sentido de amenizar esse aspecto. 
Figura 5- A- Conhecimento de artefatos, B- interesse em uma cooperativa de reciclagem, C- quem realiza e D- para onde vão os resíduos.
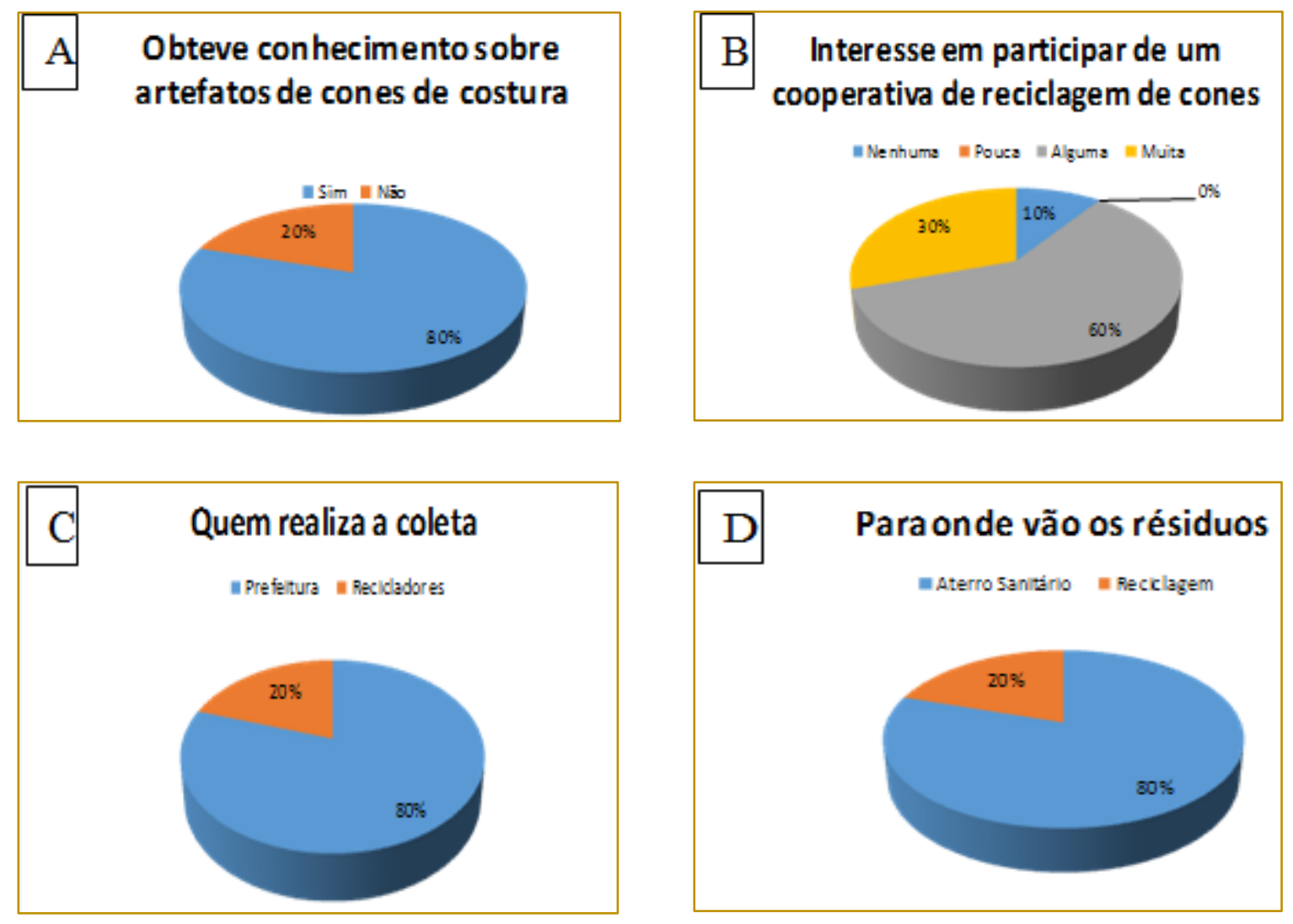

Fonte: o autor

Ao analisarmos questões como conhecimentos sobre práticas ambientais, processos de produção mais limpa e treinamento de pessoal sobre produção mais limpa, observou-se que as respostas são contraditórias. Na pesquisa, 80\% declararam não possuir conhecimentos sobre práticas ambientais, mas 50\% dos entrevistados conheciam a prática de produção mais limpa e $40 \%$ declararam que seus funcionários passaram por treinamentos. Respostas contraditórias e flagrantes que podem ser traduzidas como falta de conhecimento sobre qualquer ferramenta utilizada para a gestão ambiental. Um outro fator preocupante e que corrobora a observação anterior foi que constatou que 100\% das empresas não possuem Plano de Gerenciamento de Resíduos Sólidos (PGRS), deixando evidente que não estão preocupadas com a forma correta de gerenciarem seus resíduos e com a legislação federal vigente. 
Figura 6- - A- Práticas de separação dos resíduos, B- treinamento dos funcionários sobre produção mais limpa, C- separação por tipos de resíduos e D- separação dos cones dos demais resíduos.
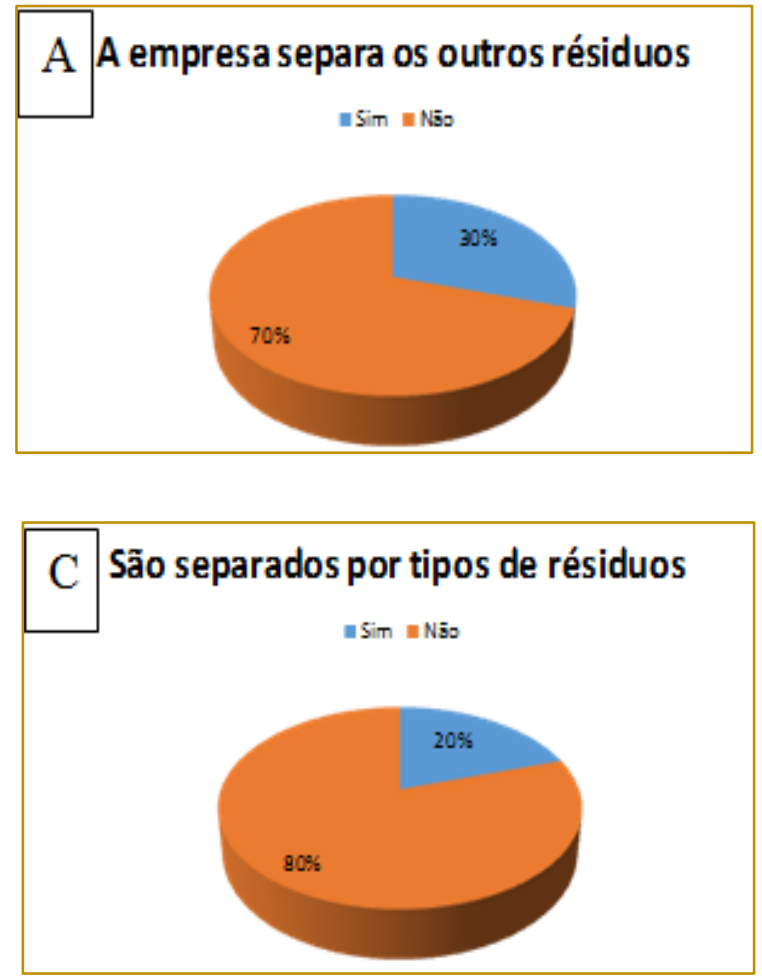
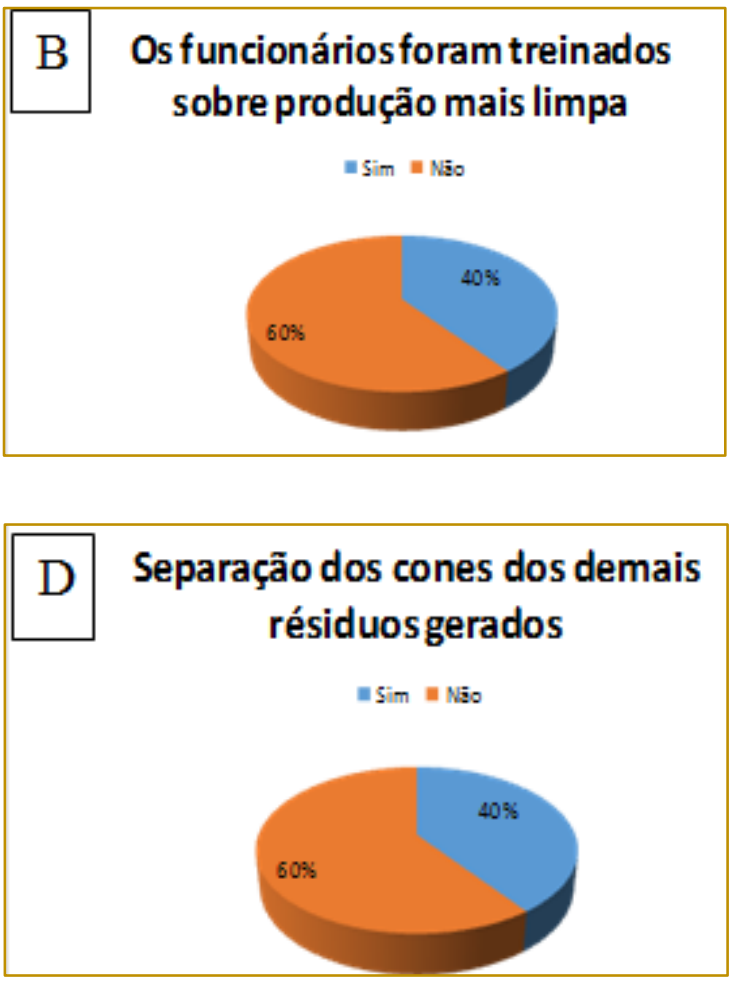

Fonte: o autor

O estudo mostrou que no espaço amostral da pesquisa há falta de interesse por parte do empresariado, e conscientização do empresariado e dos funcionários, de fiscalização por órgãos competentes, de participação da população e de falta de políticas públicas para o problema dos resíduos gerados. Os resíduos podem ser reciclados e se tornarem fonte de renda para outras pessoas. A ideia de uma cooperativa com fins educacionais, laborais e ambientais ajudariam a resolver vários problemas da sociedade moderna de do APL. O conceito do ecodesign poderia ser implantado. Um estudo preliminar com as artesãs do município pode servir como exemplo de reciclagem e desenvolvimento de novos produtos com os cones descartados. Na Figura 7 observa-se alguns modelos do que se pode ser realizado no projeto em questão. Foram criados vários tipos de peça desde uma porta pulseiras Figura 7A, até um vaso decorativo para flores Figura 7B.

Figura 7- Suporte para acessórios e vaso decorativo para flores.
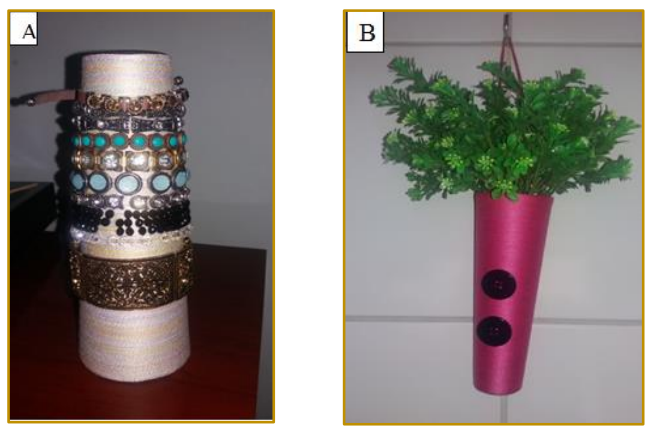

Fonte: o autor 


\section{CONCLUSÃO E PROPOSTA DE MELHORIA}

Com a condução da pesquisa conclui-se que o acelerado crescimento do APL do ramo têxtil produz um considerável volume de resíduos e especificamente, uma grande quantidade de cones sem perspectiva de reutilização. Percebe-se que há pouco interesse dos proprietários para 0 desenvolvimento de práticas ambientais, muito menos de implantar gestão ambiental na empresa. Não conhecem os benefícios da produção mais limpa ou de qualquer outra ferramenta de gestão ambiental. Falta um trabalho de conscientização do empresariado e dos funcionários, fiscalização por órgãos competentes, participação da população e políticas públicas para o problema dos resíduos gerados.

Não existe legislação municipal sobre destinação dos resíduos industriais e desde o início do crescimento do número de empresas do ramo até a finalização dessa pesquisa não houve fiscalização de nenhum órgão ambiental.

Os impactos ambientais do APL têxtil estão relacionados a toda a cadeia de produção, sendo mais evidente nas etapas de corte e costura, devido à retalhos gerados no corte e aos cones para a etapa da costura. O estudo propõe um novo paradigma para o desenvolvimento de produtos, associando o sistema de gestão ambiental e processos de produção. Neste contexto, propõem-se o reaproveitamento dos cones de costura por meio da prática do ecodesign (com o intuito de reutilizar materiais antes já descartados, projetando novos produtos com pouco impacto no meio ambiente), criando oficinas de artesanatos envolvendo todos os tipos de gênero e de idade, em ação social e ambiental, tornando também uma possível fonte de renda.

Com auxílio de ferramentas de ecodesign foi possível identificar possíveis aplicações para os cones de costura. Dificuldades foram

\section{REFERÊNCIAS}

[1] Adhikari, B.; Maiti,De D.. S. Reclamation and Recycling of waste rubber: Progress in Polymer Science, 2000.

[2] Barata, M. M. DE L.. O setor empresarial e a sustentabilidade no Brasil. Revista Pensamento Contemporâneo em Administração, 2007.

[3] Borchardt, M.; Poltosi, L. A. C.; Sellitto, M. A.; Pereira, G. M.. Considerações sobre ecodesign: encontradas, principalmente no que se refere ao interesse do empresariado, já que é necessário a separação dos resíduos. Observou-se que os entrevistados apresentaram apreensão na abordagem ao tema da pesquisa. O APL é formado na maioria por pequenas e médias empresas, muitas delas familiares, o que diversifica as respostas entre elas e a postura da carga ambiental de cada uma. Existe a necessidade de um trabalho informativo sobre as modernas tecnologias de produção e conscientização dos problemas causados ao meio ambiente que poderiam evitar falhas na gestão, pois evitariam desperdícios e teriam um desempenho melhor nos processos da empresa. A conscientização das empresas é de grande valor à busca pela sustentabilidade. O conhecimento de práticas sustentáveis e a disseminação de informações relacionadas à minimização de impactos ambientais podem melhorar a qualidade do ambiente.

Frente a isto, a pesquisa traz benefícios ao setor ao avaliar seus processos para um menor impacto ambiental, a sociedade e ao planeta. O designer e, as artesãs, por vez atuarão no auxílio de desenvolvimento de projetos referenciados aos materiais e técnicas de produção resultantes na qualidade do produto e menos impacto ambiental. A cooperativa ou mesmo, o designer e as artesãs, ainda, deveriam integrar -se na cadeia produtiva das empresas do APL e fazer parte das decisões ambientais.

Conclui-se que as empresas representaram vários tipos de impacto ambiental, em todas as etapas apresentadas, a partir deste trabalho se espera que as empresas assem a adotar medidas de gestão mais eficientes para um melhor desempenho das práticas ambientais, valorizar profissionais da área do design e assim alcançar a sustentabilidade no setor.

um estudo de caso na indústria eletrônica automotiva. Ambiente \& Sociedade, 2008.

[4] Broega, A. C.; Carvalho, C.; Moraes, C. Metodologia de Eco-Design no Ciclo da Moda: Reutilização e reciclagem do desperdício de vestuário. In: Anais do VI Congresso Nacional de Pesquisa em Design, 2011.

[5] Kwasnicka, E. L.. Teoria geral da administração, São Paulo: Atlas, 2003.

[6] Lastres, H. M. M.; Cassiolato, J. E.. Novas políticas na era do conhecimento: o foco em 
arranjos produtivos e inovativos locais. Parcerias Estratégicas. Brasília, 2003.

[7] Lima Junior, F. R.; Fracarolli, R. L.; Galdamez, E. V. C.. Gestão de Resíduos Têxteis: Um Estudo de Caso em Um Arranjo Produtivo do Setor de Vestuário. XII Encontro Internacional sobre Gestão Empresarial e Meio Ambiente, 2010.

[8] Mascena, KMC; Figueiredo, F. C.; Boaventura, J. M. G. Clusters, sistemas e arranjos produtivos locais: análise das publicações nacionais no período de 2000 a 2011. XV Simpósio de Administração da Produção, Logística e Operações Internacionais, 2012.

[9] Oliveira Guimarães, K.; Baruque Ramos, J.. Potencial de reciclagem têxtil no Brasil em âmbito de gestão ambiental. $2^{\circ}$ CONTEXMOD, 2014.
[10] Uniethos. Série de estudos setoriais: Sustentabilidade e competitividade na cadeia da moda. São Paulo, 2013.

[11] Valporto, M. S.; Azevedo, P. S.. Gestão do design na identificação dos fatores de impactos ambientais da construção civil. Estudos em Design, 2016.

[12] Zaccarelli, S. B.; Telles, R.; Siqueira, J. P. L.; Boaventura, J. M. G.; Donaire, D.. Clusters e redes de negócios: uma nova visão para a gestão dos negócios. São Paulo: Atlas, 2008.

[13] ZAT, A. L.. Uma experiência em ecodesign na indústria têxtil: aplicação ao projeto de um cabide. Rio Grande do Sul:UFRGS, 2003. Dissertação (Mestrado Profissionalizante) - Escola de Engenharia. Mestrado Profissionalizante em Engenharia. Universidade Federal do Rio Grande do Sul, Porto Alegre, 2003. 


\section{Capítulo 2}

\section{LIDERA - UM SISTEMA VOLUNTÁRIO DE APOIO AO DESENVOLVIMENTO E AVALIACÃO DA SUSTENTABILIDADE DE MATERIAIS E PRODUTOS DA CONSTRUÇÃO CIVIL}

\section{João Luiz Rissardi}

Vanessa do Rocio Nahhas Scandelari

\section{Manuel Duarte Pinheiro}

Resumo: Com a crescente demanda no setor da construção civil, grande parte das construtoras utilizam serviços, materiais e produtos que não atendem as responsabilidades ambientais para baixar seus custos e terem maiores lucros, alguns exemplos são os descartes de resíduos em lugares inapropriados, utilização de produtos não sustentáveis, entre outros, fazendo com que a preocupação ambiental aumente, surgindo assim novos sistemas de avaliação ambiental, tanto das obras como dos materiais, produtos e serviços. Nesta discussão sobre uma construção mais sustentável, é necessário estudar os materiais e produtos utilizados na construção civil, seja nas vertentes ambiental, social e econômica. Torna-se importante identificar e certificar os materiais e produtos que possuem menores impactos ambientais em seu ciclo de vida. O presente trabalho tem como objetivo apresentar o LiderA, um sistema europeu de avaliação voluntário de apoio ao desenvolvimento de soluções e avaliação da sustentabilidade na construção civil. Com base em uma revisão bibliográfica, neste artigo são também apresentadas sumariamente aplicações do sistema em materiais e produtos da construção civil. São discutidas as potencialidades deste sistema como sendo um apoio à procura pela sustentabilidade na construção.

Palavras-chave: Sistema de avaliação LiderA, Sustentabilidade, Materiais e Produtos, Construção Civil. 


\section{INTRODUÇÃO}

Desde os primórdios da civilização, o homem tem usado os materiais conjuntamente com a energia, para melhorar os padrões de vida. Toda a engenharia depende dos materiais para processos: quanto melhores forem estes, melhores são as obras de engenharia. Os materiais podem ser definidos como substâncias tangíveis com as quais se constroem artefatos (produtos), que são parte integrante do cotidiano da sociedade (SMITH, 1998).

O setor da construção civil consome cerca de $15 \%$ a $50 \%$ de recursos naturais, $66 \%$ de toda a madeira extraída, $40 \%$ da energia consumida e $16 \%$ da água potável, sendo ainda um grande gerador de resíduos, produzindo uma quantidade duas vezes maior que o lixo urbano (GRAÇAS, 2010; GAEDE, 2008; JOHN, 2000). Este fato mostra que no caso da construção é iminente a necessidade de estudar soluções e métodos para amenizar a sua contribuição à degradação do ambiente.

A partir da evolução do setor da construção civil, o mercado já não se contenta apenas em construir edifícios resistentes e a um baixo custo de acordo com a sua concepção. Nos dias atuais $\mathrm{o}$ ato de edificar adotou outra dimensão, engloba diversos fatores, que vão desde a utilização de materiais e produtos com efeitos diretos na própria obra, com um sistema de gestão de qualidade na construção, até o compromisso com as consequências dessa atividade para a sociedade, como a preocupação de se construir em condições ambientalmente corretas. Para conhecer a importância ambiental dos produtos que a montante utiliza é necessário que se proceda à contabilização de todos os impactos ambientais causados por um determinado material, desde o início da extração das matérias-primas (cradle), até à fase de deposição e fim de vida (grave) (FREIXO, 2011).

A construção sustentável é um conceito que nos Estados Unidos pela First World Conference for Sustainable Construction, onde Charles Kibert a definiu como "a criação e gestão de um ambiente saudável, tendo em consideração os princípios ecológicos e a utilização eficiente dos recursos". Kibert também sugeriu os seis princípios para a sustentabilidade na construção: minimizar o consumo de recursos, maximizar a reutilização dos recursos, utilizar recursos renováveis e recicláveis, proteger o ambiente natural, criar um ambiente saudável e não tóxico, e por fim fomentar a qualidade ao criar o ambiente construído (PEREIRA, 2009; PINHEIRO, 2006; TOZZI, 2006).

Para que os materiais e produtos da construção contribuam para a redução do impacto ambiental dos edifícios, é necessário promover a certificação da ecoeficiência, disseminá-la, mas principalmente, inovar. O conceito da ecoeficiência foi apresentado pela primeira vez em 1991 pelo World Business Council for Sustainable Development e compreende o "desenvolvimento de produtos e serviços, com preços competitivos que satisfazem as necessidades da espécie humana com qualidade de vida, enquanto progressivamente reduzem o seu impacto ecológico e o consumo de matérias-primas, ao longo do seu ciclo de vida, até um nível compatível com a capacidade do Planeta" (SOUZA, 2011).

Para serem conhecidos e selecionados materiais, produtos e serviços mais sustentáveis para edificados e zonas urbanas, torna-se essencial classificar produtos quanto ao seu desempenho ambiental, ,no entanto, a informação dos produtos com melhor desempenho ambiental existentes no mercado ainda é muito escassa (SANTOS, 2012). É importante destacar que o conceito de desempenho ambiental, segundo a ISO 14001 é "resultados mensuráveis do sistema de gestão ambiental, relacionados com o controle da organização sobre os aspectos ambientais, baseados na sua política, seus objetivos e metas".

Estes produtos apresentam elevada importância junto do cliente/consumidor uma vez que os clientes procuram nos produtos uma satisfação das suas necessidades, uma forma de assegurar a saúde e o bem-estar. No processo de escolha, que cada vez é mais exigente e consciente, 0 desempenho energético, o menor consumo de água, a menor toxicidade, maior durabilidade e o fato de contribuir positivamente para o ambiente, para a sociedade e para a economia local são fatores tidos em consideração (PINHEIRO, 2011a).

Alguns dos principais sistemas de avaliação presentes no mundo são: o BREEAM (Reino Unido), o LEED (Estados Unidos), o NABERS 
(Austrália), O BEPAC (Canadá), O HQE (França) e o CASBEE (Japão). Segundo Leite (2011) os dois sistemas mais utilizados no Brasil são o LEED e o AQUA (Alta Qualidade Ambiental) que é baseada no $\mathrm{HQE}$.

O LiderA é um sistema de apoio, avaliação e contribuição para o desenvolvimento da sustentabilidade, no âmbito de edifícios, recursos, espaços exteriores e zonas construídas. Em 2000 foram iniciadas pesquisas preliminares de investigação desse sistema, sendo fundado oficialmente em Portugal no ano de 2005, pelo Doutor Manuel Duarte Pinheiro, emitindo suas primeiras certificações em 2007, atualmente tem vindo a ser aplicado em vários países lusófonos.

O sistema LiderA está presente no Brasil desde 2013 e já certificou os níveis de desempenho de varios empreendimentos, dentre eles dois edifícios, Hotel Marina All Suites e Hotel Marina Palace. Ambos se encontram em fase de operação e estão localizados na cidade do Rio de Janeiro, bairro do Leblon, onde tendo-se obtido uma classe A para Marina Palace o e A+ para o Marina All Suites (PINHEIRO et al., 2013).

O presente trabalho tem como objetivos apresentar o LiderA, que é um sistema de avaliação voluntário de apoio ao desenvolvimento de soluções e avaliação da sustentabilidade da construção civil. Também, por meio deste trabalho os autores anseiam expor a importância da classificação do grau de sustentabilidade de materiais e produtos utilizados na construção e como esta é realizada pelo sistema LiderA.

\section{METODOLOGIA}

O presente trabalho consiste em uma revisão bibliográfica (GIL, 2010), a qual sumariza os conceitos sobre a importância da aplicação de materiais e produtos mais sustentáveis na construção civil, tendo um enfoque maior em publicações sobre o sistema de avaliação ambiental português LiderA.

\section{DESENVOLVIMENTO}

\subsection{ENQUADRAMENTO SOBRE MATERIAIS E PRODUTOS SUSTENTÁVEIS}

Os aspectos econômicos, ambientais e sociais que formam o conceito "Triple Bottom Line" são fundamentais na definição de material sustentável. Este conceito compreende $\mathrm{O}$ anseio de alcançar um equilíbrio ótimo entre a proteção ambiental, a equidade social e a prosperidade econômica, sem dispensar os requisitos mínimos dos produtos tradicionais, como a qualidade, mercado, as questões técnicas e os custos associados (MAXWELL, 2003).

Para Gomes (2012), materiais sustentáveis são aqueles que, além de desempenhar as funções a que se destinam, apresentam também menores prejuízos ambientais, associados aos efeitos sociais e econômicos. Este conceito se estende ao desenvolvimento de novas técnicas, materiais, produtos e serviços, com desempenho melhor, ou ao menos tão bom como os tradicionais. Tendo como vantagens a utilização eficiente dos recursos naturais e a geração de menos poluição e resíduos.

Os produtos utilizados na construção são de grande importância no desafio da sustentabilidade, logo a sua escolha não deve ser realizada de maneira fortuita, e sim com uma abordagem global e integrada de todos os impactos ambientais causados pelos materiais. A avaliação de sustentabilidade dos materiais de construção possui várias dimensões que dificultam o processo de seleção daqueles. A busca pela sustentabilidade analisa três fatores básicos: a qualidade, os custos e o prazo. Associados aos critérios ecológicos, resultam na minimização dos aspectos negativos sobre o ser humano, como a saúde, a segurança e o conforto (FREIXO, 2011).

De acordo com Pinheiro (2006) o Ciclo de Vida de qualquer produto, no contexto ambiental, considera a contabilização dos impactos gerados durante todas as suas fases, desde a extração das matérias-primas até à sua deposição ou fim de vida, denominado por "Cradle-to-grave". O método desenvolvido para avaliar os impactos ao longo do ciclo de vida de um material é correntemente designado por Análise de Ciclo de Vida (ACV), sendo um processo iterativo com a finalidade objetivo de permitir a seleção de produtos tendo em conta o seu perfil ambiental.

A análise do ciclo de vida "inclui [...], a extração e o processamento de matériasprimas, a fabricação, o transporte, a distribuição e comercialização, a utilização, a manutenção, a reciclagem, a reutilização e a deposição final do produto na Natureza" (SETAC, 1993). Já a ISO 714040 (2006) define 
ACV como "compilação dos fluxos de entradas e saídas e avaliação dos impactos ambientais associados a um produto ao longo do seu Ciclo de Vida".

Os resultados da ACV possibilitam identificar os impactos ambientais dos materiais de construção que ocorrem em todas as fases do seu Ciclo de Vida conforme a Figura 1, comparar diretamente os produtos, processos de fabricação e soluções de eliminação de desperdícios. A otimização dos métodos de concepção, construção, renovação e demolição dos edifícios e do ambiente construído pode permitir melhorias significativas no desempenho ambiental e econômico dos espaços edificados e na qualidade de vida dos cidadãos.

Figura 1 - Ciclo de Vida dos Materiais e Produtos da Construção Civil

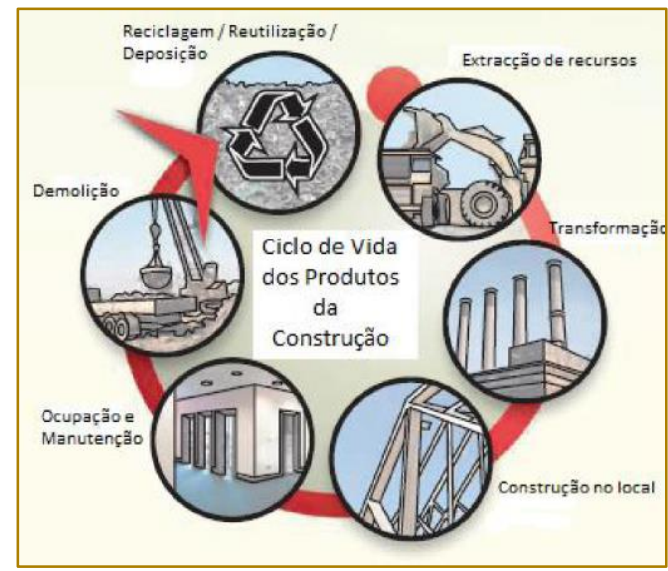

Fonte: FREIXO (2011)

Santos (2012) afirma que os sistemas de classificação que atribuem os rótulos ambientais possibilitam realizar a distinção entre os produtos que apresentam um bom perfil ecológico ou sustentável daqueles que são prejudiciais ou com pior desempenho para o meio ambiente. A ACV é provavelmente o método de avaliação de impacto ambiental mais importante de materiais, serviços e processos, sendo empregado em uma das ferramentas mais utilizadas como sistema de classificação, o rótulo ambiental.

Com o desejo de atender a procura dos consumidores por produtos mais ecológicos é que em alguns países surgiu, a partir do final dos anos de 1980, um grande número de sistemas de rotulagem, como mostra a Figura 2. disponibilizando uma orientação fundamentada aos consumidores que desejam optar por este tipo de produtos. O rótulo ambiental é um rótulo oficial para produtos "verdes", sendo que os produtos, para poderem obter o rótulo, têm de obedecer aos critérios estabelecidos pelo sistema que comprova que foram fabricados por processos e procedimentos com um impacto ambiental baixo ou mínimo. São determinados vários critérios com base em procedimentos de avaliação de ciclo de vida para cada categoria de produtos. Este procedimento envolve todas as etapas do ciclo de vida do produto, desde a extração das matérias-primas utilizadas, a fabricação, distribuição, utilização e deposição final do produto e abrange os efeitos desfavoráveis e benéficos no ambiente em cada uma destas etapas (SANTOS, 2012). 
Figura 2 - Cronologia de Rótulos Ambientais para Materiais e Produtos da Construção Civil

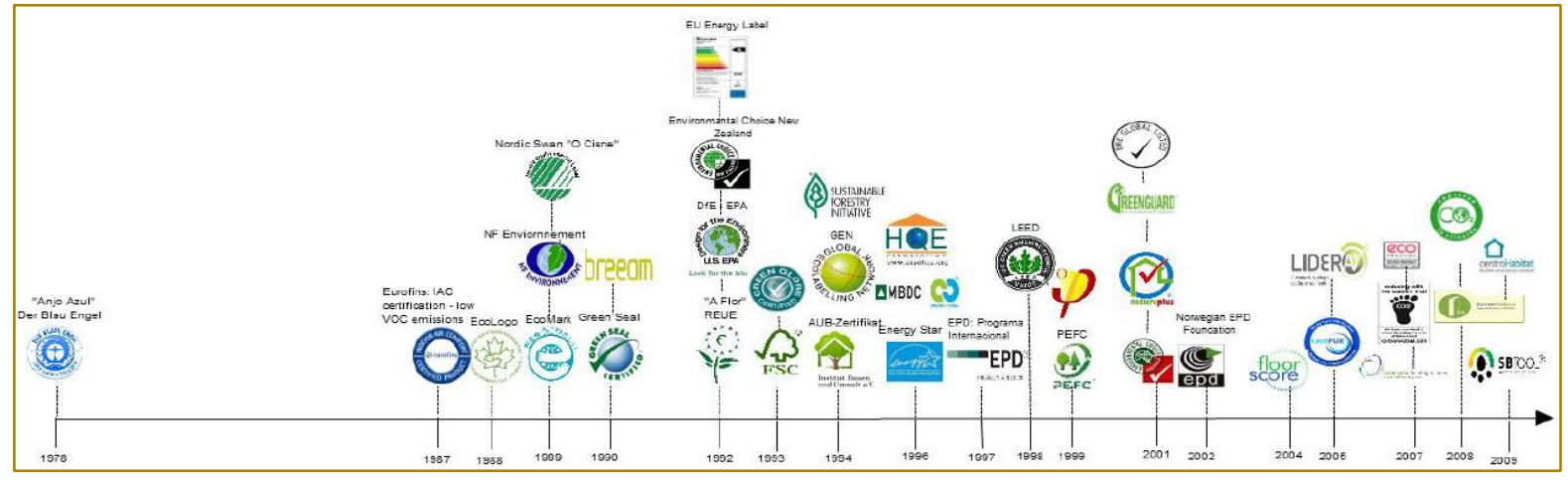

Fonte: FREIXO (2011)

\subsection{SISTEMA LIDERA}

O LiderA é um sistema voluntário que apoia projetos tidos como sustentáveis e certifica produtos do mercado da construção como, por exemplo, edifícios, materiais, empreendimentos, entre outros, desde a fase de concepção do projeto até a utilização. O nome do sistema LiderA é acrônimo de Liderar pelo Ambiente para a construção sustentável, sendo neste aspecto que ele procura reposicionar $\mathrm{O}$ ambiente na construção, através da orientação e da avaliação do nível de busca pela sustentabilidade.

De acordo com Pinheiro (2010), o sistema se organiza em um conjunto de seis vertentes de bom desempenho ambiental, sendo eles:
Valorizar a dinâmica local e promover uma adequada integração; Fomentar a eficiência no uso dos recursos; Reduzir o impacto das cargas ambientais; Assegurar a qualidade do ambiente, focada no Conforto Ambiental; Fomentar as vivências socioeconômicas sustentáveis; Assegurar a melhor utilização sustentável dos ambientes construídos, através da gestão ambiental e da inovação.

Conforme a Figura 3, estas vertentes são tratadas em 22 áreas. Já estas áreas são divididas em 43 critérios, nos quais se avaliam os ambientes construídos em função do seu desempenho, no caminho para a sustentabilidade.

Figura 3 - Vertentes e Áreas do Sistema LiderA

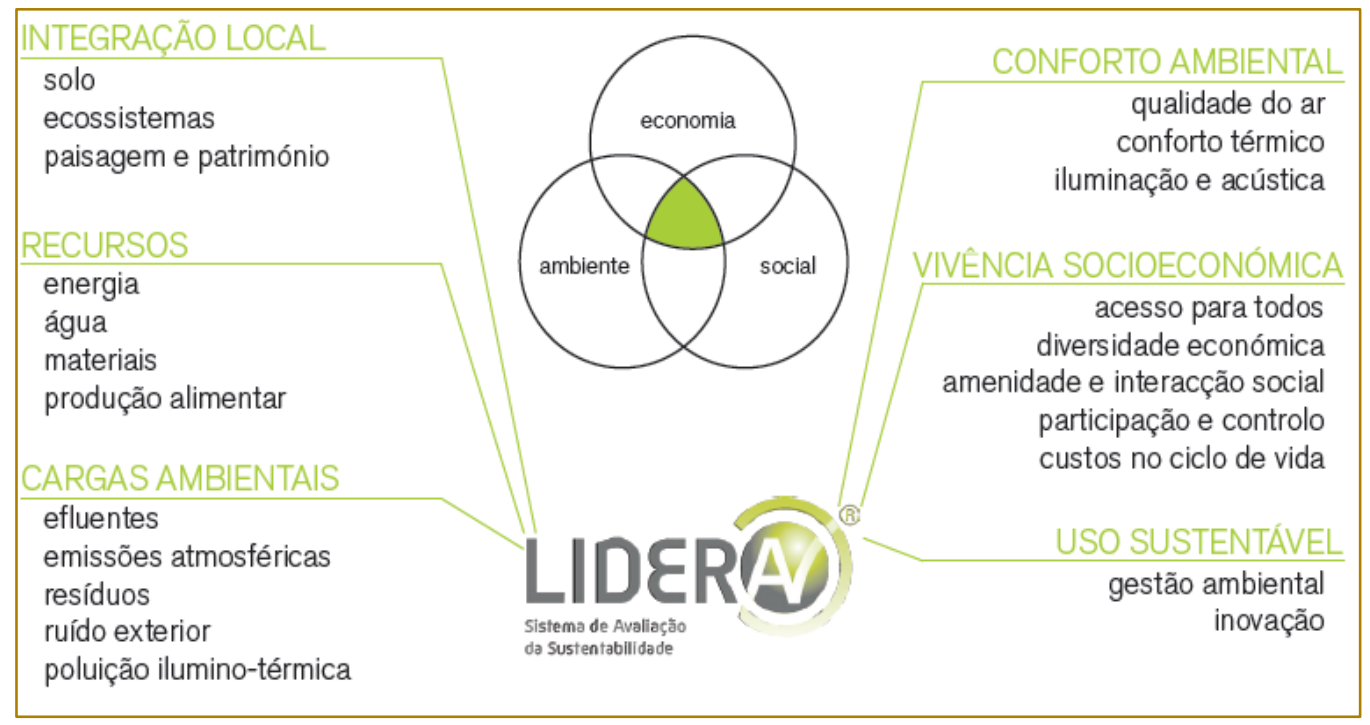

Fonte: PINHEIRO(2011b) 
Para cada critério são estabelecidos níveis de desempenho que possibilitam indicar se a solução é ou não sustentável. Estes níveis são indicados de forma numérica e posteriormente são transformados em classes que vão de $\mathrm{G}$ a $\mathrm{A}+++$, visando um melhor entendimento da avaliação.

Para Pinheiro (2011b) a contabilização dos critérios já referidos é realizada através de vertentes e áreas. Como descrito no Quadro 1 , as vertentes posicionam como mais relevante os recursos (energia, água e materiais) com $32 \%$ do peso, seguido da vivência socioeconômica (19\%), conforto ambiental (15\%), integração local (14\%), cargas ambientais (12\%) e por fim o uso sustentável

(8\%).

Quadro 1 - Vertentes, áreas e critérios do sistema LiderA

\begin{tabular}{|c|c|c|c|}
\hline VERTENTE & ÁREA & № & CRITÉRIO \\
\hline \multirow{6}{*}{$\begin{array}{l}\text { Integração Local } \\
(14 \%)\end{array}$} & \multirow{2}{*}{ Solo } & C1 & Valorização Territorial \\
\hline & & C2 & Otimização ambiental da implantação \\
\hline & \multirow{2}{*}{ Ecossistemas naturais } & C3 & Valorização Ecológica \\
\hline & & C4 & Interligação de habitats \\
\hline & \multirow{2}{*}{ Paisagem e Património } & $\mathrm{C} 5$ & Valorização Paisagística \\
\hline & & C6 & Proteção e valorização do património \\
\hline \multirow{9}{*}{ Recursos (32\%) } & \multirow{3}{*}{ Energia } & $\mathrm{C7}$ & $\begin{array}{l}\text { Eficiência nos consumos e certificação } \\
\text { energética }\end{array}$ \\
\hline & & C8 & Desenho passivo \\
\hline & & C9 & Intensidade em carbono \\
\hline & \multirow{2}{*}{ Água } & C10 & Consumo de água potável \\
\hline & & C11 & Gestão de águas locais \\
\hline & \multirow{3}{*}{ Materiais } & C12 & Durabilidade \\
\hline & & $\mathrm{C} 13$ & Materiais locais \\
\hline & & C14 & Materiais de baixo impacto \\
\hline & Produção Alimentar & C15 & Produção local de alimentos \\
\hline \multirow{8}{*}{$\begin{array}{l}\text { Cargas Ambientais } \\
\qquad(12 \%)\end{array}$} & \multirow{2}{*}{ Efluentes } & C16 & Tratamento das águas residuais \\
\hline & & $\mathrm{C} 17$ & Caudal da reutilização de águas usadas \\
\hline & Emissões Atmosféricas & C18 & Caudal de emissões atmosféricas \\
\hline & \multirow{3}{*}{ Resíduos } & C19 & Produção de resíduos \\
\hline & & $\mathrm{C} 20$ & Gestão de resíduos perigosos \\
\hline & & $\mathrm{C} 21$ & Valorização de resíduos \\
\hline & Ruído Exterior & C22 & Fontes de ruído para o exterior \\
\hline & Poluição Ilumino-térmica & $\mathrm{C} 23$ & Poluição ilumino-térmica \\
\hline \multirow{4}{*}{$\begin{array}{l}\text { Conforto Ambiental } \\
\qquad(15 \%)\end{array}$} & Qualidade do Ar & $\mathrm{C} 24$ & Níveis de qualidade do ar \\
\hline & Conforto Térmico & $\mathrm{C} 25$ & Conforto térmico \\
\hline & \multirow{2}{*}{ Iluminação e Acústica } & C26 & Níveis de iluminação \\
\hline & & $\mathrm{C} 27$ & Conforto sonoro \\
\hline
\end{tabular}


(continuação...)

\begin{tabular}{|c|c|c|c|}
\hline VERTENTE & ÁREA & № & CRITÉRIO \\
\hline \multirow{13}{*}{$\begin{array}{c}\text { Vivência } \\
\text { Socioeconômica } \\
(19 \%)\end{array}$} & \multirow{3}{*}{ Acesso para todos } & C28 & Acesso aos transportes públicos \\
\hline & & C29 & Mobilidade de baixo impacto \\
\hline & & C30 & Soluções inclusivas \\
\hline & \multirow{3}{*}{ Diversidade Econômica } & C31 & Flexibilidade - adaptabilidade aos usos \\
\hline & & C32 & Dinâmica económica \\
\hline & & C33 & Trabalho local \\
\hline & \multirow{2}{*}{$\begin{array}{l}\text { Amenidades e Interação } \\
\text { Social }\end{array}$} & C34 & Amenidades locais \\
\hline & & C35 & Interação com a comunidade \\
\hline & \multirow{4}{*}{ Participação e Controle } & С36 & Capacidade de controle \\
\hline & & C37 & Condições de participação e governança \\
\hline & & C38 & Controle de riscos naturais (safety) \\
\hline & & С39 & Controle das ameaças humanas (security) \\
\hline & Custos no Ciclo de Vida & C40 & Custos no ciclo de vida \\
\hline \multirow{3}{*}{$\begin{array}{l}\text { Uso Sustentável } \\
(8 \%)\end{array}$} & \multirow{2}{*}{ Gestão Ambiental } & C41 & Condições de utilização ambiental \\
\hline & & C42 & Sistema de gestão ambiental \\
\hline & Inovação & C43 & Inovações \\
\hline
\end{tabular}

Ainda segundo Pinheiro (2011b), os liminares do sistema LiderA são derivados de três pontos de referência. O primeiro se baseia no desempenho tecnológico mais utilizado, pelo que a prática construtiva existente é considerada como nível usual (Classe E). Já no segundo nível, o melhor desempenho decorre da melhor prática construtiva viável à data (Classe C, B e A), já o terceiro enfoca na definição do nível de sustentabilidade elevado (Classes $\mathrm{A}++$ ).

Para cada critério é possível, utilizando os limiares do sistema LiderA e comparando com as soluções ou níveis de desempenhos, verificar como se posiciona face à prática de referência, se for igual a esta prática é classe E, se melhorar o desempenho em $12,5 \%$ será uma classe D, em $25 \%$ será uma classe C, em $37,5 \%$ uma classe $B$, em $50 \%$ uma classe $A$, em $75 \%$ uma classe $A+$ e em $90 \%$ uma classe $A++$. E ainda discorre que no futuro, reserva-se a possibilidade de existir o nível $\mathrm{A}+++$, um representativo de um estado regenerativo (PINHEIRO, 2010).

\subsection{LINHAS DE BOAS PRÁTICAS DO SISTEMA LIDERA}

Cada critério do sistema LiderA remete à linhas de boas práticas, ou seja, o que se espera das áreas avaliadas, afim deste obter uma boa classificação. Algumas das boas práticas consideradas pelo sistema são, por exemplo:

Valorização Territorial: Promover aglomerados urbanos compactos (média densidade), minimizando a expansão suburbana; Promover a adoção de vários usos do solo simultâneos; Promover a construção de redes de infraestruturas locais; Minimizar a erosão e promover a permeabilidade do solo (PINHEIRO et al., 2013).

Valorização Ecológica: Minimizar a destruição ou alteração da fauna e flora local; Promover a integração de espaços e estruturas verdes nos aglomerados urbanos (PINHEIRO et al., 2013)

Valorização Paisagística: Adequar as intervenções às condições naturais locais (topografia, fauna, flora, estruturas verdes); Adequar as intervenções à envolvente construída local (edificado, infraestruturas, espaços público); Respeitar os valores, tradições e técnicas construtivas locais (PINHEIRO et al., 2013).

Gestão da Energia: Diminuição das necessidades nominais de energia - otimizar o ciclo da energia; Construir com base em princípios bioclimáticos; Incentivar a utilização 
de sistemas de fontes renováveis (solares térmicos, fotovoltaicos, eólicos, geotérmico, biomassa) adaptados às condições locais (PINHEIRO et al., 2013).

Gestão da Água: Garantir o ciclo da água nos ecossistemas locais; Desenvolver o acesso a água potável - promover a qualidade da água; Otimizar o consumo de água primária proveniente da rede de abastecimento pública, de poços, de fontes ou de furos; Recolha e utilização de águas pluviais; Reutilização de águas tratadas para consumos secundários; Promover a introdução de sistemas waterless; Garantir a higiene e salubridade evitando a existência de locais com águas estagnadas ou poluídas (PINHEIRO et al., 2013).

Gestão dos Materiais: Fomentar o uso de materiais locais e materiais reciclados; Conjugação de materiais de modo a obter soluções duráveis; Adoção de materiais e técnicas construtivas que promovam a conservação de energia (PINHEIRO et al., 2013).

Produção local de alimentos: Promover a produção local de alimentos de origem animal e/ou vegetal (PINHEIRO et al., 2013).

Gestão dos Efluentes: Desenvolver sistemas de tratamento de águas residuais locais; Promover a recolha, separação e tratamento das águas residuais e posterior reutilização das mesmas para consumos secundários (PINHEIRO et al., 2013).

Gestão das Emissões Atmosféricas: Eliminar ou diminuir soluções que recorram ao processo de combustão; Evitar a utilização de soluções que impliquem a emissão de substâncias acidificantes; Promover a aplicação de sistemas e equipamentos ou ventilação natural que evitem a acumulação de partículas nocivas (poeiras, fungos, bactérias) (PINHEIRO et al., 2013).

Gestão dos Resíduos: Promover o tratamento local de resíduos; Reduzir a produção de resíduos e aumentar a percentagem de resíduos valorizados na construção, operação e demolição; Implementar a compostagem de resíduos orgânicos ou a produção de energia da biomassa como forma de tratamento de resíduos; Reduzir a produção de resíduos perigosos, otimizar as suas condições de armazenamento e deposição final (PINHEIRO et al., 2013).

Gestão do ruído: Controlo das fontes de ruído para o exterior; Reduzir os níveis de ruído exteriores para níveis ambientalmente aceitáveis (PINHEIRO et al., 2013).

Gestão ilumino-térmica: Reduzir o efeito da "ilha de calor" e da poluição ilumino-térmica (PINHEIRO et al., 2013).

Gestão da Qualidade do Ar: Implementar a ventilação natural no edifício, promover a ventilação cruzada; Promover a circulação e ventilação do ar nos espaços envolventes ao edifício; Implementar medidas com vista a redução de contaminações no ar (COV's, micro-contaminações, odores, gases); Garantir a salubridade dos espaços interiores assegurando a sua proteção a doenças (PINHEIRO et al., 2013).

Gestão do Conforto Térmico: Desenvolver estratégias de desempenho passivo com vista a assegurar o conforto térmico dos utilizadores tanto internamente como externamente; Introduzir e assegurar a aplicação de isolamentos térmicos adequados no edificado (paredes, cobertura, pavimentos); Assegurar boas condições de conforto térmico nos espaços públicos exteriores (orientação e exposição solar, sombreamento, ventilação, evaporação) (PINHEIRO et al., 2013).

Gestão de outras condições de Conforto: Promover e assegurar bons níveis de iluminação natural no interior e exterior do edificado, através da adoção de técnicas de desempenho passivo; Promover a introdução ponderada de iluminação artificial no edificado assegurando bons níveis de iluminação artificial no interior do edificado, nos locais em que tal seja necessário; Assegurar bons níveis de iluminação artificial no exterior do edificado, em especial nos espaços de concentração da população; Localização correta do edificado de forma a garantir a proteção a fontes de ruído locais e assegurar bons níveis de conforto sonoro no interior dos espaços, aplicando isolamentos acústicos adequados; Adotar organizações espaciais que favoreçam os usos dos espaços considerados (PINHEIRO et al., 2013)

Contribuir para acessibilidade: Promover a construção de infraestruturas que facilitem os deslocamentos cotidianos que servem de apoio aos meios de transporte locais (estradas, abrigos, passeios, faixas de pedestres, ciclovias, estações); Oferecer uma variedade de soluções e espaços públicos nas imediações do edificado que facilitem e incentivem a atividade física e favoreçam os 
deslocamentos de baixo impacto; Promover a criação e favorecer a utilização de transportes coletivos que abranjam o maior número de utilizadores possível; Assegurar a mobilidade e o acesso a pessoas com mobilidade condicionada, quer seja nos espaços interiores, quer nos exteriores, evitando essencialmente as barreiras arquitetônicas (PINHEIRO et al., 2013).

Contribuir para a Dinâmica Econômica: Concepção de soluções espaciais, redes e sistemas auxiliares flexíveis, modulares e ajustáveis às necessidades evolutivas locais; Criar soluções espaciais e arquitetônicas que permitam criar valor no local e no mercado imobiliário; Adotar soluções que favoreçam trocas comerciais que potenciem o comércio local; Tipologias de soluções, produtos e espaços adequados a diferentes classes sociais; Promover a localização de postos de trabalho nos ambientes construídos locais, com ênfase na empregabilidade da população local; Promover a igualdade de género e de estatuto social; Criação de empregos qualificados e formação da população local (PINHEIRO et al., 2013).

Contribuir para as Amenidades: Promover a valorização das amenidades locais fomentando a sua presença e criação, a sua manutenção e a sua proximidade aos usuários como uma prioridade para os ambientes locais; Promover atividades, espaços e soluções que solicitem a participação da população local com a comunidade envolvente (PINHEIRO et al., 2013).

Condições de controle: Aplicação de medidas de controle e inibição da criminalidade e vandalismo no edificado e espaços construídos (iluminação, vigilância, permeabilidade do espaço e campos de visão); Fomentar o controle do nível do conforto (temperatura, umidade, ventilação, sombreamento e iluminação), adequando as condições do edificado às estações de Verão e Inverno; Adequar as intervenções aos riscos naturais existentes e evitar os riscos inerentes às soluções arquitetônicas adotadas; Prever medidas que permitam melhorar as condições de higiene locais, garantindo a salubridade dos espaços construídos de forma a evitar riscos associados a doenças contagiosas; Promover a participação ativa dos cidadãos com intuito de melhorar a sua qualidade de vida, as suas condições de conforto e o usufruto ou a vivência do ambiente construído; Promover a participação ativa dos cidadãos em igualdade de género e de estatuto social (PINHEIRO et al., 2013).

Contribuir para os Baixos Custos no Ciclo de Vida: Maximizar a rentabilidade do edifício e ambientes construídos e minimizar a sua manutenção, promovendo baixos custos no ciclo de vida dos elementos constituintes da comunidade; Escolha de materiais, equipamentos e soluções construtivas simples, duráveis e resistentes, que possam posteriormente ser reaproveitados e reciclados; Ponderar a adopção de soluções flexíveis, que permitam uma fácil adaptação a diferentes realidades, sem o encargo de custos adicionais (PINHEIRO et al., 2013).

Promover a Utilização e Gestão: Contribuir para a formação da população em relação à utilização dos espaços edificados e do desempenho ambiental dos mesmos; Criar modos de utilização simplificados que permitam potenciar os níveis de desempenho ambiental quer no edificado, quer nos espaços exteriores; Introduzir modos de gestão simplificados que permitam assegurar a adequada manutenção, utilização e operação do edificado e dos espaços exteriores (PINHEIRO et al., 2013).

Promover a Inovação: Reforçar e incentivar a aplicação de soluções que promovam a sustentabilidade e a adopção de medidas inovadoras que melhorem o desempenho ambiental; Aplicação de soluções inovadoras que contribuam para a melhoria da qualidade de vida da população local (PINHEIRO et al., 2013).

\subsection{SISTEMA LIDERA E A CERTIFICAÇÃO DE MATERIAIS E PRODUTOS DA CONSTRUÇÃO CIVIL}

De acordo com Pinheiro (2010), a integração do ciclo de vida dos materiais e produtos na envolvente dos critérios comporta algumas problemáticas que tornam urgente a alteração do paradigma caracterizador deste setor, mas também comporta desafios na dimensão ambiental, capazes de fazer a transição de um setor poluente para um setor mais sustentável e amigo do ambiente, como ilustra a Figura 4. 
Figura 4 - Integração do Ciclo de Vida dos Materiais e Produtos com o Sistema LiderA

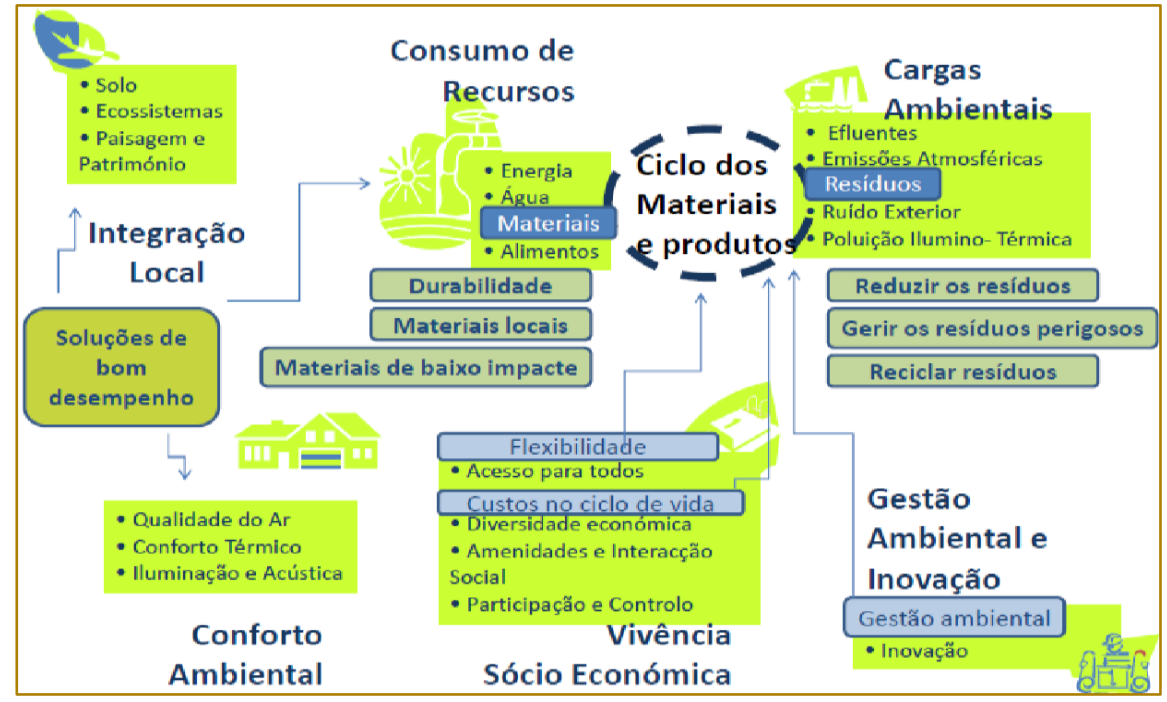

Fonte: FREIXO (2011)

Segundo a metodologia LiderA, a área dos materiais engloba três critérios fundamentais que têm como propósito: assentar a procura da Durabilidade (C12), no fomento da utilização de Materiais Locais (C13) de forma ponderada e na procura estruturante de Materiais de Baixo Impacto (C14).

De acordo com LiderA (2011), o critério de Durabilidade (C12) é de difícil determinação, pois depende da estrutura física, da composição química, dos sistemas construtivos, do local como é aplicado o material, do ambiente, das condições climáticas, dos sistemas de gestão e da manutenção do empreendimento, entre outros fatores. Este critério liga-se ao consumo de materiais, especialmente com foco nos acabamentos, nas redes prediais e entre outras. Para uma estratégia de sustentabilidade, a durabilidade do ambiente construído deve ser aumentada, já que dessa forma se minimizam o consumo de novos materiais de construção, os encargos ambientais que estão associados às fases de renovação e demolição dos ambientes construídos existentes e da construção dos novos ambientes construídos e, consequentemente deve-se aumentar o tempo de vida da construção. No Quadro 2 encontra-se o enquadramento do Sistema LiderA para o critério de Durabilidade.

\section{Quadro 2 - Enquadramento do Critério C12}

\section{Limiares no enquadramento do Sistema LiderA para o critério C12 - Durabilidade}

Fatores relevantes na Durabilidade: estrutura, acabamentos, canalizações e equipamentos comuns, em média (elevadores, instalações elétricas, sensores interiores e exteriores, painel solar, fotovoltaico, tratamento de efluentes, caldeira, etc.). Sendo que a durabilidade da estrutura e dos acabamentos são considerados mais relevantes do que os outros. Esta consideração prende-se muito pelo fato de estarem a ocorrer constantemente inovações ao nível dos equipamentos e ao baixo peso das canalizações face aos restantes materiais. Verificar que pelo menos $50 \%$ dos fatores são considerados.

\begin{tabular}{|c|c|c|c|c|c|c|c|c|}
\hline $\mathrm{A}++$ & $A+$ & $A$ & $B$ & C & $D$ & $E$ & $F$ & $G$ \\
\hline 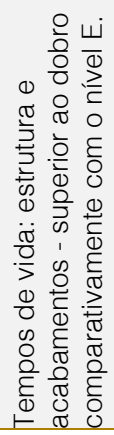 & 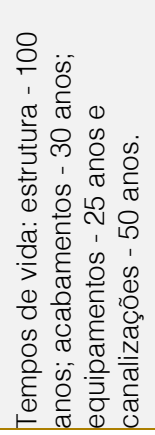 & 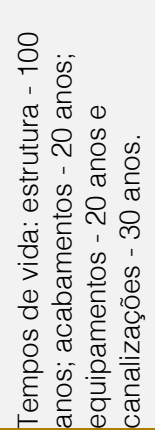 & 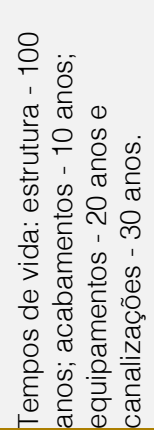 & 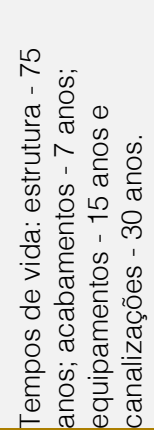 & 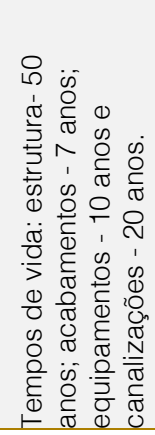 & 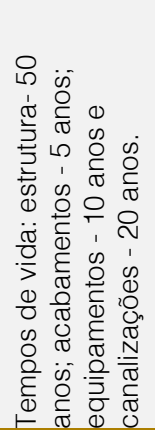 & 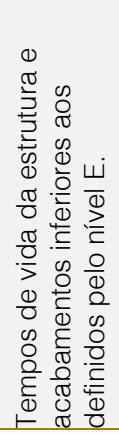 & 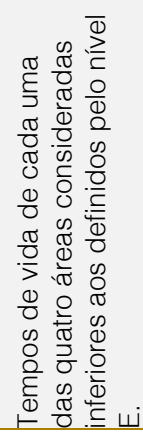 \\
\hline
\end{tabular}


A abordagem ao critério Material Local (C13) tem por base a distância entre a área do empreendimento e a área de produção do material a utilizar. Consequentemente na avaliação deste descritor interessa apostar numa utilização preferencial de materiais locais ou fomentar a prioridade local, em que as quantidades de materiais envolvidos, materiais e produtos fornecidos e produzidos localmente não excedam a distância indicativa de $100 \mathrm{~km}$. A disponibilidade deste critério e a sua utilização pode contribuir para a atenuação das necessidades de transporte (incluindo a respectiva energia e emissões), bem como para fomentar a integração da construção e a dinâmica da economia local. Neste sentido, deve-se privilegiar o uso de materiais locais. No Quadro 3 encontram-se os limiares do enquadramento do Sistema LiderA para o critério de Materiais Locais.

Quadro 3 - Enquadramento do Critério C13

\section{Limiares no enquadramento do Sistema LiderA para o critério C13 - Materiais Locais}

Fatores relevantes nos Materiais Locais: Porcentagem de materiais, face ao total utilizado, produzidos a distância inferior a $100 \mathrm{~km}$. Só contabilizar os materiais que pelo menos $50 \%$ de seus componentes tenham origem e sejam manufaturas dentro do perímetro de $100 \mathrm{~km}$.

\begin{tabular}{|c|c|c|c|c|c|c|c|c|}
\hline$A++$ & $A+$ & $A$ & $B$ & C & D & E & F & G \\
\hline$[90-100] \%$ & {$[75-90[\%$} & {$[50-75[\%$} & {$[37,5-50[\%$} & {$[25-37,5[\%$} & {$[12,5-25[\%$} & {$[10-12,5[\%$} & {$[5-10[\%$} & {$[0-5[\%$} \\
& & & & & & & & \\
\hline
\end{tabular}

Fonte: Adaptado de PINHEIRO (2011a)

Ao adotar o critério Materiais de Baixo Impacto (C14) pretende-se fomentar o uso de materiais com reduzido impacto ambiental, nomeadamente através do recurso a materiais certificados ambientalmente, por exemplo, pelo rótulo ecológico ou por outros Sistemas de Certificação reconhecidos, assim como de materiais reciclados ou materiais com melhor desempenho ambiental e sustentável. O consumo destes materiais permite minimizar os efeitos provocados pela extração e produção dos materiais, constituindo uma opção preferencial ao assegurar o baixo impacto desta indústria, que assegura o respeito para além da dimensão ambiental, dos aspectos relacionados com a saúde pública e conforto. No Quadro 4 encontra-se as liminares do enquadramento do Sistema LiderA para o critério de Materiais de Baixo Impacto.

\section{Quadro 4 - Enquadramento do Critério C14}

Limiares no enquadramento do Sistema LiderA para o critério C14 - Materiais de Baixo Impacto

Fatores relevantes nos Materiais de Baixo Impacto: Porcentagem de materiais, face ao total utilizado, que são certificados, de baixo impacto, reciclados e renováveis.

\begin{tabular}{|c|c|c|c|c|c|c|c|c|}
\hline$A++$ & At & A & B & C & D & E & $\mathrm{F}$ & G \\
\hline$[90-100] \%$ & {$[75-90[\%$} & {$[50-75[\%$} & {$[37,5-50[\%$} & {$[25-37,5[\%$} & {$[12,5-25[\%$} & {$[0-12,5[\%$} & $\begin{array}{c}\text { [0-12,5[\% } \\
\text { dos materiais } \\
\text { previstos } \\
\text { utilizar na } \\
\text { construção } \\
\text { contém pelo } \\
\text { menos } 1 \\
\text { composto } \\
\text { perigoso na } \\
\text { sua } \\
\text { composição }\end{array}$ & $\begin{array}{l}\text { mais de } \\
12,5[\% \text { dos } \\
\text { materiais } \\
\text { previstos } \\
\text { utilizar na } \\
\text { construção } \\
\text { contém pelo } \\
\text { menos } 1 \\
\text { composto } \\
\text { perigoso na } \\
\text { sua } \\
\text { composição }\end{array}$ \\
\hline
\end{tabular}

Fonte: Adaptado de PINHEIRO (2011a) 


\subsection{CASOS DE APLICAÇÃO DO SISTEMA LIDERA EM MATERIAIS E PRODUTOS}

Conforme apresentado no item 3.3 do presente trabalho, a certificação de materiais e produtos é baseada em três critérios fundamentais para $\mathrm{O}$ bom desempenho ambiental, sendo eles os critérios C12, C13 e C14. Ainda o Sistema LiderA relata que, dependendo do material a ser estudado, podem ser adicionados novos critérios com o intuito de fornecer informações mais detalhadas, desde que faça sentido para o caso em questão, ou seja, cada material é um material, e o método de avaliação deve ser consistente entre eles, avaliando materiais de construção, independente das suas propriedades desde que prestem o mesmo serviço. Assim, outros critérios que não pertençam à área de recursos podem vir a ser integrados na avaliação dos materiais em questão.
Para exemplificar a utilização dos critérios de avaliação do LiderA, são apresentados três estudos realizados em Portugal com materiais de construção distintos, utilizados em vários componentes construtivos e em etapas diferentes de uma obra. Os seguintes estudos foram realizados no Instituto Superior Técnico da Universidade Técnica de Lisboa, sob a orientação do Doutor Manoel Pinheiro que é responsável pelo Sistema LiderA, sendo estes:

- "Categorização ambiental de produtos para a construção segundo a metodologia do LiderA - caso das Tintas e Vernizes", elaborado por Rui Freixo em 2011, tendo como concluído que para a uma eficiente avaliação de tintas e vernizes foram necessários analisar os critérios apresentados no Quadro 5.

Quadro 5 - Critérios do LiderA para Tintas e Vernizes

\begin{tabular}{|l|l|c|c|}
\hline \multicolumn{1}{|c|}{ VERTENTE } & \multicolumn{2}{|c|}{ ÁREA } & № \\
\multirow{2}{*}{ Recursos } & Materiais & C12 & CRITÉRIO \\
\cline { 3 - 4 } & C13 & Materiais Locais \\
\cline { 2 - 4 } & C14 & Materiais de baixo impacto \\
\hline Conforto Ambiental & Qualidade do Ar & C24 & Níveis de qualidade do ar \\
\hline Vivência Socioeconômica & $\begin{array}{l}\text { Custos no Ciclo de } \\
\text { Vida }\end{array}$ & C40 & Baixos custos no ciclo de vida \\
\hline
\end{tabular}

Fonte: Adaptado de FREIXO (2011)

- "lluminação e Ecoprodutos Classificação do seu Grau de Procura da Sustentabilidade", realizado por Ana Santos no ano de 2012, que contou com os critérios exibidos no Quadro 6, para uma competente análise sobre a sustentabilidade de alguns materiais de iluminação.

Quadro 6 - Critérios do LiderA para Materiais de lluminação

\begin{tabular}{|c|c|c|c|}
\hline VERTENTE & ÁREA & № & CRITÉRIO \\
\hline \multirow{5}{*}{ Recursos } & \multirow{2}{*}{ Energia } & $\mathrm{C} 7$ & $\begin{array}{l}\text { Eficiência nos consumos e certificação } \\
\text { energética }\end{array}$ \\
\hline & & C9 & Intensidade de Carbono \\
\hline & \multirow{3}{*}{ Materiais } & C12 & Durabilidade \\
\hline & & C13 & Materiais Locais \\
\hline & & C14 & Materiais de baixo impacto \\
\hline \multirow{2}{*}{ Cargas Ambientais } & \multirow{2}{*}{ Resíduos } & C19 & Produção de resíduos \\
\hline & & $\mathrm{C} 20$ & Gestão de resíduos perigosos \\
\hline Conforto Ambiental & Iluminação e Acústica & C26 & Níveis de lluminação \\
\hline Vivência Socioeconômica & Custos no Ciclo de Vida & C40 & Baixos custos no ciclo de vida \\
\hline Uso Sustentável & Gestão Ambiental & C41 & Condições de Utilização Ambiental \\
\hline
\end{tabular}


- "Isolamentos Térmicos e

Revestimentos de Pavimento - Classificação do seu Grau de Procura de Sustentabilidade" desenvolvido por Inês Gomes em 2012, que para a avaliação dos materiais estudados abordou os critérios mencionados no Quadro 7.

Quadro 7 - Critérios do LiderA para Isolamentos Térmicos e Revestimentos de Pavimento

\begin{tabular}{|c|c|c|c|}
\hline VERTENTE & ÁREA & № & CRITÉRIO \\
\hline \multirow{5}{*}{ Recursos } & Energia & $\mathrm{C7}$ & $\begin{array}{l}\text { Eficiência nos consumos e certificação } \\
\text { energética }\end{array}$ \\
\hline & Água & $\mathrm{C} 10$ & Consumo de água potável \\
\hline & \multirow{3}{*}{ Materiais } & $\mathrm{C} 12$ & Durabilidade \\
\hline & & $\mathrm{C} 13$ & Materiais Locais \\
\hline & & C14 & Materiais de baixo impacto \\
\hline \multirow{3}{*}{ Cargas Ambientais } & \multirow{3}{*}{ Resíduos } & C19 & Produção de resíduos \\
\hline & & $\mathrm{C} 20$ & Gestão de resíduos perigosos \\
\hline & & $\mathrm{C} 21$ & Valorização de resíduos \\
\hline \multirow{2}{*}{ Conforto Ambiental } & Qualidade do Ar & $\mathrm{C} 24$ & Níveis de qualidade do ar \\
\hline & Conforto Térmico & C25 & Conforto térmico \\
\hline Vivencia Socioeconômica & Custos no Ciclo de Vida & $\mathrm{C} 40$ & Baixos custos no ciclo de vida \\
\hline
\end{tabular}

Nota: O critério C24 (Níveis de qualidade do ar) foi considerado apenas para os revestimentos de pavimento e o critério C25 (Conforto térmico) para os isolamentos térmicos.

\section{CONCLUSÕES}

A construção tem grande importância e grande impacto na sociedade, desafiando cada vez mais os promotores, construtores, projetistas e gestores a procurarem uma abordagem que integre o bom desempenho ambiental, social e econômico, isto é, buscarem a construção mais sustentável. A necessidade de procurar essa sustentabilidade na construção tem levado ao desenvolvimento de sistemas de avaliação e certificação, neste artigo apresenta-se o sistema LiderA, presente no Brasil desde 2013.

O LiderA é um sistema desenvolvido originalmente na língua portuguesa e aplicada de forma alargada em Portugal e tem vindo a ser aplicado em vários países lusófonos, incluindo embora de forma reduzida também no Brasil. O sistema LiderA apresenta numa abordagem que considera não apenas o desempenho ambiental, mas também o socioeconômico, sendo por isso um sistema para apoio à procura da sustentabilidade, contribuindo para interligar as construções e seus utilizadores.

A metodologia LiderA dispõe de todos os critérios necessários para uma avaliação completa dos produtos, uma vez que dispõe de critérios que englobam os pontos principais, mesmo que por vezes os critérios tenham de ser adaptados para os produtos em questão. Conclui-se que a ACV é o método mais eficiente na avaliação do desempenho ambiental dos produtos quando é possível ter acesso às informações completas de seu ciclo de vida.

A maior parte dos edifícios projetados na atualidade possui um tempo de vida útil superior a 40 anos, causando impacto considerável no meio ambiente. É importante destacar ainda que os materiais de construção apresentam grande potencialidade para a melhoria do desempenho energético e ambiental dos edifícios, e consequentemente para o bemestar da sociedade. Embora os primeiros rótulos para produtos tenham aparecido há quase 30 anos, não existem muitos estudos na área da certificação dos materiais. Também não se observa muita divulgação das vantagens dos materiais certificados e apenas uma pequena parcela da população tem consciência da necessidade de utilizar produtos mais sustentáveis. 


\section{REFERÊNCIAS}

[1]. FREIXO, R. M. G. Categorização ambiental de produtos para a construção segundo a metodologia do LiderA - Caso das Tintas e Vernizes. Dissertação (Mestrado em Engenharia e Gestão Industrial) - Instituto Superior Técnico, Universidade Técnica de Lisboa, Lisboa, 2011.

[2]. GAEDE, L. P. F. Gestão dos Resíduos da Construção Civil no Município de Vitória-ES e Normas Existentes. Monografia (Curso de Especialização em Construção Civil) - da Escola de Engenharia da Universidade Federal de Minas Gerais, Belo Horizonte, 2008.

[3]. GIL, A. C. Métodos e técnicas de pesquisa social. São Paulo: Atlas, 2010.

[4]. GOMES, I. N. Isolamentos Térmicos e Revestimentos de Pavimento - Classificação do seu Grau de Procura de Sustentabilidade. Dissertação (Mestrado em Engenharia do Ambiente) - Instituto Superior Técnico, Universidade Técnica de Lisboa, Lisboa, 2012.

[5]. GRAÇAS, J. A. Residências Sustentáveis e sua Contribuição ao Meio Ambiente, 2010. Dissertação (Mestrado em Construção e Reabilitação Sustentáveis) - Escola de Engenharia, Universidade do Minho, Minho, 2010.

[6]. ISO - (International Standards Organization) 14001: Sistema de Gestão Ambiental, Especificação e Diretrizes Para Uso (1996).

[7]. ISO - (International Standards Organization) 14040: Gestão Ambiental Análise de Ciclo de Vida - Princípios e procedimentos (2006).

[8]. JOHN, V. M. Reciclagem de resíduos na construção civil: Contribuição para metodologia de pesquisa e desenvolvimento. Tese (Livre Docência) - Escola Politécnica da Universidade de São Paulo. Departamento de Engenharia de Construção Civil, São Paulo, 2000.

[9]. LiderA: Sistema Voluntário Para A Sustentabilidade Dos Ambientes Construídos. Disponível em: <http://www.lidera.info/resources/LiderA_Apresenta cao_geral_2011_v1. pdf>. Acesso em: 25 nov. 2015.

[10]. MAXWELL, D., 2003. Developing sustainable products and services. Journal of Cleaner Production, pp.883-895.
[11]. PEREIRA, P. I. Construção Sustentável: o desafio, 2009. Monografia (Licenciatura em Engenharia Civil) - Universidade Fernando Pessoa, Porto, 2009. Disponível em: <http://bdigital.ufp.pt/bitstream /10284/267 4/3/ T_13485.pdf>. Acesso em: 27 nov. 2015.

[12]. PINHEIRO, M. D. Ambiente e Construção Sustentável. 1ed. Portugal: Instituto do Ambiente, 2006, 243 p.

[13]. PINHEIRO, M. D. LiderA: Sistema Voluntário Para A Sustentabilidade Dos Ambientes Construídos. Versão 2.00c. 2011b. 48p.

[14]. PINHEIRO, M. D.; PEREIRA, F. C., RISSARDI, J. L.; SCHWANZ, M. V., GOES, J. L. N.; LiderA - um sistema de apoio à procura eficiente da sustentabilidade na construção civil no Brasil. Anais do Encontro Latinoamericano de Edificações e Comunidades Sustentaveis. 2013.

[15]. PINHEIRO, M. D. Manual Para Projectos De Licenciamento Com Sustentabilidade Segundo O Sistema LiderA. 1a edição digital. 2010. 43p.

[16]. PINHEIRO, M. D. Produtos e Serviços Sustentáveis, Sistematização segundo o LiderA. Lisboa: LiderA. 2011a.

[17]. SANTOS, A. R. C. M. Iluminação e Ecoprodutos - Classificação do seu Grau de Procura da Sustentabilidade. Dissertação (Mestrado em Engenharia do Ambiente) - Instituto Superior Técnico, Universidade Técnica de Lisboa, Lisboa, 2012.

[18]. SETAC. Societty of Environmental Toxicology and Chemistry - Guidelines for LifeCycle Assessment: A code of Practice, Bruxelas, Bélgica. 1993.

[19]. SMITH, W. F. Princípios de Ciência e Engenharia dos Materiais. 3a edição. McGraw-Hill, Portugal, pp. 102-147. 1998.

[20]. SOUSA, S.J. Materiais de Construção Sustentáveis: A sustentabilidade como mote para a Inovação. Jornal arquiteturas no 58 , (Fevereiro de 2011), pp. 27- 29. 2011.

[21]. TOZZI, R.F. Estudo Da Influência Do Gerenciamento $\mathrm{Na}$ Geração Dos Resíduos Da Construção Civil (RCC) - Estudo De Caso De Duas obras Em Curitiba/Pr. Dissertação (Mestrado em Engenharia de Recursos Hídricos e Ambiental) Universidade Federal do Paraná, Curitiba, 2006. 


\section{Capítulo 3}

\section{APROVEITAMENTO DE ÁGUA DE CHUVA EM ESTABELECIMENTO DE PEQUENO PORTE SITUADO EM NITERÓI/RJ}

\section{Marcela Dutra Tenorio Campany}

Resumo: Diante de um cenário em que as empresas estão cada vez mais preocupadas com a questão ambiental por conta do esgotamento dos recursos naturais associado ao aumento da demanda global por água e devido as pressões exercidas pelo ambiente competitivo, pela sociedade e órgãos gestores, os pequenos estabelecimentos possuem dificuldades em investir em projetos de alto custo que promovam a sustentabilidade. O aproveitamento de água de chuva é uma alternativa sustentável que vem sendo cada vez mais praticada pelas grandes empresas, e que pode ser adequada também para as pequenas empresas. $O$ objetivo geral deste trabalho é propor um sistema de aproveitamento de água pluvial em uma empresa de pequeno porte e avaliar a viabilidade econômica do projeto. Calculou-se a demanda mensal a ser atendida pelo sistema, realizou-se o estudo das séries históricas e sintéticas das precipitações da região do Rio de Janeiro, em seguida, dimensionou-se o reservatório para armazenamento da água de chuva, utilizando o método prático australiano, e por fim, calculou-se o período para retorno do investimento. Os resultados demonstraram que a implantação de um sistema de aproveitamento de água de chuva, com um projeto de baixo custo, pode ser viável economicamente para estabelecimentos de pequeno porte, além de contribuir com o meio ambiente. 


\section{INTRODUÇÃO}

O esgotamento dos recursos naturais associado a demanda global por água, que tem aumentado a uma taxa de cerca de 1\% ao ano nas últimas décadas (UNESCO, 2018) em função do crescimento populacional, do desenvolvimento econômico e da mudança nos padrões de consumo, entre outros fatores, representa um grande desafio que a humanidade enfrenta.

Em vista disso, em 2015, durante a Cúpula de Desenvolvimento Sustentável, realizada na Assembleia Geral da ONU, 2018-2028 foi declarada como a década internacional para a ação "Água para o Desenvolvimento Sustentável". (UNITED NATIONS, 2018), que visa o desenvolvimento sustentável e gestão integrada dos recursos hídricos para implementar o ODS 6 (objetivo de desenvolvimento sustentável 6), um dos objetivos dentre os 17 que foram estabelecidos na Assembleia, com a criação da nova agenda de desenvolvimento sustentável para acabar com a pobreza, promover a prosperidade e o bem-estar para todos, proteger o meio ambiente e enfrentar as mudanças climáticas. (ONUBR, 2018)

A Política Nacional de Recursos hídricos, instituída em 1997 pela Lei ํo 9.433 (Lei das Águas), que define que a água é um recurso natural limitado, incluiu, por meio da Lei $n^{\circ}$ 13.501/2017, o novo objetivo de incentivar e promover a captação, a preservação e o aproveitamento de águas pluviais. De acordo com Jabur et al (2011), o aproveitamento de água pluvial está sendo considerado como uma das alternativas para a minimização do escoamento superficial urbano e também na redução do uso da água potável para fins não nobres.

O cenário de desequilíbrio entre a oferta e a demanda de água em grande parte das bacias hidrográficas do Brasil, traz consigo a maior pressão dos órgãos gestores e da sociedade para que o setor empresarial adote práticas responsáveis e transparentes em relação ao uso da água (FIESP, 2017). A gestão ineficiente da água nas empresas aumenta os riscos de danos à sua imagem, podendo comprometer o atendimento legal, aumentar os gastos da produção e o risco de escassez de água (GERBENS-LEENES; HOEKSTRA, 2008).

Ao analisarmos os pequenos negócios existentes, percebemos que causam pouco impacto no ambiente onde estão inseridos.
No entanto, precisamos considerar a existência de cerca de 11 milhões de pequenos negócios no Brasil, que todos os dias utilizam recursos naturais, como água e energia. (SEBRAE, 2018). Diante do exposto, este artigo tem como objetivo geral propor um sistema de aproveitamento de água pluvial em uma empresa de pequeno porte, avaliando a viabilidade econômica do projeto.

\section{REFERENCIAL TEÓRICO \\ 2.1 CAPTAÇÃO DE ÁGUAS PLUVIAIS}

As precipitações na forma de chuva, granizo, orvalho e neve fazem parte do ciclo hidrológico, que é o movimento contínuo da água presente nos oceanos, continentes (superfície, solo e rocha) e na atmosfera.

Gould \& Nissen-Petersen (1999) afirmam que o sistema de captação de água pluvial mais utilizado é por meio de coberturas, principalmente por estar livre de poluentes como animais, veículos, circulação de pessoas, entre outros. A área de contribuição de água de chuva corresponde toda a área do telhado que direciona a água para as calhas, considerando os incrementos devidos à inclinação da cobertura (ABNT NBR 10844, 1989).

Para a captação da água pluvial, dispositivos para remoção de detritos, como grades e telhas, devem ser instalados e recomenda-se o descarte de $2 \mathrm{~mm}$ da precipitação inicial, ou conforme definido pelo projetista (ABNT NBR 15527, 2007). Esse descarte é uma prática empregada visando a qualidade da água pluvial produzida, e busca a eliminação das sujeiras acumuladas na superfície de captação, podendo ser folhas e galhos de árvores, evitando carreamento para a cisterna.

Segundo Tomaz (2003), o volume de água de chuva aproveitável não é o mesmo que o precipitado, pois depende do coeficiente de escoamento superficial da cobertura (relação entre o volume total de escoamento superficial e o volume precipitado, variando conforme a superfície), bem como da eficiência do sistema de descarte do escoamento inicial (ABNT NBR 15527:2007). As perdas de água por evaporação, vazamentos, ente outras (CALDEIRA, 2016) e o tipo de material utilizado no sistema de captação interfere no valor do coeficiente de aproveitamento. A Tabela 1 apresenta diferentes valores para o coeficiente de 
escoamento superficial adotados por materiais de cobertura. diferentes autores, para diferentes tipos de

Tabela 1. Valores para o coeficiente de escoamento superficial

\begin{tabular}{|l|c|c|}
\multicolumn{1}{|c|}{ Material } & Coeficiente de escoamento & Autores \\
\hline Telha de cerâmica & 0,8 a 0,90 & Hofkes e Frasier (1996) \\
\hline Telha corrugada de metal & 0,70 a 0,90 \\
\hline Telhados em geral & 0,70 a 0,95 & Wilken (1978) \\
\hline Telha de chapa corrugada & 0,85 & Khan (2001) \\
\hline Telha de metal & 0,90 a 0,95 & Waterfall \\
\hline Telha de cerâmicaa & 0,75 a 0,95 & Van den Bossche(1997) \\
\hline
\end{tabular}

Fonte: Tomaz (2003)

A norma ABNT NBR 15527:2007 faz menção a seis métodos para o cálculo do dimensionamento do reservatório de água de chuva, são eles: método de Rippl, método da simulação, método Azevedo Neto, método prático alemão, método prático inglês, e método prático australiano. Para este estudo, utilizaremos o método prático australiano, que, em relação aos demais, é menos complexo, de fácil aplicação, e mais indicado para pequenos estabelecimentos, pois reduzem o volume do reservatório e consequentemente, os gastos com a implantação (AMORIM, 2008).

Utilizando o método prático australiano, o volume de chuva é obtido pela seguinte equação:

$$
Q=A \times C \times(P-I)
$$

Sendo, $Q$ = volume mensal produzido pela chuva; $A$ = área de coleta; $C$ = coeficiente de escoamento superficial (pode ser utilizado o valor de 0,80$) ; \quad P=$ precipitação média mensal; I =interceptação da água que molha as superfícies e perdas por evaporação, geralmente $2 \mathrm{~mm}$.
O cálculo do volume do reservatório é realizado por tentativas, até que sejam utilizados valores otimizados de confiança e volume do reservatório, utilizando a seguinte equação para obtenção do volume de água presente no fim de cada mês:

$$
V_{t}=V_{t-1}+Q_{t}-D_{t}
$$

Sendo, $V_{t}=$ volume de água que está no tanque no fim do mês $t ; V_{\mathrm{t}-1}=$ volume de água que está no tanque no início do mês t; $Q_{t}=$ volume mensal produzido pela chuva no mês $\mathrm{t} ; \mathrm{D}_{\mathrm{t}}=$ demanda mensal

\section{METODOLOGIA DA PESQUISA}

O método científico de pesquisa que será empregado para elaboração do trabalho será o estudo de caso de um estabelecimento de pequeno porte, com abordagem exploratória. A pesquisa é de fim prático e explicativa.

Para a estruturação do projeto de captação de água, serão realizados o cálculo da demanda mensal a ser atendida pelo sistema, o estudo das séries históricas e sintéticas das precipitações da região do Rio de Janeiro, o cálculo para o dimensionamento do reservatório de água de chuva, utilizando o método prático australiano, constante na ABNT NBR 15527 e por fim, o período para retorno do investimento será calculado, a 
partir do valor da economia anual gerada e do custo da implantação do sistema.

Os dados utilizados no cálculo da demanda e do volume de água captada serão coletados na empresa e serão elaborados através de pesquisas bibliográficas em normas técnicas, artigos, monografias, e fontes confiáveis de internet. Os dados utilizados para o cálculo do payback, também foram obtidos, alguns por meio de coleta de dados diretamente na empresa, e, outros, de fontes confiáveis da internet.

\section{ESTUDO DE CASO}

\subsection{APRESENTAÇÃO}

O objeto de estudo do presente trabalho é um laboratório analítico de produtos da área da saúde e ambiental, localizado em Niterói/RJ. O prédio em que a empresa está estabelecida possui uma área total de $398 \mathrm{~m}^{2}$, dividida em 2 pavimentos, porém 0 funcionamento da empresa ocorre somente no 2 o andar. Atendendo a 18 funcionários, sendo 14 no turno da manhã e da tarde e 4 somente no turno da tarde, o estabelecimento possui 3 banheiros de uso de seus colaboradores e clientes.
Segundo Frendich; Oliynik (2002) ocorrem dificuldades em construir um sistema de coleta de águas pluviais em edificações já existentes, pois é difícil instalar um reservatório de grande dimensão para armazenamento da água captada, devido a limitações de espaço.

Este trabalho propõe o uso da água da chuva captada em descargas das bacias sanitárias da empresa, utilizando para o armazenamento dessa água, a cisterna de 10 $\mathrm{m}^{3}$ já existente na edificação. Para este fim, o reservatório será secionado em duas partes iguais, tendo $5 \mathrm{~m}^{3}$ para água potável e $5 \mathrm{~m}^{3}$ para água pluvial.

\subsection{ANÁLISE E DISCUSSÃO DOS RESULTADOS}

O consumo mensal de água para fins sanitários foi calculado considerando o consumo de 6 L/descarga (ABNT NBR 15097, 2017) e a frequência de uso indicada por Tomaz (2003) em seu trabalho. De acordo com o estudo realizado, a demanda mensal a ser atendida pelo sistema é de aproximadamente $11000 \mathrm{~L}$ (Tabela 2).

Tabela 2 - Demanda mensal de água utilizada em bacias sanitárias

\begin{tabular}{|c|c|c|}
\hline \multirow{2}{*}{ № Funcionários } & Frequência de uso & Volume de água/dia \\
\hline 15 (manhã e tarde) & 5 vezes/dia & $75 \times 6 \mathrm{~L}=450 \mathrm{~L}$ \\
\hline 4 (tarde) & 2 vezes/dia & $8 \times 6 \mathrm{~L}=48 \mathrm{~L}$ \\
\hline Volume Total de água/mês & \multicolumn{2}{|c|}{$498 \times 22=10956 \mathrm{~L}$} \\
\hline
\end{tabular}

Fonte: Autor do texto

Os dados pluviométricos da região do Rio de Janeiro foram localizados no site do Instituto Nacional de Metrologia (INMET), após cadastro no Banco de Dados Meteorológicos para Ensino e Pesquisa (BDMEP). Utilizou-se dados oficiais de 01/01/2003 até 31/12/2016, com as seguintes entradas: latitude (graus): 22.89; longitude (graus): -43.18; Altitude (metros): 11.10. O período estipulado para o estudo foi exclusivamente definido pela disponibilidade na estação escolhida.

A Figura 1 apresenta a precipitação total dos anos de 2003 a 2016. O índice pluviométrico anual da região do Rio de Janeiro é em média de $1129,59 \mathrm{~mm}$ 
Figura 1 -Volume da precipitação total anual na cidade do Rio de Janeiro - 2003 a 2016 (mm)

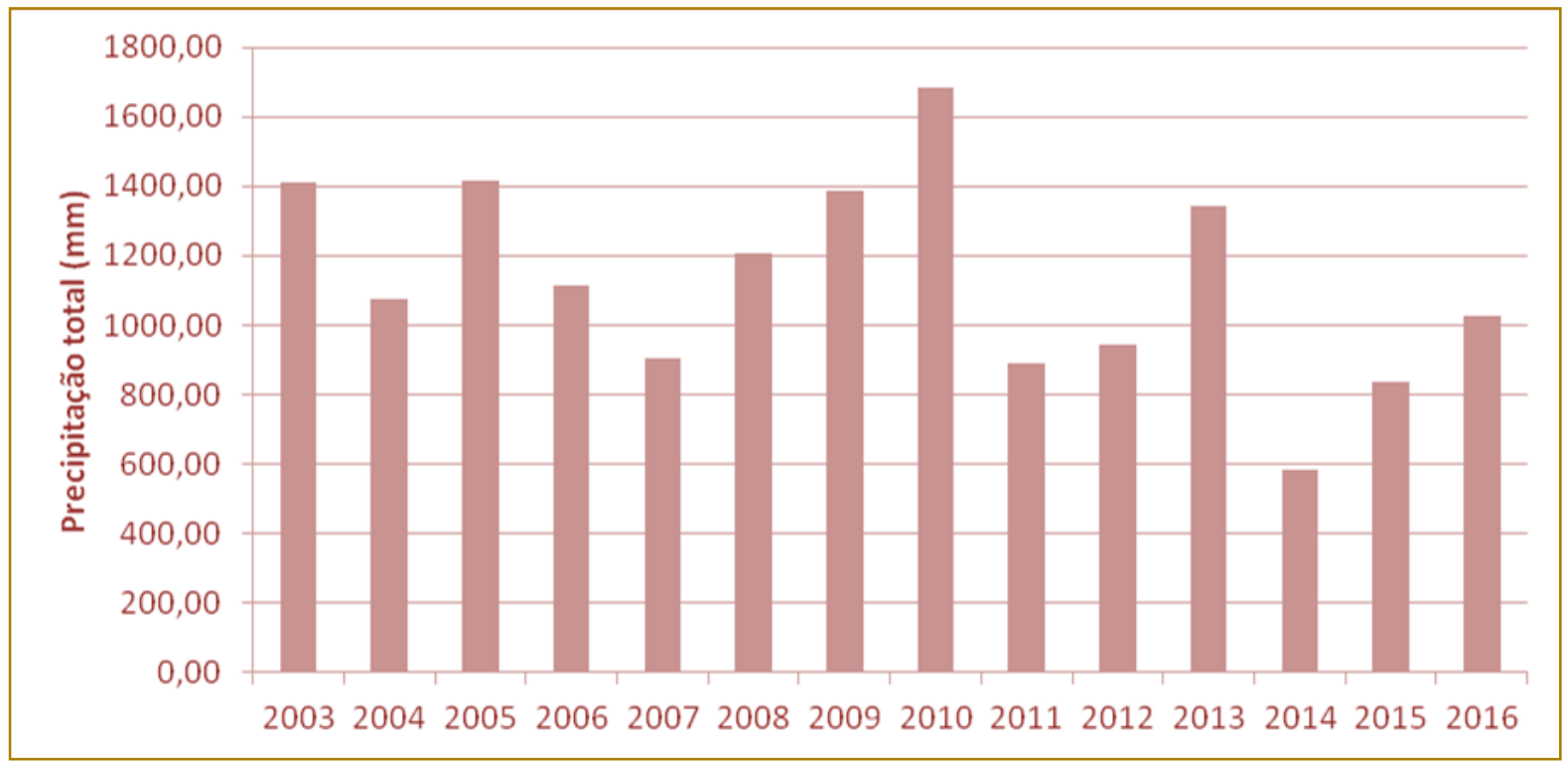

Fonte: Dados INMET

A Figura 2 apresenta a média mensal de precipitação na cidade do Rio de Janeiro, considerando os anos de 2003 a 2016.
Analisando o gráfico é possível perceber que ocorre menor volume de precipitação nos meses de maio a setembro.

Figura 2 - Média da precipitação total mensal - 2003 a 2016 - Rio de Janeiro

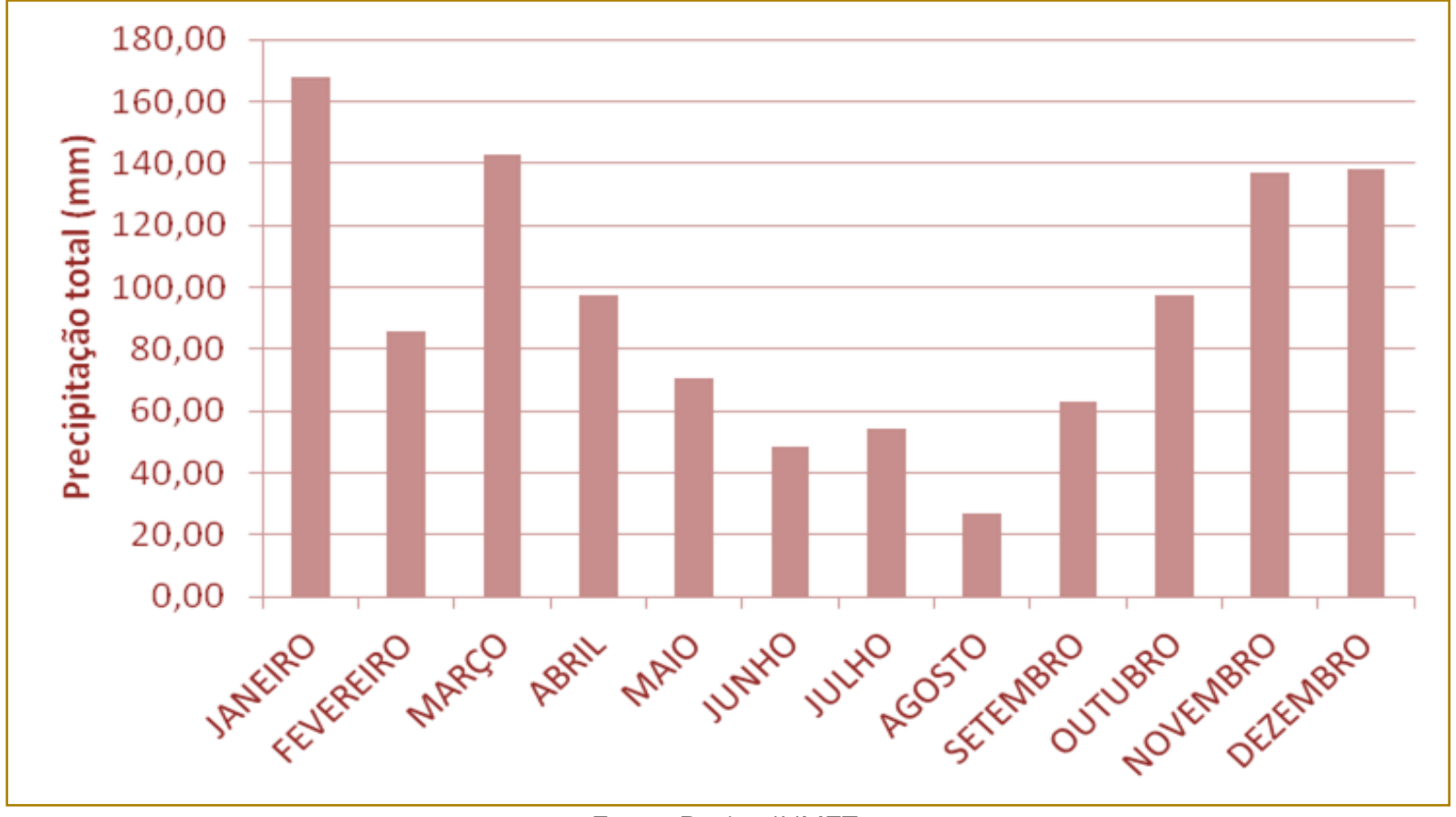

Fonte: Dados INMET

Os reservatórios foram dimensionados para atender o volume de $7000 \mathrm{~L}$ de água captada (Tabela 3). Utilizou-se neste estudo o coeficiente de escoamento superficial igual a
0,80 e considerou o valor de $2 \mathrm{~mm}$ para interceptação da água que molha as superfícies e perdas por evaporação. 
Tabela 3 - Dimensionamento do reservatório utilizando o método prático australiano.

\begin{tabular}{|c|c|c|c|c|c|c|}
\hline & $\mathrm{P}(\mathrm{mm})$ & $A\left(m^{2}\right)$ & $\mathrm{Q}\left(\mathrm{m}^{3}\right)$ & $D\left(m^{3}\right)$ & $V_{t-1}\left(m^{3}\right)$ & $V_{t}\left(m^{3}\right)$ \\
\hline JANEIRO & 167,65 & 200,00 & 26,50 & 11,00 & 0,00 & 7,00 \\
\hline FEVEREIRO & 85,79 & 200,00 & 13,41 & 11,00 & 7,00 & 9,41 \\
\hline MARÇO & 142,84 & 200,00 & 22,53 & 11,00 & 7,00 & 18,53 \\
\hline ABRIL & 97,49 & 200,00 & 15,28 & 11,00 & 7,00 & 11,28 \\
\hline MAIO & 70,66 & 200,00 & 10,99 & 11,00 & 7,00 & 6,99 \\
\hline JUNHO & 48,51 & 200,00 & 7,44 & 11,00 & 6,99 & 3,43 \\
\hline JULHO & 54,21 & 200,00 & 8,35 & 11,00 & 3,43 & 0,78 \\
\hline AGOSTO & 26,85 & 200,00 & 3,98 & 11,00 & 0,78 & $-6,24$ \\
\hline SETEMBRO & 63,03 & 200,00 & 9,76 & 11,00 & 0,00 & $-1,24$ \\
\hline OUTUBRO & 97,39 & 200,00 & 15,26 & 11,00 & 0,00 & 4,26 \\
\hline NOVEMBRO & 137,18 & 200,00 & 21,63 & 11,00 & 4,26 & 14,89 \\
\hline DEZEMBRO & 137,99 & 200,00 & 21,76 & 11,00 & 7,00 & 17,76 \\
\hline
\end{tabular}

$\mathrm{Q}=$ volume mensal produzido pela chuva; $\mathrm{A}$ = área de coleta; $P=$ precipitação média mensal; $V_{t}=$ volume de água que está no tanque no fim do mês $\mathrm{t} ; \mathrm{V}_{\mathrm{t}-1}=$ volume de água que está no tanque no início do mês t; $\mathrm{D}=$ demanda mensal

Apesar da soma das capacidades dos reservatórios ser igual a $7 \mathrm{~m}^{3}$ e a demanda mensal igual a $11 \mathrm{~m}^{3}$, diariamente (exceto aos finais de semanas), serão consumidos aproximadamente $0,5 \mathrm{~m}^{3}$ de água para fins sanitários, logo os reservatórios serão parcialmente esvaziados dando lugar a novas águas captadas.

O projeto para implantação do sistema de aproveitamento de água da chuva na empresa em questão é composto pelo reservatório inferior de $5000 \mathrm{~L}$ (já existente) e reservatório superior de 2000L, conforme esquema representado na Figura 3.

Figura 3 - Esquema vertical em perspectiva do projeto de aproveitamento de água de chuva

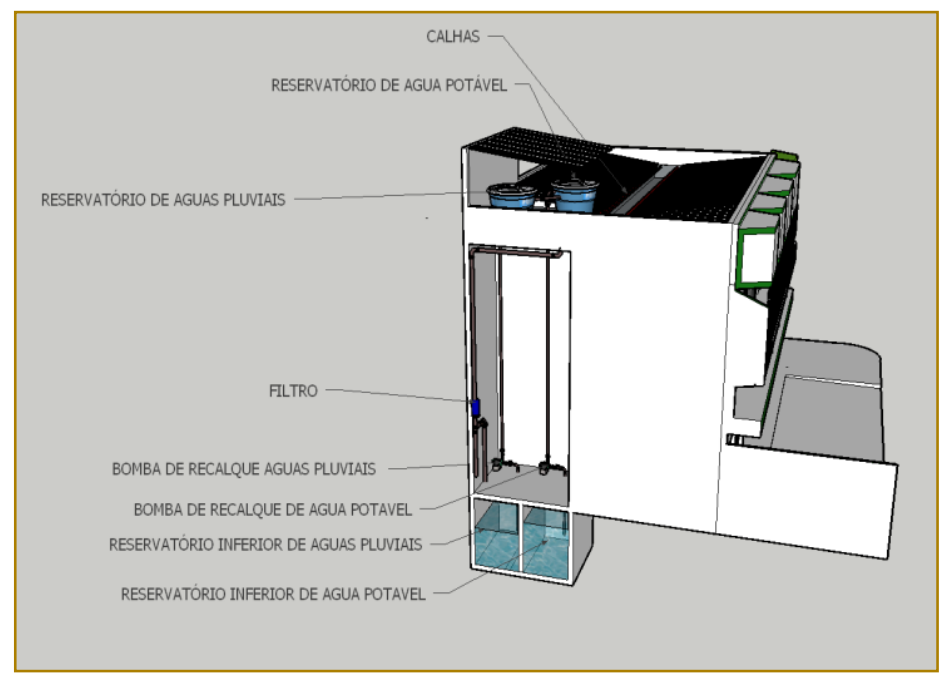


O custo para implantação do sistema foi estimado em $R \$ 5200,00$ (Tabela 4). Os meses em que ocorrerem baixo volume de precipitação, e o volume de água presente no tanque não for suficiente, a demanda será suprida por água potável oriunda do reservatório interligado ao sistema.

Tabela 4 - Custo estimado do projeto

\begin{tabular}{|l|c|}
\hline \multicolumn{1}{|c|}{ Produto } & Valor \\
\hline Reservatório superior 2000 L & $R \$ 790,94$ \\
\hline Filtro modelo 3P VF1 & $R \$ 1390,00$ \\
\hline Bomba & $R \$ 600,00$ \\
\hline Boia elétrica & $R \$ 33,54$ \\
\hline Boia comum & $R \$ 11,20$ \\
\hline Disjuntor & $R \$ 17,30$ \\
\hline Tubulações, válvulas e conexões & $R \$ 300,00$ \\
\hline Cisterna (secionamento) & $R \$ 1000,00$ \\
\hline Mão de obra & $R \$ 1000,00$ \\
\hline & $R \$ 5142,98$ \\
\hline
\end{tabular}

Considerando que a tarifa vigente da concessionária responsável pelo abastecimento de água potável na cidade de Niterói/RJ para faixa de uso entre 21 a $30 \mathrm{~m}^{3}$, categoria comercial, é de $R \$ 19,15 / \mathrm{m}^{3}$, e que a tarifa do esgoto corresponde a $100 \%$ deste valor, a economia gerada com o uso da água captada da chuva em bacias sanitárias é de aproximadamente $R \$ 4500,00 /$ ano (tabela 5).

Tabela 5 - Economia gerada com a captação de água de chuva para uso em bacias sanitárias

\begin{tabular}{|c|c|c|c|c|c|}
\hline \multirow{2}{*}{ Mês } & Água economizada $\left(\mathrm{m}^{3}\right)$ & \multicolumn{1}{c}{$\begin{array}{c}\text { Valor } \\
\text { água }\end{array}$} & Esgoto & $\begin{array}{c}\text { Valor } \\
\text { esgoto }\end{array}$ & Total \\
\hline JANEIRO & 11 & $\mathrm{R} \$ 210,62$ & $100 \%$ & $\mathrm{R} \$ 210,62$ & $\mathrm{R} \$ 421,24$ \\
\hline FEVEREIRO & 11 & $\mathrm{R} \$ 210,62$ & $100 \%$ & $\mathrm{R} \$ 210,62$ & $\mathrm{R} \$ 421,24$ \\
\hline MARÇO & 11 & $\mathrm{R} \$ 210,62$ & $100 \%$ & $\mathrm{R} \$ 210,62$ & $\mathrm{R} \$ 421,24$ \\
\hline ABRIL & 11 & $\mathrm{R} \$ 210,62$ & $100 \%$ & $\mathrm{R} \$ 210,62$ & $\mathrm{R} \$ 421,24$ \\
\hline MAIO & 11 & $\mathrm{R} \$ 210,62$ & $100 \%$ & $\mathrm{R} \$ 210,62$ & $\mathrm{R} \$ 421,24$ \\
\hline JUNHO & 7,44 & $\mathrm{R} \$ 142,48$ & $100 \%$ & $\mathrm{R} \$ 142,48$ & $\mathrm{R} \$ 284,96$ \\
\hline JULHO & 8,35 & $\mathrm{R} \$ 159,90$ & $100 \%$ & $\mathrm{R} \$ 159,90$ & $\mathrm{R} \$ 319,80$ \\
\hline AGOSTO & 3,98 & $\mathrm{R} \$ 76,21$ & $100 \%$ & $\mathrm{R} \$ 76,21$ & $\mathrm{R} \$ 152,42$ \\
\hline SETEMBRO & 9,76 & $\mathrm{R} \$ 186,88$ & $100 \%$ & $\mathrm{R} \$ 186,88$ & $\mathrm{R} \$ 373,76$ \\
\hline OUTUBRO & 11 & $\mathrm{R} \$ 210,62$ & $100 \%$ & $\mathrm{R} \$ 210,62$ & $\mathrm{R} \$ 421,24$ \\
\hline NOVEMBRO & 11 & $\mathrm{R} \$ 210,62$ & $100 \%$ & $\mathrm{R} \$ 210,62$ & $\mathrm{R} \$ 421,24$ \\
\hline DEZEMBRO & 11 & $\mathrm{R} \$ 210,62$ & $100 \%$ & $\mathrm{R} \$ 210,62$ & $\mathrm{R} \$ 421,24$ \\
\hline
\end{tabular}


Neste estudo, não foram considerados os custos referentes a energia elétrica utilizada para o funcionamento da bomba, de depreciação e nem de manutenção do sistema. Assim, o prazo de retorno do investimento (payback) é de menos de 2 anos, conforme a tabela 6 . O período de payback é o prazo necessário para que uma empresa recupere o investimento inicial em um projeto, sem considerar explicitamente o valor do dinheiro no tempo (GITMAN, 2010).

Tabela 6 - Prazo de retorno do investimento

\begin{tabular}{|c|c|c|}
\hline Valor investido & Economia $1^{\circ}=$ ano & Economia $2^{\circ}$ ano \\
\hline$R \$-5200,00$ & $\mathrm{R} \$ 4500,86$ & $\mathrm{R} \$ 4500,86$ \\
\hline Payback simples & $R \$-699,14$ & $\mathrm{R} \$ 3801,72$ \\
\hline
\end{tabular}

Baseado nas contas da concessionária local responsável pelo abastecimento de água, foi possível estimar que a empresa tem o custo de $R \$$ 900,00/mês (média dos últimos 12 meses) com o uso de água potável. Com a implantação deste sistema de aproveitamento de água de chuva, é previsto redução de $42 \%$ deste orçamento mensal.

\section{CONCLUSÃO}

Em um cenário em que as empresas estão cada vez mais se preocupando com a questão ambiental, devido as pressões exercidas pelo ambiente competitivo e pela sociedade, as micro e pequenas empresas se deparam com dificuldades como a mobilização de recursos, próprios ou de terceiros, para financiar projetos e investimentos capazes de contribuir para a melhoria das condições ambientais. (Fonseca et al, 2010)

Algumas referências encontradas na literatura, como o manual "O uso racional da água no setor industrial" (CNI, 2017), define que construções com área impermeabilizada inferior a $500 \mathrm{~m}^{2}$ não viabilizam um projeto de aproveitamento de águas pluviais, pela quantidade de água armazenada ser incompatível ao alto custo gasto com tubulações, reservatórios e com o sistema de tratamento necessário. Fonseca et al (2016) demonstrou em seu trabalho, que a implantação de um sistema de aproveitamento de água de chuva não é viável economicamente para moradias com uma ou duas pessoas, porém o estudo com quatro residentes e uma área de captação de $200 \mathrm{~m}^{2}$ demonstrou boa relação custo benefício.
O presente trabalho demonstrou a viabilidade da implementação de um sistema de aproveitamento de água de chuva em empresa com área de captação igual a 200 $\mathrm{m}^{2}$, sendo um recurso aplicável também à pequenos negócios, pois o projeto de baixo custo proposto aliado a alta tarifa cobrada pela concessionária de abastecimento de água da cidade de Niterói geram um período para retorno do investimento menor do que outros trabalhos já realizados com valores de áreas de captação próximos ao do estudo realizado. Concluímos também, que apesar do tamanho da área de captação do estudo em questão não ser o indicado, o número de pessoas contempladas pelo sistema de aproveitamento contribui para a viabilidade econômica do projeto.

A simplificação do sistema de aproveitamento proposto é possível devido a finalidade imposta no trabalho, o uso em bacias sanitárias. É importante salientar que a qualidade da água de chuva para usos restritivos não potáveis deve ser verificada e, em alguns casos, a adição de cloro no reservatório para a eliminação de contaminação microbiológica é necessária. Os padrões de qualidade são definidos pelo projetista de acordo com a finalidade do uso da água, porém, para usos mais restritivos, devem ser verificados os parâmetros descritos na norma ABNT NBR 15527:2007: coliformes totais, coliformes termotolerantes, cloro residual livre, turbidez, cor aparente e $\mathrm{pH}$.

Os benefícios ambientais gerados pela implantação de projetos deste cunho incluem, além da redução do uso da água potável, a questão da drenagem urbana, minimizando a ocorrência de cheias, já que promove o reuso 
de águas que seriam descartadas no ambiente.

\section{AGRADECIMENTOS}

Agradeço ao arquiteto Vinicius Brigido Campany pelo suporte técnico e elaboração da representação do projeto.

[11]. GOULD, John; NISSEN-PETERSEN. Rainwater Catchment Systems for Domestic Suplly. 1999

[12]. GRUPO ÁGUAS DO BRASIL. Estrutura tarifária - Águas de Niterói. Disponível em: $<$ http://www.grupoaguasdobrasil.com.br/aguasniteroi/agencia-virtual/estrutura-tarifaria/>. Acesso em 02 de abril, 2018.

[13]. INMET. Instituto Nacional de Meteorologia. Disponível em: <http://www.inmet.gov.br> Acesso em: 02 abril, 2018

[14]. JABUR, Andrea Sartori; BENETTI, Heloiza Piassa; SILIPRANDI, Elizangela Marcelo. Aprimoramento da Água Pluvial para Fins Não Potáveis. Curitiba: UTFPR, VII Congresso Nacional de Excelência em Gestão. 2011.

[15]. LEI № 9.433. Institui a Política Nacional de Recursos Hídricos, Cria o Sistema Nacional de Gerenciamento de Recursos Hídricos. Brasília, 8 de janeiro de 1997.

[16]. LEI №13.501. Altera o artigo $2^{\circ}$ da Lei $\mathrm{n}$ ㅇ 9.433 de 8 de janeiro de 1997. Brasília, 30 de outubro de 2017

[17]. ONUBR, Nações Unidas no Brasil. 17 Objetivos para Transformar Nosso Mundo. Disponível em: <http:// nacoesunidas.org/pos2015/>. Acesso em: 02 de abril, 2018.

[18]. UNESCO, United Nations Educational, Scientific and Cultural Organization. WWDR 2018 Nature-Based Solutions for Water. Paris, 2018.

[19]. SEBRAE, Sustentabilidade Para os Pequenos Negócios. 2018. Disponível em: <http://www.sebrae.com.br/sites/PortalSebrae/artig os/sustentabilidade-para-os-pequenosnegocios,b6ad6ca28e87e510VgnVCM1000004c00 210aRCRD>. Acesso em: 18 de abril, 2018.

[20]. TOMAZ, Plínio. Aproveitamento de água de chuva: para áreas urbanas e fins não-potáveis. São Paulo, 2003.

[21]. UNITED NATIONS. International Decade for Action on Water for Sustainable Development, 2018-2018. Disponível em: <http://www.un.org/en/events/waterdecade/> Acesso em: 02 abril, 2018. 


\section{Bapítulo 4}

\section{GESTÃO ESTRATÉGICA DE SUSTENTABILIDADE: CONECTANDO LUCRO $\mathrm{COM}$ IMPACTOS SOCIOAMBIENTAIS!}

\section{Maria Christina Barbosa da Costa}

Sonia Lopes da Silva

Resumo: A sustentabilidade é uma dimensão que não pode ser ignorada pelas organizações no século XXI sob a pena de verem sua perenidade ameaçada. Ela engloba aspectos econômicos, sociais e ambientais, sendo importantíssima para tomada de decisão na escolha de onde aplicar investimentos. Para ser efetiva, a visão de sustentabilidade deve estar presente em diversas instâncias na governança corporativa, desde o seu planejamento estratégico, passando pela gestão de portfólio, programas e projetos, sem desprezar as operações. Assim, os resultados do alinhamento da alocação de capital e do comportamento corporativo aos objetivos de estabilidade financeira e de desenvolvimento sustentáveis, mais amplos e longevos, poderão ser apresentados em relatórios de desempenho integrados, para qualquer público e em qualquer formato.

Palavras-chave: Sustentabilidade, governança corporativa, planejamento estratégico sustentável, relatórios integrados. 


\section{INTRODUÇÃO}

\subsection{CONTEXTUALIZAÇÃO}

Em qualquer segmento de negócio, uma organização existe para gerar valor. Ele deve estar muito claro para todos os stakeholders, pois é o responsável pela longevidade de sua organização e base para definição de toda a estratégia a ser adotada. O valor é diretamente influenciado pelos impactos positivos e negativos (riscos e oportunidades) que a organização produz com suas atividades, produtos e serviços, nos ambientes interno e externo a ela. Os impactos podem afetar outros capitais que não o econômico/financeiro e, por isso, devem ser mapeados no gerenciamento de riscos, associados aos processos de governança.

Nesse contexto, a sustentabilidade contribui fortemente, e de forma imprescindível, para que as organizações continuem existindo em um mundo cheio de incertezas.

Sustentabilidade é muito mais do que plantar árvores, separar o lixo, apagar as luzes ou economizar água. Todos esses exemplos podem contribuir para que o indivíduo e sua organização se tornem sustentáveis, mas não necessariamente isso vai acontecer somente com ações isoladas. É necessário ter conhecimento estruturado dos reais impactos sociais, ambientais e/ou econômicos, positivos e negativos, criados.

Equivocadamente, o assunto sustentabilidade tem sido abordado, na maior parte das vezes e nos últimos anos, relacionado somente aos impactos ambientais, mais fortemente às mudanças climáticas, decorrentes da emissão de Gases de Efeito Estufa (GEE). Na verdade, os impactos ambientais negativos são os efeitos mais visíveis ao ser humano de suas ações irresponsáveis, pessoais ou profissionais, em relação ao planeta, que culminam no aquecimento global.

Algumas leis, no Brasil e no mundo, foram estabelecidas com o objetivo de melhorar esse cenário a partir da regulamentação ambiental. A maioria das organizações ainda não conseguem tangibilizar os impactos ambientais que produzem e o seu efeito no valor agregado real. Elas só reconhecem as ações relacionadas a regulamentações como custo extra, que acaba afetando negativamente o lucro. Em alguns casos, o marketing verde poderia também ser um benefício identificado com essas ações, já que melhoraria a imagem da organização para o mundo. Mas sem rastreabilidade e transparência nas ações executadas e resultados alcançados, o marketing verde acaba produzindo o efeito inverso, negativo e sendo considerado green washing.

$\mathrm{Na}$ verdade, não há como tratar a sustentabilidade sem equilibrar os aspectos sociais, ambientais e econômicos (triple bottom line). Alguns serão mais relevantes do que outros para determinadas organizações, mas esse entendimento a partir da definição da materialidade ficará bem claro (ver figura 1).

Figura 1: Três pilares da sustentabilidade

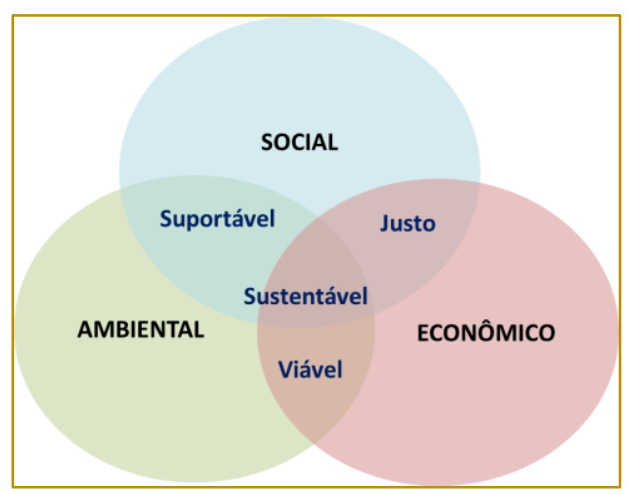

A sustentabilidade é tão importante que tem sido tratada globalmente desde a elaboração do Protocolo de Quioto, elaborado em 1997. Para citar somente as iniciativas mais recentes, na Conferência das Partes da Convenção das Nações Unidas sobre a Mudança Climática de 2015 - COP21, em Paris, foram lançados 17 Objetivos de 
Desenvolvimento Sustentável (ODS) pela ONU, com 169 metas (ORGANIZAÇÃO DAS NAÇÕES UNIDAS, 17 OBJETIVOS PARA TRANSFORMAR NOSSO MUNDO, 2015) e
232 indicadores (ORGANIZAÇÃO DAS NAÇÕES UNIDAS, 2017), definidos para 195 países em 2030.

Figura 2: Objetivos de Desenvolvimento Sustentável (ODS)

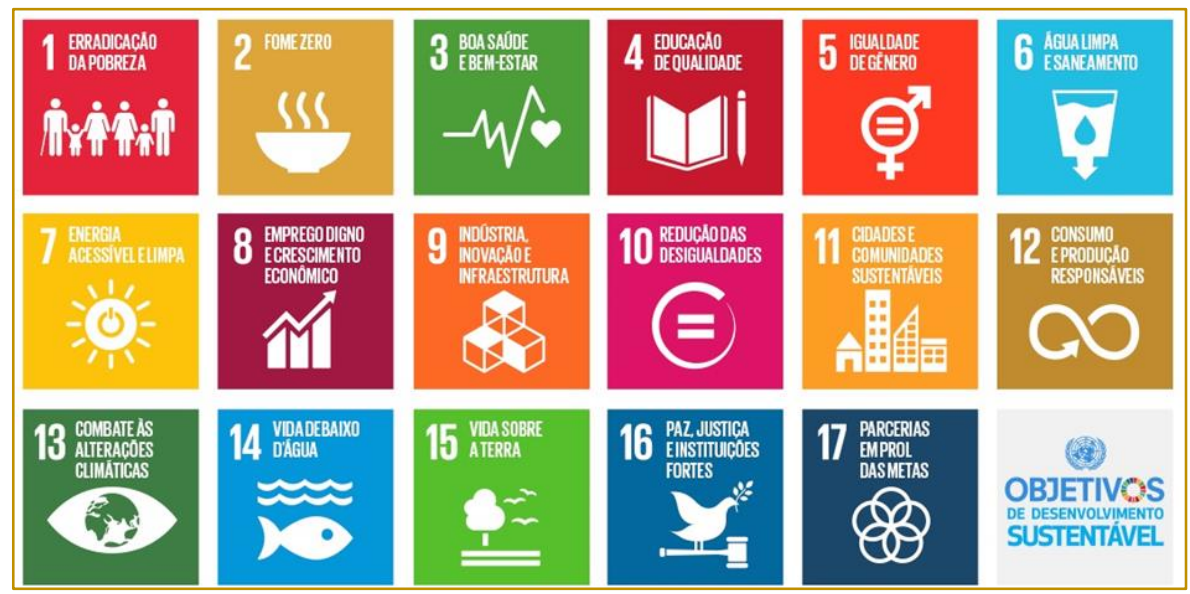

$\mathrm{Na}$ COP21, as metas assumidas pelo Brasil foram:

- Cortar as emissões de gases de efeito estufa em 37\% até 2025 e em 43\% até 2030 (com base nos resultados de 2005);

- Aumentar a participação na sua matriz energética de bioenergia sustentável para $18 \%$ até 2030 ;

- Restaurar e reflorestar 12 milhões de hectares de florestas;

- Zerar o desmatamento ilegal da Amazônia.

Em 2016, na COP22, foram realizadas negociações técnicas para a regulamentação e concretização destas metas, para a cooperação internacional e entre os setores público e privado.

Apesar da relevância dos acordos anteriores, em 31/10/2017, a ONU Meio Ambiente divulgou o Emissions Gap Report (UNITED NATIONS ENVIRONMENT PROGRAMME [UNEP], 2017), demonstrando que não será possível evitar os piores impactos das mudanças climáticas até 2030, mesmo cumprindo todos os compromissos assumidos, até aquele momento. Assim, o holofote da COP23, realizada em Bonn, em novembro de 2017, focou nas medidas urgentes que os países têm que implantar, para que o acordo da COP 21 possa entrar em vigor em 2020. A principal meta do encontro foi continuar controlando as emissões de gases de efeito estufa para limitar o aquecimento máximo do planeta a uma temperatura média de $2^{\circ} \mathrm{C}$, nos termos fixados em 2015, apesar de novas previsões já determinarem que o mais provável é que ela chegue a $3^{\circ} \mathrm{C}$ em 2030.

Entidades nacionais e internacionais estão tratando a sustentabilidade, algumas de forma isolada e outras já integradas, buscando parcerias e colaboração. Elas têm promovido acordos, políticas, pesquisas, projetos, eventos, cursos, certificações, etc.

Além dos ODSs, muitas estruturas têm sido desenvolvidas, para auxiliar o entendimento e a aplicação de ações para implementar a sustentabilidade. $\mathrm{Na}$ medida em que o assunto é relativamente novo e fruto de muitos estudos, não é difícil encontrar novidades frequentemente. Observar alguns exemplos de estruturas de sustentabilidade que podem servir de base na escolha do que será utilizado pela sua organização é útil para a definição dos aspectos socioambientais e econômicos relevantes, para definição e acompanhamento de ações para tratá-los, e também para a divulgação de resultados, podemos citar: Sistema B (BCorp), Global Report Initiative (GRI), International Integrated Reporting Council (IIRC), Índice de Sustentabilidade Empresarial (ISE), Dow Jones Sustainability Index (DJSI). 
Quadro 1: Critérios para escolha de estrutura de sustentabilidade

\begin{tabular}{|l|l|}
\hline $\begin{array}{l}\text { Objetivos de desenvolvimento } \\
\text { sustentável (ods) }\end{array}$ & $\begin{array}{l}\text { Organizações que usam ou pretendem usar qualquer outra } \\
\text { estrutura e podem associá-la aos ODSs. }\end{array}$ \\
\hline Global report initiative (gri) & $\begin{array}{l}\text { Organizações que fazem ou pretendem fazer relatórios de } \\
\text { sustentabilidade usando a estrutura GR/. }\end{array}$ \\
\hline Relato integrado (iirc) & $\begin{array}{l}\text { Organizações que fazem ou pretendem fazer relatórios } \\
\text { integrando contabilidade e sustentabilidade no formato do } \\
\text { Relato Integrado. }\end{array}$ \\
\hline Sistema b & \begin{tabular}{l} 
Organizações que já têm ou pretendem ter a certificação B. \\
\hline $\begin{array}{l}\text { Índice de sustentabilidade } \\
\text { organizacional (ise) }\end{array}$
\end{tabular}$\quad \begin{array}{l}\text { Empresas listadas ou que pretendem ser listadas na } \\
\text { BM\&FBOVESPA. }\end{array}$ \\
\hline Dow jones sustainability index (djsi) & $\begin{array}{l}\text { Empresas listadas ou que pretendem ser listadas na Bolsa } \\
\text { de Nova York. }\end{array}$ \\
\hline
\end{tabular}

As organizações podem adotar uma estrutura de sustentabilidade, baseada em um ou mais direcionadores descritos anteriormente (Sistema B, ODSs, GRI, IIRC, ISE, DJSI, etc.). A escolha se dará em função do ambiente em que seu negócio opera e a forma como sua organização quer divulgar suas informações relacionadas à sustentabilidade. O Quadro 1 pode ajudar a selecionar a estrutura de sustentabilidade mais adequada, tanto para o gerenciamento como para emissão de relatórios de resultados.

\subsection{SITUAÇÃO PROBLEMA}

As organizações são responsáveis pela maior parte das causas dos eventos geradores das mudanças climáticas! Além disso, com o avanço do neoliberalismo após a Segunda Guerra Mundial, os governos passaram a transferir as responsabilidades sociais para as organizações privadas. Consequentemente, os governos só alcançarão suas metas através de ações implementadas pelas organizações, a partir de novos modelos de negócios e de gestão. E, como já se sabe, as organizações só alcançam resultados a partir das atitudes dos indivíduos (acionistas, sócios, colaboradores, fornecedores, reguladores e até clientes).

Novos princípios passam a regular o mundo dos negócios como:
- A harmonização entre os interesses econômicos, sociais e ambientais garantem a criação de valor sustentável para o negócio;

- Não se pode mais pensar somente em curto e médio prazo, pois é pensar em longo prazo que permite transformar ativos vulneráveis em resistentes;

- A noção de responsabilidade intra e intergeracional induz à escolha de opções mais longevas;

- A abordagem sobre o que deve ser local, regional e global determinará escolhas relacionadas a fornecedores, logística, comunicação, etc.;

- Consumir a receita e não o capital proporcionará continuidade;

- Transparência e prestação de contas (accountability) possibilitarão parcerias, investimentos e engajamento mais efetivos;

- Valores pessoais e ética passam a ter peso na escolha de ações, equipes, fornecedores, clientes, etc.;

Como a responsabilidade pela integração de sustentabilidade recai sobre todos seus stakeholders, todos têm que mudar. A cadeia produtiva e de logística precisam assumir a responsabilidade por sua cota, mas nem sempre sabem como. Este "como" é o objetivo deste trabalho.

\subsection{OBJETIVO}

A partir da situação descrita acima passamos a trabalhar no desenvolvimento de um modelo que ajudasse as organizações a identificar 
sua materialidade, definir objetivos estratégicos sustentáveis e os indicadores de sustentabilidade que fossem desdobrados em ações que permitissem o monitoramento contínuo destes indicadores, facilitando a emissão dos relatórios consolidados, qualquer que tenha sido o tipo definido pela organização.

\subsection{MÉTODO}

Assim, quanto aos fins, a pesquisa elaborada foi do tipo aplicada, aquela que é "motivada pela necessidade de resolver problemas concretos [...] Tem, portanto, finalidade prática" (VERGARA, 2007, p. 47). Por ter como objetivo o desenvolvimento de uma forma das organizações conduzirem as suas questões relacionadas à sustentabilidade, desdobrando-as em projetos e ações com indicadores para o acompanhamento de desempenho, podemos dizer que a pesquisa, ainda quanto aos fins, também é do tipo metodológica, que "está associada a caminhos, formas, maneiras, procedimentos para atingir determinados fins" (VERGARA, 2007, p. 47)

A fase inicial foi estruturada como uma pesquisa bibliográfica inicialmente com foco em todos os aspectos da Sustentabilidade e expandindo-se para temas como Governança Corporativa, Gestão de Mudança Cultural e Métodos Ágeis, estes últimos com o objetivo de chegarmos a um modelo enxuto, sem desperdícios, com empoderamento dos colaboradores e uso de ferramentas como canvas, kanban e o framework scrum.

A partir da consolidação do conhecimento inicial, partimos para uma pesquisa, quanto aos fins, experimental, aquela que "o pesquisador manipula e controla variáveis e observa as variações que tais manipulações e controle produzem em variáveis dependentes" (VERGARA, 2007, p. 48), o que foi feito a partir da definição de um Produto Mínimo Viável (Minimum Viable Product MVP) que foi testado entre fevereiro e novembro de 2017 em 16 organizações de pequeno e médio porte, privadas, de áreas como: limpeza de lagoas, moda, design, propaganda, hospedagem, projetos de arquitetura, ....

O modelo escolhido foi o de workshop com a participação dos colaboradores das empresas foram feitas de forma interativa com uso de ferramentas visuais e colaborativas como canvas e kanbans customizados para os objetivos das seções.

Com a participação ativa das organizações em que aplicamos o MVP fizemos ajustes até chegarmos ao modelo final, que será apresentado na seção 2 .

\section{RESULTADO}

O resultado obtido está expresso no Modelo de Gestão Estratégica de Sustentabilidade (Modelo GES), aqui apresentado, e é um conjunto de boas práticas para auxiliar qualquer organização no seu caminho de evolução para aumentar sua maturidade em sustentabilidade. Este processo é uma Mudança Organizacional, desta forma, modelo considera em seu formato passos de um Projeto de Mudança Organizacional.

\subsection{O MODELO GES}

O roteiro básico das etapas do Modelo GES pode ser visto na

Cada Etapa é desdobrada em ações que permitem que cada organização tenha seu modelo customizado, em que a organização estrutura e implementa o seu caminho de acordo com as suas necessidades específicas. O desdobramento das etapas pode ser observado na Figura . 
Figura 3: Etapas do Modelo GES

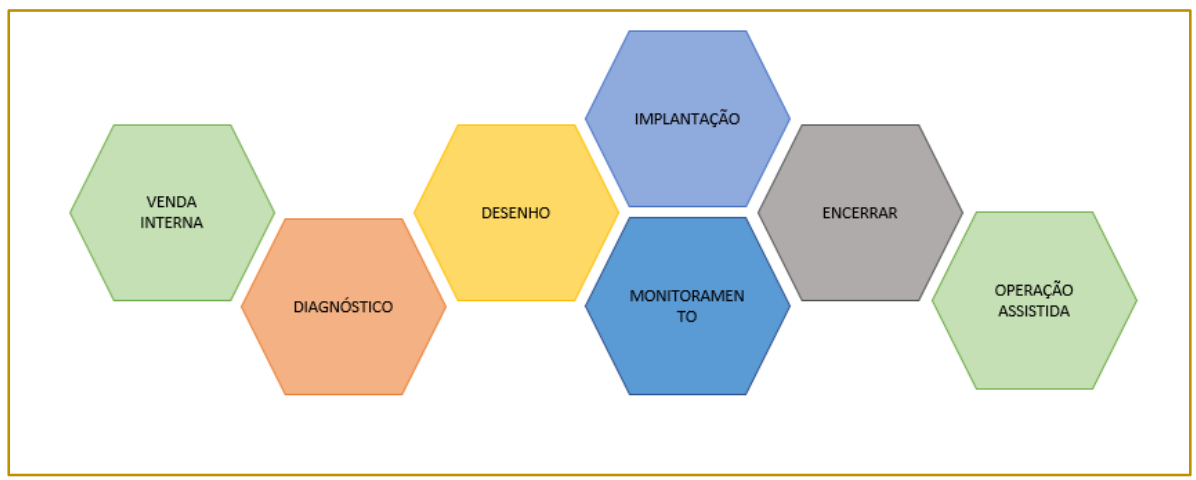

Figura 4: Detalhamento do Modelo GES

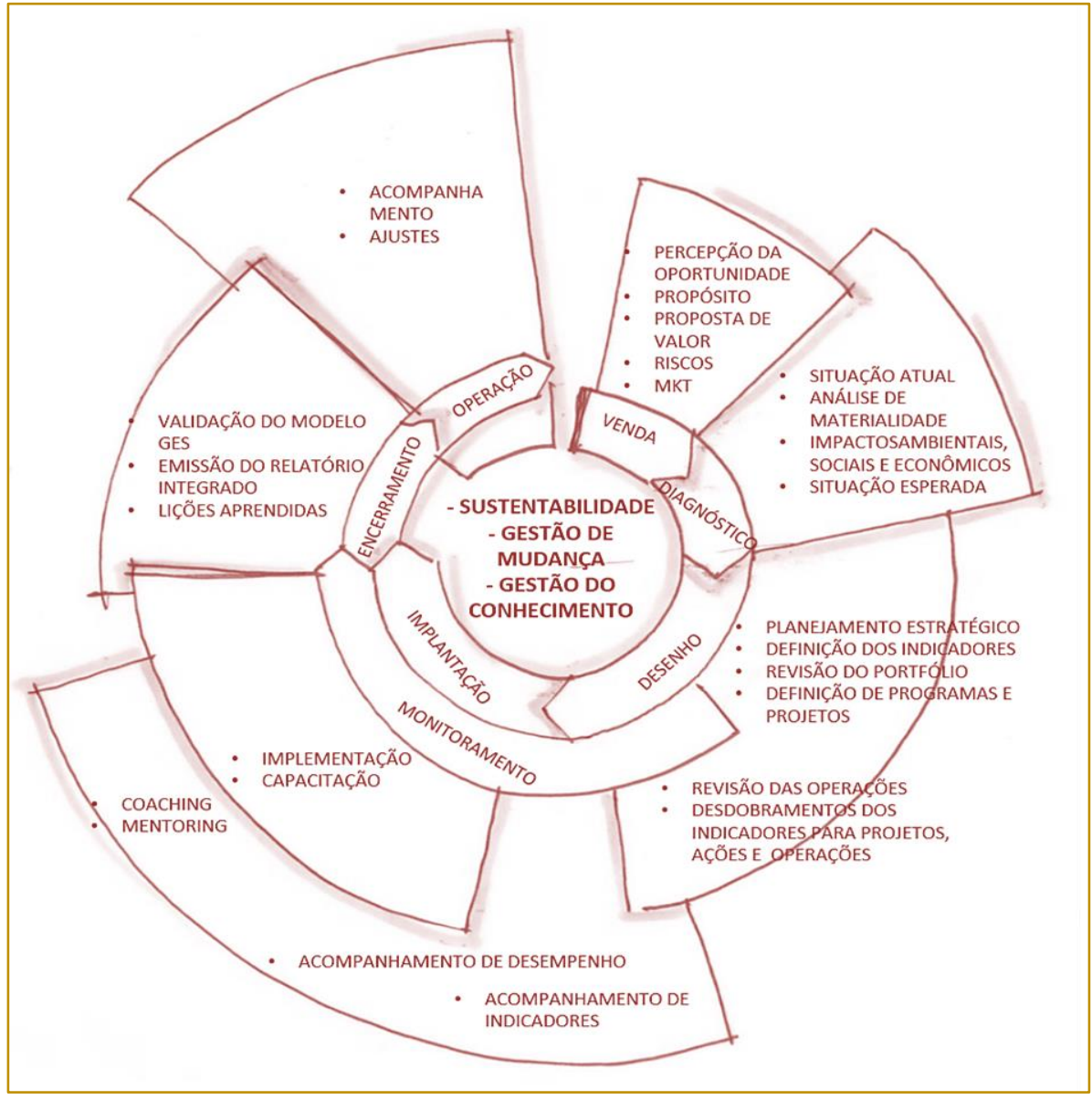

O Modelo GES é baseado no princípio de que todas as ações escolhidas para serem executadas por uma organização, sejam para responder a mudanças ou para dar continuidade ao negócio, mantendo ou aumentando o seu valor, devem ser resultado de uma reflexão corporativa sobre como desdobrar a estratégia, gerando impactos sociais, ambientais e/ou econômicos positivos de forma equilibrada.
De modo geral o lucro é a primeira preocupação das organizações, mas o investimento em sustentabilidade pode, por exemplo, reduzir custos e, consequentemente, melhorar os resultados financeiros. Ou usar capital financeiro pode aumentar outros capitais como, por exemplo, o intelectual e o social/relacionamento, aumentando o valor da organização. Mas para que isso aconteça, as ações devem ser bem planejadas. 
Implementar sustentabilidade é uma mudança de cultura organizacional e deve ser tratada como tal. É um caminho virtuoso que traz muitos benefícios. Logo, envolver e comprometer as pessoas certas é fundamental.

É preciso conhecer o assunto sustentabilidade para entender como ele vai agregar valor. Sabendo isso, é mais fácil convencer pares sobre as vantagens que podem ser alcançadas. E ganhar um patrocinador ou padrinho, fator primordial para a implantação!

Treinamentos e coaching auxiliam em todas as etapas, na medida em que proveem conhecimento e, consequentemente, comprometimento, além de espaços em que a obtenção de feedbacks pode auxiliar eventuais correções de rota.

$\mathrm{Na}$ sequência, é importante conhecer os impactos positivos e negativos que a organização já produz com o seu negócio, os que ela tem potencial para realizar $e$ as práticas já usadas. Normalmente, o potencial para gerar impactos positivos é muito maior do que os que já são produzidos, principalmente porque a materialidade não é bem compreendida. Ela é essencial para definir as prioridades de uma organização que quer ser sustentável. Revisitar o planejamento estratégico e torná-lo sustentável será a base para todo o caminho que o Modelo GES propõe, em que todos os resultados produzidos pela organização têm que estar alinhados com a estratégia para geração de valor. E, como o lucro não pode ser esquecido, ele tem que estar bem representado na estratégia. Dependendo do porte da organização, pode acontecer que nem um planejamento estratégico tradicional seja utilizado como ferramenta de gestão. Nesses casos, ele deverá ser realizado pela primeira vez já considerando a sustentabilidade.

A solução a ser definida para implementação do Modelo GES será adequada às características da organização. Nem complicada e nem simples demais. Ela deve considerar o tamanho da organização, seus recursos, sua disponibilidade de tempo e as prioridades envolvidas. A forma de customização do modelo deve garantir que todos esses aspectos estarão equilibrados tanto na composição do portfólio de projetos e programas sustentáveis, como na estruturação das operações.
A implementação da solução escolhida deve ser monitorada para que os resultados (baseados em ODSs, Sistema B, GRI, IIRC, ISE, DJSI, ou quaisquer outras estruturas para sustentabilidade) possam ser gerados de forma transparente, automática e rastreável.

Fazendo isso, sua organização aprenderá novas práticas e mudará sua cultura, construindo uma parte do seu caminho para a sustentabilidade. Mas esse caminho gera frutos que devem crescer. Durante todo o seu ciclo de vida, produtos e serviços geram externalidades, que podem ser minimizadas por um bom planejamento, mas que precisam ser monitoradas, para que os impactos projetados possam ser garantidos. Às vezes há necessidades de ajustes, mesmo já em fase de operação do Modelo GES.

A implantação do projeto de mudança para o Modelo GES fará com que a organização vivencie dois períodos distintos. O primeiro, em que ela desenvolverá 0 projeto em paralelo com suas outras atividades de rotina, e o segundo, em que o projeto terá acabado e as atividades de rotina já terão sido afetadas pela mudança para o Modelo GES.

Quando a proposta é implantar algo novo, isto é, gerar uma mudança em uma organização, seja em processos ou em comportamentos, a abordagem deve ser estruturada desde a concepção do projeto para que haja a sensibilização de influenciadores a fim de que ele se viabilize. Será necessário vender a ideia da mudança internamente e para isso deve-se deixar claro o valor que será agregado.

$\mathrm{Na}$ fase de Desenho, o planejamento estratégico sustentável será redefinido e o projeto de mudança para uso do Modelo Ges, incluído no portfólio sustentável de projetos e programas da organização. Durante o Monitoramento e Controle da implantação, relatórios de desempenho serão emitidos para documentar status, ações preventivas/ corretivas e lições aprendidas. Ao final da fase de Encerramento, o Relatório de Encerramento consolidará todas as informações do projeto, registrando tudo que é importante para ser reutilizado. A fase de Operação Assistida colocará em prática, em uma escala real tudo o que foi proposto, e poderá exigir ajustes, consequente revisão do Planejamento e, ainda, acréscimos no relatório de Encerramento. Tudo isso acontecerá pela primeira vez com o "avião no ar". Ou seja, a organização não vai parar de 
funcionar enquanto o Modelo GES estiver sendo customizado e implantado. Adaptá-lo e aplica-lo vai exigir apoio e liderança, mas também trará resultados imediatos, que contribuirão para maior aderência dos stakeholders ao seu uso. Portanto, não se esqueça de que todas as sugestões, críticas, observações, etc. são úteis para a melhor customização e, consequente, comprometimento de todos.

\subsection{AS ETAPAS DO MODELO GES}

\subsubsection{ETAPA: VENDA INTERNA}

Esta é a etapa de sensibilização para o tema da sustentabilidade e a mudança no modelo mental e da cultura da organização. O foco principal são os tomadores de decisão da organização. Em Gestão de Mudança esta é uma etapa obrigatória (GONÇALVES \& CAMPOS, 2016), (KOTTER, 2013), (SCHARMER, 2017), (SOARES, 2013).

Inicia-se um processo de Gestão da Expectativa e da Resistência dos Stakeholders (GONÇALVES \& CAMPOS, 2016) e (PROJECT MANAGEMENT INSTITUTE [PMI], 2016).

Esta "venda da ideia" dentro da organização deve partir do propósito e da proposta de valor. Quando falamos de venda da ideia é necessário desenvolver algumas técnicas como a argumentação e a persuasão (PINK, 2013). Neste contexto entender o propósito de cada stakeholder é extremamente importante, da mesma forma que deixar claro a proposta de valor e os riscos envolvidos (EGGER, 2015) e (OSTERWALDER, 2014).

\subsubsection{ETAPA: DIAGNÓSTICO}

O projeto de mudança para implantação do Modelo GES tem seu início efetivo com a etapa de DIAGNÓSTICO que possui dois grandes objetivos: aprofundar $\mathrm{O}$ conhecimento sobre a organização (o negócio e as pessoas) e engajar mais ainda os stakeholders já mapeados e identificar novos, fazendo-os pensar em sustentabilidade estrategicamente e nos seus benefícios para a organização, decorrentes de uma aplicação estruturada.

O Diagnóstico, sob o ponto de vista de mudança organizacional, deve responder a três questões:
- Como o projeto de mudança para o Modelo GES sustenta missão, visão e valores da organização?

- Que outras mudanças estão ocorrendo na organização que podem demandar atividades das mesmas pessoas?

- O que cada stakeholder precisa entender para apoiar o DESENHO da estratégia de mudança?

A seguir identifica-se a maturidade da organização no quesito sustentabilidade e é feito o levantamento da situação atual para o entendimento dos impactos ambientais, sociais e econômicos da organização e sua materialidade, também são consideradas as ações em andamento e as previstas, além do alinhamento destas com o planejamento estratégico.

Pode-se começar escolhendo um número reduzido de tipos de impactos, para que o grupo se familiarize com eles. Por exemplo, pode-se iniciar votando em cinco tipos de impactos, de acordo com a estrutura de sustentabilidade escolhida, e, na medida em que o processo seja absorvido pelos participantes, pode-se aumentar o número de tipos de impactos considerados.

\subsubsection{ETAPA: DESENHO}

Por melhor que tenha sido elaborado, um bom Diagnóstico só mostrará o que a sua organização já faz. Portanto, você precisa usá-lo como base para desenhar qual será a melhor solução para o caminho da sua organização em direção à sustentabilidade. $\mathrm{O}$ Modelo GES deve ser customizado para que seja útil sem ser burocrático.

O período em que a etapa DESENHO é desenvolvida pode ser aproveitado para ações de apoio à Gestão de Mudança, como parte da comunicação e consolidação da visão da mudança. A comunicação estruturada ao longo deste período será muito útil para manter os stakeholders envolvidos com o projeto, não permitindo que se "desliguem" do tema. As ações de comunicação devem comtemplar o que cada stakeholder precisa saber sobre a mudança, ações genéricas nem sempre geram bons resultados.

Nesta etapa são elaborados: revisão do planejamento estratégico, definição dos indicadores, definição do formato de um escritório de gestão sustentável, revisão do 
portfólio, programas e projetos da organização, bem como da operação.

Assim são definidas ações e ferramentas para criar uma cultura que gerencie resultados sustentáveis.

\subsubsection{ETAPA: IMPLANTAÇÃO, MONITORAMENTO E CONTROLE}

O MONITORAMENTO e CONTROLE Ocorrem ao mesmo tempo em que a IMPLANTAÇÃO acontece. Durante a implantação teremos uma grande parte da organização tendo acesso pela primeira vez ao real conteúdo da transformação. Portanto é um período que deve ser monitorado bem de perto pelo gerente de projeto, agentes de mudança e sponsor, já que obstáculos e resistências devem surgir e precisam ser avaliados e trabalhados. A comunicação tem um papel importantíssimo.

Nestas etapas, os colaboradores, de todos os níveis hierárquicos devem ter clareza dos benefícios da mudança e uma percepção positiva sobre ela e seus resultados. As resistências devem ter sido reduzidas ao mínimo e as competências necessárias devem estar sendo desenvolvidas.

Nesta etapa é feita a capacitação dos envolvidos e a implementação do que foi definido na etapa DESENHO. Além disso, usa-se o coaching e o mentoring, além do acompanhamento do desempenho.

\subsubsection{ETAPA: ENCERRAMENTO}

Finalizar um projeto requer encerrar todas as atividades relacionadas ao seu desenvolvimento, técnicas e administrativas. Ao final dessa etapa, o projeto deve ser reconhecido e aceito pelas partes como tendo seu desenvolvimento concluído. Podese ainda encerrar uma fase e, nesse caso, todas as atividades referentes ao encerramento do projeto serão executadas parcialmente, relativamente à fase em questão.

No encerramento é feita a validação do modelo, a emissão do relatório integrado (GLOBAL REPORTING INITIATIVE [GRI], s.d.) e o registro das lições aprendidas.

O registro das lições aprendidas faz parte da gestão do conhecimento do projeto e deve acontecer ao longo do seu ciclo de vida e não apenas no ENCERRAMENTO. Seu objetivo é gerar melhoria técnica e Comportamental. No caso da melhoria técnica pode-se ajustar processos, precedências, especificações, etc. As lições aprendidas em relação aos comportamentos dos envolvidos podem gerar feedback para obter resultados individuais, e da própria organização, cada vez melhores.

O conhecimento, como uma preocupação das organizações, assumiu uma importância crescente a partir de meados do século XX. As instituições começaram a perceber a necessidade da gestão do conhecimento e de ações para que haja um aprendizado organizacional, e não apenas do indivíduo. Esse fenômeno é agravado com a mudança nas relações empregado-empregador e com a redução do tempo médio que um funcionário permanece em uma instituição.

A gestão do conhecimento é o esforço realizado pela organização para identificar, criar, desenvolver, preservar, registrar, compartilhar e aplicar o conhecimento de forma estratégica. Ela não é uma iniciativa isolada. Deve ser integrada à organização como um todo. Ela se apoia em lideranças, pessoas, processos e cultura, com o objetivo de gerar valor para o negócio, reduzindo o retrabalho, melhorando o desempenho, promovendo o aprendizado dos colaboradores e a inovação.

\subsubsection{ETAPA: OPERAÇÃO ASSISTIDA}

A Operação Assistida é um instrumento de gestão de mudança, pois visa à consolidação de novas práticas e de um novo mindset. Busca-se nesse momento que a mudança passe a fazer parte da rotina da organização e esteja integrada à sua cultura com o "menor sofrimento possível" dos indivíduos.

Neste momento será posto em prova o comprometimento dos colaboradores nos diversos níveis da organização.

A etapa de Operação Assistida precisa ter o escopo bem definido, assim como o período de tempo e custo previstos. Um projeto que entra em operação pode necessitar ajustes em determinados aspectos mesmo quando a implantação monitorada já gerou algumas adaptações. A Operação Assistida também pode despertar novas necessidades, criando demandas.

Novas demandas têm que ser aprovadas. Elas podem ser objeto de proposta comercial complementar e/ou de novas versões do 
plano de gerenciamento do projeto, com o novo escopo proposto.

Os ajustes necessários podem caracterizar mudanças no projeto e, consequentemente, alterações em planos, contratos, soluções. O importante é que sejam gerenciados de perto para que possam ser planejados, caso não tenham sido previstos, e executados com acompanhamento dos stakeholders envolvidos. Os indicadores tradicionais e de sustentabilidade têm que ser acompanhados para que se tenha certeza de que os ajustes tiveram o seu efeito alinhado com os resultados esperados.

É importante lembrar novamente que o Modelo GES propõe uma integração desde a fase de planejamento estratégico, quando se definem os indicadores e suas metas, até a emissão de relatórios integrados, quando se reporta os resultados desses mesmos indicadores. Os ajustes podem ser fundamentais para que se tenha aceitações finais de resultados, ou mesmo a identificação de novas necessidades a serem implementadas no período seguinte.

Ao final da etapa de Operação Assistida será assinado pelo cliente o Aceite Definitivo do Projeto.

\section{CONCLUSÃO}

A organização que hoje quer crescer não pode mais desprezar os aspectos sociais e ambientais do seu negócio. Não tratá-los significar assumir riscos de não conseguir investimentos, perder clientes e pagar mais caro por insumos, entre tantos outros.

O Modelo GES traz uma mudança de cultura importante para as organizações na medida em que altera o mindset de todos os que direta ou indiretamente participam do negócio. Por isso as práticas de gestão de mudanças não podem ser descartadas. Além

\section{REFERÊNCIAS}

[1] Almeida, N. O. (2011). Gerenciamento De Portfólio. Rio De Janeiro: Brasport.

[2] Almeida, N. O., \& Neto, R. O. (2015). Gestão Profissional De Portfólio De Projetos. Maturidade E Indicadores. Rio De Janeiro: Brasport.

[3] Arango, F. (2 De Março De 2017). The Need To Build Organizational Capacity For Integrated Thinking And Reporting. Acesso Em 1 De Março De 2018, Disponível Em Integrated disso, o projeto gera novos conhecimentos, ativo valioso para as organizações, e a gestão de conhecimento vai garantir que eles não se percam e nem fiquem somente em poder das pessoas, mas que possam ser reaplicados para incentivar a melhoria contínua.

O foco em integração do Modelo GES faz com que todos os stakeholders da organização passem a ter o mesmo entendimento sobre a estratégia escolhida, sua implementação e os resultados alcançados. Isso é possível a partir de tornar sustentáveis os processos de governança de planejamento estratégico, de escolha de programas e projetos para portfólios, de operações, além de reportar as informações financeiras alinhadas com as de sustentabilidade.

Dessa forma, entendendo o valor econômicofinanceiro que a sustentabilidade traz, em curto, médio e longo prazo, e avaliando bem todas as iniciativas em que serão gastos os seus recursos, muitas vezes escassos, as organizações terão maior possibilidade de obter um retorno sobre o investimento sustentável positivo, contribuindo para o seu lucro.

A chave para o sucesso do projeto de mudança para o Modelo GES é engajar os stakeholders certos! Isso deve acontecer desde o nascimento da ideia, passando pela sua venda, entendimento da materialidade, escolha da estrutura de sustentabilidade, revisão da estratégia, transformação dos portfólios e mudança nas operações, até o acompanhamento da operação assistida. O conhecimento e a experiência das pessoas envolvidas são os "ingredientes" fundamentais para "dar a liga" a todos esses processos, trazendo mudança do clima organizacional, aumento de produtividade, melhoria de imagem e, consequentemente, tornando as pessoas mais felizes!

Reporting [Ir]: Http://Integratedreporting.Org/News/The-Need-ToBuild-Organizational-Capacity-For-IntegratedThinking-And-Reporting/

[4] Barbosa, C. (2008). Aspectos "Não Tão Técnicos" Da Tomada De Decisão Na Seleção De Portfólio De Uma Organização.

[5] Barbosa, C. (2013). Fatores Determinantes Da Subjetividade Humana Que Afetam Efetividade De Gerentes De Projetos. Acesso Em 07 De Março De 2018, Disponível Em By Conn: 
Http://Www.Byconn.Com.Br/Factores-

Determinantes-De-La-Subjetividad-Humana-QueAfectan-La-Efectividad-De-Directores-DeProyectos/

[6] Barbosa, C. (10 De Setembro De 2013) Fatores Subjetivos Que Afetam Efetividade De Gps Recuperado El 2013 De Setembro De 24, De Surveymonkey:

Https://Pt.Surveymonkey.Net/Analyze/Browse/?Surv ey_ld $=44226779$

[7] Barbosa, J. (2013). Espelho - Entrevista Com Joaquim Barbosa (Parte 1 De 2). (L. Ramos, Entrevistador) Canal Brasil. Http://Www.Youtube.Com/Watch?V=H01mxvfjogc Rio De Janeiro.

[8] Basgal, D., \& Silvério, M. (S.D.) Gerenciamento Sustentável De Projetos: Metodologia De Aplicação. Acesso Em 27 De Fevereiro De 2018, Disponível Em Pmi São Paulo: Https://Pmisp.Org.Br/Document-Repository/ArtigosE-News/172-2016-05-Gerenciamento-SustentavelDe-Projetos-Metodologia-De-Aplicacao/File

[9] Bauman, Z. (1998). O Mal-Estar Da PósModernidade. Rio De Janeiro: Jorge Zahar.

[10] Bauman, Z. (1999). La Globalización: Consequencias Humanas. San Pablo: Fondo De Cultura Económica.

[11] Bauman, Z. (2001). Modernidade Líquida. Rio De Janeiro: J. Zahar.

[12] Beedle, M. E. (2001). Manifesto Para Desenvolvimento Ágil De Software. Recuperado El 23 De 07 De 2013, De Http://Agilemanifesto.Org/lso/Ptbr/

[13] Bmf\&Bovespa. (2016). Índice De Sustentabilidade Empresarial (Ise). Acesso Em 18 De Dezembro De 2017, Disponível Em Bmf\&Bovespa - A Nova Bolsa: Http://Www.Bmfbovespa.Com.Br/Pt_Br/Produtos/ln dices/Indices-De-Sustentabilidade/Indice-DeSustentabilidade-Empresarial-Ise.Htm

[14] Centro De Estudos Em Sustentabilidade [Gvces], Emerging Market Mult. N. For Sustainability [Emm], \& Deutsche Gesellschaft Für Int. Z. Gmbh [Giz]. (Agosto De 2016). Retorno Econômico De Projetos De Sustentabilidade: Redefinindo $O$ Valor De Multinacionais No Brasil. Acesso Em 2 De Fevereiro De 2017, Disponível Em Http://Mediadrawer.Gvces.Com.Br/Publicacoes/Ori ginal/Giz_Emm_Roi_Sustentabilidade.Pdf

[15] Egger, D. (2015). Geração De Valor Futuro: Conectando A Estratégia, Inovação E O Futuro. Rio De Janeiro: Elsevier.

[16] Ellen Macarthur Foundation. (2017) Economia Circular. Acesso Em 12 De Dezembro De 2017, Disponivel Em Https://Www.Ellenmacarthurfoundation.Org/Pt/Econ omia-Circular-1/Conceito

[17] Federação Brasileira De Bancos
[Febraban]. (Agosto De 2017). Transparência De Informações Relacionadas Às Mudanças Climáticas - Recomendações Do Financial Stability Board. Acesso Em 24 De Fevereiro De 2018, Disponível Em Café Com Sustenabilidade: Https://Cafecomsustentabilidade.Febraban.Org.Br/ Edicoes/Edicao-52/

[18] García-Benau, M., Rivera-Arrublaa, Yaismir, A., \& Zorio-Grima, A. (S.D.). The Integrated Reporting Concept As An Innovation In Corporate Reporting. Acesso Em 25 De Maio De 2016, Disponível Em Sciencedirect: Http://Www.Sciencedirect.Com/Science/Article/Pii/S 2444569×16000184

[19] Gareis, R. (2010). Changes Of Organizations By Projects. International Journal Of Project Management, 28(4).

[20] Global Reporting Initiative [Gri]. (S.D.). Global Reporting Initiative. Acesso Em 25 De Fevereiro De 2018, Disponível Em Https://Www.Globalreporting.Org/Pages/Default.As $\mathrm{px}$

[21] Goedknegt, D. (2012). Sustainability In Project Management: A Case Study At University Of Applied Sciences Utrecht. Pm World Journal, 1(4).

[22] Gonçalves, V., \& Campos, C. (2016). Hcmbok: O Fator Humano $\mathrm{Na}$ Lideança De Projetos. Rio De Janeiro : Brasport.

[23] Green Building Council Brasil [Gbcb]. (S.D.). Certificação Leed. Acesso Em 25 De Fevereiro De 2018, Disponível Em Http://Gbcbrasil.Org.Br/Sobre-Certificado.Php

[24] Holanda, A. B. (2008). Http://Www.Dicionariodoaurelio.Com/. Recuperado El 06 De Maio De 2013, De Dicionário Do Aurélio.

[25] Hope, A., \& Moehler, R. (2014). Balancing Projects With Society And The Environment: A Project, Programme And Portfolio Approach. 27th Ipma World Congress. Londres: Elsevier. Acesso Em 27 De Fevereiro De 2018, Disponível Em Https://Ac.Els-Cdn.Com/S1877042814021326/1S2.0-S1877042814021326-Main.Pdf?_Tid=Spdf46edee72-Feb8-4db6-B902-

8395f2e9b88f\&Acdnat=1519747973_795a821ceb9 3d5b9e32aa1acff50ea63

[26] Ibm. (S.D.). Kris E Valores De Kri. Acesso Em 21 De 02 De 2018, Disponível Em lbm Knowledge Center: Https://Www.Ibm.Com/Support/Knowledgecenter/Pt

Br/Ssfueu_7.2.0/Com.lbm.Swg.Ba.Cognos.Op_App _Help.7.2.0.Doc/C_About_Kri_Val.Html

[27] Innovare, E. (S.D.). Geração Y: Quem São E O Que Querem Os Millennials? Acesso Em 18 De Dezembro De 2017, Disponível Em Innovare Pesquisa:

Http://Www.Innovarepesquisa.Com.Br/Blog/Geraca o-Y-Quem-Sao-E-O-Que-Querem-Os-Millennials/

[28] Instituto Brasil. De Governança 
Corporativa [lbgc]. (S.D.). Governança Corporativa - Princípios Básicos. Acesso Em 25 De Maio De 2016, Disponível Em Ibgc - Instituto Brasileiro De Governança Http://Www.Ibgc.Org.Br/Inter.Php?ld=18163

[29] International Integrated Reporting Council [lirc]. (S.D.). The lirc - Integrated Reporting. Acesso Em 25 De Fevereiro De 2018, Disponível Em Https://Integratedreporting.Org/

[30] Jeffrey, D. (2015). The Age Of Sustainable Development. Nova York: Columbia University Press.

[31] Kaplan, D. P., \& Norton, R. S. (2004) Mapas Estratégicos. Balanced Scorecard (7a. Ed.). Rio De Janeiro: Elsevier.

[32] Kaplan, D. P., \& Norton, R. S. (2006). Alinhamento. Utilizando O Balanced Scorecard Para Sinergias Corporativas. (4a. Ed.). Elsevier.

[33] Kotter, J. (2013). Liderando A Mudança. Rio De Janeiro : Elsevier .

[34] Kotter, J. (2015). Acelere: Tenha Agilidade Estratégica Em Um Mundo Em Constante Transformação. São Paulo: Hsm.

[35] Nações Unidas No Brasil [Onubr]. (2017) Transformando Nosso Mundo: A Agenda 2030 Para O Desenvolvimento Sustentável. Acesso Em 04 De Janeiro De 2018, Disponível Em Nações Unidas: Https://Nacoesunidas.Org/Pos2015/Agenda2030/

[36] Organização Das Nações Unidas, [. (2015). 17 Objetivos Para Salvar O Mundo. Acesso Em 02 De 11 De 2017, Disponível Em Onubr Nações Unidas No Brasil: Https://Nacoesunidas.Org/Pos2015/

[37] Organização Das Nações Unidas, [. (6 De Julho De 2017). Sdg Indicators - Global Indicator Framework For The Sustainable Development Goals And Targets Of The 2030 Agenda For Sustainable Development. Acesso Em 18 De Dezembro De 2017, Disponível Em Sustainable Development Goals: Https://Unstats.Un.Org/Sdgs/Indicators/IndicatorsList/

[38] Osterwalder, A. E. (2014). Value Proposition Design. São Paulo: Hsm Brasil.

[39] Pink, D. (2013). Saber Vender É Da Natureza Humana. São Paulo: Leya.

[40] Project Management Institute [Pmi]. (2007). Project Manager Competency Development Framework. Newtown Square: Project Management Institute Inc.

[41] Project Management Institute [Pmi]. (2012). Estudo De Benchmarking Em Gerenciamento De Projetos. Acesso Em 01 De 06 De 2013, Disponível Em Http://Www.Pmsurvey.Org

[42] Project Management Institute [Pmi] (2012). Guia De Conjunto De Conhecimento Em Gerenciamento De Projetos (5a. Ed.). Newtown
Square: Pmi.

[43] Project Management Institute [Pmi]. (2012). Opm3 - Project Management Maturity Model (2a Ed.)

[44] Project Management Institute [Pmi]. (2012). Pulse Of The Profession. Recuperado El 31 De 08 De 2012, De Project Management Institute: Http://Www.Pmi.Org/Business-Solutions/Pulse.Aspx

[45] Project Management Institute [Pmi]. (2013). Pmi Online Credential Registry. Acesso Em 31 De 07 De 2013, Disponível Em Pmi: Http://Certification.Pmi.Org/Registry.Aspx

[46] Project Management Institute [Pmi]. (01 De 06 De 2013). Project Manager Career Framework. Fonte: Career Framework For Organizations: Https://Pathpro.Pmi.Org/Whycareerframework.Aspx \#What

[47] Project Management Institute [Pmi]. (2016). Governance Of Portfolios, Programs And Projects: A Practice Guide. Newtown Square: Project Management Institute. Acesso Em 15 De Outubro De 2013, Disponível Em Project Management Institute: Http://Www.Pmi.Org/En/About-

Us/Ethics/ /Media/Pdf/Ethics/Ap_Pmicodeofethics_ Por-Final.Ashx

[48] Project Management Institute [Pmi]. (2016). Guia De Conjunto De Conhecimento Em Gerenciamento De Projetos (5a. Ed.). Newtown Square: Pmi.

[49] Project Management Institute [Pmi]. (2017). The Standard For Portfolio Management. Newtown Square: Project Management Institute. Recuperado El 14 De Outubro De 2013, De Project Management Http://Www.Pmi.Org/En/About-

Us/Ethics/ /Media/Pdf/Ethics/Ethical-DecisionMaking-Frmwk-Portuguese.Ashx

[50] Project Management Institute [Pmi]. (2017). The Standard For Program Management. Newtown Square: Project Management Institute.

[51] Rad, P. F., \& Levin, G. (2006). Metrics For Project Management - Formalized Approaches. Vienna: Management Concepts.

[52] Rebecosam. (2015). Robecosam Corporate Sustainability Assessment. Acesso Em 03 De Janeiro De 2018, Disponível Em Rebecosam: Http://Www.Robecosam.Com/Images/SampleQuestionnaire-Diversified-Consumer-Services.Pdf

[53] Robecosam. (2017). The Corporate Sustainability Assessment At A Glance. Acesso Em 03 De Dezembro De 2018, Disponível Em Robecosam:

Http://Www.Robecosam.Com/Images/Djsi2017_Co mponentlist_World.Pdf

[54] Santos, M. (5 De Novembro De 2014). Gestão De Metas: Como Implementar A Metodologia Okr? Acesso Em 18 De Dezembro De 
2017, Disponível Em Endeavor: Https://Endeavor.Org.Br/Gestao-MetasMetodologia-Okr/

[55] Scharmer, C. O. (2017). Teoría U: Liderar Desde El Futuro A Medida Que Emerge. Barcelona : Eleftheria.

[56] Senado Federal. (2006). Portal Atividade Legislativa. Recuperado El 14 De Outubro De 2013, De Plc - Projeto De Lei Da Câmara, № 122 De 2006: Http://Www.Plc122.Com.Br/EntendaPlc122/\#Axzz2hjnfyvtl

[57] Silva, M., \& Callado, A. (07 A 09 De Novembro De 2011). Balanced Scored Card Sustentável. Acesso Em 06 De 11 De 2017, Disponível Em Xviii Congresso Brasileiro De Custos Rio De Janeiro: Https://Anaiscbc.Emnuvens.Com.Br/Anais/Article/Vi ewfile/449/449

[58] Silveira, A. M. (2014). Governança Corporativa. O Essencial Para Líderes. Elsevier.

[59] Silvius, A., \& Schipper, R. (2010). A Maturity Model For Integrating Sustainability In Projects And Project Management. 24th World Congress Ipma. Istanbul. Acesso Em Maio De 2016, Disponível Em Www.Hu.NI/ /Media/HuPortal/Images/Duurzaam/Description.Pdf

[60] Silvius, G. E. (2012). Sustainability In Project Management. Londres: Gower Publishing.
[61] Soares, K. (2013). A Transição Na Gestão De Mudança: O Que Preciso Mudar Em Mim Para Que O Outro Mude? São Paulo: Barany Editora.

[62] United Nations [Un]. (S.D.). Global Indicator Framework For The Sustainable Development Goals And Targets Of The 2030 Agenda For Sustainable Development. Fonte: Sustainable Development Goals: Https://Unstats.Un.Org/Sdgs/Indicators/IndicatorsList/

[63] United Nations Environment Programme [Unep]. (11 De 2017). The Emissions Gap Report 2017. Acesso Em 2 De 11 De 2017, Disponível Em Https://Wedocs.Unep.Org/Bitstream/Handle/20.500 .11822/22070/Egr_2017.Pdf

[64] United Nations Environment Programme Fi [Unepfi]. (S.D.). Acesso Em 25 De Fevereiro De 2018, Disponível Em Changing Finance - Finance Change: Http://Www.Unepfi.Org/About/

[65] Vergara, S. (2007). Projetos E Relatórios De Oesquisa Em Administração (8a. Ed. Ed.). São Paulo: Atlas.

[66] World Bank. (2017). The World Bank / Data. Acesso Em 12 De Dezembro De 2017, Disponível

Em Https://Data.Worldbank.Org/Indicator/Sp.Pop.Totl.F e.In 


\section{Eapítulo 5}

\section{DESPERTAR DO CONSUMO CONSCIENTE NA CIDADE DO RIO DE JANEIRO}

\section{Yuri Pinheiro Santos}

Regina Rianelli de Brito

Jesus Domech Moré

Jose Carlos Beker

Jorge Julio Landeiro de Vaz

Resumo: Este estudo tem por objetivo ratificar a importância do marketing esportivo para o fortalecimento dos esportes e, por consequência, dos clubes de futebol, além de mostrar o potencial do Brasil nessa área. Pois, o futebol é paixão nacional e o esporte possui características únicas como: subjetividade, intangibilidade, efemeridade, imprevisibilidade e experimentação; intensificados pela paixão. Discorreu-se sobre a importância do torcedor para o fortalecimento dos clubes enquanto gerador de receitas. Também, serão abordados conceitos de marketing, marketing esportivo e suas ferramentas, o programa sócio torcedor do Clube de Regatas Vasco da Gama, entre outros. Buscou-se apresentar o tema, já que o país encontra-se na agenda internacional dos esportes por ser sede de diversos megaeventos esportivos.

Palavras-Chave: Marketing, Marketing Esportivo, Torcedor. 


\section{INTRODUÇÃO}

Diversos índices observados (IBGE, 2013) apontam que a sociedade de consumo de massa atingiu padrões insustentáveis no mundo moderno. Ao assumir o consumo como principal articulador da vida social (KLOZINETS e HANDELMAN, 2004), a aquisição de bens materiais organiza, define e nivela o papel de cada indivíduo na sociedade de consumo (BAUDRILLARD, 1995). As aspirações consumistas e dos desejos de posse de objetos legitimam a manutenção do sistema capitalista, viabilizando o acesso à felicidade e sucesso (BURROUGHS e RINDFLEISCH, 2002). Neste cenário, diz-se que os níveis atuais de produção e consumo ultrapassam a capacidade de regeneração dos recursos naturais do planeta, por isso as inúmeras catástrofes. Socialmente, a miséria absoluta assola grande parte da população mundial enquanto a fortuna e abundancia privilegia alguns, cujas riquezas se multiplicam dia após dia, aumentando a desigualdade social estratificada. Eticamente, os valores pregados pela sociedade atual divergem de suas ações, pois o homem valoriza mais o "ter" do que o "ser" (KLEIN, 2002; HOLT, 2002).

Estudos apontam que a sociedade pósindustrial moderna estaria revendo seus conceitos e repensando alguns de seus hábitos. A pressão por ações socioambientais benéficas teriam surtido efeito em diversas práticas empresariais (ROBERTS, 1995; ROBERTS, 1996). Contudo, existem longas etapas a serem percorridas pela sociedade do ter, do status, da exposição etc. Inicialmente, a mudança dos padrões de consumo voraz vigorados atualmente.

Para alcançar tal meta ecologicamente correta, os consumidores não são os únicos que devem mudar suas práticas. As empresas, como responsáveis por cultivar e incentivar os atuais padrões de consumo, também devem repensar suas ações, que são voltadas para a maximização do lucro, deixando de lado outros fatores importantes como a sociedade na qual está inserida (AKATU, 2012). Essa revisão das práticas empresariais e gestoras é um processo majoritariamente imposto pelo próprio mercado e não uma ação proativa dessas organizações. Isso se deve ao fato de que as práticas gerenciais estão motivadas por questões de caráter econômico-financeiro, ao invés de sociais, éticas e ambientais mais equânimes.
Parasuraman et al. (2007) afirmam que más práticas gestoras são causadas por enfoque excessivo em fatores financeiros, exclusivamente materialistas. Acontecimentos danosos emergem diretamente de uma abordagem proposta pelas Escolas de Administração, de colocar o acionista como principal stakeholder, deixando `a margem clientes externos e a sociedade.

Segundo Mintzberg (2005), as Escolas de Administração devem mudar o caráter predominantemente econômico de práticas gerenciais que apenas maximizam o lucro e devem refletir sobre as consequências de suas ações no planeta em que vivemos. Acadêmicos também estão aderindo a um movimento de reflexão crítica, repensando o papel socioambiental das Empresas e suas inserções locais. Em contrapartida, a sociedade vem se tornando a cada dia mais consciente e crítica sobre os impactos de suas ações no mundo, reavaliando os atuais padrões de consumo.

\section{CONSUMIDOR CONSCIENTE NO RIO DE JANEIRO}

\subsection{ATITUDE DO CONSUMIDOR VERDE}

Neste estudo, a atitude foi o elemento central de análise escolhido. Blackwell, Engel \& Miniard (2005) definem que as atitudes de um indivíduo representam suas escalas de preferências individuais. Isto posto, a atitude de gostar de um determinado produto ou serviço cria uma predisposição para que ele fosse consumido, o que não necessariamente implica na ação de consumir, visto que existem outros fatores que a influenciam. A atitude é uma construção organizada por crenças, valores e comportamentos que geram sentimentos sobre o objeto de consumo (LUTZ, 1991). Essas práticas incidem no comportamento do consumidor (SMITH, 2005) e esse objeto resulta em um produto ou serviço, gerando uma predisposição positiva ou negativa aos padrões de consumo.

Sheth et al. (2001) afirmam que as atitudes precedem e formam o comportamento. Baseadas em experiências e informações, as atitudes são formadas nas mentes dos indivíduos, tornando-se predispostos em resposta a uma situação consistentemente favorável ou desfavorável. 
Existem diferentes abordagens na literatura científica que explicam o que é atitude. São teorias derivadas de correntes da psicologia que formam uma relação entre cognição, atitude e comportamento (LUTZ, 1991). Geralmente, as crenças de um indivíduo a cerca de um determinado objeto constroem a atitude pessoal, podendo ser bons indicadores do comportamento. Assim, se uma pessoa reflete que suas ações como consumidor podem ter impactos no meio ambiente e na sociedade, isto demonstrará uma atitude favorável ao consumo conscientemente quem implicará em suas atitudes rotineiras.

Lutz (1991) aponta, esse processo não é contínuo, pois existem outros fatores envolvidos, a exemplo da precificação, fatores normativos, isto é, fatores conjunturais e grupais que podem influenciar no comportamento e ritmo de compra. Assim sendo, mesmo alguém que tenha uma atitude favorável ao consumo consciente pode não exercê-lo por não valer o esforço segundo influência do meio social ao qual pertence (familiares, amigos, parentes, sociedade em geral).

Por esse motivo os exemplos atitudinais são apenas predisposições a um determinado comportamento, podendo ou não se traduzir no mesmo (SMITH, 2005). Alguns autores acreditam em uma etapa entre a atitude e o comportamento em si, que seria a intenção, o que torna ainda mais complexo esse processo de escolha, compra por impulso, compra por necessidade, ou para atender a um simples desejo consumista. Estudos de Comportamento do Consumidor propõem que as atitudes ainda são os melhores indicadores de ações esperadas dos consumidores e possuem uma grande aplicabilidade de ritmo na área, informa Lutz (1991).

De forma complementar, será interessante que sejam realizados estudos futuros sobre esse Tema, a fim de analisar o comportamento efetivo de consumo consciente, ações propostas de marketing verde e fazer uma comparação entre estas práticas e as atitudes de consumo verde.

\subsection{CONSUMO CONSCIENTE}

O consumo consciente desafia a concepção atual do consumo, uma vez que praticá-lo significa romper com os hábitos atuais da sociedade de massa. Dessa forma, a prática do consumo consciente configura-se em um dilema no qual, de um lado, tem-se o aumento do consumo pelas sociedades em geral e, de outro, uma maior reflexão por parte da sociedade sobre a forma de se consumir (BARROS, 2011).

Teóricos de Marketing Verde apontam na última década uma série de comportamentos de consumo alternativo e/ou de comportamentos anticonsumo desde os movimentos mais radicais, que não consomem nada que seja produzido pela sociedade industrial, até movimentos mais brandos, que tentam apenas rever seus hábitos de consumo e modificá-los, mesmo que de forma bastante branda (SMITH, 2005). Mintzberg (2009) classifica esses últimos movimentos como sendo parte integrante de Novas Sociedades de Consumo, conceito mais ligado à definição de consumo consciente que surgem no Brasil.

O último Relatório do Instituto Akatu em parceria com o Instituto Ethos (2012) mostra que o cidadão brasileiro está cada vez mais consciente dos impactos de seu consumo e teria cada vez mais adotado práticas de consumo ambientalmente mais corretos em sua vida cotidiana. As empresas brasileiras também estão se tornando mais ambientalmente, social e eticamente responsáveis, a fim de impor novos processos e melhores práticas em seus processos e produtos que envolvem práticas de marketing verde e, com isso, descarregam impostos pela postura ecoeficiente.

A riqueza do mundo está detida em $10 \%$ dos indivíduos e $90 \%$ da humanidade é pobre ou está abaixo da linha de miserabilidade (SPRÄNGER, 2009). A ideia de que é possível consumir causando mínimo impacto possível no meio ambiente e à sociedade, é um processo recente no Brasil e como Barros (2011) mostra em sua pesquisa, ainda é um ideal não totalmente realizado no país, basicamente por falta de legitimidade desta sociedade de consumo, que por sua vez é impulsionado pelas forças de mercado, pelo imediatismo e descarte sucessivos. "a identidade do consumidor consciente é percebida como uma atitude positiva, de alguém responsável, capaz de elaborar e compreender complexas estratégias e informações globais, alguém que é possuidor de um certo grau de abnegação ao adotar um estilo de vida diferenciado."(BARROS, 2011, p. 183) 
As classes sociais encontradas na amostra deste trabalho não apresentaram médias estatisticamente diferentes nas escalas resultantes, o que pode ter acontecido devido ao fato de só existir representantes de quatro classes mais altas: $A, A B, B$, e BC . O nível de formação apresentou diferentes níveis na escala apenas entre aqueles com nível médio completo / nível superior incompleto e nível superior completo, este último apresentou maiores médias com um percentil de <0,004. É possível perceber que a formação educacional de nível superior possui uma contribuição mais positiva em suas atitudes e práticas de consumo consciente e no aspecto ambiental especificamente. Contudo, práticas essas que ainda não influenciam nas atitudes relacionadas aos impactos do consumo em sociedade (CASI, 2013).

\section{CARIOCAS SÃO FAVORÁVEIS AO CONSUMO CONSCIENTE E ECO- COMPROMETIDO}

As escalas de atitudes de consumo consciente ambiental, sócio, ético e geral se mostraram confiáveis neste estudo e se mostraram correlacionadas entre si. Isso quer dizer que as atitudes gerais de consumo consciente podem ser divididas em diferentes esferas relacionadas entre si, como as utilizadas neste estudo: ambiental, social e ética. Neste ponto, é importante salientar os resultados positivos obtidos na elaboração da escala de atitudes gerais, apesar de ser necessário estudos mais profundos para seu aperfeiçoamento em um futuro próximo.

Devido ao fato do conceito consumo consciente estar sem solidez é difícil se criar uma única escala que abranja todos os seus aspectos. Isso ficou claro quando se analisou os fatores das escalas resultantes das entrevistas realizadas. Mais estudos devem ser realizados com mais especificidades, já que não foi o principal objetivo deste artigo.

A escala de atitudes de consumo consciente ambiental (ECCB) foi dividida em dois fatores. Analisando-os, foi fácil notar que ainda não abrangem todas as crenças de consumo ambientalmente conscientes. Examinando item por item, percebeu-se que certas crenças poderiam ser incluídas. Por exemplo, crenças com relação aos hábitos de consumo dentro de casa, como economizar uso de energia ou de utilizar a água de chuva para molhar as plantas, lavar a calçada e os carros da unidade familiar, que não foram incluídos na escala utilizada neste estudo. Isso não anula nem diminui a validade da escala, pois os resultados foram muitos satisfatórios e expressivos. Contudo, é um ponto de atenção para aperfeiçoamento futuro de escalas que serão desenvolvidas.

Sem dúvida, esse problema se origina em bases da literatura de consumo consciente e praticas de marketing verde. De qualquer forma, diversos estudos conseguiram atingir resultados satisfatórios com relação às escalas de consumo consciente, como os utilizados como base para as escalas neste trabalho (ROBERTS, 1995; ROBERTS, 1996; CREYER E ROSS, 1977; GROHMANN, 2012; ROUX E NANTEL, 2009).

Como o próprio conceito de consumo consciente, marketing verde, bem como seus componentes, ainda está em evolução e se mostra cada vez mais complexo, é provável que as escalas sobre o tema sofram alterações. Em outras palavras, as escalas de consumo consciente ambiental, social, ético e de marketing verde entre outras (i.e. político) ainda devem sofrer aperfeiçoamentos até que uma escala robusta de consumo consciente geral, que será composta pela fusão das primeiras, seja criada e aplicada globalmente.

Os cariocas são favoráveis às atitudes com relação ao consumo consciente geral e nas três esferas adotadas neste estudo: ambiental, social e ética. Contudo, pelos escores obtidos, é possível concluir que o público-alvo de estudo ainda pode se tornar mais favorável a essas atitudes. Além disso, o fato de apresentarem atitudes positivas com relação ao ato de consumir se preocupando com os efeitos dessa ação na sociedade e no meio ambiente não quer dizer que seus comportamentos sejam integralmente da mesma forma, como demonstrado no estudo de Barros (2011).

Em relação às crenças de consumo consciente, os cariocas se mostraram mais preocupados com os impactos de suas ações na sociedade do que no meio ambiente. Como discutido no capítulo anterior, os resultados obtidos pelas escalas de consumo social e eticamente responsáveis foram superiores ao consumo ambientalmente responsável.

Além disso, as consumidoras cariocas se mostraram mais conscientes do que os do sexo oposto em todas as dimensões. A única exceção foi a dimensão de consumo geral, isso significa dizer que as mulheres cariocas 
têm as mesmas crenças que os homens cariocas em relação aos impactos de seu consumo, contudo são mais preocupadas com o meio ambiente, com a sociedade e com a ética das empresas em que confiam.

As classes sociais representadas pela amostra não apresentaram diferenças entre si com relação às atitudes de consumo consciente. Contudo, como houve representantes apenas das classes média e média-alta, é possível que existam diferentes atitudes de acordo com a classe social.

\section{CONSIDERAÇÕES FINAIS}

A pesquisa mostrou que a idade impacta positivamente na atitude com relação ao consumo consciente em geral e nas dimensões adotadas neste estudo. Essa relação ainda precisa de estudos mais profundos, mas sem dúvida um de seus elementos está relacionado à formação escolar, pois mostrou-se que o nível de escolaridade, sobretudo o ensino superior, é importante para a formação de crenças favoráveis ao consumo consciente, gerando uma atitude mais positiva de um consumo responsável.

Visto o importante papel que o ensino traz para a formação de consumidores conscientes, é importante que a academia de marketing e de administração como um todo dê mais destaque ao tema nas universidades, a fim de formar profissionais engajados com suas ações como clientes e como tomadores de decisões dentro das empresas, e seus impactos no meio ambiente e na sociedade.

Assim como há décadas atrás as teorias de marketing (KOTLER E LEVY, 1969) precisaram sofrer uma ampliação de visão e de escopo, mais uma vez os acadêmicos dessas áreas devem refletir sobre a necessidade de uma mudança, visando criar profissionais e clientes mais responsáveis sobre suas ações. A partir desta evolução, a literatura sobre consumo consciente irá progredir e se difundir, criando a possibilidade de que existam de fato mercados com consumidores conscientes.

Notadamente, a cidade do Rio de Janeiro, mostra-se receptiva à práticas mais ecocomprometidas e a lei de agosto de 2013 que taxa o lixo jogado no chão no centro da cidade, Tijuca e Méier, reflete essa aceitação por parte da sociedade como um todo. Grupos sociais formadores de opinião tendem a difundir práticas verdes e inúmeros trabalhos solidários possuem representações locais: ongs que replantam árvores, grupos de catadores de lixo e jovens que deixam a drogaadicção através de plantio de produtos orgânicos que, a cada dia, possuem seus preços mais barateados e já são encontrados em mercados locais, além de feiras semanais de produtores do cinturão verde carioca. Programas exitosos de sacolas de pano em supermercados substituindo sacolas plásticas, roupas customizadas de algodão orgânico e outras a partir de folhas de cânhamo possuem maior durabilidade e práticas de marketing verde difundem seu uso glocal com êxito.

O indivíduo que esse estudo entrevistou demonstrou que já entende a importância do seu papel em sociedade, que seu lixo também lhe pertence, por isso ele necessita cuidar e dar melhor destino aos itens que descarta. Aprendeu que é melhor ser do que ter (KLEIN, 2002; HOLT, 2002) e que suas ações não mais estão circunscritas ao seu núcleo familiar apenas, consanguíneo, pois o outro reside no mesmo planeta que ele escolheu para viver.

O seu quintal deixou de ser atrás de sua residência e agora faz parte da Terra como um todo, por isso é tão importante ter uma consciência cósmica, solidária e pensar verde. Dessa forma, o futuro assegurado aos seus descendentes possui ecos de saúde, práticas com energia limpa e ainda estão asseguradas fontes de água pura, cristalina. $O$ ar pode ser respirado sem pagar impostos, desprovido de níveis tóxicos poluentes resultantes de anos de má educação ambiental. Ainda há tempo para resgatar Gaia com segurança!

As melhores escolhas que fizermos hoje certamente impactarão o nosso amanhã de uma forma ética, justa e mais equânime para todos. Os seres, as organizações e o planeta são um. Herança são os nossos atos que apresentam soluções da educação, dos valores humanos com Responsabilidade Humanitária. 


\section{REFERENCIAS}

[1] Abep, Associação Brasileira das Empresas de Pesquisa. CCEB: Critério de Classificação Econômica. Disponível em: www.abep.org. Acesso em 19.08. 2013 as 20:00.

[2] Barros, D. F. Consumo Consciente como Resistência: Possibilidade ou Oxímoro? 2011. 227 f. Tese (Doutorado em Administração) - Escola Brasileira de Administração Pública e de Empresas, Fundação Getulio Vargas, Rio de Janeiro, 2011

[3] Barros, D. F.; Costa, A. M. Consumo Consciente no Brasil: Um Olhar Introdutório Sobre Práticas de Resistência ao Consumo por meio da Análise do Discurso do Instituto Akatu pelo Consumo Consciente. In: Encontro de Marketing da ANPAD, 3, 2008, Rio de Janeiro. CD-ROM EMA 2008. Anais...Rio de Janeiro/RJ: ANPAD, 2008.

[4] Blackwell, R. D.; Engel, J. F.; MINIARD, P. W. Comportamento do Consumidor. São Paulo: Pioneira Thomson Learning, 2005.

[5] Casi 2013 - Congresso DE Administração, Sociedade E Inovação http://www.congressocasi.uff.br/.Acesso em 20.08.2013 as 20:00.

[6] Churchill, G. A. A Paradigm for Developing Better Measures of Marketing Constructs. Journal of Marketing Research, v. 16, p. 64-73, 1979.

[7] Cova, B.; Kozinets, R.; Shankar, A. Consumer Tribes. Oxford, UK: Elsevier, 2007.

[8] Creyer, E. H.; Ross, W. T. The Influence of Firm Behavior on Purchase Intention: Do Consumers Really Care About Business Ethics? Journal of Consumer Marketing, v. 14 (6), p. 421432, 1997

[9] Cuperschmidt, Nair Regina Mizrahy; Tavares, Mauro Calixta. Atitudes Em Relação ao Meio Ambiente e Sua Influência no Processo de Compra de Alimentos, ANPAD, 2001.

[10] Fabi, M. J. S.; Lourenço, C. D. S.; Silva, S. S. Consumo Consciente: a Atitude do Cliente perante 0 Comportamento Socioambiental Empresarial. In: Encontro de Marketing da ANPAD, 4, 2010, Florianópolis. CD-ROM EMA 2010.

[11] Feital, J. C.; Netto, A. F.; Ponchio, M. C.; Spers, E. E.; Spers, V. R. O Consumo Consciente da Água: um Estudo do Comportamento do Usuário Doméstico. In: Encontro de Marketing da ANPAD, 3, 2008, Rio de Janeiro. CD-ROM EMA 2008. Anais...Rio de Janeiro/RJ: ANPAD, 2008.

[12] Fishbein, M.; Ajzen, I. Belief, attitude, intention and behavior: an introduction to theory and research. Menlo Park, CA: Addison-Wesley Publishing Co., 1975.

[13] Ghoshal, S. Bad Management Theories are Destroying Good Management Practices.
Academy of Management Learning and Education, v.4, n.1, p. 75-91, 2005.

[14] Grohmann, M. Z.; Battistella, L. F.; Velter, A. N.; Casasola, F. Comportamento Ecologicamente Consciente do Consumidor: Adaptação da Escala ECCB Para o Contexto Brasileiro. Revista de Gestão Social e Ambiental, v. 6, n. 1, p. 102-116, 2012

[15] Hellman, K.; Schrage, D.; Ostergaard, P. Different Perspectives on Consumption, Consumer, Culture and Society. Call for Abstracts, Different Perspectives on Consumption, Consumer, Culture and Society Workshop, Berlin, 26-27 mar., 2010

[16] Instituto Akatu. Institucional: O Akatu. Disponível

em:

http://www.akatu.org.br/Institucional/OAkatu

Acesso em 19.08. 2013 as 20:00

[17] Instituto Akatu; Ethos. O Consumidor Brasileiro e a Sustentabilidade: Atitudes e Comportamentos frente ao Consumo Consciente, Percepções e Expectativas sobre a RSE Pesquisa 2010. Disponível em: http://www.akatu.org.br/Content/Akatu/Arquivos/file/ 10_12_13_RSEpesquisa2010_pdf.pdf Acesso em: Acesso em 20.08. 2013 as 20:00.

[18] Klein, N. Sem Logo. São Paulo: Record, 2002

[19] Kotler, P.; Levy, S. J. Broadening the Concept of Marketing. Journal of Marketing, v. 83, p. 10-16, 1969.

[20] Kozinets, R.V.; Handelman, J. M.; Lee, M. S. Editorial: Don't read this; or, who cares what the hell anti-consumption is, anyways? Consumption, Markets and Culture, v. 13, n. 3, p. 225-233, 2010.

[21] Lutz, R. J. The Role of Attitude Theory in Marketing. In: KASSARJIAN, H. H.; ROBERTSON, T. S. Perspectives in Consumer Behavior. New Jersey: Prentive Hall, 1991.

[22] Maclaran, P. Thinking Outside the Box: Circling Around Consumer Culture. In: HELLMAN, K.;

[23] Schrage, D.; OSTERGAARD, P. Different Perspectives on Consumption, Consumer, Culture and Society Workshop, Berlin, 26-27 mar., 2010.

[24] Mintzberg, Henry. Criando organizações eficazes. São Paulo: Atlas, 2009

[25] Naresh, M. K.; Birks, D.F. Marketing Research: An Applied Approach. UK: FT Prentice Hall, 2007.

[26] OSTEGAARD, P.; Jantzen, C. Shifting perspectives in consumer research: from buyer behavior to consumption studies. In: ECKMANN, S. X.; ELLIOTT, R. H. Interpretative Consumer Research: paradigms, methodologies \& applications. Copenhagen: Copenhagen Business School Press, 2002 
[27] Parasuraman, Addison-Wesley; Grewal, Dhruv; Krishnam, Ramayya. A Marketing Research. USA: Houghton Mifflin Harcourt Publishing Company, 2007.

[28] Roberts, J. A. Profiling Levels of Socially Responsible Consumer Behavior: A Cluster Analytic Approach and its Implications for Marketing. Journal of Marketing Theory and Practice, v. 3 (4), p. 97-117, 1995.

[29] Roberts, J. A. Green Consumers in the 1990s: Profile and Implications for Advertising. Journal of Business Research, v. 36, p. 217-231, 1996.

[30] Roux, C; Nantel, J. Conscious Consumption and its Components: An Exploratory Study. Advances in Consumer Research, v. 36, p. 903-905, 2009

[31] Sheth, J.N.; Mittal, B.; Newmann, B.I. Comportamento do Cliente indo além do
Comportamento do Consumidor. São Paulo: Atlas, 2001.

[32] Smith, Sandra Burle-Marx. MARKETING AMBIENTAL COMO DIFERENCIAL COMPETITIVO DA

[33] NATURA - dissertação de mestrado. Rio de Janeiro: UNESA 2005.

[34] Szmigin, I.; Bekin, C.; Carrigan, M. Communally Living the Positive Alternative. In: CHERRIER, H.; GANDOLFI, F. Downshifting: A Theoretical and Practical Approach to Living a Simplified Life. ICFAI University Press, 2007.

[35] Vergara, S. C. Projetos e Relatórios de Pesquisa em Administração. São Paulo: Editora Atlas, 2009. 


\title{
Bapítulo 6
}

\section{ESTRATÉGIAS PARA A APLICACÃO DOS CONCEITOS DE SUSTENTABILIDADE EM UNIVERSIDADES: O CASO DO TELHADO VERDE NA PUC-SP}

\author{
Tatiane de Oliveira Amancio \\ Igor Polezi Munhoz. \\ Alessandra Cristina Santos Akkari \\ Neusa Maria Bastos Fernandes dos Santos
}

Resumo: O telhado verde apresenta diversas vantagens, uma vez que funciona como isolante acústico, térmico, retém as águas pluviais, contribui na redução dos níveis de particulados e poluentes na atmosfera e recicla as chamadas águas cinzas (todo esgoto gerado em uma habitação, exceto o proveniente da bacia sanitária). Além dos benefícios citados, baseado na experiência de grandes multinacionais como a Ford (EUA), pode-se alcançar uma economia energética de $30 \%$, após a implantação do telhado verde. O objetivo deste trabalho é apresentar um estudo de viabilidade de implantação do telhado verde na Faculdade de Ciências Exatas e Tecnologia (FCET) da Pontifícia Universidade Católica de São Paulo (PUC-SP). Além da aplicação do tripé da sustentabilidade, ou seja, alinhar o cuidado com o planeta (proteção ambiental, recursos renováveis, eco eficiência), com a responsabilidade social e com o desenvolvimento econômico nas atividades cotidianas. Trata-se de uma pesquisa de natureza aplicada, orientada à geração de informações e conhecimentos que podem ser empregados na solução ou melhoria de problemas específicos. O estudo apresenta uma abordagem quantitativa, com ênfase em análises numéricas dos dados coletados, envolvendo o uso de métodos numéricos aplicados à engenharia. Nos ensaios experimentais, utilizando-se dois protótipos (um controle e outro contendo o telhado verde), constatou-se uma amplitude térmica significativa, de até $9,1^{\circ} \mathrm{C}$ e uma redução de escoamento superior a $70 \%$ com a terra do telhado úmida. No entanto, como o edifício é tombado, isso impossibilita uma futura implantação, além da necessidade de adequações estruturais. Baseado nos fatores econômicos, sociais e ambientais, verificou-se uma possível redução de até $R \$ 3067,00$ ao ano no consumo de energia elétrica caso o telhado verde fosse adotado em um único edifício do campus, ao invés do uso do ar condicionado para conforto térmico similar.

Palavras-chave: telhado verde, sustentabilidade, construções eficientes. 


\section{INTRODUÇÃO}

A procura por ideias que reduzam o impacto ambiental da atividade humana tem sido o motivo de maior empenho dos ambientalistas, a solução para construções pode estar mais perto do que se imagina: o Telhado Verde. Historiadores relatam que a ideia não é recente, acredita-se que no século VI a. C. o rei Nabucodonosor tenha ordenado a construção de um palácio que possuísse terraços sobrepostos onde seriam plantados jardins, os famosos jardins suspensos da Babilônia.

Segundo informações da IGRA (International Green Roof Association), o telhado verde, também chamado de ecotelhado ou telhado vivo, traz consigo uma série de vantagens para os usuários, além dos benefícios estéticos, uma vez que funciona como isolante acústico, térmico, retém as águas pluviais para posterior acúmulo, contribui na redução dos níveis de particulados e poluentes na atmosfera e recicla as chamadas "águas cinzas", que segundo Gelt (2001) é definida como todo esgoto gerado em uma habitação, exceto o proveniente da bacia sanitária, como chuveiro, banheira, pias de lavatório, entre outros.

A vegetação do telhado verde funciona como um isolante térmico tanto no verão como no inverno, e, sabendo-se que o adensamento urbano e o tráfego geram um efeito chamado de Ilhas de Calor, as temperaturas nesses locais aumentam em aproximadamente $10 \stackrel{\circ}{ } \mathrm{C}$ durante o verão, no entanto, áreas verdes e parques podem absorver até $80 \%$ da entrada de energia (BLACKHURST; HENDRICKSON; MATTHEWS, 2010)

Por outro lado, temos também a questão da eficiência energética, uma vez que grandes empresas têm economizado até 30\% da energia gasta com refrigeração após a implantação deste tipo de telhado. É o caso da fábrica de caminhões da Ford em Michigan (BOCK, 2008) e edifícios como a prefeitura de São Paulo. Estima-se que na Alemanha já existam mais de 14 milhões de metros quadrados de telhados verdes e, junto com os Estados Unidos, já somam mais de 2000 empresas especializadas somente nesse tipo de construção.

Apenas para efeitos comparativos, estima-se que no Brasil podem ser necessárias até três usinas com capacidade equivalente à Itaipu para refrigeração de ambientes em 2100. Uma vez que as temperaturas médias da
Terra estão aumentando e, paralelamente, temos a elevação de renda da população, tornando os equipamentos mais acessíveis. Sivak (2013) usa como exemplo o consumo de ar condicionado nos Estados Unidos, país no qual cerca de $87 \%$ das residências já são equipadas com o dispositivo, consumindo 185 milhões de MWh de energia por ano com refrigeração.

Neste trabalho busca-se uma alternativa de baixo custo para contribuição tanto na esfera micro, que é o próprio ambiente universitário da PUC-SP, até os desdobramentos macro, por meio da conscientização social, da aplicação do tripé da sustentabilidade e da integração das atividades de ensino e pesquisa para o design de construções eficientes, que resultarão em ganhos a longo prazo para o Brasil e o planeta.

\section{REVISÃO BIBLIOGRÁFICA}

O fenômeno da urbanização, aliado à impermeabilização do solo, impede a infiltração das águas pluviais, evitando a recarga de aquíferos e gerando um aumento da variável "escoamento superficial" durante os períodos de chuva. Esse problema provoca danos econômico-ambientais (POLETO, 2011). O telhado verde além de reduzir a velocidade do escoamento da água, se comparado ao telhado convencional, ainda é mencionado como agente na modificação do microclima e na redução de poluentes atmosféricos. Nesse último quesito, resultados indicam a remoção de cerca de $1.700 \mathrm{~kg}$ de poluentes em 20 ha de telhado verde (MORUZZI; MOURA; BARBASSA, 2014)

A implantação do telhado verde pode ser implantada em novas ou velhas construções. Desde que tenha os seguintes itens:

1. Laje: elemento estrutural no qual devem ser observadas as cargas e definir a escolha do tipo de vegetação, devido ao peso das demais camadas.

2. Impermeabilização: impede a infiltração de água na laje, através do uso da manta asfáltica e de produtos químicos que limitem a profundidade das raízes.

3. Proteção: necessária para impedir danos à impermeabilização, sendo composta basicamente de argamassa simples.

4. Drenagem: regulagem da retenção e drenagem do excesso da água. 
5. Filtragem: retém o substrato, impedindo-o de passar para a camada de drenagem.

6. Substrato: camada de nutrientes que dão suporte à vegetação. $O$ tipo $e$ a espessura do substrato dependem da vegetação escolhida e dá tecnologia empregada.

7. Vegetação: depende do tipo de telhado proposto, da altura com relação ao solo e do substrato disponível e, de preferência, que a espécie escolhida seja nativa e a avaliação em relação a manutenção. Os telhados extensivos (plantas de pequeno porte e geralmente um substrato com menor preço), querer uma manutenção menor que os intensivos (que possuem uma carga maior e espécies de maior porte).

Além da classificação pelo tipo de manutenção, é importante ressaltar a necessidade de ampliar as áreas verdes em ambientes urbanizados, pois as plantas desempenham um papel vital no fluxo de energia através de todos os ciclos ecológicos (CAPRA, 2006). As raízes extraem água e sais minerais, que são combinados com o dióxido de carbono $\left(\mathrm{CO}_{2}\right)$ extraído do ar para formar compostos orgânicos (processo de fotossíntese - conversão energia solar em energia química). Capra (2006) afirma, ainda, que a celulose e alguns outros compostos orgânicos são formados principalmente por átomos de carbono, hidrogênio e oxigênio que se originam do $\mathrm{CO}_{2}$ e da água $\left(\mathrm{H}_{2} \mathrm{O}\right)$ do substrato.

Observa-se também na Figura 1, a diferença na espessura da camada de substrato em função da vegetação (altura de crescimento), uma vez que o substrato é responsável pelo suporte da plantação. A camada de isolamento térmico não é necessária, embora exista em alguns casos, pois a própria composição do telhado verde funciona eficientemente para o conforto térmico das construções.

Figura 1 - Execução dos telhados verdes: vegetação e camadas

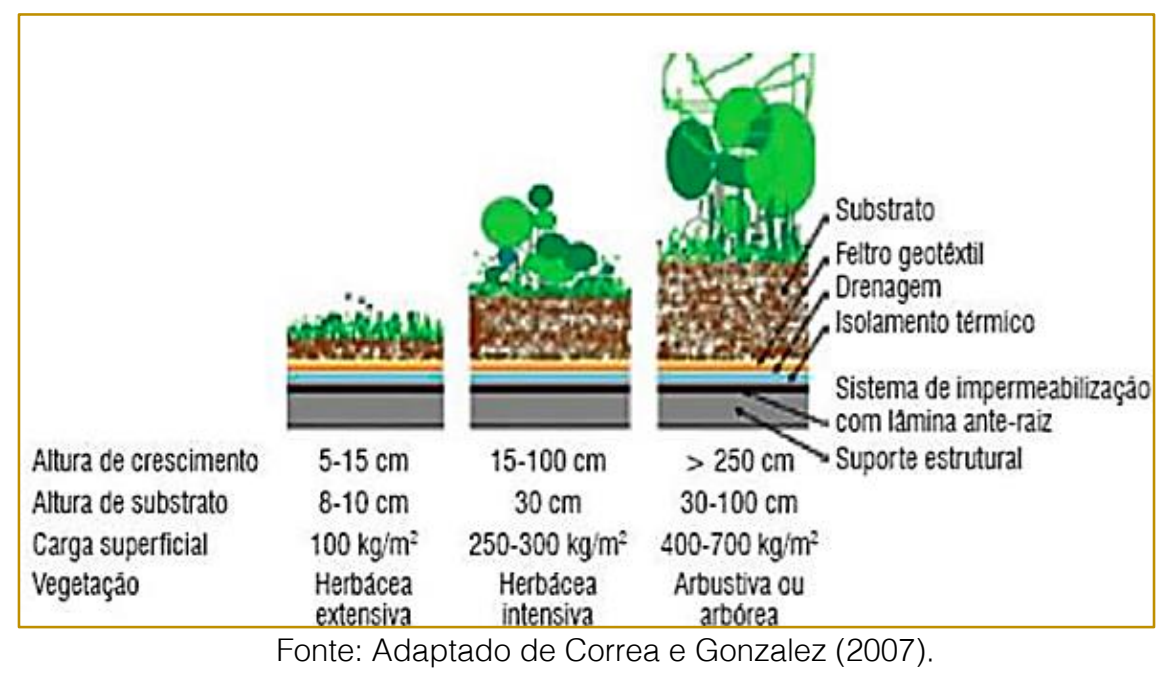

O conforto térmico é resultado da transformação da água para a forma de vapor, conforme explicado por Collischonn e Tassi (2008). Ainda de acordo Catuzzo (2013), a variação da temperatura do edifício com telhado verde, chega em média 5,3 graus abaixo do edifício sem telhado verde e, a umidade relativa do ar aumentou em 15,7\%. Fatores que contribuem na diminuição das ilhas de calor dos centros urbanos.

\section{METODOLOGIA}

Trata-se de uma pesquisa de natureza aplicada, orientada à geração de informações e conhecimentos que podem ser empregados na solução ou melhoria de problemas específicos. O estudo apresentado neste relatório tem uma abordagem quantitativa, com ênfase em análises numéricas dos dados coletados, envolvendo o uso de métodos numéricos aplicados à engenharia.

Com relação aos objetivos propostos, podese considerar um trabalho descritivo, que proporcione familiaridade com o problema 
central, descrevendo em detalhes as partes e suas relações, a fim de torná-lo explícito. Os procedimentos envolvem a pesquisa bibliográfica, a coleta e a análise de dados primários e secundários, por meio de simulações experimentais, do levantamento de custos e de informações técnicas, para realizar estudo de viabilidade técnica e econômica.

Utiliza-se o método de investigação dedutivo, de forma que as leis ou teorias que se adequam a determinados fenômenos, são aplicadas em situações específicas a fim de descobrir as suas relações, explicando os fenômenos particulares por meio das generalizações.

O desenvolvimento deste trabalho implica a realização de um conjunto de atividades para a futura implementação do conceito de telhado verde na Faculdade de Ciências Exatas e Tecnologia (FCET) da Pontifícia Universidade Católica de São Paulo (PUC$\mathrm{SP})$, no Brasil. As ferramentas fornecidas para o desenvolvimento das atividades e os procedimentos para coleta de dados primários e secundários, que foram utilizados como uma plataforma de aplicação, permitem a análise e validação dos resultados.

Dois protótipos de telhado foram feitos, um com o telhado verde e outro sem, para fins de controle. A temperatura de ambos os protótipos foi avaliada em dias diferentes, assim como a temperatura dos quatro edifícios da FCET (sete medições em diferentes momentos do dia e para cada edifício). Foi possível calcular a eficiência energética resultante do processo de isolamento térmico com o valor médio da amplitude térmica registrada pelos protótipos. Portanto, para calcular a eficiência energética, foi realizada uma modelagem matemática que considera a temperatura satisfatória do ar dentro do ambiente em torno de 21-22으 C. A partir desta informação, a temperatura do teto em diferentes momentos do dia foi medida para obter o valor médio. A Figura 2 mostra uma ilustração dos protótipos desenvolvidos, bem como sua instalação para obter dados pluviométricos, temperatura e vazão.

Figura 2 - Protótipos com e sem o telhado verde

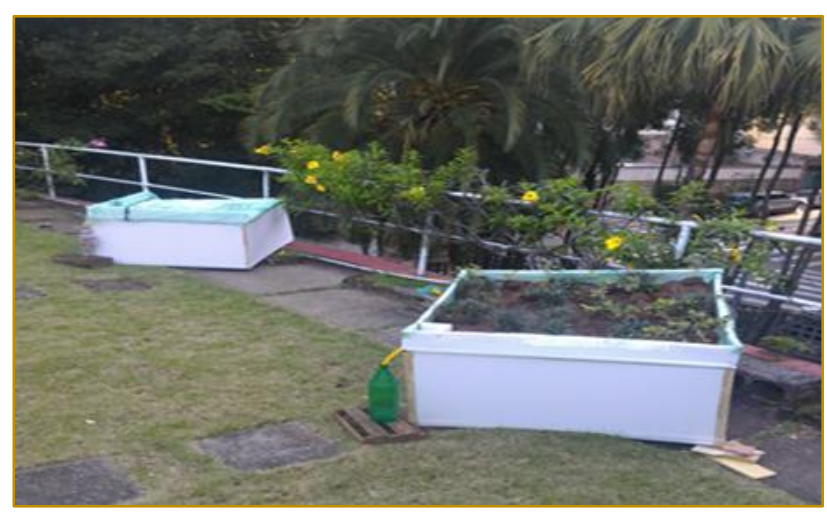

Fonte: elaborado pelo autor.

As trocas de calor por radiação, tanto dentro do ambiente como entre o ambiente interno e o externo foram desconsideradas, e assumiuse que a única fonte de remoção de calor seria pelo aparelho de refrigeração, para simplificação nos cálculos.

O modelo matemático usado é uma analogia com um circuito elétrico, no qual os resistores representam a transferência de calor por condução na laje e a transferência de calor pela convecção natural do ar na sala, para comparar os gastos de energia com ar condicionado e uso do telhado verde. Para os experimentos, foram utilizados termômetros, além dos materiais necessários para a construção de modelos funcionais d

\section{RESULTADOS E DISCUSSÃO}

No primeiro experimento, a temperatura foi medida em todos os andares dos quatro edifícios da FCET. Alguns dados estavam fora do padrão esperado, uma vez que o subsolo e o piso térreo deveriam ter uma temperatura mais baixa do que os andares superiores, especialmente o último andar de cada prédio. Isso pode ser explicado pelas incertezas e erros nas medições e termômetros. A planta é mostrada na Figura 3, onde é possível observar cinco salas (L1, L2, L3, L4 e L5) e o armazém. 
Figura 3 - Planta dos andares

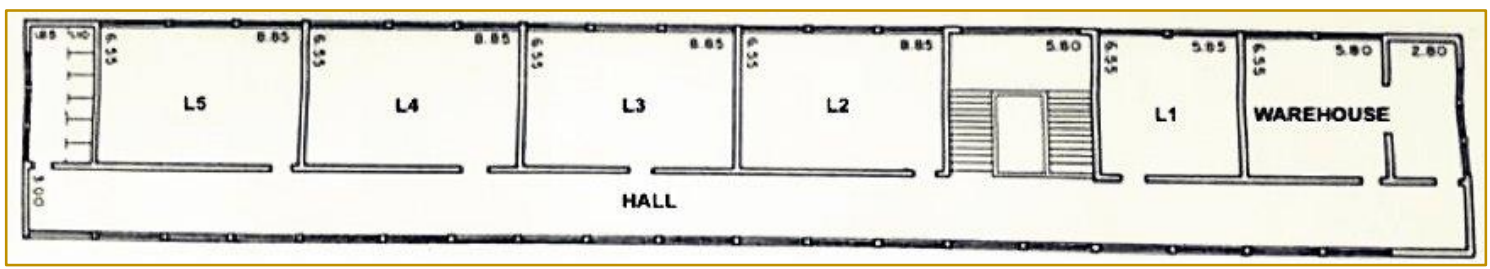

Fonte: acervo da PUC-SP.

Nas datas disponíveis para coleta dos dados nos prédios, uma reforma estava sendo executada na marquise e as obras podem ter interferido na medição. A partir da análise dos dados coletados, o prédio II foi escolhido para estudo de implantação de telhado verde, pois os resultados podem ser implementados em outros prédios do corpo docente. A Tabela 1 mostra as medições de temperatura obtidas para o edifício II.

Tabela 1 - Temperaturas obtidas para o prédio II

\begin{tabular}{|l|c|c|c|c|}
\hline $\begin{array}{l}\text { Período } \\
\text { do dia }\end{array}$ & \multicolumn{5}{|c|}{ Biblioteca $\left({ }^{\circ} \mathrm{C}\right)$} & Hall $\left({ }^{\circ} \mathrm{C}\right)$ & $1^{\circ}$ piso $\left({ }^{\circ} \mathrm{C}\right)$ & $\begin{array}{c}2^{\circ} \text { piso } \\
\left({ }^{\circ} \mathrm{C}\right)\end{array}$ \\
\hline $10-11$ & 25,50 & 22,05 & 21,65 & 21,15 \\
\hline $11-12$ & 24,50 & 22,35 & 22,60 & 22,10 \\
\hline $12-13$ & 25,60 & 23,60 & 22,55 & 23,05 \\
\hline $13-14$ & 25,70 & 22,65 & 21,95 & 22,55 \\
\hline $14-15$ & 25,60 & 22,95 & 23,30 & 22,35 \\
\hline $15-16$ & 25,50 & 22,70 & 22,80 & 22,15 \\
\hline $16-17$ & 24,80 & 21,05 & 21,70 & 21,35 \\
\hline
\end{tabular}

Fonte: elaborado pelo autor

A partir do monitoramento dos protótipos, houve uma amplitude térmica significativa de até $9,1^{\circ} \mathrm{C}$, registrada em 8 de dezembro de 2016, e um aumento no tempo de fluxo superior a $70 \%$ com o solo de telhado molhado, comparado ao protótipo de controle. A Tabela 2 mostra as temperaturas médias obtidas para os protótipos durante as análises.

Tabela 2 - Temperaturas médias dos protótipos de acordo com o dia analisado

\begin{tabular}{|c|c|c|c|}
\hline Data & $\begin{array}{c}\text { Temperatura } \\
\text { ambiente } \\
\left({ }^{\circ} \mathrm{C}\right)\end{array}$ & $\begin{array}{c}\text { Temperatura com } \\
\text { telhado verde }\left({ }^{\circ} \mathrm{C}\right)\end{array}$ & $\begin{array}{c}\text { Temperatura } \\
\text { sem telhado } \\
\text { verde }\left({ }^{\circ} \mathrm{C}\right)\end{array}$ \\
\hline $12 / 06 / 2016$ & 27,60 & 20,30 & 26,10 \\
\hline $12 / 07 / 2016$ & 30,90 & 22,85 & 29,40 \\
\hline $12 / 08 / 2016$ & 27,10 & 19,25 & 28,35 \\
\hline $12 / 09 / 2016$ & 27,30 & 22,10 & 26,60 \\
\hline $12 / 12 / 2016$ & 20,80 & 15,40 & 17,80 \\
\hline $12 / 13 / 2016$ & 33,50 & 19,70 & 26,60 \\
\hline $12 / 14 / 2016$ & 23,00 & 10,15 & 18,65 \\
\hline $12 / 15 / 2016$ & 18,50 & 8,70 & 13,40 \\
\hline
\end{tabular}

O cálculo de viabilidade econômica utilizou o valor médio da amplitude térmica dos protótipos, que foi de $6^{\circ} \mathrm{C}$, para a aplicação do modelo matemático. Para esta análise, um modelo matemático simplificado foi usado para calcular o gasto de condicionadores de ar para manter a sala 6 graus Celsius abaixo da temperatura. É uma estimativa, já que não é um cálculo trivial com várias variáveis. Como mencionado anteriormente, o teto do edifício II, é feito de gesso, coberto com telhas, para o cálculo isso não foi adotado. 
Ainda assim, o cálculo desloca as janelas e as trocas de calor por radiação.

Portanto, o sistema não é fechado, mas no modelo foi considerado que a única troca de calor seria feita pelo ar condicionado. Além disso, as únicas fontes de calor são o sol e os condicionadores de ar e o cálculo do calor transferido pelo ar condicionado, portanto, não foi necessário realizar uma análise estatística experimental entre o controle e o verde estrutura de telhado.

Com base no desempenho de um condicionador de ar split classe A, que possui a maior economia de energia, que é ativado para remover $6 \stackrel{\circ}{\circ}$ da sala, é possível calcular o calor transferido $(\mathrm{Q})$, conforme mostrado na Tabela 3, com a Equação 1.

$$
Q=\Delta T /\left[1 /\left(h^{\star} A\right)+e /\left(k^{*} A\right)\right]
$$

\section{Equação (1)}

Sabendo-se que $h$ é o coeficiente de convecção do ar (adotado como $5.11 \mathrm{~W} / \mathrm{m}^{2} \mathrm{~K}$ ), $k$ é a condutividade térmica do concreto (aproximadamente $1,4 \quad \mathrm{~W} / \mathrm{mK}), e$ é a espessura $(0,12 \mathrm{~m}), A$ é a área da sala e $\Delta T$ é a diferença entre a temperatura $\left(6^{\circ} \mathrm{C}\right)$.

Tabela 3 - Calor transferido

\begin{tabular}{|c|c|c|}
\hline & Área $\left(m^{2}\right)$ & Calor (Watts) \\
\hline Almoxarifado & 56,33 & 1200,00 \\
\hline L1 & 38,32 & 821,92 \\
\hline L2, L3, L4 ou L5 & 57,97 & 1224,49 \\
\hline
\end{tabular}

Fonte: elaborado pelo autor

A energia calculada na Tabela 3 seria consumida pelos condicionadores de ar para resfriar os ambientes com a mesma temperatura que o telhado verde forneceria. $O$ valor da energia no Brasil é de $R \$ 0,30$ por kWh, então foi possível observar uma economia anual de energia de aproximadamente $R \$ \quad 3067,00$ apenas no prédio II. O valor da economia tende a aumentar, uma vez que a aplicação pode ocorrer em outros prédios da Faculdade de Ciências Exatas e Tecnologia e foram desconsideradas as trocas de calor por radiação, e principalmente porque o sistema não é fechado.

No entanto, após uma visita à seção técnica de materiais iconográficos da Universidade de São Paulo (USP) e uma consulta ao site da prefeitura, verificou-se que o prédio da FCET é um edifício tombado, o que implica em limitações para modificações e dificulta a implementação futura do telhado verde do ponto de vista técnico.

\section{CONCLUSÕES}

Analisando os resultados obtidos, podemos destacar fatores decisivos, como: econômicos, sociais e ambientais. Do ponto de vista econômico, segundo Mello, Costa,
Alberti e Filho (2010), é possível em menos de 5 anos recuperar o dinheiro investido.

As medidas dos protótipos foram adequadas e uma amplitude térmica significativa de até 9,1 ${ }^{\circ} \mathrm{C}$ foi verificada. Além disso, observou-se que o telhado verde reduziu o fluxo em mais de 70\%. Com base na análise econômica, houve uma redução possível de até $R \$$ 3067,00 por ano no consumo de eletricidade se o telhado verde fosse adotado em um único prédio do câmpus, em vez de usar o ar condicionado para um conforto térmico similar.

Especificamente para a FCET, por se tratar de um edifício tombado, houve a necessidade de uma análise mais detalhada dos aspectos arquitetônicos e do patrimônio histórico para permitir a implantação do telhado verde.

Por meio das visitas, experiências, levantamento bibliográfico e consulta no site da prefeitura de São Paulo, é possível constatar uma inviabilidade futura de implementar do telhado verde, tanto pelo fato dos prédios serem tombados, quanto pela necessidade de reforço estrutural para que o peso do novo telhado verde seja suportado.

Ressalta-se que os resultados obtidos foram promissores, sugerindo que esse mesmo estudo sistemático seja desenvolvido para as demais faculdades da PUC-SP ou mesmo 
para outras universidades e instituições brasileiras, a fim de otimizar os indicadores

\section{REFERÊNCIAS}

[1] Blackhurst, M.; Hendrickson, C.; Matthews, H. S. Cost-effectiveness of green roofs. Journal of Architectural Engineering, v. 16, p. 136143, 2010

[2] Bock, L. O jardim subiu no telhado. Revista Época, Rio de Janeiro, v. 505, jan. 2008. Disponível em: <http://revistaepoca.globo.com/Revista/Epoca/0,,E DG81177-6010-505,00.html>. Acesso em: 04 abr. 2016.

[3] Capra, F. A Teia da Vida: uma nova compreensão científica dos sistemas vivos. São Paulo: Editora Cultrix, 1996. 249p.

[4] Catuzzo, H. Telhado Verde: impacto positivo na temperatura e umidade do ar. O Caso da Cidade de São Paulo. Tese (Doutorado em geografia física) - Faculdade de Filosofia, Letras e Ciências Humanas, Universidade de São Paulo, São Paulo, 2013.

[5] Collischonn, W; TASSI, R. Introduzindo Hidrologia. Porto Alegre: IFH- UFRGS, 2008. 149p.

[6] Correa, C. B.; Gonzalez, F. J. N. O uso de coberturas ecológicas na restaurac,ão de coberturas planas. In: Anais do Núcleo de Pesquisa em Tecnologia de Arquitetura e socioambientais

Urbanismo - NUTAU. São Paulo: Pró-reitoria de Pesquisa, Universidade de São Paulo, 2002.

[7] Gelt, J. et al. Water in the Tucson area: seeking sustainability. Water Resources Research Center, n. 20, p. 1-55, 2001.

[8] Inmetro. Tabelas de consumo/eficiência energética. Disponível em: http://www.inmetro.gov.br/consumidor/pbe/condici onadores.asp. Acesso em 05 ago. 2017.

[9] Moruzzi, R. B.; Moura, C. C.; Barbassa, A. P. Avaliação do efeito da inclinação e umidade antecedente na qualidade e quantidade das parcelas escoadas, percoladas e armazenadas em telhado verde extensivo. Revista Ambiente Construído, p. 59-73, 2014.

[10] Poleto, C. Suds (Sustainable Urban Drainage Systems): Uma Contextualização Histórica .Revista Thema, 2011.

[11] Prefeitura. Cadastro de Imovéis Tombados - CIT. Disponível em: http://www3.prefeitura.sp.gov.br/cit/Forms/frmResul tadoConsulta.aspx>. Acesso em 29 jun. 2017.

[12] Sivak, M. Will AC Put a Chill on the Global Energy Supply? American Scientist, v. 101, n. 5, p. 330,2013 


\section{Capítulo 7}

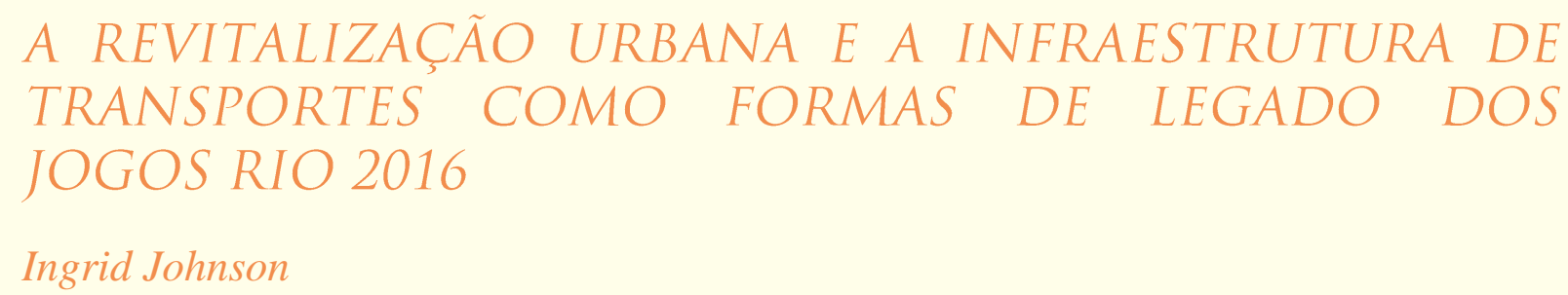

Paulo Roberto Rocha Aguiar

Resumo: Este artigo apresenta uma análise do projeto de legado para o Rio de Janeiro, por sediar os Jogos Olímpicos e Paralímpicos de Verão de 2016, da perspectiva da regeneração urbana, com o projeto Porto Maravilha, e da melhoria da infraestrutura de transportes, com os projetos de mobilidade do Plano de Políticas Públicas (LEGADO). Para isto observa-se, a evolução dos Jogos na Era Moderna e o crescimento de seus respectivos legados. Procura-se compreender a escolha do Rio de Janeiro, entender a distribuição do legado nas regiões que receberão os Jogos, e avaliar o peso do Plano de Políticas Públicas (LEGADO) no total do orçamento Olímpico. Apresenta-se o projeto Porto Maravilha, e os nove projetos de mobilidade do Plano de Políticas Públicas (LEGADO). Verifica-se a regeneração urbana e a melhoria da infraestrutura de transportes nas duas últimas Olimpíadas, Londres 2012 e Pequim 2008, e também em Barcelona 1992, por ser esta última a base da transformação urbana e inspiração para o projeto dos Jogos Rio 2016. Conclui-se que a regeneração urbana e a melhoria da infraestrutura de transportes são primordiais no projeto dos Jogos Rio 2016, mostrando que a cidade do Rio de Janeiro, assim como outras cidades-sede, utilizaram os Jogos como estratégia para viabilizar projetos urbanos.

Palavras Chave: Jogos Rio 2016. Legado. Revitalização Urbana. Regeneração Urbana. Infraestrutura de Transportes. Projeto Porto Maravilha. Projetos de Mobilidade do Plano de Políticas Públicas (LEGADO). 


\section{INTRODUÇÃO}

Os Jogos Olímpicos nasceram na Antiguidade e foram reeditados na Era Moderna pelo francês Pierre de Coubertin (1863-1937) (KELLY, 1972). A idéia de legado, não foi inicialmente pensada, porém surgiu e evoluiu com o tempo (GOLD e GOLD, 2008).

Em outubro de 2009, a cidade do Rio de Janeiro foi eleita a cidade-sede dos Jogos Olímpicos e Paralímpicos de 2016 e, desde então, a mídia divulga os esportes e o legado para a cidade. Então sugerem as seguintes perguntas: O projeto dos Jogos Rio 2016 ponderava o legado como fator primordial? Qual seria o legado a ser priorizado? O legado estava presente nas Olimpíadas anteriores?

O objetivo deste artigo é analisar o projeto de legado para o Rio de Janeiro, da perspectiva da regeneração urbana, com o Projeto Porto Maravilha, e da melhoria da infraestrutura de transportes, com os projetos de mobilidade do Plano de Políticas Públicas (LEGADO). Para isto contextualizou-se os Jogos Olímpicos e a crescente importância do legado; verificou-se a razão de escolha do Rio de Janeiro; explicou-se a distribuição dos Jogos e do legado pela cidade; avaliou-se o peso do Plano de Políticas Públicas (LEGADO) no total do orçamento Olímpico; apresentou-se o projeto Porto Maravilha e os projetos de mobilidade do Plano de Políticas Públicas (LEGADO); e verificou-se a regeneração urbana e a melhoria na infraestrutura de transportes nas últimas Olimpíadas, Londres 2012 e Pequim 2008, e em Barcelona 1992, por ser esta a base para transformação urbana e inspiração para o projeto Rio 2016.

\section{METODOLOGIA}

Quanto aos fins, esta pesquisa é classificada como exploratória, na medida em que busca um maior conhecimento sobre o legado urbano para a cidade do Rio de Janeiro dos Jogos de 2016. É um tema atual e um projeto único, por ser um projeto de Jogos Olímpicos referente à uma cidade-sede específica, o Rio de Janeiro.

Esta pesquisa também apresenta elementos de pesquisa descritiva, uma vez que explica o Projeto Rio 2016, da perspectiva da regeneração urbana através do projeto Porto Maravilha, bem como relata os projetos de infraestrutura de transportes que constam no Plano de Políticas Públicas (LEGADO), um dos instrumentos que compõem o orçamento Olímpico.

Quanto aos procedimentos técnicos utilizados para a coleta de dados (meios), este trabalho fez uma pesquisa bibliográfica e uma pesquisa documental. A pesquisa bibliográfica foi feita a partir de livros; sites oficiais de entidades; artigos científicos apresentados em congressos, seminários, elaborados em centros de estudos de pesquisa e publicados em revistas e jornais técnicos; e dissertações de mestrado. A pesquisa documental foi feita por acompanhamento de notícias em jornais e revistas; relatórios de instituições; documentos oficiais disponibilizados pelo Governo Brasileiro, pelo Estado e Prefeitura do Rio de Janeiro e pela Autoridade Pública Olímpica (APO); e documentos oficiais disponibilizados pelo Governo Britânico e pela Prefeitura de Londres.

Esta pesquisa estuda o legado urbano dos Jogos Rio 2016 antes da realização destes. Uma análise mais consistente só será possível após um certo período da realização dos Jogos.

\section{UM BREVE RESUMO SOBRE A HISTÓRIA DOS JOGOS OLÍMPICOS}

A data mais aceita para o início dos Jogos Olímpicos da Idade Antiga é 776 a.C., quando foi aberto o registro público na cidade de Olímpia, dos vencedores de uma corrida a pé realizada a cada quatro anos. De uma única prova, foram sendo incorporadas novas modalidades esportivas com o passar dos anos. A cidade de Olímpia era um grande santuário ao Deus Zeus, e os Jogos eram realizados em sua homenagem a cada quatro anos. Depois de um grande apogeu, os Jogos declinaram com a Grécia conquistada pelos romanos. Os Jogos foram extintos em 393 d.C., através da publicação de um decreto pelo Imperador Romano Teodósio, em função da ascensão do cristianismo contra o paganismo (KELLY, 1972).

A reedição dos Jogos Olímpicos na Era Moderna, foi um projeto do francês Pierre de Coubertin (1863-1937), que entendeu o esporte como parte integrante da educação, ao observar o surgimento do esporte amador e das práticas esportivas, na Inglaterra e nos Estados Unidos, através de competições em 
clubes e universidades. A descoberta e a reconstituição da cidade de Olímpia, e a tentativa do governo grego em reviver os Jogos, organizando duas competições esportivas em Atenas no final do século XIX, incentivaram Coubertin a trabalhar pelo renascimento dos Jogos Olímpicos (KELLY, 1972).

Em um Congresso Internacional na Universidade de Sorbonne, para discutir o amadorismo no esporte em 1894, foi apresentada e aprovada por unanimidade, uma proposta de retorno imediato dos Jogos Olímpicos. O Congresso constituiu então o Comitê Olímpico Internacional (COI) e definiu os primeiros Jogos Olímpicos da Era Moderna para Atenas em 1896, e os segundos para Paris em 1900, estabelecendo a realização destes a cada quatro anos, com a escolha prévia da cidade-sede a ser definida pelo $\mathrm{COI}$ (KELLY, 1972).

\section{A CRESCENTE IMPORTÂNCIA E A EVOLUÇÃO DO LEGADO DOS JOGOS}

As Olimpíadas foram pensadas para instalações já existentes ou temporárias. O primeiro estádio feito para uma Olimpíada foi o de Londres, em 1908, e a primeira vila Olímpica construída para atletas foi a de Paris, em 1924. Mesmo Berlim, em 1936, criando o maior complexo esportivo até então, teve impacto mínimo na cidade. Somente a partir de Roma, em 1960, com o fim das restrições do pós-guerra, os Jogos se tornaram um potencial para a transformação urbana. Em Roma, várias partes da cidade foram modificadas permanentemente, e esta maior transformação urbana para sediar os Jogos, tornou-se uma característica dos anos de 1960 e 1970 (GOLD e GOLD, 2008).

Vale destacar os Jogos de Tokyo, em 1964, que criaram projetos de infraestrutura com visão até o ano 2000. E também os Jogos de Montreal, em 1976, que confirmaram a tendência de mega-projeto dos Jogos, que com uma má gestão financeira e construções superdimensionadas, especialmente $\mathrm{O}$ Estádio Olímpico, geraram um enorme déficit nas finanças da cidade (GOLD e GOLD, 2008).

O estrago à credibilidade dos Jogos causados por Montreal foi recuperado por Los Angeles, em 1984, e Barcelona, em 1992. Os Jogos de Los Angeles mostraram um novo modelo de financiamento, com grande participação da iniciativa privada, completando o setor público, tornando-se este modelo um fator de sucesso para os Jogos. Os Jogos de Barcelona, tornaram-se um marco do potencial para regeneração urbana, restaurando os Jogos como uma poderosa forma de promover uma cidade e sua transformação urbana. Los Angeles 1984 e Barcelona 1992 são a base da política atual para sediar os Jogos Olímpicos (GOLD e GOLD, 2008).

A partir dos anos 2000, o COI passou a priorizar a sustentação ambiental e depois a sustentação do legado total. Os Jogos de Sidney, em 2000, tiveram um forte foco em projetos ambientais, mas o Estádio Olímpico foi superdimensionado. Os Jogos de Atenas, em 2004, reconstruíram a infraestrutura turística e criaram o Parque Arqueológico, mas os complexos esportivos também foram superdimensionados. Após os Jogos de Sidney e Atenas, a sustentabilidade das instalações esportivas tornou-se uma prioridade (GOLD e GOLD, 2008).

\section{AS TRANSFORMAÇÕES URBANAS COMO FORMAS DE LEGADO OLÍMPICO}

Com a atenção global dada aos Jogos Olímpicos, estes acabaram se tornando muito mais do que um evento esportivo, evoluíram para uma ferramenta de renovação urbana e catalisador de grandes transformações. Devido aos elevados custos para organizar e sediar os Jogos, as cidades-sede passaram a buscar o desenvolvimento econômico e a regeneração urbana como justificativa para a realização dos Jogos (ESSEX e CHALKLEY, 2003)

De acordo com Essex e Chalkley (2003), abaixo encontram-se os tipos de infraestrutura relacionados com a realização dos Jogos Olímpicos:

a. Instalações esportivas;

b. Transporte: aumento da capacidade aeroportuária, novas estradas e melhoria do transporte público;

c. Hospedagem: construção de hotéis e da Vila Olímpica para os atletas;

d. Outras melhorias urbanas voltadas para a infraestrutura em geral como abastecimento de água, tratamento de esgotos, tratamento do lixo, melhoria da qualidade do ar, telecomunicações, etc.; a valorização da paisagem e do meio ambiente; 
e a valorização cultural com a criação de museus e galerias de arte; e

e. Novas formas de gestão e organização urbanas.

\section{A ESCOLHA DOS JOGOS RIO 2016}

A cidade-sede dos Jogos Olímpicos e Paralímpicos de Verão de 2016 foi decidida em Copenhague, na Dinamarca, em 02 de outubro de 2009, entre as seguintes cidades candidatas: Chicago, Tóquio, Madri e Rio. Observa-se pela Tabela 1 que os orçamentos para a realização dos Jogos estavam na mesma ordem de grandeza, enquanto os orçamentos para investimento de capital nas cidades eram bem diferentes, demonstrando o grande investimento necessário na cidade do Rio de Janeiro no total de USD 11,10 bilhões para receber os Jogos.

Tabela 1 - Orçamento proposto para os Jogos de 2016

\begin{tabular}{|c|c|c|c|c|c|c|c|c|}
\hline $\begin{array}{l}\text { Orçamento para os } \\
\text { jogos de } 2016 \text { em } \\
\text { bilhôes de USD }\end{array}$ & Chicago & Distribuiçâo & Tóquio & Distribuiçâo & Madri & Distribuiçâo & $\begin{array}{l}\text { Rio de } \\
\text { Janeiro }\end{array}$ & Distribuiçâo \\
\hline $\begin{array}{l}\text { Comitế organizador } \\
\text { dos jogos olímpicos }\end{array}$ & 3,80 & $78,7 \%$ & 2,86 & $48,1 \%$ & 2,67 & $43,7 \%$ & 2,82 & $20,3 \%$ \\
\hline $\begin{array}{l}\text { Investimento de } \\
\text { capital }\end{array}$ & 1,03 & $21,3 \%$ & 3,09 & $51,9 \%$ & 3,44 & $56,3 \%$ & 11,10 & $79,7 \%$ \\
\hline $\begin{array}{l}\text { Orçamento proposto } \\
\text { para os jogos de } 2016\end{array}$ & 4,83 & $100,0 \%$ & 5,95 & $100,0 \%$ & 6,11 & $100,0 \%$ & 13,92 & $100,0 \%$ \\
\hline
\end{tabular}

Fonte: Adaptado de GOLD, Compiled from Candidature Files, 2009.

Além da grande diferença que os Jogos fariam para a cidade do Rio de Janeiro, de acordo com Luzenfichter (2010), havia outros critérios que também influenciaram a escolha do Rio de Janeiro:

a. Chicago. Os Estados Unidos já tinham organizado os Jogos de Verão e Inverno por oito vêzes. Houve um excesso de pressão pela candidatura de Chicago, o quê não agradou ao COI (Luzenfichter, 2010);

b. Tóquio. Já havia sediado os Jogos de 1964 e seria complicado votar pelo Japão em 2009, logo após Pequim 2008. O COI preza pela rotatividade dos continentes (Luzenfichter, 2010);

c. Madri. Num intervalo de menos de 25 anos entregar novamente os Jogos à Espanha, e principalmente quatro anos depois da realização de Jogos na Europa, Londres 2012 (Iuzenfichter, 2010); e

d. Rio de Janeiro. Representava o Brasil, um país emergente que buscava a oportunidade de mostrar a América do Sul pela primeira vez nos Jogos. A candidatura do Rio de Janeiro recebeu forte apoio político e econômico do Governo Brasileiro. Embora a cidade não tivesse os recursos das demais candidaturas, o país apresentava uma conjuntura econômica favorável em meio à crise global (Luzenfichter, 2010).

\section{OS JOGOS OLÍMPICOS E PARALÍMPICOS RIO 2016 E SEU LEGADO URBANO}

Os Jogos Olímpicos e Paralímpicos Rio 2016 estão agendados, respectivamente, de 5 a 21 de agosto, e de 7 a 18 de setembro de 2016. Os Jogos ocorrerão em quatro grandes regiões metropolitanas do Rio de Janeiro, com a idéia de distribuição do legado pelas diferentes áreas: Barra da Tijuca, Copacabana, Deodoro e Maracanã. (Comitê Organizador Dos Jogos Olímpicos e Paralímpicos Rio 2016, 2014).

A Região da Barra da Tijuca será a região central dos Jogos, com a Vila Olímpica e Paralímpica, o Parque Olímpico da Barra, o Riocentro, o Centro Internacional de Radiodifusão, o Centro Principal de Mídia e a Vila de Mídia da Barra. As prioridades são as novas instalações esportivas, com o Centro Olímpico de Treinamento (COT), um Laboratório de Pesquisas para o esporte, e a melhoria na infraestrutura de transportes (Comitê Organizador dos Jogos Olímpicos E Paralímpicos Rio 2016, 2014).

A Região de Copacabana engloba o bairro de Copacabana, o Parque do Flamengo, a Lagoa Rodrigo de Freitas e a Marina da Glória. Aqui serão realizadas competições de esportes ao ar livre em instalações temporárias, mostrando as belezas naturais do Rio de Janeiro (COMITÊ Organizador dos Jogos Olímpicos e Paralímpicos Rio 2016, 2014). 
A Região de Deodoro na Zona Oeste circunda uma vila de treinamento militar. O foco é a construção de instalações esportivas para o desenvolvimento de jovens, a melhoria da infraestrutura de transportes e a criação do Parque Radical de Deodoro (Comitê Organizador dos Jogos Olímpicos E Parlímpicos rio 2016, 2014). Este se tornará a segunda maior área de lazer da cidade, menor apenas que o Aterro do Flamengo (Prefeitura do Rio de Janeiro, 2014).

A Região do Maracanã inclui o Estádio Olímpico João Havelange, o Sambódromo e o Estádio do Maracanã. Este último terá além das partidas de futebol, as Cerimônias de Abertura e Encerramento dos Jogos. Esta região que faz parte da Zona Norte do Rio de Janeiro e está próxima do centro, também inclui a Região do Porto do Rio. O grande legado será a revitalização da zona portuária, com o projeto Porto Maravilha (COMITÊ Organizador dos Jogos Olímpicos e Paralímpicos Rio 2016, 2014).

\subsection{PLANEJAMENTO E ORÇAMENTO}

A Autoridade Pública Olímpica (APO), um consórcio público formado pelo governo federal, e pelos governos do Estado e da Prefeitura do Rio de Janeiro, foi criada pela Lei Federal no 12.396, de 21 de março de 2011, para garantir a coordenação das ações governamentais, conforme acordado com o Comitê Olímpico Internacional (APO, 2014).

Segundo a APO (2014), as obras de infraestrutura, os serviços e os investimentos, para os Jogos Rio 2016, estão demonstrados em três diferentes instrumentos:

1. Orçamento do Comitê Rio 2016. Os investimentos para organização e realização dos Jogos. O Comitê Organizador dos Jogos Rio 2016 é uma entidade privada sem fins lucrativos criada especificamente para organizar e realizar os Jogos (APO, 2014);

2. Matriz de Responsabilidades. Os projetos governamentais executados com recursos públicos e privados, inteiramente associados à organização e realização dos Jogos (APO, 2014); e

3. Plano de Políticas Públicas (Legado). Os projetos com baixa ou nenhuma relação direta com os Jogos, que antecipam ou ampliam investimentos federais, estaduais e municipais em infraestrutura e políticas públicas, incentivados pela realização dos Jogos Rio 2016 (APO, 2014).

Segundo a APO (2015), o Orçamento do Comitê Rio 2016 com valores do 1o trimestre de 2014, a Matriz de Responsabilidades com os valores da $2^{\underline{a}}$ atualização em janeiro de 2015, e o Plano de Políticas Públicas (Legado) com os valores da $1^{a}$ atualização em abril de 2015, encontram-se na tabela 2.

Tabela 2 - Total do orçamento dos Jogos Rio 2016

\begin{tabular}{|l|c|c|c|c|}
\hline $\begin{array}{c}\text { Orçamento dos jogos rio } 2016 \mathrm{em} \\
\text { bilhões de reais }\end{array}$ & $\begin{array}{c}\text { Recursos } \\
\text { privados }\end{array}$ & $\begin{array}{c}\text { Recursos } \\
\text { públicos }\end{array}$ & $\begin{array}{c}\text { Total de } \\
\text { recursos }\end{array}$ & Distribuição \\
\hline Orçamento do comitê rio 2016 & 7,0 & 0 & 7,00 & $18,3 \%$ \\
\hline Matriz de responsabilidades & 4,2 & 2,4 & 6,6 & $17,3 \%$ \\
\hline Plano de políticas públicas (legado) & 10,6 & 14,0 & 24,6 & $64,4 \%$ \\
\hline Total do orçamento dos jogos rio 2016 & 21,8 & 16,4 & 38,2 & $100,0 \%$ \\
\hline
\end{tabular}

Fonte: Adaptado da APO, Comitê Organizador dos Jogos Olímpicos, 2014 e Matriz de

Responsabilidades e Plano de Políticas Públicas (Legado), 2015.

É importante notar a participação majoritária de $64,4 \%$ do Plano de Políticas Públicas (Legado) no total do orçamento Olímpico. Conforme a APO (2015), o Plano de Políticas
Públicas (Legado) segundo a $1^{\text {a }}$ atualização em abril de 2015, compreende 27 projetos, de acordo com a tabela 3 , com seus respectivos orçamentos em milhões de reais e a previsão de conclusão dos mesmos. Para temas com mais de um projeto, utilizou-se o prazo de entrega do último. 
Tabela 3 - Resumo do Plano de Políticas Públicas (LEGADO) 1aa atualização abril de 2015

\begin{tabular}{|c|c|c|c|c|}
\hline Tema ou projeto & $\begin{array}{l}\text { Número } \\
\text { de } \\
\text { projetos }\end{array}$ & $\begin{array}{l}\text { Orçamento em } \\
\text { milhões de reais }\end{array}$ & Distribuição & $\begin{array}{l}\text { Prazo para } \\
\text { conclusão }\end{array}$ \\
\hline VLT do Porto & 1 & $1.188,75$ & $4,8 \%$ & $2^{\circ} \operatorname{trim} / 16$ \\
\hline BRT Transolímpica & 2 & $2.280,46$ & $9,3 \%$ & $2^{\circ} \operatorname{trim} / 16$ \\
\hline BRT Transoeste & 1 & 114,43 & $0,5 \%$ & $1^{\circ} \mathrm{trim} / 16$ \\
\hline Duplicação do elevado do Joá & 1 & 457,95 & $1,9 \%$ & $2^{\circ}$ trim/16 \\
\hline Viário do Parque Olímpico & 1 & 514,36 & $2,1 \%$ & $10 \operatorname{trim} / 16$ \\
\hline Sistema metroviário - Linha 4 & 2 & $8.790,88$ & $35,8 \%$ & $2^{\circ} \operatorname{trim} / 16$ \\
\hline Renovação e acessibilidade de estações ferroviárias & 1 & 259,83 & $1,1 \%$ & $2^{\circ} \mathrm{trim} / 16$ \\
\hline TOTAL PROJETOS DE MOBILIDADE & 9 & $13.606,66$ & $55,3 \%$ & \\
\hline Porto Maravilha & 1 & $8.200,00$ & $33,3 \%$ & $2^{\circ} \operatorname{trim} / 16$ \\
\hline Outros Projetos de Renovação Urbana & 4 & 757,58 & $3,1 \%$ & $2^{\circ} \operatorname{trim} / 16$ \\
\hline TOTAL PROJETOS DE RENOVAÇÃO URBANA & 5 & $8.957,58$ & $36,4 \%$ & \\
\hline Projetos de Meio Ambiente & 9 & $1.728,93$ & $7,0 \%$ & $20 \operatorname{trim} / 16$ \\
\hline Projeto Social & 1 & 31,20 & $0,1 \%$ & 3o trim/17 \\
\hline Projetos de educação, ciência e tecnologia & 2 & 188,36 & $0,8 \%$ & $2^{\circ}$ trim/15 \\
\hline Projeto de infraestrutura esportiva & 1 & 76,05 & $0,3 \%$ & $2^{\circ}$ trim/16 \\
\hline TOTAL OUTROS PROJETOS & 13 & $2.024,54$ & $8,2 \%$ & \\
\hline $\begin{array}{c}\text { TOTAL PLANO DE POLÍTICAS PÚBLICAS } \\
\text { (LEGADO) }\end{array}$ & 27 & $24.588,78$ & $100,0 \%$ & \\
\hline
\end{tabular}

Fonte: Adaptado da APO, Plano de Políticas Públicas (LEGADO), 2015

\subsection{O PROJETO PORTO MARAVILHA}

Existem no total cinco projetos de renovação urbana no Plano de Políticas Públicas (LEGADO), todos na esfera municipal. Destes, o mais importante é o projeto Porto Maravilha destacado na tabela 3, por ser o maior projeto de regeneração urbana da cidade, correspondendo a $\mathrm{R} \$ 8,2$ bilhões ou $91,5 \%$ do total do orçamento dos cinco projetos (APO, 2015).

A Lei Complementar $\mathrm{n}^{\circ}-101$ de 23 de novembro de 2009 do município do Rio de Janeiro, instituiu a Operação Urbana Consorciada (OUC) da região do Porto do Rio de Janeiro, com o objetivo de promover a reestruturação local da região (LC 101/2009, 2009). Uma área de 5 milhões de metros quadrados, tendo como limites as Avenidas Presidente Vargas, Rodrigues Alves, Rio Branco e Francisco Bicalho (CDURP, 2014). Esta mesma lei também autorizou o aumento do potencial construtivo da região, permitindo a construção além dos limites até então permitidos (CDURP, 2014). Os interessados em explorar este novo potencial necessitam comprar os Certificados de Potencial Adicional Construtivo (CEPACs), os quais financiam as obras de renovação urbana e serviços da Região do Porto (CDURP, 2014).

Para coordenar o processo de implantação da OUC Porto Maravilha, foi criada através da Lei Complementar no 102, também de 23 de novembro de 2009, a Companhia de Desenvolvimento Urbano da Região do Porto do Rio de Janeiro (CDURP) (LC 102/2009, 2009). A CDURP é uma empresa de economia mista controlada pela Prefeitura do Rio de Janeiro, responsável pela gestão da OUC Porto Maravilha, através da concessão de obras e serviços públicos, administração dos recursos patrimoniais e financeiros do projeto, aprovação de empreendimentos imobiliários e disponibilização de terrenos (CDURP, 2014).

Os principais resultados esperados são: aumento da população de 22 Mil para 100 Mil habitantes em 10 anos; aumento da área verde de 2,46\% para 10,96\%; aumento de $50 \%$ na capacidade do fluxo de tráfego na região; diminuição da poluição; aumento e melhoria da qualidade da oferta de serviços públicos; e a transformação da região em referência para a cidade (CDURP, 2014). Para efeito de análise, o projeto Porto Maravilha, pode ser subdividido em três grandes grupos 
de projetos, cada um com seus subprojetos específicos: projetos de obras para a requalificação urbana; projetos de mobilidade urbana; e projetos para a valorização do patrimônio histórico da região.

\subsubsection{PROJETOS DE OBRAS PARA A REQUALIFICAÇÃO URBANA}

De acordo com a CDURP (2014) os principais projetos são:

1. Reconstrução de redes de infraestrutura urbana. Água (120 Km), esgoto $(85 \mathrm{Km})$ e drenagem $(66 \mathrm{Km})$;

2. Construção de três novas estações de tratamento de esgoto;

3. Reurbanização de vias $(70 \mathrm{Km})$;

4. Criação de novas vias exclusivas para pedestres $(3 \mathrm{Km})$; e

5. Execução de $650.000 \mathrm{~m}^{2}$ de calçadas com plantio de 15.000 árvores.

\subsubsection{PROJETOS DE MOBILIDADE URBANA}

Segundo a CDURP (2014), a Região do Porto do Rio de Janeiro passará por uma mudança no conceito de mobilidade urbana, priorizando o transporte público coletivo e integrando os diversos modais. Os principais projetos são:

1. Demolição do Elevado da Perimetral. Objetiva a recuperação da área, acabando com a imagem de passagem da Região Portuária, e o aumento da capacidade de tráfego, de 7.600 veículos por hora em horário de pico para 10.500. A remoção será progressiva até 2016 em paralelo à implantação do novo sistema viário, que ampliará de oito para doze as faixas de rolamento (CDURP, 2012);

2. Via Expressa. A transformação da Avenida Rodrigues Alves em Via Expressa, uma parte em túnel e outra parte na superfície, possibilitará o novo sistema viário e a criação de um grande passeio público entre a praça XV e o Armazém 8. A Via Expressa fará a ligação direta do Aterro do Flamengo à Avenida Brasil e à Ponte Rio-Niterói, cruzando a região sem acesso às ruas internas. Término previsto para março de 2016 (CDURP, 2013);

3. Via Binário do Porto. Parte do novo sistema viário, paralela à Av. Rodrigues Alves, faz a ligação em um sentido da rodoviária Novo Rio à Avenida Rio Branco, e no sentido inverso da rua Primeiro de Março ao Viaduto do Gasômetro, com várias saídas para distribuição interna do trânsito na Região Portuária. Término completo para fevereiro de 2015 (CDURP, 2013);

4. Teleférico da Providência. Para melhorar a mobilidade dos habitantes do Morro da Providência, conectando-o à Central do Brasil e à Cidade do Samba na Gamboa. A urbanização dos Morros da Região Portuária termina em 2015 (CDURP, 2013); e

5. Ciclovias. Construção de $17 \mathrm{Km}$ na Região Portuária, integradas aos demais meios de transporte público (CDURP, 2013).

\subsubsection{PROJETOS PARA A VALORIZAÇÃO DO PATRIMÔNIO HISTÓRICO DA REGIÃO}

Conforme a CDURP (2014), a implantação de projetos de grande impacto cultural, mudará o visual de entrada da área do Porto do Rio de Janeiro:

1. Museu de Arte do Rio de Janeiro (MAR). É um espaço dedicado à arte, à educação e a cultura visual. Localizado na Praça Mauá tem dois edifícios, o Palacete D. João VI para exposições, e a Escola do Olhar para educação das artes visuais. Inaugurado em março de 2013 custou $R \$ 79,5$ milhões (CDURP, 2013);

2. Museu do Amanhã. O museu será voltado para as Ciências permitindo ao visitante fazer uma reflexão sobre o futuro que ainda será construído. Localizado no Píer Mauá, tem inauguração prevista para 2015 e orçamento de $\mathrm{R} \$ 215$ milhões (Cdurp, 2014); e

3. Outros equipamentos públicos já prontos compondo a valorização histórica e cultural da área: Cais da Imperatriz (Cais do Valongo), Jardins Suspensos do Valongo, Galpões da Gamboa, Centro Cultural Jose Bonifácio, Igreja São Francisco da Prainha e Pedra do Sal entre outros (Cdurp, 2014).

\subsection{OS PROJETOS DE MOBILIDADE DO PLANO DE POLÍTICAS PÚBLICAS (LEGADO)}

Segundo o Plano de Políticas Públicas (Legado), são nove os projetos agrupados no tema mobilidade, sendo seis na esfera municipal e três na esfera estadual (APO, 
2015). O custo e o prazo para conclusão de cada um deles encontram-se na tabela 3.

\subsubsection{OS PROJETOS DE MOBILIDADE DO GOVERNO MUNICIPAL}

1. Veículo Leve sobre Trilhos, o VLT do Porto. Integrado ao projeto Porto Maravilha, é um novo meio de transporte público, que conectará a região portuária ao centro, ao aeroporto Santos Dumont e aos modais existentes, com 28 quilômetros, 6 linhas e 42 pontos (Cdurp, 2014). Transportará 300 mil passageiros por dia (APO, 2014);

2. BRT Transolímpica. São dois projetos: 1) Via Expressa e desapropriações BRT Transolímpico; e 2) Conexão Magalhães Bastos - Deodoro, objetivando fazer a ligação entre o Parque Olímpico na Barra da Tijuca com o Complexo Esportivo de Deodoro, as duas principais regiões olímpicas, com 26 quilômetros, 17 estações, 2 terminais, e transportando 70 mil pessoas por dia com redução do tempo de viagem entre a Barra da Tijuca e Deodoro em 54\% (APO, 2015);

3. BRT Transoeste. Para melhorar a conexão de Santa Cruz e Campo Grande com a Barra da Tijuca e fazer a integração com a linha 4 do metrô, a Prefeitura já inaugurou 95\% deste corredor expresso, faltando apenas a última etapa, que consiste no trecho entre Alvorada-Shopping Città América e a conexão com o Jardim Oceânico (APO, 2014). Terá 59 quilômetros e 66 estações, transportando 190 mil pessoas por dia no trecho já pronto, que liga Santa Cruz e Campo Grande ao Terminal Alvorada, com redução do tempo de viagem em 50\% (APO, 2015). Com a finalização deste último trecho, a expectativa é de transportar até 230 mil pessoas (APO, 2015);

4. Duplicação do Elevado do Joá. A construção de complexo viário com túneis, elevado, pontes e ciclovia, objetiva melhorar o acesso entre a Zona Sul e a Barra da Tijuca com aumento de $35 \%$ da capacidade de tráfego e ampliação da malha cicloviária da cidade (APO, 2015); e

5. Viário do Parque Olímpico. A duplicação das avenidas Salvador Allende e Abelardo Bueno mais o Terminal Olímpico BRT, visam o aumento da capacidade de tráfego e a requalificação urbana nas vias de conexão entre o Parque Olímpico da Barra da Tijuca, a Vila dos Atletas, o Parque dos Atletas e o Riocentro (APO, 2014).

\subsubsection{OS PROJETOS DE MOBILIDADE DO GOVERNO ESTADUAL}

1. Sistema Metroviário Linha 4: São dois projetos. 1) Metrô Linha 4 - Obras Civis e Acessibilidade; e 2) Metrô Linha 4 - Material Rodante e Sistemas Operacionais, objetiva integrar a Barra da Tijuca ao sistema metroviário (APO, 2015). Terá 16 quilômetros e 6 estações, reduzindo o trajeto Jardim Oceânico - General Osório de 1hora e 6 minutos para 23 minutos, sendo o principal investimento do Estado no Plano de Políticas Pública - Legado (APO, 2015). Vai transportar mais de 300 mil pessoas por dia e tirar das ruas em torno de dois mil veículos por hora/pico (Concessionária Rio Barra S.A., 2014); e

2. Renovação e acessibilidade de estações ferroviárias. A reforma das estações São Cristovão, Engenho de Dentro, Deodoro, Vila Militar, Magalhães Bastos e Ricardo de Albuquerque visa melhorar 0 acesso às estações ferroviárias (APO, 2015).

\section{UMA BREVE ANÁLISE DO LEGADO URBANO DOS JOGOS LONDRES 2012, PEQUIM 2008 E BARCELONA 1992 COMPARADOS AO LEGADO ESPERADO PARA OS JOGOS RIO 2016}

Abaixo encontra-se um breve resumo do que foi alcançado, em termos de regeneração urbana e melhoria da infraestrutura de transportes em cada uma destas Olimpíadas anteriores.

\subsection{LONDRES 2012}

A regeneração do Leste de Londres era central na proposta dos Jogos para 2012. O desenvolvimento do Parque Olímpico seria utilizado como um catalisador para a revitalização da região do Lower Lee Valley, no distrito de Stratford (Governo Britânico e Prefeitura de Londres, 2013). Segundo o Jornal O Globo (2013), Stratford foi uma região negligenciada após a Segunda Guerra Mundial, quando foi alvo de grandes bombardeios, com edifícios e armazéns abandonados. Esta região tornou-se uma área com diversos problemas sócio-econômicos, nacionalidades e religiões, com baixo nível educacional e alto desemprego (Cunningham, 2014). 
O significante investimento e o desenvolvimento da infraestrutura no Parque Olímpico e nas suas proximidades, aceleraram o processo de regeneração do Leste de Londres que já vinha ocorrendo há 30 anos, desde o desenvolvimento de London's Docklands nos anos de 1980, com o Parque Olímpico após os Jogos, passando a chamar-se Queen Elizabeth Olympic Park, e tornando-se o maior parque a ser construído na Europa em mais de 150 anos (GOVERNO BRITÂNICO Y PREFEITURA DE LONDRES, 2013). Conforme o Jornal O Globo (2013), os rios foram limpos e o solo descontaminado antes da construção do Parque Olímpico, e de cada 100 libras gastas 75 foram investimentos em infraestrutura de longo prazo. Para a Prefeitura de Londres (2012) o Parque Olímpico e seus arredores são o projeto mais importante para a regeneração da cidade pelos próximos 25 anos.

De acordo com Summer (2012), os Jogos de Londres 2012, priorizaram o transporte público, e os investimentos em melhorar a rede de transportes já existente. Segundo a Prefeitura de Londres (2012), a maioria do legado físico em transportes está no leste e sudeste de Londres, mas outras melhorias ocorreram pela cidade. Conforme Summer (2012), os projetos essenciais que representaram um grande valor de legado foram: estação de Stratford com aumento da capacidade, da conectividade e da internacionalização; DLR (Docklands Light Railway) com a conversão de parte da Linha Norte dos trens de Londres; linha Jubilee do metrô com trens maiores e mais frequentes; trens de Londres com novos trens e reforma de estações; novas ciclovias; e estradas como parte da construção do Parque Olímpico.

\subsection{PEQUIM 2008}

Conforme Broudehoux (2007), Pequim reinventou sua paisagem física e sua imagem internacional, buscando ser uma cidade global, e executando o planejamento dos Jogos numa escala sem precedentes, que refletisse a posição da China como líder mundial emergente. Segundo Ong (2004), a China encarou as Olimpíadas como uma oportunidade de desenvolvimento, para impulsionar o crescimento de Pequim e seus arredores por um longo prazo, através de investimentos em sua infraestrutura.
Segundo Bovy (2009), Pequim realizou a construção do maior Parque Olímpico de todos os Jogos (The Beijing Olympic Green), incluindo o Estádio Olímpico (o Ninho do Pássaro). Conforme Zhang e Zhao (2009), diversas transformações ocorreram pela cidade, porém não foram uniformes, destacando-se as ocorridas nas áreas próximas às instalações Olímpicas.

Para Bovy (2009), Pequim desenvolveu melhorias marcantes no sistema de transporte em seus sete anos de preparação para os Jogos, destacando-se: a triplicação da capacidade do aeroporto de Pequim; a expansão das estradas metropolitanas e autoestradas; uma grande extensão e renovação do metrô de Pequim, passando de três para sete linhas incluindo uma ligação ferroviária para o aeroporto; e a expansão da frota de ônibus.

\subsection{BARCELONA 1992}

As Olimpíadas de Barcelona de 1992 representam um marco do ponto de vista da transformação urbana. Segundo Mascarenhas (2013), desde o início dos anos 1980, o poder municipal percebia a possibilidade de realizar os Jogos Olímpicos como estratégia para realizar as alterações urbanas previstas no Plano Geral Metropolitano de 1976. Este, segundo o autor, foi seguido até meados dos anos 1980 com destaque para a regeneração do centro histórico. Os Jogos permitiram um grande aporte de recursos públicos e privados, com a mudança de escala das intervenções (NEL-LO, 1997).

Segundo Mascarenhas (2013), o projeto Olímpico de Barcelona tinha como objetivo preponderante a transformação da cidade, não priorizando a construção de um grande Parque Olímpico, mas optando pela desconcentração, criando quatro parques menores espalhados pela cidade. Conforme Nel-lo (1997), o ponto comum entre as quatro áreas era a localização nos limites entre a relativamente bem organizada cidade do século XIX e as áreas de periferia das décadas de 1960 e 1970. Assim, segundo Nel-lo (1997), a regeneração urbana de Barcelona se baseava na revitalização de espaços centrais, bem como no reequilíbrio entre centro e periferia.

De acordo com Brunet (1995), vale destacar a revitalização da área costeira de Barcelona, com a criação do acesso para o mar na 
construção da Vila Olímpica, com a remoção da estrada de ferro costeira.

Segundo Brunet (1995), considerando-se a melhoria na infraestrutura de transportes, o foco foram os projetos de construção de estradas, principalmente a construção do anel viário no entorno de Barcelona, que trouxe grande impacto para a melhoria do tráfego na cidade.

\subsection{LONDRES 2012, PEQUIM 2008, BARCELONA 1992 E RIO 2016}

Embora seja difícil uma comparação entre projetos olímpicos, pois são únicos, aqui encontra-se um pequeno exercício. O projeto olímpico de Londres definiu a construção de um Parque Olímpico único, concentrado numa região degradada para incentivar sua regeneração (GOVERNO BRITÂNICO e PREFEITURA DE LONDRES, 2013). Pequim construiu o maior Parque Olímpico da história (BOVY, 2009), mas buscou realizar transformações por toda a cidade (ONG, 2004). Barcelona optou pela criação de quatro parques olímpicos menores situados entre o centro e a periferia (NEL-LO, 1997), destacando-se a construção da Vila Olímpica, que abriu a cidade para o mar (BRUNET, 1995). O projeto do Rio de Janeiro, também definiu quatro Regiões Olímpicas, sendo a principal a da Barra da Tijuca com o Parque Olímpico, porém esta região representa a nova área de expansão da cidade, e não uma regeneração. Esta última concentra-se na Região do Porto do Rio de Janeiro, através do projeto Porto Maravilha, que tem uma relação baixa com os Jogos.

Quanto à infraestrutura de transportes, Londres que possui um excelente transporte público, segundo Summer (2012), focou em criar novas alternativas para a mobilidade na Região Leste de Londres, nos modais já existentes. Conforme Bovy (2009), Pequim investiu de forma colossal na melhoria da infraestrutura de transportes como um todo. Para Brunet (1995), Barcelona priorizou o anel viário e as conexões metropolitanas e regionais. Quanto ao Rio de Janeiro, no Plano de Políticas Públicas (LEGADO), 9 dos 27 projetos, referem-se à mobilidade (APO, 2015). A maioria dos projetos de mobilidade visa melhorar a conexão da Região da Barra da Tijuca e da Região de Deodoro, com as demais áreas da cidade, destacando-se os BRTs, a linha 4 do metrô e a duplicação da estrada do Joá, criando-se assim a infraestrutura de transportes correspondente à expansão da Barra da Tijuca (APO, 2015). Por sua vez, o VLT do Porto integrará a região portuária com o aeroporto Santos Dumont e os demais modais (APO, 2015).

Assim observa-se que os Jogos estão sendo utilizados como um catalisador de projetos, tanto do ponto de vista da regeneração urbana, quanto à criação da infraestrutura de transportes.

\section{CONCLUSÃO}

Este artigo faz uma análise do principal projeto de renovação urbana do Rio de Janeiro, o projeto Porto Maravilha, e dos nove projetos de mobilidade, todos do Plano de Políticas Públicas (LEGADO) referentes aos Jogos Rio 2016. Para isto considerou a história dos Jogos Olímpicos; a crescente importância do legado e suas possibilidades de transformação urbana; a presença do fator legado na escolha dos Jogos; uma visão geral das áreas que receberão os Jogos; e a regeneração urbana e a melhoria da infraestrutura de transportes, nos projetos Olímpicos de Londres 2012, Pequim 2008 e Barcelona 1992.

O projeto Porto Maravilha está orçado em $\mathrm{R} \$$ 8,2 bilhões, ou seja, o principal projeto de regeneração urbana da cidade corresponde à $33,3 \%$ do Plano de Políticas Públicas (LEGADO) e à 21,5\% do total do orçamento Olímpico (APO, 2015). Os nove projetos de mobilidade do Plano de Políticas Públicas (LEGADO), estão orçados em $R \$ 13,6$ bilhões, equivalendo à $55,3 \%$ deste Plano e a $35,6 \%$ do orçamento total (APO, 2015). Assim, os dez projetos que compõem o escopo deste artigo, o Porto Maravilha e os nove projetos de mobilidade somam $\mathrm{R} \$ 21,8$ bilhões, ou seja, $88,6 \%$ do Plano de Políticas Públicas (LEGADO) e 57,1\% do total do orçamento Olímpico (APO, 2015). A regeneração urbana e a melhoria da infraestrutura de transportes ficam demonstradas como projetos primordiais para a realização dos Jogos, mostrando que o Rio de Janeiro, como outras cidades-sede, utilizou os Jogos como estratégia para viabilizar projetos urbanos. No entanto, enquanto as outras cidades de uma forma geral, buscaram a criação de capacidade futura em termos de infraestrutura, o Rio de Janeiro está construindo a infraestrutura há muito já necessária para a cidade. 


\section{REFERÊNCIAS}

[1] Autoridade Pública Olímpica. História. 2014 Disponível em: <http://www.apo.gov.br/index.php/historia/>. Acesso em 10 de out. 2014.

[2] Autoridade Pública Olímpica. Matriz de Responsabilidades 2aa $\quad$ Atualização. 2015. Disponível em: <http://transparencia.gov.br/rio2016/_arquivos/Matr iz_de_Responsabilidades_Olimpiadas_Versao2_Ja n-2015.pdf>. Acesso em 25 de fev. 2015.

[3] Autoridade Pública Olímpica. Metodologia para Elaboração do Plano de Políticas Públicas Legado. 2014. Disponível em: <http://www.apo.gov.br/downloads/legado/plano_d e_politicas_publicas_metodologia.pdf $>$. Acesso em 09 de out. 2014.

[4] Autoridade Pública Olímpica. Plano de Políticas Públicas - Legado. 2014. Disponível em: $<$ http://www.apo.gov.br/wp-

content/uploads/2014/04/plano-de-politicas-

publicas-apresentacao-site.pdf >. Acesso em 09 de out. 2014

[5] Autoridade Pública Olímpica. Plano de Políticas Públicas - Legado - 1aㅗ Atualização. 2015. Disponível em: <http://www.apo.gov.br/wpcontent/downloads/abril/PlanodePoliticasPublicasV 2.pdf?66df7a>. Acesso em 24 de abr. 2015.

[6] Bovy, Philippe. Beijing 2008 Olympic Games success:massive public transport developments and major road traffic reduction. 2009. UITP - Public Transport International (PTI), Mai./Jun. 2009. Disponível em: $<$ http://www.mobility-

bovy.ch/resources/13.UITP_Beijing-EN.09.pdf> Acesso em 17 de dez. 2014.

[7] Broudehoux, Anne.-Marie. Spectacular Beijing: the conspicuous construction of an Olympic metropolis. 2007. Journal of Urban Affairs, University of Quebec, Montreal, Canadá. Disponível em:

<http://www.gamesmonitor.org.uk/files/Broudehoux -Spectacular-Beijing.pdf>. Acesso em 17 de dez. 2014.

[8] Brunet, Ferran. An economic analysis of the Barcelona'92 Olympic Games: resources, financing and impact. 1995. Barcelona: Centre d'Estudis Olímpics UAB. Disponível em: <http://olympicstudies.uab.es/pdf/wp030_eng.pdf> . Acesso em 13 de Nov. 2014

[9] Cdurp - Operação Urbana Porto Maravilha. Apresentação do Projeto. 2014. Disponível em: <http://www.portomaravilha.com.br/web/sup/OperU rbanaApresent.aspx >. Acesso em 29 de set. 2014. [10] Cdurp - Operação Urbana Porto Maravilha. Série Mobilidade Urbana. 2014. Disponível em: <http://portomaravilha.com.br/materias/mobilidadeurbana/m-u.aspx> Acesso em 04 de out. 2014 [11] Comitê Organizador dos Jogos Olímpicos e Paralímpicos Rio 2016. Mapa de Instalações Rio 2016. 2014. Disponível em: <http://www.rio2016.org/os-jogos/locais-de- competicao/mapa-de-instalacoes $>$. Acesso em 15 de set. 2014, 13 de nov. 2014 e 26 de mar. 2015.

[12] Concessionária Rio Barra S.A.. Metro Linha 4. 2014. Disponível em: <http://www.metrolinha4.com.br/> Acesso em 17 de out. 2014.

[13] Cunningham, J. The Olympics - Going for gold and what else? Can London 2012 urban regeneration legacy be considered as sustainable development? 2014. Dissertação (Mestrado em Estudos Ambientais e Ciência da Sustentabilidade) - Lund University. Lund, Scania, Suécia. Disponível em:

<http://lup.lub.lu.se/luur/download?func=download File\&recordOId $=4463501 \&$ fileOld $=4463533>$

Acesso em 01 de nov. 2014

[14] Essex, Stephen; Chalkley Brian. Urban transformation from hosting the Olympic Games: university lecture on the Olympics. 2003. Barcelona: Centre d'Estudis Olímpics UAB. International Chair in Olympism (IOC-UAB). Disponivel em: <http://olympicstudies.uab.es/lectures/web/pdf/ess ex.pdf>. Acesso em 27 de mai. 2014.

[15] Gerhardt, Tatiana Engel; Silveira, Denise Tolfo. Métodos de Pesquisa. Porto Alegre: Editora da UFRGS, 2009.

[16] Gil, Antonio Carlos. Como Elaborar Projetos de Pesquisa. 5a edição. São Paulo: Atlas, 2008.

[17] Gold, John R. e Gold, Margaret M. (editors). Olympic Cities: City Agendas, Planning and the World's Games, 1896 - 2016. Second edition. New York: Routledge, 2011.

[18] Gold, John R.; Gold, Margaret M.. Olympic Cities: Regeneration, City Rebranding and Changing Urban Agendas. 2008. Oxford and London, Geography Compass 2/1, p. 300-318, $2008 . \quad$ Disponivel em: <http://www.umsl.edu/ naumannj/professional\%20 geography\%20articles/Olympic\%20Cities\%20\%20Regeneration,\%20City\%20Rebranding\%20and $\% 20$ Changing\%20Urban\%20Agendas.pdf>.

Acessso em 25 de mai. 2014.

[19] Governo Britânico E Prefeitura de Londres. Inspired by 2012: The Legacy from the London 2012 Olympic and Paralympic Games. 2013. Disponível

em:<https://www.gov.uk/government/uploads/syste m/uploads/attachment_data/file/224148/2901179_O lympicLegacy_acc.pdf $>$. Acessso em 30 de out. 2014.

[20] Mascarenhas, Gilmar. Londres 2012 e Rio de Janeiro 2016: Conceito e Realidade na Produção da Cidade Olímpica. 2013.Revista Continentes (UFRRJ) ano 2, n.3. Disponível em:<http://r1.ufrrj.br/revistaconti/pdfs/3/ART3.pdf>. Acesso em 04 de nov.2014.

[21] Nel-Lo, Oriol. The Olympic Games as a tool for urban renewal: the experience of Barcelona'92 Olympic Village. 1997. Barcelona: Centre d'Estudis Olímpics UAB. Disponível em: <http://olympicstudies.uab.es/pdf/wp090_eng.pdf> . Acesso em 13 de nov. 2014 
[22] Prefeitura de Londres. Leaving a transport legacy. $2012 . \quad$ Disponível em: <http://www.london.gov.uk/sites/default/files/leavin g-a-transport-legacy.pdf>. Acesso em 03 de nov. 2014.

[23] Prefeitura do Rio de Janeiro. Lei Complementar no 101, de 23 de novembro de 2009. 2009. Disponível em: <http://www. portomaravilha.com.br/conteudo/legisl acao/2010/06/LC101_-_23112009.pdf>. Acesso em 01 de out. 2014.

[24] Prefeitura do Rio de Janeiro. Lei Complementar no 102, de 23 de novembro de 2009.2009. Disponível em: <http://www.portomaravilha.com.br/conteudo/legisl acao/2010/05/LC102_-_23112009_-_CDURP.pdf>. Acesso em 01 de out. 2014.

[25] Ong, Ryan. New Beijing, Great Olympics: Beijing and its Unfolding Olympic Legacy. 2004.
Standford Journal of East Asian Affairs, Standford University, Standford, Estados Unidos. Disponível em:

<http://web.stanford.edu/group/sjeaa/journal42/chi na3.pdf>. Acesso em 17 de dez. 2014.

[26] Oswald, Vivian. Londres Já Desfruta Legado das Olimpíadas. O Globo, Rio de Janeiro, p.19, 15 ago. 2013.

[27] Summer, Hugh. Delivering London 2012: Transport legacy. 2012. Disponível em:<http://www.icevirtuallibrary.com/content/article /10.1680/tran.12.00041>. Acesso em 03 de nov. 2014.

[28] Zhang, L e Zhao S.X. City branding and the Olympic effect: A case study of Beijing. 2009. Journal homepage: www.elsevier.com/locate/cities Disponível em: $<$ http://isiarticles.com/bundles/Article/pre/pdf/223.p df>. Acesso em 17 de dez. 2014 


\section{Capítulo 8}

\section{PRODUCEÃO E EXPORTAÇÃO DE FRUTAS TROPICAIS: UMA ANÁLISE DA REGIÃO NORDESTE DO BRASIL}

\section{Richeliel Albert Rodrigues Silva}

Genival Jardel Trajano Teixeira

Lúcia de Fátima Lúcio Gomes da Costa

Mônica Almeida Gavilan

\section{Rodrigo Mackssuel Silva de Melo}

Resumo: Esta revisão bibliográfica apresenta a relação entre o produção e exportação de frutas tropicais no Nordeste. Nas últimas décadas ocorreram grandes avanços no agronegócio, principalmente no setor da fruticultura, que tem sido beneficiado com os avanços tecnológicos, logísticos e econômicos, gerando resultados significativos na balança comercial brasileira, especialmente nos estados exportadores. A região Nordeste do Brasil apresenta as condições climáticas ideais, além de grandes extensões de terras para o cultivo de espécies frutíferas tropicais. Destaca-se como os principais produtores dessa região, os estados da Bahia, Ceará, Pernambuco e Rio Grande do Norte. Apesar da elevada produção e exportação de frutas tropicais, principalmente na região Nordeste, esses percentuais ainda são baixos no âmbito internacional. Finalmente, novas estratégias para aberturas comerciais são necessárias, além de políticas públicas mais efetivas no setor.

Palavras-chave: Fruticultura. Economia. Agronegócio. Comércio exterior 


\section{INTRODUÇÃO}

A evolução das máquinas, em especial as de apoio agrícola causaram uma grande transformação, facilitando a vida do homem do campo. Júnior (2012) apontou que no Brasil a expansão das indústrias de máquinas, apetrechos e matérias-primas do setor agropecuário, assim como outras indústrias voltadas para este setor, serviram como base, para uma modernização de base técnica em 1970.

Neste sentido, as cadeias produtivas da agropecuária brasileira têm alcançando elevados ganhos de produtividade nas últimas décadas, relacionados principalmente aos novos padrões e configurações que vêm sendo delineados com os avanços tecnológicos do setor (GILIO et al., 2016). Entretanto, sabe-se que a economia brasileira é atualmente muito dependente da exportação de commodities, incluindo aquelas do agronegócio (PEROBELLI et al., 2016), que influencia na balança comercial brasileira, por meio de incrementos significativos na economia.

Assim, os ganhos tecnológicos, logísticos e econômicos na agropecuária têm fortalecido cada vez mais o agronegócio, que é conceituado como "a soma das operações de produção e distribuição de suprimentos agrícolas, das operações de produção nas unidades agrícolas, do armazenamento, processamento e distribuição dos produtos agrícolas e itens produzidos a partir deles" (BATALHA, 2008, p. 5).

No Nordeste, o crescimento das culturas de maior valor comercial, como cacau, fumo e frutas tropicais apresentou maior crescimento entre as décadas de 1960 e 1990 (PEROBELLI et al., 2016). Atualmente, com os avanços tecnológicos, por meio do aprimoramento da irrigação, como também a introdução de diversas espécies frutíferas, a região tem se destacado no cenário nacional como um importante exportador de frutas tropicais.

Diante isso, o presente artigo consiste em uma revisão bibliográfica, relacionando a produção e a exportação de frutas tropicais, nas escalas mundial, nacional e regional, com destaque para a região Nordeste, que atualmente é detentora de elevados índices de produção e exportação de frutas.

\section{METODOLOGIA}

O presente estudo caracteriza-se como exploratório e bibliográfico, uma vez que foi necessária a utilização de dados secundários para a sua construção. Foram consultados artigos, livros, sites de instituições e outros materiais relacionados ao tema trabalhado nesta pesquisa. Conforme Gil (1991), a pesquisa exploratória visa oferecer uma aproximidade com o problema com o propósito de torna-lo explícito ou a formular hipóteses, envolvendo também trabalhos bibliográficos.

\section{RESULTADOS E DISCUSSÕES}

A produção de frutas tropicais predomina em todas as regiões do Brasil, com destaque para o Nordeste, que apresenta vantagens quando comparada com as demais, isso devido aos fatores ecológicos e territoriais (disponibilidade de terras), visto que o Nordeste ocupa uma área de $1.556 .000 \mathrm{~km}^{2}$, que equivale a $18 \%$ do território brasileiro (PASSOS; SOUZA, 1994).

Assim, ao relacionar a fruticultura com o Nordeste brasileiro, passou-se a analisar os dados quantitativos, a partir dos principais estados produtores da região: Bahia (BA), Ceará (CE), Pernambuco (PE) e Rio Grande do Norte (RN) (Figura 1). 
Figura 1 - Produção da fruticultura na Região Nordeste no ano de 2014.

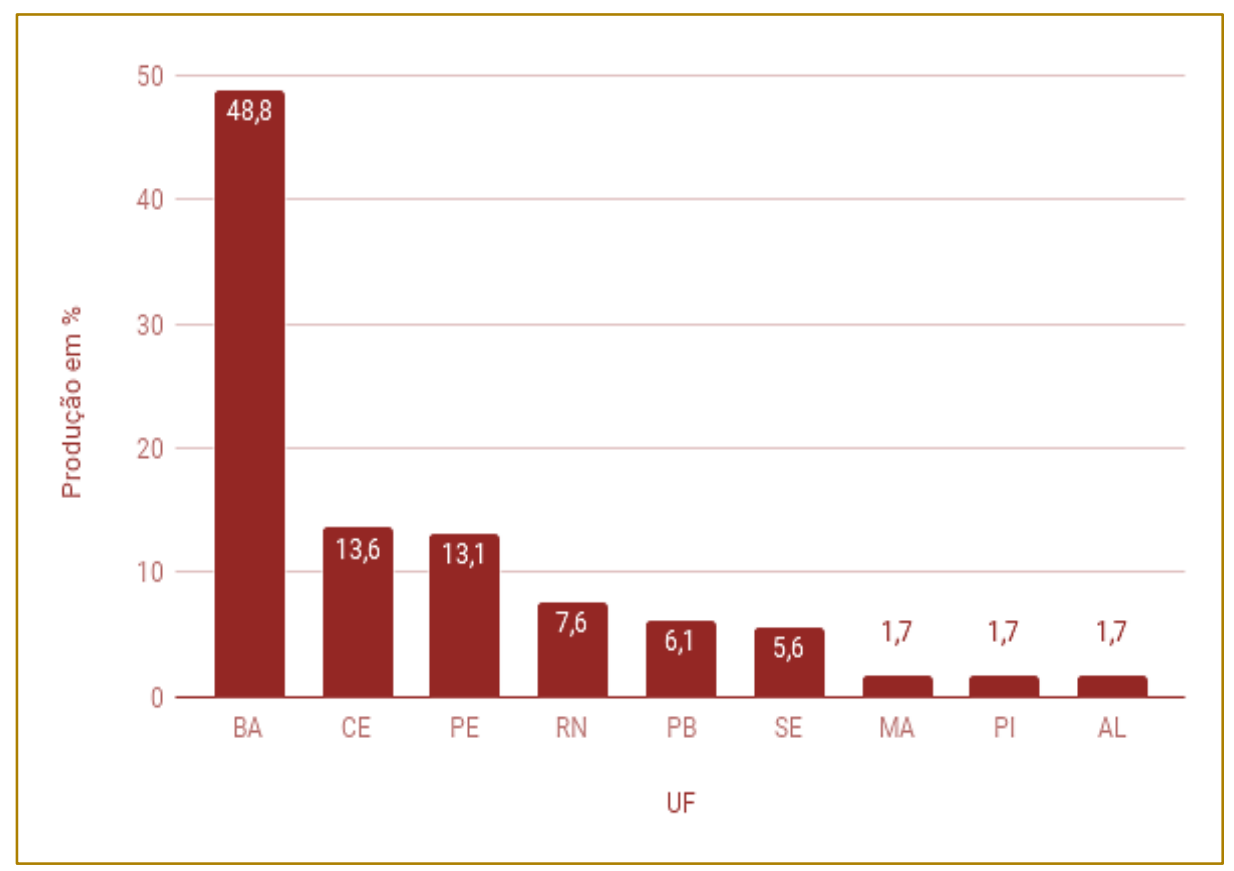

Fonte: IBGE (2016)

Como se observa, o estado da Bahia suplanta a produção dos estados do Ceará, Pernambuco, Rio Grande do Norte, Paraíba, Sergipe e do estado do Maranhão. Diante dessas estatísticas é considerável dizer que o estado da Bahia é bastante relevante para a fruticultura da Região Nordeste.

\subsection{A FRUTICULTURA NO ESTADO DA BAHIA}

O setor fruticultura da Bahia vem se aperfeiçoando gradualmente, isso devido a inclusão de novas tecnologias, fatores climáticos e da presença da água para a irrigação das frutas, que apresentam qualidade, tendo como resultado a aceitação no mercado interno e externo (FERRAZ, 2013).

A Região Oeste da Bahia possui vantagens tanto para a agropecuária quanto para as várias culturas oriundas do setor agrícola, quanto para a pecuária. A região está localizada próximo ao Rio São Francisco e possui facilidade para o escoamento dos produtos pelos modais rodoviário e hidroviário, podendo interligar outras regiões (BATISTELLA et al., 2002).

De acordo com Vidal e Ximenes (2016), uma das culturas que fazem o estado destacar-se em relação aos demais, é a cultura do cacau que ocupa uma área superior a 500 mil hectares. Além do mais, o cacau se adequou ao Sul da Bahia e trouxe desenvolvimento e melhorias para as famílias localizadas nesta Região (CUENCA; NAZÁRIO, 2004).

Apesar do cacau ocupar uma área bastante ampla, a banana, a laranja e o mamão estão entre as principais culturas produzidas pelo estado, onde em 2015 foram produzidas 1,068 milhão de toneladas da banana, 962 mil toneladas da laranja e 723 mil toneladas do mamão (BAHIA, 2017).

\subsection{A FRUTICULTURA NO ESTADO DO CEARÁ}

O Ceará é um dos estados que possui uma área muito ampla para o cultivo de frutas. Diante isso, é considerado o segundo estado com a maior área explorada pela fruticultura de toda Região Nordeste, onde o cajueiro ocupa uma área de 380 mil hectares (VIDAL e XIMENES, 2016).

A fruticultura do estado do Ceará obteve uma grande evolução no decorrer dos anos. No ano de 1998, as exportações de frutas totalizavam US\$885 mil, enquanto no ano de 2007 as exportações alcançaram US\$ 77,2 milhões (CAMPOS; CARVALHO, 2010). Quando se trata exclusivamente da melancia, $70 \%$ da sua produção é destinada ao comércio externo, para países como 
Inglaterra, Alemanha, Holanda e Bélgica (ALVES, 2009).

De acordo com os dados estatísticos do MDIC, o Ceará é o estado que mais compete posição com o Rio Grande do Norte, no que se refere ao melão, principal fruta exportada pelo RN. Ao acompanhar os números das exportações de melão até o momento, pressupõe-se que no ano de 2017 o estado do Rio Grande do Norte feche com percentual acima das exportações do Ceará.

\subsection{A FRUTICULTURA NO ESTADO DE PERNAMBUCO}

No Nordeste existem dois grandes polos de grande relevância para o setor fruticultor: 0 Vale do Assú e o Vale São Francisco, onde o estado da Bahia encontrase dentro do Vale São Francisco, que segundo Bustamante (2009), Petrolina (PE) e Juazeiro (BA) podem ser consideradas regiões incentivadoras da economia local, uma vez que as regiões demandam mão de obra e são ocupadas pelos moradores locais.

No estado pernambucano, o maior volume de produção encontra-se na bacia do Vale São Francisco, que é a região mais produtora de goiaba e uva (VIDAL; XIMENES, 2016). O polo Petrolina/Juazeiro tem sua economia voltada as atividades agrícolas, mais especificamente na fruticultura irrigada (LACERDA et al., 2004).

Como se pode observar na Figura 2 (p.16), o estado de Pernambuco encontra-se como o terceiro maior estado produtor de frutas da Região Nordeste, ficando atrás apenas da Bahia e do estado do Ceará sendo responsável por uma produção de 13,1\%. De acordo com Correia et al. (2001), o município de Petrolina possui um percentual de $51 \%$ da população empregada na agricultura, sendo o comércio com 39,75 e a indústria 8,7\%.

\subsection{A FRUTICULTURA NO ESTADO DO RIO GRANDE DO NORTE}

O estado do Rio Grande do Norte destaca-se por ser o que mais exporta frutas em todo o território nacional, ressaindo também como um importante polo na produção de melões e castanhas (COSTA, 2009).

Segundo as estatísticas da Federação das Indústrias do Rio Grande do Norte (FIERN), as principais frutas exportadas pelo estado seguem na seguinte classificação: melão, melancia, manga, mamão e banana (Figura 2). Assim, conforme as estatísticas do Ministério da Agricultura, Pecuária e Abastecimento, nota-se a participação da fruticultura no agronegócio do estado (Tabela 1).

Figura 2 - Exportações das frutas frescas do estado do Rio Grande do Norte nos últimos quinze anos.

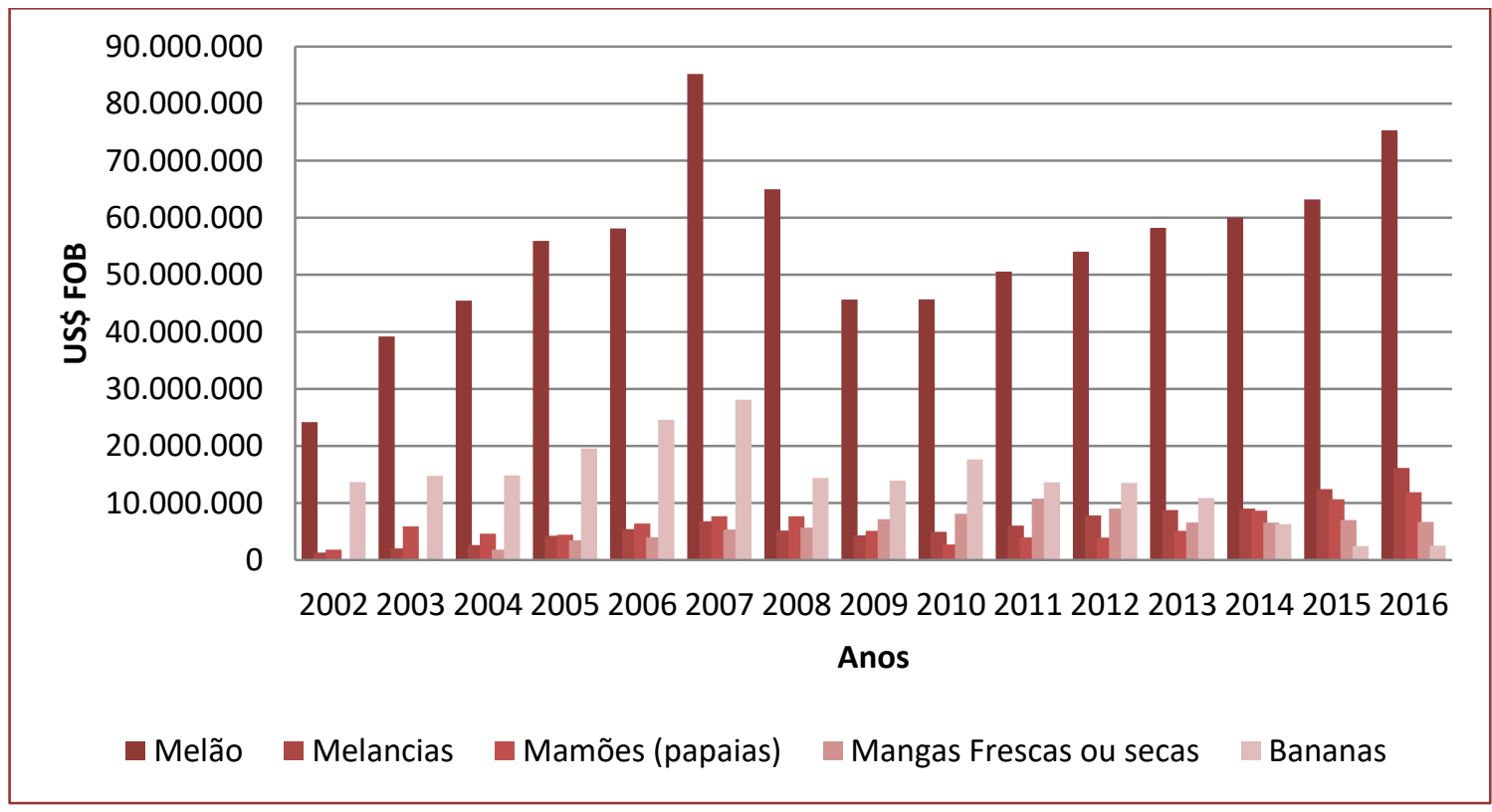

Fonte: Fonte: Aliceweb (2017) 
Tabela 1 - Exportações dos produtos do agronegócio do Rio Grande do Norte.

\begin{tabular}{|l|c|c|}
\hline \multicolumn{1}{|c|}{ Produtos exportados } & Valor (US\$) & 521 \\
\hline Bebidas & 2.107 & 520 \\
\hline Cacau e seus produtos & 692 & 6.311 .590 \\
\hline Complexo sucroalcooleiro & 2.890 .761 & 1.514 \\
\hline Couro, produtos de couro e peleteria & 14.529 & 2.990 .709 \\
\hline Demais produtos de origem animal & 3114052 & 1.571 .650 \\
\hline Demais produtos de origem vegetal & 956.923 & 5.048 .888 \\
\hline Fibras e produtos têxtis & 27.994 .212 & 188.663 .612 \\
\hline Frutas (incluindo nozes e castanhas) & 142.814 .104 & 1.040 \\
\hline Lácteos & 13.073 & 3.262 .558 \\
\hline Pescados & 24.840 .225 & 13.156 \\
\hline Plantas vivas e produtos de fruticultura & 53.566 & 8.363 .802 \\
\hline Outros produtos & 17.617 .141 & 216.229 .560 \\
\hline Total & 220.312 .385 & (20) \\
\hline
\end{tabular}

Fonte: Adaptado de MAPA (2017).

As exportações de frutas frescas do estado do Rio Grande do Norte, têm cooperado para expansão do agronegócio brasileiro, isso por destacar-se com uma das atividades mais dinâmicas do estado (COSTA et al., 2007). De acordo com os dados disponíveis da Empresa Brasileira de Pesquisa Agropecuária - EMBRAPA, o município de Baraúna é responsável pela maior produção do $\mathrm{RN}$, no qual corresponde a $50 \%$ da produção (EMBRAPA, 2016).

O melão é a fruta que o estado mais produz e exporta. Com origem na África, sua dispersão ocorreu na Índia, onde a partir deste país foi disseminado para os demais países. O melão (Cucumis melo) atualmente é conhecido em todo o mundo. Somente no ano de 2002 ocupou uma área de 1.162.136 hectares, atingindo uma produção de 21.588.746 toneladas (FAO, 2015).

Ainda neste contexto, no âmbito mundial, o Brasil é um dos maiores produtores entre os países Sul-americanos, indicando que ainda existem grandes tendências de crescimento para a sua cultura, isso, resultante do consumo interno e das exportações (COSTA et al., 2000). Ganhando então um forte espaço no mercado internacional, no ano de 2014 o melão foi à fruta com maior nível de exportação, com 196.840 toneladas (SEBRAE, 2015).
Outro fruto que o estado se destaca é a produção de melancia, que é uma fruta originária do continente africano. A melancia é uma fruta consumida em vários países, sendo a Índia, o Irã e Estados Unidos os principais países que fazem uso da cultura da melancia (AZEVEDO et al., 2004).

Assim, a melancia produzida no RN tem bastante relevância no mercado. Conforme os dados do Instituto Brasileiro de Geografia e Estatística (IBGE), o RN aparece em terceiro lugar no quesito produção em todo o nordeste e o nono em todo o território nacional brasileiro (IBGE, 2012). O Semiárido brasileiro, com o seu clima quente, confere uma melhor qualidade à melancia. Os estados do RN e do CE destacam-se como os maiores exportadores do fruto (VILELA et al., 2006).

Conforme os dados estatísticos da balança comercial do RN, disponível pela Federação das Indústrias, do estado do Rio Grande do Norte (FIERN), países pertencentes à União Europeia como Alemanha e Portugal são destinos das exportações potiguares de mamão (FIERN, 2016).

O Rio Grande do Norte é o terceiro maior exportador de mamão do Brasil, isso devido à ação do governo diante a competitividade da fruticultura, como a criação da Estrada do Melão, por exemplo, que vai reduzir o 
desperdício das frutas, assim como o escoamento da produção (SILVA et al., 2011).

Sabendo então que o mamão é um fruto de fácil amadurecimento, na exportação, os modais marítimo e aéreo apresentam bons resultados para os exportadores (SOUZA, 2007). Em relação aos modais mais utilizados na exportação do mamão potiguar no ano de 2016, $15 \%$ do fruto foi exportado por via marítima, enquanto $85 \%$ pelo modal aéreo.

Outra fruta importante é a manga, que no estado do Rio Grande do Norte, a região do Vale do Assú é considerado um das maiores produtoras, sendo comercializada nos mercados externo e interno (MORAIS et al., 2017). Além disso, a manga é produzida em sete a nove municípios do Vale do Assú, onde em 2010, Ipanguaçu foi o município que mais produziu o fruto, com 20.000 toneladas (COSTA, 2013).

Além dessas frutas, outra fruta relevante na economia do RN é a banana (FIORAVANÇO, 2003). Com isso, como as demais frutas, tal produção promove o aumento da renda para a agricultura familiar, sendo responsável assim, para o desenvolvimento da região produtora.

\section{REFERÊNCIAS}

[1]. ALICEWEB. Sistema de Análise das Informações de Comércio Exterior. Consultas. Disponível em: <http://aliceweb.mdic.gov.br>. Acesso em 15 ago. 2017.

[2]. ALVES, L. M. M. Uma análise da competitividade das exportações da fruticultura cearense e brasileira: $O$ caso do abacaxi e da melancia. 2009. 100 f. Tese (Doutorado em Economia Rural) - Universidade Federal do Ceará, Fortaleza, 2009.

[3]. AZEVEDO, B. M.; BASTOS, F. G. C.; VIANA, T. V. A.; RÊGO, J. L.; D'ÁVILA, J. H. T. Efeitos de níveis de irrigação na cultura da melancia. Revista Ciência Agronômica, v. 36, n. 1, p. 9-15, 2004.

[4]. BATALHA, M. O. Gestão Agroindustrial. v. 1. São Paulo: Atlas, 2008.

[5]. BAHIA. Secretaria da Agricultura, Pecuária, Irrigação, Pesca e Aquicultura. Anuário Brasileiro da Fruticultura. Disponível em: http://www.seagri.ba.gov.br/sites/default/files/PDF\% 20Fruticultura_2017.pdf>. Acesso em: 2 out. 2017.

[6]. BATISTELLA, M.; GUIMARÃES, M.; MIRANDA, E. E.; VIEIRA, H. R.; VALLADARES, G. S.; MANGABEIRA, J. A. C.; ASSIS, M. C. (INFOTECA-E), 2002. Disponível em: <https://www.infoteca.cnptia.embrapa.br/infoteca/b
Sendo considerado o trigésimo polo frutícola do Brasil, a maior produção de banana se localiza no Vale do Assú (BIDJEKE et al., 2004). A maior parte da produção desta fruta é consumida no mercado interno, onde apenas $1,5 \%$ da produção brasileira da banana são exportadas (EMBRAPA, 2012).

\section{CONCLUSÃO}

Como foi observado, o agronegócio é considerado um grande propulsor econômico na Região Nordeste, principalmente o setor da fruticultura irrigada, devido apresentar as condições climáticas ideais, além de grandes extensões de terras para o cultivo de espécies frutíferas tropicais. Entre os maiores produtores de frutas tropicais destacam-se os estados da Bahia, Ceará, Pernambuco e Rio Grande do Norte. Entretanto, para melhorar o impacto econômico da produção e exportação de frutas são necessárias novas estratégias para aberturas comerciais, como também políticas públicas mais efetivas no setor.

itstream/doc/16804/1/d20babndes.pdf>. Acesso em 12 out. 2017

[7]. BIDJEKE, R.; VITAL, T. W.; MÖLLER, H. D. Competitividade entre empresas de exportação da banana no Nordeste brasileiro. In: XLII Congresso da SOBER, 2004, Cuiabá. Anais... Cuiabá: XIII Congresso da SOBER, 2004.

[8]. BRASIL. Ministério da Agricultura, Pecuária e Abastecimento. AGROSTAT Estatísticas de Comércio Exterior do Agronegócio Brasileiro. Disponível em: http://indicadores.agricultura.gov.br/index.htm. Acesso em: 21 ago. 2017.

[9]. BUSTAMANTE, P. M. A. C. A fruticultura no Brasil e no Vale do São Francisco: Vantagens e desafios. Revista Econômica do Nordeste, v. 40, n. 01, p. 153-171, 2009.

[10]. CAMPOS, K. C.; CARVALHO, F. M. A. Produção, mercados e emprego no arranjo produtivo local de fruticultura irrigada no estado do Ceará. Revista Econômica do Nordeste, v. 41, n. 3, p. 557-579, 2010.

[11]. CORREIA, R. C.; ARAÚJO, J. L. P.; CAVALCANTI, E. B. A fruticultura como vetor de desenvolvimento: o caso dos municípios de Petrolina (PE) e Juazeiro (BA). In: Embrapa Semiárido - Artigo em anais de congresso (ALICE). 
In: Congresso Brasileiro de Economia e Sociologia Rural, 39, 2001, Recife. Anais... Recife: SOBER/ESALQ/EMBRAPA/UFPE/URFPE, 2001. 1 CD-ROM, 2001.

[12]. COSTA, A. C. R.; TRINDADE, D. C.; PAIVA, F. H. D.; CAMELO, G. L. P.; COSTA, P. C. P. O potencial fruticultor do Rio Grande do Norte no mercado internacional. Cadernos Temáticos, Brasília. 2007. Disponível em: $<$ http://portal.mec.gov.br/setec/arquivos/pdf3/cade rnos4_gestao_admi.pdf\#page=57>Acesso em: 12 out. 2017.

[13]. COSTA, A. M. B.; SILVA, F. M.; LOPES JUNIOR, F. C.; MARTINS, M. E. R. Espacialização Socioeconômica da Microrregião do Vale do Açu/RN por geoprocessamento. in: Congresso de Iniciação Científica do IFRN, 2013, Currais Novos RN. Anais... Currais Novos: Congresso de Iniciação Científica do IFRN, 2013.

[14]. COSTA, L. F. L. G. Estratégias internacionais da fruticultura do $\mathrm{RN}$ : o caso finobrasa processo e evolução. 2009. $121 \mathrm{f}$. Dissertação (Mestrado em Administração) Universidade Federal do Rio Grande do Norte, Natal, 2009.

[15]. COSTA, N. D. Cultivo do melão. Petrolina: Embrapa Semiárido. 2000. Disponível em:<http://www.almanaquedocampo.com.br/image ns/files/O\%20cultivo\%20do\%20mel\%C3\%A3o.pdf> . Acesso em: 22 ago. 2017.

[16]. CUENCA, M. A. G.; NAZÁRIO, C. C. Importância econômica e evolução da cultura do cacau no Brasil e na região dos tabuleiros costeiros da Bahia entre 1990 e 2002. Embrapa Tabuleiros Costeiros-Documentos (INFOTECA-E), Aracaju - SE. 2004. Disponível em:< https://www.infoteca.cnptia.embrapa.br/bitstream/d oc/876224/1/doc72.pdf>. Acesso: 12 out. 2017.

[17]. EMBRAPA. Polos de Produção de Mamão no Brasil. Cruz das Almas - BA, 2016. Disponível em:<https://www.embrapa.br/busca-de-

publicacoes/-/publicacao/1062698/polos-deproducao-demamao-no-brasil>. Acesso em: 12 Jan 2017.

[18]. Banana: o produtor pergunta, a EMBRAPA responde, Brasília - DF. 2 ed. 2012. Disponível em: Acesso em 14 jul. 2017.

[19]. FERRAZ, A. Fruticultura. 2013. Disponível em:

<http://www.ifcursos.com.br/sistema/admin/arquivo s/151944apostilafruticultura.pdf $>$. Acesso em: 10 de nov. 2017.

[20]. FEDERAÇÃO DAS INDÚSTRIAS DO ESTADO DO RIO GRANDE DO NORTE. Dados Estatísticos Comércio Exterior, 2016. Disponível em:

<http://www2.fiern.org.br/images/pdf/espaco_empr esarial/cin/Exportacoes_do_RN>. Acesso em: 20 nov. 2017.
[21]. FIORAVANÇO, J. C. Mercado mundial da banana: produção, comércio e participação brasileira. Informações econômicas, v. 33, n. 10, p. 15-27, 2003.

[22]. FOOD AND AGRICULTURE ORGANIZATION. Downloads, 2015. Disponível em: <http://www.fao.org.br/download/PA20142015CB.p df>. Acesso em: 22 ago. 2017.

[23]. GIL, A. C. Como elaborar projetos de pesquisa. São Paulo: Atlas, 1991

[24]. GILIO, L.; SILVA, A. F.; BARROS, G. S. C.; FACHINELLO, A. L.; CASTRO, N. R. O agronegócio em Minas Gerais: evolução do produto interno bruto entre 2004 e 2015. Revista de Economia e Agronegócio, v. 14, n. 1, 2 e 3, p. 41-76, 2016

[25]. IBGE. Estatística de Produção, 2016. Disponível em: Acesso em: 11 ago. 2017.

[26]. - Produção Agrícola, 2012. Disponível em: < http://www.ibge.gov.br/home/>. Acesso em: 12 jan. 2017

[27]. JUNIOR, M. P. Ambiente institucional e desempenho diferenciado na agropecuária norteriograndense: quais as relações? 2012. $71 \mathrm{f}$. Dissertação de Mestrado - Universidade Federal do Rio Grande do Norte, 2012.

[28]. LACERDA, M. A. D.; LACERDA, R. D.; ASSIS, P. C. O. A participação da fruticultura no agronegócio brasileiro. Revista de Biologia e Ciências da Terra, Campina Grande - PB. v. 4, n. 1 , 2004.

[29]. MORAIS, P. L. D.; PINHEIRO, E. B.; ARAUJO, E. L.; AMBRÓSIO, M. M. Q.; PONTES, F. M. Diagnóstico Fitossanitário da Produção Integrada de Manga no Vale do Assu (RN). Revista Magistra, v. 26, n. 2, p. 231-241, 2017.

[30]. PASSOS, O. S.; SOUZA, J. S. Considerações sobre a fruticultura brasileira, com ênfase no Nordeste. Cruz das Almas - BA. ed. 1994. Disponível em:< https://www.infoteca.cnptia.embrapa.br/infoteca/bit stream/doc/637987/1/COnsideracoessobreFruticult uraOrlandoPassosDocumentos541994.pdf>. Acesso em: 2 nov. 2017.

[31]. PEROBELLI, F. S.; VALE, V. A.; BELGO, T. M.; LANZIOTTI, F. Avaliação espacial das fontes de crescimento de um conjunto de commodities agrícolas brasileiras exportáveis entre 2003-2013. Revista de Economia e Agronegócio, v. 14, n. 1, 2 e 3, p. 3-40, 2016

[32]. SEBRAE. Serviço Brasileiro de Apoio às Micro e Pequenas Empresas. Arquivos. Disponível em:

http://www.bibliotecas.sebrae.com.br/chronus/ARQ UIVOS_CHRONUS/bds/bds.nsf/64ab878c176e510 3877bfd3f92a2a68f/\$File/5791.pdf>. Acesso em: 6 jun. 2017.

[33]. SILVA, F. A.; GOMES, M. F. M.; CORONEL, D. A.; GOMES, M. T. M. 
Competitividade das exportações brasileiras de mamão, 1995 a 2008. Revista de Economia e Sociologia Rural, v. 9, n. 3, p. 393-420, 2011.

[34]. SOUZA, S. A. M. Mamão no Brasil: distribuição regional da produção e comportamento dos preços no período 1996-2005. Informações Econômicas, v. 37, n. 9, set. 2007.

[35]. VIDAL, M. F.; XIMENEZ, L. J. F. Comportamento recente da fruticultura nordestina: área, valor da produção e comercialização.
Caderno Setorial ETENE, ano $1^{\circ}$ ํำ 2, (2016). Disponível em: $<$ https://www.bnb.gov.br/documents/80223/113834 7/3_fruta.pdf/e5f76cc8-c25a-ff08-6402-

9d75f3708925>. Acesso em: 1 nov. 2017.

[36]. VILELA, N. J.; AVILA, A. C.; VIEIRA, J. V. Dinâmica do agronegócio brasileiro da melancia: produção, consumo e comercialização. Brasília DF. Embrapa Hortaliças. Circular Técnica, 2006. Disponível em: Acesso em: 22 ago. 2017. 


\title{
Capítulo 9
}

\section{NOVAS ESTRATÉGIAS TECNOLÓGICAS NO SETOR DE ENERGIA: UM ESTUDO PATENTÁRIO}

\author{
Igor Polezi Munhoz \\ Alessandra Cristina Santos Akkari \\ Neusa Maria Bastos Fernandes dos Santos
}

Resumo: A bateria de Magnésio - Ar é considerada uma fonte promissora de energia elétrica, sobretudo por ser menos poluente, ter baixo custo, possuir energia especifica elevada e ser o magnésio o sétimo elemento químico em abundância no planeta; essas características tornaram-na uma potencial substituta para outras tecnologias convencionais. O objetivo deste artigo é realizar um mapeamento tecnológico e industrial desse dispositivo, através de indicadores patentários, no Brasil, no Japão e no mundo. O estudo baseou-se na coleta e na análise de dados secundários, obtidos de bancos de patentes internacionais (World Intellectual Property Organization - WIPO e Derwent), bem como o desenvolvimento de previsão de cenários, a partir da aplicação do Método dos Mínimos Quadrados no MATLAB. Os indicadores da WIPO demonstraram que no Brasil, no Japão e no mundo as patentes concedidas para equipamentos elétricos estão crescendo, embora, no caso brasileiro, participação desse setor ocupe o $8^{\circ}$ lugar, enquanto no Japão está em 1‥ Os indicadores do Derwent também demonstram que o número de patentes específicas ligadas às baterias de magnésio está em ascensão, mas a previsão é de desaceleração. As principais detentoras dessa tecnologia são as empresas japonesas e as principais aplicações encontram-se na área de Engenharia e Química. Ainda há pontos a serem explorados, visando a otimização, no que se refere às baterias de magnésio, sendo interessante a aplicação de recursos em P\&D por empresas brasileiras, a fim de se engajarem no desenvolvimento de novas tecnologias e alavancarem sua competitividade no cenário mundial por meio da geração de inovação.

Palavras-chave: bateria de magnésio, mapeamento tecnológico, patentes. 


\section{INTRODUÇÃO}

No setor energético, o aquecimento global tem provocado crescentes debates internacionais com o objetivo de reduzir as emissões de gases de efeito estufa, podendose destacar as resoluções do protocolo de Kyoto (MOREIRA; GIOMETTI, 2008). Ainda, o crescimento das crises energéticas no mundo tem inspirado preocupação e motivado o desenvolvimento de novas políticas públicas a fim de minimizar problema. Somente nos EUA, por exemplo, a crise de energia tem sido tema de discussão ao longo dos últimos quarenta anos, sendo que, entre 2001 e 2012, apenas no Congresso norte-americano o termo "crise energética" foi empregado cerca de 1.200 vezes em debates (GROSSMAN, 2015).

O contexto brasileiro não se mostra diferente, valendo a lembrança do ano 2001, no qual a ocorrência da crise e o consequente racionamento de energia geraram perturbações econômicas, bem como elevação do desemprego, acréscimo no déficit da balança comercial, diminuição de arrecadação de impostos, aumento da inflação e, ainda, desconforto na sociedade devido à privação de energia. De fato, o consumo de energia no Brasil cresceu de forma rápida e expressiva a partir da década de 70 , especialmente em função do avanço de alguns setores intensivos em energia, alcançando um aumento de 250\%, entre 1975 e 2000, e também uma expansão de $60 \%$ no consumo per capita de energia, no mesmo período (TOLMASQUIM, 2000; GELLER et al., 2004)

Nesse sentido, as inovações na área de acumuladores de energia, muitas vezes resultantes dos investimentos em atividades de Pesquisa e Desenvolvimento (P\&D), tornam-se essenciais a fim de conferir melhorias para esse cenário, principalmente visando promover o cuidado com o meio ambiente e o desenvolvimento sustentável.

Li et al. (2013) afirmam que as células de metal - ar são aquelas cujo ânodo é um metal, sendo consideradas fontes promitentes de energia, como consequência da sua alta voltagem, alta energia específica (quantidade de energia elétrica que uma célula ou bateria pode armazenar), baixo custo e peso reduzido. Alguns metais são frequentemente usados como ânodo pelas suas características elétricas, como o magnésio (Mg), zinco, alumínio e lítio.
Os estudos ligados a pilha de Mg iniciaram-se em 1980, sendo que esse elemento já era bem conhecido pela sua elevada capacidade específica teórica, tornando-o um excelente candidato ao uso como ânodo nas células metal-ar (MACHADO; CARDOSO, 2004). Desta forma, tem-se a bateria de Mg - Ar que, além de ser reciclável e não poluir o meio ambiente, destaca-se a abundância do Mg, que representa $2 \%$ da crosta terrestre, sendo o sétimo elemento químico mais abundante da Terra. Além disso, no mercado de commodities, o $\mathrm{Mg}$ tem excesso de oferta, tornando o preço final um dos atrativos para a tecnologia citada (JARVIS, 1992). Essas características transformaram esse sistema de armazenamento de energia em uma potencial alternativa para as baterias convencionais de íon-lítio, por exemplo, uma vez que o lítio possui menor energia específica que o Mg, além de reagir violentamente na presenc,a de água, sendo altamente inflamável e muito corrosivo (REIDLER; GUNTHER, 2003).

Jarvis (1990) afirma ainda que as pilhas de $\mathrm{Mg}$ possuem excelente capacidade de armazenamento inicial e a habilidade de reter essa capacidade, durante o armazenamento (mesmo sob temperaturas elevadas), ocorre por uma película de proteção de hidróxido de magnésio - $\mathrm{Mg}(\mathrm{OH})_{2}$, que se forma no ânodo da liga. No entanto, durante a descarga, essa película é removida e a corrosão do ânodo ocorre, gerando hidrogênio e calor. Com o uso da bateria, a camada de $\mathrm{Mg}(\mathrm{OH})_{2}$ não volta a sua passividade normal e a corrosão do ânodo continua a ocorrer, permitindo que o dispositivo perca sua capacidade de armazenamento após ser parcialmente descarregado, devendo a tecnologia ser otimizada para usos longos e intermitentes. Logo, percebe-se o apelo ambiental e a aplicação comercial dessa bateria, abrindo espaço para novas realizações em P\&D a fim de aprimorar o dispositivo e expandir seu uso.

Sob essa perspectiva, este artigo propõe realizar um mapeamento científico e tecnológico das baterias de magnésio, utilizando-se o número de patentes depositadas e concedidas na área como um indicador de P\&D, assim como identificar as principais características da tecnologia, seus principais detentores e suas aplicações. A fim de apresentar a pesquisa realizada, este trabalho está dividido em seis partes, incluindo a presente introdução, o referencial teórico, a metodologia adotada, a análise dos resultados obtidos e as conclusões. 


\section{METODOLOGIA}

Trata-se de uma pesquisa de natureza aplicada, orientada à geração de informações e conhecimentos que podem ser aplicados na solução ou melhoria de problemas específicos. O estudo apresenta uma abordagem quantitativa, com ênfase em analises numéricas dos dados coletados, envolvendo o uso de métodos numéricos aplicados à computação.

Com relação aos objetivos propostos, podese considerar um trabalho exploratório, que proporciona familiaridade com o problema central, a fim de torná-lo explícito, integrando a pesquisa bibliográfica e a coleta e análise de dados secundários. Os dados secundários foram levantados na Intellectual Property Statistics Data Center, promovido pela World Intellectual Property Organization (WIPO), considerando o campo tecnológico Eletrical machinery, Apparatus, Energy, o qual engloba dispositivos do tipo bateria de magnésio, objeto de estudo deste artigo. Logo, vale ressaltar que não se trata de um análise de todo o setor elétrico, embora os dados obtidos façam parte deste segmento.

Informações patentárias também foram retiradas do Derwent Innovation Index, que é uma ferramenta de pesquisa de patentes produzida pela Thomson Reuters Cientific e permite que as análises de proteções sejam aprofundadas, por meio de buscas específicas por itens como tópico, inventor, país, e outros. Nessa base de dados foi possível levantar informações mais precisas sobre a tecnologia estudada (Magnesium battery) e traçar perfis compostos pelas principais empresas detentoras do conhecimento, principais áreas de aplicação e evolução das patentes concedidas no período analisado.

Após a coleta dos dados foram realizadas análises numéricas utilizando-se o Método dos Mínimos Quadrados, para aproximar o comportamento dos valores para uma função polinomial conhecida e prever cenários, por meio de extrapolações para um período de cinco anos. Nessa etapa, para obter maior precisão nos resultados algébricos, implementou-se um algoritmo no MATLAB尺. Também foram realizados cálculos de variação relativa para analisar o comportamento do número de patentes, comparando-se os últimos cinco anos divulgados com o período previsto.

\section{RESULTADOS E DISCUSSÃO}

Considerando-se a importância de uma análise crítica que responda ao objetivo proposto no início do artigo, essa seção está dividida em duas partes. A primeira delas introduz os dados obtidos no Intellectual Property Statistics Data Center, no qual analisou-se a evolução no número de patentes concedidas no campo Eletrical machinery, Apparatus, Energy. Posteriormente, utilizou-se o Derwent para o mapeamento tecnológico e industrial, por meio de informações localizadas por assunto. Identificou-se a quantidade de proteções concedidas com o tópico específico baterias de magnésio, como também a evolução no número de patentes num intervalo de tempo, os principais depositantes e as principais aplicações.

\subsection{INTELLECTUAL PROPERTY STATISTICS DATA CENTER - WIPO}

Conforme apresentado pela OCDE (2011), a P\&D é uma das atividades de inovação tecnológica e pode ser realizada em diferentes estágios do processo inovativo. Ainda, uma das formas de medir a atividade inovadora de um pais é através das publicações dos dados fornecidos pelas patentes, que podem ser entendidas como o output da inovação. Para fins de comparação internacional, o Manual de Frascati orienta que sejam utilizadas estatísticas patentárias de escritórios nacionais e internacionais, como o Instituto Europeu de Patentes (IEP) ou da WIPO, que são as principais fontes de dados primários. Os dados utilizados nessa seção foram obtidos no sítio eletrônico da WIPO, através do banco estatístico de propriedade intelectual.

Inicialmente, ao se analisar os setores tecnológicos com maior índice de inovação, observa-se que o Japão possui um percentual mais elevado de participação no campo Eletrical machinery, Apparatus, Energy $(8,37 \%)$, sendo o segmento que desponta no número de proteções. Diferentemente, no Brasil, o campo estudado aparece somente em 8 o lugar nos pedidos de patentes, representando $4,77 \%$, de modo a demonstrar a situação reinante da geração de inovação no Japão sobre o Brasil.

Essa primeira constatação torna-se notória ao se avaliar a evolução temporal no número de 
patentes (Tabela 1), em ambos os países, entre 1980 (início aproximado de pesquisas na área de baterias de magnésio) a 2011. Ainda, são mostrados os valores estimados até 2016 .

De acordo com a Tabela 1, até 2011, havia no mundo, aproximadamente, 977 mil patentes no campo avaliado, sendo que 253.649 eram japonesas contra, somente, 356 patentes brasileiras. As proteções nessa área, no Brasil, iniciaram-se apenas a partir de 1999 devido à reestruturação do Sistema de Propriedade Intelectual brasileiro, em 1996, com a criação da Lei de Propriedade
Industrial (também conhecida como Lei de Patentes - Lei n. 9.279/1996) como uma forma de adequação do país ao acordo TRIPS (PALMEIRA FILHO et al., 2012).

As previsões apontam um avanço no número de patentes nos dois países, de modo que se espera, até 2016, que o Japão conquiste 391.434 proteções, correspondendo a $29,3 \%$ do total previsto no mundo, no mesmo período. Para o Brasil, estima-se um alcance de 1.714 proteção, apresentando uma baixíssima contribuição no âmbito mundial $(0,13 \%)$.

Tabela 1 - Patentes concedidas e dados previstos, no campo tecnológico Eletrical machinery, Apparatus, Energy, considerando o Brasil, o Japão e o mundo, de acordo com os dados da WIPO.

\begin{tabular}{|c|c|c|c|c|c|c|c|}
\hline Ano & Brasil & Japão & Mundo & Ano & Brasil & Japão & Mundo \\
\hline 1980 & 0 & 4.743 & 25.077 & 1999 & 1 & 10.045 & 30.787 \\
\hline 1981 & 0 & 4.925 & 26.334 & 2000 & 11 & 8.607 & 28.831 \\
\hline 1982 & 0 & 5.256 & 26.910 & 2001 & 6 & 8.890 & 29.073 \\
\hline 1983 & 0 & 5.221 & 24.951 & 2002 & 5 & 9.142 & 30.477 \\
\hline 1984 & 0 & 4.445 & 24.132 & 2003 & 2 & 9.866 & 32.841 \\
\hline 1985 & 0 & 5.099 & 26.631 & 2004 & 7 & 8.797 & 32.922 \\
\hline 1986 & 0 & 4.572 & 24.604 & 2005 & 3 & 8.822 & 35.641 \\
\hline 1987 & 0 & 4.596 & 24.414 & 2006 & 5 & 8.999 & 43.277 \\
\hline 1988 & 0 & 5.778 & 23.985 & 2007 & 2 & 10.897 & 46.868 \\
\hline 1989 & 0 & 4.782 & 22.827 & 2008 & 23 & 12.308 & 45.065 \\
\hline 1990 & 0 & 4.231 & 21.555 & 2009 & 75 & 13.093 & 47.384 \\
\hline 1991 & 0 & 5.628 & 23.490 & 2010 & 84 & 15.454 & 54.453 \\
\hline 1992 & 0 & 5.539 & 22.761 & 2011 & 132 & 18.540 & 59.183 \\
\hline 1993 & 0 & 6.072 & 22.050 & $2012 e$ & 159 & 20.101 & 62.380 \\
\hline 1994 & 0 & 7.028 & 22.788 & $2013 e$ & 206 & 23.205 & 66.968 \\
\hline 1995 & 0 & 8.482 & 24.680 & $2014 e$ & 262 & 26.897 & 71.828 \\
\hline 1996 & 0 & 6.220 & 21.154 & $2015 \mathrm{e}$ & 327 & 31.249 & 76.956 \\
\hline 1997 & 0 & 7.926 & 24.089 & $2016 e$ & 404 & 36.333 & 82.351 \\
\hline 1998 & 0 & 9.646 & 27.380 & & & & \\
\hline
\end{tabular}

Fonte: Autoria própria (2014).

Os resultados pouco expressivos obtidos para - Brasil, que refletem seu baixo índice de inovação, atrelam-se ao fato da exploração do processo inovativo no país ser recente, já que a adoção de políticas públicas de fomento à ciência, tecnologia e inovação, bem como a estruturação de um sistema de propriedade intelectual, ocorreu há menos de duas décadas (MARZANO, 2011). Ainda, contatase o pouco engajamento do setor produtivo brasileiro em P\&D, de modo que, enquanto o Japão destina quase $3,4 \%$ do PIB para esse tipo de atividade, o Brasil investe somente 1\% (sendo o sector público responsável por 63\% dos investimentos), conferindo uma debilidade para as empresas brasileiras, que se tornam pouco competitivas no mercado mundial (MATIAS PEREIRA, 2011).

Diferentemente, desde muito cedo o Japão enxergou no processo inovativo uma forma de sobrevivência e geração de ganhos. O processo de industrialização pós-guerra se baseou em tecnologia e inovação, começando pela imitação e melhoria de produtos estrangeiros, considerados inovações incrementais. Em seguida, novos processos foram desenvolvidos pelas organizações japonesas e, simultaneamente, ocorreu o lançamento de produtos inovadores no mercado. Com o desenvolvimento proporcionado no pós-guerra, nos anos 1970/1980 o Japão mostrou sua capacidade 
tecnológica e de inovação ao se projetar nos segmentos automotivo (que teve como marco a entrada no mercado automotivo norteamericano) e eletrônico (líder no desenvolvimento da microeletrônica). Em 1980, o país já era considerado uma potência mundial e as empresas japonesas desafiavam as estrangeiras em alguns segmentos importantes, como robótica, automotivo e eletrônico, preocupando países líderes, como os Estados Unidos. A parir de 1990, o Estado começou a repensar seu sistema de inovação a fim de aprimorar a eficiência do mesmo, culminando no desenvolvimento de políticas públicas audaciosas e eficazes de apoio à inovação, como a Lei Básica de Ciência e Tecnologia - introduziu os Planos Quinquenais de Ciência e Tecnologia, definindo áreas e orçamentos que seriam priorizados pelo governo japonês (SALERMO; MIRANDA, 2010).

A fim de se obter uma análise mais assertiva, estudou-se o grau relativo de variação entre os dados, considerando os cinco últimos períodos registrados, bem como os próximos cinco anos, conforme apresentado na Tabela 2.

Tabela 2 - Variação relativa no número de patentes concedidas, considerando o campo tecnológico Eletrical machinery, Apparatus, Energy

\begin{tabular}{|c|c|c|c|}
\hline Variação Relativa & Brasil & Japão & Mundo \\
\hline$(2007-2011)$ & $6500 \%$ & $70 \%$ & $26 \%$ \\
\hline Próximos períodos $(2012-2016)$ & $154 \%$ & $80 \%$ & $32 \%$ \\
\hline
\end{tabular}

Fonte: Autoria própria (2014).

Constata-se que o Brasil teve um crescimento relativo muito acentuado entre 2007 e 2011, saltando de 2 para 132 patentes. De fato, conforme apresentado na Tabela 1, a partir de 2008 o país aumentou seu índice de inovação no campo estudado e esses dados vinculamse às políticas públicas desenvolvidas para a alavancagem do processo inovativo no segmento elétrico. Assim, pode-se citar a Lei no 9.991/2000, que impôs a obrigatoriedade de investimentos em P\&D para todas as empresas autorizadas, permissionárias e concessionárias. Contudo, é necessário uma avaliação mais específica a fim de mensurar os efetivos impactos (diretos e indiretos) desse tipo de política no contexto brasileiro, não sendo o objetivo deste artigo.

Os dados previstos indicam um crescimento mais lento no Brasil, embora no Japão e no âmbito mundial seja esperado uma aceleração, em relação aos anos anteriores, sugerindo um incremento no esforços empregados para a geração de inovação no setor.

\subsection{ANÁLISE DE PATENTES - DERWENT INNOVATION INDEX}

Nesta seção, utilizou-se o Derwent para o mapeamento tecnológico e industrial, empregando o tópico específico baterias de magnésio.

A Figura 1 apresenta os valores de patentes concedidas, com referência à tecnologia bateria de magnésio, para um intervalo de tempo de 1980 a 2012, como também a previsão até 2017. Os dados levantados reforçam a compatibilidade entre o início aproximado de pesquisas apontado pela literatura para esse tipo de dispositivo (década de 80) e as informações coletadas na base patentária internacional, demonstrando um crescimento, ao longo dos anos, no número de proteções, de forma a alcançar 892 patentes em 2012, totalizando 5.303 patentes, desde 1980. Utilizando-se o Método dos Mínimos Quadrados, o cenário previsto aponta para a continuação desse avanço de forma expressiva, sendo esperada 1.684 patentes somente em 2017, atingindo um total de 11.827 proteções. 
Figura 1 - Patentes concedidas para a tecnologia bateria de magnésio, bem como as previsões desenvolvidas, de acordo com a base de dados Derwent

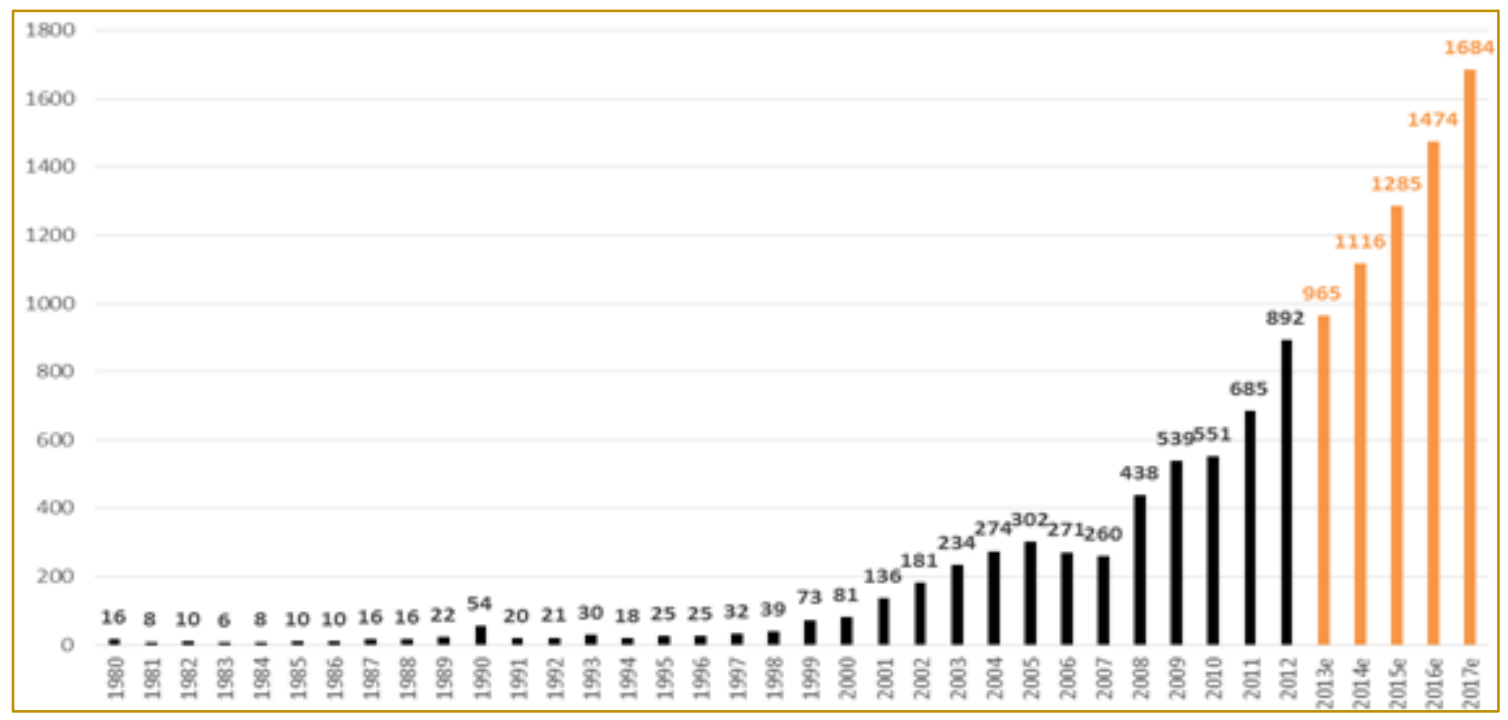

Fonte: Autoria própria (2014)

O cálculo de variação relativa foi desenvolvido (Tabela 3) a fim de se comparar o crescimento nos cinco últimos períodos registrados (2008-2012) com os próximos cinco anos (2013-2017). Entre 2008 a 2012, houve um maior aumento relativo, indicando que a expansão no número de inovações para essa tecnologia, embora ainda significativa, tende a uma desaceleração nos anos posteriores. Esse dado já era esperado, uma vez que, no início do desenvolvimento da tecnologia, ainda há muito para ser realizado e otimizado, favorecendo a geração mais rápida de inovação. Posteriormente, o indicador se estabiliza e tende a decrescer após um período, quando novas tecnologias começarem a assumir o lugar desse dispositivo. Contudo, o dado previsto (crescimento relativo > 70\%) mostra-se, até 2017, bastante positivo, sugerindo que ainda há um campo a ser desbravado no tocante às baterias de magnésio.

Tabela 3 - Variação relativa no número de patentes

\begin{tabular}{|c|c|}
\hline \multicolumn{2}{|c|}{ Variação Relativa } \\
\hline Urimos períodos (2008 - 2012) & $103 \%$ \\
\hline Próximos períodos (2013 - 2017) & $74 \%$ \\
\hline \multicolumn{2}{|c|}{ Fonte: Autoria própria (2014) } \\
\hline
\end{tabular}

Dentre os maiores depositantes (Figura 2), destacam-se as empresas de origem japonesa, sobretudo a Sanyo Electric Co Ltd., a Sony Corporation e a Matsushita Battery Industrial Co. Ltd (MBI). No entanto, são comuns joint ventures, como pode ser observado no caso da Toyota, que não possuía conhecimentos internos em baterias, mas estava desenvolvendo um carro híbrido (Toyota Prius) e fez uma parceria com a MBI para a produção desses dispositivos. Atualmente, a Toyota investe no desenvolvimento interno de novas tecnologias, abrangendo o uso da bateria de magnésio para substituição da bateria de íon lítio nos veículos híbridos. 
Figura 2 - Os 10 maiores depositantes para a tecnologia bateria de magnésio, de acordo com dados do Derwent

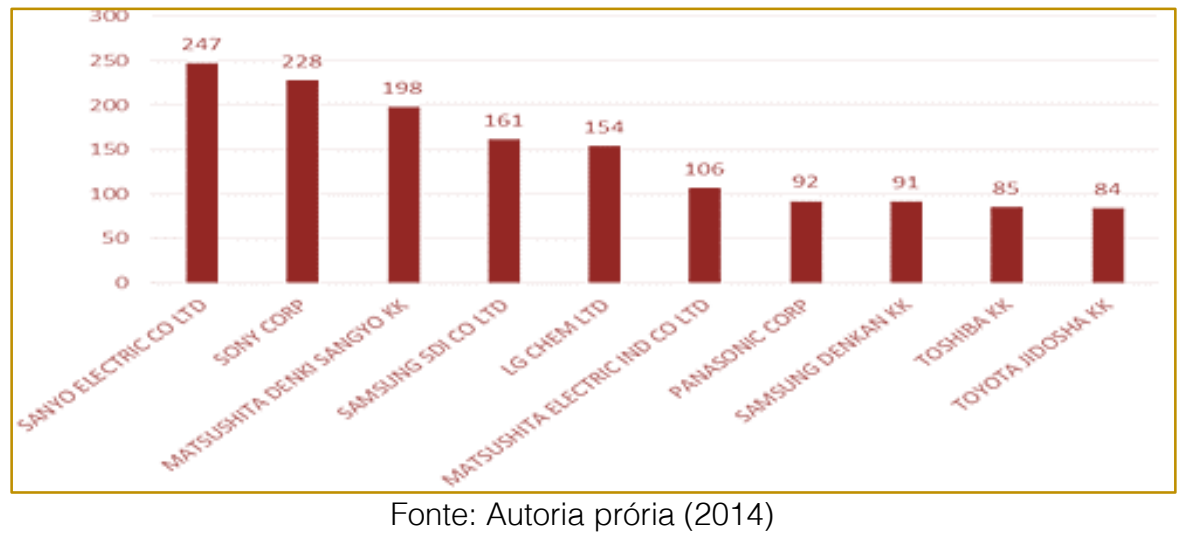

A posição destacada do Japão no cenário tecnológico pode ser explicada por meio de seus indicadores, sendo uma das maiores economias do mundo. Em 2007, tratava-se da segunda maior economia com participação no PIB global de 8,08\%, atrás dos Estados Unidos (com 25,51\%), sendo o terceiro país que mais investe em P\&D proporcionalmente ao PIB (média de $3 \%$ ao ano). Assim, comummente o país sobressai pelo seu volume de patentes registradas não somente no setor elétrico, mas também em outros segmentos estratégicos como no campo farmacêutico, por exemplo, apresentando intensa participação do setor privado em P\&D (mais de 70\% dos recursos são) (SALERNO; MIRANDA, 2010).

As dez maiores aplicações para a tecnologia avaliada são apresentadas na Figura 3, sendo que podem existir patentes que sirvam a mais de uma área de aplicação. Destaca-se o uso desse dispositivo na Engenharia, na Química e na Energia e Combustíveis, embora a aplicação em transportes (6o lugar) ainda seja uma das mais exploradas na literatura, em veículos elétricos e híbridos.

Figura 3 - As 10 maiores áreas de aplicação para a tecnologia bateria de magnésio, de acordo com dados do Derwent

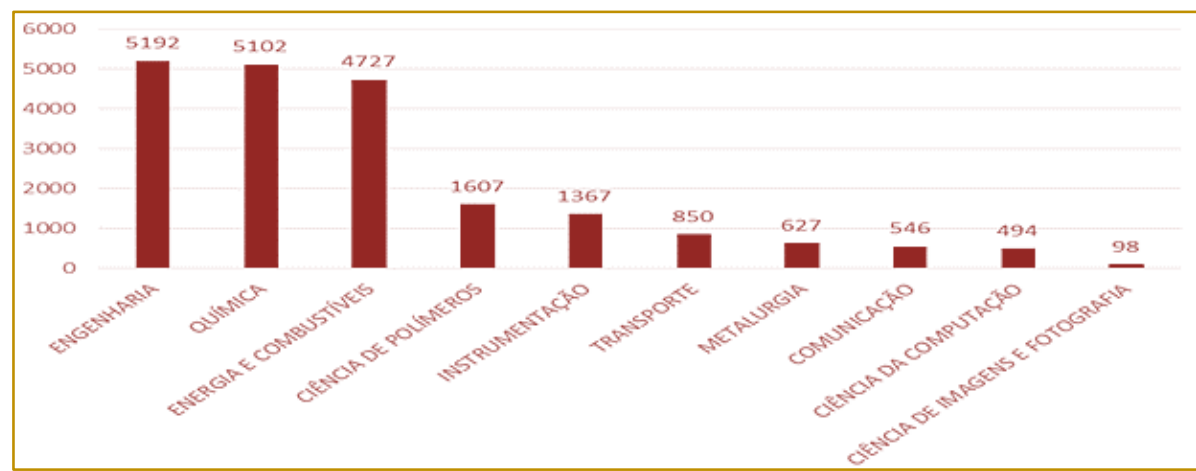

Fonte: Autoria própria (2014)

Com as recentes preocupações sobre a poluição do meio ambiente e a procura por soluções de transporte alternativas, as aplicações nessa área tendem a crescer nos próximos anos, o que é atestado pela presença da Toyota entre os dez maiores depositantes. De fato, uma análise específica no Derwent mostrou ainda, desde 2002, a
Toyota possui patentes concedidas em baterias de magnésio, saltando de 5 proteções, em 2010, para 32, em 2012. Esses resultados confirmam uma geração expressiva de inovação na tecnologia estudada, podendo ser um reflexo do alto investimento em P\&D pela organização, conforme apresentado no 2014 EU Industrial 
R\&D Investment Scoreboard (HERNANDEZ et al., 2015), que classificou a Toyota na $7^{\circ}$ posição dentre as 100 empresas que mais destinam recursos para esse tipo de atividade no mundo.

\section{CONCLUSÕES}

Esse artigo desenvolveu um mapeamento tecnológico e industrial das baterias de magnésio, utilizando-se o número de patentes como um indicador de P\&D, assim como identificou as principais características da tecnologia, incluindo os detentores e as aplicações.

A comparação com o Japão permitiu inferir que o Brasil é um país com processo de inovação recente e o baixo percentual do PIB brasileiro investido em P\&D deve ser encarado como um entrave para a alavancagem dos índices de inovação no país, exigindo políticas públicas audazes de fomento ao processo inovativo nos diversos setores, a fim de estimular uma cultura organizacional voltada para a geração de novos, ou aprimorados, produtos/processos, de modo a conferir competitividade ao setor produtivo brasileiro.

Os indicadores da WIPO demonstraram que no Brasil e no Japão as patentes concedidas no campo Eletrical machinery, Apparatus, Energy estão crescendo, assim como no mundo. No entanto, no Brasil esse setor está em $8^{\circ}$ lugar no número de pedidos de patentes, enquanto que no Japão está em 1ํ. Essa constatação foi corroborada pela análise

\section{REFERÊNCIAS}

[1] Geller, H.; Schaeffer, R.; SZLO, A.; Tolmasquim, M. Policies for advancing energy efficiency and renewable energy use in Brazil. Energy Policy, v. 32, p. 1437-1450, 2004.

[2] Grossman, P. Z. Energy Shocks, Crises and the Policy Process: A Review of Theory and Application. Energy Policy, v. 77, p. 56-69, 2015.

[3] Hernandez, H.; TÜBKE, A.; Hervás, F.; Vezzani, A.; Dosso, M.; Amoroso, S.; Grassano, N. EU R\&D Scoreboard: the 2014 EU industrial R\&D investment scoreboard. European Commission's Joint Research Centre, 2015. Disponível

em: <http://iri.jrc.ec.europa.eu/scoreboard14.html> Acesso em: 30 jan. 2015

[4] Jarvis, L. The beneficial effect of increased cathode water content on magnesium battery performance. Proceedings of the 34th International Power Sources Symposium, p.107-109, 1990. de dados do Derwent, que mostrou que principais empresas detentoras de patentes de baterias de magnésio são japonesas, com destaque para a Sanyo Electric Co Ltd., a Sony Corporation e a MBI.

Os indicadores obtidos na base de dados do Derwent também confirmaram que o número de patentes ligados à tecnologia estudade está em ascenção, embora a variação relativa tenha demonstrado que haverá uma desaceleração na geração de inovação, justificada pelo fato da tecnologia possuir limitações, que farão o indicador se estabilizar e decrescer, quando novas tecnologias começarem a surgir.

Os principais usos da bateria de magnésio encontram-se na Engenharia, na Química e na Energia e Combustíveis. Contudo, com a inquietude sobre a poluição do meio ambiente e a procura por soluções de transporte alternativas, as aplicações nessa área tendem a aumentar nos próximos anos, sendo que a posição da Toyota no ranking de inovação atesta este fato, bem como sugere uma correlação positiva entre os índices de inovação e os investimentos em P\&D.

Ainda, pode-se concluir que há pontos a serem explorados, visando a otimização, no que se refere às baterias de magnésio, sendo interessante a aplicação de recursos em P\&D por empresas brasileiras do setor elétrico, a fim de se engajarem no desenvolvimento de novas tecnologias e alavancarem sua competitividade no cenário mundial por meio da geração de inovação.

[5] Jarvis, L. Low cost, improved magnesium battery. Proceedings of the 35th International Power Sources Symposium, p.26-29, 1992.

[6] LI, Z.; Yang, J.; XU, G.; Wang, S. Nonprecious cathode electrocatalyst for magnesium air fuel cells: activity and durability of ironpolyphthalocyanine absorbed on carbon black. Journal of Power Sources, v. 242, p.157-165, 2013.

[7] Machado, C. A. C.; Cardoso, J. V. M. Desenvolvimento de uma pilha metal / ar / água do mar. 2004. 68p. TCC (Trabalho de Conclusão de Curso de Graduação em Eletrotécnica) Departamento de Engenharia Eletrotécnica e de Computadores, Faculdade de Engenharia, Universidade do Porto, Porto, 2004.

[8] Marzano, F. M. Políticas de Inovação no Brasil e nos Estados Unidos: a busca da competitividade - oportunidades para a ação diplomática. Brasília: Fundação Alexandre de Gusmão, 2011.

[9] Matias Pereira, J. A gestão do sistema de proteção à propriedade intelectual no Brasil é 
consistente? Revista de Administração Pública, v. 45, n.3, p. 567-590, 2011.

[10] Moreira, H. M.; Giometti, A. B. dos R. Protocolo de Quioto e as possibilidades de inserção do Brasil no Mecanismo de Desenvolvimento Limpo por meio de projetos em energia limpa. Contexto Internacional, v. 30, n.1, p. 9-47, 2008.

[11] Ocde. Organização de Cooperação e Desenvolvimento Econômico. Manual de Frascati 2002: metodologia proposta para definição da investigação e desenvolvimento experimental. São Paulo: F. Iniciativas, 2011. 386p.

[12] Palmeira Filho, P. L.; Pieroni, J. P.; Antunes, A.; Bomtempo, J. V. O desafio do financiamento à inovação farmacêutica no Brasil: a experiência do BNDES Profarma. Revista do Bndes, n.37, p. 67-90, 2012.

[13] Reidler, N. M. V. L.; Gunther, W. M. R. Impactos ambientais e sanitários causados por descarte inadequado de pilhas e baterias usadas. Revista Limpeza Pública, v. 60, p. 20 - 26, 2003.

[14] Salerno, M. S.; MIRANDA, Z. Japão e as mudanças institucionais e políticas de C, T\&l. In: Inovação: estratégia de sete países. Brasília: ABDI, p. 282-311, 2010.

[15] Tolmasquim, M. As origens da crise energética brasileira. Ambiente e Sociedade, n. 67, 2000. 


\section{Bapítulo 10}

\section{ESTRATEGIAS DE CARREIRA E IDENTIFICAÇÃO DE VALORES EM DISCENTES DO CURSO DE ENGENHARIA \\ Neusa Maria Bastos Fernandes dos Santos \\ Igor Polezi Munhoz \\ Alessandra Cristina Santos Akkari}

Resumo: Desenvolveu-se um estudo exploratório com 252 estudantes de engenharia, mapeando seus valores pessoais, âncoras de carreira e a associação desses parâmetros, baseado nos inventários de valores de Rokeach (1981) e de âncoras de carreira de Schein (1993). No tratamento de dados, aplicou-se a estatística descritiva e inferencial. A maioria dos respondentes pertenciam à Geração Y (92,46\%), sendo que a Felicidade e a Honestidade destacaram-se, respectivamente, como valor terminal e instrumental; carreiras ancoradas no Estilo de Vida e Segurança-Estabilidade predominaram. Constatou-se que os valores pessoais/ profissionais, muitas vezes, sobressaem aos valores peculiares a indivíduos de diferentes formações acadêmicas. A análise de correspondência indicou interações entre os valores pessoais e a carreira, apontando a importância desse tipo de estudo para direcionar gestores a refletirem sobre valores, motivações e expectativas de novos profissionais, bem como educadores e novas políticas públicas, visando otimizar a empregabilidade e o desenvolvimento do jovem no mercado.

Palavras-chave: Valores, carreira, geração Y, engenharia. 


\section{INTRODUÇÃO}

Ao conceito de carreira, sob uma perspectiva de evolução histórica, foi sendo atribuídos outros elementos além do sentido meramente do trabalho, o qual the era designado inicialmente (MCDANIELS; GYSBERS, 1992). $\mathrm{Na}$ língua inglesa, por exemplo, a palavra carreira correspondia, originalmente, à estrada para carruagens, mas, a partir do século XIX, esse conceito foi empregado no âmbito do trabalho, passando a designar "um canal para as atividades econômicas de alguém durante a vida inteira" (SENNETT, 2006). Assim, pode-se definir carreira como a sequência de experiências relacionadas ao trabalho e vivenciadas pelo ser humano ao longo do tempo (ARTHUR; KHAPOVA; WILDEROM, 2005).

A permanência do trabalhador em uma mesma organização durante toda a sua vida é uma característica destacada da carreira tradicional e, atualmente, diante de um ambiente cada vez mais dinâmico e complexo, é incompatível com a necessidade de mudança que as diversas empresas demandam para enfrentar as turbulências de desse mercado. Assim, atualmente, constatase que as carreiras são constituídas por ciclos vinculados à alternância entre aprendizagem, domínio do conhecimento e reaprendizado (HALL; MIRVES, 1995).

Segundo Gouveia et al. (2001), a influência da centralidade do sistema cognitivo afeta as predisposições profissionais, ou seja, a carreira de um indivíduo pode ser influenciada por seus valores que são concebidos como critérios utilizados pelas pessoas para avaliar ações, indivíduos e eventos, de acordo com a pluralidade científica de Milton Rokeach (SCHWARTZ, 2005).

Os valores pessoais são capazes de interferir nas ações, nas escolhas e no comportamento do ser humano, influenciando na maneira pela qual o indivíduo julga a si mesmo e aos outros (GASTALDELLO, 1999) e permitindo com que sejam percebidos tanto como produto como ponto de referência do processo de reflexão e avaliação dos desejos (SCHWARTZ; LACEY, 1995). Ademais, os valores afetam as reações das pessoas sobre seu trabalho (STACKMAN, PINDER; CONNOR, 2004) e, aliados às motivações e ao talento, estimulam as decisões de carreira (SCHEIN, 1993). Diante disto, as ambições da vida profissional e a satisfação das necessidades prioritárias do indivíduo também são impulsionadas pelos valores pessoais.

Nesse contexto, destaca-se a importância da chamada Geração Y, constituída por jovens entre 18 e 30 anos que entraram no mercado de trabalho nesta década. Trata-se de uma geração que apresenta maior potencial em relação às passadas, uma vez que esses jovens já adentram nas organizações munidos de informações sobre o que acontece ao redor e estão sempre dispostos a apresentar soluções criativas (CARNEIRO, 2010; BARBOSA, 2012).

Baseando-se nos anseios e nas expectativas de uma geração sobre sua carreira profissional, organizações atentas e preocupadas com os valores, motivações e expectativas dos novos profissionais podem adequar seus cargos e planos de carreira, contribuindo para que seus funcionários alcancem posições de sucesso e otimizem a efetividade de colaboração com a empresa (FERRAZ; GALLI; TREVISAN, 2008). Vale citar ainda a necessidade de educadores em conhecer o perfil das gerações a fim de refletirem sobre metodologias educacionais e componentes curriculares com o objetivo de atender às novas demandas do mercado.

Nesse sentido, conforme estudo de Lemos (2012), o problema do desemprego no Brasil, muito debatido na esfera pública, vincula-se à falta de preparo dos trabalhadores para assumirem novos posições no mercado. Assim, por meio da expressão "oferta inadequada de força de trabalho", os autores explicam a crise contemporânea do mercado de trabalho. De fato, o relatório da Organização Internacional do Trabalho World Employment and Social Outlook 2016 estima que o índice mundial de desemprego dos jovens com idades entre 15 e 24 anos deve atingir $13,1 \%$ em 2016, contra 12,9\% em 2015, isto é, uma elevação de meio milhão de pessoas. Com isso, aproxima-se do nível recorde alcançado em 2013, que foi de $13,2 \%$ (OIT, 2016).

Sob o exposto, o objetivo deste trabalho é realizar um estudo exploratório com universitários do curso de Engenharia de Produção, na sua maioria pertencentes à Geração Y, de uma universidade federal do estado de São Paulo, a fim de mapear os seus valores pessoais e as suas principais âncoras de carreira, bem como investigar, estatisticamente, a ocorrência de associação entre os valores e os diferentes tipos de 
âncoras de carreira. Pretende-se, assim, melhor compreender os anseios e expectativas dos indivíduos, por meio de uma análise quantitativa e qualitativa pautada em valores pessoais, âncoras de carreira, geração e formação acadêmica. Os resultados apresentados nesse artigo podem direcionar gestores e recrutadores, bem como educadores e novas políticas públicas, visando otimizar a entrada e permanência do jovem no mercado de trabalho, bem como seu desenvolvimento profissional e pessoal.

\section{REFERENCIAL TEÓRICO}

\subsection{VALORES HUMANOS À LUZ DAS CONTRIBUIÇÕES DE ROKEACH}

Ao definir o termo valor, deve-se restringir seu significado à realidade estudada, pois o mesmo carrega consigo uma dimensão de pluralista, vinculada a diferentes situações do cotidiano (SANTOS; MUNHOZ; LELIS, 2013). Alguns estudiosos de valores apresentaram suas definições, sendo que delimitaram suas pesquisas em valores humanos. Kluckohn (1951, p. 443), por exemplo, parte da interação social e define valor como "uma concepção explícita, ou implícita, distinta, ou característica de um grupo do que é desejável, que influencia a seleção de modos, meios e finalidades da ação acessível". Entende-se, assim, que um valor supõe um código ou uma norma que, por sua vez, tem alguma persistência ao longo do tempo, com seu uso. Trata-se de um valor é o aceito pelo grupo, de forma que o desejável é contrastado com o desejado.

Schwartz (2005) assevera que valores são aquilo que os indivíduos tomam como importante em suas vidas, ou seja, são crenças, ou um construto motivacional, que transcendem situações e ações específicas e que guiam a seleção e avaliação de atitudes, de políticas, de pessoas e de eventos. Ainda segundo o autor, os valores são ordenados pela sua importância relativa e formam um conjunto de metas conscientes dos indivíduos ou sociedades, devendo atender aos três requisitos universais: (1) as necessidades biológicas dos indivíduos; (2) os requisitos de interação social; (3) e os requisitos para o correto funcionamento e sobrevivência dos grupos (SCHWARTZ; BARDI, 2001).

Rokeach (1973, p. 5) apresenta sua definição de valor como sendo uma crença constante de que um modo específico de conduta ou estado final de existência é preferível a um modo de conduta ou estado final de existência inverso. Sob esse entendimento, um sistema de valores refere-se à organização das crenças de modos de conduta ou estados finais de existência preferidos, considerados como referência em uma escala de importância relativa. O autor ainda afirma que os indivíduos diferem nas práticas dos valores devido aos graus de importância atribuídos a cada um deles, ordenando-os e articulando-os entre si dentro de um sistema de valores, que é acionado diante das escolhas pessoais. Quando isso ocorre, os valores considerados mais relevantes no sistema predominam sobre os demais (ROKEACH, 1981).

Rokeach (1981) apresenta uma distinção entre dois tipos de valores, isto é, os valores terminais e os valores instrumentais. Os valores terminais, também denominados valores finais, referem-se aos estados finais preferidos de ser e estar e os indivíduos costumam defender até doze valores desse tipo; os valores instrumentais correspondem aos modos preferidos de conduta social ou comportamentos para o alcance dos objetivos pessoais, sendo que os indivíduos defendem um número muito maior desse tipo de valor, não ultrapassando cem.

Um valor terminal pode ser identificado pela seguinte sentença: "eu acredito que este e aquele estado de existência (por exemplo, a salvação, um mundo de paz) é pessoal e socialmente um valor que se deve lutar para obter". Um valor instrumental, por sua vez, pode ser identificado pela afirmativa: "eu acredito que este e aquele modo de conduta (a honestidade, a coragem, por exemplo) é pessoal e socialmente preferível em todas as situações com respeito a todos os objetos" (Rokeach, 1973). Dessa maneira, apenas os valores que podem ser inseridos em cada uma das frases podem ser classificados como terminais ou instrumentais (ABRAHIM, 2008).

Diante do exposto, é possível afirmar que os valores representam a centralidade do sistema cognitivo (GOUVEIA et al., 2001), representando abstrações que estimulam atitudes e que se refletem no comportamento humano, tanto no que diz respeito a uma perspectiva mais geral quanto em contextos mais específicos, como o trabalho. 


\subsection{GERAÇÃO Y E AS ÂNCORAS DE CARREIRA}

De acordo com Kupperschmidt (2000), as diferenças entre gerações em uma empresa, se não compreendidas, podem gerar tensão, confronto, insatisfação e diminuir a produtividade. Os membros pertencentes à Geração Y são indivíduos que nasceram entre os anos de 1982 e 2000 (RUGIMBANA, 2007). A Geração Y faz parte do chamado ciclo idealista, porque se pode fazer uma correlação entre as suas características principais, o empreendedorismo, a independência e a honestidade. Essa geração vem sendo foco de muitos estudos nos últimos anos devido ao fato de ser a mais recente geração a entrar no mercado de trabalho e, entender como atraí-la e retê-la em uma empresa, torna-se um desafio (MCCRINDLE, 2002; LISSITSA; KOL, 2016; SHIRISH; BOUGHZALA; SRIVASTAVA, 2016)

Os indivíduos pertencentes a essa geração não têm medo de arriscar e a buscam novos desafios, detestam monotonia, não costumam ficar muito tempo numa mesma organização, tem conhecimentos técnicos e capacitação profissional. Eles trabalham melhor em equipes e procuram empregos que ofereçam flexibilidade de horário, mobilidade e planos de carreira. Algumas características específicas destacam-se dentre este grupo de indivíduos, tais como a predominância virtual; o comportamento empreendedor; as ideias inovadoras, o espírito de liderança; a criatividade; a responsabilidade; a paixão pela área de atuação; a visão de futuro; a persistência; a coragem para assumir riscos; e a facilidade de expressão (CARNEIRO, 2010; BARBOSA, 2012). Conhecer a Geração $Y$ com mais detalhes, com enfoque em seu valores e inclinação profissional, poderá ajudar os gestores a trabalhar efetivamente para que haja uma maior produtividade e melhor aproveitamento de suas competências e potenciais, contribuindo para uma reestruturação das políticas do ambiente de trabalho.

No âmbito da esfera profissional, diferentes conotações foram atribuídas à palavra carreira ao longo da história. Sob a perspectiva da abordagem tradicional, três características limitantes do conceito de carreira podem ser consideradas: (i) ausência de expectativa de progressão vertical hierárquica dentro uma organização; (ii) associação de carreiras às profissões mais difundidas e reconhecidas; (iii) e pressuposição de estabilidade, em que o funcionário exerce as mesmas atividades relacionadas à sua profissão até sua aposentadoria (MARTINS, 2001).

Ultrapassando as limitações da abordagem tradicional, tem-se o conceito de carreira proteana, que possibilita a compreensão da carreira como uma série de aprendizados pessoais relacionados ao trabalho ao longo da vida (MUNHOZ, 2014). O termo proteana, derivado do deus grego Proteu, abrange a referência a um processo em que o indivíduo, e não a organização, gerencia sua própria trajetória profissional, permitindo que a carreira seja redirecionada, de tempos em tempos, para atender às suas próprias necessidades e anseios (HALL, 1996). O profissional proteano consegue ajustar-se às demandas do ambiente de carreiras, com flexibilidade e investimento em suas habilidades, qualificações e competências, mas sempre apresentando consciência de seus objetivos pessoais. Ademais, esse indivíduo sabe definir os atributos de sucesso que espera alcançar, coerentes com seus valores, interesses e aptidões, além de ser capaz de priorizar suas ações de carreira, conciliando com suas pretensões de vida (MARTINS, 2001; ROBBINS, 1998).

\subsubsection{ABORDAGEM DE SCHEIN E A DESCRIÇÃO DAS ÂNCORAS DE CARREIRA}

Ao considerar diferentes aspectos, tais como necessidades; desejos; ansiedade; capacidades; potencialidades pessoais; pressões e condicionantes ambientais da empresa; e responsabilidades na vida particular, observa-se que a ideia de desenvolvimento de carreira está diretamente relacionada ao desenvolvimento pessoal. A concepção do conceito de âncoras de carreira, que abrange uma combinação competência, motivos e valores do indivíduo, foi uma contribuição da Sloan School of Management - Massachusetts Institute of Technology (MIT), a partir de um estudo realizado com 44 profissionais que foram entrevistados por Edgar Schein (ABRAHIM, 2008).

Com o conhecimento da sua inclinação profissional de um indivíduo, é possível perceber suas aptidões, preferências, objetivos e valores que caracterizam suas escolhas, como fatores que não renunciaria em sua carreira. Quando as ocupações não são compatíveis com a âncora de seu 
ocupante, esse indivíduo tende a apresentar um desempenho mediano, onde não se sente completamente feliz e satisfeito. O modelo de âncora reforça a noção de que o autoconhecimento favorece a eficácia na tomada de decisão ocupacional e seu caráter processual (MARTINS, 2001). Definidas pela área de maior importância para um indivíduo e os valores que ele prioriza, foram identificadas oito categorias de inclinações profissionais, conforme o Quadro 1.

Quadro 1: Categorias de âncoras de carreira e suas respectivas descrições gerais

\begin{tabular}{|c|c|}
\hline Âncora de carreira & Descrição geral \\
\hline $\begin{array}{l}\text { Aptidão Técnica e } \\
\text { Funcional (TF) }\end{array}$ & $\begin{array}{l}\text { indivíduos que exercitam suas aptidões e continuam a desenvolvê-las ao máximo, } \\
\text { buscando ser referência de especialista na área que atuam }\end{array}$ \\
\hline Gerência geral (GG) & $\begin{array}{l}\text { indivíduos têm como objetivo subir os degraus hierárquicos da empresa até alcançar } \\
\text { os cargos de maior responsabilidade }\end{array}$ \\
\hline $\begin{array}{l}\text { Autonomia } \\
\text { Independência (Al) }\end{array}$ & $\begin{array}{l}\text { indivíduos que não suportam estar presos a normas, regras, métodos e expedientes } \\
\text { de trabalho e sua necessidade é a de fazer as coisas do seu jeito, priorizam sua } \\
\text { liberdade e autonomia }\end{array}$ \\
\hline $\begin{array}{l}\text { Segurança } \\
\text { Estabilidade (SE) }\end{array}$ & $\begin{array}{l}\text { indivíduos que priorizam a segurança financeira e estabilidade no vínculo } \\
\text { empregatício ao longo de toda sua trajetória profissional, dessa maneira, buscam } \\
\text { emprego em organizações sólidas }\end{array}$ \\
\hline $\begin{array}{l}\text { Criatividade } \\
\text { Empreendedora (CE) }\end{array}$ & $\begin{array}{l}\text { indivíduos motivados a criar novos negócios próprios, dispostas a correr riscos e } \\
\text { superar obstáculos para verem o resultado de seu próprio esforço }\end{array}$ \\
\hline $\begin{array}{l}\text { Dedicação a uma } \\
\text { Causa (SD) }\end{array}$ & $\begin{array}{l}\text { indivíduos que se sentem satisfeitos em contribuir para a melhoria da sociedade, } \\
\text { solucionando questões ambientais e sociais. }\end{array}$ \\
\hline Puro Desafio (PD) & $\begin{array}{l}\text { indivíduos competitivos, que objetivam superar obstáculos e solucionar problemas } \\
\text { aparentemente insolúveis }\end{array}$ \\
\hline Estilo de Vida (EV) & $\begin{array}{l}\text { indivíduos que buscam equilibrar as esferas pessoais e profissionais, integrando as } \\
\text { necessidades do trabalho com as necessidades individuais e familiares }\end{array}$ \\
\hline
\end{tabular}

\section{METODOLOGIA DE PESQUISA}

Trata-se de um estudo exploratório descritivo, integrando a pesquisa bibliográfica e a pesquisa de campo. A investigação iniciou-se com a busca de referências nas áreas de Administração, Psicologia, Sociologia e Engenharia em bibliotecas eletrônicas, nacionais e internacionais, que abrange coleções selecionada de periódicos científicos brasileiros. Após esse levantamento, decidiu-se pela utilização de questionário como forma de coleta de dados.

\subsection{PLANO AMOSTRAL E COLETA DE DADOS}

A escolha dos participantes deu-se inicialmente pelo critério de acessibilidade (VERGARA, 2007) ao se optar pela investigação de universitários de curso de graduação em Engenharia de Produção em uma instituição pública de ensino superior, localizada no estado de São Paulo. Como o foco do presente trabalho não está na instituição de ensino, optou-se por não divulgar seu nome. A amostra é não probabilística, pois durante a coleta de dados os questionários foram distribuídos em sala de aula aos indivíduos presentes e dispostos a participar da pesquisa, apresentando distribuição aleatória. Dessa forma, obteve-se como resultado uma amostra com 252 participantes.

Para a coleta de dados, foi utilizado como instrumento de pesquisa um questionário composto por quatro partes: (i) apresentação do estudo; (ii) perfil do respondente, formada por 10 perguntas; (iii) instrumento de pesquisa de valores; (iv) inventário das âncoras de carreira de Schein (1993).

A hierarquia de valores pessoais do grupo analisado foi identificada pela utilização da Escala de Valores de Rokeach (Rokeach value Survey - RSV), pois se considera o instrumento mais apropriado para a mensuração de valores e pela sua parcimônia ante aos demais instrumentos como o Inventário de Valores Humanos de Schwartz, composto por 56 questões. O inventário RVS é composto por duas listas com 36 valores, sendo 18 terminais e 18 instrumentais, permitindo aos indivíduos que atribuam os graus de importância a cada um dos valores das duas listas em escala decrescente, de 1 a 18. A pontuação de menor valor corresponde à maior importância e a pontuação maior valor representa a menor importância. 
O inventário das âncoras de carreira de Schein (1993) consiste em um questionário com 40 afirmativas, que o respondente atribui classificação, em escala tipo Likert, de 1 a 6 , sendo que os valores extremos significam nunca verdadeiro (valor 1) e mais verdadeiro (valor 6); o valor 2 e o valor 3 correspondem a ocasionalmente verdadeiro; e o valor 4 e o valor 5 equivalem a frequentemente verdadeiro, utilizado para identificar os oito tipos de âncoras de carreira predominantes.

$\mathrm{O}$ instrumento de pesquisa foi aplicado em disciplinas específicas do curso de Engenharia de Produção, durante 4 meses. A aplicação do questionário, em cada sala de aula, durou em média 30 minutos sendo que, primeiramente, foi entregue, aos alunos dentro da sala de aula, uma folha individual contendo o questionário; após o preenchimento, as folhas foram recolhidas para serem analisadas. É importante ressaltar que não foram coletados dados que identificassem os participantes.

\subsection{TRATAMENTO DE DADOS}

Após a aplicação do instrumento de pesquisa, os dados foram tabulados, formando um banco de dados no Microsoft Excel. O tratamento dos dados foi feito com o auxílio do pacote estatístico SPSS (versão 13.0) e os resultados organizados em análise descritiva, inferencial e de correspondência.

Utilizando-se a análise descritiva, identificouse o perfil do participante, o valor terminal primário (classificado como 1 - o mais importante), o valor terminal secundário (classificado como 2 - o segundo mais importante), o valor instrumental primário e o valor instrumental secundário de cada aluno participante do estudo. Posteriormente, calculou-se também a pontuação de cada âncora de carreira. Os indivíduos que colocaram mais de um valor como o mais importante ou o segundo mais importante não foram considerados no cálculo dessas variáveis.

Para as análises inferenciais, foram utilizados testes de qui-quadrado, avaliando a ocorrência de associação dos valores terminais e instrumentais com a faixa etária. Igualmente, buscou-se correlações com as âncoras de carreira. O teste de qui-quadrado foi utilizado por ser um teste não paramétrico que permite avaliar a associação entre duas variáveis categóricas (nominais ou ordinais) por meio de uma tabela de contingência. Valores de qui-quadrado maiores ou iguais a 0,05 indicam que há independência das variáveis; da mesma forma, valores de quiquadrado inferior a 0,05 representa a dependência das variáveis, com presença de associação entre elas (BRUNI, 2009). As hipóteses testadas nas análises inferenciais foram:

a. Hipótese 1a: Há associação entre a idade e a âncora de carreira.

b. Hipótese 1b: Há associação entre a idade e o valor terminal primário.

c. Hipótese 1c: Há associação entre a idade e o valor instrumental primário.

Por fim, a análise de correspondência verificou a existência de associação entre os valores terminais e instrumentais e as âncoras de carreira.

\section{RESULTADOS E DISCUSSÃO}

Nessa seção são apresentados os dados obtidos, a análise descritiva e inferencial, bem como a discussão dos resultados.

\subsection{ANÁLISE DESCRITIVA DO PERFIL E DOS SISTEMAS DE VALORES}

A fim de se obter o perfil dos graduandos da amostra, foi realizada uma análise considerando os parâmetros idade, gênero e formação anterior. A maioria dos respondentes (92,46\%) tinha entre 18 e 25 anos, ou seja, eram pertencentes à Geração Y. Adicionalmente, observou-se o predomínio do sexo masculino $(59,13 \%)$, sendo que um percentual considerável de indivíduos, superior a 17\%, preferiu não informar o gênero. De modo complementar, constatou-se a preponderância de alunos que possuíam apenas o ensino médio (68,25\%), seguidos por aqueles que concluíram o ensino técnico de nível médio $(24,21 \%)$ e, em menor magnitude, discentes que já apresentavam outra graduação completa $(6,75 \%)$.

No tocante ao sistema de valores, por meio da Figura 1 constata-se que o valor terminal primário predominante foi a felicidade, sendo o mais importante para 46 respondentes (18\%). Seguidamente, para $17 \%$, a vida confortável foi o valor mais importante e, 
então, a segurança familiar(10\%). De fato, um estudo anterior mostra que, para a Geração Y, a realização no trabalho é um fator de importância primária, vinculando-se com prazer em realizar um determinado trabalho e realização pessoal. Assim, esses futuros profissionais e gestores primam por desenvolver atividades prazerosas e interessantes a fim de, desta forma, obterem satisfação pessoal e sucesso em suas carreiras, alcançando uma almejada vida confortável (PAPAVASILEIOU; LYONS, 2015). O item considerado como não definido, na Figura 1, representa os participantes desconsiderados por preenchimento incorreto.
$\mathrm{Na}$ Figura 2, novamente observa-se a importância da felicidade (11\%) para os respondentes, despontando como o valor terminal secundário predominante seguido, para $8 \%$ dos indivíduos, pelo valor vida confortável e, então, o sentimento de realização foi considerado o segundo valor mais importante para 18 alunos (7\%).

De fato, refletindo-se a respeito da formação da Geração Y, entende-se que foram crianças superprotegidas pelos pais e que estavam habituadas a terem suas opiniões sempre consideradas, de modo a serem estimuladas a alcançar sonhos que thes tratariam felicidade, reforçando valores como segurança e confiança (TULGAN, 2009; TWENGE; CAMPBELL; FREEMAN, 2012).

Figura 1: Valor terminal primário obtido para a amostra estudada

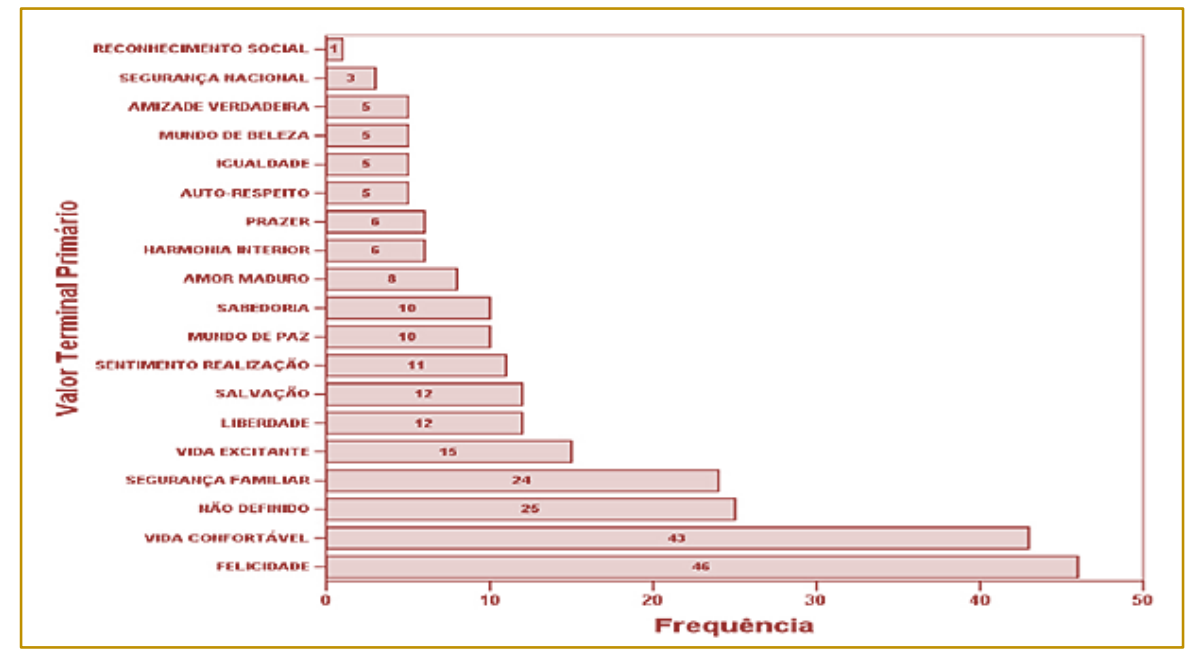

Fonte: Elaborado pelos autores.

Figura 2: Valor terminal secundário obtido para a amostra estudada

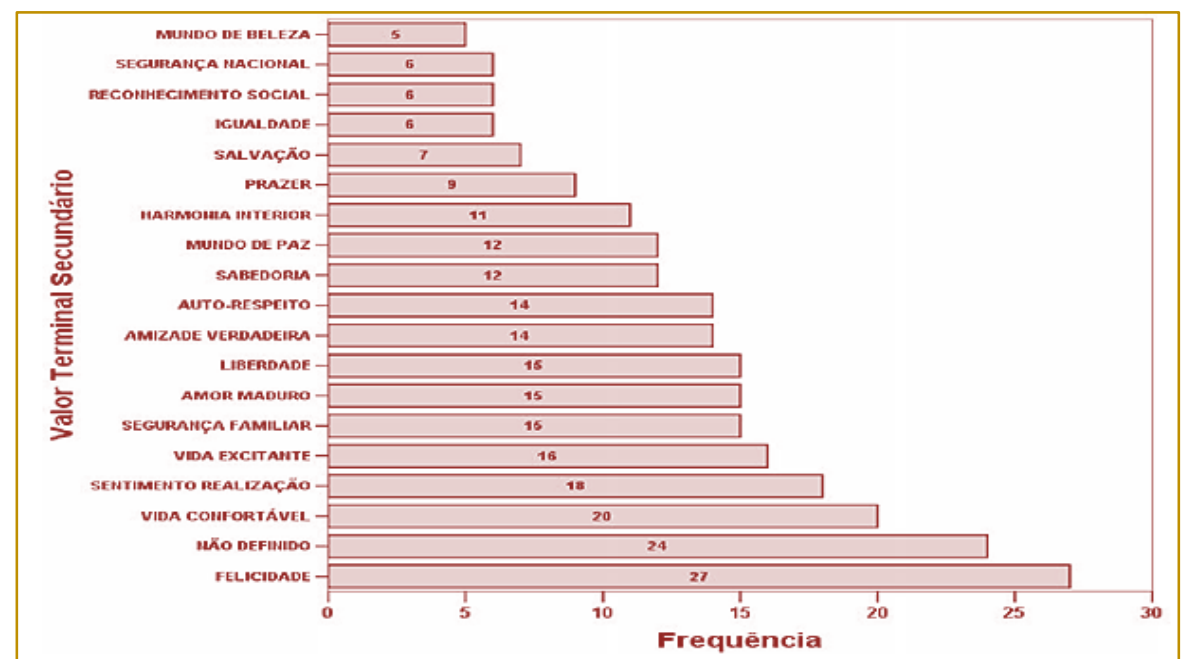

Fonte: Elaborado pelos autores. 
Em relação aos valores instrumentais, a Figura 3 mostra que o valor instrumental primário dominante foi a honestidade, sendo o mais importante para 46 respondentes (18\%), de modo a confirmar que a sociedade que essa geração almeja é pautada na ética e transparência. Para 12\%, a ambição foi o valor mais importante, seguida pela responsabilidade, para 27 discentes (11\%). Esses valores apontam que a Geração Y tende a escolher empresas que the proporcione um acelerado desenvolvimento profissional, fundamentado na responsabilidade e ganhos por competência. A Figura 4 comprova a importância da responsabilidade e da honestidade para a Geração Y, sendo os valores instrumentais secundários predominantes para 33 (13\%) e $26(10 \%)$ respondentes, respectivamente. A prestatividade foi considerada o segundo valor mais importante para $8 \%$ dos indivíduos, confirmando que, nas relações sociais, esses jovens enaltecem o bom relacionamento com colegas de trabalho, bem como ambicionam serem úteis para a sociedade.
Corroborando os resultados do presente estudo, o trabalho desenvolvido por Abrahim (2008), com alunos dos cursos de Administração, Engenharia de Produção, Direito, Ciências Ambientais e Ciências Contábeis, apontou como valores terminais a predominância da felicidade (16,28\% dos participantes) e da segurança familiar $(16,28 \%$ dos participantes), bem como evidenciou a honestidade $(34,88 \%$ dos participantes) e a responsabilidade (16,28\% dos participantes) como princípios de vida para guiarem suas escolhas. Um trabalho comparativo entre estudantes (idade média dos respondentes igual a 21,57) nas áreas de Administração, Economia e Ciências Contábeis de universidades brasileiras e tailandesas, também destacou como valores terminais o sentimento de realização e a segurança, tanto nos jovens brasileiros quanto nos jovens tailandeses. Quanto aos valores instrumentais, o mesmo estudo destacou a ambição e o sentimento de se sentir capaz como valores norteadores dos respondentes de ambos os países (GERVAZIO et al., 2016).

Figura 3: Valor instrumental primário obtido para a amostra estudada

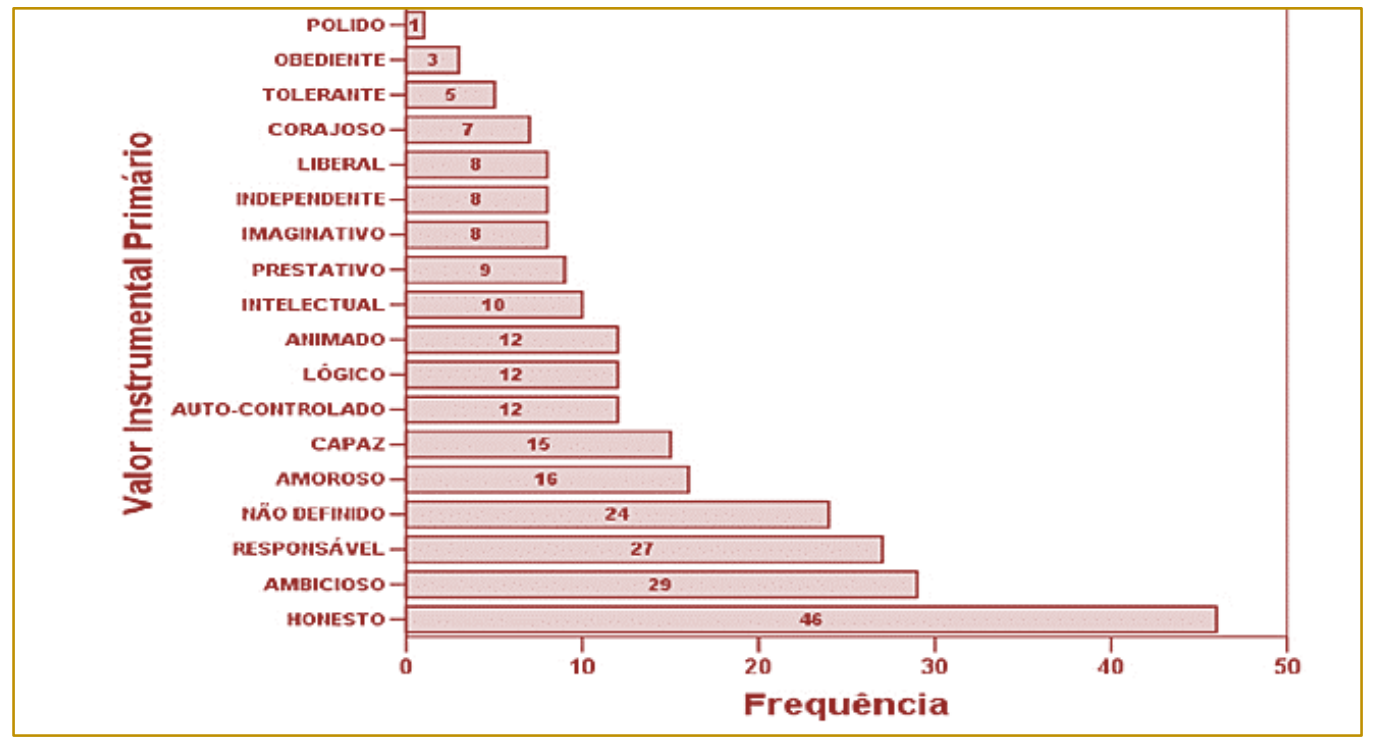

Fonte: Elaborado pelos autores. 
Figura 4: Valor instrumental secundário obtido para a amostra estudada

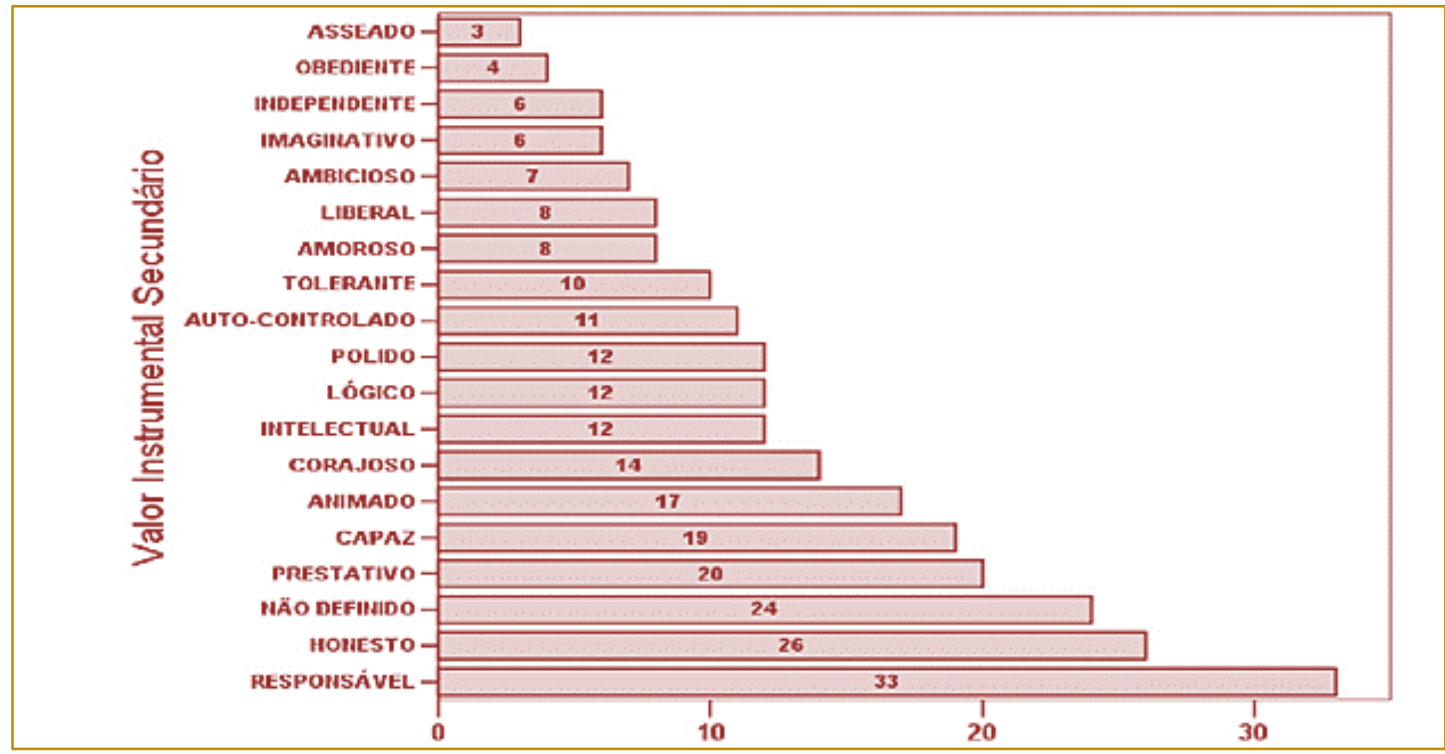

Fonte: Elaborado pelos autores.

\subsubsection{INFLUÊNCIAS DO PERFIL DO} RESPONDENTE NO SISTEMA DE VALORES

Nas tabelas 1 e 2 são apresentados os resultados de contingência entre os valores instrumentais e terminais e o perfil do participante. A Tabela 1 expõe a contingência entre o valor terminal primário e a idade, sendo possível verificar que, no nível de significância de 5\%, não houve associação entre o valor terminal primário e a idade, de modo que não foi afirmada a hipótese $1 b$. Na Tabela 2 é apresentada a contingência entre o valor instrumental primário e a idade, bem como o resultado do teste de qui-quadrado. Verifica-se que, no nível de significância de $5 \%$, não há associação entre o valor instrumental primário e a idade, de modo que a hipótese $1 c$ não foi validada.

Tabela 1: Análise de contingência entre o valor terminal primário e a idade

\begin{tabular}{llll|}
\hline Valor Terminal & \multicolumn{2}{c}{ Idade } & Total \\
& Até 25 anos & Mais de 25 anos \\
\hline Felicidade & 45 & 1 & 46 \\
Segurança Familiar & 20 & 4 & 24 \\
Vida Confortável & 41 & 2 & 43 \\
Vida Excitante & 14 & 1 & 15 \\
Outros & 93 & 5 & 98 \\
TOTAL & 213 & 13 & 226 \\
\hline qui-quadrado $=6,56$ & & \\
valor-p $=0,16$ & & & \\
\hline
\end{tabular}


Tabela 2: Análise de contingência entre o valor instrumental primário e a idade

\begin{tabular}{|llll|}
\hline Valor Instrumental & \multicolumn{2}{c|}{ Idade } & Total \\
& Até 25 anos & Mais de 25 anos & \\
\hline Ambicioso & 29 & 0 & 29 \\
Amoroso & 15 & 1 & 16 \\
Capaz & 12 & 2 & 14 \\
Honesto & 42 & 4 & 46 \\
Responsável & 25 & 2 & 27 \\
Outros & 90 & 5 & 95 \\
TOTAL & 213 & 14 & 227 \\
\hline qui-quadrado $=3,22$ & & & \\
valor- $p=0,52$ & & & \\
\end{tabular}

Fonte: Elaborado pelos autores

A ausência de correlação estatisticamente significativa entre a idade e os valores do indivíduo, mesmo com indivíduos em um curso de Engenharia, permite inferir que a Geração Y apresenta características bem definidas, permitindo uma extrapolação dos resultados no âmbito qualitativo. Essa constatação pode ser comprovada por estudos anteriores que obtiveram resultados semelhantes ao presente trabalho, embora a amostra não contemplasse apenas futuros engenheiros da Geração Y. Nesse estudo, não foi desenvolvida a análise de relação entre o gênero e os valores, uma vez que o enfoque do trabalho era pautado na Geração Y sem distinção.

\subsection{ANÁLISE DESCRITIVA DAS ÂNCORAS DE CARREIRA E A INFLUÊNCIA DO PERFIL DO RESPONDENTE}

No âmbito de âncoras de carreira, a Figura 5 indica que 46 respondentes (18\%) tinham o estilo de vida (EV) como fator de ancoramento de sua carreira, enquanto para $16 \%$ (40 sujeitos) a segurança e estabilidade (SE) foi a âncora principal, permitindo-se inferir sobre a importância atribuída à qualidade de vida e ao sentimento de prazer naquilo que atuam, associado à estabilidade no emprego, corroborando estudos anteriores com outras classes de indivíduos pertencentes à Geração Y (HENSEN; LEUTY, 2012; SILVA; MENDONÇA; ZANINE, 2010; CRAMPTON; HODGE, 2009). Vale ressaltar que a valorização da estabilidade no emprego é um fator que aproxima essa geração das anteriores e, hoje, a empregabilidade já pode ser considerada um novo alvo profissional (MARTINS, 2001).
De fato, a instabilidade do mercado de trabalho tem estimulado a busca dos jovens por organizações que ofereçam estabilidade, planos de carreiras definidos, efetivas oportunidades de ascensão e bons salários associado a um equilíbrio entre vida profissional e vida pessoal (CAVAZOTTE, LEMOS; VIANA, 2012). Esse cenário acaba por exigir dos jovens profissionais que adquiram habilidades de gerenciamento da própria carreira profissional, a fim de alcançarem os resultados almejados.

A gerência geral (GG), que se encontra na terceira posição no presente estudo com maior número de indivíduos ancorados (11\%), é uma das competências de maior valorização no mundo empresarial e está associada às tendências do mercado de trabalho, com enfoque na visão de solucionar problemas e na tomada de decisão em situações de incerteza. Lemos e Pinto (2008) afirmam que as organizações, no momento do recrutamento, priorizam os aspectos comportamentais em detrimento dos conhecimentos técnico-científico dos jovens. A relevância da gerência como âncora de carreira, bem como sua importância em um mercado mutável e dinâmico, possibilita repensar na necessidade de superação de currículos tradicionais nos cursos de graduação de base tecnológica, bem como no estímulo de um aluno que é ativo na construção do seu próprio conhecimento (LABURÚ; BARROS; SILVA, 2011).

Essa constatação pode ser corroborada pelo baixo predomínio da âncora de carreira técnico-funcional (TF - 7\%), demonstrando que esta geração está buscando novas perspectivas comportamentais e interpessoais que extrapolam a esfera técnica. Essa âncora, 
de fato, representa o que mais se aproxima dos ideais de carreira do passado recente, que tinham como premissas a estabilidade e um vínculo entre organização e funcionário (BALASSIANO, 2009).

A âncora autonomia e independência (AI) foi identificada por $10 \%$ dos sujeitos da amostra, confirmando uma rejeição à rígida submissão ao controle pela organização e pelo ambiente profissional, em benefício da flexibilidade nas relações de trabalho (SCHEIN, 1993; CAVAZOTTE; LEMOS; VIANA, 2012). Conforme demonstrado no trabalho de Silva (2010), a autonomia almejada pela Geração Y estimula esses jovens a planejarem suas carreiras de modo independente da empresa nas quais atuam, embora procurem por estabilidade no trabalho, permitindo que ainda utilizem o know-how adquirido na organização para expandirem seus conhecimentos e linha de atuação futura no mercado, exibindo características de Carreiras Inteligentes (SILVA, 2010).

A âncora puro desafio (DP) representou 9\% dos respondentes e muitas vezes tem-se a associação entre desafio e prestígio, ilustrando que os respondentes entendem o enfretamento de desafio como um meio de ascensão profissional e conquista de prestígio e status no ambiente de trabalho.

A âncora, quando singular, com menor frequência foi a de serviço e dedicação a uma causa (SD), representando $5 \%$ do total de alunos que participaram do estudo, confirmado pela noção proteana de carreira, na qual a carreira profissional de hoje pode assumir diferentes formas, não apresentando apenas uma causa exclusiva (ECARD et al., 2016). Outro ponto de discussão, no tocante à importância de se dedicar a uma causa, se faz interessante por meio da comparação entre os resultados obtidos por brasileiros e estrangeiros no trabalho de Papavasileiou e Lyons (2015), que constataram uma adesão maior de jovens da Geração $Y$ de outras nacionalidades ao combate de injustiça social e à vontade de mudar o mundo, ilustrando que estrangeiros estão mais propensos a se motivarem frente a causas sociais.

No presente estudo, 42 respondentes (17\%) evidenciaram duas âncoras de carreira igualmente fortes, valendo a reflexão sobre o número de âncoras de carreira dominantes em um determinado indivíduo. Segundo Feldman e Bolino (1996), as âncoras podem ser analisadas de acordo com três dimensões específicas: talentos (Competência Técnica/Funcional, Competência de Gestão Global e Criatividade Empreendedora) motivos/necessidades

(Segurança/Estabilidade,

Autonomia/Independência e Modo de Vida) e valores (Serviço/Dedicação a uma Causa e Desafio Puro). Logo, os autores defendem que é possível que um indivíduo expresse afinidade por mais de uma âncora de carreira, uma vez que poderá apresentar uma âncora ao nível dos talentos, outra ao nível dos motivos/ necessidades e, por fim, uma ao nível dos valores.

Nesse sentido, percebe-se que indivíduos com carreira ancorada na criatividade empreendedora, associado à âncora de gerência geral (GC-CE), são os perfis de competência de maior valorização no discurso empresarial e compatíveis com as tendências do mercado de trabalho atual. Considerando um cenário cada vez mais dinâmico e complexo, com inovações aflorando a um ritmo crescente, Schein (1996) coloca que indivíduos ancorados em criatividade empreendedora certamente terão um aumento de oportunidades, devido a valorização de novas ideias. Vale destacar que a Comissão de Educação, Cultura e Esporte do Senado Federal aprovou o projeto de lei do Senado no 772/2015 de 2015 que inclui o estudo do empreendedorismo no currículo da educação básica, como também estabeleceu como finalidade da educação superior o estímulo ao empreendedorismo e à inovação (BRASIL, 2015).

A multiplicidade de âncoras de carreiras também foi observada em outros estudos (TAN; QUEK, 2001; RAMAKRISHNA; POTOSKY, 2003), destacando-se o trabalho de Martineau, Wils e Tremblay (2005) em cuja amostra de 900 engenheiros, $30.3 \%$ possuiam uma âncora de carreira dominante, demonstrando que $69.7 \%$ apresentavam âncoras de carreira múltiplas. 
Figura 5: Âncoras de carreira obtidas para a amostra estudada

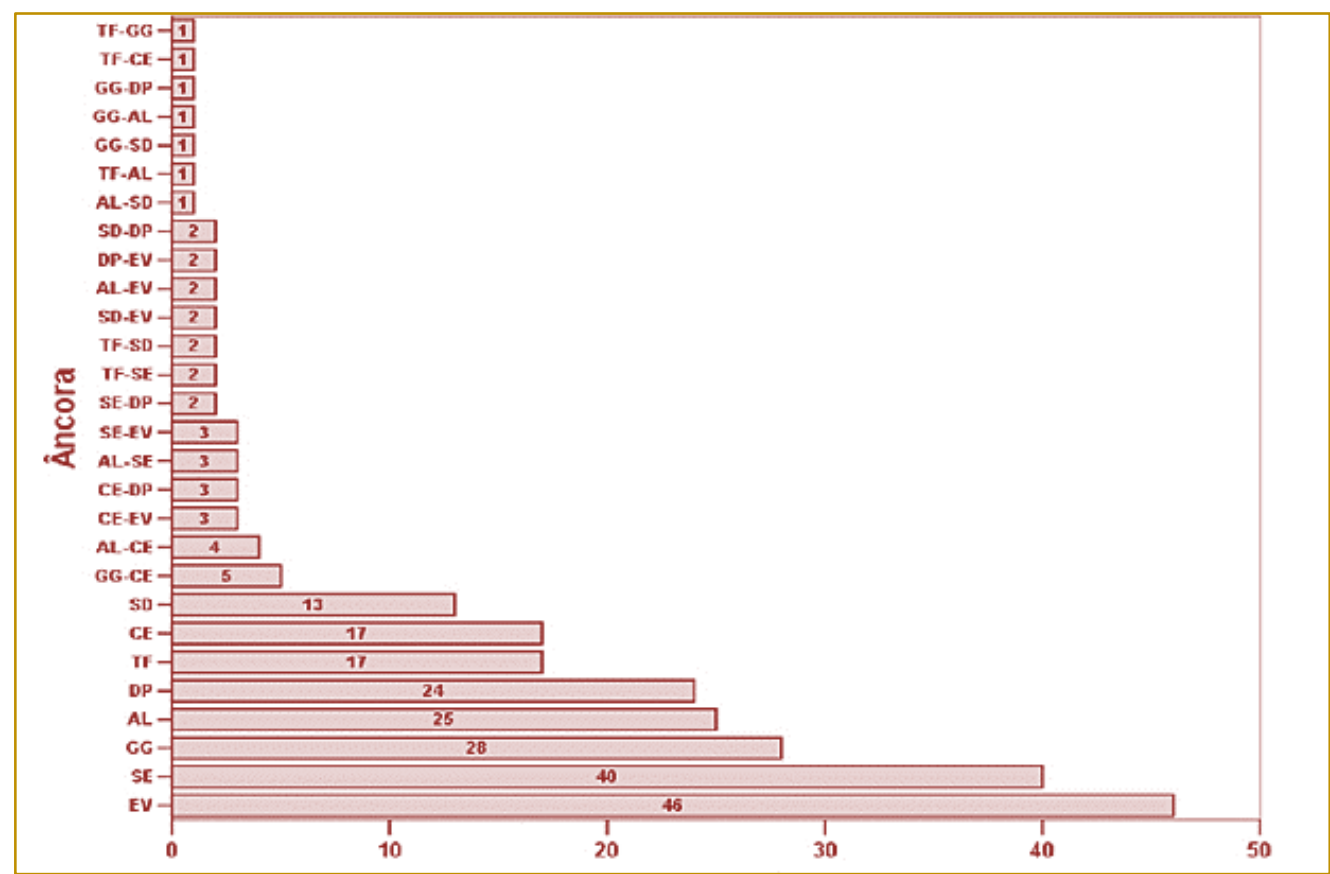

Fonte: Elaborado pelos autores.

A Tabela 3 apresenta a contingência entre a âncora de carreira e a idade, bem como resultado do teste de qui-quadrado. Por meio da análise da Tabela 3 verifica-se que, no nível de significância de 5\%, não há associação entre a âncora de carreira e a idade, refutando-se a hipótese $1 a$ e comprovando, novamente, a caracterização bem definida dessa geração. Nesse estudo, não foi desenvolvida a análise de relação entre o gênero e as âncoras de carreira, uma vez que o enfoque do trabalho era pautado na Geração Y sem distinção.

Tabela 3: Análise de contingência entre a âncora de carreira e a idade

\begin{tabular}{|c|c|c|c|}
\hline \multirow{2}{*}{ Valor Terminal } & \multicolumn{2}{|c|}{ Idade } & \multirow{2}{*}{ Total } \\
\hline & Até 25 anos & Mais de 25 anos & \\
\hline Autonomia e Independência - AI & 25 & 0 & 25 \\
\hline Criatividade Empreendedora - CE & 16 & 1 & 17 \\
\hline Puro Desafio - PD & 23 & 1 & 24 \\
\hline Estilo de Vida - EV & 42 & 4 & 46 \\
\hline Gerência Geral - GG & 27 & 1 & 28 \\
\hline Dedicação a uma causa - SD & 12 & 1 & 13 \\
\hline Segurança e Estabilidade - SE & 37 & 2 & 39 \\
\hline Aptidão Técnica e Funcional - TF & 14 & 3 & 17 \\
\hline Mais de uma Âncora & 37 & 4 & 41 \\
\hline TOTAL & 233 & 17 & 250 \\
\hline
\end{tabular}

Fonte: Elaborado pelos autores 


\subsection{CORRESPONDÊNCIA ENTRE OS VALORES PESSOAIS E AS ÂNCORAS DE CARREIRA}

Verifica-se, por meio da análise da Figura 6, a associação entre a âncora de carreira (para os alunos que possuem apenas uma âncora) e os valores terminais primários.

É possível notar que os sujeitos ancorados em gerência geral (GG) consideraram como valores importantes a liberdade e o mundo de beleza. Diferentemente, aqueles ancorados em autonomia e independência (Al) acreditam que o prazer é um valor importante. A igualdade é considerada um valor importante para os indivíduos com âncora em serviço e dedicação a uma causa (SD), enquanto que para estilo de vida (EV) como âncora de carreira a vida excitante e segurança familiar predominam. Os indivíduos que escolheram criatividade empreendedora (CE) como ponto de ancoragem de carreira atribuíram maior importância ao um mundo de paz; já a felicidade e uma vida confortável são valores importantes para os sujeitos com a carreira ancorada em segurança e estabilidade (SE). Aqueles com âncoras de puro desafio (PD) prezam pelo amor maduro e pela harmonia interior, sendo indivíduos ancorados em aptidão técnico-funcional (TF) também consideram a harmonia interior fundamental.

Apresenta-se, na Figura 7, a associação entre a âncora de carreira (para os alunos que possuem apenas uma âncora) e os valores instrumentais primários.

Figura 6: Análise de correspondência entre a âncora de carreira e o valor terminal

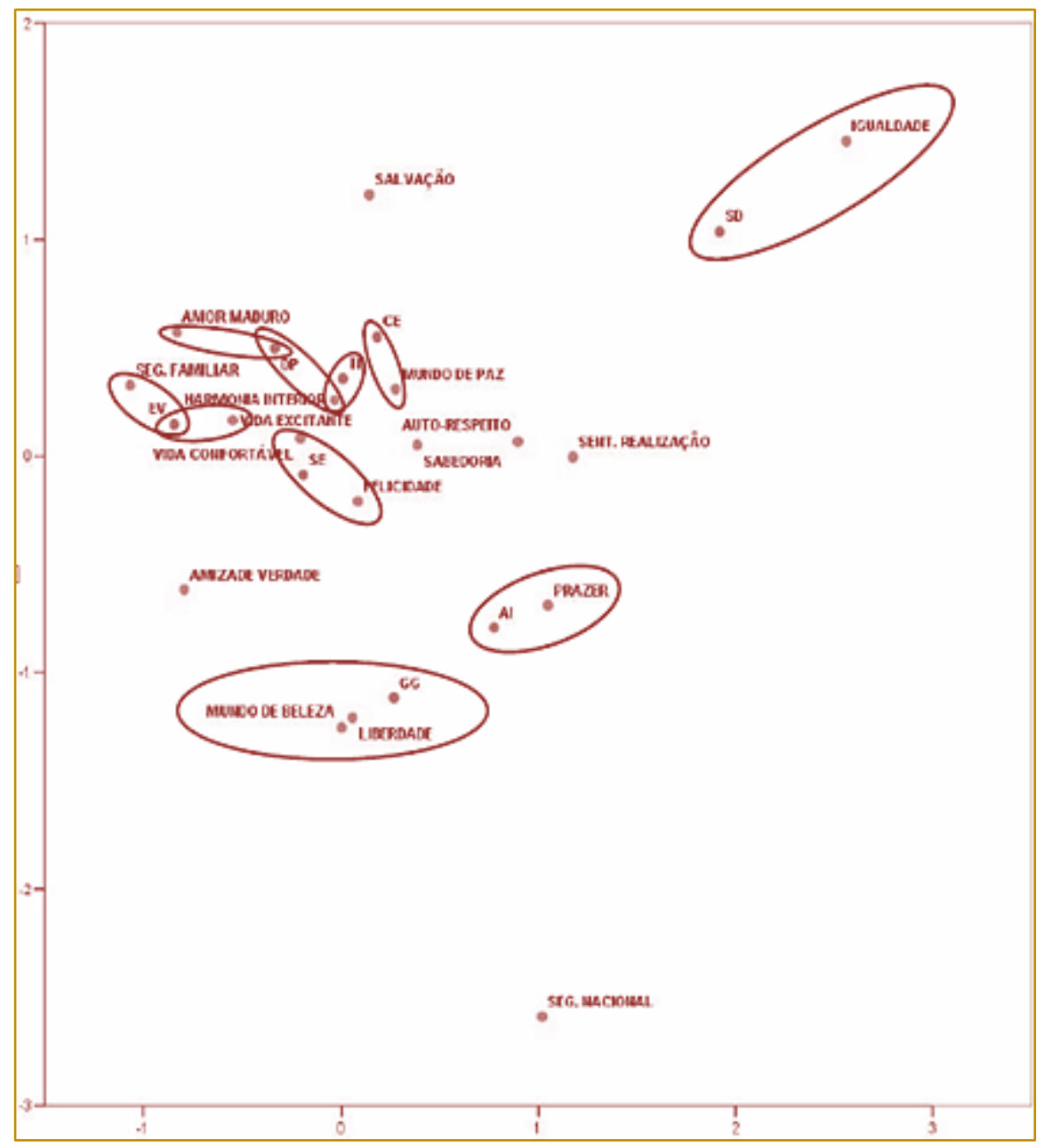

Fonte: Elaborado pelos autores 
Figura 7: Análise de correspondência entre a âncora de carreira e o valor instrumental

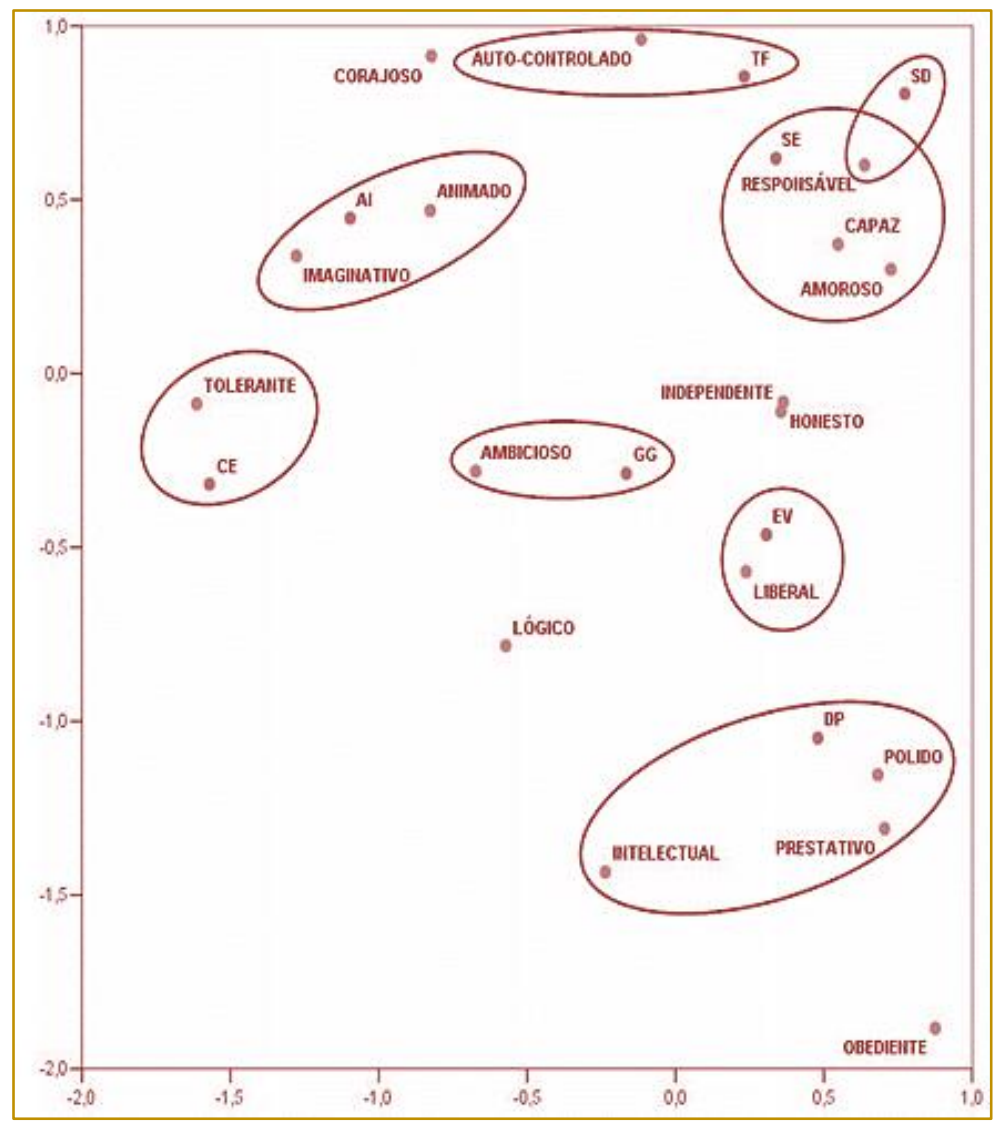

Fonte: Elaborado pelos autores (2016)

Os respondentes com âncora em puro desafio (PD) consideram importante a polidez, a prestatividade e a intelectualidade. O valor liberal é prezado por aqueles ancorados em estilo de vida (EV). A ambição é considerada o valor mais importante para os indivíduos com âncora em gerência geral (GG), enquanto para os indivíduos com âncora em criatividade empreendedora (CE), a tolerância é um valor fundamental. A imaginação e a animação destacam-se como valores para os indivíduos que possuem carreira ancorada em autonomia e independência (Al); em contrapartida, indivíduos vinculados com o ancoramento técnico-funcional (TF) prezam pelo autocontrole. A responsabilidade, a capacidade e o amor são importantes para os sujeitos que tem a carreira ancorada em segurança e estabilidade (SE), enquanto a âncora em serviço dedicado a uma causa está mais associado com o valor de responsabilidade.

Stackman, Pinder e Connor (2004) mostram a existência de um relacionamento aproximado entre os valores pessoais e as âncoras de carreira, dado que os valores são prioridades e necessidades pessoais que direcionam 0 comportamento, atitudes e escolhas.

Sob o exposto, de forma qualitativa, no presente estudo é possível constatar uma correspondência entre o tipo de âncora de carreira e os valores pessoais dos indivíduos, tanto valores terminais quanto valores instrumentais. De fato, segundo Abrahim (2008), indivíduos com carreira ancorada em gerência geral valorizam a liberdade, o reconhecimento social, a ambição e a independência, assumindo cargos altos e prezando pela admiração das outras pessoas. Nos indivíduos vinculados com 0 ancoramento em autonomia e independência, há um predomínio de realizar as coisas do seu modo, de acordo com ritmo e padrões próprios. Ademais, preferem optam por uma posição de trabalho que Ihes confira menores ganhos financeiros, mas que thes proporcionem mais autonomia e prazer de realização. Quando possui carreira ancorada no estilo de vida, os indivíduos buscam harmonizar a necessidade pessoal e familiar com a carreira profissional, priorizando a qualidade de vida (SCHEIN, 1993; Schein, 
1996). Indivíduos que estão ancorados em aptidão técnico-funcional, valorizam amizade verdadeira e, principalmente, o autocontrole, pois esses indivíduos gostam de trabalhar com bastante autonomia (Abrahim, 2008).

\section{CONCLUSÕES}

Constatou-se que a maioria dos indivíduos indivíduos pertencia à Geração $\mathrm{Y}$, apresentando valores e ancoramento de carreira compatíveis com o perfil dessa geração. Por meio das análises descritivas, foi possível mapear os valores terminais predominantes para os indivíduos, destacando a felicidade, a vida confortável e a segurança familiar. Complementarmente, os três valores instrumentais predominantes foram a honestidade, a ambição e a responsabilidade. Esses valores apontam que os futuros profissionais e líderes atribuem importância significativa à escolha de atividades prazerosas e interessantes como meio de obterem satisfação pessoal e sucesso em suas carreiras, alcançando uma almejada vida confortável. Ainda, a Geração Y prioriza organizações que the apresente um claro plano de carreira com efetiva oportunidade de desenvolvimento profissional, fundamentado na responsabilidade e ganhos por competência, além de almejarem a formação de uma sociedade ética e honesta.

As principais âncoras identificadas foram estilo de vida e segurança e estabilidade, o demonstrando a busca pela estabilidade da carreira tradicional e pelo equilíbrio das esferas pessoais e profissionais, primando pela integração das necessidades do trabalho com as necessidades individuais e familiares.

Análises inferenciais foram realizadas, comparando-se os valores terminais e instrumentais com a idade dos participantes. Contudo, não foi identificada associação entre esses parâmetros, indicando a existência de homogeneidade na amostra estudada, devido ao perfil bem delineado da Geração Y. De fato, foi observado que, embora se tratasse

\section{REFERÊNCIAS}

[1] Abrahim, G. S. O Papel dos Valores Pessoais nas Decisões de Carreira. Revista Contemporânea de Economia e Gestão, v. 6, n. 2, p. 35-44, 2008.

[2] Arthur, M. B.; Khapova, S. N.; Wilderom, C. P. M. Career Success in a Boundaryless Career de alunos de Engenharia, os valores e as âncoras de carreira identificados neste estudo apresentaram grande semelhança com trabalhos anteriores que utilizaram como amostra outras classes de indivíduos (inclusive, estrangeiros) pertencentes à mesma faixa etária, evidenciando que os valores pessoais e profissionais dos indivíduos da Geração Y muitas vez se sobressai em relação aos valores que poderiam ser peculiares a indivíduos de diferentes formações acadêmicas. Também não se constatou associação entre as âncoras e a idade; portanto as hipóteses formuladas não foram validadas no presente estudo.

A análise de correspondência mostrou interações interessantes entre os valores pessoais e as âncoras de carreira. Como exemplo, a âncora estilo de vida está associada aos valores de vida excitante e da segurança familiar, indo ao encontro ao desejo da âncora segurança e estabilidade, que foi a segunda mais frequente no estudo. Nesse caso, observa-se uma transposição do valor segurança para a carreira.

Percebe-se, assim, a importância de estudos no âmbito de âncoras de carreira, bem como a análise de correlação com valores terminais e instrumentais, a fim de delinear um melhor perfil de uma determinada geração, auxiliando os gestores a se atentarem aos valores, motivações e expectativas dos novos profissionais, além dos educadores a refletirem sobre componentes curriculares que atendam a este novo perfil de jovem.

Por fim, constatou-se a atual necessidade do jovem da Geração Y em saber administrar as transições em sua carreira e em sua vida, estimulando novos estudos na área. Cabe ainda o desenvolvimento de pesquisas futuras que possam aprofundar as correlações existentes entre os valores, as âncoras e o perfil dos participantes, englobando uma análise por gênero. Novos estudos podem ser feitos para atribuir a influência dos valores na inclinação profissional, utilizando-se um plano amostral maior que contemple o estudo com Geração Y de outras nacionalidades.

World. Journal of Organizational Behavior, v. 26, p. 177-202, 2005.

[3] Barbosa, L. (org.) Juventudes e Geração no Brasil Contemporâneo. Porto Alegre: Sulina, 2012.

[4] Brasil. Projeto de Lei do Senado no 772, de 2015. Brasília, 2015. 
[5] Bruni, A. L. SPSS aplicado à pesquisa acadêmica. São Paulo: Atlas, 2009.

[6] Carneiro, N. A. Turismo de Negócios e a Geração Y no Cenário de Eventos Empresariais. Dissertação (Mestrado em Hospitalidade), Universidade Anhembi Morumbi, São Paulo: Anhembi Morumbi, 2010.

[7] Cavazotte, F. S. C. N.; Lemos, A. H. C.; Viana, M. D. A. Novas gerações no mercado de trabalho: expectativas renovadas ou antigos ideais? Cadernos Ebape.BR, v. 10, n. 1, p. 162180, 2012

[8] Crampton, S. M.; Hodge, J. W. Generation Y: Unchartered Territory. Journal of Business \& Economics Research, v. 7, n. 4, 2009.

[9] Ecard, D. B. T; Souza-Silva, J. C.; Paixão, R. B.; Chiappa, D. S.A Contribuição do Processo de Life Coaching no Desenvolvimento das Carreiras dos Coachees. Rev. Ciênc. Admin., Fortaleza, v. 22, n. 2, p. 507-541, 2016.

[10] Feldman, D.; Bolino, M. Careers within careers: Reconceptualizing the nature of career anchors and their consequences. Human Resource Management Review, v. 6, n. 2, p. 89-112, 1996.

[11] Ferraz, I.; Galli, D.; Trevisan, L. Âncoras de Carreira: uma questão de gênero? Revista de Administração em Diálogo, v.2, n. 11, p. 90-117, 2008

[12] Gastaldello, A. T. A Influência de Valores Pessoais de Executivos Brasileiros e Argentinos em Negociações Comerciais. Dissertação (Mestrado em Administração), Universidade Federal do Rio Grande do Sul, Porto Alegre: UFRGS, 1999.

[13] Gervazio, F. V. et al. Dimensões de Valores Pessoais Instrumentais e Terminais: um Estudo Comparativo entre Brasil e Tailândia. Faces: Revista de Administração (Belo Horizonte. Online), v. 15, p. 97-117, 2016.

[14] Gouveia, V. V. et al. A estrutura e o conteúdo universais dos valores humanos: análise fatorial confirmatória da tipologia de Schwartz. Estudos de Psicologia (Natal), v., n. 2, p. 133-142, 2001.

[15] Hall, D. T.; MIRVIS, P. H. Careers as Lifelong Learning, in The Changing Nature of Word. San Francisco: Jossey Bass, 1995.

[16] Hall, D. T. The career is dead, long live the career: A relational approach to careers. San Francisco: Jossey-Bass, 1996.

[17] Hansen, J.; Leuty, M. Work values across generations. Journal of Career Assessment, v. 20, n. 1, p. 34-52, 2012.

[18] Kluckhohn, C. Los valores y las orientaciones de valor em la teoria de la acción. In Parsons, T.; Shils, E. A. (Orgs.). Hacia una teoría general de la acción, p. 435-485. Buenos Aires: Exdfditorial Kapelusz, 1951.
[19] Kupperschmidt, B. R. Multigeneration Employees: strategies for effective management. The Health Care Manager, v. 19, n. 1, p. 65-76, 2000.

[20] Laburú, C. E.; Barros, M. A. ; Silva, O. H. M. Da. Multimodos e múltiplas representações, aprendizagem significativa e subjetividade: três referenciais conciliáveis da educação científica. Ciência e Educação (UNESP. Impresso), v. 17, p. 469-487, 2011.

[21] Lemos, A. H. C. Juventude, Gerações e Trabalho: ampliando o debate. Cadernos Ebape, v. 19, n. 63, p. 739-743, 2012.

[22] Lemos, A. H. C.; Pinto, M. C. S. Empregabilidade dos administradores: quais os perfis profissionais demandados pelas empresas? Cadernos Ebape, v. 6, n. 4, 2008.

[23] LISSITSA, S.; KOL, O. Generation X vs. Generation $Y-A$ decade of online shopping. Journal of Retailing and Consumer Services, v. 31, p. 304-312, 2016.

[24] Martineau, Y.; WILS, T.; Tremblay, M. La multiplicité des ancres de carrière chez les ingénieurs québécois: Impacts sur les cheminements et le succès. Relations Industrielles, v. 60, n. 3, p. 455-482, 2005.

[25] Martins, H. T. Gestão de carreiras na era do conhecimento: abordagem conceitual \& resultados de pesquisa. Rio de Janeiro: Qualitymark. Ed., 2001.

[26] Mccrindle, M. Understanding Generation Y. Austrália: The Australian Leadership Foundation, 2002

[27] Mcdaniels, C.; Gysbers, N. C. Counseling for Career Development: Theories, Resources and Practice. San Francisco: Jossey Bass, 1992

[28] Munhoz, I. P. et al. Âncoras de Carreira um estudo de campo com os alunos de engenharia. Interfaces Científicas - Humanas e Sociais, v. 3, p. 81-92, 2014.

[29] Oit. Organização Internacional do Trabalho. World Employment and Social Outlook 2016. Geneva: International Labour Office, 2016.

[30] Papavasileiou, E. F.; Lyons, S. T. A comparative analysis of the work values of Greece's Millennial generation. International Journal of Human Resource Management, v. 26, p. 2166-2186, 2015.

[31] Ramakrishna, H. V.; Potosky, D. Conceptualization and exploration of composite career anchors: An analysis of information systems personnel. Human Resource Development Quarterly, v. 14, n. 2, p. 199-214, 2003.

[32] Robbins, S. P. Comportamento Organizacional. Rio de Janeiro: Prentice Hall, 1998.

[33] Rokeach, M. The nature of human values. New York: Free Press, 1973. 
[34] Rokeach, M. Crenças, Atitudes e Valores: uma teoria de organização e mudança. Rio de Janeiro: Interciência, 1981.

[35] Rugimbana, R. Generation Y: How cultural values can be used to predict their choice of electronic financial services. Journal of Financial Services Marketing, v. 11, n. 4, p. 301-313, 2007.

[36] Santos, N. M. B. F.; Munhoz, I. P. ; Lelis, J. W. F. . Valores Individuais: Uma Pesquisa com o Corpo Discente da Área de Engenharia. Interfaces Científicas - Humanas e Sociais, v. 1, p. 57-79, 2013

[37] Schein, E. H. Career Anchors: discovering your real values. San Diego: Pfeiffer \& Company, 1993.

[38] Schein, E. H. Identidade Profissional: como ajustar suas inclinações a suas opções de trabalho. São Paulo: Nobel, 1996.

[39] Schwartz, B.; Lacey, H. A. Formação e a Transformação de Valores. Revista da Faculdade de Psicologia da PUC-SP, v. 1, p. 91-123, 1995.

[40] Schwartz, S. H.; Bardi, A. Value hierarchies across cultures: Taking a similarities perspective. Journal of Cross-Cultural Psychology, v. 32, n. 2 , p. 268-290, 2001

[41] Schwartz, S. H. Valores Humanos Básicos: seu contexto e estrutura intercultural. In: A. Tamayo, A.; Porto, J. B. (Orgs). Valores e Comportamento nas Organizações. Petrópolis: Vozes, 2005.

[42] Sennett, R. A Corrosão do Caráter: as consequências pessoais do trabalho no novo capitalismo. Rio de Janeiro: Record, 2006.

[43] Shirish, A.; Boughzala, I.; Srivastava, S. C. Adaptive use of social networking applications in contemporary organizations: Examining the motivations of Gen Y cohorts. International Journal of Information Management, v. 36, p. 1111-1123, 2016.

[44] Silva, J. R. da. Processos Pessoais de Carreiras: uma análise com

[45] servidores públicos do Estado do Espírito Santo. 2010. 124 f. Dissertação (Mestrado

[46] em Administração de Empresas) Fundação Instituto Capixaba de Pesquisas em

[47] Contabilidade, Economia e Finanças, Vitória: FUCAPE, 2010.

[48] Silva, M. R. M. S.; Mendonça, H..; Zanine, D. S. Diferenças de gênero e valores relativos ao trabalho. Paideia. v. 20, n. 45, p. 39-45, 2010.

[49] Stackman, R. W.; Pinder, C. C.; Connor, P. $E$. Values Lost: redirecting research on values in the workplace. In: Ashkanasy, N. M.; Wilderom, C. P. M.; Peterson, M. F. Handbook of Organizational Culture and Climate, p. 37-54. Thousand Oaks: Sage, 2004

[50] Tan, H. H.; Quek, B. C. An exploratory study on the career anchors of educators in Singapore. Journal of Psychology, v. 135, n. 5, p. 527-545, 2001.

[51] Tulgan, B. Not Everyone Gets a Trophy: how to manage generation $Y$. San Francisco: Jossey-Bass, 2009.

[52] Twenge, J. M.; Campbell, W. K.; Freeman, E. C. Generational differences in young adults'life goals, concern for others, and civic orientation, 1966-

2009. Journal of Personality and Social

Psychology, v. 102,p. 1045-1062, 2012.

[53] Vergara, S. C. Projetos e Relatórios de Pesquisa em Administração. (9 ed). São Paulo: Atlas, 2007. 


\section{Bapítulo 11}

\section{ESTRATEGIAS DE TRANSFERENCIA DE CONHECIMENTO EM PROJETOS: UM ESTUDO COM GERENTES DE PROJETOS}

\section{Neusa Maria Bastos Fernandes dos Santos Nelson José Rosamilha}

Resumo:Num cenário de rápida mudança do ambiente de negócios, as empresas buscam aumento de produtividade e manutenção da competividade. As organizações que aumentarem seus conhecimentos estarão melhor preparadas e esse recurso estratégico, quando corretamente gerenciado, permite criar valor pela exploração da produção, cenário em que os projetos são o mecanismo de entrega de produtos e serviços e o maior desafio de negócios. Os projetos utilizam trabalhadores do conhecimento que se beneficiam do conhecimento acumulado e aprendem com outros projetos. A transferência de conhecimento passa a ter papel importante na integração do conhecimento para a entrega de produtos e serviços. Este estudo, resultado de uma dissertação de mestrado, é uma pesquisa quantitativa cujo objetivo é identificar essas práticas de transferência de conhecimento e se são aplicáveis em gerenciamento de projetos. Para isso, foi realizado um levantamento teórico, identificando as práticas de transferência de conhecimento e, posteriormente, um questionário aplicado à comunidade de gerenciamento de projetos para saber se essas práticas poderiam ser aplicadas na transferência de conhecimento em gerenciamento de projetos. Obteve-se 365 respostas válidas, categorizadas nos grupos Comunicação, Técnica, Liderança, Ferramenta, Procedimento e Cultura e, por meio de análises de estatísticas descritivas, identificou-se 22 práticas de transferência de conhecimento.

Palavras-chave: Transferência de Conhecimento; Gerenciamento de Projetos; Gestão do Conhecimento; Compartilhamento de Conhecimento; Disseminação do Conhecimento 


\section{INTRODUÇÃO}

O ambiente de negócios muda rapidamente em um contexto em que o conhecimento e gestão do conhecimento têm papel crítico no aumento da produtividade e na manutenção da competitividade das empresas (BRADSHAW; PULAKANAM; CRAGG, 2015). As organizações que aumentarem seus conhecimentos estarão melhor preparadas para enfrentar as incertezas do ambiente organizacional, dinâmica do mercado, ciclos econômicos e se manterão competitivas e sustentáveis (ALMEIDA; SOARES, 2014). Nesse cenário, o conhecimento é o recurso mais importante na organização e a vantagem competitiva mais duradoura (BRADSHAW; PULAKANAM; CRAGG, 2015), ele é considerado um recurso estratégico que, quando corretamente gerenciado, permite às organizações criar valor pela exploração da produção (DEEDS; MARIE DECAROLIS, 1999). Em virtude da relevância do compartilhamento de conhecimento, as organizações se esforçam em criar condições para que os funcionários compartilhem seus conhecimentos (REYCHAV; WEISBERG, 2010), e a habilidade de compartilhar este conhecimento é positivamente associada ao desempenho organizacional superior (MUELLER, 2014). Os projetos se tornaram o veículo de entrega mais importante para produtos e serviços em uma economia caracterizada por uma forte concorrência, com ciclos de vida cada vez mais reduzidos (JACKSON; KLOBAS, 2008) e são apontados frequentemente como o maior desafio de negócios das organizações. O Project Management Institute (PMI) é uma entidade de gestão de projetos com cerca de 470 mil associados (ANDERSON; GREENBERG, 2017, p. 4), cuja missão é impulsionar e desenvolver a carreira de gestão de projetos pelo mundo e divulgar as melhores práticas de gerenciamento de projetos. Em relatório publicado pelo PMI em 2015, cujo título é "Capturando o valor do gerenciamento de projetos" (PMI, 2015), concluiu-se que um processo formal de transferência de conhecimento aumenta consideravelmente as chances de entrega do projeto (PMI, 2015, p. 11). De acordo com esse relatório:

a) $75 \%$ das empresas de alto desempenho que completam $80 \%$ ou mais dos projetos no prazo, atingindo o orçamento e objetivos previstos, possuem um processo formal de transferência de conhecimento; b) Somente 35\% das empresas de baixo desempenho possuem um processo formal de transferência de conhecimento; estas completam apenas $60 \%$ de seus projetos no prazo e possuem orçamento e objetivos alcançados;

c) Organizações mais efetivas em transferência de conhecimento melhoram os resultados dos projetos em 35\%;

d) A transferência de conhecimento é uma ferramenta de aprendizagem que pode fortalecer o desempenho da equipe, enfatizando a colaboração e a inovação (PMI, 2015, p. 13).

As organizações usam cada vez mais equipes de trabalhadores do conhecimento para realizar projetos e acreditam que elas podem se beneficiar do conhecimento acumulado e aprender com outros projetos (ZHAO; ZUO; DENG, 2015). Devido à volatilidade dos projetos, eles se tornaram um problema informacional interessante: são configurações transitórias, na maioria das vezes utilizando recursos distribuídos, parcial ou totalmente virtualizados em relação à interação, e intensiva utilização de fluxos de informação com grandes quantidades de conteúdo para ser gerenciado (ALMEIDA; SOARES, 2014). Em uma equipe de projeto, o compartilhamento de conhecimento é muito importante porque:

a) Fornece uma ligação entre o membro e a equipe do projeto, reduz os custos e aumenta o desempenho da equipe (JAFARI NAVIMIPOUR; CHARBAND, 2016);

b) Aumenta consideravelmente as chances de entrega do projeto (PMI, 2015, p. 14);

c) As interações e comunicações que ocorrem entre os membros incrementam a capacidade do time em desenvolver novos conhecimentos dentro da própria equipe, que são cruciais para o sucesso do projeto (BARTSCH; EBERS; MAURER, 2013).

Zhao, Zuo e Deng (2015) relataram que as equipes de projetos enfrentam pressões de prazo rigorosos para completar suas atividades e efetuar suas entregas de projetos, tornando-os fortemente focados; como consequência, a equipe se concentra 
mais nas tarefas para entregar o projeto do que na transferência de conhecimento, acarretando falta de aprendizado em outros projetos que poderiam usufruir dessa experiência. Sem uma partilha eficaz de conhecimento, as organizações podem não integrar os conhecimentos críticos, as competências e as capacidades dos especialistas para realizar 0 trabalho complexo (ZHANG; PABLOS; ZHOU, 2013). Uma vez terminado o projeto, o conhecimento criado deve ser transferido para a organização como um todo, com a finalidade de aprendizagem organizacional e contribuir, dessa maneira, para uma base de conhecimento comum entre os projetos (ALMEIDA; SOARES, 2014). Almeida e Soares (2014) enfatizam particularmente que a gestão do conhecimento e a transferência de conhecimento na literatura de gestão de projetos é um campo de pesquisa que terá grande atenção nos próximos anos. Goyette e outros (2015) discorrem sobre a necessidade da existência de um mecanismo formal de transferência de conhecimento para servir como base de conhecimento para projetos futuros. Jafari Navimipuor e Charband (2016) concluíram que estudos antecedentes ao trabalho deles são raros e as práticas de transferência de conhecimento e pesquisas sobre o tema continuam sendo desafiadas quanto à capacidade efetiva de alcançar resultados eficazes (WIEWIORA et al., 2014). Quando aplicadas efetivamente na organização, elas melhoram o desempenho dos projetos, como apresentado pelo relatório "Capturando o Valor do Gerenciamento de Projetos" (PMI, 2015), situação em que as empresas que adotam práticas de transferência de conhecimento têm $70 \%$ dos objetivos de negócio atingidos contra 57\% das que não adotam, 59\% das empresas terminam o projeto no prazo contra $41 \%$ e, por fim, $62 \%$ finalizam os projetos dentro do orçamento contra $48 \%$. O desafio é identificar as práticas de transferência de conhecimento, que podem transmitir introspecções e conhecimentos valiosos de um projeto para outro, independentemente de onde os profissionais residem (PMI, 2015, p. 14). A finalidade deste artigo é, por meio da pesquisa da literatura, identificar as melhores práticas de transferência de conhecimento, aplicar um questionário de pesquisa junto à comunidade de gerenciamento de projetos e verificar a aplicabilidade dessas práticas em gerenciamento de projetos.

\section{O REFERENCIAL TEÓRICO}

Projeto é definido como um esforço com início e fim bem definidos, realizado para criar um produto, serviço ou resultado exclusivo (PMI, 2013, p. 3a). Um projeto pode ser dividido em fases, isto é, um conjunto de atividades logicamente relacionadas cujo objetivo, ao seu término, é entregar parte do trabalho do projeto que pertence a uma entrega principal do projeto, facilitando, assim, o planejamento e controle (PMI, 2013, p. 40). Essas fases de projetos possuem algumas características em comum (PMI, 2013, p. 40):

a) o trabalho realizado tem um foco distinto que difere de qualquer outra fase. Isso geralmente envolve diferentes organizações, locais e conjuntos de habilidades;

b) atingir a principal entrega ou objetivo da fase requer controles ou processos exclusivos para a fase ou suas atividades;

c) o encerramento de uma fase termina com alguma forma de transferência ou transferência do produto do trabalho produzido como produto de fase.

Para que os objetivos de um projeto sejam atingidos, ele deve ser gerenciado. O gerenciamento de projetos é a aplicação de conhecimentos, habilidades e técnicas para atingir os requisitos do projeto (PMI, 2013, p. $5)$ e é executado pelo gerente de projetos, que é a pessoa autorizada pela organização que irá liderar a equipe do projeto (PMI, 2015b, p. 8).

A equipe de projeto é geralmente composta por membros de diferentes áreas funcionais que atuam juntos para compartilhar seu conhecimento para atingir os resultados do projeto (MEHTA; HALL; BYRD, 2014); eles diferem de outras equipes pela natureza não repetitiva de suas tarefas. A aplicação de conhecimento pelo gerente de projetos requer a gestão efetiva dos processos de gerenciamento de projetos. O guia PMBOK 5 Ed (PMI, 2013, p. 46) estabelece que, para que um projeto tenha sucesso, o gerente de projetos junto com sua equipe devem selecionar os processos adequados para atingir os objetivos do projeto, definir uma abordagem que possa ser adaptada para atender aos requisitos do projeto, cumprir os requisitos para atingir as expectativas dos interessados do projeto e balancear as 
restrições de escopo, prazo, orçamento, qualidade, riscos e recursos para produzir o produto, serviço ou resultado esperado do projeto. O gerente de projetos e sua equipe devem cuidadosamente endereçar cada processo, suas entradas e saídas, os quais são aplicados no projeto em que estão atuando (PMI, 2013, p. 48). Ao longo do ciclo de vida do projeto, uma quantidade significativa de dados e informações é coletada, analisada, transformada e distribuída em vários formatos para os membros da equipe do projeto e outras partes interessadas (PMI, 2013, p. 58) e, durante o ciclo de vida do projeto, as informações são intercambiadas entre $\mathrm{o}$ projeto e a organização.

\subsection{GESTÃO DO CONHECIMENTO}

Conhecimento pode ser definido como a capacidade individual de encontrar interpretações e significados, levando uma ação a criar valor para a organização (NONAKA; TAKEUCHI, 1995). Segundo os autores, ele é um patrimônio fundamental para as empresas, ao invés da fábrica ou equipamento (TAKEUCHI; NONAKA, 2008, p. 166) e pode ser explícito ou tácito; o explícito é articulado em linguagem formal e é fácil de codificar, transferir ou armazenar, enquanto o tácito é pessoal e difícil de codificar porque ele é esculpido nas ações, procedimentos, rotinas, valores e emoções dos indivíduos envolvidos. O processo de capturar a experiência coletiva da organização de diferentes fontes (pessoas, banco de dados, documentos etc.) e utilizar essa base de conhecimento para desenvolver a organização é chamado Gestão do Conhecimento e é composto por subcomponentes (GOYETTE et al., 2015), esclarecidos pelo modelo de quatro fases (SEDERA; GABLE, 2010), como exposto a seguir.

1. Criação de conhecimento: engloba tudo o que está relacionado ao processo de criação do conhecimento obtido através de recursos internos ou especialistas externos.

2. Retenção do conhecimento: consiste em manter o conhecimento em uma forma referencial para permitir que esse conhecimento dure ao longo do tempo.

3. Transferência de conhecimento: implica o uso de canais informais e formais para permitir a distribuição de conhecimento dentro de uma organização.

4. Aplicação do conhecimento: é o uso do conhecimento por um ou mais indivíduos que receberam o conhecimento durante a transferência.

Nonaka e Takeuchi (1995) propuseram o modelo SECl unificado de criação e transferência de conhecimento organizacional e argumentaram que o conhecimento é criado por meio da interação e intersecção entre conhecimento tácito e explícito, interações que ocorrem ao longo de quatro estágios:

1. socialização é o processo de converter o novo conhecimento tácito na base existente de conhecimento tácito. É o processo de compartilhamento de experimentos, por meio do qual a pessoa adquire conhecimento tácitos diretamente dos demais, o fundamento para a aquisição deste conhecimento é a experiência compartilhada (TAKEUCHI; NONAKA, 2008, p. 60);

2. externalização é o processo de articulação do conhecimento tácito no conhecimento explícito. É o processo de conexão do conhecimento tácito tornando-se explícito através de imagens, comparações, figuras, símbolos ou modelos, promovendo a reflexão entre as pessoas e transformando o conhecimento tácito em articulável (TAKEUCHI; NONAKA, 2008, p. 61);

3. Combinação é o processo de conversão do conhecimento explícito em conjuntos mais complexos e sistêmicos de conhecimento explícito. As pessoas trocam e substituem conhecimento explícito podendo levar a novo conhecimento (TAKEUCHI; NONAKA, 2008, p. 66);

4. Internalização é o processo de incorporar o conhecimento explícito no conhecimento tácito. Quando as experimentações de Socialização, Experimentação e Combinação são adotadas de modo inconsciente (aprender fazendo) na base de conhecimento tácito do indivíduo (TAKEUCHI; NONAKA, 2008, p. 67).

A relação contínua entre conhecimento tácito e explícito, por meio dos diferentes modos de conversão de conhecimento entre os indivíduos da organização, desencadeia o 
conhecimento organizacional e, quando o conhecimento tácito e o explícito agem mutualmente, emerge uma inovação que, no modelo SECI, de Takeuchi e Nonaka (2008), é chamada de espiral do conhecimento. A utilização conjunta dos processos de socialização, externalização, combinação e internalização com a intenção de criar, capturar, armazenar e aplicar os conhecimentos cruciais para a organização é definida como gestão do conhecimento (TAKEUCHI; NONAKA, 2008) e tem como preceito a recuperação, o compartilhamento, a utilização e a assimilação do conhecimento presentes na organização, os processos de construção e gestão do conhecimento no contexto organizacional é uma tarefa complexa (JORGE; FALÉCO, 2016).

\subsection{IMPORTÂNCIA DA TRANSFERÊNCIA DE CONHECIMENTO EM GERENCIAMENTO DE PROJETOS}

Kirsch e King (2005) e Szulanski (1996) veem a transferência de conhecimento como dois subprocessos - enviar conhecimento e receber conhecimento - durante os quais a fonte comunica conhecimento com 0 destinatário. Argote e Ingram (2000) destacam a consequência do processo e as diferenças nos contextos ao examinar a transferência de conhecimento, em que a unidade de uma organização, como grupo ou departamento, é afetada pela experiência do outro. Goyette e outros (2015) adicionam que há também atividades de comunicação de transferência de conhecimento entre um projeto de origem para um projeto de destino, de modo que o conhecimento útil seja absorvido e reutilizado pelo projeto de destino. Zhao, Zuo e Deng (2015) acrescentam que a dissolução dos membros da equipe após a conclusão do projeto pode aumentar o risco de perda de conhecimento. Segundo Almeida e Soares (2014), uma vez que um projeto termine, o conhecimento criado deve ser transferido para a organização como um todo, com a finalidade de aprendizagem organizacional, e contribuir dessa maneira para uma base de conhecimento comum. Para ocorrer esse compartilhamento de conhecimento, diversos mecanismos de transferência de conhecimento podem ser utilizados.

Goyette e outros (2015) elucidam que a transferência de conhecimento é um subcomponente da gestão do conhecimento e ocorre por meio de mecanismos formais e informais que integrem, interpretem e compartilhem conhecimento ancorado em indivíduos ou grupos de indivíduos, permitindo que os membros da organização compartilhem, disseminem e reproduzam informações, difundindo essa informação em locais que necessitem e possam pôr em prática o conhecimento existente da empresa (DONATE; SÁNCHEZ DE PABLO, 2015).

A transferência de conhecimento em projetos é um processo desafiador e complexo, porque os projetos são formas organizacionais temporárias por natureza (ZHAO; ZUO; DENG, 2015), em que a equipe é geralmente composta por membros de diferentes áreas funcionais que se reúnem para compartilhar seus conhecimentos para alcançar os resultados do projeto (MEHTA; HALL; BYRD, 2014). Já Goyette e outros (2015) demonstram a necessidade de contar com mecanismos formais e informais de troca de conhecimento entre diferentes interessados no projeto. O compartilhamento de conhecimento fornece uma ligação entre os membros da equipe do projeto, reduzindo custos e aumentando o desempenho da equipe (JAFARI NAVIMIPOUR; CHARBAND, 2016). Para Reychav e Weisberg (2010), as organizações se esforçam para criar condições para que os funcionários compartilhem conhecimento. O gerente de projetos procura padronizar as práticas de gerenciamento de projetos de acordo com suas experiências passadas (VICENTEOLIVA; MARTÍNEZ-SÁNCHEZ; BERGESMURO, 2015). Há um consenso de que a aplicação de melhores práticas de processos de gerenciamento de projetos demonstra aumento nas chances de sucesso na entrega dos projetos (PMI, 2013, p. 47). O desafio, então, é identificar as práticas de transferência de conhecimento que podem transmitir introspecções e conhecimentos valiosos de um projeto para outro (PMI, 2015, p. 14), para que a execução da transferência de conhecimento seja bem-sucedida.

\section{METODOLOGIA}

A estratégia desta pesquisa foi dividida em pesquisa bibliográfica, mapeamento das melhores práticas de transferência de conhecimento, elaboração de questionário com questões fechadas, por meio do Survey Mokey, aplicação de pré-teste, ajustes no questionário, aplicação do questionário e, por 
fim, análise de dados. Pesquisa bibliográfica feita por meio do Web of Science permitiu a obtenção de referencial teórico sobre o tema práticas de transferência de conhecimento. Para a identificação das melhores práticas, as seguintes palavras chaves foram levadas em consideração na pesquisa: Project management and. knowledge exchange .or. transfer of knowledge .or. knowledge transfer .or. exchange of knowledge $E$ Project management .and. (knowledge dissemination) .or. (dissemination of knowledge).

\subsection{INSTRUMENTO DE PESQUISA}

O questionário de pesquisa foi dividido em três partes: informações demográficas, experiência profissional e melhores práticas. $\mathrm{Na}$ primeira parte, procurou-se obter informações demográficas como gênero, idade e escolaridade e informações sobre o ramo de trabalho da empresa. Na segunda parte, buscou-se aprofundar sobre o tempo que o profissional exerce a prática de gerenciamento de projetos e se é certificado por alguma entidade de gerenciamento de projetos ou associado a ela. Na terceira parte, são apresentadas aos respondentes as práticas identificadas neste estudo, que, por meio do método Likert, indicam atitudes negativas e positivas sobre um objeto (RICHARDSON, 1999; SZULANSKI, 1996). Na escala Likert, os respondentes marcam o item em uma das categorias: 5. Concordo plenamente; 4. Concordo; 3. Indeciso; 2. Discordo e 1. Discordo plenamente. No Quadro 1, é apresentado o mapeamento das melhores práticas referenciado na pesquisa bibliográfica e a questão relacionada a ela.

\section{Quadro 1 - Lista de Melhores práticas x Questão}

\begin{tabular}{|c|c|}
\hline Melhor prática & Questão \\
\hline Treinamentos formais & $\begin{array}{l}\text { Sessões de capacitação para a equipe de projetos provida por especialistas } \\
\text { ou fornecedores }\end{array}$ \\
\hline Manuais e procedimentos & $\begin{array}{l}\text { Documentação produzida voluntariamente pelos membros das equipes de } \\
\text { projetos }\end{array}$ \\
\hline Documentos informais & $\begin{array}{l}\text { Intercâmbio informal de documentos não estruturados entre os membros da } \\
\text { equipe de projetos }\end{array}$ \\
\hline Documentos e guias & $\begin{array}{l}\text { Documentos de lições aprendidas, guias e passo a passo produzido pela } \\
\text { equipe }\end{array}$ \\
\hline Utilização de oficinas & $\begin{array}{l}\text { Utilização de laboratórios com práticas e processos para a equipe refletir sobre } \\
\text { os resultados do projeto }\end{array}$ \\
\hline Técnicas de narrativas & $\begin{array}{l}\text { Utilização de recursos visuais de maneira relevante para explicar e auxiliar na } \\
\text { capacitação de conhecimento }\end{array}$ \\
\hline Comunidades de prática & $\begin{array}{l}\text { Utilização de reuniões regulares na organização para criar condições que } \\
\text { proporcionem o aumento de conhecimento entre os membros }\end{array}$ \\
\hline Comunicação frequente & $\begin{array}{l}\text { Comunicação consistente e verossímil aumenta a eficácia da transferência de } \\
\text { conhecimento entre os membros da equipe de projetos }\end{array}$ \\
\hline $\begin{array}{l}\text { Estratégia para gerenciamento } \\
\text { de informação corporativa } \\
(\mathrm{GIC})\end{array}$ & $\begin{array}{l}\text { As informações do projeto devem ser criadas, organizadas e acessadas por } \\
\text { todos os membros da organização de uma base de conhecimento mantida por } \\
\text { profissionais de gestão de conteúdo que se utilizam de ferramentas e modelos } \\
\text { de gestão de conhecimento }\end{array}$ \\
\hline Cultura organizacional & $\begin{array}{l}\text { Comprometimento da administração em valorizar e apoiar métodos de } \\
\text { transferência de aprendizado }\end{array}$ \\
\hline $\begin{array}{l}\text { Suporte, apoio e motivação dos } \\
\text { líderes }\end{array}$ & $\begin{array}{l}\text { A liderança valoriza, encoraja e motiva a equipe para compartilhar } \\
\text { conhecimento }\end{array}$ \\
\hline Prêmios e reconhecimentos & $\begin{array}{l}\text { A liderança reconhece e premia os indivíduos que têm maior disposição em } \\
\text { compartilhar conhecimento }\end{array}$ \\
\hline $\begin{array}{l}\text { Tempo disponível para } \\
\text { compartilhar conhecimento }\end{array}$ & $\begin{array}{l}\text { A empresa proporciona condições para a equipe ter tempo para realizar a } \\
\text { transferência de conhecimento }\end{array}$ \\
\hline $\begin{array}{l}\text { Valorizar o sentimento de } \\
\text { confiança entre os membros da } \\
\text { equipe }\end{array}$ & $\begin{array}{l}\text { O sentimento de confiança mútuo entre os membros da equipe de projeto é } \\
\text { valorizado e incentivado. }\end{array}$ \\
\hline
\end{tabular}


Quadro 1 - Lista de Melhores práticas x Questão (continuação)

\begin{tabular}{|c|c|}
\hline Melhor prática & Questão \\
\hline $\begin{array}{l}\text { Utilização de equipes } \\
\text { multifuncionais }\end{array}$ & $\begin{array}{l}\text { Equipes multifuncionais de projetos proporcionam rápida resolução de } \\
\text { problemas e facilitam a transferência de conhecimento }\end{array}$ \\
\hline Adoção do papel de facilitador & $\begin{array}{l}\text { A atuação de um facilitador na equipe de projetos dinamiza o apoio à equipe, } \\
\text { coordenação, gestão das partes interessadas tornando a comunicação mais } \\
\text { eficiente }\end{array}$ \\
\hline $\begin{array}{l}\text { Utilização de especialistas em } \\
\text { assuntos técnicos }\end{array}$ & $\begin{array}{l}\text { Utilização de especialistas técnicos aconselhando, suportando e } \\
\text { implementando produtos e serviços }\end{array}$ \\
\hline $\begin{array}{l}\text { Diálogo dentro das redes } \\
\text { sociais }\end{array}$ & $\begin{array}{l}\text { Diálogos informais entre os membros da equipe de projetos enfatizam a } \\
\text { transferência de conhecimento }\end{array}$ \\
\hline Autonomia da equipe & $\begin{array}{l}\text { A equipe de projetos possui autonomia para definir quais ações são } \\
\text { necessárias para a execução de seu trabalho }\end{array}$ \\
\hline Entrevistas de saída & $\begin{array}{l}\text { Existência de entrevista de saída da empresa organizada em temas-chave a } \\
\text { ser utilizada pelo colaborador que ocupará a mesma posição }\end{array}$ \\
\hline $\begin{array}{l}\text { Equipe de suporte } \\
\text { compartilhada }\end{array}$ & A rotação de função de trabalho utilizado pelas equipes \\
\hline Objetivo e visão do Projeto & O propósito e o cenário do projeto são compartilhados com a equipe \\
\hline $\begin{array}{l}\text { Adoção de Escritório de } \\
\text { Projetos }\end{array}$ & $\begin{array}{l}\text { O escritório de projetos incorpora e compartilha o conhecimento acumulado } \\
\text { dos projetos, assegurando a utilização em projetos futuros }\end{array}$ \\
\hline $\begin{array}{l}\text { Uso de tecnologias } \\
\text { colaborativas }\end{array}$ & $\begin{array}{l}\begin{array}{l}\text { Utilização de tecnologias colaborativas para equipes dispersas } \\
\text { (videoconferência, áudio, correio eletrônico) }\end{array} \\
\end{array}$ \\
\hline Lições aprendidas & Aplicação do processo de lições aprendidas em projetos \\
\hline
\end{tabular}

Foram coletados 575 questionários de Gerentes de Projetos nos meses de maio e junho de 2017.

\section{3, RESULTADOS}

Identificou-se as melhores práticas de transferência de conhecimento descritas na Quadro 2.

Quadro 2 - Lista de Melhores práticas e Citações

\begin{tabular}{|c|c|c|}
\hline Cit. & Melhor Prática & Autor citado \\
\hline 1 & $\begin{array}{l}\text { Estratégia para gerenciamento de } \\
\text { informação corporativa (GIC) }\end{array}$ & (ALMEIDA; SOARES, 2014) \\
\hline 4 & $\begin{array}{l}\text { Valorizar o sentimento de confiança entre } \\
\text { os membros da equipe }\end{array}$ & $\begin{array}{l}\text { (ALMEIDA E SOARES, 2014; PERALTA E SALDANHA, 2014; } \\
\text { STEPHENS E CARMELI, 2016; WIEWIORA ET AL., 2014) }\end{array}$ \\
\hline 2 & Utilização de equipes multifuncionais & (BOSCH-SIJTSEMA E HENRIKSSON, 2014) \\
\hline 4 & Adoção do papel de facilitador & $\begin{array}{l}\text { (BOSCH-SIJTSEMA E HENRIKSSON, 2014; GHOBADI, 2015; } \\
\text { WIEWIORA ET AL., 2014; ZHAO, ZUO E DENG, 2015) }\end{array}$ \\
\hline 5 & Comunicação frequente & $\begin{array}{l}\text { (DONATE E SÁNCHEZ DE PABLO, 2015; DUFFIELD E } \\
\text { WHITTY, 2016; GHOBADI, 2015; PARK, LEE E LEE, 2015; } \\
\text { WIEWIORA ET AL., 2014) }\end{array}$ \\
\hline 4 & $\begin{array}{l}\text { Utilização de especialistas em assuntos } \\
\text { técnicos }\end{array}$ & $\begin{array}{l}\text { (BRADSHAW E PULAKANAM; CRAGG, 2015; GHOBADI, } \\
\text { 2015; MASSINGHAM, 2014; WIEWIORA ET AL., 2014) }\end{array}$ \\
\hline 2 & Treinamentos formais & $\begin{array}{l}\text { (BRADSHAW, PULAKANAM E CRAGG, 2015; GHOBADI, } \\
\text { 2015) }\end{array}$ \\
\hline 2 & Manuais e procedimentos & $\begin{array}{l}\text { (BRADSHAW, PULAKANAM E CRAGG, 2015; GHOBADI, } \\
\text { 2015) }\end{array}$ \\
\hline 1 & Documentos informais & (BRADSHAW, PULAKANAM E CRAGG, 2015) \\
\hline 3 & Documentos e guias & $\begin{array}{l}\text { (BRADSHAW, PULAKANAM E CRAGG, 2015; DUFFIELD E } \\
\text { WHITTY, 2016; ZHAO, ZUO E DENG, 2015) }\end{array}$ \\
\hline 2 & Utilização de oficinas & (DUFFIELD E WHITTY, 2016; HARTMANN E DORÉE, 2015) \\
\hline 3 & Cultura organizacional & $\begin{array}{l}\text { (DUFFIELD E WHITTY, 2016; MUELLER, 2014; VICENTE- } \\
\text { OLIVA, MARTÍNEZ-SÁNCHEZ E BERGES-MURO, 2015) }\end{array}$ \\
\hline
\end{tabular}


Quadro 2 - Lista de Melhores práticas e Citações (continuação)

\begin{tabular}{|l|l|l|}
\hline Cit. & \multicolumn{1}{|c}{ Melhor Prática } & \multicolumn{1}{|c|}{ Autor citado } \\
\hline 4 & Técnicas de narrativas & $\begin{array}{l}\text { (DUFFIELD E WHITTY, 2016; GHOBADI, 2015; HARTMANN E } \\
\text { DORÉE, 2015; KOZAK-HOLLAND E PROCTER, 2014) }\end{array}$ \\
\hline 4 & Comunidades de prática & $\begin{array}{l}\text { (DUFFIELD E WHITTY, 2016; DUTTON, TURNER E LEE- } \\
\text { KELLEY, 2014; GHOBADI, 2015; MASSINGHAM, 2014) }\end{array}$ \\
\hline 5 & Suporte, apoio e motivação dos líderes & $\begin{array}{l}\text { (DONATE E SÁNCHEZ DE PABLO, 2015; DUFFIELD E } \\
\text { WHITTY, 2016; GHOBADI, 2015; JAFARI NAVIMIPOUR E } \\
\text { CHARBAND, 2016; MASSINGHAM, 2014) }\end{array}$ \\
\hline 5 & Prêmios e reconhecimentos & $\begin{array}{l}\text { (DONATE E SÁNCHEZ DE PABLO, 2015; DUFFIELD E } \\
\text { WHITTY, 2016; GHOBADI, 2015; JAFARI NAVIMIPOUR E } \\
\text { CHARBAND, 2016; ZHANG, PABLOS E ZHOU, 2013) }\end{array}$ \\
\hline 2 & Adoção de Escritório de Projetos & $\begin{array}{l}\text { (DUTTON, TURNER E LEE-KELLEY, 2014; ZHAO, ZUO E } \\
\text { DENG, 2015) }\end{array}$ \\
\hline 2 & Diálogo dentro das redes sociais & $\begin{array}{l}\text { (DUTTON, TURNER E LEE-KELLEY, 2014; GOYETTE ET AL., } \\
\text { 2015) }\end{array}$ \\
\hline 1 & Autonomia da equipe & (GHOBADI, 2015) \\
\hline 1 & Uso de tecnologias colaborativas & (GHOBADI, 2015) \\
\hline 1 & Entrevistas de saída & (MASSINGHAM, 2014) \\
\hline 2 & $\begin{array}{l}\text { Tempo disponível para compartilhar } \\
\text { conhecimento }\end{array}$ & (HARTMANN E DORÉE, 2015; MUELLER, 2014) \\
\hline 1 & Equipe de suporte compartilhada & (GOYETTE ET AL., 2015) \\
\hline 1 & Objetivo e visão do Projeto & (PARK E LEE, 2014) \\
\hline 4 & Lições aprendidas & $\begin{array}{l}\text { (ALMEIDA E SOARES, 2014; DUFFIELD E WHITTY, 2016; } \\
\text { GOYETTE ET AL., 2015; ZHAO, ZUO E DENG, 2015) }\end{array}$ \\
\hline
\end{tabular}

Fonte: elaborada pelo autor

\subsection{DIAGNÓSTICO DA BASE DE DADOS E TRANSFORMAÇÃO DE DADOS}

Para facilitar a análise dos dados e realizar as correlações e comparações entre os grupos, as perguntas dos questionários foram agrupadas nas categorias Comunicação, Técnica, Liderança, Ferramenta, Procedimento e Cultura.
Com as respostas do participante, foi somado a nota total do Grupo vs. Nota Máxima (neste caso 5), criando um percentual e, transformando os dados em índice (Dado Contínuo), apresentando a nota máxima de cada comportamento conforme a classificação da Tabela 2.

Tabela 1 - Grupo x Questões

\begin{tabular}{|l|c|c|}
\multicolumn{1}{c}{ Grupo } & \multicolumn{1}{c}{$\begin{array}{c}\text { Nota } \\
\text { Máxima }\end{array}$} & $\begin{array}{c}\text { Quantidade } \\
\text { de questões }\end{array}$ \\
\hline Comunicação & 15 & 3 \\
\hline Técnica & 60 & 12 \\
\hline Ferramenta & 10 & 2 \\
\hline Liderança & 30 & 6 \\
\hline Procedimento & 5 & 1 \\
\hline Cultura & 5 & 1 \\
\hline
\end{tabular}

Fonte: elaborada pelo autor

As perguntas do Quadro 1 (Lista de Melhores Práticas $x$ Questão) estão agrupadas conforme a Tabela 1 (Grupo x Questões), resultando no Tabela 2. 
Tabela 2 - Melhores práticas agrupadas

\begin{tabular}{|c|c|c|c|c|c|c|c|}
\hline Ano & Brasil & Japão & \multicolumn{1}{|c|}{ Mundo } & Ano & Brasil & \multicolumn{1}{|c|}{ Japão } & Mundo \\
\hline 1980 & 0 & 4.743 & 25.077 & 1999 & 1 & 10.045 & 30.787 \\
\hline 1981 & 0 & 4.925 & 26.334 & 2000 & 11 & 8.607 & 28.831 \\
\hline 1982 & 0 & 5.256 & 26.910 & 2001 & 6 & 8.890 & 29.073 \\
\hline 1983 & 0 & 5.221 & 24.951 & 2002 & 5 & 9.142 & 30.477 \\
\hline 1984 & 0 & 4.445 & 24.132 & 2003 & 2 & 9.866 & 32.841 \\
\hline 1985 & 0 & 5.099 & 26.631 & 2004 & 7 & 8.797 & 32.922 \\
\hline 1986 & 0 & 4.572 & 24.604 & 2005 & 3 & 8.822 & 35.641 \\
\hline 1987 & 0 & 4.596 & 24.414 & 2006 & 5 & 8.999 & 43.277 \\
\hline 1988 & 0 & 5.778 & 23.985 & 2007 & 2 & 10.897 & 46.868 \\
\hline 1989 & 0 & 4.782 & 22.827 & 2008 & 23 & 12.308 & 45.065 \\
\hline 1990 & 0 & 4.231 & 21.555 & 2009 & 75 & 13.093 & 47.384 \\
\hline 1991 & 0 & 5.628 & 23.490 & 2010 & 84 & 15.454 & 54.453 \\
\hline 1992 & 0 & 5.539 & 22.761 & 2011 & 132 & 18.540 & 59.183 \\
\hline 1993 & 0 & 6.072 & 22.050 & $2012 e$ & 159 & 20.101 & 62.380 \\
\hline 1994 & 0 & 7.028 & 22.788 & $2013 e$ & 206 & 23.205 & 66.968 \\
\hline 1995 & 0 & 8.482 & 24.680 & $2014 \mathrm{e}$ & 262 & 26.897 & 71.828 \\
\hline 1996 & 0 & 6.220 & 21.154 & $2015 e$ & 327 & 31.249 & 76.956 \\
\hline 1997 & 0 & 7.926 & 24.089 & $2016 e$ & 404 & 36.333 & 82.351 \\
\hline 1998 & 0 & 9.646 & 27.380 & & & & \\
\hline & & & Fonte: elaborado pelo autor & & \\
\hline
\end{tabular}

\subsection{ANÁLISE E PRIORIZAÇÃO DOS GRUPOS}

Para analisar quais grupos possuem o maior impacto para Transferência de Conhecimento em Gerenciamento de Projetos, utilizamos as ferramentas: Test for Equal Variances, para comparar o desvio padrão, verificando se pelo menos um grupo possui uma variação diferente dos outros, e One Way ANOVA, para comparar a média de comportamento entre os grupos e verificar se um grupo é menos importante que os outros. Problema Estatístico:

\section{a) Test for Equal Variances}

$\mathrm{H}_{\mathrm{o}}: \sigma_{\text {Liderança }}=\sigma_{\text {Comunicação }}=\sigma_{\text {Técnica }}=$

$\sigma_{\text {Procedimento }}=\sigma_{\text {Ferramenta }}=\sigma_{\text {Cultura }}:$ p-value $>$ 0,05
$\mathrm{H}_{\mathrm{a}}$ : Pelo menos UM grupo possui Desvio Padrão Diferente : p-value $<0,05$

b) One-way ANOVA

$\mathrm{H}_{\mathrm{o}}: \mu_{\text {Liderança }}=\mu_{\text {Comunicação }}=\mu_{\text {Técnica }}=$

$\mu_{\text {Procedimento }}=\mu_{\text {Ferramenta }}=\mu_{\text {Cultura }}:$ p-value $>$ 0,05

$\mathrm{H}_{\mathrm{a}}$ : Pelo menos UM grupo possui uma Média Diferente : p-value $<0,05$

Realizados os Testes de Hipóteses para cada um dos grupos e comparando-se os resultados entre eles, foi possível priorizá-los.

Tabela 3 - Ordem de priorização dos grupos

\begin{tabular}{|c|l|c|c|c|c|c|c|c|}
\hline Ordem & \multicolumn{1}{c|}{ Grupo } & Média & Desvio & Ordem & \multicolumn{2}{c|}{ Grupo } & Média & Desvio \\
\hline 1 & Cultura & $90,9 \%$ & $11,4 \%$ & 4 & Ferramenta & $84,8 \%$ & $9,7 \%$ \\
\hline 2 & Comunicação & $86,7 \%$ & $8,9 \%$ & 5 & Técnica & $72,4 \%$ & $7,9 \%$ \\
\hline 3 & Liderança & $86,5 \%$ & $9,9 \%$ & 6 & Procedimento & $63,5 \%$ & $23,1 \%$ \\
\hline
\end{tabular}

Fonte: elaborada pelo autor 


\subsection{CORRELAÇÃO DE INFLUÊNCIA ENTRE OS GRUPOS}

As práticas apresentadas neste estudo estão distribuídas na tabela a seguir.

Tabela 4 - Média das Melhores práticas

\begin{tabular}{|c|c|c|c|}
\hline Questão & Médié & Questão & Média \\
\hline $\begin{array}{l}\text { Comunicação consistente e } \\
\text { verossímil aumenta a eficácia da } \\
\text { transferência de conhecimento entre } \\
\text { os membros da equipe }\end{array}$ & 4.64 & $\begin{array}{l}\text { O sentimento de confiança mútuo entre } \\
\text { os membros da equipe de projeto é } \\
\text { valorizado e incentivado }\end{array}$ & 4.13 \\
\hline $\begin{array}{l}\text { Liderança valorizar, encorajar e } \\
\text { motivar a equipe para compartilhar } \\
\text { conhecimento }\end{array}$ & 4.55 & $\begin{array}{l}\text { Equipes multifuncionais de projetos } \\
\text { proporcionam rápida resolução de } \\
\text { problemas e facilitam a transferência de } \\
\text { conhecimento }\end{array}$ & 4.12 \\
\hline $\begin{array}{l}\text { O propósito e o cenário do projeto } \\
\text { são compartilhados com a equipe }\end{array}$ & 4.41 & $\begin{array}{l}\text { O Escritório de Projetos incorpora e } \\
\text { compartilha o conhecimento acumulado } \\
\text { dos projetos assegurando a sua } \\
\text { utilização em projetos futuros? }\end{array}$ & 4.11 \\
\hline $\begin{array}{l}\text { Comprometimento da administração } \\
\text { em valorizar e apoiar métodos de } \\
\text { transferência de aprendizado }\end{array}$ & 4.39 & $\begin{array}{l}\text { Liderança reconhecer e premiar os } \\
\text { indivíduos que têm maior disposição em } \\
\text { compartilhar conhecimento }\end{array}$ & 4.08 \\
\hline $\begin{array}{l}\text { Utilização de recursos visuais de } \\
\text { maneira relevante para explicar e } \\
\text { auxiliar na capacitação de } \\
\text { conhecimento }\end{array}$ & 4.38 & $\begin{array}{l}\text { Utilização de laboratórios com práticas e } \\
\text { processos para a equipe refletir sobre os } \\
\text { resultados do projeto }\end{array}$ & 4.04 \\
\hline $\begin{array}{l}\text { Utilização de tecnologias } \\
\text { colaborativas para } \\
\text { dispersas (videoconferência, áudio, } \\
\text { correio eletrônico) }\end{array}$ & 4.35 & $\begin{array}{l}\text { Diálogos informais entre os membros da } \\
\text { equipe de projetos enfatizam a } \\
\text { transferência de conhecimento }\end{array}$ & 3.95 \\
\hline $\begin{array}{l}\text { Sessões de capacitação para a } \\
\text { equipe de projetos provida por } \\
\text { especialistas ou fornecedores }\end{array}$ & 4.35 & $\begin{array}{l}\text { Empresa proporciona condições para a } \\
\text { equipe ter tempo para realizar a } \\
\text { transferência de conhecimento }\end{array}$ & 3.89 \\
\hline $\begin{array}{l}\text { Documentos de lições aprendidas, } \\
\text { guias e passo a passo produzidos } \\
\text { pela equipe }\end{array}$ & 4.32 & $\begin{array}{l}\text { A equipe de projetos possui autonomia } \\
\text { para definir quais ações são necessárias } \\
\text { para execução de seu trabalho }\end{array}$ & 3.78 \\
\hline $\begin{array}{l}\text { Aplicação do processo de lições } \\
\text { aprendidas em projetos }\end{array}$ & 4.32 & $\begin{array}{l}\text { Documentação } \\
\text { voluntariamente pelos membros das } \\
\text { equipes de projetos }\end{array}$ & 3.72 \\
\hline $\begin{array}{l}\text { Reuniões regulares na organização } \\
\text { para criar condições que } \\
\text { proporcionem o aumento de } \\
\text { conhecimento entre os membros }\end{array}$ & 4.31 & $\begin{array}{l}\text { A rotação de funções de trabalho entre } \\
\text { os membros da equipe }\end{array}$ & 3.51 \\
\hline $\begin{array}{l}\text { Atuação de um facilitador na equipe } \\
\text { de projetos dinamiza o apoio à } \\
\text { equipe tornando a comunicação } \\
\text { mais eficiente }\end{array}$ & 4.29 & $\begin{array}{l}\text { Intercâmbio informal de documentos não } \\
\text { estruturados entre os membros da } \\
\text { equipe de projetos }\end{array}$ & 3.10 \\
\hline $\begin{array}{l}\text { Utilização de especialistas técnicos, } \\
\text { aconselhando, suportando e } \\
\text { implementando produtos e serviços }\end{array}$ & 4.28 & $\begin{array}{l}\text { Entrevista formal de saída do funcionário } \\
\text { da empresa a ser utilizada pelo } \\
\text { colaborador que ocupará a mesma } \\
\text { posição }\end{array}$ & 3.06 \\
\hline
\end{tabular}

Fonte: elaborada pelo autor

A análise e priorização dos grupos apresentou a seguinte ordem de priorização (Tabela 3): Cultura, Comunicação, Liderança,
Ferramenta, Técnica e Procedimento. Utilizando a ferramenta estatística Matriz Plot, separou-se a análise em três tipos de 
correlação: Fraca, Moderada e Forte. Verificamos que os grupos possuem uma Alta Interação e Correlação entre eles. O grupo Cultura foi considerado o mais importante; estatisticamente os grupos Liderança e Comunicação são iguais em relação à média e considerados os mais importantes se comparados aos grupos restantes depois do grupo Cultura. No quadro 3 - Práticas de Liderança e Comunicação, são apresentadas as práticas que compõem esses dois grupos.

Quadro 3 - Práticas de Liderança e Comunicação

\begin{tabular}{|l|l|}
\multicolumn{2}{|c|}{ Grupo } \\
\hline Liderança & Suporte, apoio e motivação dos líderes \\
\hline Liderança & Prêmios e reconhecimentos \\
\hline Liderança & $\begin{array}{l}\text { Valorizar o sentimento de confiança entre os } \\
\text { membros da equipe }\end{array}$ \\
\hline Liderança & Autonomia da equipe \\
\hline Liderança & Tempo disponível para compartilhar conhecimento \\
\hline Liderança & Objetivos e visão do projeto \\
\hline Comunicação & Diálogo nas redes sociais \\
\hline Comunicação & Adoção do papel de facilitador \\
\hline Comunicação & Comunicação frequente \\
\hline
\end{tabular}

Fonte: elaborado pelo autor

Quanto às correlações entre os grupos, conclui-se que o grupo Liderança tem uma relação forte com outros grupos e, quanto mais reconhecido este grupo de práticas de transferência de conhecimento, maior é a nota média dos outros grupos. O grupo Cultura afeta positivamente os outros grupos e, quanto mais reconhecida esta prática de transferência de conhecimento maior é a nota média das outras práticas dos grupos restantes. O grupo Técnica tem relação forte com os grupos Ferramenta e Liderança e, quanto maior a média das práticas do grupo Técnica, maior é a utilização das práticas dos grupos Ferramenta e Liderança e, por fim, o grupo Ferramenta apresenta correlação forte com o grupo Liderança ou, em outras palavras, quanto mais reconhecida é a prática do grupo Ferramenta mais assentida é a prática do grupo Liderança.

\section{CONCLUSÃO}

As empresas estão enfrentando diversos desafios em seus mercados, como rápidas mudanças tecnológicas, ciclos econômicos e incertezas organizacionais (ALMEIDA; SOARES, 2014). Para que essas empresas sobrevivam neste cenário é necessário que elas se tornem cada vez mais competitivas, devendo criar condições para criação de valor pelo conhecimento, tema este sustentado por autores como Bradshaw,
Pulakanam e Cragg (2015), Deeds e Marie Decarolis (1999), Reychav e Weisberg (2010), entre outros citados neste trabalho. Essa criação de valor se dá por meio de novos produtos e serviços cuja forma de entrega são os projetos, tornando-os um dos maiores desafios de negócios das organizações $(\mathrm{BOH}, 2007)$ e o veículo de entrega mais importante (JACKSON; KLOBAS, 2008).

Para que os projetos sejam entregues com sucesso, é necessária a adoção de melhores práticas de gerenciamento de projetos para assegurar sua execução com sucesso (ALMEIDA; SOARES, 2014). Somando-se a isso, o relatório intitulado "Capturando o valor do gerenciamento de projetos" (PMI, 2015) e os estudos publicados por autores como Reychav e Weisberg (2010), Mueller (2014), Jafari Navimipour e Charband (2016) destacam a importância do compartilhamento do conhecimento nas organizações, associado a um desempenho positivo das empresas e dos projetos executados por elas juntamente com seus colaboradores cujo conhecimento produzido, retido e compartilhado é considerado estratégico. A relevância do compartilhamento do conhecimento, as condições necessárias para seu incentivo e as práticas associadas para assegurar o sucesso nesse compartilhamento tornaram-se estratégicos para que as empresas se mantenham e cresçam em um mercado competitivo. Cada vez mais, os 
projetos se tornam mais complexos, em função da tecnologia, da utilização de parceiros na sua execução, que possivelmente estão em diferentes localidades e equipes. Além disso, pela transitoriedade dos projetos, 0 compartilhamento do conhecimento se tornou um problema informacional importante (ZHAO; ZUO; DENG, 2015), (ALMEIDA; SOARES, 2014) para as organizações, porque esse conhecimento criado pelo projeto deve ser compartilhado entre os membros da organização e entre os membros da própria equipe (BARTSCH; EBERS; MAURER, 2013), (JAFARI NAVIMIPOUR; CHARBAND, 2016). Como mencionado no relatório do $\mathrm{PMI}$, o processo formal de transferência de conhecimento aumenta consideravelmente as chances de entrega do projeto no prazo, orçamento e dentro dos objetivos de negócio esperados (PMI, 2015, p. 11), tornando as empresas mais competitivas. Nesse cenário, este estudo procurou identificar, por meio de pesquisa da literatura, quais são as práticas de transferência de conhecimento: das 25 práticas identificadas, 22 são utilizadas pelos profissionais de gerenciamento de projetos, as práticas: documentos informais, entrevistas de saída e equipe de suporte compartilhada demonstraram incerteza quanto às respostas fornecidas.

Neste estudo não foi abordada a correlação entre as práticas de transferência de conhecimento e o tempo de experiência em gerenciamento de projetos e também a associação do gestor de projetos a uma entidade de gerenciamento de projetos. Durante a análise, foi percebida a alta correlação matemática entre os próprios grupos de Cultura, Liderança, Comunicação, Técnica e Procedimento. Liderança e Comunicação são competências do gerente de projetos, que deve demonstrá-las durante a execução do projeto ou das atividades pertencentes a ele. A eficácia pessoal do gerente de projetos engloba atitude, características fundamentais de personalidade e liderança. Essas habilidades são necessárias para guiar a equipe do projeto durante a execução do projeto, para

\section{REFERÊNCIAS}

[1] Almeida, M. V.; Soares, A. L. Knowledge sharing in project-based organizations: Overcoming the informational limbo. International Journal of Information Management, v. 34, p. 770779, 2014 atingir os objetivos do projeto (PARK; LEE, 2014) e balancear suas restrições (PMI, 2015, p. 17). Para o gerente de projetos realizar 0 trabalho por meio da equipe do projeto e dos interessados no projeto, ele necessita balancear habilidades técnicas, pessoais e conceituais, analisando situações do projeto de maneira proativa. Uma dessas habilidades é a liderança. De acordo com o PMBOK 5d (PMI, 2015, p. 513-514), liderança é fazer as pessoas trabalharem como um time para atingir o objetivo comum do projeto, com respeito, confiança e inspiração dos membros da equipe. Nesse cenário onde há forte correlação entre os grupos, principalmente da liderança, seria interessante que estudos futuros abordassem as causas dessa correlação e, por fim, possam analisar a possibilidade de criação de simulador matemático utilizando a ferramenta estatística Design of Experiments, gerado pelo Minitab, com o objetivo de otimizar o processo de transferência de conhecimento contendo as variáveis utilizadas neste estudo:

- $\quad$ Tempo de experiência profissional;

- Participação em entidade de gerenciamento de projetos;

- Setor;

- Certificação em gerenciamento de projetos;

- Tempo de experiência em gerenciamento de projetos;

- Todos os seis grupos gerados pelas perguntas do questionário inicial.

Este simulador poderia ser utilizado na prática para orientar o profissional nas seguintes situações exemplificadas a seguir:

- $\quad$ Escolher um candidato a uma vaga de gerenciamento de projetos;

- Realizar avaliações internas de colaboradores e;

- $\quad$ Até realizar a avaliação de um curso em gerenciamento de projetos, adaptando o questionário.

[2] Anderson, C. W.; Greenberg, D. PMI Today. PMI Today, March, p. 20, 2017.

[3] Argote, L.; Ingram, P. Knowledge Transfer: A Basis for Competitive Advantage in Firms. Organizational Behavior and Human Decision Processes, v. 82, n. 1, p. 150-169, maio 
2000.

[4] Bartsch, V.; Ebers, M.; Maurer, I. Learning in project-based organizations: The role of project teams' social capital for overcoming barriers to learning. International Journal of Project Management, v. 31, n. 2, p. 239-251, February 2013.

[5] Boh, W. F. Mechanisms for sharing knowledge in project-based organizations. Information and Organization, v. 17, n. 1, p. 27-58, 2007.

[6] Bosch-Sijtsema, P. M.; Henriksson, L. H. Managing projects with distributed and embedded knowledge through interactions. International Journal of Project Management, v. 32, n. 8, p. 14321444, 2014.

[7] Bradshaw, A.; Pulakanam, V.; Cragg, P. Knowledge sharing in IT consultant and SME interactions. Australasian Journal of Information Systems, v. 19, p. S197-S217, 2015.

[8] Deeds, D. L.; Marie Decarolis, D. The Impact of Stocks and Flows of Organizational Knowledge on Firm Performance: An Empirical Investigation of the Biotechnology Industry. Deeds Source: Strategic Management Journal, v. 20, n. 10, p. 953-968, 1999.

[9] Donate, M. J.; Sánchez de Pablo, J. D. The role of knowledge-oriented leadership in knowledge management practices and innovation. Journal of Business Research, v. 68, n. 2, p. 360-370, 2015.

[10] Duffield, S. M.; Whitty, S. J. Application of the Systemic Lessons Learned Knowledge model for Organisational Learning through Projects. International Journal of Project Management, v. 34, n. 7, p. 1280-1293, 2016

[11] Dutton, C.; Turner, N.; Lee-Kelley, L. Learning in a programme context: An exploratory investigation of drivers and constraints. International Journal of Project Management, v. 32, n. 5, p. 747-758, 2014.

[12] Ghobadi, S. What drives knowledge sharing in software development teams: A literature review and classification framework. Information \& Management, v. 52, n. 1, p. 82-97, 2015.

[13] Goyette, S. et al. The ERP postimplementation stage: a knowledge transfer challenge. International Journal of Information Syste ms and Project Management, v. 3, n. 2, p. 5-19, 2015.

[14] Hartmann, A.; Dorée, A. Learning between projects: More than sending messages in bottles. International Journal of Project Management, v. 33, n. 2, p. 341-351, 2015.

[15] Jackson, P.; Klobas, J. Building knowledge in projects: A practical application of social constructivism to information systems development. International Journal of Project Management, v. 26, n. 4, p. 329-337, 2008.
[16] Jafari Navimipour, N.; Charband, Y. Knowledge sharing mechanisms and techniques in project teams: Literature review, classification, and current trends. Computers in Human Behavior, v. 72, p. 730-742, September 2016.

[17] Jorge, Carlos Francisco Bitncourt; Faléco, Lyvia Luppi. A aplicação da gestão do conhecimento como estratégia de competitividade organizacional. Brazilian Journal of Information Science: Research Trends, v. 10, n. 3, p. 69-75, 2016.

[18] Kirsch, L. J.; King, W. R. Antecedents of knowledge transfer from consulnants to clients in enterprise system implementations. MIS Quarterly, v. 29, n. 1, p.59-85, 2005.

[19] Kozak-Holland, M.; Procter, C. Florence Duomo project (1420-1436): Learning best project management practice from history. International Journal of Project Management, v. 32, n. 2, p. 242255, 2014

[20] Massingham, P. Knowledge Sharing: What Works and What Doesn't Work: A Critical Systems Thinking Perspective. Systemic Practice and Action Research, v. 28, n. 3, p. 197-228, 2014.

[21] Mehta, N.; Hall, D.; Byrd, T. Information technology and knowledge in software development teams: The role of project uncertainty. Information and Management, v. 51, n. 4, p. 417429, 2014

[22] Mueller, J. A specific knowledge culture: Cultural antecedents for knowledge sharing between project teams. European Management Journal, v. 32, n. 2, p. 190-202, 2014.

[23] Nonaka, I.; Takeuchi, H. The KnowledgeCreating: How Japanese companies create the dynamics of innovation. Oxford University Press, v. 3, n. 4-5, p. 25-27, 1995.

[24] Park, J.-G.; Lee, J. Knowledge sharing in information systems development projects: Explicating the role of dependence and trust. International Journal of Project Management, v. 32, n. 1, p. 153-165, 2014.

[25] Peralta, C. F.; Saldanha, M. F. Knowledgecentered culture and knowledge sharing: The moderator role of trust propensity. Journal of Knowledge Management, v. 18, n. 3, p. 538-550, 2014.

[26] Pmi. Capturing the value of project management. Newtown Square: [s.n.].

[27] Project Management Institute. A Guide to The Project Management Body Of Knowledge. Fifth edit ed. Newtown Square, Pennsylvania 190733299: Project Management Institute, Inc., 2013.

[28] Richardson, R. J. Pesquisa social: métodos e técnicas. São Paulo: Atlas, 2015.

[29] Sedera, D.; Gable, G. G. Journal of Strategic Information Systems Knowledge Management Competence for Enterprise System 
Success. Journal of Strategic Information Systems, v. 19, n. 4 , p. 296-306, 2010

[30] Stephens, J. P.; Carmeli, A. The positive effect of expressing negative emotions on knowledge creation capability and performance of project teams. International Journal of Project Management, v. 34, n. 5, p. 862-873, 2016.

[31] Szulanski, G. Impediments to the transfer of best practice within the firm. Strategic Management Journal, v. 17, n. 1, p. 27-43, 1996.

[32] Takeuchi, H.; Nonaka, I. Gestão do Conhecimento. 2. ed. [s.l.]. Porto Alegre: Artmed, 2008.

[33] Vicente-Oliva, S.; Martínez-Sánchez, Á.; Berges-Muro, L. Research and development project management best practices and absorptive capacity: Empirical evidence from Spanish firms.
International Journal of Project Management, v. 33, n. 8, p. 1704-1716, 2015.

[34] Wiewiora, A. et al. Interactions Between Organizational Culture, Trustworthiness, and Mechanisms for Inter-Project Knowledge Sharing. Project Management Journal, v. 45, n. 2, p. 48-65, 2014.

[35] Zhang, X.; Pablos, P. O. de; Zhou, Z. Effect of knowledge sharing visibility on incentivebased relationship in Electronic Knowledge Management Systems: An empirical investigation. Computers in Human Behavior, v. 29, n. 2, p. 307313, 2013

[36] Zhao, D.; Zuo, M.; Deng, X. (Nancy). Examining the factors influencing cross-project knowledge transfer: An empirical study of IT services firms in China. International Journal of Project Management, v. 33, n. 2, p. 325-340, 2015. 


\section{Bapítulo 12}

\section{UTILIZACÃO DA TÉCNICA DE MODELAGEM DATA FLOW DIAGRAMMING (DFD) PARA MELHORIA NO PROCESSO DE APROVAÇÃO DE PROJETOS ESTRATEGICOS DE GRANDE PORTE}

Roquemar de Lima Baldam

João Caldeira Lélis

Lourenço Costa

Thalmo de Paiva Coelho Junior

Leandro Colombi Resendo

Resumo: Apesar da apresentação de projetos para aprovação estar alinhada com as diretrizes da empresa analisada, a mesma vem enfrentando dificuldades após a liberação do projeto para o comitê de aprovação, devido ao significante número de retrabalho, antes da reunião de aprovação. O objetivo deste artigo é mostrar a utilização da técnica de modelagem Data Flow Diagramming (DFD), para melhoria no processo de aprovação de projetos estratégicos de grande porte. Assim, a proposta é associar uma técnica pouco utilizada na modelagem de processos de negócios, Data Flow Diagramming, verificando sua eficácia na aplicação em um caso prático e, com isso, interá-la na lista de ferramentas para apoio às tomadas de decisões dentro das organizações. As opções de melhorias identificadas foram aceitas pelo comitê de aprovação e tiveram a sua eficácia apurada através dos dois últimos projetos submetidos em fevereiro e março de 2011.

Palavras-chave: Técnicas de modelagem, Modelagem, Processos de Negócios, Gestão de projetos, Investimentos, Diagrama de Fluxo de Dados. 


\section{INTRODUÇÃO}

Técnicas e ferramentas de modelagem são aplicadas como ferramentas de apoio e suporte às tomadas de decisão dentro das organizações.

O processo de tomadas de decisões é uma das funções gerenciais de maior importância dentro das organizações. Cada decisão tomada pode definir o futuro das operações da empresa e, consequentemente, o futuro do próprio gerente como parte integrante dessa organização.

Moreira (1996, p.25), define modelagem como um processo de transformação e organização de dados de determinado problema segundo as características de um modelo matemático.

Modelos são representações simplificadas de situações reais, em razão da dificuldade de captar sua realidade em um aspecto mais amplo e geral. Podem ser identificados e separados em três tipos: (a) icônicos, replicando fisicamente um objeto real mantendo as proporções de sua forma, (b) analógico, que também são representações físicas de objetos reais, porém, não mantêm a forma do projeto em estudo e (c) matemáticos, representando o problema ou as propriedades de um objeto real através de símbolos ou equações matemáticas, que podem ser manipuladas para buscar a solução do problema ou estudar o comportamento de um objeto em condições específicas (MOREIRA, 1996, p.27-29).

O objetivo deste artigo é mostrar a utilização da técnica de modelagem DFD, para melhoria no processo de aprovação de projetos estratégicos de grande porte. Esta área, transformada em gerências específicas com um grau de importância muito grande dentro das organizações devido à sua atuação, com elevado grau de responsabilidade, através da busca pela excelência na implementação de projetos de investimentos.

Para desenvolvimento deste artigo, a metodologia de pesquisa utilizada teve como base uma pesquisa documental, com levantamento de dados históricos da empresa, identificando os últimos acontecimentos relacionados às aprovações de projetos de investimento junto ao comitê de aprovação do grupo. É uma empresa de grande porte do ramo de siderurgia. A pesquisa teve como referências os anos de 2009 e 2010, abordando quatro grandes projetos de investimento aprovados nestes períodos. A partir da pesquisa e análise de algumas técnicas de modelagem de processos mais utilizadas e análise do problema identificado a decisão foi orientada para a utilização da técnica DFD como apropriada para mostrar a situação atual do processo de aprovação e propor melhoria para esse processo.

$\mathrm{Na}$ próxima sessão, são apresentadas definições importantes ao entendimento do trabalho, incluindo projetos de grande porte, gestão de projetos, processos de negócio, e definições das principais técnicas de modelagem, na Sessão 3 é detalhada a proposta de trabalho, apresentado um histórico do problema e melhorias propostas e, finalmente, na Conclusão, o relato dos resultados alcançados com a implementação das ações de melhorias.

\section{REFERENCIAL TEÓRICO}

\subsection{DEFINIÇÃO DE PROJETO DE GRANDE PORTE E GESTÃO DE PROJETOS}

Segundo O PMI (Project Management Institute), em seu PMBOK® Guide (2013), um projeto tem natureza temporária com início e fim definidos, cuja conclusão se dá quando os objetivos são alcançados ou quando se chega à conclusão de que o objetivo não é possível de ser atingido e então, o projeto é encerrado.

Um projeto obtém sucesso quando atende ou excede aos desejos e expectativas dos stakeholders, que são as pessoas que investem para que o projeto seja realizado e que tem autoridade para alocar recursos e autonomia para tomar decisões relacionadas ao projeto (HELDMAN, p.3, 2003).

O PMBOK® Guide (2013), trata a gestão de projetos como sendo a utilização do conhecimento, habilidades, ferramentas e técnicas disponíveis para obter o melhor desenvolvimento na execução das atividades de um projeto atendendo aos seus requisitos e objetivos. Além disso, o PMBOK® Guide distribui os 42 processos inerentes à gestão de projetos, agrupando-os e integrando-os em cinco grupos que são: Iniciação, Planejamento, Execução, Monitoramento e Controle e Encerramento.

Processo de gerenciamento de projetos engloba atividades relacionadas a planejamento, execução do plano do projeto e acompanhamento do progresso e 
desempenho. Planejamento é uma importante função a executar e que define o padrão que será adotado ao longo do ciclo de vida do projeto com objetivo de rastrear o desempenho final do projeto (HELDMAN, p.4, 2003).

\subsection{PROCESSO DE NEGÓCIO}

Processo de negócio e tecnologia da informação sempre trabalhou junto, mas este relacionamento não tem sido explorado na prática conforme deveria. Trata-se de uma relação definida como um padrão recursivo. Espera-se que a escolha de como conduzir os negócios de uma organização vá influenciar a concepção e a estrutura dos sistemas de informação que irá apoiar este processo. Por outro lado, os avanços da tecnologia da informação geram novas oportunidades para as organizações influenciando os leiautes de processos de negócios específicos (DAVENPORT e SHORT, 1990).

Para que a visão da empresa seja direcionada por processos de negócios é preciso identificar, mapear e representar estes processos de forma que as atividades, informações e recursos disponíveis sejam conhecidos e compreendidos por todos na organização (BREMER e LENZA, 2000). Processo de negócio, segundo Scheer (1998), é uma série contínua de tarefas realizadas por uma empresa visando a geração de um produto ou informação. Para Rozenfeld (1996), processo de negócio é um fenômeno formado por um conjunto de atividades realizadas dentro da empresa, através da manipulação de informações utilizando os recursos e a própria organização. Deve ser focado em um tipo específico de negócio, direcionado a clientes determinados e com fornecedores definidos.

\subsection{TÉCNICAS DE MODELAGEM}

Metodologias de modelagem são suportadas por várias técnicas que são usadas por meio de diagramas ou outras notações com a finalidade de estudar e analisar os sistemas modelados (GIAGLIS, 2001). Processo é elaborado de forma a organizar as etapas necessárias para o alcance de seus objetivos e metas (CURTIS, 1992). Vernadat (1996) direciona o conceito de modelagem de processos para uma finalidade mais afinada com a gestão de processos quando a classifica, também, como uma ferramenta de comunicação, análise e apoio à tomada de decisão. Tal definição é mais apropriada para esse trabalho, do que a apresentada por Sheer (1998), pois, a definição de Vernadat (1996) vai além de uma sequência lógica de tarefas, enquanto associa a modelagem ao processo decisório dentro do projeto, tratando-a como uma ferramenta importante na gestão da comunicação e nos processos decisórios.

Segundo Giaglis (2001), o conceito de técnicas de modelagem pode ser mais bem representado, dentro de uma estrutura hierárquica dos elementos da modelagem, através da figura 1, seguindo a mesma linha de raciocínio utilizada por Kettinger, Teng e Guha (1997).

Figura 1 - Modelagem, Metodologias, Técnicas e ferramentas.

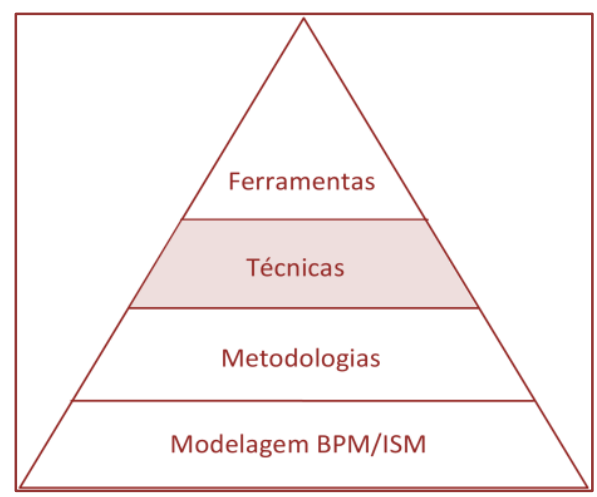

Fonte: adaptado de Giaglis, 2001. 
A decomposição ilustrada na figura 1 sugere a modelagem sendo sustentada por uma ou mais metodologias. Metodologias são tomadas como referências aos paradigmas de modelagem e suportadas por uma série de técnicas. As técnicas são usadas como referência às notações diagramáticas para estudo e análise de sistemas modelados. Estas técnicas específicas e metodologias subjacentes, na maioria dos casos, são suportadas por ferramentas de modelagem de software, tais como: ferramentas CASE, Workflow Management Systems, software de modelagem de processos, entre outros. (GIAGLIS, 2001).

A opinião de Bremer e Lenza (2000) reforça o conceito de Vernadat (1996), quando ele classifica a modelagem de processos como suporte ao processo de comunicação e de tomada de decisões. A seguir são apresentadas algumas das principais técnicas de modelagem, com ênfase na técnica DFD que é o objeto deste trabalho.

Deste modo, pode-se apresentar as técnicas de modelagem mais comumente encontradas na literatura:

a) Redes Petri: De acordo com Reising, Muchnick, e Schnupp (1992), dentre as técnicas de modelagem de sistemas, talvez a rede Petri, tenha recebido maior atenção com alto potencial para utilização em modelagem de processos de negócio. Redes Petri básicas são representações matemáticas e gráficas de sistemas, com objetivo de apoiar a análise da estrutura e do comportamento dinâmico dos sistemas modelados, em especial daqueles sistemas que precisam trabalhar com a interação de componentes concomitantes (PETERSON, 1981).

b) Business Process Modeling and Notation BPMN: A especificação BPMN (Business Process Model and Notation), mantida pelo OMG (Object Management Group-2015), tornou-se a mais popular notação de processos no ambiente de negócios (MARTÍNEZ et al., 2014), um dos motivos para ser o método empregado nesta pesquisa. Sua representação em diagramas se dá por meio de uma notação bastante intuitiva, garantindo o seu alicerce na perspectiva funcional e ampla compreensão sobre o funcionamento dos processos modelados, até mesmo quando trabalho com processos complexos.

c) Integrated Definition - IDEF: Segundo Mayer et al, (1998), diagramas IDEF (Integrated Definition) surgiram em 1981 como parte do projeto Integrated Computer-Aided Manufacturing (ICAM). Existem inúmeros métodos IDEF, mas dois deles se aplicam ao desenvolvimento dos modelos de processo de negócio: o método IDEFO incidindo sobre a atividade de modelagem e o método IDEF3 realizando a descrição do processo e usado para gerar rapidamente especificações do modelo de simulação para eventos discretos. O método IDEFO foi projetado para modelar as decisões, ações e atividades de uma organização ou sistema, com objetivo de comunicar e analisar um sistema sob uma perspectiva funcional (Mayer et al, 1998).

d) Flowcharting: Flowcharting é uma das primeiras técnicas de modelagem gráfica, em uso desde a década de 1960. As vantagens da utilização de flowcharting destaca-se por sua capacidade de mostrar a estrutura geral de um sistema, rastrear o fluxo de informação e de trabalho, descrever o meio físico no qual os dados são inseridos, produzidos e armazenados, e destacar o processamento chave e pontos de decisão (Jones, 1986).Inicialmente, flowcharting era usado somente para representar a lógica do programa de computador, mas devido ao seu carácter genérico, a sua utilização em outras áreas de aplicação, incluindo modelagem de processos de negócios tem se tornado muito frequente. Apesar de suas vantagens, como familiaridade e facilidade de utilização, o flowcharting já não é uma técnica de modelagem dominante, devido a sua limitação em fornecer apenas serviços básicos de representação de processos (GIAGLIS, 2001).

e) Simulação: Segundo Doran e Gilbert (1994), os conceitos básicos que definem a técnica de simulação é bem simples. A técnica de simulação pode ter várias formas identificadas através da simulação de eventos discretos, simulação contínua, dinâmica de sistemas, simulação de Monte Carlo e simulação qualitativa. Porém, duas delas, a dinâmica de sistemas e a simulação de eventos discretos, são mais bem evidenciadas em relação a BPM e a ISM (GIAGLIS, 2001).

\subsubsection{DFD}

DFD é uma técnica utilizada para mostrar o fluxo de informações entre entidades externas, etapas do processamento interno destes dados e elementos utilizados para armazenar estes dados em um processo de 
negócio (Kettinger, Teng e Guha,1997). Segundo Yourdon (1989), a ampla utilização da técnica DFD para modelagem de dados é considerada como uma notação padrão para desenhos e análises de sistemas tradicionais.

Yourdon (1989) diz que os DFDs são representações estáticas de um sistema e suas as funções, provavelmente baseando-se na visão de que não há uma relação de precedência clara dentro da representação. Não se pode afirmar que o DFD é incapaz de fornecer subsídios para análise e tomada de decisão. A utilização do DFD possibilita visualizar a situação do processo viabilizando a formação de opinião sobre quais ações tomar para torná-lo mais eficaz.

Figura 2 - Exemplo de DFD.

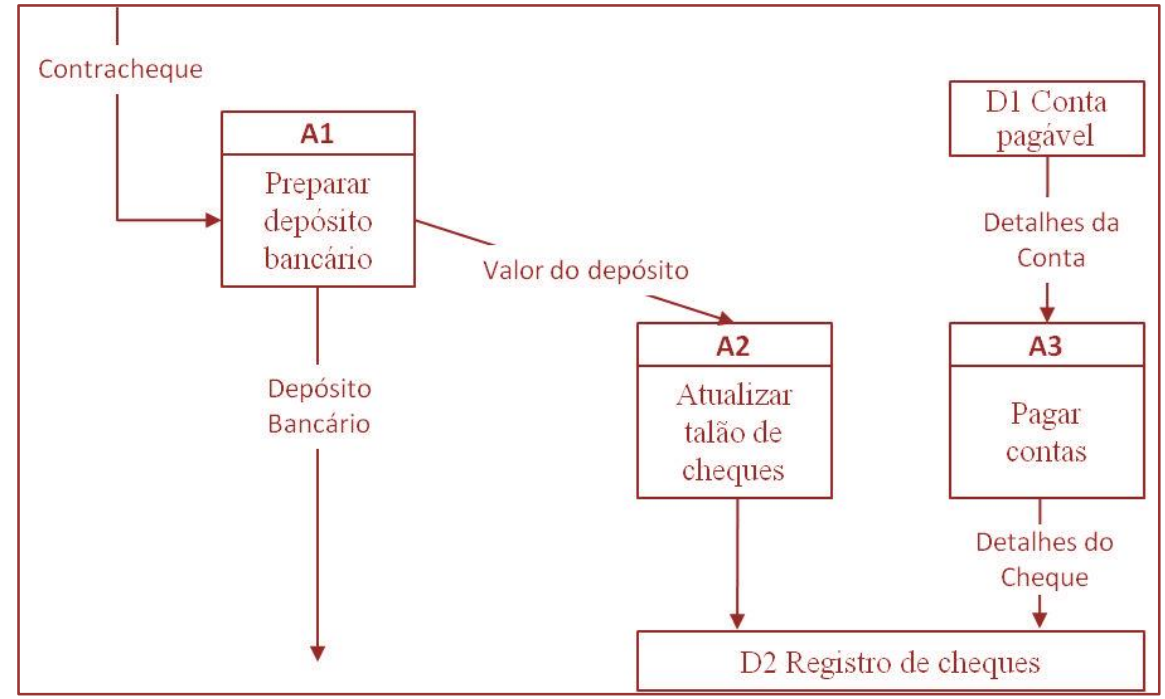

Fonte: adaptado de Le Vie, 2000.

\section{PROPOSTA DE TRABALHO}

\subsection{OBJETIVO E SITUAÇÃO ATUAL}

O objetivo deste artigo é mostrar a utilização da técnica de modelagem DFD, para melhoria no processo de aprovação de projetos estratégicos de grande porte. O modelo ou técnica escolhida para a solução do problema ou apoio à tomada de decisão deve ser capaz de analisar a quantidade de informações geradas, buscando um melhor aproveitamento dos recursos humanos e financeiros disponíveis dentro da organização.

Para que essa prestação de contas aos acionistas ocorra faz-se necessário a elaboração de estudos conceituais que por sua vez devem ser aprovados para que sejam iniciados os estudos de viabilidade dos projetos antes que se inicie a implementação desses projetos. Estes estudos de viabilidades também precisam ser aprovados por um comitê especial para que sejam liberadas as verbas necessárias para a realização do projeto.
Estes processos de aprovação têm sido muito penosos e desgastantes para a equipe responsável pela preparação dos documentos necessários à aprovação. O grande número de questionamentos de pessoas indicadas pelo comitê de aprovação, muitas delas completamente alheias ao processo é um grande gargalo que dificulta a entrega da documentação para aprovação na data planejada. Daí, a importância da identificação de uma ferramenta de modelagem de processos capaz de contribuir para a eliminação dos possíveis gargalos capazes de contribuir para o insucesso na busca por bons resultados.

A opção por utilizar a técnica DFD deve-se ao fato da existência de uma demanda desordenada de informações, vindas de direções diversas, necessitando de respostas e adequação na documentação preparada. Com esta técnica de modelagem foi possível fazer um retrato da situação atual, identificando os conflitos, questionamentos às vezes duplicados por pessoas diferentes e, ao mesmo tempo, propor uma alteração na maneira de tratar estas informações. 
A figura 3 representa uma situação de conflito e estresse enfrentada durante o processo de aprovação de um projeto estratégico de grande porte.

A situação atual para preparação dos documentos necessários à aprovação dos projetos estratégicos de grande porte na empresa em questão era para ser tratado normalmente em três etapas. A primeira, cujas informações e entidades estão identificadas na figura 3 por (1), consiste em definir o escopo do projeto, especificações técnicas, captação de propostas orçamentárias no mercado, tudo realizado em comum acordo com a equipe do projeto, áreas de apoio e equipe financeira da empresa e, suportado pela equipe indicada pelo comitê de aprovação para facilitar e agilizar o processo de aprovação. A primeira etapa é concluída quando o documento contendo todas as informações, em consenso com toda equipe, é enviado para o comitê de aprovação nível 1. A segunda etapa seria a análise do documento pelo comitê nível 1 , esclarecimentos de dúvidas através da equipe indicada por ele para acompanhar a preparação do documento finalizando com a emissão do parecer favorável ou não pela implementação ou, em caso do valor a ser aprovado superar o limite de alçada, submetê-lo a título de recomendação para aprovação no comitê nível 2. O problema ocorre, quando os comitês de aprovação enviam o projeto para análise (2) e (3), conforme indicação no fluxo, para outros especialistas de outras unidades em outros países, com uma realidade totalmente diferente das locais, situações econômicofinanceiras adversas, mão de obra a baixo custo. Tais especialistas começam a questionar (4) diretamente para a equipe do projeto, os custos, comparando com outros projetos similares já implementados sem considerar ou equiparar o escopo e sem considerar as leis locais. Neste momento, a equipe indicada pelo comitê se isola e não é consultada por estes outros especialistas, ficando a equipe do projeto com responsabilidade pelas respostas (4).

Apesar da apresentação de projetos para aprovação do comitê de aprovação estar totalmente alinhada com as diretrizes do Grupo, as práticas atuais na empresa têm enfrentado algumas dificuldades após a liberação do documento do Projeto para o secretariado do comitê. O desenvolvimento deste trabalho possui as seguintes premissas:

a) Analisar o fluxo atual dos dados que envolvem a preparação deste documento de aprovação com o relacionamento externo durante a discussão do projeto e consolidação desses dados;

b) Apresentar as referidas dificuldades com base histórica de projetos já apresentados e;

c) Propor ações de melhorias para o processo de desenvolvimento desses dados e esclarecimento de dúvidas para que o documento chegue ao comitê com apresentação clara e mais bem definido.

Figura 3: DFD - Situação atual do processo de aprovação de projetos estratégicos

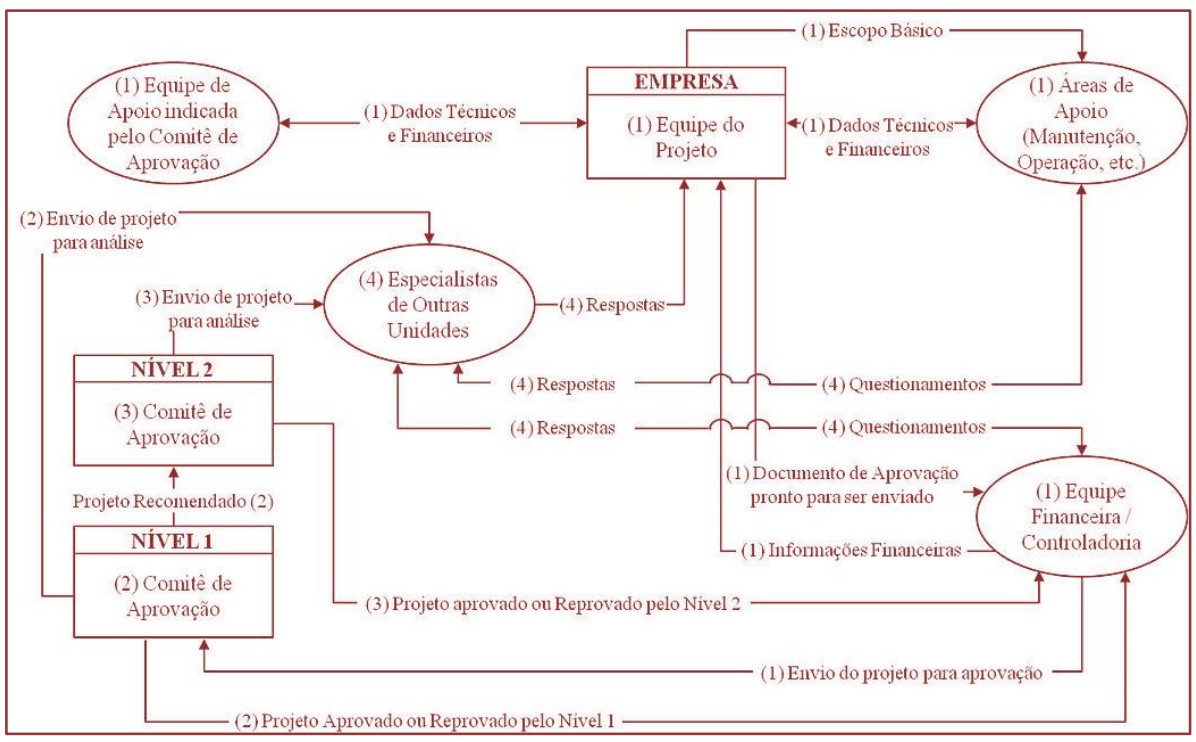




\subsection{HISTÓRICO DO PROBLEMA}

Os dados históricos apresentados a seguir, evidenciam alguns dos problemas enfrentados em três processos de aprovação de projetos dentro da empresa. Por questões de sigilo, o nome da empresa, bem como dos equipamentos não serão divulgados.

O primeiro exemplo refere-se a um equipamento prioritário para a produção que estava apresentando avarias por fim de vida útil e que poderia quebrar a qualquer momento, causando parada total da produção. A negociação para aquisição já havia sido concluída, em Nov/09, após confirmação e entendimento do comitê sobre a necessidade do equipamento. Outro membro do comitê questionou a real necessidade de aquisição e mesmo após longa troca de informações e esclarecimentos o projeto não foi aprovada na reunião do comitê de dez/09.

Depois de algum tempo o comitê concordou com a necessidade de aquisição, porém solicitou que fosse consultado outro fornecedor indicado por eles, o qual não quis ofertar. Após esse impasse o comitê voltou atrás e concordou pela aquisição do fornecedor inicial nas mesmas condições já negociadas, que se deu em Jan/10. Com isso, esse atraso estendeu o tempo de exposição ao risco de parar a produção, considerando que não havia sobressalente para esse equipamento.

O segundo exemplo é um projeto de reforma de uma unidade produtiva por fim de vida útil e desgaste prematuro de sua estrutura. $O$ processo contou com a participação de especialistas indicados pelo comitê. Os questionamentos, após o documento de aprovação ter sido concluído, foram feitos diretamente à equipe do projeto, por outro especialista do comitê, que não participou da fase de estudos e preparação do documento, com perguntas que poderiam ser facilmente resolvidas com antecedência.

O envolvimento da equipe central de negociação do grupo só entrou para o processo no final, com dúvidas e solicitações de esclarecimentos, retardando o processo de envio do documento. Houve, neste projeto, várias questões recorrentes, que já haviam sido levantadas e esclarecidas com a equipe do comitê que estava envolvida desde o início. Várias questões foram levantadas no dia definido para a reunião do comitê de aprovação. Estresse e corrida contra o tempo para buscar as respostas solicitadas.

O terceiro exemplo abrange dois projetos de reforma de equipamentos de uma mesma unidade produtiva, também por fim de vida útil. Esses dois processos foram iniciados com a participação de todas as equipes, envolvendo indicados pelo comitê e equipe de negociação central. Apesar de ter a participação de todos, desde o início do projeto, questões novas e recorrentes foram suscitadas na manhã do dia da reunião de aprovação, num total de 21 questões sendo 6 recorrentes, incluindo questões de especialistas de empresas de outro país que fazem parte do grupo.

A linha do tempo da figura 4 mostra a localização do problema.

Figura 4: Linha do tempo para o processo de aprovação de projetos estratégicos

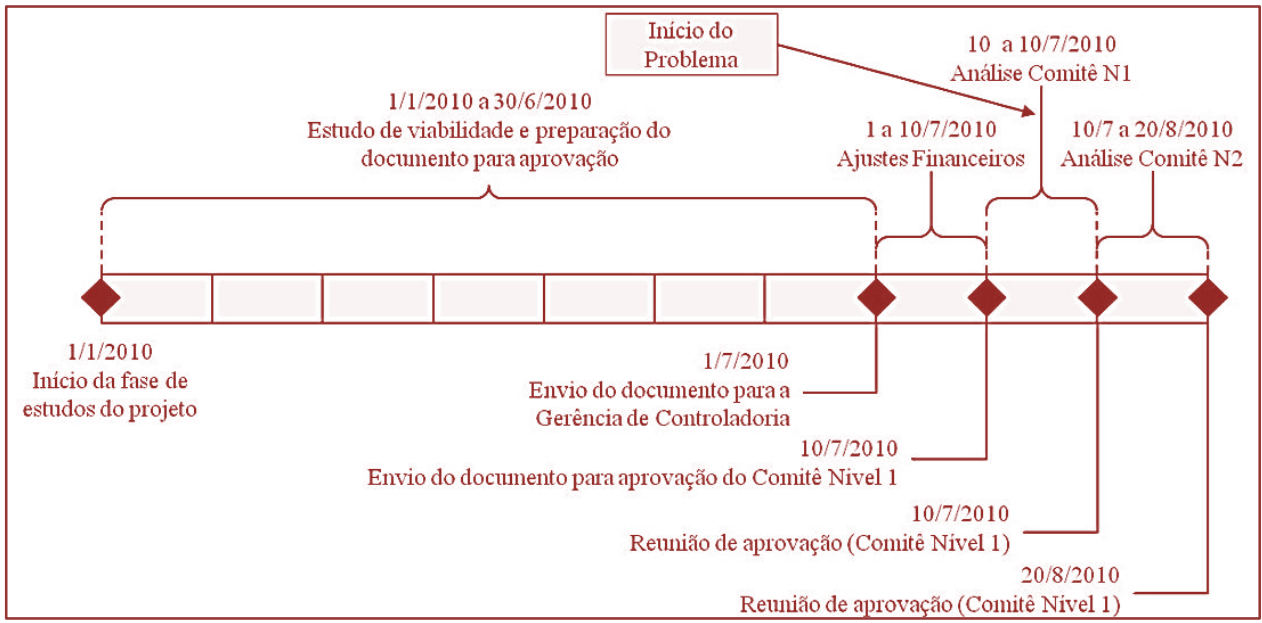


O tempo de estudo e preparação do documento de aprovação do projeto está estimado em seis meses, mas este tempo varia de acordo com a complexidade do projeto em estudo. Após este estudo, o documento deve ser enviado para a gerência de controladoria com, no mínimo, 10 dias de antecedência a data definida para envio ao comitê de aprovação Nível 1. O problema deste trabalho surge após o recebimento deste documento pelo comitê. Neste momento são disparados diversos questionamentos tanto relacionados ao escopo quanto aos cálculos financeiros que envolvem todo o projeto e que foram exaustivamente discutidos durante todo 0 período inicial.

\subsection{PROPOSTA DE MELHORIAS}

A proposta de melhorias sugerida pelo projeto teve como meta reduzir o número de intervenções externas no documento de aprovação dos projetos estratégicos de grande porte e minimizar o estresse causado por questionamentos surgidos de última hora.

Essas práticas consistem em:

a) Nomeação de todos os especialistas para compor a equipe do projeto. Interno (cliente do projeto, áreas de apoio e de controladoria) e externo (comitê de aprovação e negociação central);

b) Elaboração de documento de aprovação do projeto coordenada pelo Gerente do Projeto com a interação das áreas interna e externa;

Figura 5: DFD - Configuração proposta para o processo de aprovação de projetos estratégicos da

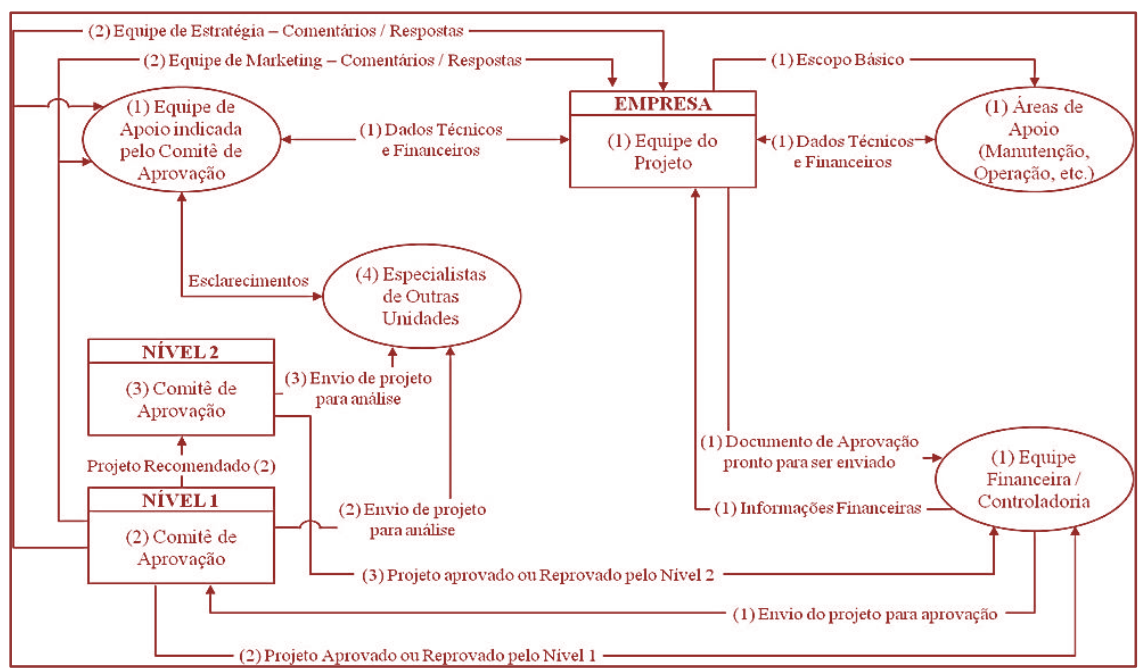

c) A Gerência de Projetos é responsável pela preparação do documento para aprovação e a Gerência de Controladoria é a responsável por encaminhar esse documento ao comitê de aprovação;

d) Distribuição do projeto, pelos membros do comitê de aprovação, para análise dos outros especialistas;

e) Os questionamentos dos novos especialistas empenhados na análise do arquivo, por solicitação do comitê de aprovação, devem interagir com os especialistas nomeados inicialmente que acompanharam toda a evolução do trabalho, a fim de esgotar as dúvidas e questões pouco claras;

f) Para manter o mesmo canal de comunicação, caso sejam necessários esclarecimentos complementares, tais questões poderão ser tratadas com a equipe do projeto, através dos especialistas nomeados no início do projeto e;

g) Os esclarecimentos finais, decorrentes da análise provenientes de novos especialistas ou dos especialistas nomeados inicialmente, serão enviados diretamente aos membros do comitê de aprovação.

h) Incluir membros das equipes de estratégia e de marketing, a partir do recebimento do documento pelo comitê de aprovação nível 1.

i) As melhorias propostas estão representadas através do novo fluxo proposto através da técnica DFD, pela figura 5.

\section{empresa}


Neste novo fluxo proposto, a primeira etapa de elaboração do documento de aprovação, com o envolvimento de toda a equipe suportada pelos especialistas representantes do comitê de aprovação continua sendo como no fluxo anterior, até o envio do documento para o comitê de aprovação nível 1. O que há de novo no fluxo é que os questionamentos dos especialistas de outras unidades serão direcionados para a equipe do projeto através dos especialistas indicados pelo comitê desde o início do projeto.

Com isso, fica minimizada a possibilidade de questionamentos recorrentes, uma vez que essa equipe funcionará como um filtro e com capacidade de responder e defender o projeto perante o comitê, em razão de estarem envolvidos desde o início do processo de elaboração do documento. A outra novidade no fluxo, é que quando o projeto for ser aprovado no comitê de nível dois, a partir do momento que o projeto chega ao comitê de nível 1, ocorre o envolvimento de membros da equipe de estratégia e marketing, ajudando a refinar o documento para que a aprovação no nível 2 seja mais eficiente.

\section{CONCLUSÃO}

A adoção desta nova modelagem para tratamento das informações durante 0

\section{REFERÊNCIAS}

[1]. BREMER, Carlos F. e LENZA, Rogério de P. Um modelo de referência para gestão da produção em sistemas de produção assembly to order: ato e suas múltiplas aplicações. Gestão \& Produção. São Carlos, 2000, vol.7, n.3, pp.269-282.

[2]. CURTIS B., KELLNER M. Process Modeling. Communications of the ACM. 1992, vol.35, n.9. pp 75-90.

[3]. DAVENPORT, T. H. and SHORT, J. E. The New Industrial Engineering: Information Technology and Business Process Redesign, Sloan Management Review, vol. 31, n.4 (Summer 1990), pp. 11-27.

[4]. Doran, J. and Gilbert, N. Simulating Societies: An Introduction in Simulating, Societies: The Computer Simulation of Social Phenomena. UCL Press, London (1994).

[5]. GIAGLIS, George M. A taxonomy of business process modeling and information systems modeling techniques. The International processo de preparação do documento de aprovação do projeto, utilizando a técnica DFD, baseando no envolvimento do comitê de aprovação desde a fase de estudos, através da nominação de especialistas de sua confiança, está proporcionando ganhos em sinergia nos estudos e consolidação do documento com informações necessárias à tomada de decisão sobre o futuro do projeto.

As melhorias propostas para o processo de aprovação de projetos foram apresentadas e aceitas pelo comitê. Com isso, o êxito obtido no convencimento dos membros do comitê para a aprovação dos dois últimos projetos submetidos aumentou consideravelmente. A continuidade da verificação da eficácia da proposta implementada continuará, considerando que já estão em andamento mais alguns projetos em estudos pela empresa e que serão submetidos ainda este ano.

Como sugestões para a continuação desse trabalho destacam-se, a análise histórica sobre os reais benefícios da implantação dessa proposta e a modelagem da fase subsequente à aprovação que é o processo de contratação de projetos estratégicos de grande porte. Outro ponto que pode ser explorado é o processo de elaboração do orçamento e composição dos custos, que será levado à aprovação do comitê.

Journal of Flexible Manufacturing Systems. Vol. 13, 2001, pp. 209-228.

[6]. HELDMAN, Kin. Gerência de Projetos: guia para exame official do PMI. Tradução de Teresa Félix. 6. ed. Rio de Janeiro: Elsevier, 2003.

[7]. Jones, J. L., Structured Programming Logic: A Flowcharting Approach. Prentice-Hall, Englewood Cliffs, NJ (1986).

[8]. Kettinger, W. J., Teng, J. T. C., and Guha, S. Business Process Change: A Study of Methodologies, Techniques, and Tools. MIS Quarterly, vol. 21, n.1, pp. 55-80 (1997).

[9]. Le Vie, Donald S. jr. Understanding Data Flow Diagrams. Disponível em: http://ratandon.mysite .syr.edu/cis453/notes/DFD_o ver_Flowcharts.pdf . Acesso em 31 Jan. 2011.

[10]. MARTÍNEZ, J. S.; ESPADA, J. P.; BUSTELO, B. C. P.; LOVELLE, J. M. C. BPMN MUSIM: approach to improve the domain expert's efficiency in business processes modeling for the 
generation of specific software applications. Expert Systems with Applications, v. 41, p.1864-1874, 2014.

[11]. Mayer, R. J. et alli. IDEF3 ProcessDescription Capture Method report. Interim technical report for period april 1992 - September 1995 - Texas, 1998.

[12]. Mayer, R. J., Benjamin, P. C., Caraway, B. E., and Painter, M. K., A Framework and a Suite of Methods for Business Process Reengineering, in: Business Process Change: Concepts, Methods and Technologies. V. Grover and W. J. Kettinger (Eds.), Idea Group Publishing, Harrisburg, PA, pp. 245290 (1995).

[13]. MOREIRA, Daniel A. Administração da produção e operações. 2. ed. São Paulo: Pioneira, 1996.

[14]. OMG. Business Process Model and Notation (BPMN) - Version 2.0.2 (2013). Disponível em: $\quad<$ http://www.omg.org/spec/BPMN/2.0.2>. Acesso em: 27 junho 2015.
[15]. Peterson, J. L., Petri Net Theory and the Modeling of Systems. Prentice-Hall, Englewood Cliffs, NJ (1981).

[16]. PMI. A Guide to the Project Management Body of Knowledge (PMBOK® Guide) 5th edition. 2013.

[17]. Reising, W., Muchnick, S. S., and Schnupp, P. (Eds.), A Primer in Petri Net Design. Springer-Verlag, Berlin (1992).

[18]. ROZENFELD, H. Reflexões sobre a Manufatura Integrada por Computador (CIM), Manufatura Classe Mundial: Mitos e Realidade, São Paulo, 1996.

[19]. SCHEER, A.W. ARIS - Business Process Frameworks, 2. ed. Springer-Verlag, Berlin, 1998.

[20]. VERNADAT, F.B. Enterprise Modelling and Integration: Principles and Applications. Londom: Chapmam \& Hall, 1996.

[21]. Yourdon, E. Modern Structured Analysis. Prentice-Hall International, Englewood Cliffs, NJ (1989). 


\section{Gapítulo 13}

\section{AS FERRAMENTAS DE COMPARTILHAMENTO DE CONHECIMENTO NOS JOGOS RIO 2016: UM ESTUDO DE CASO}

\section{Raphael Alves Soares}

Déborah Daniel Ferreira Coelho Soares

\section{Leonardo Mangia Rodrigues}

Resumo:Em um âmbito de busca incessante de inovação e perfeição, utiliza-se a gestão do conhecimento para fomentação de novas ideias (inspiração) e handover de seu legado intelectual das lições aprendidas.

Para isso é de fundamental aplicação de ferramentas para aplicação de uma gestão de conhecimento adequado e efetivo na instituição. Essas ferramentas foram configuradas, a partir de procedimentos sugeridos pelo COI, através de entrevistas, pesquisas e análises de funcionários, torcedores e clientes, que e serviu de base para elaboração e implementação da gestão do conhecimento na empresa. O projeto entregou ao Comitê Organizador dos Jogos Olímpicos e Paralímpicos Rio2016 a possibilidade de capturar, fomentar, organizar e compartilhar o seu capital intelectual de forma eficiente. 


\section{INTRODUÇÃO}

\subsection{CONSIDERAÇÕES INICIAIS}

Para STEWART (1998), na atualidade a informação e o conhecimento converteram-se em um recurso de valor elevado, ele se encontra mais relevante do que a matéria prima, ou até mesmo, mais importante que o dinheiro. Não adianta a empresa possuir capital financeiro, possuir colaboradores e a matéria-prima, sem o conhecimento do processo.

É essencial para a empresa gerir, em tempos de globalização e de procura incessante de excelência, os conhecimentos organizacionais produzidos, sendo o conhecimento um recurso intangível, no entanto, de grande valor.

A gestão do conhecimento, de acordo com DAVENPORT (1999), posiciona a empresa a estar sempre atualizada, pois reduz o tempo de desenvolvimento e de produção dos projetos e eventos, onde melhora as operações e fluidez dos processos internos (agilidade), aperfeiçoa a prestação de serviços. Torna-se necessária na administração das organizações modernas, uma vez que, a sociedade seguinte será a do conhecimento (DRUCKER, 2003).

Empresas no ramo de eventos que permanecem competitivas são aquelas que geram conhecimento, estimula a criação e inovações de produtos e serviços.

O conjunto de atividades da indústria de eventos abrange diversas extensões: festivais, festas, convenções e de competição. A corporação RIO 2016 se junta neste contexto uma vez que toda sua produção e vantagem competitiva está sujeito a da criatividade e imaginação, ou seja, na criação de conhecimento.

Pesquisa realizada em 2013 com mais de sessenta mil empresas do setor e publicada no II Dimensionamento Econômico da Indústria de Eventos no Brasil revela que a indústria de eventos no Brasil movimenta cerca de $\mathrm{R} \$ 209,2$ bilhões em receita, representado 4,32\% do PIB do Brasil no período. Avalia-se que no segmento de eventos origine cerca de 7,5 milhões de empregos diretos e indiretos.

Após a análise do conselho executivo do Comitê Olímpico Brasileiro (COB) verificou a possibilidade da cidade do Rio de Janeiro ser postulante dos Jogos Olímpicos de Verão de
2016, por ser a cidade mais preparada no Brasil para o evento poliesportivo mencionado, em razão da efetuação dos Jogos Pan-Americanos de 2007 e porque a cidade sediaria a realização dos eventos: Campeonato Mundial de Judô de 2007, o Campeonato Mundial de Futsal de 2008, os Jogos Mundiais Militares de 2011, Copa das Confederações de 2013 e a Copa do Mundo FIFA de 2014. Em 2 de outubro de 2009, na $121^{a}$ Sessão do Comitê Olímpico Internacional a cidade a cidade do Rio de Janeiro foi eleita sediar os XXXI Jogos Olímpicos e Paralímpicos de Verão em 2016.

\subsection{FORMULAÇÃO DA SITUAÇÃO PROBLEMA}

Em uma época de globalização e concorrência acirrada, a corporação RIO 2016, para permanecer competitiva, buscou incessantemente a inovação e a perfeição. Para tal fim aplicou-se "ferramentas" de gestão do conhecimento que fomentassem novas ideias, uma vez que, a gestão do conhecimento posiciona a empresa a estar sempre atualizada e reduz o tempo de desenvolvimento e de produção dos projetos e eventos, onde melhora as operações e fluidez dos processos internos e aperfeiçoa a prestação de serviços. (DAVENPORT e PRUSAK, 1999)

\subsection{OBJETIVO GERAL}

Organizar, valorizar e compartilhar as informações e conhecimentos organizacionais nas empresas de promoção eventos esportivos, tornando-os úteis e compreensíveis, tendo em vista que propiciam nas vantagens competitivas.

\subsection{METODOLOGIA}

A presente pesquisa teve como objetivo analisar as ferramentas de compartilhamentos de conhecimento usadas nas organizações de eventos esportivos.

Para tal fim, foi essencial buscar como as informações e o conhecimento são gerados e propagados, quais são os tipos de conhecimentos, as ferramentas que são empregadas nas empresas, como de fato foi implantada na organização e outros temas pertinentes para a investigação. 
Os dados oriundos deste estudo são de pesquisas e de relatórios técnicos da empresa estudada, que foi elaborado com uma análise de conteúdo qualitativo, para identificação e correlação entre as indagações. No qual, o presente artigo apresenta desde o seu planejamento até o resultado.

O presente trabalho pode ser classificado como descritivo, por ter o propósito de documentar as fases, desde a criação até a conclusão da atividade, da área funcional de Gestão Conhecimento e sua importância na corporação RIO 2016. Mesmo sendo algo restrito, tornara-se essência para as demais empresas de promoção de eventos esportivos no mundo. (DANE, 1990) (YIN, 2015) (ROSSMAN e MARSHALL, 2010)

Em relação à metodologia da pesquisa, foi utilizado $\mathrm{O}$ método de estudo de caso.
Escolhido este método por ser recomendado para a graduação de engenharia de produção e por permitir um estudo profundo capaz de investigar os pontos implícitos e a conjuntura extensa e típica, capaz de proporcionar o entendimento do todo. (MIGUEL, 2011)

O objetivo foi analisar e aprofundar o conhecimento detalhado da Gestão do Conhecimento, que aprofundou nas ferramentas para compartilhamento de conhecimento criados na corporação RIO 2016 que promove eventos esportivos, estimula a compreensão, as questões e as hipóteses. (YIN, 2015)

Diante disto, foi proposta a utilização adaptada de três macros-etapas de condução para o estudo: definição do planejamento, preparação e desenvolvimento e análise. (YIN, 2015)

Figura 1 - Proposta de condução de estudo

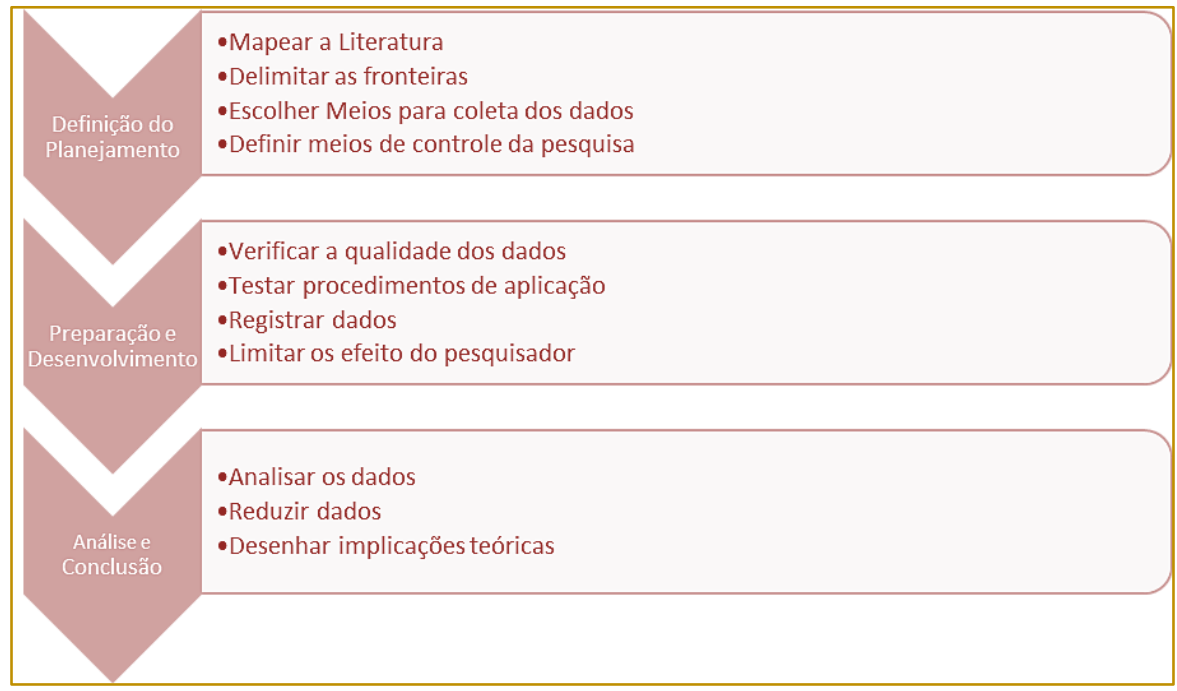

Fonte: Autor, baseado YIN (2015)

\section{REVISÃO DA LITERATURA}

\subsection{GESTÃO DO CONHECIMENTO}

HENSEN (2012) afirma que, a teoria do conhecimento pergunta pela verdade do pensamento, isto é, pela sua concordância com o objeto. SENGE (2013) definem conhecimento como a capacidade para ação eficaz.

O filósofo Manuel Kant (1724-1804), citado pelo autor HENSEN (2012), aponta que o conhecimento possui dois tipos de elementos: a priori e a posteriori. A priori é quando se obtém conhecimento independente da experiência e de toda as impressões dos sentidos. A posteriori só pode ser obtido da experiência, o conhecimento empírico.

Informação, para DRUCKER (2000), são um conjunto de dados que agrupados em função de uma determinada lógica, estabelecem o sentido ou uma ação. 
Quadro 1 - Características dos Dados, Informações e Conhecimento

\begin{tabular}{|c|c|}
\hline TIPO & CARACTERISTICAS \\
\hline DADO & $\begin{array}{l}\text { - simples observaçōes sobre o estado do mundo; } \\
\text { - facilmente estruturados; } \\
\text { - facilmente obtidos por máquinas; } \\
\text { - freqũentemente quantificados; } \\
\text { - facilmente transferiveis. }\end{array}$ \\
\hline INFORMAÇĀO & $\begin{array}{l}\text { - dados dotados de relevância e propósito; } \\
\text { - requer unidade de análise; } \\
\text { - exige consenso em relaçăo ao significado; } \\
\text { - exige necessariamente a mediaçăo humana. }\end{array}$ \\
\hline CONHECIMENTO & $\begin{array}{l}\text { - informaçăo valiosa da mente humana; } \\
\text { - inclui reflexão, síntese, contexto; } \\
\text { - de difícil estruturaçăo; } \\
\text { - de difícil captura em máquinas; } \\
\text { - frequentemente tácito; } \\
\text { - de difícil transferência. }\end{array}$ \\
\hline
\end{tabular}

Fonte: Autor, baseado Davenport e Prusak (1999, p. 18).

Quando falamos sobre dados, estamos nos aludindo à matéria prima de uma cadeia, como mostra a Figura 2 - Cadeia de evolução dos dados. A evolução desta cadeia é transformar dados em informações confiáveis e usa-las como base de conhecimento para tomadas de decisão com sabedoria.

Figura 2 - Cadeia de evolução dos dados

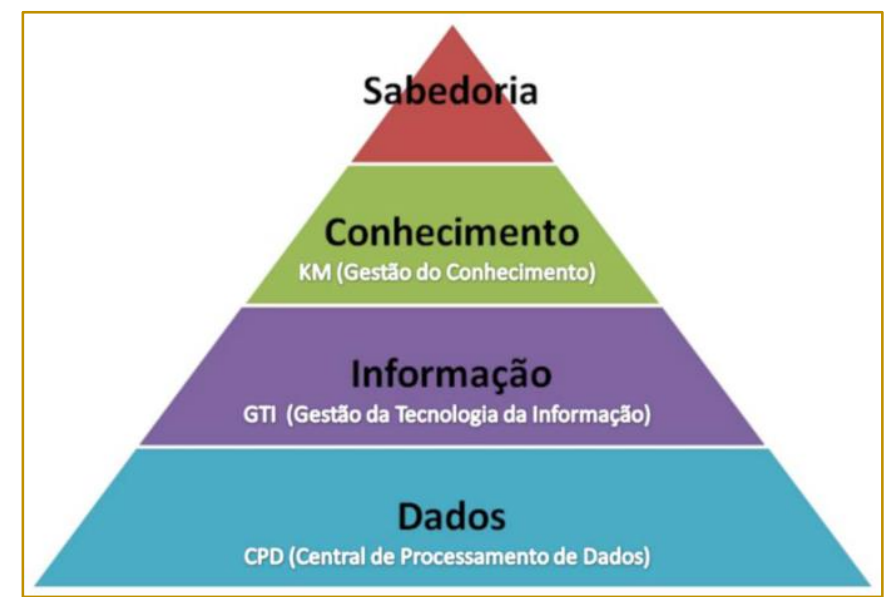

Fonte: Infoway (2013).

De acordo com a FNQ (2014) para uma boa governança de uma corporação, a forma com que os dados e conhecimentos contínuos que a empresa cria e possui são gerenciados, disponibilizados e utilizados por todos os envolvidos são fatores cruciais para se atingir a excelência da gestão em suas operações.

\subsection{MODELO DE GESTÃO DO CONHECIMENTO PROPOSTO POR NONAKA E TAKEUCHI}

Conhecimento, segundo NONAKA E TAKEUCHI (1997), se classifica em tácito ou explícito, não sendo entidades separadas, mas sim complementares. Assim, o conhecimento é gerado por meio da interação entre conhecimento tácito e explícito. Ou seja, 
conhecimento humano é criado e expandido através da interação social entre conhecimento tácito e o conhecimento explícito.

O conhecimento explícito é o mais fácil de ser adquirido, são os procedimentos e documentos que o usuário realiza, normalmente tangíveis. Onde os colaboradores já possuem a consciência deste conhecimento. (CHOO, 2003)
Já o conhecimento tácito (know-how) é a informação que o profissional não tem consciência, sendo difícil de ser explicado por ela ou de ser formalizada, por sua vez, é o resultado das experiências (erros e sucessos) ao longo da vida, como as percepções de cenário e ideias. Este conhecimento é muito importante, pois as corporações não podem utilizar este conhecimento pela ausência deste colaborador. O conhecimento implícito, são informações que se deduz de outras informações. (CHOO, 2003)

Quadro 2 - Dois tipos de conhecimento

\begin{tabular}{|l|l|}
\hline \multicolumn{1}{|c|}{ Conhecimento Tácito (subjetivo) } & \multicolumn{1}{c|}{ Conhecimento explícito (objetivo) } \\
\hline Conhecimento da experiência (corpo) & Conhecimento da racionalidade (mente) \\
\hline Conhecimento simultâneo (aqui agora) & Conhecimento sequencial (lá e então) \\
\hline Conhecimento análogo (prática) & Conhecimento digital (teoria) \\
\hline \multicolumn{2}{|c|}{ Fonte: Autor, baseado no Nonaka E Takeuchi (2000) }
\end{tabular}

O conhecimento é formado por meio das interações entre seres humanos e seu ambiente. TAKEUCHI e NONAKA (2008) apresentam um modelo (processo SECI) que pressupõe que a criação do conhecimento organizacional é criada e expandida através da conversão do conhecimento tácito em explícito, e vice-versa (ilustrado na Figura 2 Processo SECI). Neste modelo são postulados quatro modos diferentes de conversão do conhecimento:

- Socialização - compartilhamento do conhecimento tácito em tácito (indivíduo para indivíduo) através de experiências diretas;
- $\quad$ Externalização - conversão do conhecimento tácito em explícito (indivíduo para grupo), por meio da articulação do conhecimento tácito através do diálogo e da reflexão;

- Combinação - compartilhamento do conhecimento explícito em explícito (grupo para organização), através da sistematização e aplicação do conhecimento explícito e a informação;

- Internalização - conversão do conhecimento explícito em tácito (organização para 0 indivíduo), onde aprende-se e adquire novo conhecimento tácito na prática.

Figura 3 - Processo SECI

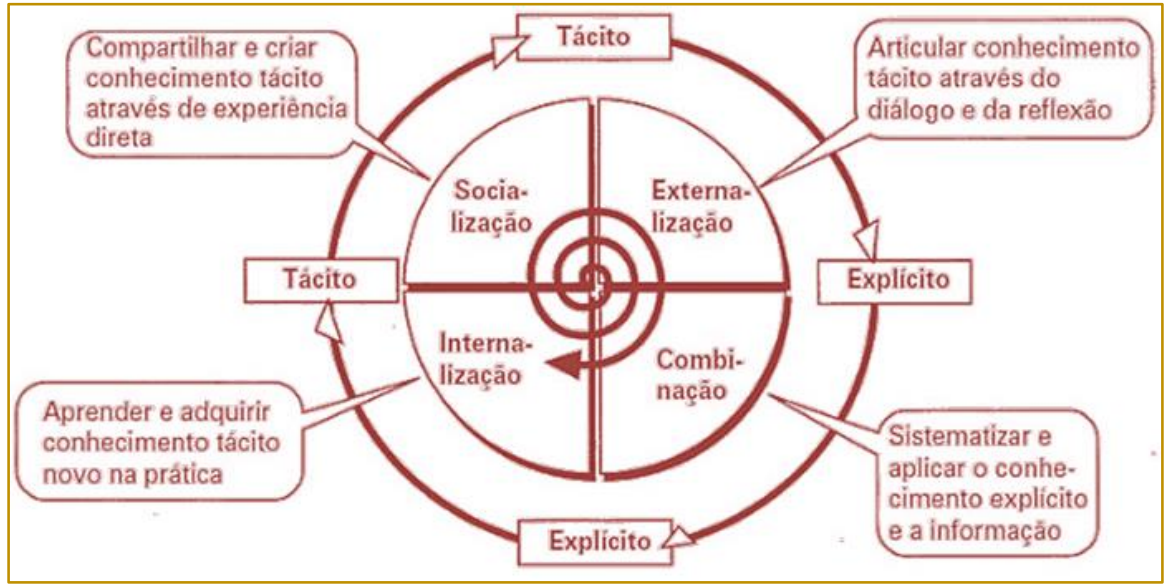

Fonte: Figura adaptada de Nonaka E Takeuch (2008) 
Para criação do conhecimento Takeuchi e Nonaka (2008, p. 128) creem em cinco promotores mais valoroso da criação do conhecimento organizacional: incutir uma visão de conhecimento, a gestão de conversação, a mobilização de ativistas do conhecimento, a criação do contexto correto e globalização.

Takeuchi e Nonaka (2008, p. 128) declaram ainda que para a criação eficiente do conhecimento, existe a necessidade de um contexto promotor, que é uma zona compartilhada que contribui as relações os colaboradores, fundado no Ba (ou "espaço"), tal conjuntura empresarial pode ser física, virtual ou mental - ou os três juntos.

\subsubsection{DISSEMINAÇÃO DO CONHECIMENTO ORGANIZACIONAL}

De acordo com Takeuchi e Nonaka (2008, p. 99), o conhecimento é sujeito a um tempo e espaço delimitado, não apenas da cognição de um indivíduo e não pode ser criado no vácuo, depende-se de um lugar em que é disseminado, utilizado e criado o conhecimento. Sendo assim, a instituição tem o dever de prover um lugar (contexto) para que as informações ganhem significado por meio das interpretações e tornem conhecimento. Ainda de acordo com os autores, tal lugar é denominado "Ba".

Naturalmente é fácil imaginar o $\mathrm{Ba}$ como interações em espaços físicos (salas de reunião), no entanto $\mathrm{O} \quad \mathrm{Ba}$ é um local existencial, os nos indivíduos compartilham seu contexto através de interações que podem ocorrer em espaços virtuais, grupos de trabalho ou grupos de e-mail.

Figura 4 - Representação conceitual do Ba

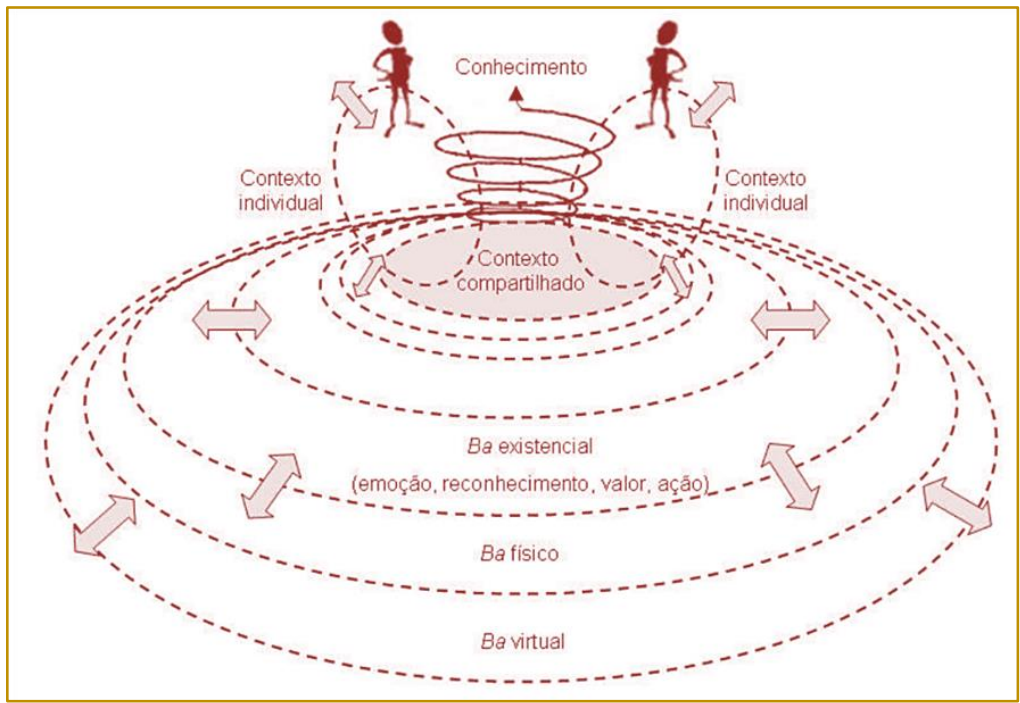

Fonte: Takeuchi e Nonaka (2008, p. 100)

Os autores Nonaka, Toyama e Konno (2000, p. 16) revelam quatros tipos de Ba que ocorre em tempo e espaço específico sendo conveniente para nível o modelo SECl:

- Ba da Criação ou Originário - é a conjuntura no qual os indivíduos trocam sentimentos, emoções, experiências e modelos mentais, removendo, pela empatia e pela confiança, as barreiras que dificultam a troca de conhecimento tácito entre os indivíduos;
- Ba da Interação ou Ba Interativo - é o contexto conscientemente construído para reunir uma mistura de pessoas com específicos conhecimentos e capacidades em eventos na organização (ex: projetos, força-tarefa, reuniões etc.). A reflexão coletiva que acontece nesses eventos é chave para tornar o conhecimento comum a todos;

- Ba Virtual / Cyber Ba - quando as interações entre o conhecimento explícito novo e o existente acontece no mundo virtual em vez de no local físico; 
- $\quad$ Ba Prático / Ba do Treinamento - é o contexto em que o conhecimento explícito torna-se tácito para os indivíduos, suportado principalmente por: treinamento e coaching recebido por mentores, conhecimento formalizado (manuais) e aplicativos que permitam simulações e experiências.

\subsection{SISTEMA DE GESTÃO DO CONHECIMENTO RELACIONADO COM A TECNOLOGIA DA INFORMAÇÃO}

Em um mundo globalizado a tecnologia da informação tem um papel essencial de ser uma ferramenta que viabiliza os processos e auxiliam aos gestores na tomada de decisão. Dentro dos princípios fundamentais da Gestão do Conhecimento organizacional, a tecnologia da informação tem o papel essencial da captação, disseminação e armazenamento da informação. (Angeloni, 2008).

Segundo Rossetti e Morales (2007) , a tecnologia da informação precisa ser uma aliada a gestão do conhecimento, para que propicie um Ba Virtual eficiente e organizado, onde o papel a tecnologia da informação é dar suporte.

Na Tecnologia da informação, as informações são divididas em estruturadas e não estruturadas. As informações estruturadas são informações que foram refinadas, são elas: relatórios, formulários dentre outros dispositivos que ligam informações. (Melo, 2003, p. 57)

Figura 5 - As interações de TI e Gestão do Conhecimento

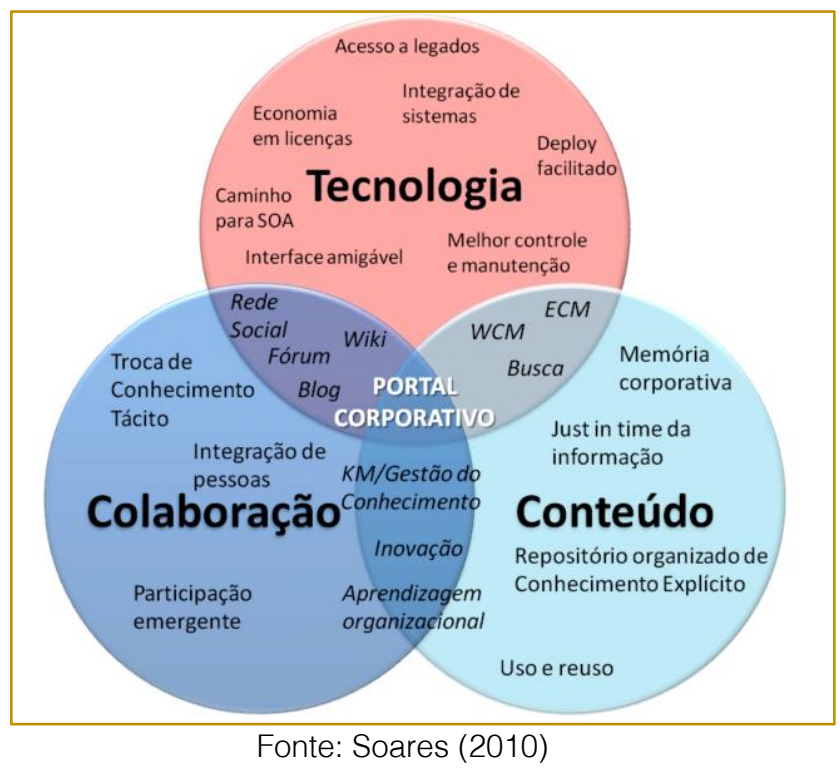

O conhecimento é oriundo dos indivíduos, eles que interpretam, agregam e transformam as informações em conhecimento. Para MELO (2003), algumas ferramentas da tecnologia da informação para apoio à gestão ao conhecimento são:

- Web Services: Integração entre sistemas de diferentes empresas;

- Web logs: também conhecido como Blog, um site que registra experiências pessoais;

- Cursos interativos e a distância: são cursos eletrônicos que podem ser realizados fora do ambiente corporativo ou em salas de aulas, possibilitando também a acessibilidades com as novas tecnologias;

- Rede de conhecimento: ambiente virtual em que pessoas que têm interesses em comum;

- Rede de relacionamento: ambiente virtual em que pessoas compartilham suas vidas com seu círculo de relacionamento; 
- Fóruns especializados: são páginas de internet que promovem debates de um assunto específico;

- Intranets: rede local, circunscrita aos limites internos da organização;

- Workflow gerenciamento de fluxo de documentos.

\section{ESTUDO DE CASO}

\subsection{COMPARTILHAMENTO \\ CONHECIMENTO}

Entendido que o $\mathrm{Ba}$ como interações em espaços físicos é essencial para a criação do conhecimento organizacional (TAKEUCHI e NONAKA, 2008), por esta razão, a corporação RIO 2016 planejou a organização com um arranjo físico que fomentasse a interações das áreas funcionais.

Cada gestor de uma área funcional, utilizou os modos de externalização em conjunto com $\mathrm{Ba}$ Interação (conversão do conhecimento tácito para o explícito), através de reuniões e batepapos, incentivando também o modo de combinação (conhecimento explícito com conhecimento explícito), no qual os indivíduos do grupo buscam no sistema de gestão do conhecimento do IOC arquivos que auxiliem e facilitem na sua tarefa.

A área de tecnologia da informação era responsável para dar apoio na interligação de comunicação e compartilhamento de arquivos e garantir a segurança externa e interna (documentos com restrição). No entanto, diversos arquivos eram de interesse geral para o planejamento. A área funcional de IKM (gestão de conhecimento e informação) identificava essas informações e as gerenciava para que todos tivessem acesso à informação atualizada. Trabalhando as áreas funcionais de tecnologia da informação e a de IKM em conjunto, foi escolhido utilizar a ferramenta Sharepoint que é um software de gestão de documentos. Utilizando esta ferramenta, a corporação RIO 2016criou seu portal do conhecimento chamado: Colaboração RIO 2016, no qual, cada área funcional possui uma comunidade (lugar virtual) para criar, editar, gerir e compartilhar seus documentos.

Eram também criadas comunidades de acordo com os encargos compartilhados, onde colaboradores de diversas áreas funcionais compartilhavam os desafios e soluções através dos fóruns que a ferramenta possibilitada criar e o armazenamento e compartilhamento dos documentos relacionados ao encargo.

Para todo controle, planejamento e gestão, algumas informações são de interesses comuns entre todas as áreas, a área funcional IKM identificava estas informações e documentos e eram compartilhados em comunidades de acesso irrestrito de leitura.

Para conversões de conhecimento tácito para explícito a corporação RIO 2016 utilizou treinamentos e incentivou outras áreas a realizar, trabalhando juntamente com departamento de recursos humanos. Um dos treinamentos obrigatórios ensinava $\mathrm{o}$ uso destes portais e a grande importância do compartilhamento das informações, para dissuadir a resistência a mudança das pessoas.

Figura 6 - Treinamentos realizados - RIO 2016

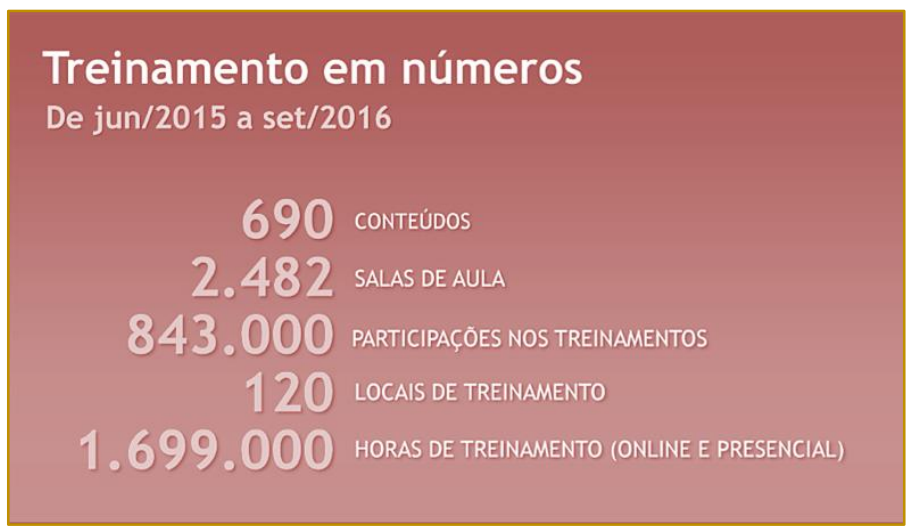

Fonte: Corporação Rio2016. 
Uma das formas de fazer o compartilhamento de conhecimento tácito para tácito entre os colaboradores, a IKM realizava demonstrações internas, onde cada área funcional, em uma data, demostrava no auditório para todos que quisessem ouvir, sobre as atividades realizadas pela área funcionar na atualidade e compartilhava os planejamentos e motivos dessa elaboração, estando aberto para perguntas.

Mais uma forma deste compartilhamento decorria por meio da observação de eventos de grande porte. A IKM realizava visitas técnicas, com vagas limitadas, chamadas Observações RIO 2016, no qual era divulgando na intranet a possibilidade de observações como Rock in Rio 2013, Nanjing 2014, Toronto 2015; a todos os funcionários que se interessava. Essas observações o grupo de funcionários acompanhava a execução do evento e seus bastidores, vivenciando e capturando esses conhecimentos compartilhados.

Observado que Ba não se limita os limites da organização (TAKEUCHI e NONAKA, 2008), a RIO2016 utilizava também como estratégia de inovação a parceria de compartilhando de conhecimento Inter organizacional. Esse compartilhamento ocorria através do compartilhamento do planejamento do uso e necessidade de produtos e serviços dos fornecedores, ocorrendo uma parceria de planejamento, pois as empresas fornecedoras detinham maior conhecimento do produto ou serviço, colocando novas ideias, sugestões e até mesmo criação de novos produtos ou serviços de acordo com a demanda do RIO 2016. Esses apoiadores teve um papel essencial nos jogos RIO 2016 que através do

\section{REFERÊNCIAS}

[1] Angeloni, M. T. Organizaçoes do Conhecimento: Infra-Estrutura, Pessoas e Tecnologia. $2^{\circ}$. ed. São Paulo: Saraiva, 2008.

[2] Choo, C. W. A Organização do Conhecimento: como as organizações usam a informação para criar significado, construir conhecimento e tomar decisões. São Paulo: Senac, 2003

[3] Dane, F. C. Research Methods. California: Pacific Grove, 1990

[4] Davenport, T. H.; Prusak, L. Conhecimento empresarial: como as organizações gerenciam o seu capital intelectual. Rio de Janeiro: Campus, 1999. compartilhamento das informações de ambas se criou a solução.

Um dos exemplos dessa interação foi do trabalho em conjunto da corporação RIO 2016 com a Embratel que foi a patrocinada e fornecedora oficial, que além de possibilitar a transmissão dos Jogos Rio 2016, ao vivo e $24 \mathrm{~h}$, para cerca de 5 bilhões de espectadores de 200 países, a Embratel forneceu também soluções de vídeo, dados, voz, Wi-Fi, Internet 3G e 4G, Segurança e 2 Data Centers dedicados. Foram 370 quilômetros de fibra ótica interligando as mais de 110 instalações olímpicas. (EMBRATEL, 2016)

Outro exemplo foi com a patrocinadora GE que desenvolveu de acordo com a demanda vista por ela, novas lâmpadas capazes de emitir perfeição a todos os espectros deluz captados pelo olho humano, com uma potência e frequência suficiente par filmagens em alta definição a centenas de quadro por segundo (slow motion) e com projetos de Big Data para estudo de dados para maior eficiência do atleta e projetos sustentáveis.

\section{CONCLUSÕES}

Este trabalho teve a pretensão de apresentar as ferramentas de gestão de conhecimento usadas pela corporação RIO 2016, como fonte de inovação em seus serviços prestados. Também se mostrou evidente que o compartilhamento de conhecimento é inseparável na criação de novos conhecimentos e como o conhecimento é essencial para uma empresa ser competitiva e inovadora.

[5] Drucker, P. Sociedade Pós-capitalista. $3^{a}$. ed. São Paulo: Actual Editora, 2003.

[6] Drucker, P. F. Desafios Gerenciais para o Século XXI. São Paulo: Pioneira, 2000.

[7] Embratel. Portal Embratel. Portal Embratel, 2016. Disponivel em: <http://portal.embratel.com.br/rio2016/>. Acesso em: 1 Abril 2017

[8] Fundação Nacional da Qualidade. Informação e conhecimento: imprescindíveis para uma boa gestão. FNQ - Gestão para Excelência, $2014 . \quad$ Disponivel em: <http://www.fnq.org.br/informe-se/artigos-eentrevistas/artigos/informacao-e-conhecimentoimprescindiveis-para-uma-boa-gestao>. Acesso em: 22 Abril 2016. 
[9] Hessen, J. Teoria do Conhecimento. Tradução de João Vergílio Gallerani Cuter. 4a․ ed. São Paulo: Wmf Martins Fontes, 2012.

[10] Infoway. InfoWay. Click Infoway, 2013. Disponivel

em:

$<$ https://clickinfoway.wordpress.com/2013/03/10/un idade-3-e-4/>. Acesso em: 22 Maio 2016.

[11] Melo, L. E. V. D. Gestão do Conhecimento - Conceitos e Aplicações. São Paulo: Érica, 2003.

[12] Miguel, P. A. C. Metodologia de pesquisa em engenharia de produção e gestão de operações. Rio de Janeiro: Augusto Cauchick, 2011.

[13] Nonaka, ; Toyama, R.; Konno, N. Seci, Ba and Leadership: a Unified Model of Dynamic Knowledge Creation. Long Range Planning, v. 33, p. 5-34, February 2000

[14] Nonaka, I.; Takeuchi,. Criação de Conhecimento $\mathrm{Na}$ Empresa. 20aㅡ. ed. Rio de Janeiro: Elsevier Brasil, 1997.

[15] Rossetti, A. G.; morales, A. B. T. O papel da tecnologia da informação na gestão na Gestão do Conhecimento. Ci. Inf, Brasília, v. 36, n. 1, p. 124 - 135, Janeiro 2007.

[16] Rossman, G. B.; Marshall, C. Designing qualitative research. Nova lorque: Sage Publications, 2010.

[17] Senge, P. M. A Quinta Disciplina - A Arte e A Prática da Organização Que Aprende. 29ª . ed. São Paulo: Best Seller, 2013.

[18] Soares, L. Gestão do Conhecimento. Competitive Intelligence, 2010. Disponivel em: $<$ https://lilianasoares.wordpress.com/2010/06/08/g estao-do-conhecimento>. Acesso em: 22 Maio 2016.

[19] Stewart, T. A. Capital Intelectual: a nova vantagem competitiva das empresas. $2^{2}$. ed. Rio de Janeiro: Campus, 1998.

[20] Takeuchi, H.; Nonaka, I. Gestão do Conhecimento. Tradução de Ana Thorell. Porto Alegre: Bookman, 2008.

[21] Yin, R. K. Estudo de Caso - Planejamento e Métodos. Tradução de Cristhian Matheus Herrera. 5a. ed. Porto Alegre: Bookman, 2015. 


\section{Capítulo 14}

\section{O PROCESSO DE INOVAÇÃO DISRUPTIVA ATRAVÉS DO EMPREENDEDORISMO}

\section{Alyne Madeira Kautnick}

Resumo: Este artigo tem como escopo analisar de que modo o empreendedorismo pode colaborar na criação de oportunidades para a inovação disruptiva. Considerase que é necessária uma melhor compreensão acerca de como ocorrem essas inovações, haja vista sua importância sócio-econômica. Com base em uma revisão bibliográfica e uma busca sistemática da literatura existente sobre os temas, buscou-se traçar um panorama teórico que pudesse contribuir com as pesquisas na esfera das inovações disruptivas e do empreendedorismo, de modo a entender as condições e os mecanismos causais que influenciam esse modelo de inovação. Como resultado obteve-se que empresas com maior capacidade empreendedora possuem mais oportunidades para inovar disruptivamente. 


\section{INTRODUÇÃO}

O termo "inovação" pode ser classificado sob vários pontos de vista e variações no que concerne ao seu conceito (TROTT, 2008). Quanto ao seu grau de impacto, Tidd, Bessant e Pavitt (2015) separam em inovações incrementais, radicais e disruptivas, cada qual com suas respectivas particularidades.

No caso das inovações disruptivas, há geralmente 0 envolvimento de novas tecnologias, o que exige mudanças nos padrões de consumo. São consideradas bastante desafiadoras, haja vista o alto nível de incerteza quanto à sua viabilidade tecnológica e à sua comercialização. Somase a capacidade de vinculá-las à oportunidades de mercado, uma vez que criam seu próprio mercado. Por fim, essas inovações são atípicas, ou seja, podem surgir de empresas heterogêneas em diferentes setores (Sandberg, 2002).

Nesse sentido, entende-se que os "disruptores" veem as oportunidades de modo diferente dos operadores históricos. E é através dessa visão diferenciada que ocorrem as mudanças nas economias emergentes, tais como China, Índia e outros países asiáticos. Observando que a maioria de suas populações não podem pagar produtos estrangeiros projetados para o "mundo desenvolvido", essas nações emergentes desenvolvem inovações que são acessíveis e suficientemente boas para atender as necessidades básicas de seus consumidores a um custo relativamente baixo em comparação aos produtos importados (HANG, GARNSEY E RUAN, 2014).

Esses disruptores podem, eventualmente, ameaçar mercadologicamente a versão mais alto-nível e custosa desses produtos; ou seja, essas inovações, inicialmente direcionadas aos mercados emergentes, se levadas à escala global ao longo do tempo, podem reverter o progresso usual da inovação de países desenvolvidos para esses mercados.

No decorrer dos últimos anos, o conceito de inovação disruptiva foi sendo mais esclarecido à medida que mais casos foram examinados na literatura (YU; HANG, 2009). Esses estudos evidenciam que os empreendedores, cujas inovações se tornam disruptivas, estão ativamente envolvidos na descoberta e criação de oportunidades.
Em virtude da relevância desse modelo de inovação, tanto nas economias emergentes como nas mais avançadas, faz-se necessário entender como a busca de oportunidades pode resultar em inovações disruptivas.

Christensen e Bower (1996), afirmam que as inovações disruptivas têm implicações na detecção e criação de oportunidades empreendedoras, uma vez que ocorrem quando os operadores históricos não estão preparados para a erosão de seus mercados por uma inovação inicialmente inferior em termos de desempenho.

Por essa razão, o empreendedorismo é um fator crítico e relevante no estudo da inovação disruptiva, posto que ele permite explorar novas oportunidades, bem como envolve a criação de novos mercados (HANG; GARNSEY; RUAN, 2014).

Segundo Timmons e Spinelli (2008), o empreendedorismo é "uma maneira de pensar, raciocinar e agir [...], com o propósito de criação e captura de valor". Isso significa que, essencialmente, o empreendedorismo está atrelado ao reconhecimento de oportunidades, seguidas pela vontade e iniciativa para aproveitar essas oportunidades, o que exige uma disposição para assumir riscos - tanto pessoais como financeiros -, mas de forma bastante calculada, a fim de mudar constantemente as chances de sucesso, equilibrando o risco com a recompensa potencial (TIMMONS; SPINELLI, 2008).

Salienta-se que, apesar de muitos pesquisadores relacionarem constantemente os temas "inovação" e "empreendedorismo", poucos adentram na esfera das inovações disruptivas (CHANDRA; YANG 2011).

Ademais, Chandra e Yang (2011) também destacam a importância do papel da dinâmica empreendedora no que concerne o estudo das inovações disruptivas, buscando preencher essa lacuna em suas extensivas pesquisas.

De modo similar, este artigo busca entender de que modo o empreendedorismo pode colaborar na criação de inovações disruptivas, através de uma revisão bibliográfica e uma busca sistemática da literatura existente sobre esses dois temas.

Este artigo está estruturado em 5 seções, considerando esta introdução. Na seção 2, apresenta-se a metodologia, baseada em 
uma revisão da literatura e uma busca sistemática. Essa revisão serviu como base para definir os conceitos de empreendedorismo e inovação disruptiva, que são apresentados na seção 3, bem como discutir a contribuição do empreendedorismo para inovação disruptiva, apresentado na seção 4. Por fim, na seção 5 estão dispostas as considerações finais.

\section{METODOLOGIA}

Esta pesquisa pode ser caracterizada como descritiva, uma vez que este tipo de pesquisa tem "[...] como objetivo primordial a descrição das características de determinada população ou fenômeno ou, então, o estabelecimento de relações entre variáveis"(GIL, 2002).

Referente à coleta de dados, foi realizada por meio de pesquisas bibliográficas em bases científicas, em dois momentos. Primeiramente, foram coletadas publicações referentes aos temas de estudo "empreendedorismo" e "inovação disruptiva" em bases de dados a fim de formar um referencial teórico base.

Em um segundo momento, realizou-se uma busca sistemática da literatura sobre os temas visando identificar de que modo os estudos sobre empreendedorismo podem contribuir na criação de oportunidades no âmbito da inovação disruptiva.

Desse modo, seguiu-se os seguintes passos:

Identificação da base de dados: Foi utilizada a base de dados Scopus, por ser uma base interdisciplinar e a maior base de dados de produções científicas (literatura revisada por pares: revistas científicas, livros e conferências), compondo mais de 60 milhões de registros (ELSEVIER, 2018).

Definição da estratégia de busca: Os artigos foram selecionados usando os termos "disruptive innovation" and "entrepreneurs*" (apenas em títulos, resumos e palavraschave), durante o período de setembro de 2017 a maio de 2018. Essa pesquisa limitouse aos anos 2000 e 2018, de modo a abranger os estudos mais recentes desenvolvidos nas temáticas propostas. Salienta-se que estes são os anos de maior concentração de documentos. Com base nesses parâmetros, foram encontrados 78 (setenta e oito) documentos.

Critérios de eleição: Como principal critério verificou-se se o artigo relaciona as duas variáveis (empreendedorismo e inovação disruptiva), além de apresentar a definição clara de inovação disruptiva e empreendedorismo.

Seleção dos estudos: Os estudos foram selecionados utilizando os critérios de elegibilidade a partir da leitura dos títulos, palavras-chave e resumos dos artigos. Desse modo, verificou-se que apenas 15 (quinze) apresentavam os critérios necessários. Estes artigos foram lidos integralmente.

Inclusão de registros: Com a leitura mais detalhada dos artigos constatou-se, nas referências destes, documentos que poderiam ser incluídos. Com isso, outros 7 (sete) artigos foram adicionados, alguns deles são clássicos como Kirzner (1973), Mises (1978), Casson (1983), Stevenson e JarilloMossi (1986), Bull e Willard (1993), Christensen e Bower (1996), Morris (1998). Ao final, formou-se um portfólio com 22 (vinte e dois) artigos.

Coleta de dados: Foram coletados dados dos artigos selecionados, em uma planilha eletrônica, referentes ao seu objetivo, metodologia, contexto e resultados. Estes dados permitiram fazer as análises apresentadas neste artigo.

Síntese dos resultados: Obteve-se como resultado o portfólio com 22 (vinte e dois) artigos, dos quais 19 (dezenove) foram utilizados para definir os conceitos de inovação disruptiva e empreendedorismo. Os demais foram utilizados para discutir a contribuição do empreendedorismo na inovação disruptiva. No Quadro 1, observa-se o portfólio final, o qual permite compreender como estão distribuídos os estudos sobre as temáticas empreendedorismo e/ou inovação disruptiva no decorrer dos anos. 
Quadro 1: Distribuição dos estudos sobre empreendedorismo e/ou inovação disruptiva

\begin{tabular}{|c|c|c|}
\hline Autor & Ano & Temática \\
\hline Kirzner & 1973 & Empreendedorismo \\
\hline Mises & 1978 & Empreendedorismo \\
\hline Casson & 1983 & Empreendedorismo \\
\hline Stevenson e Jarillo-Mossi & 1986 & Empreendedorismo \\
\hline Bull e Willard & 1993 & Empreendedorismo \\
\hline Christensen \& Bower & 1996 & Inovação Disruptiva e Empreendedorismo \\
\hline Morris & 1998 & Empreendedorismo \\
\hline Swedberg & 2000 & Empreendedorismo \\
\hline Shane e Venkataraman & 2000 & Empreendedorismo \\
\hline Sandberg & 2002 & Inovação Disruptiva \\
\hline Thomond \& Lettice & 2002 & Inovação Disruptiva \\
\hline Anthony e Christensen & 2005 & Inovação Disruptiva \\
\hline Hwang e Christensen & 2007 & Inovação Disruptiva \\
\hline Timmons e Spinelli & 2008 & Empreendedorismo \\
\hline Yu e Hang & 2009 & Inovação Disruptiva \\
\hline Morris, Kuratko \& Covin & 2010 & Empreendedorismo \\
\hline Martes & 2010 & Empreendedorismo \\
\hline Chandra e Yang & 2011 & Inovação Disruptiva e Empreendedorismo \\
\hline Hang, Garnsey e Ruan & 2014 & Inovação Disruptiva \\
\hline Hang, Garnsey e Ruan & 2014 & Inovação Disruptiva e Empreendedorismo \\
\hline Christensen, Raynor e McDonald & 2015 & Inovação Disruptiva \\
\hline Kuratko & 2016 & Empreendedorismo \\
\hline
\end{tabular}

Fonte: os autores

\section{REVISÃO TEÓRICA DOS CONCEITOS}

\subsection{INOVAÇÃO DISRUPTIVA}

O termo "inovação disruptiva" refere-se a uma nova tecnologia com custos e desempenho relativamente menores em relação às dominantes no mercado. Isso significa que estas tecnologias geralmente focam seus esforços em seus clientes mais exigentes e/ou lucrativos, excedendo as necessidades de alguns segmentos e ignorando as de outros. Já as tecnologias advindas da inovação disruptiva possuem a capacidade de atingir de forma satisfatória esses segmentos esquecidos, visto que oferecem funcionalidades mais adequadas com um preço mais acessível (CHRISTENSEN, RAYNOR; MCDONALD, 2015).
Logo, essas inovações disruptivas elevam seu nível de mercado e passam a oferecer a mesma performance das tecnologias dominantes, preservando as vantagens iniciais, e atingindo os segmentos mais exigentes. Dessa forma, quando esses segmentos passam a adotar essas inovações de modo significativo, considera-se que ocorreu uma "disrupção".

Hwang e Christensen (2007) afirmam que, apesar de esse não ser o foco inicial de uma inovação disruptiva, uma vez que o produto e/ou serviço disruptivo está consideravelmente estabelecido no mercado, este pode tornar-se alvo de clientes alto-nível, visto que suas necessidades podem ser atendidas por essa nova tecnologia. 
Considerando as análises de Thomond e Lettice (2002), "uma inovação disruptiva é um produto, serviço ou modelo de negócios explorado com sucesso, que transforma significativamente as demandas e necessidades de um mercado convencional e perturba seus antigos jogadores-chave".

Ainda de acordo com Thomond e Lettice (2002), esse modelo de inovação possui as seguintes características:

1) Começa seu sucesso atendendo às necessidades insatisfeitas de um mercado emergente ou de um nicho.

2) Seu conjunto de atributos de desempenho, altamente avaliados por clientes de nicho de mercado, não são inicialmente apreciados pelos mercados convencionais. Os clientes principais do mercado, bem como os concorrentes, valorizam diferentes conjuntos de atributos de desempenho e, portanto, consideram a inovação como de qualidade inferior.

3) A adoção do mercado de nicho permite que o investimento no modelo de produto, serviço ou negócio aumente seu desempenho. Pode, então, criar ou inserir novos mercados de nicho e expandir os números de clientes.

4) A conscientização do produto, serviço ou modelo de negócio aumenta, forçando e influenciando a mudança na percepção dos mercados convencionais sobre o que estes valorizam.

5) A mudança na percepção do mercado dominante sobre o que valoriza é o catalisador que permite que a inovação perturbe e substitua produtos, serviços ou modelos comerciais existentes.

Yu e Hang (2009) afirmam que "a inovação disruptiva ocorre através de um processo". Citando os estudos de Christensen, os autores discorrem sobre como as tecnologias disruptivas fornecem valores diferentes das tecnologias convencionais. Durante o processo transitório, quando ocorre a "disrupção", é possível traçar as trajetórias de desempenho do produto fornecidas pelas empresas e exigidas pelos clientes para diferentes tecnologias e segmentos de mercado, demonstrando que a inovação disruptiva ocorre quando essas trajetórias se cruzam.

Os autores ainda mencionam que "a inovação disruptiva é um poderoso meio de ampliar e desenvolver novos mercados e fornecer novas funcionalidades, o que, por sua vez, pode prejudicar as ligações existentes no mercado" (YU; HANG, 2009).

De acordo com Chandra e Yang (2011), a inovação disruptiva não deve ser definida meramente do ponto de vista do sucesso tecnológico, mas também deve incluir o sucesso comercial. Ou seja, a teoria da inovação disruptiva pode ajudar a entender de que forma produtos e serviços muitas vezes inacessíveis a um determinado segmento do mercado podem ser convertidos em modelos mais simples e disponíveis comercialmente.

Deve-se salientar que, em sua fase inicial de desenvolvimento, cada produto baseado em uma determinada inovação disruptiva serve os segmentos que valorizam seus atributos de desempenho não-convencionais. Com o passar do tempo, conforme for se desenvolvendo, o desempenho dessa inovação pode alcançar nível suficiente para satisfazer os clientes convencionais. Chandra e Yang (2011) também ponderam que, embora o desempenho de uma inovação disruptiva seja aperfeiçoado, esta tende a permanecer inferior se comparada com as tecnologias já estabelecidas.

Christensen, Raynor e McDonald (2015) propõem o modelo abaixo para ilustrar de que forma a inovação disruptiva está inserida no mercado: 


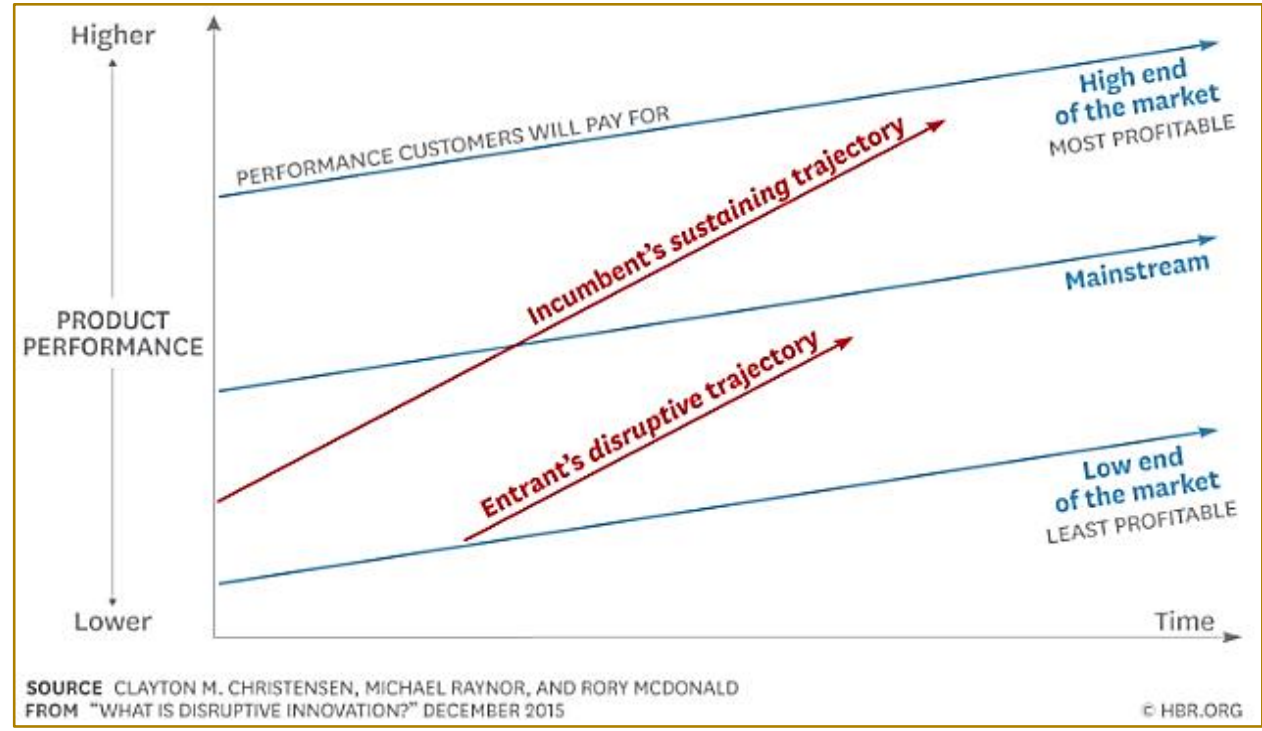

Esse modelo contrasta as trajetórias de desempenho de um determinado produto (linhas vermelhas que mostram como os produtos ou serviços melhoram ao longo do tempo) com as trajetórias da demanda do cliente (linhas azuis mostrando a disposição dos clientes de pagar pelo desempenho). Percebe-se que, à medida que as empresas em exercício introduzem produtos ou serviços de alta qualidade (linha vermelha superior) para satisfazer $\mathrm{O}$ alto mercado (onde a rentabilidade é mais alta), ultrapassam as necessidades dos clientes de baixo custo e de muitos clientes convencionais. Isso deixa uma abertura para que os participantes encontrem pontos de apoio nos segmentos menos lucrativos, que os operadores históricos estão negligenciando. Em seguida, os participantes em uma trajetória disruptiva (linha vermelha mais baixa) melhoram o desempenho de suas ofertas e se mudam (onde a rentabilidade é mais alta para eles também), desafiando o domínio dos operadores históricos.

De acordo com os teóricos Thomond e Lettice (2002), pode-se considerar que:

\footnotetext{
A inovação disruptiva só começa a ser realmente percebida quando o mercado muda para adotar um novo paradigma no que ele chama de "tornado" de adoção. Uma vez que o tornado começa, não demora muito para que a maioria dos potenciais clientes no mercado tenha sofrido mudanças dramáticas em seu comportamento passado com a promessa de obter benefícios igualmente dramáticos do novo paradigma. (THOMOND; LETTICE, 2002)
}

De modo resumido, conforme as empresas tendem a inovar mais rapidamente do que as necessidades de seus clientes evoluem, elas acabam produzindo produtos ou serviços que são muito sofisticados, caros e complicados para muitos clientes em seu mercado.

Essas empresas buscam atender as demandas dos níveis mais altos de seus mercados, uma vez que, ao cobrar os preços mais altos aos seus clientes mais exigentes e sofisticados no topo do mercado, elas alcançam uma maior rentabilidade.

Todavia, atendendo apenas às demandas dos clientes mais rentáveis, essas empresas, involuntariamente, permitem que inovações disruptivas conquistem espaço na parte inferior do mercado, trazendo alternativas com custos mais acessíveis.

Por fim, essas alternativas, com desempenho inicial não adequado aos padrões exigidos pelos níveis mais altos de mercado, são capazes de melhorar esses critérios e atender às demandas de clientes mais exigentes.

\subsection{EMPREENDEDORISMO}

$O$ ato de empreender, também conhecido como "empreendedorismo", é o "processo de criação de valor, reunindo uma combinação única de recursos para explorar uma oportunidade" (STEVENSON; JARILLOMOSSI, 1986).

Embora esse termo esteja em uso há mais de 200 anos, pode-se considerar que existe bastante desacordo em relação ao seu significado. Diversos autores e estudiosos da 
área possuem opiniões consideravelmente diferentes sobre o tema, seja a respeito de como identificar um empreendedor ou até mesmo a natureza das atividades que o constituem (MORRI, KURATKO; COVIN, 2010).

Martes (2010) afirma que "adaptar, crescer, administrar eficientemente a rotina de uma empresa não significa empreender". Mais do que isso, a autora ressalta que é necessário inovar para que ocorra o empreendedorismo; e não somente adequar-se às mudanças de modo a manter-se competitivo no mercado. Ela ainda pondera, citando os estudos de Schumpeter, que "competir para sobreviver não é empreender" (MARTES, 2010).

\section{Ainda de acordo com Martes (2010):}

O tipo de empreendedor schumpeteriano guarda uma grande distância dos empreendedores atualmente retratados na literatura em administração, principalmente porque para este autor empreender é sobretudo inovar. E aqui não se trata de qualquer tipo de inovação, senão aquela de caráter pioneiro e transformador. 0 empresário pioneiro inova e lidera um processo de mudança que extrapola os domínios de seu negócio e da sua própria esfera de atuação (MARTES, 2010).

Os teóricos Morris, Kuratko e Covin (2010) consideram que empreendedorismo é "criar organizações, mudanças, inovação e riqueza". Através desse conceito, é possível perceber que o termo "criação" é a base do empreendedorismo, o qual pode ser visto como "a aplicação de energia para iniciar um conceito novo ou construir um empreendimento, em vez de apenas assistir ou analisar" (MORRIS; KURATKO; COVIN, 2010).

Ademais, segundo Morris (1998), existem sete perspectivas sobre a natureza do empreendedorismo, sendo elas: 1. Criação de riqueza; 2. Criação de empresa; 3. Criação de inovação; 4. Criação de mudança; 5. Criação de empregos; 6. Criação de valor; e 7 . Criação de crescimento. Isso significa que o empreendedorismo envolve, essencialmente, um processo de criação.

Schumpeter, no seu livro The Theory of Economic Development (1911), pontua que "o empreendedorismo pode ser definido como a criação de uma nova combinação de materiais e forças já existentes", demonstrando que empreender consiste em fazer inovações e não invenções. O autor também sustenta a ideia de que ninguém é um empreendedor para sempre; apenas quando ele ou ela está realmente fazendo a atividade inovadora (SWEDBERG, 2000).

Segundo Bull e Willard (1993), "o ambiente indubitavelmente influencia o empreendedorismo: pode ser solidário, mas também pode fornecer obstáculos". Esses autores acreditam que o empreendedorismo ocorrerá, sob condições de: 1. Motivação relacionada à tarefa; 2. Expertise; 3. Expectativa de ganho para si próprio; e 4. Um ambiente de apoio.

Swedberg (2000), citando os estudos de Mark Casson e Israel Kirzner, discorre sobre duas formas de entender o empreendedorismo: a primeira, de acordo com Casson (1983), define o empreendedor como "uma pessoa especializada em tomar decisões sobre como coordenar os recursos escassos"; a segunda, segundo Kirzner (1973), afirma que "o empreendedorismo significa alerta para as oportunidades de lucro, as quais ajudam a restaurar o equilíbrio do mercado".

Nesse âmbito, deve-se atentar para o contraste entre as teorias de Kirzner e Schumpeter, visto que este vê o empreendedor como alguém que justamente rompe o equilíbrio através de uma inovação (SWEDBERG, 2000).

Outro teórico que também concentrou seus estudos na área de empreendedorismo é Ludwig von Mises. Ele, ao contrário de Kirzner, possui uma visão bastante similar à de Schumpeter. Mises (1978) considera que "quando a economia está em um ciclo estável e repetitivo de equilíbrio, não há lugar para o empreendedorismo". Todavia, Mises difere-se de Schumpeter ao definir o fenômeno empreendedor como "antecipação de eventos incertos e não como inovações" (SWEDBERG, 2000).

Sobre a relação entre empreendedorismo e inovação, Swedberg (2000) considera que:

\footnotetext{
Embora as palavras "inovação" e "empreendedorismo" sejam agora tão familiares quanto eram estranhas aos executivos e gerentes de pessoas há uma década, a prática de ambos ainda é limitada em grande parte às empresas que as praticavam há uma década - isto é, para as empresas de quem o autor aprendeu a ser um inovador e um empreendedor. A maioria
} 
das outras empresas - a grande maioria de ambas, grandes e pequenas empresas ainda acredita que a inovação é inspiração e empreendedorismo é pura sorte. (SWEDBERG, 2000)

Timmons e Spinelli (2008) vêem o empreendedorismo como a aplicação de energia para iniciar um novo conceito, em vez de apenas assistir ou analisar. Essa visão exige uma disposição para assumir riscos calculados e, em seguida, fazer todo o possível para reduzir as chances de falha. Enfim, o empreendedorismo também pode ser visto como a habilidade de perceber a oportunidade onde outros veem caos, contradição e confusão.

\section{RESULTADOS}

É possível perceber que, de acordo com os artigos analisados neste estudo, durante as décadas de '70 e '90, foram desenvolvidos diversos estudos sobre empreendedorismo (Kirzner, 1973; Mises, 1978; Casson, 1983; Stevenson e Jarillo-Mossi, 1986; Bull e Willard, 1993; Morris, 1998). Já no que concerne os estudos desenvolvidos na esfera das inovações disruptivas, pode-se verificar que são consideravelmente mais recentes (Sandberg, 2002; Thomond e Lettice, 2002; Anthony e Christensen, 2005; Hwang e Chritensen, 2007; Yu e Hang, 2009). Constata-se também que os estudos sobre ambos os temas, de forma relacionada, exceto o pioneiro desenvolvido por Christensen e Bower (1996), estão concentrados na última década (Chandra e Yang, 2011; Hang, Garnsey e Ruan, 2014).

Bastante similar ao conceito de "destruição criativa" de Schumpeter, pode-se considerar que a inovação disruptiva está implícita no discurso e nas tradições da pesquisa sobre empreendedorismo. Contudo, deve-se salientar que há uma escassez de pesquisas naquele domínio que adotam a perspectiva empreendedora.

Segundo Chandra e Yang (2011), "há três elementos importantes da investigação do empreendedorismo que não são bem compreendidos no contexto da inovação disruptiva: (1) as fontes de oportunidade (2) a incerteza na ação empreendedora e (3) a lógica empresarial".

Isso significa que "qualquer discussão sobre empreendedorismo pode ser incompleta se não houver referência a um de seus conceitos fundamentais: a incerteza". Ou seja, apesar dos inúmeros questionamentos acerca de como os empresários, sejam operadores históricos ou novos operadores, podem perceber e lidar com essas incertezas, ainda não é possível compreender a natureza dessa incerteza, visto que "cada tipo [de incerteza] requer diferentes tipos de ações empreendedoras" (CHANDRA; YANG, 2011).

Os autores Anthony e Christensen (2005) consideram que algumas empresas interessadas na criação de inovações disruptivas nem sempre são capazes de identificar as melhores estratégias para sua implantação:

[... uma empresa de eletrônicos com a qual trabalhamos pensou que tinha uma inovação disruptiva no mercado. Houve dois problemas com sua avaliação. Primeiro, a inovação ofereceu benefícios semelhantes ao produto existente da empresa, mas a um preço mais baixo. Em segundo lugar, a empresa planejava oferecer a inovação aos seus clientes mais exigentes - os clientes que ainda estavam insatisfeitos com 0 desempenho do produto existente que estavam comprando. Essa era uma incompatibilidade entre a inovação e a sua implantação, mas não significava que a inovação deveria ser descartada. Ao realizar um diagnóstico de cliente, a empresa identificou clientes em um mercado adjacente que procuravam um desempenho "bom o suficiente" a preços mais baixos. A empresa moldou a inovação em uma inovação disruptiva de baixo custo direcionada a esses clientes. Esta estratégia proporcionou uma melhor combinação entre a inovação, o mercado-alvo e as habilidades da organização. (ANTHONY; CHRISTENSEN, 2005)

De acordo com Shane e Venkataraman (2000), "a inovação disruptiva pode ser descrita como uma forma de oportunidade empreendedora que é radical e não de natureza incremental". Ou seja, ela não vem para acrescentar algo novo a um produto ou serviço já existente, mas para mudar o fluxo de mercado, buscando atingir um nicho específico que não possui suas demandas atendidas.

Nesse âmbito, Hang, Garnsey e Ruan (2014) afirmam que "a definição de inovação disruptiva sugere que uma certa quantidade 
de esforço empreendedor facilita a sua evolução".

Timmons e Spinelli (2008), consideram que o empreendedorismo:

[... pode ocorrer - ou não ocorrer - em empresas antigas e novas; pequenas e grandes; de forma rápida ou lenta; nos setores privado, sem fins lucrativos e público; em todos os pontos geográficos; e em todas as etapas do desenvolvimento de uma nação, independentemente da política. (TIMMONS; SPINELLI, 2008)

Ou seja, o fato de que grandes empresas coinovam cada vez mais com empresas menores e comunidades inovadoras fora de seus limites da empresa e que isso precisa estar atrelado com as teorias existentes sobre inovação disruptiva (CHANDRA; YANG, 2011).

Evidencia-se que a tecnologia desse tipo de inovação oferece um desempenho "bom o suficiente" ao longo das métricas tradicionais, o qual é suportado por um modelo de negócios que gera retornos financeiros atrativos a preços baixos (ANTHONY; CHRISTENSEN, 2005).

Anthony e Christensen (2005), acreditam que, mesmo a tecnologia apresentando menor desempenho, ela ainda oferece benefícios em termos de conveniência, customização e simplicidade, que se encaixam diretamente nos padrões de comportamento e nas prioridades de um cliente. $\bigcirc$ modelo comercial suporta esses novos benefícios, tipicamente com preços mais baixos e um processo de distribuição diferente, geralmente mais simples.

Com base nos estudos de Kuratko (2016), "o empreendedor é aquele que se compromete a organizar, administrar e assumir os riscos de uma empresa". Todavia, nos últimos anos, essa definição passou a abranger novos paradigmas:

Hoje, um empreendedor é um inovador ou desenvolvedor que reconhece e aproveita as oportunidades; converte essas oportunidades em idéias viáveis e comercializáveis; acrescenta valor através do tempo, esforço, dinheiro ou habilidades; assume os riscos do mercado competitivo para implementar essas ideias; e percebe as recompensas desses esforços. (KURATKO, 2016)

Uma visão amplamente aceita acerca do empreendedor é de que este atua como um agente de mudança, fornecendo ideias criativas e inovadoras para empresas e ajudando-as a crescerem e tornarem-se mais lucrativas. Ou seja, pode-se considerar que o empreendedorismo está consideravelmente atrelado à criação e identificação de oportunidades, principalmente no que diz respeito àquelas nomeadas inovações disruptivas.

Chandra e Yang (2011) compartilham dessa visão, declarando que "o conhecimento e a capacidade de criar e lidar com a inovação disruptiva são críticos para a longevidade corporativa, especialmente para empresas que operam em um ambiente veloz".

\section{CONSIDERAÇÕES FINAIS}

Considera-se que a teoria da inovação disruptiva criou um impacto significativo nas práticas de gestão, além de ter instigado a curiosidade de diversos estudiosos.

Este artigo buscou avançar na compreensão da inovação disruptiva e enfatizar a relevância e contribuição potencial da pesquisa do empreendedorismo sobre esse tema, através da sistematização de um panorama teórico.

Por meio das diferentes perspectivas aqui apresentadas, foi possível identificar diversas direções de pesquisa dentro do domínio da pesquisa de inovação disruptiva, sendo o principal deles, apesar de ainda relativamente restrito, o empreendedorismo.

Embora a literatura sobre o empreendedorismo mostre exemplos de inovações verdadeiramente acidentais, acredita-se que o processo de criação da inovação disruptiva pode ser amplamente influenciado por fatores advindos daquele.

Uma vez que a inovação disruptiva não é um evento isolado, mas envolve desenvolvimento de oportunidades e outros processos de refinamento, as estratégias para uma empresa permanecer inovadora é justamente aproveitar-se de sua capacidade empreendedora.

Nesse sentido, a inovação disruptiva pode ser melhor estudada e compreendida através de uma lente empreendedora holística, observando as interações de vários fatores, como por exemplo: empresa, produto e consumidor.

É importante ressaltar que, assim como a inovação disruptiva, os estudos sobre 
empreendedorismo demonstram que não se trata de uma atividade única, mas um processo contínuo ao longo da vida de um inovador/empreendedor.

Por essa razão, os estudos na área de empreendedorismo podem ser muito benéficos no que concerne ampliar a

\section{REFERÊNCIAS}

[1]. ANTHONY, Scott D.; CHRISTENSEN, Clayton M. Innovation handbook: A road map to disruptive growth. Harvard Business School Publishing, 2005.

[2]. BULL, Ivan; WILLARD, Gary E. Towards a theory of entrepreneurship. Journal of business venturing, v. 8, n. 3, p. 183-195, 1993.

[3]. CHANDRA, Yanto; YANG, Shu-Jung Sunny. Managing disruptive innovation: Entrepreneurial strategies and tournaments for corporate longevity. Journal of General Management, v. 37, n. 2, p. 23-50, 2011.

[4]. CHRISTENSEN, Clayton. The innovator's dilemma: when new technologies cause great firms to fail. Harvard Business Review Press, 2013

[5]. CHRISTENSEN, Clayton M.; RAYNOR, Michael E.; MCDONALD, Rory. Disruptive innovation. Harvard Business Review, v. 93, n. 12, p. 44-53, 2015.

[6]. DRUCKER, Peter. Innovation and entrepreneurship. Routledge, 2014.

[7]. ELSEVIER. Scopus. Disponível em: https://www.elsevier.com/americalatina/ptbr/scopus. Acessado em março de 2018.

[8]. GIL, A. C. Como elaborar projetos de pesquisa. São Paulo, Editora:Atlas, 2002.

[9]. HANG, Chang Chieh; GARNSEY, Elizabeth W. Opportunities and resources for disruptive technological innovation. 2011.

[10]. HANG, Chang Chieh; GARNSEY, Elizabeth; RUAN, Yi. Disruptive innovation and entrepreneurial opportunity. Technovation, 2014.

[11]. HANG, Chang-Chieh; GARNSEY, Elizabeth; RUAN, Yi. Disruptive innovation and the two views of entrepreneurial opportunity. In: Management of Engineering \& Technology (PICMET), 2014 Portland International Conference on. IEEE, 2014. p. 670-681.

[12]. HWANG, Jason; CHRISTENSEN, Clayton M. Disruptive innovation in health care delivery: a framework for business-model innovation. Health Affairs, v. 27, n. 5, p. 1329-1335, 2008. dinâmica de criação e desenvolvimento de oportunidades disruptivas, podendo colaborar não só na teoria como também na prática.

Desse modo, evidencia-se que, considerando a escassa produção científica sobre a relação existente entre essas duas temáticas, este é um campo passível de maiores pesquisas.

[13]. KURATKO, Donald F. Entrepreneurship: Theory, process, and practice. Cengage Learning, 2016.

[14]. MARKIDES, Constantinos. Disruptive innovation: In need of better theory. Journal of product innovation management, v. 23, n. 1, p. 1925, 2006.

[15]. MARTES, Ana Cristina Braga. Weber e Schumpeter: a ação econômica do empreendedor. Revista de Economia Política, v. 30, n. 2, p. 254270,2010

[16]. MONITOR, GLOBAL ENTREPRENEURSHIP. Empreendedorismo no Brasil: 2008/Simara Maria de Souza Silveira Greco et al. Curitiba: IBQP, 2009.

[17]. MORRIS, Michael H.; KURATKO, Donald F.; COVIN, Jeffrey G. Corporate entrepreneurship \& innovation. Cengage Learning, 2010.

[18]. RAMOGLOU, Stratos; TSANG, Eric WK. In defense of common sense in entrepreneurship theory: beyond philosophical extremities and linguistic abuses. Academy of Management Review, v. 42, n. 4, p. 736-744, 2017.

[19]. SANDBERG, Birgitta. Creating the market for disruptive innovation: Market proactiveness at the launch stage. Journal of Targeting, Measurement and Analysis for Marketing, v. 11, n. 2, p. 184-196, 2002.

[20]. SHANE, Scott; VENKATARAMAN, Sankaran. The promise of entrepreneurship as a field of research. Academy of management review, v. 25, n. 1, p. 217-226, 2000.

[21]. SWEDBERG, Richard. The social science view of entrepreneurship: Introduction and practical applications. Entrepreneurship and Small Business Research Institute (ESBRI), 2001.

[22]. THOMOND, Peter; LETTICE, Fiona. Disruptive innovation explored. In: Cranfield University, Cranfield, England. Presented at: 9th IPSE International Conference on Concurrent Engineering: Research and Applications (CE2002). 2002.

[23]. TIDD, J.; BESSANT, J.; PAVITT, K. Gestão da Inovação. 5. Ed. Porto Alegre: Bookman, 2015. 
[24]. TIMMONS, Jeffry A.; SPINELLI, Stephen; TAN, Yinglan. New venture creation: Entrepreneurship for the 21st century. Burr Ridge, IL: Irwin, 1994.

[25]. TROTT, P. Innovation management and new product development. Pearson education, 2008 .
[26]. YU, Dan; HANG, Chang Chieh. A reflective review of disruptive innovation theory. International Journal of Management Reviews, v. 12, n. 4, p. 435-452, 2009. 


\section{Capítulo 15}

\section{CONTRIBUIÇÕES DA CRIATIVIDADE PARA A RETENÇÃO DE CLIENTES EM CLINICAS MÉDICAS \\ Joiceli Rossoni Lapolli \\ Paulo César Lapolli \\ Leandro Maciel Nascimento}

Inara Antunes Vieira Willerding

Édis Mafra Lapolli

Resumo: Organizações, no século XXI, enfrentam grandes desafios para se manterem competitivas e sustentáveis. A crescente utilização de ferramentas que possam contribuir para superar estas dificuldades vem recebendo atenção especial por parte das empresas. Neste novo cenário, aspectos transformadores das organizações, como criatividade e inovação estão sendo valorizados e entendidos como potenciais diferenciadores, mesmo sendo aspectos intangíveis, ou seja, abstratos, porém mensuráveis, estão sendo cada vez mais valorizados. A energia despendida pelas organizações visa principalmente a satisfação dos clientes, mesmo dos clientes que mudam seu comportamento de consumo motivado pelo aumento da oferta de produtos e serviços. As clínicas médicas são exemplos de empresas que adotam uma posição centrada nos clientes. Para tal, necessitam introduzir em seus processos de relacionamento com clientes ferramentas que ofereçam diferenciais aumente a satisfação dos clientes. Os problemas de relacionamentos com clientes não são recentes, e cientes disto, as clínicas médicas se deparam com grandes problemas relacionados com a retenção de seus clientes, que podem ser observados pelos diferentes motivos que levam um cliente a deixar de utilizar os serviços de um fornecedor específico. A melhoria da relação com o cliente somente se torna tangível a partir do uso de estratégias que agreguem valor para o cliente. Desta forma, este artigo tem por objetivo principal apresentar a criatividade e seu processo como um diferencial que pode contribuir para potencializar a retenção de clientes em clínicas médicas. Para obter os resultados, realizou-se uma pesquisa qualitativa, descritiva e bibliográfica. Em linhas gerais, pode-se verificar, que é imprescindível o uso da criatividade nas organizações, em especial, nas clínicas médicas para reter seus clientes, neste ambiente complexo e competitivo da área da saúde em que atuam. 


\section{INTRODUÇÃO}

\subsection{CONSIDERAÇÕES INICIAIS}

Ao longo dos últimos anos, a procura por serviços especializados na área de saúde vem crescendo exponencialmente. Este fato gerou a necessidade de um aumento na oferta de serviços especializados de saúde, resultando no surgimento de inúmeras clínicas para atender a demanda de serviços. Em face deste aumento, oferecer serviços com diferenciais para o cliente passou a ser um fator de sustentabilidade para a grande maioria das instituições de saúde. Serviços de qualidade que venham de encontro as necessidades do cliente passam a ser uma realidade deste setor de prestação de serviços.

O aumento da concorrência, clientes mais seletivos exigem transformações significativas das clinicas médicas que se defrontam com a necessidade de implementar melhorias em seus processos organizacionais para ofertar de produtos/serviços inovadores. Para as organizações, reter clientes nos dias atuais requer dedicação e criatividade, representa ir além de surpreender o cliente, é necessário encantar, criar valor, despertar o sentimento da necessidade nas pessoas.

Definir um processo de desenvolvimento da criatividade organizacional pode contribuir para a redução da evasão de clientes no setor de clínicas médicas, como também, no aumento do número de clientes fidelizados, crescimento dos lucros, valorização da marca, competitividade e sustentabilidade.

\subsection{FORMULAÇÃO DA SITUAÇÃO PROBLEMA}

Organizações, no século XXI, enfrentam grandes desafios para se manterem competitivas e sustentáveis. A crescente utilização de ferramentas que possam contribuir para superar estas dificuldades vem recebendo atenção especial por parte das empresas. Neste novo cenário, aspectos transformadores das organizações, como criatividade e inovação estão sendo valorizados e entendidos como potenciais diferenciadores, mesmo sendo aspectos intangíveis, ou seja, abstratos, porém mensuráveis, estão sendo cada vez mais valorizados.

As clínicas médicas são exemplos de empresas que adotam uma posição centrada nos clientes. Para tal, necessitam introduzir em seus processos de relacionamento com clientes ferramentas que ofereçam diferenciais e tragam satisfação para os clientes.

Os problemas de relacionamentos com clientes não são recentes, e cientes disto, as clínicas médicas se deparam com grandes problemas relacionados com a retenção de seus clientes, que podem ser observados pelos diferentes motivos que levam um cliente a deixar de utilizar os serviços de um fornecedor específico.

A melhoria da relação com o cliente somente se torna tangível a partir do uso de estratégias que agreguem valor para o cliente.

\subsection{OBJETIVO GERAL}

O presente artigo tem por objetivo principal compreender a criatividade como um diferencial que pode contribuir para potencializar a retenção de clientes em clínicas médicas.

\subsection{METODOLOGIA}

Esta pesquisa possui uma abordagem qualitativa sob o ponto de vista de Lakatos e Marconi (2011, p. 269), "em analisar e interpretar aspectos mais profundos, descrevendo a complexidade do comportamento humano".

Quanto aos objetivos, a pesquisa é descritiva, pois possui como objetivo primordial a descrição das características de determinada população ou fenômeno ou o estabelecimento de relações entre variáveis (Gil, 2009), que no caso desta pesquisa, compreender a criatividade como contribuição para a retenção de clientes em clinicas médicas.

E como técnica de pesquisa, o estudo utilizou a pesquisa bibliográfica tendo em vista que, segundo Triviños (2002, p. 104), "não é possível interpretar, explicar e compreender a realidade sem um referencial teórico". E ainda, diz respeito a "[...] quando elaborada a partir de material já publicado, constituído principalmente de livros, artigos de periódicos e atualmente com material disponibilizado na internet" (Matias-Pereira, 2012, p. 89).

É importante ressaltar, que este estudo se justifica por perceber que existe ainda na literatura poucas publicações sobre o tema, permitindo assim, gerar contribuições para o meio acadêmico e social, agregando mais conhecimento 


\section{REVISÃO DA LITERATURA}

\subsection{CRIATIVIDADE}

A origem da palavra criatividade remonta ao verbo creare do latim, que significa gerar ou produzir. O produto da criatividade é a ideia, o novo, uma forma diferente de olhar para as coisas. Quinn, Thompson e Faerman (2003) consideram que as habilidades criativas presentes no indivíduo permitem relacionar conceitos independentes e construir uma nova maneira de pensar. Todo ser humano é criativo por natureza, o que diferencia um do outro é a atitude criativa de cada um. O ser criativo é curioso, tem olhar crítico para o mundo a sua volta, busca criar maneiras inovadoras de melhorar o que para muitos já é bom. Ao longo da história da humanidade observamos que as descobertas e inovações estão relacionadas com pessoas que buscaram entender forma totalmente diferente algo que as demais pessoas viam como certas (TORRANCE, 1976).

$\mathrm{Na}$ literatura pode-se encontrar inúmeros conceitos de criatividade, sendo que, na grande maioria, existe um consenso de que criatividade se trata da construção de algo novo. Nesta linha de pensamento, Torrance (1976, p. 34) define a criatividade e o pensamento criativo como:

- processo de perceber lacunas ou elementos faltantes perturbadores; formar ideias ou hipóteses a respeito deles; testar essas hipóteses; e comunicar os resultados, possivelmente modificando e retestando as hipóteses.

Torquato (2017) em seu estudo, apresentou uma compilação dos proincipais conceitos de criatividade em várias áreas de pesquisa. 0 quadro 1 apresenta estes conceitos em ordem cronológica.

\section{Quadro 1: Conceitos de Estudiosos sobre a Criatividade}

\begin{tabular}{|c|c|}
\hline Estudioso & Conceito \\
\hline Stein (1974) & $\begin{array}{l}\text { É o processo que resulta em um produto novo, que é aceito como útil e/ou satisfatório } \\
\text { por um número significativo de pessoas em algum ponto no tempo. }\end{array}$ \\
\hline Kneller (1978) & Consiste em rearranjar o que sabemos, a fim de achar o que não sabemos. \\
\hline $\begin{array}{l}\text { Torrance; } \\
\text { Mourad (1981) }\end{array}$ & $\begin{array}{l}\text { É o processo de tornar-se sensível a problemas, deficiências, lacunas no } \\
\text { conhecimento, desarmonia; identificar a dificuldade; buscar soluções, formulando } \\
\text { hipóteses a respeito das deficiências; testar e retestar essas hipóteses; e finalmente } \\
\text { comunicar os resultados. }\end{array}$ \\
\hline Amabile (1983) & $\begin{array}{l}\text { É um produto ou uma resposta julgada como criativo na medida em que é novo e } \\
\text { apropriado, útil ou de valor para uma tarefa, sendo ela heurística e não algorística. }\end{array}$ \\
\hline Alencar (1996) & $\begin{array}{l}\text { É uma das expressões da capacidade inesgotável do ser humano de se transformar e } \\
\text { transformar o meio onde vive. Tem a ver com os processos de pensamentos que se } \\
\text { associam com imaginação, insight, invenção, inovação, intuição, inspiração, iluminação } \\
\text { e originalidade. Ela diz respeito a uma disposição de pensar diferente e para "brincar" } \\
\text { com ideias. }\end{array}$ \\
\hline Toro (2002) & $\begin{array}{l}\text { É o ato de parir a si mesmo num processo de autocriação constante e evolutiva, pois os } \\
\text { impulsos de inovação inerentes aos sistemas biológicos culminam na criatividade. }\end{array}$ \\
\hline Pope (2005) & $\begin{array}{l}\text { É a capacidade de produzir, fazer ou tornar algo em uma coisa nova e válida tanto para } \\
\text { si como para os outros, isto é, um atributo humano comum, pois a grande maioria das } \\
\text { pessoas resolve problemas de todas as espécies no seu dia a dia com algum grau de } \\
\text { criatividade. Ressalta-se que a criatividade implica incerteza, desconhecimento, e não } \\
\text { é fácil de ser avaliada. }\end{array}$ \\
\hline $\begin{array}{l}\text { Fialho et al. } \\
(2006)\end{array}$ & $\begin{array}{l}\text { É geradora de ideias, responsável pela solução de problemas, permite aprender } \\
\text { através do erro ou acerto e possibilita identificar as necessidades dos clientes e as } \\
\text { novas oportunidades. }\end{array}$ \\
\hline Pasinatto (2007) & $\begin{array}{l}\text { Criatividade tem relação com a necessidade intrínseca de inovar, de buscar novas } \\
\text { soluções para as dificuldades encontradas, de criar novas formas condizentes com as } \\
\text { possibilidades de cada um ser o autor e protagonista de sua existência. }\end{array}$ \\
\hline $\begin{array}{l}\text { Ulbricht e Vanzin } \\
\text { (2010) }\end{array}$ & $\begin{array}{l}\text { Decorre da passagem da fantasia à realização. Converte-se em um bem intangível de } \\
\text { valor inestimável à vantagem competitiva, e, portanto, compreendê-la como resultante } \\
\text { de um processo cognitivo conduz, com toda certeza, a resultados cada vez mais } \\
\text { satisfatórios. }\end{array}$ \\
\hline $\begin{array}{l}\text { Zeng; } \quad \text { Proctor; } \\
\text { Salvendy (2010) }\end{array}$ & $\begin{array}{l}\text { A criatividade está ganhando destaque na academia e na indústria e, há mais de } 50 \\
\text { anos, pesquisas indicam que a criatividade é fundamental para a inovação de produtos } \\
\text { e serviços. }\end{array}$ \\
\hline
\end{tabular}

Fonte: Adaptado de Torquato (2017, p. 63-64) 
Em um estudo sobre os aspectos relacionados com a criatividade no indivíduo e no contexto organizacional, Pereira (2016) identificou as seguintes teorias sobre criatividade, apresentadas no quadro 1.

Quadro 2: Teorias da Criatividade

\begin{tabular}{|l|c|l|}
\hline \multicolumn{1}{|c|}{ Teoria } & Autor(es) \\
$\begin{array}{l}\text { Teoria Componencial } \\
\text { da Criatividade e } \\
\text { Inovação } \\
\text { Organizacional }\end{array}$ & $\begin{array}{c}\text { Amabile } \\
(1983)\end{array}$ & $\begin{array}{l}\text { O impacto do ambiente organizacional sobre a } \\
\text { criatividade das pessoas. }\end{array}$ \\
\hline $\begin{array}{l}\text { Modelo Sistêmico } \\
\text { da Criatividade }\end{array}$ & $\begin{array}{c}\text { Csikszentmihali } \\
(1988)\end{array}$ & $\begin{array}{l}\text { A criatividade resulta da interação de um sistema } \\
\text { composto por: uma cultura, um campo de } \\
\text { especialistas que reconhecem e validam a inovação. }\end{array}$ \\
\hline $\begin{array}{l}\text { Teoria do } \\
\text { Investimento em } \\
\text { Criatividade }\end{array}$ & $\begin{array}{c}\text { Sternberg } \\
\text { inteligência depende de três habilidades } \\
\text { cognitivas: a capacidade sintética, analítica e a } \\
\text { habilidade prática, contextual. }\end{array}$ \\
\hline $\begin{array}{l}\text { Modelo Interacionista } \\
\text { da Criatividade } \\
\text { Organizacional }\end{array}$ & $\begin{array}{c}\text { Wodman et al } \\
(1983)\end{array}$ & $\begin{array}{l}\text { As características individuais, do grupo e da } \\
\text { organização influenciam os processos criativos e, por } \\
\text { sua vez, a criatividade organizacional. }\end{array}$ \\
\hline $\begin{array}{l}\text { Teoria da Ação } \\
\text { Criativa em Domínios } \\
\text { Sociais Múltiplos }\end{array}$ & $\begin{array}{l}\text { Sobre os domínios específicos e seus campos de } \\
\text { conhecimento, incluíndo regras e práticas, grupos, } \\
\text { organizações, ambientes iorganizacionais e } \\
\text { mercados. }\end{array}$ \\
\hline
\end{tabular}

Fonte: elaborado pelos autores com base em Pereira (2016, p. 55)

Todas as teorias pesquisadas pelos autores relacionam fatores que influenciam diretamente sobre a criatividade e sobre os processos criativos Essas teorias e modelos auxiliam a compreensão dos fatores que interferem na criatividade, no pensamento criativo individual e nos processos criativos em grupos. Os indivíduos trabalham em um ambiente (acadêmico, organizacional, cultural) e, por isso, o papel dos grupos é muito importante no que tange ao estímulo ou à inibição da criatividade individual e, por consequência, nos resultados do processo criativo (PEREIRA, 2016).
Amabile (2012) defende a teoria componencial da criatividade e inovação organizacional afirmando que a mesma aumenta quando uma pessoa está intrinsecamente motivada, com grande conhecimento de domínio e habilidades no processo criativo. Sendo que isto tudo deve estar funcionando em um ambiente com alto nível de apoio à criatividade. Estes componentes estão representados na Figura 1.

Figura 1: Componentes da Teoria da Criatividade e Inovação Organizacional

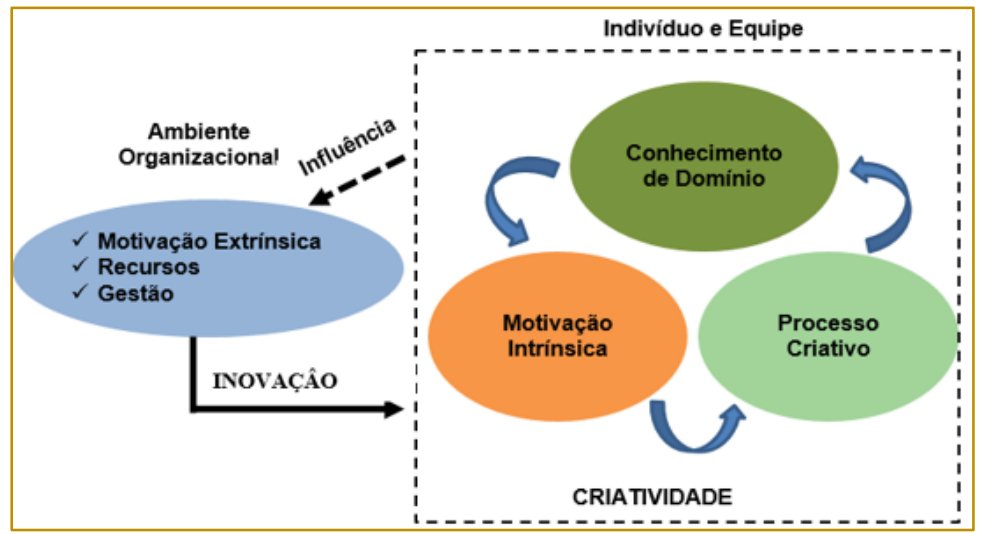

Fonte: Adaptado de Amabile (1997, p. 53). 
1) Conhecimento de domínio: representa o conhecimento que o indivíduo possui sobre técnicas disponíveis e como utilizá-las;

2) Processo criativo: são inerentes ao indivíduo, compreendem vivências, personalidade, disciplina, persistência e observar um determinado contexto ou ambiente ou problema dentro de uma perspectiva diferente;

3) Motivação: a motivação intrínsica é a paixão, a motivação para empreender uma tarefa ou resolver um problema porque é interessante, envolvente, pessoalmente desafiador ou satisfatório. A motivação extrínsica é o ambiente de trabalho com suas regras normas, exigências para se fazer algo, vigilância.

O grande desafio das pessoas é encontrar o equilíbrio, a forma de orquestrar estes componentes. A recompensa para aqueles que tem sucesso nesta empreitada é a capacidade de produzir pensamentos criativos.

No contexto organizacional o clima e a cultura são fatores que influenciam diretamente na motivação e consequentemente na promoção da criatividade. Van Gundy (1987) identifica algumas ações da empresa que podem promover a motivação e fomentar o espirito criativo nas pessoas:

$\checkmark \quad$ Autonomia: Grau em que se dá aos funcionários liberdade para criar;

$\checkmark \quad$ Sistema de premiação dependente do desempenho: premiar pelo desempenho e competência e não somente nas relações pessoais;

$\checkmark \quad$ Apoio à criatividade: uma organização aberta a novas ideias e que apoie possíveis mudanças benéficas à instituição;

$\checkmark \quad$ Aceitação das diferenças e interesse pela diversidade entre os membros: divergências de pontos de vistas e diversidades enriquecem o campo para se cultivar a criatividade das pessoas no ambiente de trabalho;

$\checkmark \quad$ Envolvimento pessoal: envolver as pessoas, fazer com que elas se sintam participantes dos processos e decisões é um motivador intrínseco da criatividade;

$\checkmark \quad$ Apoio da direção: um ambiente onde a criatividade prospera somente é possível com o patrocínio da diretoria.

Este conjunto de ações deve ser conduzido de acordo com um processo planejado e conhecido por todos na organização. Nomease este processo como sendo o processo de desenvolvimento da criatividade organizacional elaborado a partir do estudo de Kneller (1978). Para o autor o processo da criatividade compreende cinco fases distintas:

$\checkmark \quad$ Apreensão: identificação de um
problema, surgimento de uma ideia;
$\checkmark \quad$ Preparação: etapa onde se discute,
investiga, explora e propõe soluções;
$\checkmark \quad$ Incubação: momento em que a atividade não consciente é realizada com o objetivo de conectar elementos da criação;

$\checkmark \quad$ Iluminação: a mágica acontece, a solução para o problema surge, tudo começa a fazer sentido, momento de clareza, de certeza, de repente surge a solução do problema - o conceito que engloba todos os fatos, o pensamento que completa a cadeia de ideias até então trabalhadas, então tudo entra em seus lugares e faz sentido.

$\checkmark \quad$ Verificação: fase onde se verifica e valida a criação e a potencial solução para o problema. O questionamento nesta fase é muito importante.

As etapas do processo, na maioria das situações não acontece de forma sequencial. As fases se alternam e se complementam durante todo o processo de desenvolvimento da criatividade. Pode acontecer na fase de verificação novos insights que venham a contradizer tudo aquilo que foi construído anteriormente, ou seja o processo é um ciclo interativo (KNELLER, 1978).

Desta forma, destaca-se que um processo de desenvolvimento criativo traz grandes benefícios, tanto para indivíduos como para organizações. A explosão de ideias criativas obtidas na sua execução contribui em todos os setores organizacionais, destacando a retenção de talentos que envolve problemas relacionados diretamente com a convivência com pessoas externas, os clientes.

\subsection{RETENÇÃO DE CLIENTES}

A retenção de clientes se inicia pelo entendimento do que é ser cliente. $\mathrm{Na}$ literatura pode-se encontrar muitas definições para cliente. Sob um ponto de vista da relação comercial, clientes podem ser pessoas ou organizações que sofrem impacto dos produtos (KOETLER, 1993). Para Ferreira (2004), cliente é a pessoa que compra produtos e serviços mediante uma contrapartida - o pagamento. É importante ressaltar que cliente e consumidor não são a mesma coisa. 
Consumidor é uma estatística, uma figura hipotética que simboliza milhões de pessoas indistintas que compram mecanicamente bens por seu valor funcional e utilitário. Já o cliente é um indivíduo identificável, com personalidade específica e gostos altamente seletivos e distintos, que está emocionalmente ligado às criações da empresa. Depende da empresa transformar cada consumidor em cliente (LONGINOTTI-BUITONI; LONGINOTTIBUITONI, 2000, p.13).

Taraboulsi (2004, p. 41-42) traz como conceito de cliente como:

[...] um ser humano, de todos os tamanhos e cores. Um cliente é uma criança que precisa de ajuda para alcançar um brinquedo numa prateleira alta. Um cliente é um homem idoso que perdeu a direção no labirinto dos corredores de um hospital. Um cliente é uma mulher que não fala bem o seu idioma e está explicando o que precisa da única forma que pode. Um cliente é um companheiro de trabalho pedindo sua ajuda para que possa prestar serviços ao público pagante. Contribuinte, paciente, cliente, pagador de impostos, membro, hóspedes, sócio - todos são sinônimos do maior patrimônio que uma empresa pode ter - o cliente, que vem até você e paga pelo serviço ou produto. O que é um cliente? O cliente é a razão de existência da sua empresa

O cliente ao longo dos últimos anos vem modificando seu comportamento de consumo, passando de um ator que simplesmente adquiria o que the era ofertado para uma atitude mais exigente e seletiva. Desta forma, as empresas passaram a posicionar seus clientes como uma peça fundamental para a saúde financeira. Gupta (2006) afirma que clientes são um grande investimento para as organizações, o que levou muitas organizações a um modelo de negócio centrado no cliente.

Baseado nos conceitos supracitados sobre cliente, entende-se que a atividade de manter clientes deve estar internalizada na cultura da organização, ou seja, deve ser natural e fazer parte das rotinas organizacionais. Os conceitos de clientes abordados, nos conduz a concordar com a afirmação de Sviokla e Shapiro (1994, p.15) que diz que:

Manter bons clientes deveria ser tão natural para uma empresa quanto respirar para os seres humanos. Entretanto, muitas empresas se encontram tão voltadas para o esforço de atrair novos clientes que acabam não investindo recursos na preservação dos relacionamentos pós-venda, de longa duração.

O desenvolvimento de atividades com foco na retenção de clientes deve ser estruturado de forma a compreender a mecânica da relação existente entre clientes e organizações.

Para Koetler, (2000) a satisfação é o ponto chave para a retenção de clientes. Clientes satisfeitos estão mais propensos a se tornarem clientes fiéis por um longo período de tempo.

O cliente satisfeito,

Compra mais à medida que a empresa lança novos produtos ou aperfeiçoa produtos existentes; fala favoravelmente da empresa e de seus produtos; dá menos atenção a marcas e propaganda concorrentes e é menos sensível a preço; oferece ideias sobre produtos ou serviços à empresa; e custa menos para ser atendido do que novos clientes, uma vez que a transações são rotinizadas (KOTLER, 2000, p.70).

Segundo Vavra e Pruden (1995) a corrida para alcançar a competitividade sofre influências da forma como a organização retém clientes. Para conhecer o cliente, e demonstrar o quanto ele é importante para a empresa, somente o fator satisfação não é suficiente.

Michelli (2008) inclui, além da satisfação, a fidelidade e lealdade do cliente obtida a partir da construção de relacionamentos duradouros. Direcionando ações no cerne da satisfação e fidelidade, maximiza-se a possibilidade de o cliente retornar para relações futuras com a empresa, e consequentemente reduzindo a chance do cliente optar por outro fornecedor.

Por outro lado, deve-se procurar entender os fatores que podem levar uma empresa a perder clientes. Dessa forma, estratégias que venham a diminuir essa perda de clientes devem ser desenvolvidas de forma contínua e com base no comportamento e satisfação do cliente. Os passos, segundo Kotler (2000) e Reichheld (1996) que podem ser adotados pelas organizações a fim de reduzir a perda de clientes:

1) Identificar a taxa de retenção atual com base no número de clientes existentes em diversos períodos no tempo;

2) Identificar as causas ou fatores que estão diretamente relacionadas aos 
problemas com clientes e que acabam resultando em perdas e, desenvolver ações para mitigar estas causas;

3) Apurar o quanto se está deixando de ganhar com os clientes que se foram;

4) Dimensionar o valor a ser investido na retenção para diminuir a evasão de clientes e comparar com o valor não obtido (passo 3) para justificar investimentos na retenção.

Estes passos podem contribuir para desenvolver as ações adequadas e quando cada uma delas deverá ser implementada dentro das possibilidades financeiras de cada organização.

\subsubsection{RETER CLIENTES - UM DESAFIO PARA AS CLÍNICAS MÉDICAS}

$\mathrm{O}$ atendimento a clientes tem sido motivo de preocupação para qualquer empresa, e as clínicas médicas se deparam com grandes desafios nesta área. Apesar de todos os esforços aplicados, a qualidade do atendimento no setor de serviços ainda continua apresentando muitos problemas. As palavras de Ford et al (2005, p. 29) demonstram a importância deste setor dentro das organizações:

O serviço de atendimento ao cliente é mais importante no mercado atual do que em qualquer outra época, pois os clientes têm cada vez mais escolhas e baixos níveis de marcas e de fidelidade ao produto.

Muitas empresas do setor de saúde não possuem uma visão clara sobre o seu negócio, padecendo da chamada "miopia empresarial", termo cunhado por Theodore Levitt em seu texto clássico da década de 1960. Ao fazer uma comparação com o problema visual, o autor demonstra como muitos empresários focalizam apenas nos detalhes operacionais, voltando sua atenção para os produtos/serviços e, com isso, perdendo grandes chances de expansão. Evidencia-se que o segmento da saúde também apresenta tais sintomas (MAIA; GIL, 2002).

Neste sentido, a negligência com os clientes e a subsequente insatisfação gerada, traz prejuízos de diversas ordens, especialmente financeiros, uma vez que um cliente insatisfeito geralmente não retorna e acaba procurando um serviço concorrente. O indivíduo, ao buscar um profissional, clínica ou hospital, anseia por um serviço que vai além do fato de tratar um problema de saúde. Muitos trabalhos desenvolvidos por teóricos concordam que a qualidade no atendimento influencia diretamente na imagem e na fidelização de clientes. Whiteley (1992) afirma que toda organização centrada no cliente caminha a passos largos para a excelência.

Segundo a Perfomance Research Associates (2008, p. 8):

\section{As companhias que privilegiavam 0 atendimento de alta qualidade acabam se transformando em empresas melhores e mais bem-sucedidas em todos os aspectos do que as que tratavam os clientes como inimigos e encaravam esse serviço com má vontade ou como um mal necessário. Do dia para noite, manter o foco no cliente, compreender e satisfazer suas necessidades e "mimá-lo" com tratamento preferencial e de qualidade tornou-se meta organizacional - e recebeu atenção especial.}

A qualidade dos serviços prestados está constantemente sendo avaliada pelo cliente. Uma das principais causas dos problemas de qualidade no atendimento passa pela seleção e contração de pessoas. A falta de experiências e de orientações de como deve realizar os procedimentos do setor de atendimento aos clientes se refletem no grau de insatisfação dos clientes e na redução do número de consultas realizadas pelos especialistas.

Tem-se também, outros fatores que podem culminar em perdas de clientes que são os seguintes:

Falta de padrão no atendimento à clientes; não existe processos definidos para o setor de atendimento;

$\checkmark$ Descontentamento dos funcionários: pode ser gerado por baixos salários, acumulo de funções, falta de comunicação, tratamento inadequado por parte dos especialistas;

$\checkmark$ Horário das consultas em desacordo com agenda: ocorre pelo fato do especialista estar exercendo atividades não relacionadas diretamente com a agenda programada;

$\checkmark$ Documentação de clientes incompleta: equivoco nos registros de informações, perda de documentos local inadequado de armazenamento;

$\checkmark$ Inexistência ou uso equivocado de ferramentas de tecnologia de informação: controle realizado manualmente, os sistemas existentes não atendem as necessidades, desconhecimento das funcionalidades 
oferecidas pelo sistema, agenda de consultas desorganizada: registro incorreto, cobranças indevidas, duplicidade de consultas, entre outras.

E ainda, fatores externos que também podem influenciar a perda de clientes, como por exemplo:

$\checkmark$ Óbito;

$\checkmark$ Poder aquisitivo dos clientes;

$\checkmark$ Mudança de endereço.

É importante ressaltar, que os fatores externos estão fora de controle do prestador de serviços que, na maioria das situações pouco pode fazer para evitar a perda do cliente.

Todos os problemas apresentados relacionados com a retenção de clientes devem ser estudados de forma minuciosa pela empresa. A partir deste estudo, um planejamento de ações deve ser realizado a fim de minimizar estes problemas.

Assim, a criatividade na construção destas ações deve ser incentivada e envolver todos os setores da clínica, o que inclui os especialistas e pessoal de frente. A construção de um processo de retenção de clientes que traga resultados, depende das atitudes e comprometimento de todos, sem exceção. Desta forma, o retorno se materializa na satisfação dos clientes e no que eles pensam e falam da empresa.

Clínicas do setor de saúde necessitam se reinventar e implementar processos e padrões de atendimento, tanto no pessoal de frente como nos serviços prestados pelos especialistas. No sentido de atividades relacionadas com a retenção de clientes desenvolver práticas criativas e inovadoras que despertem nos clientes um sentimento de parceria.

\section{RESULTADOS}

Mesmo com as possíveis barreiras existentes em uma organização para que a criatividade possa ocorrer é preciso que exista mudança organizacional para que se possa ter criação de uma estrutura inovadora. Há de se ressaltar, que são as pessoas quem detêm a

\section{REFERÊNCIAS}

[1] Amabile, Teresa. M. Motivating Creativity in Organizations: On Doing What You Love and Loving What You Do. California Management, nr. 1, 1997).

Disponível capacidade de acumular experiências, conhecimentos e criatividade.

E é por meio dessa criatividade que levam as pessoas a criarem novas informações ou novos conhecimentos em suas ações cotidianas, podendo assim, reter seus clientes, gerando valores e garantindo diferencial competitivo.

Dessa forma, a criatividade está relacionada à agregação de valor às ideias, à invenção de produtos, à inovação e nas questões empresariais está relacionada à novas formas de solução de problemas, envolvendo a combinação de ideias de diferentes áreas de conhecimento, como é o caso da retenção de clientes nas clínicas médicas, onde requer uma retroalimentação de novos processos e padrões em seus serviços para a retenção de seus clientes, de forma criativa e inovadora neste ambiente complexo e competitivo.

\section{CONCLUSÕES}

Criatividade. Com certeza esta palavra jamais deixará de ser utilizada pelas organizações, pois está A criatividade está associada com a geração de novas ideias. Ideias estas que podem ser estimuladas pela organização e melhorar processos internos através da implementação de ações diferenciadoras.

Dessa forma, as clínicas médicas têm ciência da necessidade de implementar processos criativos como também ações que estimulem - potencial criativo dos colaboradores. Pessoas mais criativas tendem a gerar mais ideias que, quando aplicadas geram inovações.

Assim, as clínicas médicas sofrem por não ter uma visão muito clara da gestão do negócio, - que acaba resultando em perdas de clientes. Identificar os fatores que levam às clinicas a perderem seus clientes, organizar seus processos de relacionamento com clientes, compreender como o processo criativo se desenvolve e de que maneira este pode contribuir para reduzir a perda de clientes e potencializar a retenção deve fazer parte da rotina diária da organização.

<http://journals.sagepub.com/doi/pdf/10.2307/4116 5921 >. Acesso em: 03 Mai, 2018.

[2] Amabile, Teresa M. Componential Theory of creativity. Harvard Business School, 2012. Disponível 
$<$ https://www.hbs.edu/faculty/Publication\%20Files/1 2-096.pdf>. Acesso em: 07Mai, 2018.

[3] Ferreira, A.B.H. Miniaurélio - o dicionário da língua portuguesa. 6. ed. Revista e atualizada do minidicionário da língua portuguesa. Curitiba: Positivo, 2004.

[4] GIL, Antônio Carlos. Como Elaborar Projetos de Pesquisa. São Paulo: Atlas, 2009.

[5] Gupta, Sunil; Lehmann, Donald R. Gerenciando clientes como investimento: o valor estratégico dos clientes a longo prazo. Porto Alegre: Bookman, 2006.

[6] Ford, Lisa; Mcnair, David; Perry, Bill. O Excepcional Atendimento ao Cliente. São Paulo: Edicta, 2005.

[7] Kneller, G.F. Arte e Ciência da Criatividade. 5. ed. São Paulo: Ibrasa, 1978.

[8] Kotler, Philip. Administração de marketing 10. ed. São Paulo: Prentice Hall, 2000.

[9] Lakatos, Eva Maria; Marconi, Maria de Andrade. Metodologia Científica. 6 ed. São Paulo: Atlas, 2011.

[10] Longinotti-Buitoni, G.L.; Longinotti-Buitoni, K. Vendendo sonhos: como deixar qualquer produto irresistível. São Paulo: Negócio Editora, 2000

[11] Maia, A. C.; Gil, A. C. Miopia em marketing no segmento hospitalar do Brasil. Mundo Saúde, São Paulo, v. 26, n. 2, p. 244-253, 2002. Disponível em:

https://www.ibedess.org.br/imagens/biblioteca/714 _Miopia.pdf>. Acesso em: 10 Mai, 2018.

[12] Matias-Pereira, J. Gestão Estratégica na Administração Pública. São Paulo: Atlas, 2012.

[13] Michelli, M. A prática da retenção de clientes em Academias de Ginástica e de Condicionamento Físico localizadas em Caxias do Sul - RS, 2008. Dissertação (Mestrado em Administração do Programa de Pós-Graduação de Mestrado em Administração), Curso de Administração, Universidade de Caxias do Sul, Caxias do sul. Disponível em: < https://repositorio.ucs.br/xmlui/bitstream/handle/11 338/351/Dissertacao\%20Mauricio\%20Michelli.pdf? sequence $=1 \&$ isAllowed $=y>$. Data de acesso: 07 Mai, 2018

[14] Pereira, Priscila Zavadil. O Pensamento Criativo no Processo Projetual:
[15] Proposta de um framework para auxiliar a criatividade em grupos de design. Tese (Doutorado em Design). Programa de Pós-Graduação em Design da Universidade Federal do Rio Grande do Sul (UFRGS). Disponível em: < http://www.lume.ufrgs.br/bitstream/handle/10183/14 9852/001007425. pdf?sequence $=1>$. Acesso em: 07 Mai, 2018

[16] Performance Research Associates. Atendimento Nota 10. São Paulo, Sextante, 2008.

[17] Reichheld, Frederick F. A estratégia da lealdade. Rio de Janeiro: Campus, 1996.

[18] Sviokla, John R. \& Shapiro, Benson P. Mantendo clientes. Trad. Pedro Catunda. São Paulo: Makron Books, 1994.

[19] Taraboulsi, Fadi Antoine. Administração de hotelaria hospitalar. $2^{\underline{a}}$ ed. São Paulo: Editora Atlas, 2004.

[20] Triviños, A. N. S. Introdução à pesquisa em ciências sociais: a pesquisa qualitativa em educação. São Paulo: Atlas, 2002

[21] Torrance, Ellis Paul, Criatividade medidas testes e avaliações. São Paulo: Editora Ibrasa; 1976.

[22] Torquato, Mírian. O Despertar da Criatividade: Gerenciando o medo, 2017. Tese (Doutorado em Engenharia e Gestão do Conhecimento). Programa de Pós-Graduação em Engenharia e Gestão do Conhecimento (PPGEGC) da Universidade Federal de Santa Catarina (UFSC). Disponível em: <http://btd.egc.ufsc.br/wpcontent/uploads/2017/03/Mirian-Torquaro.pdf>. Acesso em: 08 Mai, 2018.

[23] Quinn, E. Robert; Thompson, P. Michael; Faerman, R. Sue. Competências gerenciais: princípios e aplicações. Rio de Janeiro: Elsevier, 2003.

[24] Van Gundy, A. Organizational creativity and innovation. In: Isaksen,S. G. (ed.). Frontiers ot creativity research.Buffalo: Bearly, 1987.

[25] Vavra, T.G. \& Pruden, D.R. Using aftermarketing to maintain a customer base. Discount Merchandiser, v.35, n.5, 1995.

[26] Whiteley, Richard C. Sature a Sua Companhia com a Voz do Cliente. A empresa totalmente voltada para o cliente. $20^{\mathrm{a}}$ ed. Rio de Janeiro: Campus, 1992. 


\section{Capítulo 16}

\section{GOVERNANCA DE TECNOLOGIA DA INFORMACÃO NA UNIVERSIDADE FEDERAL DO RECONNCAVO DA BAHIA: UM ESTUDO DA IMPLEMENTACÃO DOS MECANISMOS BASEADO NOS HABILITADORES DO COBIT 5}

\section{Richardson Silveira Almeida}

Warli Anjos de Souza

Resumo: O estudo da implementação dos mecanismos de governança de tecnologia da informação (TI) na Universidade Federal do Recôncavo da Bahia (UFRB) teve como objetivo indicar quais os mecanismos que necessitam de ações de melhorias. Para tanto, utilizou-se de questionário, com uso da escala Likert de cinco pontos, para indicar o grau de atitude dos tomadores de decisão da universidade acerca da implementação dos mecanismos de governança de $\mathrm{TI}$. Adicionalmente, buscou-se evidências de implementação no Plano de Desenvolvimento Institucional (PDI) 2015-2019, nos relatórios de gestão de 2015 e 2016, no relatório de auto avaliação institucional 2015-2017, e no site da instituição. A análise realizada indicou que a implementação dos mecanismos investigados na UFRB encontrava-se em um estágio embrionário, com inércia das estruturas de tomada de decisão estratégica de TI, e ausência da definição de princípios, políticas e modelos de $\mathrm{TI}$, o que compromete as demais categorias de mecanismos de governança de TI. A constatação acerca do estágio embrionário da implementação dos mecanismos de governança de TI permitiu concluir ausência de alinhamento estratégico entre $\mathrm{TI}$ e negócio, e por consequência comprometimento da entrega de valor proporcionado pela TI à comunidade acadêmica.

Palavras-chave: Habilitadores do COBIT 5. Mecanismos de Governança de Tecnologia da Informação. Percepção de Gestores de Negócio. Universidade Públicas. 


\section{INTRODUÇÃO}

A governança de tecnologia da informação (TI) apresenta-se como tema relevante nos ambientes corporativos. De acordo com Weill e Ross (2006), o custo, a abrangência e o entendimento do valor da TI são alguns dos motivos que justificam o debate deste tema. Por entender que uma boa governança de TI traz resultados positivos para as organizações, diversos autores e entidades têm se dedicado a desenvolver modelos de governança de TI que podem ser adaptados à realidade dos diversos ambientes corporativos. Um dos modelos mais usados para realizar avaliações e implementações da governança de TI tanto em organizações públicas quanto nas organizações privadas é - Control Objectives for Information and Related Technologies (COBIT), por reunir um conjunto de boas práticas de governança de TI reconhecidos internacionalmente.

A importância da implementação de mecanismos de governança de TI tem exigido do Tribunal de Contas da União (TCU) realizar levantamento da situação da governança de TI a cada 2 (dois) anos em órgãos e entidades da Administração Pública Federal (APF). O último levantamento disponibilizado pelo TCU, em 2016, revelou que a situação da governança de TI está longe de ser aceitável. De acordo com o TCU, desde o primeiro levantamento (Acórdão 1.603/2008 Plenário), aconteceram evoluções discretas nos níveis de adoção das práticas avaliadas pelo Tribunal. Entre as organizações que apresentaram menor capacidade de governar sua $\mathrm{TI}$, estão as Instituições Federais de Ensino Superior (IFES), e entidades vinculadas ao Ministério da Ciência, Tecnologia, Inovações e Comunicações e ao Ministério da Cultura. Para o TCU, estas organizações não tratam a TI como parte integrante dos seus negócios, o que compromete o atendimento das demandas da sociedade (TCU, 2017).

De acordo com o TCU (2014), a implementação da governança de TI em órgãos e entidades da APF tem por finalidade assegurar que o dinheiro público está sendo bem aplicado, assim como contribuir para que essas organizações atinjam seus objetivos através do alinhamento entre $\mathrm{TI}$ e negócio. As universidades públicas federais fazem parte da APF e são instituições que têm por objetivo promover ensino, pesquisa e extensão, sendo a sociedade a principal beneficiada desses serviços. Nestas instituições, a TI desempenha um papel significativo, vez que está inserida em um ambiente de produção de informação e conhecimento. A disponibilidade de sistemas cada vez mais robustos têm acabado com os procedimentos manuais. Hoje, de forma virtual, é possível realizar matrícula, emitir histórico, tramitar processos, entre outras funcionalidades de um sistema de gestão acadêmica.

De acordo com Putz (2015), diferentemente do setor privado, as universidades públicas federais com escassos recursos governamentais e pessoal pouco qualificado em novas tecnologias possuem um processo de inovação tecnológica mais lento que o setor privado. Para a autora, o "cenário é preocupante e contraditório uma vez que o próprio objeto de trabalho da universidade é a informação e o conhecimento." (PUTZ, 2015, p. 65). Diante deste cenário, como fazer com que a TI nestas organizações realize os benefícios esperados pela sociedade, principal interessada nos serviços prestados? Esta é uma questão que tem exigido do TCU avaliações e auditorias no sentido de promover a governança de TI. Neste sentido, não somente o TCU, como também a comunidade acadêmica tem se empenhado a realizar pesquisas para promover ações de indução da governança de TI na APF.

Cavalcanti (2011) pesquisou sobre a influência da governança de TI nas IFES. De acordo com o autor, apesar da dependência crítica da TI, por estas instituições, comprovou-se que o tema governança de TI ainda é pouco difundido entre os altos executivos, o que compromete as estratégias de negócio. De maneira geral, a pesquisa revelou que a situação da governança de TI nas IFES encontrava-se em um nível muito baixo, apresentando-se em um estágio incipiente, revelando os riscos da gestão dos gastos públicos com TI. De forma mais específica, através de um estudo de caso, Nascimento (2014) pesquisou sobre o alinhamento estratégico da TI na Universidade Federal do Rio Grande do Norte (UFRN). O estudo revelou que o setor responsável pela TI na UFRN executava as demandas à medida que surgem as necessidades de negócio, não participando diretamente de decisões estratégicas. Segundo o autor, a governança de TI naquela universidade encontrava-se em um estado incipiente, com ausência de definições 
específicas para a TI dentro do Plano de Desenvolvimento Institucional (PDI) e a ausência de um Plano Diretor de TI (PDTI) na UFRN.

Considerando os levantamentos do TCU acerca da governança de TI no sentido de promover ações de indução, e a importância de pesquisas realizadas no meio acadêmico, como a de Cavalcanti (2011) e Nascimento (2014), este artigo se propõe a responder a seguinte questão: como os mecanismos de governança de TI estão sendo implementados na Universidade Federal do Recôncavo da Bahia (UFRB) conforme a percepção dos executivos e as evidências documentais?

Para responder à questão de pesquisa apresentada, buscou-se atingir o seguinte objetivo geral: estudar a implementação dos mecanismos de governança de TI na UFRB conforme a percepção dos tomadores de decisão e as evidências documentais para indicar quais os mecanismos necessitam de ações de melhorias.

Para atingir o objetivo geral definiu-se os seguintes objetivos específicos:

a) Identificar a percepção dos principais tomadores de decisão da UFRB acerca da implementação dos mecanismos de governança de Tl;

b) Examinar documentos da instituição a fim de evidenciar aspectos da implementação dos mecanismos de governança de Tl;

c) Confrontar a percepção dos principais tomadores de decisão da UFRB em relação implementação dos mecanismos de governança de TI com as evidências documentais a fim de indicar quais mecanismos necessitam de melhorias pela alta administração.

Além desta introdução, este artigo está estruturado em outras 4 (quatro) seções. A segunda apresenta a fundamentação teórica. Conceitos como governança de $\mathrm{TI} e$ mecanismos de governança de TI são debatidos no sentido de questionar ou responder aos resultados encontrados. A terceira apresenta a metodologia utilizada, com a apresentação do lócus e do modelo de coleta e análise de dados. A quarta, os resultados e discussão. Nesta parte serão apresentados os dados obtidos nos questionários e pesquisa documental, com suas devidas interpretações. E na quinta, e última parte, são apresentadas as conclusões da pesquisa.

\section{FUNDAMENTAÇÃO TEÓRICA \\ 2.1 GOVERNANÇA DE TECNOLOGIA DA INFORMAÇÃO}

A informação e a TI formam a base dos processos organizacionais. De acodo com Weill e Ross (2006), o tratamento das informações tem motivado discurssões entre gestores de negócios e de TI no que concerne a aquisição e desenvolvimento de novas soluções organizacionais apoiadas por TI. Para os autores, a responsabilidade de extrair valor da TI para o negócio precisa ser desenvolvidada por todos os gestores, nos diversos níveis organizacionais.

A partir do momento que os processos organizacionais começaram a ser assistidos por $\mathrm{TI}$, muitos acadêmicos e profissionais preocuparam-se em estudar as relações entre causas e efeitos do uso da TI para a realização dos objetivos organizacionais (VAN GREMBERGER, 2004). Essas pesquisas foram importantes e contribuíram para uma variedade de definições de governança de $\mathrm{TI}$ que encontramos atualmente na literatura.

De acordo com Weill e Ross (2006), a governança de TI é definida como "a especificação dos direitos decisórios e do framework de responsabilidades para estimular comportamentos desejáveis na utilização da TI". A ABNT NBR ISO/IEC 38500, a define como "o sistema pelo qual o uso atual e futuro da TI é dirigido e controlado" (ABNT, 2009, p. 3). Segundo a Norma, a governança corporativa de TI significa "avaliar e direcionar o uso da TI para dar suporte à organização e monitorar seu uso para realizar os planos. Inclui a estratégia e as políticas de uso da TI dentro da organização" (ABNT, 2009, p. 3).

Para Van Gremberger (2004), a governança de $\mathrm{TI}$ consiste nas estruturas organizacionais e processos de liderança que assegurem que a TI sustente as estratégias organizacionais. Nesta e nas demais definições de governanças de TI é comum e implícita a ideia do elo existente entre a $\mathrm{TI}$ e os processos de negócios presentes e futuros nas organizações (Van Gremberger, 2004). Neste sentido, a interdependência entre área de negócio e de Tl exige a presença de uma liderança organizacional para conduzir as 
relações e fazer com que os objetivos corporativos sejam alcançados.

A definição de governança de TI de Weill e Ross (2006) alinha-se à de Van Gremberger (2004) quando aqueles autores analisaram a governança de $\mathrm{Tl}$ em difernetes organizações e concluiram que uma governança de TI eficaz adota três diferentes mecanismos: estruturas de tomada de decisão, processos de alinhamento e abordagens de comunicação. Segundo os autores, as organizações que possuem um sistema de governança bem estruturado, implementam esses mecanismos de forma transparente para todos os interessados na organização.

\subsection{MECANISMOS DE GOVERNANÇA DE TI}

Dentre os três mecanismos da governança de TI (estruturas de tomada de decisão, processos de alinhamento e abordagens de comunicação) concebidos por Weill e Ross (2006), no que concerce uma governança de TI eficaz, as estruturas de tomada de decisão são os mecanismos mais visíveis adotados pelas organizações que implementam governança de TI. Essas estruturas envolvem, por exemplo, a definição de comitês, comissões e papéis dentro da organização para tomar as principais decisões de TI, sendo formadas na maioria das vezes por membros da área técnica e também da área de negócio da organização. Segundo os autores, a presença das áreas de negócio nestas estruturas gera maior comprometimento para as decisões de TI, visto que muitos executivos de negócio por muito tempo deixaram as decisões de TI com a área de TI. Neste sentido, percebe-se que a implementação dos mecanismos de estruturas de tomadas decisão depende do envolvimento da área de negócio e de TI para acordarem as melhores decisões que equilibrem a capacidade tecnológica e as necessidades de negócio das organizações.

Um outro mecanismo comum de governança de TI proposto por Weill e Ross (2006) são os processos de alinhamento. Depois de conceber as estruturas de tomada de decisão, primeiro passo da implementação da governança de TI, os processos de alinhamento serão os mecanismos de implementação das ações e principalmente das decisões tomadas pelas estruturas concebidas. Os processos de alinhamento "são técnicas da administração da TI para assegurar o envolvimento geral da administração e utilização efetiva da tecnologia da informação" (WEILL e ROSS, 2006, p. 99). Segundo os autores, os principais processos de alinhamento envolvem: acordos de nível de serviços, rastreamento formal do valor de negócio da TI, processo de aprovação de investimentos de TI, processos de exceções à arquitetura, processos para alocação dos custos centrais da TI nas unidades de negócio, e processos de acompanhamento de projetos.

Por fim, os mecanismos de comunicação são os responsáveis por comunicar as principais decisões de TI dentro da organização, bem como todos os comportamentos desejáveis pela alta administração para a área de negócio. Cabe também a este mecanismo ouvir as partes interessadas, assim como entender suas necessidades para direcionar com as melhores decisões em termos de governança de TI. De acordo com Weill e Ross (2006), organizações que comunicam formalmente seus mecanismos de governança de $\mathrm{TI}$, suas funções e decisões tomadas, assim com os resultados esperados, são mais eficazes na sua governança de TI. São exemplos desses mecanismos, os comunicados da alta gerência, a implementação de escritório de governança de TI para a comunicação dos processos e propósitos da governança, e a implementação de portais web com o objeto não somente de divulgar os resultados da governança de TI, mas também para educar os membros da organização sobre os processos de governança de TI.

Para implementar as estruturas de tomada de decisão, os processos de alinhamento e a comunicação da governança de $\mathrm{TI}$, as organizações públicas têm se baseado em leis, decretos, assim como em normas e modelos já consolidados como o Control Objectives for Information and Related Technologies (COBIT).

A seguir será apresentado o COBIT, mais especificamente na sua versão 5. Este como um modelo de governança de TI que fornece um corpo de conhecimento que auxilia organizações de todos os portes e diversas finalidades a conceber mecanismos que auxiliam as organizações a atingirem seus objetivos de governança e gestão de TI. 


\subsection{CONTROL OBJECTIVES FOR INFORMATION AND RELATED TECHNOLOGIES (COBIT)}

O COBIT é um modelo de governança e gestão de $\mathrm{TI}$, desenvolvido e difundido pela Information System Audit and Control Association (ISACA), que tem por função criar valor por meio da $\mathrm{TI}$, "mantendo o equilíbrio entre a realização de benefícios e a otimização dos níveis de risco e de utilização dos recursos" (ISACA, 2012, p. 15). Por ser um modelo genérico e de fácil integração com outros padrões do mercado, pode ser utilizado por organizações públicas ou privadas de todos os portes e com diversos objetivos de negócios.

O COBIT 5 (versão divulgada em 2012) é baseado em cinco princípios básicos que, juntos, permitem que qualquer organização implemente a governança e gestão de TI de forma eficiente. Os cinco princípios do COBIT 5 são: 1 - Satisfazer necessidades das partes interessadas; 2 - Cobrir a organização de ponta a ponta; 3 - Aplicar um framework integrado e único; 4 - Possibilitar uma visão holística; 5 - Separar governança do gerenciamento.

O primeiro princípio é satisfazer as necessidades das partes interessadas. É função da equipe executiva sênior de qualquer organização satisfazer as necessidades das partes interessadas para criar valor através de um sistema de governança. De acordo com a ISACA (2012), criar valor é o objetivo da governança, e significa realizar benefícios, com uma ótima relação entre os custos e os níveis de riscos aceitáveis pela organização. Os benefícios das partes interessadas internas em organizações privadas podem ser traduzidos como o crescimento da empresa. Nas organizações públicas, por sua vez, os benefícios para as partes interessadas externas ou os usuários dos serviços públicos se traduzem na eficiência da prestação dos serviços à população. É importante considerar que as necessidades das partes interessadas nos serviços são divergentes e muitas vezes conflitantes. Em decorrência desse tipo de situação, o sistema de governança deve considerar todas as partes interessadas ao tomar decisões sobre a avaliação dos recursos, benefícios e riscos (ISACA, 2012).

O princípio de satisfazer as necessidades das partes interessadas é atendido por meio da cascata de objetivos do COBIT 5, que traduz as "necessidades das partes interessadas em objetivos corporativos específicos, personalizados, exequíveis, objetivos de $\mathrm{Tl}$ e metas de habilitador." ISACA (2012, p. 19). Os objetivos corporativos e de TI são declarações de alto nível, presentes sempre no planejamento estratégico da organização. Os habilitadores, por sua vez, "são os recursos organizacionais da governança, tais como modelos, princípios, processos e práticas, por meio dos quais a ação é orientada e os objetivos podem ser alcançados (ISACA, 2012, p.26)".

O segundo princípio é cobrir a organização de ponta a ponta. Este princípio se traduz na capacidade de o modelo ser robusto o suficiente para atender as demandas do ambiente que é implantado. Além de integrar a governança de $\mathrm{Tl}$ à governança corporativa de qualquer organização, o modelo fornece um conjunto de habilitadores que quando interligados trazem uma visão holística da organização.

O terceiro princípio é aplicar um framework integrado e único. O COBIT 5 foi desenvolvido com o objetivo de extrair de outros modelos correlatos no mercado, todo o conhecimento sobre governança e gestão de $\mathrm{Tl}$ e unificar em um único framework. A vantagem do modelo é que ele traz um conjunto de orientações em uma linguagem simples de fácil entendimento para as partes interessadas da organização. O conjunto de orientações faz parte da experiência adquirida pela ISACA ao longo do tempo no desenvolvimento de outros produtos e dos padrões e modelos. Todo o conhecimento desse framework é acessível através do ambiente colaborativo online, dos guias de habilitadores, em especial do habilitador processos, e dos guias profissionais do COBIT 5.

O quarto princípio é possibilitar uma visão holística. Para que a governança e gestão de TI funcione de forma eficiente, o modelo do COBIT 5 fornece um conjunto de habilitadores que são interdependentes. Entendidas as necessidades de negócios e definidos os objetivos corporativos, a organização define dentro das sete categorias de habilitadores, as necessárias para fazer com que os objetivos de TI sejam atingidos. De acordo com a ISACA (2012), boas decisões podem ser tomadas quando bons arranjos de governança forem concebidos levando em 
consideração as sete categorias de habilitadores, que são definidas como:

Princípios, políticas e modelos são veículos para a tradução do comportamento desejado em orientações práticas para a gestão diária.

- Processos descrevem um conjunto organizado de práticas e atividades para o atingimento de determinados objetivos e produzem um conjunto de resultados em apoio ao atingimento geral dos objetivos de TI.

Estruturas organizacionais são as principais entidades de tomada de decisão de uma organização.

- Cultura, ética e comportamento das pessoas e da organização são muitas vezes subestimados como um fator de sucesso nas atividades de governança e gestão.

- Informação permeia qualquer organização e inclui todas as informações produzidas e usadas pela organização. A Informação é necessária para manter a organização em funcionamento e bem governada, mas no nível operacional, a informação por si só é muitas vezes o principal produto da organização.

- Serviços, infraestrutura e aplicativos incluem a infraestrutura, a tecnologia e os aplicativos que fornecem à organização o processamento e os serviços de tecnologia da informação.

- Pessoas, habilidades e competências estão associadas às pessoas e são necessárias para a conclusão bem-sucedida de todas as atividades bem como para a tomada de decisões corretas e tomada de medidas corretivas. (ISACA, 2012, p.29)

O quinto princípio é distinguir a governança do gerencialmento. Esta distinção ficou mais clara no COBIT 5 e foi concebida com o objetivo de separar as atividades de governança e de gestão da organização. De acordo com a ISACA (2012), a governança:

[...] garante que as necessidades, condições e opções das partes interessadas sejam avaliadas a fim de determinar objetivos corporativos acordados e equilibrados; definindo a direção através de priorizações e tomadas de decisão; e monitorando o desempenho e a conformidade com a direção e os objetivos estabelecidos (ISACA, 2012).

Enquanto a gestão "é responsável pelo planejamento, desenvolvimento, execução e monitoramento das atividades em consonância com a direção definida pelo órgão de governança a fim de atingir os objetivos corporativos" (ISACA, 2012, p.33).

\section{METODOLOGIA}

A pesquisa foi desenvolvida na Universidade Federal do Recôncavo da Bahia (UFRB), instituição localizada na cidade de Cruz das Almas, Bahia, Brasil. De acordo com a Comissão Própria de Avaliação (CPA), em 2016, na média dos dois semestres do ano, a UFRB contava com um total de 9005 alunos matriculados, sendo 8.883 alunos ativos na graduação e 122 alunos ingressos na pósgraduação. De acordo com a CPA, o quadro de professores na instituição, naquele ano, era de 844 docentes, sendo 763 efetivos e 81 substitutos. No que tange o número de funcionários, a universidade tinha 1.196, sendo 715 técnicos administrativos e 481 terceirizados. A Coordenadoria de Tecnologia da Informação (COTEC) é a instância da UFRB responsável pela gestão da TI. Atualmente está subordinada à Pró-Reitoria de Planejamento e possui 4 (quatro) núcleos. O Figura 1 apresenta a estrutura organizacional de TI da UFRB. 
Figura 1 - Estrutura organizacional de TI

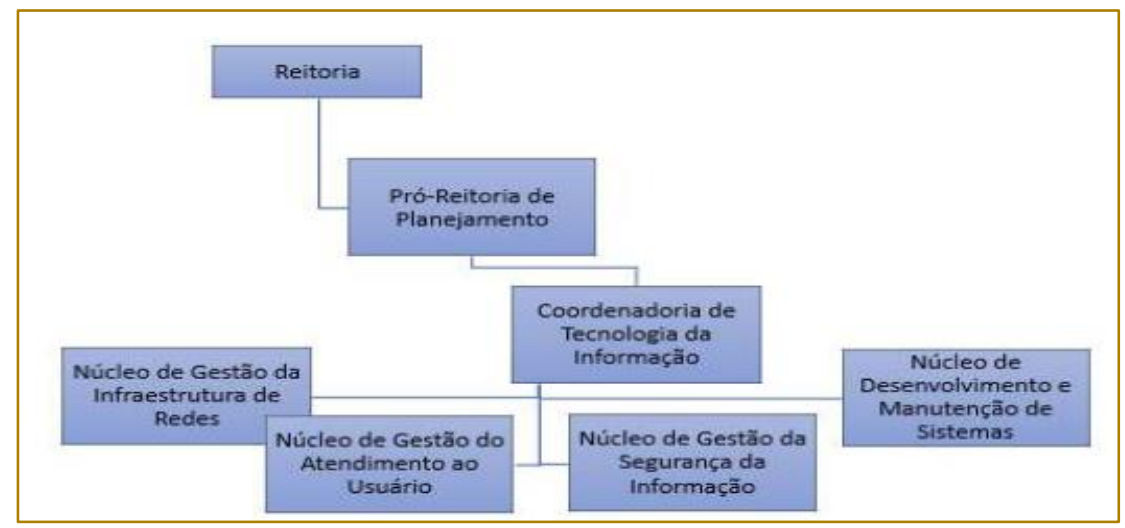

Fonte: Adaptado pelo autor, com base no relatório de autoavaliação institucional (2015-2017)

Como o tema governança de $\mathrm{TI}$ relaciona-se com as atividades estratégicas da instituição, decidiu-se incluir no universo da pesquisa 22 (vinte e dois) tomadores de decisão de nível estratégico que influenciam nas principais decisões de TI. A partir da participação desses tomadores de decisão na pesquisa, no que tange a percepção da implementação dos mecanismos de governança de TI, juntamente com a análise documental, identificou-se quais os mecanismos de governança de $\mathrm{TI}$ necessitam de maior atenção pela alta administração acerca do processo de implementação. Participaram da pesquisa: 7 (sete) Pró-Reitores; 7 (sete)
Diretores de Centros; 2 (dois) Assessores; 5 (cinco) Superintendentes e 1 (um) Auditor Interno.

A pesquisa realizada sobre os fundamentos dos mecanismos de governança de TI, propostos por Weill e Ross (2006), permitiu tratar, as 7 (sete) categorias de habilitadores do COBIT 5, de categorias de mecanismos de governança de TI, propondo para cada categoria um conteúdo para direcionar a coleta e análise dos dados. O Quadro 1 apresenta as categorias de mecanismos do COBIT 5 com os conteúdos que direcionaram a construção do questionário e a análise documental.

Quadro 1 - Modelo proposto para estudar a implementação dos mecanismos de governança de TI na UFRB

\begin{tabular}{l|l|}
$\begin{array}{l}\text { Estrutura Organizacional } \\
\begin{array}{l}\text { Princípios, políticas e } \\
\text { modelos }\end{array}\end{array}$ & Atuação das estruturas de tomada de decisão de TI. \\
\hline $\begin{array}{l}\text { Informação } \\
\text { Perviços, infraestrutura e } \\
\text { aplicações }\end{array}$ & $\begin{array}{l}\text { Utilidade e garantia de serviços, infraestrutura e aplicativos de TI às } \\
\text { necessidades de negócio. }\end{array}$ \\
\hline $\begin{array}{l}\text { Processos } \\
\text { Cultura, ética e } \\
\text { comportamento }\end{array}$ & Satisfação da área de negócio com os processos de gestão de TI. \\
\hline $\begin{array}{l}\text { Pessoas, habilidades e } \\
\text { competência }\end{array}$ & Mecanismos de controle para evitar conflitos de interesses nas decisões de TI. \\
\hline
\end{tabular}

Fonte: Elaborado pelos autores, com base nos habilitadores do COBIT 5 (2017). 
No que tange aos aspectos da estrutura do questionário, a versão final apresentada aos respondentes constou de vinte e quatro questões. Todas as questões foram extraídas dos conteúdos relacionadas aos mecanismos do COBIT 5. O questionário ficou aberto entre os meses de junho e agosto de 2017, período em que foram obtidas todas as respostas dos tomadores de decisão. O tempo estimado para a realização do questionário foi de vinte minutos. Junto ao questionário, solicitou que o respondente informasse seu e-mail para que - pesquisador pudesse monitorar as respostas e enviar lembrete, solicitando somente aos que não responderam.

Após a aplicação do questionário aos 22 (vinte e dois) tomadores de decisão, que teve o objetivo de identificar a percepção quanto à implementação dos mecanismos de governança de $\mathrm{TI}$, realizou-se uma pesquisa documental a fim de melhorar a interpretação do resultado da pesquisa de campo. No sentido de direcionar a pesquisa documental e obter os dados primários, inicialmente, realizou-se a análise do Plano de Desenvolvimento Institucional 2015-2019, dos relatórios de gestão de 2015 e 2016, do relatório de autoavaliação institucional 20152017 e no site da instituição. A consulta a outros documentos, como Portarias e Resoluções, foi realizada até o mês de agosto de 2017, período em que se encerrou a consulta aos documentos e começou a análise e interpretação dos mesmos. A consulta aos documentos foi direcionada tendo por base o modelo proposto para estudar a implementação dos mecanismos de governança de TI na UFRB conforme Quadro 1.

Após a fase de coleta de dados através do uso de questionário, iniciou-se a fase de análise e interpretação do material coletado. Com o objetivo de indicar o grau de atitude dos sujeitos pesquisados em relação ao objeto de estudo, utilizou-se no questionário a escala Likert de cinco pontos. Este método consiste em "um conjunto de itens apresentados como afirmações ou opiniões, para os quais se pede a reação dos participantes" em relação ao objeto investigado (SAMPIERI; COLLADO; LUCIO, 2013, p. 261). A escala utilizada obteve os seguintes graus de atitude em relação as questões apresentadas aos tomadores de decisão: sempre; na maioria das vezes sim; algumas fez sim, algumas vezes não; na maioria das vezes não, nunca.
Para analisar as questões, utilizou-se o cálculo do ranking médio (RM) proposto por Oliveira (2005), que é obtido através da relação entre a média ponderada (MP), e o número de sujeitos (NS) que opinaram na questão. Assim, RM = MP / NS, onde MP = $\Sigma\left(\mathrm{fi}^{*} \mathrm{vl}\right), \mathrm{NS}=\mathrm{n}^{\circ}$. de sujeitos, $\mathrm{fi}=$ frequência de cada resposta em cada item, $\mathrm{vl}=$ valor de cada item.

Como as questões foram agrupadas por conteúdo, analisou-se tanto o RM para cada questão como para cada conteúdo. Usou-se o seguinte critério para análise das questões e dos conteúdos: os valores encontrados menores que 3 (três) foram considerados com atitude negativa, e maiores que 3 foram considerados com atitude positiva, considerando a escala de 5 (cinco) pontos. Para os valores iguais a 3 , considerou-se que os sujeitos não têm opinião definida, sendo neste caso um ponto neutro da escala. A partir dos resultados obtidos, interpretou-se a opinião dos principais tomadores de decisão no que tange a implementação dos mecanismos de governança de TI na instituição.

\section{RESULTADOS E DISCUSSÃO}

\subsection{ATUAÇÃO DAS ESTRUTURAS ORGANIZACIONAIS DE TOMADA DE DECISÃO DE TI}

Os resultados da pesquisa indicaram que os tomadores de decisão da instituição tiveram uma percepção negativa em relação a atuação do Comitê de Governança Digital (CGD) (ranking médio de 2,77), e ao Comitê de Segurança da Informação (CSIC) (ranking médio de 2,95). No que tange as ações de TI desenvolvidas pela Coordenadoria de Tecnologia da Informação (COTEC), os tomadores de decisão tiveram uma percepção extremamente positiva (ranking médio de 4,05). Considerando as 3 (três) estruturas de tomada de decisão de TI na instituição, 2 (duas) com atribuições estratégicas (CGD e CSIC), e 1 (uma) com atribuições táticas e operacionais (COTEC), a média do ranking médio foi de 3,26, indicando uma percepção positiva dos tomadores de decisão.

Percebe-se que a atitude positiva dos tomadores de decisão está na estrutura organizacional de $\mathrm{TI}$ responsável por decisões táticas e operacionais. Em um trabalho realizado por Silva (2016) sobre a 
contribuição da TI para as práticas de gestão estratégica da UFRB, o autor encontrou a mesma percepção desses tomadores de decisão no que tange a esta estrutura de TI. De acordo com o autor, os tomadores de decisão avaliaram como positivamente 0 suporte prestado pela COTEC. Estes resultados revelam que a COTEC tem se tornado uma instância de referência acerca do tratamento das demandas de $\mathrm{TI}$ da instituição, principalmente porque tem dado suporte à implantação de um Sistema Integrado de Gestão (SIG), e demandas de infraestrutura e suporte aos usuários.

A análise realizada acerca da percepção negativa dos tomadores de decisão no que tange as instâncias responsáveis por tomada de decisão estratégica (CGD e CSIC), assim como a ausência de evidências documentais na instituição de que estas instâncias têm atuado, revela que estes comitês não têm cumprido com suas atribuições dentro do sistema de governança de TI da instituição.

Uma das áreas foco da governança de TI é realizar o alinhamento estratégico entre a $\mathrm{TI}$ e as áreas de negócio. Observando a percepção dos tomadores de decisão da UFRB acerca dos 2 (dois) comitês (CGD e CSIC), a ausência de evidências documentais (atas de reuniões), e levando em consideração as implicações encontradas em um trabalho realizado por Putz (2015), de que a ausência de alinhamento estratégico está relacionada a consolidação dos comitês de TI, pode-se inferir que na UFRB a não atuação destas estruturas de tomada de decisão estratégica está comprometendo o alinhamento estratégico da universidade.

\subsection{PRINCÍPIOS, POLÍTICAS E MODELOS DE TI COMO MECANISMOS DE ALINHAMENTO ESTRATÉGICO}

A investigação a partir desse mecanismo de governança de $\mathrm{Tl}$ deu-se por meio de três questões que tiveram como objetivo indicar o nível de alinhamento estratégico a partir dos princípios e políticas da instituição pesquisada. Com a intenção de mensurar o nível de alinhamento da área de negócio com esta categoria de mecanismo, questionou-se sobre a percepção dos tomadores de decisão acerca da participação ou influência destes na formulação ou atualização dos princípios, políticas e modelos de TI. Acerca do processo de comunicação deste mecanismo para a área de negócio, quando concebidos e implementados na universidade, e sobre o nível de alinhamento dessa categoria de mecanismo com as atividades desempenhadas pelos tomadores de decisão.

A percepção positiva dos tomadores de decisão concentrou-se na questão que tratou do alinhamento das atividades dos seus setores com os princípios, políticas e modelos de TI (ranking médio 3,59), assim como na questão que tratou da comunicação da concepção, implementação e atualização desse mecanismo pelos órgãos de governança de TI (ranking médio 3,09). Com relação à participação ou influência dos tomadores de decisão na construção dos princípios, políticas e modelos de TI, a percepção foi negativa (ranking médio 2,36), indicando que a maioria dos tomadores de decisão não são consultados para a construção destes que formam uma categoria de mecanismo de governança de TI responsável por conceber as regras da organização, atuando na transmissão de instruções e orientações necessárias para o bom funcionamento da governança de TI na universidade.

Da análise documental realizada, com exceção da existência da Políticas de Segurança da Informação e Comunicação POSIC da UFRB, não foram encontrados quaisquer documentos com declaração de princípios e políticas de TI na instituição. Logo, percebe-se uma contradição entre a percepção positiva desses tomadores de decisão em relação a este mecanismo e a ausência de documentos que comprovem este alinhamento estratégico.

Ao analisar o Plano de Desenvolvimento Institucional 2015-2019 da UFRB, observou-se metas relacionadas à $\mathrm{TI}$ para ampliar e melhorar a infraestrutura física e administrativa da instituição no que tange a área de gestão (UFRB, 2015, p. 120). Entretanto, apesar das metas de TI estarem declaradas para atingir os objetivos corporativos da instituição, demonstrando um ponto de origem para o desenvolvimento de estratégias de TI, não existe um Planejamento Estratégico de Tecnologia da Informação (PETI), documento que expressa os princípios de $\mathrm{TI}$ que sustentam os objetivos corporativos.

Levando em consideração a afirmação de Nascimento (2014) de que o PETI "é o 
documento que serve de ligação para o estabelecimento do Alinhamento Estratégico no Plano Geral da Organização representado pelo Planejamento Estratégico Institucional, sendo este o responsável pelas diretrizes gerais de toda organização (NASCIMENTO, 2014, p. 13)", pode-se afirmar que com a inexistência de um PETI na UFRB, não está ocorrendo alinhamento estratégico da TI com as áreas de negócio.

\subsection{QUALIDADE DAS INFORMAÇÕES PRODUZIDAS PELOS SISTEMAS AUTOMATIZADOS}

A percepção positiva dos tomadores de decisão (ranking médio de 3,18 ) deu-se para a qualidade contextual da informação, uma vez que os tomadores de decisão percebem as informações como aplicáveis e úteis para as atividades de gestão. Enquanto que a percepção negativa (ranking médio de 2,45 ) deu-se para a qualidade intrínseca dessas informações, tendo em vista que os tomadores de decisão não percebem as informações em conformidade com os valores reais e efetivos da área de negócio. Este resultado negativo é preocupante visto que essas informações estão sendo usadas por áreas estratégicas de uma instituição que trabalha com ensino, pesquisa e extensão, e que precisa de informações sempre em conformidade com os valores reais e efetivos disponíveis para a comunidade acadêmica.

Como a UFRB passa por um processo de implantação do Sistema Integrado do Gestão (SIG), o ranking médio negativo para a qualidade intrínseca das informações produzidas pelos sistemas automatizados sugere problemas nos processos de validações de migrações de dados a partir de sistemas legados, assim como de capacitação de servidores para a manutenção desses novos sistemas. Segundo o relatório de gestão do exercício de 2016, estes processos ocorreram, principalmente, na finalização da implantação do Sistema Integrado de Gestão Acadêmica (SIGAA), conforme observado:

[...] no exercício de 2016 finalizamos a implantação do Sistema Integrado de Gestão Acadêmica (SIGAA). $\mathrm{Na}$ condição de gestores do negócio, fomos requisitados pela administração central a compor comissão de implantação que foi organizada em três etapas, a saber: homologação dos roteiros de dados, validação da migração dos dados e capacitação de servidores para o uso do sistema. A expectativa com o uso deste sistema integrado é que tenhamos um grande avanço da gestão acadêmica em todos os setores. (UFRB, 2017, p. 33-34)

\subsection{HABILIDADE E COMPETÊNCIA DOS SERVIDORES TÉCNICOS E ANALISTAS DE TI}

A percepção dos executivos acerca das habilidades e competências do quadro de servidores de TI da UFRB foi positiva (ranking médio de 3,73). Esta percepção está relacionada a satisfação dos executivos com o desempenho dos servidores de TI, que por sua vez são os responsáveis por executar as ações planejadas da TI.

Com o objetivo de validar a percepção positiva dos executivos acerca desta categoria de mecanismos na instituição, procurou-se nos documentos institucionais evidências que justificassem tal percepção. Ao consultar o relatório de gestão do exercício de 2015 e 2016, observou-se que os únicos cursos oferecidos pela instituição foram: Ponto de função, IPv6, Segurança de redes, Segurança de Redes sem fio. Consta no relatório do ano de 2016 que, ao término do contrato com a empresa licenciada (ESIG software \& consultoria), realizou-se transferência de tecnologia da contratada para a contratante (UFRB).

A percepção positiva dos executivos acerca das habilidades e competências do quadro de servidores de $\mathrm{TI}$ sugere que, para além dos cursos oferecidos oriundos de demandas específicas, os servidores de TI realizam capacitações por conta própria. Devido à ausência de definições de princípios, políticas e modelos de TI, assim como de evidências de atuação das estruturas de tomada de decisão estratégicas de TI no que se refere a análise do quadro de pessoal de $\mathrm{TI}$, as capacitações e qualificações dos analistas e técnicos de $\mathrm{TI}$ podem estar ocorrendo de forma desalinhadas ao planejamento estratégico da universidade.

\subsection{UTILIDADE E GARANTIA DOS SERVIÇOS, INFRAESTRUTURA E APLICATIVOS DE TI PARA AS NECESSIDADES DE NEGÓCIOS}

Para as questões que abordaram aspectos relacionados a utilidade, os executivos tiveram uma percepção positiva (média do 
ranking médio 3,67). As questões buscaram identificar a utilidade dos serviços disponíveis no catálogo de serviços de TI, dos softwares desenvolvidos ou adquiridos para as necessidades da instituição, e dos recursos de TI utilizados para tratamento das informações do setor investigado. Cabe destacar que $77 \%$ dos executivos tiveram uma percepção positiva em relação aos softwares desenvolvidos ou adquiridos para seus setores como soluções estratégicas. No trabalho realizado por Silva (2016), o autor havia diagnosticado que as áreas estratégicas da UFRB acreditavam que a implantação do Sistema Integrado de Gestão (SIG) permitiria uma melhoria tanto da área de negócio quanto da área de TI. Estes resultados apontam para um amadurecimento dos executivos acerca da importância da automatização dos processos através do SIG, o que sugere existir na UFRB uma cultura por parte dos executivos de negócio de abertura a soluções automatizadas.

As perguntas relacionadas a garantia envolveram aspectos como prejuízo das atividades devido as interrupções nos serviços, tempo médio para tratar as solicitações de um serviço de TI, bem como o quão o acesso à internet atende as atividades do setor. Para este aspecto, os resultados da pesquisa apontaram que os executivos tiveram uma percepção negativa (média do ranking médio 2,48 ).

Os resultados da investigação desta categoria de mecanismos sinalizam que a instituição cumpre com o que o usuário espera em termos de serviços, entretanto não tem cumprido com as garantias de entrega. Este resultado indica que a instituição está com a sua capacidade de serviços de TI comprometida, visto que os aplicativos $e$ infraestrutura de $\mathrm{TI}$ disponível na instituição depende de eficiência na prestação de serviços de TI. Dessa forma, a percepção negativa dos executivos acerca da garantia revela que a entrega de valor, objetivo do modelo COBIT 5 e da governança de TI, está prejudicada, e, portanto, não atendendo as partes interessas do negócio.

\subsection{MECANISMOS DE CONTROLE PARA EVITAR CONFLITOS DE INTERESSES NAS DECISÕES DE TI}

A análise acerca da categoria de mecanismo cultura, ética e comportamento teve o objetivo de identificar o compromisso da instituição em incentivar e manter comportamentos éticos dos membros da alta administração acerca das decisões de TI. Neste sentido, perguntou-se aos executivos da instituição acerca da frequência com que a instituição implementa mecanismos de controle para evitar vieses, preconceitos ou conflitos de interesse que influenciem nas decisões de TI por membros da alta administração. A percepção dos executivos foi negativa (ranking médio 2,86).

A percepção negativa dos executivos acerca da implementação de mecanismos de controle que evitam conflitos de interesses na tomada de decisão de TI se alinha a ausência de princípios e políticas de TI como mecanismos de comunicação dos valores corporativos e comportamentos desejáveis na instituição. A implementação de mecanismos de controle como este, passa pela elaboração de normas alinhadas aos princípios corporativos, que forneçam orientação sobre o comportamento organizacional desejado no que tange ao processo de tomada de decisão de TI.

\subsection{SATISFAÇÃO DA ÁREA DE NEGÓCIO COM OS PROCESSOS DE GESTÃO DE TI}

A inspiração para a construção das questões acerca da categoria de mecanismos processos deu-se a partir da observação das atividades desenvolvidas nos 4 (quatro) núcleos da COTEC (Núcleo de Gestão do Atendimento ao Usuário; Núcleo Gestão da Infraestrutura de Redes; Núcleo de Gestão da Segurança de Informação e Núcleo de Desenvolvimento e Manutenção de Sistemas), relacionando-as com 3 (três) processos do COBIT 5, a saber: DSS01 Gerenciar Operações, DSS05 Gerenciar Serviços de Segurança, e BAI03 Gerenciar a Identificação e Desenvolvimento de Soluções.

Da análise realizada, observa-se que os executivos tiveram uma percepção positiva dos processos de gestão de TI (média do ranking médio de 3,25 ) que envolvem serviços de segurança, desenvolvimento de software e gerenciamento de operações. Este resultado demonstra a satisfação dos executivos com os processos de gestão de TI, e corrobora o encontrado sobre a atuação operacional da COTEC na instituição, avaliada pelos executivos como positiva. 
Apensar da percepção positiva acerca dos indicadores relacionados aos processos de gestão de TI, a ausência de um PETI na instituição sugere processos desvinculados de metas corporativas, e, portanto, com execução sem alinhamento estratégico.

\section{CONCLUSÕES}

A análise realizada indicou que a implementação dos mecanismos de governança de TI na UFRB no período analisado encontrava-se em um estágio embrionário. Constatou-se inércia das estruturas de tomada de decisão estratégica de TI (CGD e CSIC), e ausência da definição de princípios, políticas e modelos de TI, que, conforme o COBIT 5 são fundamentais para a implementação das demais categorias de mecanismos. A constatação acerca do estágio embrionário da implementação dos mecanismos de governança de TI permite concluir ausência de alinhamento estratégico entre $\mathrm{TI}$ e negócio, o que implica no comprometimento da entrega de valor proporcionado pela TI para a comunidade acadêmica.

A UFRB atua na indissociabilidade do EnsinoPesquisa-Extensao, por isso seu objetivo maior é atuar no tripé Ensino, Pesquisa e Extensão. Neste sentido, necessita de informações de qualidade para a tomada de decisão dos gestores deste tripé. Constatouse com a investigação que a universidade precisa melhorar seus processos de implantação de sistemas de informações, com treinamentos de usuários, validação de migração de carga de dados a partir de sistemas legados, bem como planos de capacitação para analistas e técnicos de TI.

\section{REFERÊNCIAS}

[1]. ASSOCIAÇÃO BRASILEIRA DE NORMAS TÉCNICAS (ABNT). NBR ISO/IEC 38500: governança corporativa de tecnologia da informação. Rio de Janeiro: ABNT, 2009.

[2]. CAVALCANTI FILHO, José Hermano. Investigação da influência da governança de TI nas instituições federais de ensino superior: estudo de caso. 2011. 102f. Dissertação (Pós-graduação em Ciência da Computação), Universidade Federal de Pernambuco, CIN. Recife, 2011.

[3]. ISACA. COBIT 5 a business framework for the governance and management of enterprise IT. Isaca. 2012, 98 p.
Percebeu-se com a pesquisa, um amadurecimento dos tomadores de decisão acerca da importância da automatização dos processos através do Sistema Integrado de Gestão (SIG), o que sugere existir na UFRB uma cultura, por parte dos tomadores de decisão, de abertura a soluções automatizadas. Entretanto, para a categoria de mecanismo que trata de questões relacionadas ao comportamento desejado dentro da instituição, não foram encontradas evidências que tratassem do controle de conflitos de interesses nas decisões institucionais de Tl.

Quanto a capacidade de serviços de TI, a pesquisa revelou que carece de melhorias, visto que os aplicativos e infraestrutura de TI disponíveis na instituição dependem de eficiência na prestação de serviços de $\mathrm{TI}$, o que foi percebida de forma negativa pelos tomadores de decisão. Essas melhorias passam pela implantação de um sistema de gerenciamento de serviços, com implantação do catálogo de serviços, acordos de nível de serviços e capacidade de serviços.

De acordo com a ISACA (2012), os objetivos corporativos estão vinculados a objetivos de TI (definidos no PETI), que por sua vez estão vinculadas às metas dos mecanismos de governança de TI (habilitadores do COBIT 5). No que tange aos processos de gestão $\mathrm{TI}$, percebeu-se que estão desvinculados de metas corporativas devido à ausência de um PETI, e, portanto, sendo executados sem alinhamento estratégico. Segundo Nascimento (2014), o PETI é o documento responsável por definir as diretrizes da TI alinhadas as diretrizes gerais de toda a organização que são definidas no Planejamento Estratégico Institucional.

[4]. NASCIMENTO, José Aguiar do. Alinhamento estratégico da TI: O caso da UFRN. 2014. 72f. Dissertação (Mestrado) -Centro de Ciências Sociais Aplicadas, Universidade Federal do Rio Grande do Norte, Natal, 2014.

[5]. OLIVEIRA, Luciel Henrique de. Exemplo de cálculo de Ranking Médio para Likert. Notas de Aula. Metodologia Científica e Técnicas de Pesquisa em Administração. Mestrado em Adm. e Desenvolvimento Organizacional. PPGA CNEC/FACECA: Varginha, 2005.

[6]. PUTZ, Rosane Beatriz Zanetti. Governança de $\mathrm{TI}$ nas universidades federais brasileiras: uma abordagem integrada. 2015. 191f. Dissertação 
(Mestrado) - Programa de Pós-graduação em Planejamento e Governança Pública, Universidade Tecnológica Federal do Paraná, Curitiba, 2015.

[7]. SAMPIERI, Roberto Hernandez; COLLADO, Carlos Fernández; LUCIO, María del Pilar Baptista. Metodologia de pesquisa. 5. ed. Porto Alegre: AMGH, 2013

[8]. SILVA, José Sérgio Santos da. Tecnologia da informação como elemento de qualificação da gestão estratégica da Universidade Federal do Recôncavo da Bahia. 2016. 133f. Dissertação (Mestrado Profissional) - Programa de Pósgraduação em Gestão de Políticas Públicas e Segurança Social, Universidade Federal do Recôncavo da Bahia, Cruz das Almas, 2016.

[9]. TCU - Tribunal de Contas da União. Governança Pública: referencial básico de governança aplicável a órgãos e entidades da administração pública e ações indutoras de melhoria. Brasília: TCU, Secretaria de Planejamento, Governança e Gestão. Brasília, DF, 2014. 96p Acórdão no 882/2017 - Plenário. [2017] Disponível em:<https://contas.tcu.gov.br/pesquisaJurispruden cia/\#/detalhamento/11/\%252a/NUMACORDAO\%25 3A882\%2520ANOACORDAO\%253A2017/DTRELE VANCIA\%2520desc\%252C\%2520NUMACORDAOI NT\%2520desc/false/1/false >. Acesso em: 10/06/2017

[11]. UFRB - Universidade Federal do Recôncavo da Bahia. Institucional. [2006] Disponível <https://www.ufrb.edu.br/portal/institucional >. Acesso em: 05/12/2015.

[12] Disponível Resolução nº 005/2014. [2014] $<$ https://ufrb.edu.br/soc/components/com_chronofo rms5/chronoforms/uploads/documento/resolucao05-14-consuni.pdf>. Acesso em: 05/01/2018

[13]. Plano de Desenvolvimento Institucional 2015 - 2019. [2015] Disponível em: $<$ https://ufrb.edu.br/soc/images/PDI/PDI_2_ETAPA_ 28_07_2016.pdf>. Acesso em: 10/02/2018.

[14] Portaria no 721. [2016a] Disponível em:

<https://ufrb.edu.br/reitoria/components/com_chron oforms5/chronoforms/uploads/cadastroportarias/20160926095812_Portaria_7212016.pdf>. Acesso em: 05/01/2018.

[15]. Disponível Relatório de Gestão. [2016b] <https://ufrb.edu.br/proplan/documentos/category/ 8-relatorio-de-gestao>. Acesso em: 10/02/2018.

[16]. Relatório de Gestão. [2017] Disponível em: <https://ufrb.edu.br/proplan/documentos/category/ 8-relatorio-de-gestao>. Acesso em: 10/02/2018.

[17]. VAN GREMBERGER, W. Strategies for information technology governance. O Hershey, PA: Idea Group Publishing. 2004

[18]. WEILL, Peter; ROSS, Jeanne W. Governança de tecnologia da informação. São Paulo: M. Books do Brasil Editora LTDA, 2006. 


\section{Capítulo 17}

\section{CLASSIFICACÃO E ANÁLISE DAS PRÁTICAS DE GESTÃO DE PROJETOS SOB A LUZ DA GESTAOO DO CONHECIMENTO: ESTUDO DE CASO DE UM PROJETO DE IMPLANTAÇÃO DE ERP}

\section{Bernardo Almeida Mudjalieb \\ Jéssica Galdino de Freitas \\ Denise Terezinha Lisboa Bassani}

Resumo: O gerenciamento da informação e do conhecimento na execução de projetos se tornou um diferencial competitivo para o alcance de bons resultados. Porém, esta prática não aparece como prioridade nas boas práticas de gestão de projetos. Neste contexto, se insere este estudo de caso de um projeto de implantação de sistema de gestão integrada denominado ERP - Enterprise Resource Planning para uma empresa pública de tecnologia. Foi utilizada como metodologia a revisão da literatura e a análise documental para o estudo de caso, além da identificação e classificação das práticas de gestão de projetos de acordo com o PMI, dos pressupostos da gestão do conhecimento e da teoria de Nonaka e Takeuchi (1997). Em análise documental do estudo de caso foram identificadas 32 práticas de gestão de projetos, com maior ênfase na dimensão epistemológica do conhecimento na sua forma explícita, e na dimensão ontológica alinhada a nível da interorganização, sendo possível perceber um grande esforço da gerência do projeto no âmbito do processo de gerenciamento de projetos de planejamento e na orientação para a área do conhecimento de comunicação. As avaliações das práticas identificadas servem de insumo para melhorias em novos projetos e para profissionais que atuem em projetos com grandes volumes de informação e conhecimento, além de servir de base bibliográfica para estudos futuros. 


\section{INTRODUÇÃO}

A implantação de sistemas de gestão integrada denominado ERP - Enterprise Resource Planning se popularizou no universo organizacional, principalmente no Brasil, devido à necessidade de melhoria da produtividade, flexibilidade e redução de custos (CAMARGO JUNIOR et al., 2010).

O aumento da eficiência através da melhoria da interface de processos empresariais e de visualização das transações realizadas nos processos em tempo real são benefícios que surgiram da evolução dos sistemas de gestão da produção MRP e MRP II até se consolidar no ERP, sendo este dividido em módulos de acordo com os processos realizados pela empresa, e que atuam de forma integrada através do sistema (PADILHA et al., 2004).

Diversos problemas ocorreram no momento da implantação do ERP, como atrasos no cronograma, ausência de análise dos processos e funcionalidades, má gestão do projeto, ausência de comprometimento da alta direção e dos usuários, mudanças organizacionais entre outros fatores (MENDES et al., 2002).
Além destes problemas também são observadas as dificuldades na aplicação de boas práticas de gestão do conhecimento em projetos deste tipo identificadas nos problemas advindos da dificuldade de comunicação entre os participantes de toda a operação. Apesar de estar claro o papel da gestão do conhecimento para criação de valor dentro deste universo, esta prática não aparece como prioridade nas práticas preconizadas pelo PMI através do PMBOK® (Project Management Body of Knowledge).

Tendo em vista o cenário apresentado, essa pesquisa buscou: Avaliar as práticas de gestão de projetos de uma implantação de ERP para uma empresa pública de tecnologia através dos processos de gerenciamento de projetos, áreas do conhecimento e pressupostos da gestão do conhecimento.

\section{MÉTODO}

Com o intuito de expor as etapas executadas em cada etapa da metodologia, o desenho de pesquisa foi ilustrado na Figura 1.

Figura 1: Etapas da metodologia de pesquisa

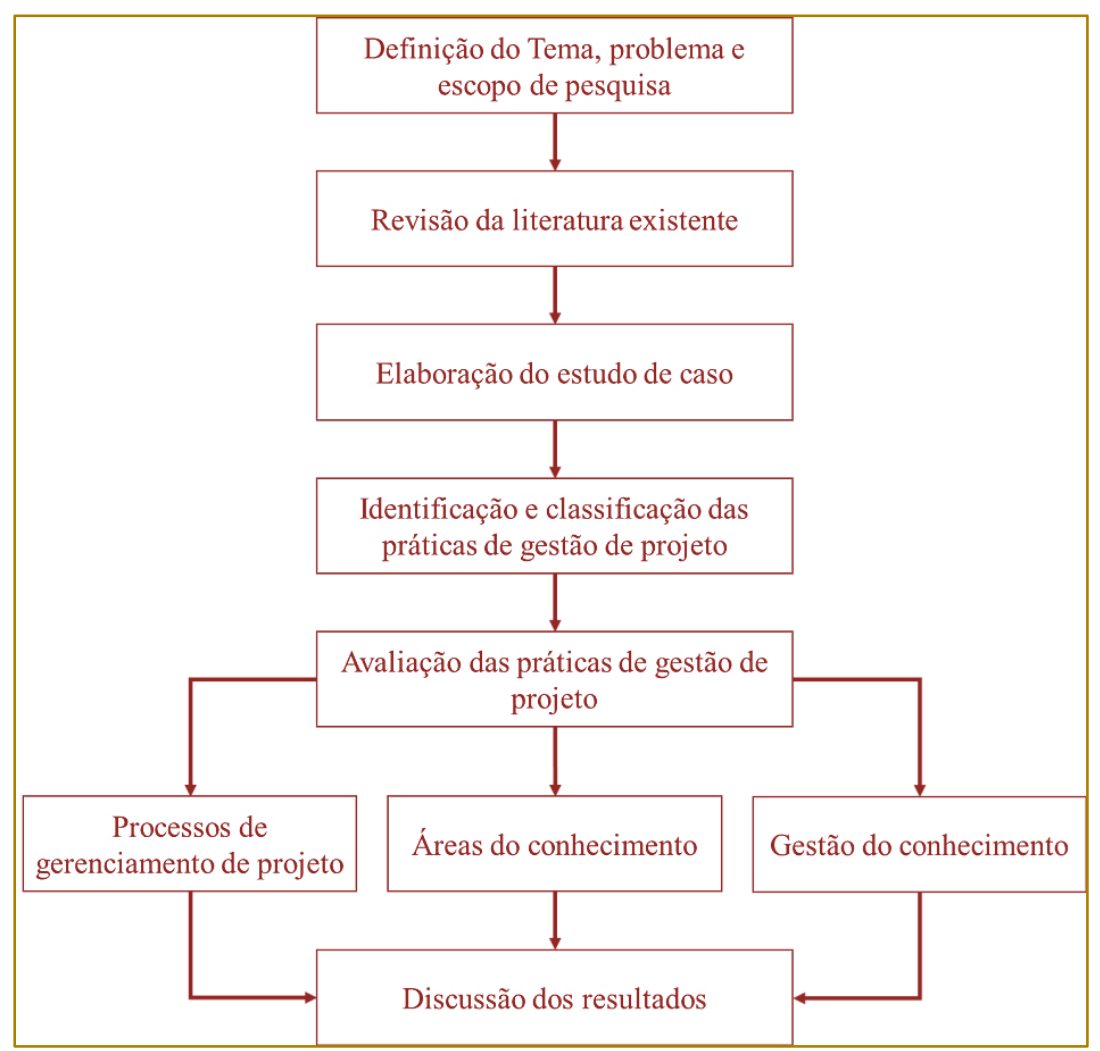

Fonte: Elaboração própria. 
A metodologia de pesquisa utilizada neste estudo de caso está baseada em uma perspectiva exploratória, tendo como suporte da análise os preceitos do PMI na área de conhecimento referente à comunicação e dos conceitos sobre a gestão do conhecimento, essencialmente sobre técnicas para conversão do conhecimento conforme os autores Nonaka e Takeuchi (1997).

A revisão da literatura existente, foi realizada através do levantamento de registros disponíveis sobre os temas, e o estudo de caso foi elaborado a partir da análise dos documentos do projeto e registros efetuados durante a consultoria em questão, cujo o presente pesquisador participou.

O estudo de caso foi a estratégia de pesquisa escolhida, pelo fato da área de conhecimento ter sido pouco explorada na literatura e por se tratarem de questões de "como" e "por que", tendo o pesquisador pouco controle sobre os acontecimentos e o foco do estudo estando em fenômenos contemporâneos no contexto da vida real (YIN, 2005).

\section{REVISÃO BIBLIOGRÁFICA}

\subsection{GESTÃO DE PROJETOS}

Segundo o PMI (2013, p. 30), um projeto é "um esforço temporário empreendido para criar um produto, serviço ou resultado exclusivo". Para realizar esse esforço, que possui tempo determinado e foco na criação de algo único, diversos conhecimentos são colocados em prática, passando pelo ciclo de vida deste esforço, desde a iniciação do projeto, organização e preparação, execução do trabalho e encerramento do projeto.

O PMBOK® apresenta dez áreas de conhecimento para projetos com diversos conceitos e práticas para cada uma destas áreas, ficando a cargo do gerente dosar a medida da utilização destes e outros conhecimentos. Essas áreas são (i) integração do projeto, (ii) escopo, (iii) tempo, (iv) custos, (v) qualidade, (vi) recursos humanos, (vii) comunicações, (viii) riscos, (ix) aquisições $\mathrm{e}(\mathrm{x})$ partes interessadas (PMI, 2013).

A área de conhecimento de comunicações do projeto inclui os esforços para assegurar que as informações do projeto sejam gerenciadas de forma efetiva, garantindo que o tempo dedicado à sua realização seja bem utilizado.
Mesmo o PMBOK® sendo "Um guia do conhecimento em gerenciamento de projetos" e possuir em seu conteúdo as áreas de conhecimento explicitadas acima, ele aborda a gestão do conhecimento de forma pulverizada nas diversas áreas citadas e mais profundamente dentro da área de comunicação. O estudo de Cruz (2011), ressalta que o PMI aborda o assunto de gestão do conhecimento no PMBOK®, demonstrando preocupação e atenção ao assunto, mas ao mesmo tempo não o destaca como uma área de conhecimento propriamente dita.

\subsection{GESTÃO DO CONHECIMENTO}

A definição do que é informação a partir da transformação e acréscimo de valor dos dados, pode ser definida como "dados dotados de relevância e propósito" (DAVENPORT e PRUSAK, 2003). Esta definição passa a colocar a informação dentro de uma estrutura maior em que esta pertence, a do conhecimento.

Para Nonaka e Takeuchi (1997), o processo de construção do conhecimento organizacional começa a partir de um indivíduo que transforma seu conhecimento pessoal em conhecimento internalizado da organização. A lógica de criação do conhecimento passa por vários momentos até este virar de fato um conhecimento, começando em sua menor parte ou sua origem, os dados.

Com a visão da criação do conhecimento organizacional começando a partir do indivíduo e sendo difundida até chegar para toda organização, é apresentada uma das dimensões da criação de conhecimento, a dimensão ontológica. Esta dimensão aborda diferentes níveis de entidades geradoras do conhecimento, como: individual, grupal, organizacional e inter organizacional, demonstrando a preocupação e importância do ser humano nesta teoria organizacional (NONAKA E TAKEUCHI, 1997).

Para Nonaka e Takeuchi (1997), este conhecimento inicial que parte do indivíduo é chamado de tácito e forma uma parte da outra dimensão do conhecimento, a dimensão epistemológica. O conhecimento tácito é pessoal, subjetivo e prático, e leva em consideração a realidade vivida pelo indivíduo (contexto), tornando ainda mais difícil a missão de formular e comunicar este 
tipo de conhecimento. Já o seu oposto e segunda parte desta dimensão, o conhecimento explícito, pode ser transmitido dentro de uma linguagem formal, é objetivo, teórico e pode ser sistematizado.
A Figura 2 representa as dimensões e a forma como o conhecimento interage entre o tácito e explícito e as entidades criadoras de conhecimento, mostrando como o conhecimento é convertido, mobilizado e ampliado no contexto organizacional.

Figura 2: Duas dimensões da criação do conhecimento

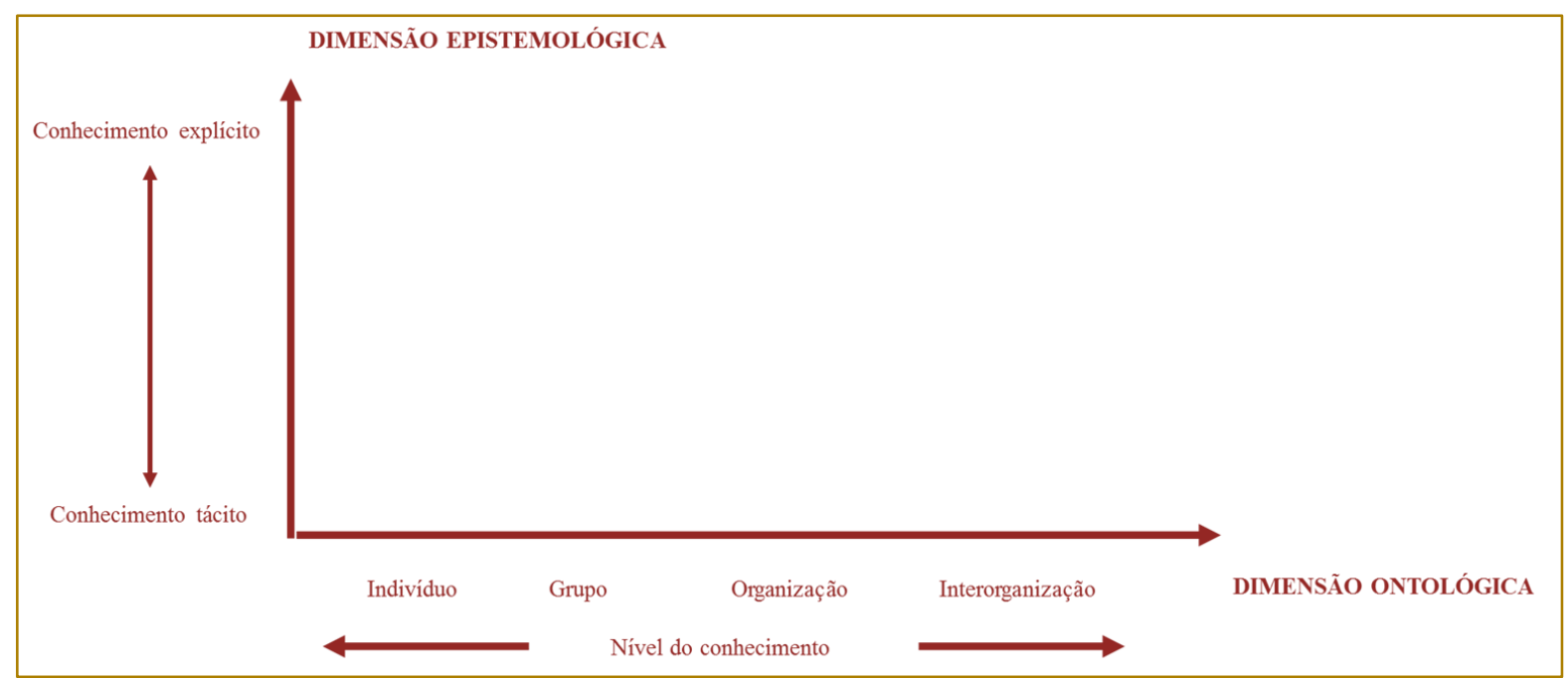

Fonte: Nonaka e Takeuchi (1997) adaptado pelos autores

São postulados quatro modos de conversão do conhecimento, a partir da interação do tácito com o explícito e o conteúdo de conhecimento criado por cada modo de conversão a partir de sua interação são expostos na Figura 3.

Figura 3: Quatro modos de conversão do conhecimento e o conteúdo do conhecimento criado.

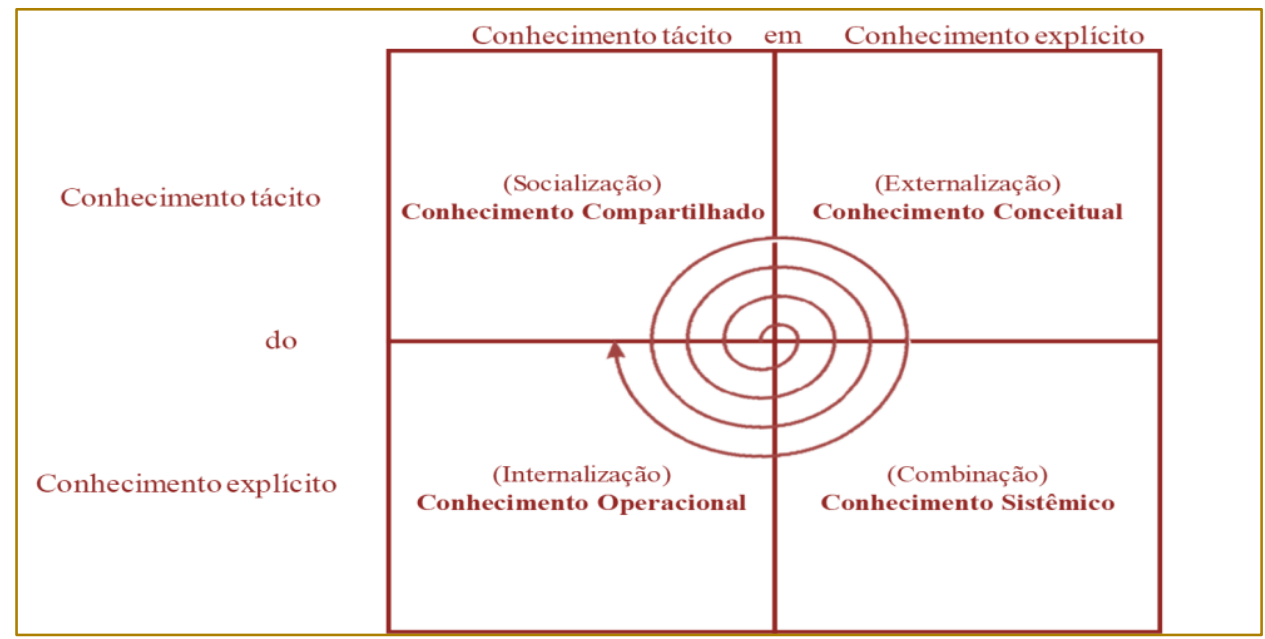

Fonte: Nonaka e Takeuchi (1997) adaptado pelos autores

Para De Abreu et al. (2015) a teoria de gestão do conhecimento postulada por Nonaka e Takeuchi (1997) e posteriormente criticada por outros autores como Von Krogh et al. (2001) e Behr e Nascimento (2008), apresenta pontos para reflexão como questões práticas e conceituais no momento de implantar as práticas de gestão do conhecimento. 
O uso de técnicas e ferramentas que tenham como foco a produtividade ou conversão do conhecimento pode acabar gerando mecanismos de controle do trabalhador, passando a pressionar os funcionários a transmitirem seus conhecimentos tácitos tornando eles explícitos, gerando assim vantagem competitiva para a organização (DE ABREU, 2015).

Com as diversas necessidades de melhorar a gestão e aproveitamento da informação e do conhecimento organizacional, as empresas passaram a adotar o uso de sistemas da informação para otimizar suas interfaces de processos e comunicações visando o aumento de competitividade e sobrevivência no mercado. Um dos sistemas empresariais mais comumente utilizados é o ERP que possibilita a integração dos múltiplos processos e recursos empresariais na gestão do negócio.

\subsection{IMPLANTAÇÃO DE ERP}

Com o amadurecimento e avanço da Tecnologia da Informação (TI), várias organizações passaram a utiliza-la através do uso de Sistemas de Informações como forma de apoio a execução de suas atividades de suporte e finalísticas. Para Davalos (2016) um sistema de informação pode ser entendido como um grupo de componentes interrelacionados com objetivo de coletar, processar, armazenar, e distribuir informações, facilitando o controle e a visualização do processo decisório.

Neste contexto entra em cena o ERP como grande expoente dos sistemas de informação e suas diversas aplicações, sendo várias as suas definições. Esse tipo de sistema possui o controle de toda a empresa desde os processos de produção até a área financeira, processando e registrando as informações lançadas no sistema e distribuídas de maneira clara, segura e em tempo real.

O ERP pode ser entendido como uma evolução dos primeiros sistemas de informação, mais precisamente o MRP I e II, que controlam os diversos recursos utilizados para a operação da manufatura e os demais recursos necessários a operação de uma empresa (CORRÊA, 1998).

Já para Davenport e Prusak (2003), o ERP é um software que promove a integração da informação entre as diversas áreas de uma empresa, trazendo a lógica do sistema para a estratégia e cultura organizacional. Este tipo de sistema possui soluções genéricas para atender as diversas necessidades das empresas, mas cada cliente precisa definir qual é a melhor prática para sua organização. A Figura 4 ilustra a estrutura comumente apresentada para um ERP, funcionando a partir de uma única base de dados comum a todos os usuários do sistema.

Figura 4: Estrutura típica de funcionamento de um ERP

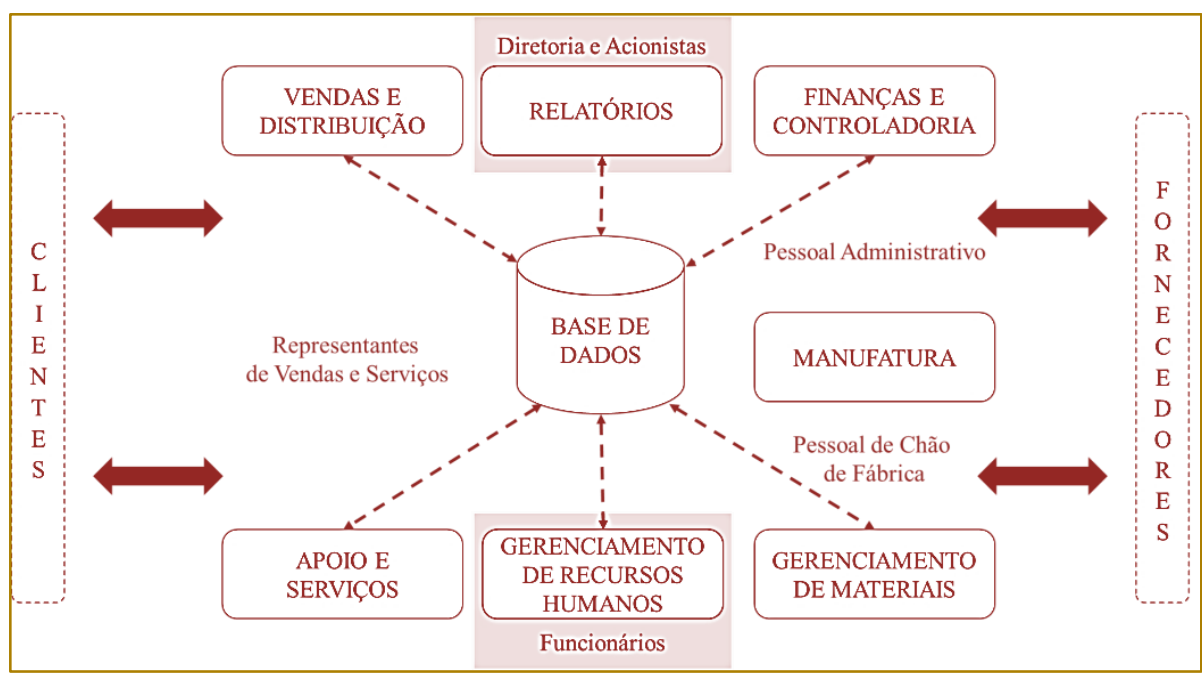

Fonte: Davenport (1998), adaptado pelos autores

Mendes e Escrivão Filho (2002) realizaram um levantamento bibliográfico na literatura científica do conceito de ERP e suas funcionalidades citado por diversos autores, 
sintetizando assim as características comuns dos sistemas ERPS. A Tabela 1 traz as características levantadas pelos diversos autores identificados, e mostra uma orientação do uso do ERP como um sistema que atende a todas as áreas da empresa e voltada a execução dos processos organizacionais.

Tabela 1: Características dos sistemas ERPS

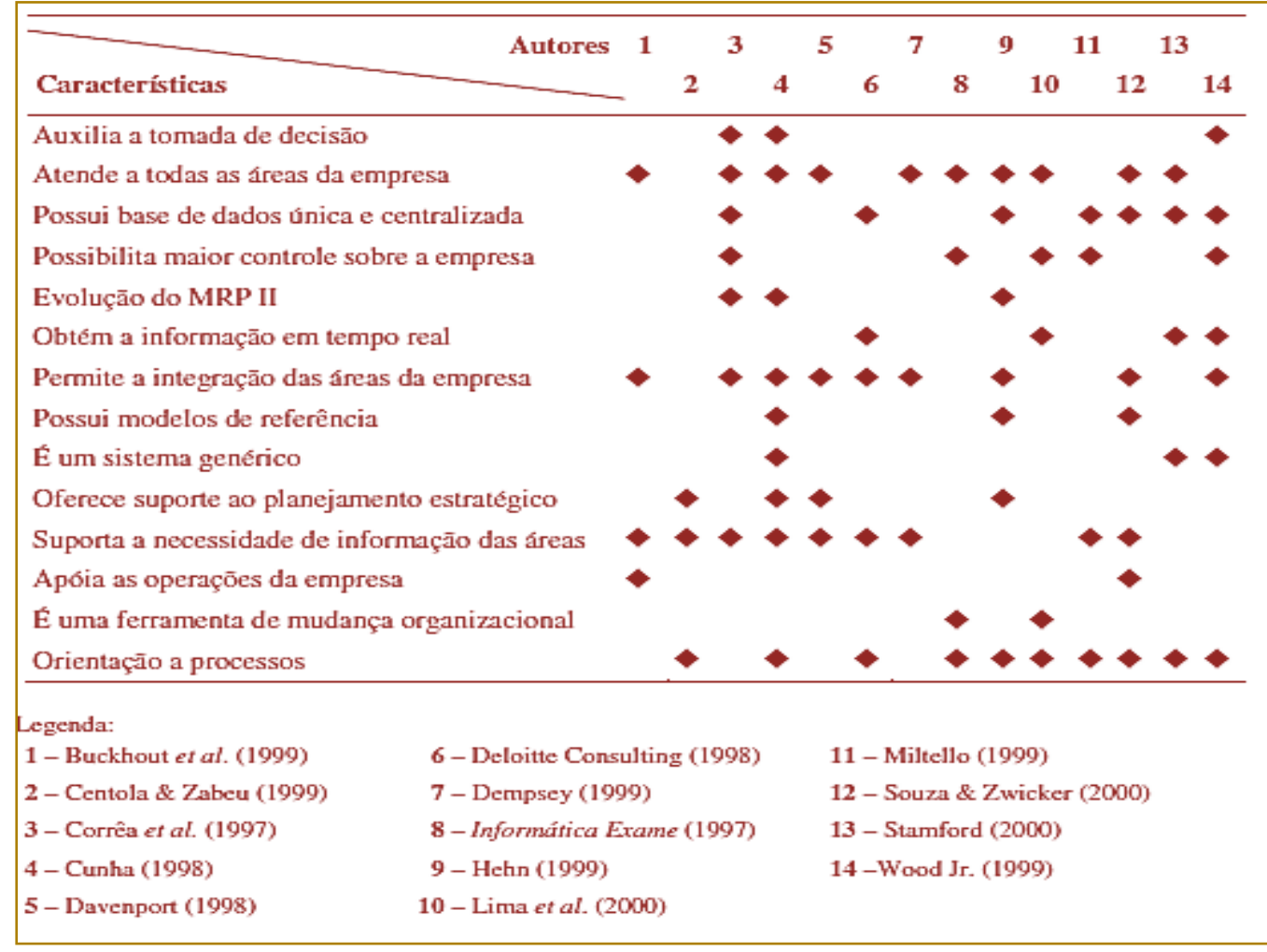

Fonte: Mendes e Escrivão Filho (2002) adaptado pelos autores

Para realizar a implantação de um ERP, a empresa cliente precisa passar por diversas etapas, desde a seleção do sistema, sua aquisição, realização dos testes até a entrada do sistema no ar, e que para De Souza e Zwicker (2000), a implantação é a fase mais crítica neste tipo de projeto. Segundo estes mesmos autores, para a realização de uma boa implantação são destacados diversos fatores críticos para o sucesso, como checar as funcionalidades e adequação do sistema às particularidades da empresa, e quem será o fornecedor da solução.

Diante dos cenários de barreiras e dificuldades, muitos projetos fracassam em sua execução ao perderem de vista os resultados esperados pela implantação de um ERP, como a documentação e contabilização dos processos, regras de negócios claras e bem definidas e adoção de um sistema único para toda empresa, pondo fim a colcha de retalhos que são os diversos sistemas organizacionais quando não são integrados, com informações redundantes e dificultando a consolidação da informação como insumo para tomada de decisão (MILTELLO, 1999).

\section{O CASO ESTUDADO}

\subsection{A EMPRESA ANALISADA - XYZ}

A $X Y Z$ é uma empresa brasileira de tecnologia, que atua há mais de 30 anos no mercado, focada principalmente em implantação de softwares de gestão (ERP), mas também presta serviço de consultoria de negócios e atua na venda de hardwares para automação de negócios.

$X Y Z$ atende a clientes que vão desde micro e pequenas empresas até empresas de grande porte. Com uma receita líquida anual superior a $R \$ 1$ bilhão, é um grande player no setor de sistemas de gestão integrada $(E R P)$ no Brasil e na América Latina. A sede da empresa fica em SP, com unidades próprias em outros estados do Brasil e em outros países. Possui 
aproximadamente 7 mil funcionários nas diversas unidades e conta também com uma rede de parceiros e franquias.

\subsection{O PROJETO REALIZADO - IMPLANTAÇÃO DO ERP}

O cliente $\mathrm{D}$ é uma empresa pública brasileira de tecnologia, com mais de 40 anos de existência, que possui patrimônio próprio, autonomia administrativa e financeira, aproximadamente 3 mil funcionários, e unidades em diversos estados do Brasil, prestando serviços de tecnologia da informação a outras empresas públicas e também para empresas privadas.

O escopo do projeto para o cliente $D$ foi de realizar a migração de versão do ERP da XYZ, de uma versão mais antiga para sua versão mais atual, além da instalação de novos módulos do sistema e novas ferramentas. A Figura 5 apresenta uma lista do escopo dos módulos do ERP que foram migrados da versão mais antiga para a nova e quais foram as novas funcionalidades implantadas.

Figura 5 - Escopo de módulos do ERP Migrados e Implantados

\begin{tabular}{|c|c|}
\hline \multicolumn{2}{|c|}{ Migração } \\
\hline Contabilidade & Compras \\
\hline Fiscal & Orçamento \\
\hline Ativo Fixo & Outras ferramentas \\
\hline Manutenção & \\
\hline Financeiro & \\
\hline Estoque & \\
\hline Custos & \\
\hline Contratos & \\
\hline Faturamento & \\
\hline
\end{tabular}

Fonte: Documento do projeto, adaptado pelos autores

Mais de dez profissionais da $X Y Z$ compuseram o time de analistas de software, subordinados ao Gerente de projetos da área de Software, responsáveis pela parte de instalação e parametrização do sistema. A equipe de Consultoria da XYZ, inicialmente contou com sete Consultores e um estagiário, além de uma Gerente de projeto, um Gerente sênior e um Diretor responsável.

O cronograma do projeto foi planejado para os meses de janeiro a outubro de 2016, conforme ilustrado na Figura 6. Para realização do controle do projeto, foi desenvolvido um cronograma no software MS
Project $\circledast$ contendo as etapas macro a serem executadas, com prazo e responsáveis.

A pasta virtual do projeto foi criada e compartilhado o acesso com todos os consultores, e em um momento futuro também foi compartilhada com os gestores da equipe. É importante destacar a ausência de procedimento de trabalho padrão para o compartilhamento de informação nos projetos realizados pela empresa $X Y Z$, havendo múltiplos modelos utilizados na empresa conforme preferência dos gerentes de projeto. 
Figura 6 - Macro cronograma do projeto

\begin{tabular}{|c|c|c|c|c|c|c|c|c|c|}
\hline Jan & Fev & Mar & Abr & Mai & Jun & Jul & Ago & Set & Out \\
\hline \multicolumn{10}{|c|}{ Gestão do Projeto } \\
\hline \multicolumn{10}{|c|}{ Levantamento } \\
\hline \multicolumn{10}{|c|}{ Migração } \\
\hline & & & \multicolumn{3}{|c|}{ Testes Integrados } & \multicolumn{4}{|c|}{ Entrada do ERP no ar - GO LIVE } \\
\hline & & & & & & \multicolumn{4}{|c|}{ Operação Assistida } \\
\hline \multicolumn{10}{|c|}{ Redesenho de Processos } \\
\hline & & \multicolumn{4}{|c|}{ Automação de processos } & & \multicolumn{3}{|c|}{ Operação Assistida } \\
\hline & $\begin{array}{l}\text { :o Ges } \\
\text { dança }\end{array}$ & & & pacitaçà & & & & & \\
\hline & & \multicolumn{7}{|c|}{ Comunicação } & \\
\hline
\end{tabular}

Fonte: Documento do projeto, adaptado pelos autores

\section{ANÁLISE DOS RESULTADOS}

\subsection{IDENTIFICAÇÃO DAS PRÁTICAS DE GESTÃO DE PROJETOS}

Para identificação das práticas de gestão de projetos a partir da análise documental do estudo de caso, foi realizada uma revisão da bibliografia do tema gestão de projetos, e foram identificadas trinta e duas práticas de gestão de projetos, conforme demonstra a Tabela 2 onde serão apresentadas a classificação das práticas pela ótica da gestão de projetos:

O ordenamento destas práticas foi feito a partir do primeiro item de análise, a classificação das práticas de gestão de projetos conforme os processos de gerenciamento de projetos de acordo com o PMI (2013). Sendo assim, a ordem das práticas de gestão de projetos identificadas está associada a classificação de cada uma delas a um dos processos de gerenciamento de projetos: iniciação, planejamento, execução, monitoramento e controle, e encerramento.

\subsection{CLASSIFICAÇÃO DAS PRÁTICAS DE GESTÃO DE PROJETOS SOB A ÓTICA GERENCIAMENTO DE PROJETOS}

A partir da seleção das práticas de gestão de projetos identificadas na análise documental do estudo de caso, foi possível realizar a classificação de cada uma das práticas sob o ponto de vista dos processos de gerenciamentos de projetos, e posteriormente a classificação das práticas sob o ponto de vista das áreas de conhecimento (PMI, 2013). Dessa forma as práticas de gestão de projetos identificadas tiveram a seguinte classificação quando aos processos de gerenciamento de projetos e as áreas de conhecimento (Tabela 2): 
Tabela 2: Classificação das práticas de Gestão de Projetos segundo os Processos de Gerenciamento de Projetos e as Áreas de Conhecimento

\begin{tabular}{|c|c|c|c|}
\hline Cód & Práticas de Gerenciamento de Projetos identificadas & $\begin{array}{l}\text { Processo de } \\
\text { Gerenciament } \\
\text { o de Projetos }\end{array}$ & $\begin{array}{l}\text { Área de } \\
\text { Conhecimento }\end{array}$ \\
\hline P-01 & Definição do gerente para a equipe do projeto & Iniciação & Integração \\
\hline P-02 & Realização de reunião de alinhamento inicial com equipe de projeto & Iniciação & $\begin{array}{l}\text { Recursos } \\
\text { Humanos }\end{array}$ \\
\hline P-03 & $\begin{array}{l}\text { Disponibilização de informações de projetos antigos por e-mail e pen } \\
\text { drive }\end{array}$ & Iniciação & Comunicação \\
\hline P-04 & $\begin{array}{l}\text { Repasse de conhecimento pelo cliente de projetos anteriores } \\
\text { realizados }\end{array}$ & Iniciação & Comunicação \\
\hline P-05 & $\begin{array}{l}\text { Disponibilização dos documentos de abertura do projeto TR e proposta } \\
\text { comercial }\end{array}$ & Iniciação & Comunicação \\
\hline P-06 & Criação de pasta virtual do projeto no Dropbox® & Iniciação & Comunicação \\
\hline P-07 & Criação de grupo do projeto no WhatsApp® & Iniciação & Comunicação \\
\hline P-08 & $\begin{array}{l}\text { Capacitação da equipe em formato de e-learning no sistema EaD no } \\
\text { escopo do projeto }\end{array}$ & Iniciação & $\begin{array}{l}\text { Recursos } \\
\text { Humanos }\end{array}$ \\
\hline P-09 & Realização do planejamento dos custos do projeto & Planejamento & Custos \\
\hline $\mathrm{P}-10$ & Elaboração de cronograma & Planejamento & Tempo \\
\hline $\mathrm{P}-11$ & Definição de frentes de trabalho para cada membro da equipe & Planejamento & Integração \\
\hline $\mathrm{P}-12$ & Definição de metas para a equipe & Planejamento & Integração \\
\hline$P-13$ & Definição de duplas de execução de trabalho (consultor e analista) & Planejamento & Integração \\
\hline$P-14$ & Definição da estrutura do projeto, com papéis e responsabilidades & Planejamento & $\begin{array}{c}\text { Partes } \\
\text { interessadas }\end{array}$ \\
\hline $\mathrm{P}-15$ & Definição do escopo & Planejamento & Escopo \\
\hline P-16 & $\begin{array}{l}\text { Estruturação da pasta virtual do projeto com base nos processos de } \\
\text { gerenciamento de projetos }\end{array}$ & Planejamento & Comunicação \\
\hline $\mathrm{P}-17$ & $\begin{array}{l}\text { Criação de templates de documentos necessários a execução do } \\
\text { projeto }\end{array}$ & Planejamento & Comunicação \\
\hline P-18 & Elaboração de plano de comunicação & Planejamento & Comunicação \\
\hline P-19 & $\begin{array}{l}\text { Definição de canais de comunicação para atendimento e problemas do } \\
\text { cliente }\end{array}$ & Planejamento & Comunicação \\
\hline P-20 & Realização Operação assistida & Execução & Escopo \\
\hline $\mathrm{P}-21$ & Documentação das reuniões realizadas com validação dos envolvidos & Execução & Qualidade \\
\hline P-22 & Elaboração e execução do plano de capacitação & Execução & $\begin{array}{l}\text { Recursos } \\
\text { Humanos }\end{array}$ \\
\hline P-23 & Realização de reuniões com rede de mudança do projeto & Execução & $\begin{array}{l}\text { Recursos } \\
\text { Humanos }\end{array}$ \\
\hline P-24 & Integração da equipe de execução do projeto & Execução & $\begin{array}{l}\text { Recursos } \\
\text { Humanos }\end{array}$ \\
\hline P-25 & $\begin{array}{l}\text { Utilização de técnicas de moderação de reunião (brainstorm, resolução } \\
\text { de conflitos, alinhamentos entre diversas áreas) }\end{array}$ & Execução & $\begin{array}{c}\text { Partes } \\
\text { interessadas }\end{array}$ \\
\hline P-26 & Utilização de ambientes de dados (testes, homologação e produção) & Execução & Aquisições \\
\hline P-27 & Realização de reunião de status semanal com o cliente & $\begin{array}{l}\text { Monitorament } \\
\text { o e controle }\end{array}$ & Integração \\
\hline P-28 & Controle do projeto feito em MS Project@ por um PMO & $\begin{array}{l}\text { Monitorament } \\
\text { o e controle }\end{array}$ & Integração \\
\hline P-29 & $\begin{array}{l}\text { Replanejamento e comunicação ao cliente de acordo com ajustes e } \\
\text { problemas na execução }\end{array}$ & $\begin{array}{l}\text { Monitorament } \\
\text { o e controle }\end{array}$ & Comunicação \\
\hline P-30 & Identificação e acompanhamento de riscos & $\begin{array}{l}\text { Monitorament } \\
\text { o e controle }\end{array}$ & Riscos \\
\hline P-31 & Identificação de LA pela equipe de execução & Encerramento & Comunicação \\
\hline P-32 & $\begin{array}{l}\text { Formalização das entregas do projeto feita com os usuários chaves por } \\
\text { parte do cliente }\end{array}$ & Encerramento & Qualidade \\
\hline
\end{tabular}

Fonte: Elaboração própria 


\subsection{CLASSIFICAÇÃO DAS PRÁTICAS DE GESTÃO DE PROJETOS SOB OS PRESSUPOSTOS DA GESTÃO DO CONHECIMENTO}

As práticas de gestão de projetos foram classificadas posteriormente sob a dimensão da epistemologia da gestão do conhecimento, ou seja, se a prática se associa ao conhecimento tácito ou explícito. Em seguida as práticas foram avaliadas sob o ponto de vista da dimensão da ontologia da gestão do conhecimento, considerando se a prática envolvia um indivíduo, grupo, organização ou interorganização.
A partir destas duas primeiras classificações no âmbito da gestão do conhecimento, foi feita a classificação das práticas de gestão de projetos sob o ponto de vista do modo de conversão do conhecimento, identificando o modo de conversão do conhecimento da prática, conforme conceitualização da conversão do conhecimento de Nonaka e Takeuchi (1997).

Sendo assim, as práticas de gestão de projetos identificadas na análise documental do estudo de caso tiveram a seguinte classificação quanto aos pressupostos da gestão do conhecimento (Tabela 3):

Tabela 3: Classificação Geral das Práticas de Gestão de Projetos sob os pressupostos da Gestão do Conhecimento

\begin{tabular}{|c|c|c|c|c|c|}
\hline Cód & $\begin{array}{c}\text { Práticas de Gerenciamento de Projetos } \\
\text { identificadas }\end{array}$ & Epistemc & gia & Ontologia & $\begin{array}{l}\text { Modo de Conversão do } \\
\text { Conhecimento }\end{array}$ \\
\hline P-01 & Definição do gerente para a equipe do projeto & Tácito & 20 & Grupo & $\begin{array}{l}\text { Socialização } \\
\text { (Compartilhado) }\end{array}$ \\
\hline P-02 & $\begin{array}{l}\text { Realização de reunião de alinhamento inicial com } \\
\text { equipe de projeto }\end{array}$ & Tácito & 18 & Grupo & $\begin{array}{l}\text { Socialização } \\
\text { (Compartilhado) }\end{array}$ \\
\hline P-03 & $\begin{array}{l}\text { Disponibilização de informações de projetos } \\
\text { antigos por e-mail e pen drive }\end{array}$ & Tácito & 22 & Indivíduo & $\begin{array}{l}\text { Socialização } \\
\text { (Compartilhado) }\end{array}$ \\
\hline P-04 & $\begin{array}{l}\text { Repasse de conhecimento pelo cliente de } \\
\text { projetos anteriores realizados }\end{array}$ & Tácito & 35 & Interorganização & $\begin{array}{l}\text { Externalização } \\
\text { (Conceitual) }\end{array}$ \\
\hline P-05 & $\begin{array}{l}\text { Disponibilização dos documentos de abertura do } \\
\text { projeto TR e proposta comercial }\end{array}$ & Tácito & 25 & Grupo & $\begin{array}{l}\text { Socialização } \\
\text { (Compartilhado) }\end{array}$ \\
\hline P-06 & Criação de pasta virtual do projeto no Dropbox® & Explícito & 70 & Indivíduo & $\begin{array}{l}\text { Internalização } \\
\text { (Operacional) }\end{array}$ \\
\hline P-07 & Criação de grupo do projeto no WhatsApp® & Tácito & 12 & Grupo & $\begin{array}{l}\text { Socialização } \\
\text { (Compartilhado) }\end{array}$ \\
\hline P-08 & $\begin{array}{l}\text { Capacitação da equipe em formato de e-learning } \\
\text { no sistema EaD no escopo do projeto }\end{array}$ & Tácito & 24 & Indivíduo & $\begin{array}{l}\text { Socialização } \\
\text { (Compartilhado) }\end{array}$ \\
\hline P-09 & Realização o planejamento dos custos do projeto & Explícito & 80 & Organização & $\begin{array}{l}\text { Externalização } \\
\text { (Conceitual) }\end{array}$ \\
\hline P-10 & Elaboração de cronograma & Explícito & 58 & Organização & $\begin{array}{l}\text { Externalização } \\
\text { (Conceitual) }\end{array}$ \\
\hline $\mathrm{P}-11$ & $\begin{array}{l}\text { Definição de frentes de trabalho para cada } \\
\text { membro da equipe }\end{array}$ & Tácito & 45 & Indivíduo & $\begin{array}{l}\text { Externalização } \\
\text { (Conceitual) }\end{array}$ \\
\hline P-12 & Definição de metas para a equipe & Tácito & 40 & Indivíduo & $\begin{array}{l}\text { Externalização } \\
\text { (Conceitual) }\end{array}$ \\
\hline$P-13$ & $\begin{array}{l}\text { Definição de duplas de execução de trabalho } \\
\text { (consultor e analista) }\end{array}$ & Explícito & 52 & Grupo & $\begin{array}{l}\text { Externalização } \\
\text { (Conceitual) }\end{array}$ \\
\hline P-14 & $\begin{array}{l}\text { Definição da estrutura do projeto, com papéis e } \\
\text { responsabilidades }\end{array}$ & Explícito & 58 & Interorganização & $\begin{array}{l}\text { Externalização } \\
\text { (Conceitual) }\end{array}$ \\
\hline$P-15$ & Definição do escopo & Explícito & 78 & Organização & $\begin{array}{l}\text { Externalização } \\
\text { (Conceitual) }\end{array}$ \\
\hline$P-16$ & $\begin{array}{l}\text { Estruturação da pasta virtual do projeto com base } \\
\text { nos processos de gerenciamento de projetos }\end{array}$ & Explícito & 80 & Grupo & Combinação (Sistêmico) \\
\hline$P-17$ & $\begin{array}{l}\text { Criação de templates de documentos necessários } \\
\text { a execução do projeto }\end{array}$ & Explícito & 76 & Grupo & $\begin{array}{l}\text { Externalização } \\
\text { (Conceitual) }\end{array}$ \\
\hline P-18 & Elaboração de plano de comunicação & Explícito & 50 & Organização & $\begin{array}{l}\text { Externalização } \\
\text { (Conceitual) }\end{array}$ \\
\hline P-19 & $\begin{array}{l}\text { Definição de canais de comunicação para } \\
\text { atendimento e problemas do cliente }\end{array}$ & Explícito & 82 & Interorganização & $\begin{array}{l}\text { Externalização } \\
\text { (Conceitual) }\end{array}$ \\
\hline P-20 & Realização Operação assistida & Explícito & 65 & Interorganização & $\begin{array}{l}\text { Internalização } \\
\text { (Operacional) }\end{array}$ \\
\hline P-21 & $\begin{array}{l}\text { Documentação das reuniões realizadas com } \\
\text { validação dos envolvidos }\end{array}$ & Explícito & 89 & Interorganização & $\begin{array}{l}\text { Externalização } \\
\text { (Conceitual) }\end{array}$ \\
\hline P-22 & Elaboração e execução do plano de capacitação & Explícito & 64 & Organização & $\begin{array}{l}\text { Externalização } \\
\text { (Conceitual) }\end{array}$ \\
\hline P-23 & $\begin{array}{l}\text { Realização de reuniões com rede de mudança do } \\
\text { projeto }\end{array}$ & Tácito & 29 & Interorganização & $\begin{array}{l}\text { Externalização } \\
\text { (Conceitual) }\end{array}$ \\
\hline
\end{tabular}


Tabela 3: Classificação Geral das Práticas de Gestão de Projetos sob os pressupostos da Gestão do Conhecimento (continuação)

\begin{tabular}{|c|l|c|c|l|l|}
\hline \multicolumn{2}{|c|}{ Práticas de Gerenciamento de Projetos } \\
identificadas
\end{tabular}

Fonte: Elaboração própria

\subsection{AVALIAÇÃO E ANÁLISE DOS DADOS}

Foi realizada a análise da classificação das trinta e duas práticas quanto aos processos de gerenciamento de projetos (iniciação, planejamento, execução, monitoramento e controle e encerramento) de acordo com o
PMI (2013). Esta análise (Figura 7) permitiu identificar onde existe maior concentração de esforço prático no dia a dia de projeto e como a gestão do projeto analisado possui caráter estruturante relacionado ao processo de planejamento.

Figura 7: Avaliação das práticas quanto aos Processos de Gerenciamento de Projetos

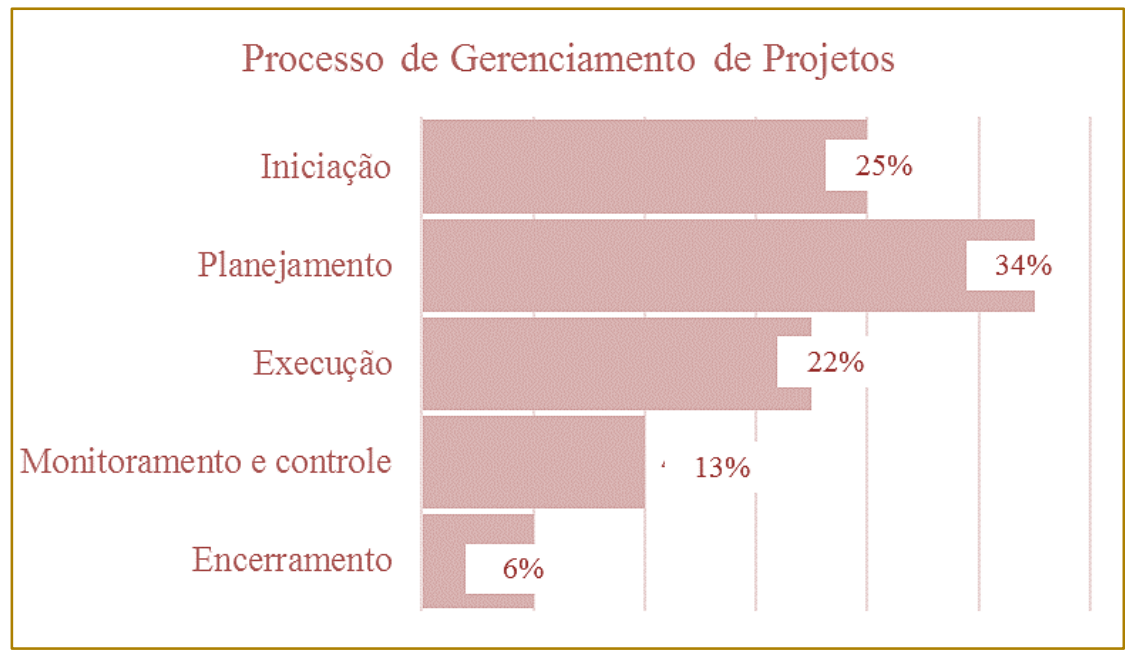

Fonte: Elaboração própria 
Esta análise reflete de forma coerente a realidade do projeto analisado, que teve grande esforço no processo de iniciação (25\%), no planejamento (34\%) e na execução (22\%). Com destaque principal para o processo de planejamento, que ficou acima dos demais processos e por possuir caráter estruturante do projeto, com a elaboração de diversos planos e documentos.
Quanto a classificação das práticas de gestão de projetos do estudo de caso quanto as áreas de conhecimento de acordo com o PMI (2013), foi possível perceber que houve uma concentração nas áreas de comunicação (34\%) e integração (19\%) (Figura 8).

Figura 8: Avaliação das práticas quanto áreas de conhecimento

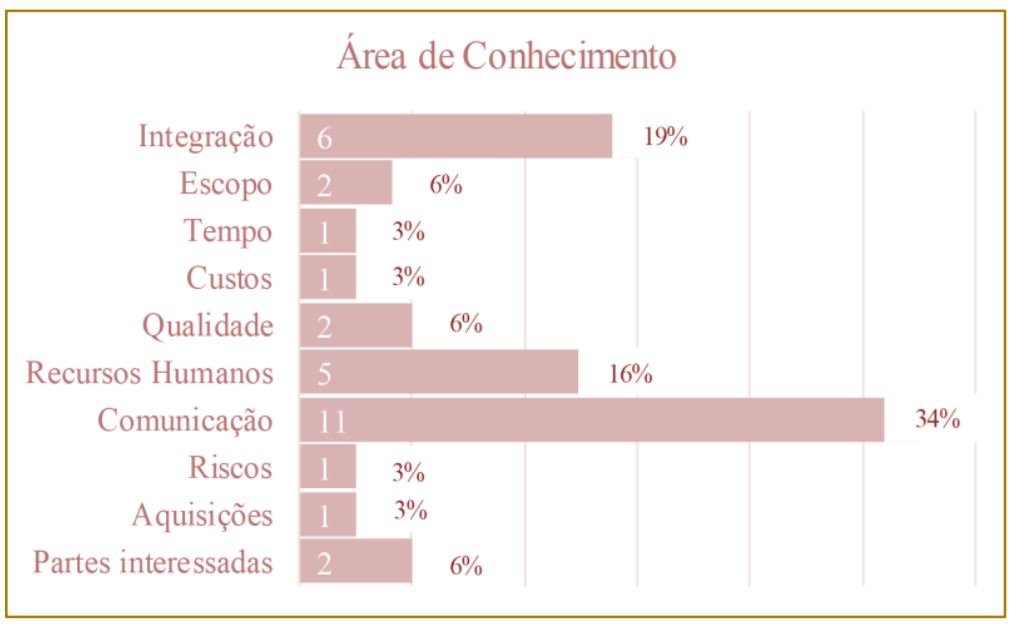

Fonte: Elaboração própria

Além da área de conhecimento da comunicação, a área de integração fica em segundo lugar e demonstra a preocupação e esforço da gerência do projeto quanto a integração do mesmo focando na orientação e direcionamento do esforço da equipe. Também é possível perceber em terceiro lugar a área de recursos humanos (16\%), com práticas de treinamento, alinhamento com equipe, plano de capacitação, entre outras práticas necessárias ao sucesso do projeto.

A análise sobre a classificação das práticas de gestão de projetos identificadas quanto aos pressupostos da dimensão epistemológica da gestão do conhecimento, tácito e explícito, visando perceber como se distribuíram as práticas quanto à este foco de classificação (Figura 9).

Figura 9: Epistemologia das práticas de gestão de projetos classificadas

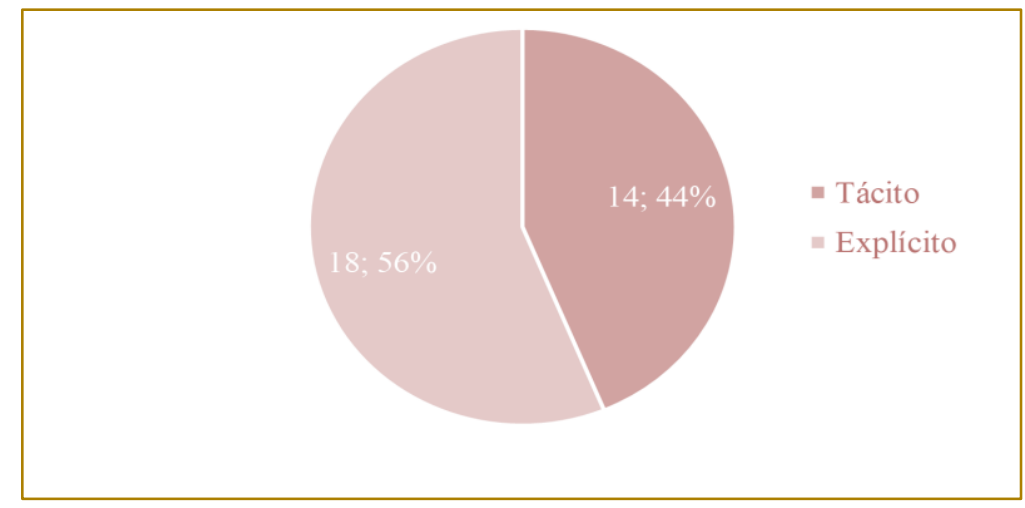

Fonte: Elaboração própria 
Esse equilíbrio entre os conhecimentos tácito e explícito das práticas identificadas no caso estudado demonstra que um projeto é composto não somente do conhecimento formal e estruturado, mas também se aproveita da experiência e troca de conhecimento tácito entre os membros da equipe.

Principalmente num projeto de implantação de ERP e com o grande foco em comunicação, esse número de práticas alinhadas ao conhecimento tácito se justifica, em contraponto ao caráter estruturante das boas práticas de gestão de projetos principalmente nos processos de iniciação e planejamento de projetos.

Outra análise realizada sobre os pressupostos da gestão do conhecimento foi quanto a ontologia ou a dimensão do indivíduo no papel da construção do conhecimento. Foi realizada a análise de frequência das práticas de gestão de projetos identificadas no estudo de caso sobre a ontologia do indivíduo, grupo, organização e interorganização (Figura 10).

Figura 10: Ontologia das práticas de gestão de projetos classificadas

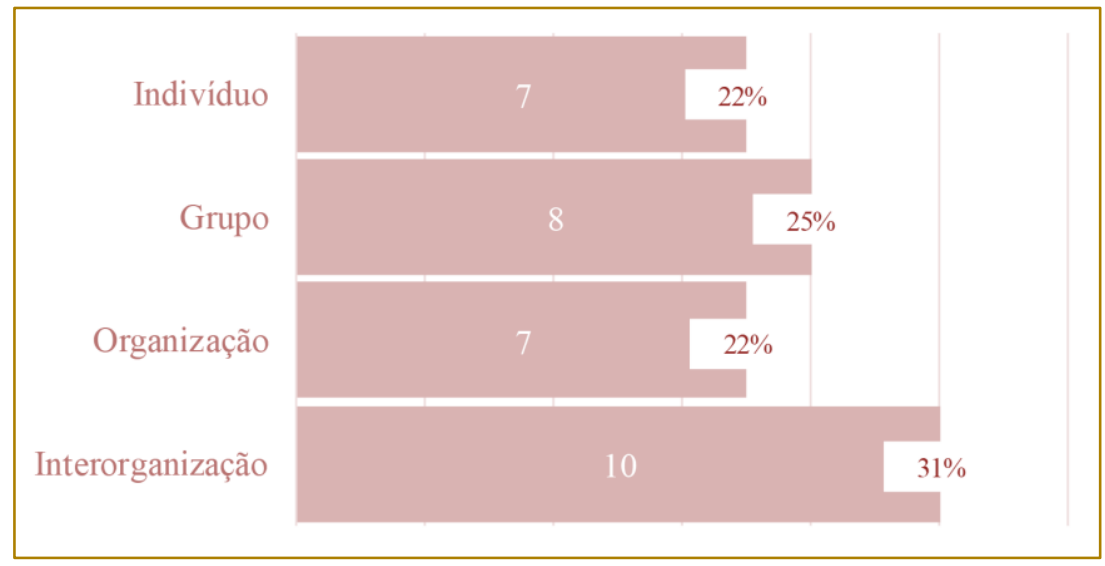

Fonte: Elaboração própria

Foi observada uma maior frequência quanto a interorganização, demonstrando a natureza da prestação de serviço, realizado para uma outra empresa cliente, passando assim muito do conhecimento elaborado no projeto de implantação do ERP para o mesmo. A análise sobre o modo de conversão do conhecimento levou em consideração os quatro modos de conversão de conhecimento, conforme conceitualização de Nonaka e Takeuchi (1997) (Figura 11).

Figura 11: Modo de conversão do conhecimento das práticas de gestão de projetos classificadas

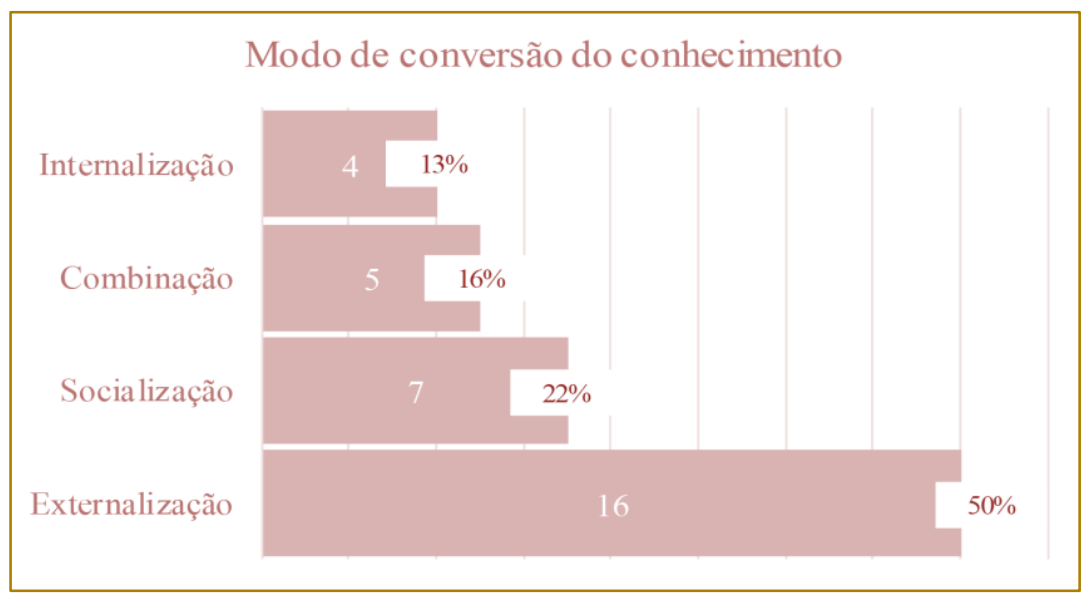

Fonte: Elaboração própria 
Considerando de forma agrupada o modo de conversão do conhecimento da combinação com a externalização, chegou-se a $66 \%$ das práticas orientadas ao conhecimento explícito, confirmando a tendência do projeto em tornar o conhecimento tangível através de documentos e práticas explícitas. Outra análise realizada, buscou avaliar a dispersão das práticas sobre os modos de conversão do conhecimento (Figura 12), permitindo visualizar que prática ficou localizada em qual modo de conversão do conhecimento, conforme seu perfil (tácito ou explícito).

Figura 12: Dispersão das práticas pelos modos de conversão do conhecimento

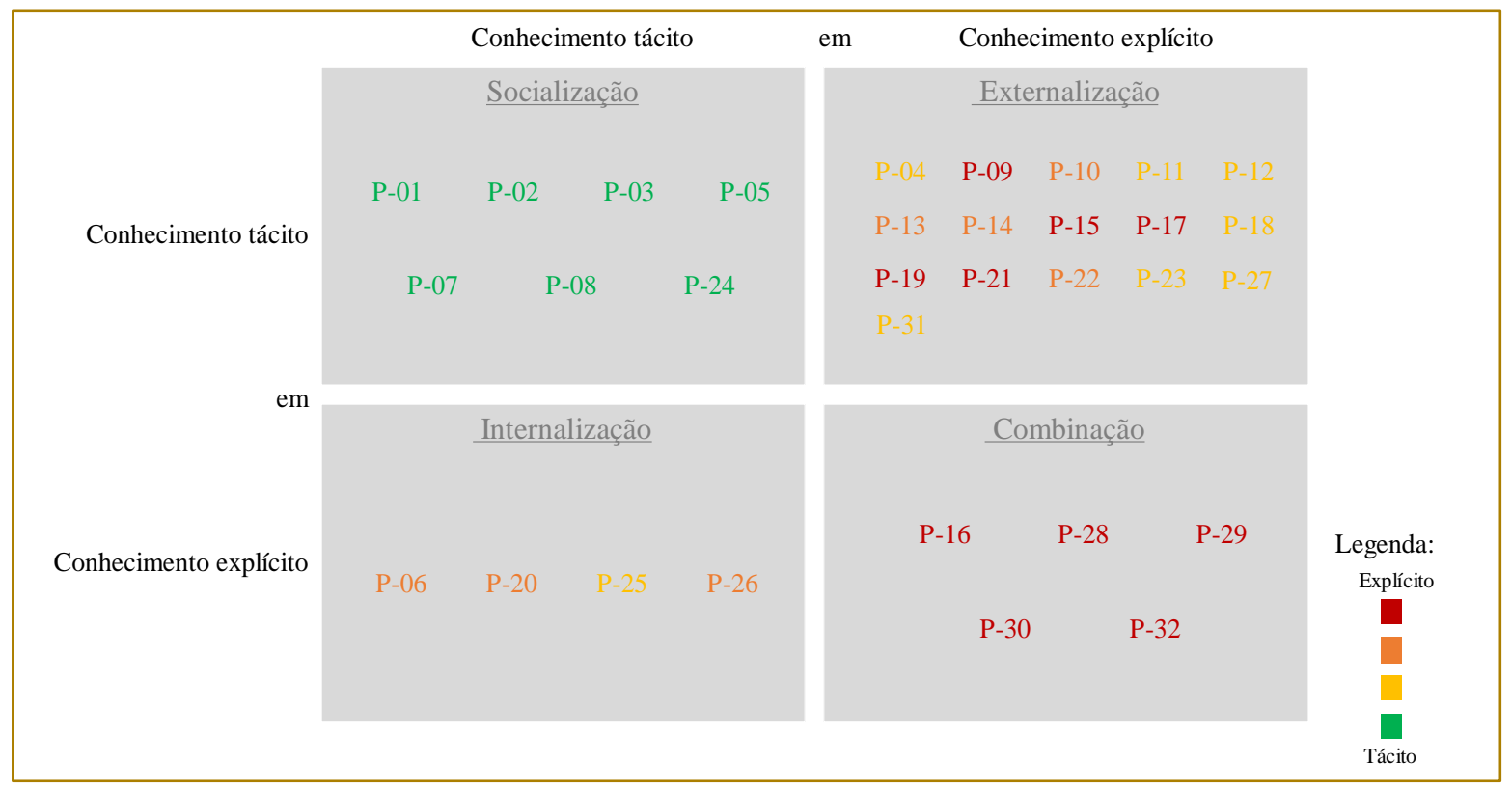

Fonte: Elaboração própria

Com esta análise foi possível perceber que as práticas de gestão de projetos localizadas nos modos de conversão do conhecimento de externalização e internalização não puderam ser classificadas exclusivamente como tácitas ou explícitas, demonstrando assim que a dimensão epistemológica do conhecimento utilizada nas práticas com esta classificação pode variar não sendo somente um tipo de conhecimento absoluto em si.

As práticas relacionadas ao indivíduo apresentarem em sua maioria como sendo tácitas, reforça o conceito postulado por Nonaka e Takeuchi (1997) de que a criação do conhecimento começa a partir do indivíduo e vai além do indivíduo e do grupo até o âmbito interorganizacional através da dimensão ontológica.

Para realização da análise de dispersão sob o ponto de vista dos processos de gerenciamento de projetos, foram utilizadas as variáveis encontradas nas dimensões epistemológica e ontológica, e como forma para representação das práticas foi utilizada a escala de cores e símbolos atribuídos a cada um dos processos de gerenciamento de projetos (Figura 13). 
Figura 13: Dispersão das práticas pela dimensão ontológica x dimensão epistemológica x processos de gerenciamento de projetos

\begin{tabular}{|c|ccc|}
\hline \multicolumn{5}{|c|}{ Dimensão Epistemológica x Dimensão Ontológica } \\
Simbolos: Processo de Gerenciamento de Projetos
\end{tabular}

Fonte: Elaboração própria

As práticas de iniciação se apresentam na ontologia entre indivíduo, grupo e interorganização e na epistemologia em sua maioria como tácitas, já as práticas de planejamento e execução apareceram em todos os níveis da ontologia, porém as práticas de planejamento na dimensão da epistemologia são em sua maioria explícitas enquanto as de execução são equilibradas entre tácitas e explícitas.

\section{CONCLUSÕES}

A área de gestão do conhecimento não aparece como uma das áreas de conhecimento do PMBOK® apesar de ser citado inúmeras vezes em seu texto, além disso não se apresenta como uma prática tangível ou alvo de preocupação do gerente de projeto do caso estudado. Porém apesar da gestão do conhecimento não ser um alvo, pode-se perceber um esforço no uso de práticas de projetos no caso analisado, principalmente orientado para comunicação.

Os objetivos propostos neste trabalho foram alcançados, através da pesquisa bibliográfica realizada sobre as temáticas selecionadas, a identificação das práticas de gestão de projetos no estudo de caso apresentado, bem como suas classificações e respectivas análises. Foi possível perceber um grande esforço da gerência do projeto no que tange ao planejamento das diversas atividades a serem executadas, e a orientação deste esforço para a área de comunicação.

Conclui-se a partir da leitura dos autores citados que não basta executar boas práticas de gerenciamento de projetos, principalmente voltadas para comunicação se estas não servirem a seu propósito, tenham uma função e se tornem um ativo valioso para a equipe do projeto. É necessário que as diversas partes interessadas do projeto usufruam da comunicação planejada e realizada, principalmente gerando condições favoráveis a conversão do conhecimento tácito em explícito.

Por fim, os resultados apresentados apontam que ainda há uma carência em estudos e práticas de aplicação da gestão do conhecimento na gestão de projetos. Porém este fato tem se apresentado como uma necessidade gerencial e operacional das equipes de projetos em usar o conhecimento de forma efetiva. 


\section{REFERENCIAS}

[1]. ABREU, E.S.; TEIXEIRA, J.C.A. Apresentação de trabalhos monográficos de conclusão de curso. Universidade Federal Fluminense, $10^{a}$ edição revisada e atualizada. 2012.

[2]. BEHR, R.; NASCIMENTO, S. A gestão do conhecimento como técnica de controle: uma abordagem crítica da conversão do conhecimento tácito em explícito. Cadernos Ebape, v. 6, n. 1, março, 2008, p. 1-11.

[3]. CAMARGO JUNIOR, J. B., PIRES, S. R. I., E SOUZA, A. Sistemas integrados de gestão ERP e cloud computing: Características, vantagens e desafios. Simpósio de administração da produção, logística e operações internacionais, 2010.

[4]. CORRÊA, H.L. ERPs: por que as implantações são tão caras e raramente dão certo. Simpósio de administração da produção, logística e operações industriais, v. 1, 1998, p. 288-300.

[5]. CRUZ, R.P. Aplicações práticas da gestão do conhecimento e da informação no gerenciamento de projetos: um ensaio teórico. Trabalho de Conclusão de Curso de PósGraduação MBA - Gerenciamento de Projetos da Universidade Federal Fluminense, Niterói, 2011.

[6]. DÁVALOS, R. V; LÓPEZ, O. C. V. Uma abordagem da implantação de um ERP visando apoio às atividades administrativas e de ensino. Atas da Conferência da Associação Portuguesa de Sistemas de Informação. 2016.

[7]. DAVENPORT, T.H.; PRUSAK, L. Conhecimento empresarial: Como as organizações gerenciam o seu capital intelectual. Rio de Janeiro: Elsevier, 14aㅡ reimpressão. 2003.
[8]. DE ABREU, A.C.D. et al. Bases epistemológicas da criação do conhecimento organizacional: uma análise a partir da teoria de Nonaka e Takeuchi. Revista Ciência e Conhecimento - ISSN: 2177-3483, 2015, p. 620.

[9]. DE SOUZA, C.A.; ZWICKER, R. Ciclo de vida de sistemas ERP. Caderno de Pesquisas em Administração (I), n. 11, 2000, p. 2-14.

[10]. MENDES, J.V.; ESCRIVÃO FILHO, E. Sistemas integrados de gestão ERP em pequenas empresas: um confronto entre o referencial teórico e a prática empresarial. Revista Gestão \& Produção, v. 9, n. 3, 2002, p. 277-296.

[11]. MILTELLO, K. Quem precisa de um ERP? Info Exame, março. 1999, p. 140.

[12]. NONAKA, I.; TAKEUCHI, H. Criação do conhecimento na empresa. Rio de Janeiro, Elsevier, 20ํㅡㄹ reimpressão, 1997.

[13]. PADILHA, T.C.C. et al. Tempo de implantação de sistemas ERP: análise da influência de fatores e aplicação de técnicas de gerenciamento de projetos. Revista Gestão \& Produção 11.1, 2004, p. 65-74.

[14]. PMI. PMBOK GUIDE - Um guia do conhecimento em gerenciamento de projetos. Quarta Edição, 2013.

[15]. VON KROGH, G; ICHIJO, K; NONAKA, I. Facilitando a criação do conhecimento. Reinventando a empresa com o poder da inovação contínua. Rio de Janeiro: Campus, 2001.

[16]. YIN, R. K. Estudo de Caso: Planejamento e Métodos. Porto Alegre: Bookmann, 2005. 


\section{Gapítulo 18}

\section{IMPLEMENTANDO A INOVAÇÃO - ESTRATÉGIAS DE INTEGRAÇÃO DOS PROCESSOS E SERVIÇOS DE UM ATACADO/DISTRIBUIDORA}

\section{Darciane Alves Justino}

Resumo: As empresas brasileiras, no contexto atual, estão despertando para a busca de uma qualidade superior e de melhores condições de competitividade. Diante desta perspectiva, as organizações passam a enfrentar uma série de desafios internos e externos. Desafios estes que precisam ser superados através da utilização de ferramentas eficazes de apoio à gestão. Neste sentido, a tecnologia da informação (TI), tornou-se uma área de apoio logístico, tanto no gerenciamento de centrais de distribuição quanto no sistema de gestão, uma vez que seu uso eficiente pode significar a diferença no mercado. Neste contexto, os investimentos para a utilização da logística associada à tecnologia da informação vêm crescendo no Brasil, e os benefícios que a mesma oferece as organizações tem sido comprovada em algumas áreas de aplicação. O presente trabalho foi realizado com o objetivo de analisar a implantação e uso de um software de gestão de informação nos processos logísticos internos de uma empresa de atacado/distribuição bem como as vantagens obtidas após sua implantação. Através da análise SWOT e a matriz GUT, a empresa implantou novo software que trouxe não somente benefícios financeiros, mas também uma reestruturação no desenvolvimento das atividades, trazendo a empresa, não apenas benefícios competitivos internos mais também externos.

Palavras-chave: Tecnologia da informação, logística, análise SWOT, matriz GUT, vantagens competitivas. 


\section{INTRODUÇÃO}

\subsection{CONSIDERAÇÕES INICIAIS}

O mercado está cada vez mais competitivo, o crescimento das organizações tem exposto as empresas a uma demanda por competência, que acaba por resultar em necessidades de melhorias continuas nas áreas de planejamento, operacionalização, armazenagem e distribuição (SORIANO, 2013).

Para se trabalhar com a melhoria continua e acompanhar o desenvolvimento industrial as empresas precisam analisar constantemente os inúmeros dados que o mercado disponibiliza, esses dados são então organizados e ordenados e aplicados internamente. No entanto a maior dificuldade é como implantar e interpretar esses dados de forma que o resultado venha a acrescentar no desenvolvimento e desempenho da empresa. Cada decisão de implantação deve sempre levar em conta os mais diversos níveis e setores organizacionais para um melhor resultado. As integrações desses dados produzem ainda um conhecimento confiável que chamamos de informações que são fatores necessários para as tomadas de decisões coerentes (Fresneda, 2007).

Choo (2011) destaca que o uso da informação e do conhecimento propicia meios de percepção e discernimento necessárias para lidar com mudanças constantes que os setores de venda, armazenagem e distribuição. Quando utilizados de formas adequadas e estruturada são instrumentos de gestão.

Esses dados afetam profundamente todas as etapas do canal logístico, pois representam uma conexão entre os diversos estágios da cadeia de suprimentos, permitindo a coordenação e sequenciamento de atividades de forma a proporcionar e colocar em prática muitos dos benefícios de maximização da lucratividade (Chopra \& Meindl, 2003).

Para Fernandes \& Correia (2012) as empresas do ramo atacadista e distribuidora possuem uma logística mais detalhada e deve ser integrada na divisão de macro e micro processos, tais como controle de estoques, compra de produtos (quando terceiriza produtos), na movimentação interna e expedição das mercadorias, no recebimento e processamento dos pedidos emitidos pelos vendedores e recebidos pelos clientes, nas embalagens e no sistema de informações.
Dessa forma, o senário logístico das empresas atacadistas e distribuidoras busca atribuir aos processos maior competência na computação e distribuição de informação, no que abrange aos resultados no relacionamento com seus fornecedores, bem como na consolidação da satisfação, agilidade e o sucesso no atendimento ao cliente, e se faz necessário que os dados sejam sempre interpretados de forma corretas (Pereira et al., 2010).

Assim as organizações vêm investindo cada vez mais em sistemas que integrem seus processos de serviços com o intuito de aprimorarem sua interação com seus clientes e colaboradores, buscando atendê-los assim na hora planejada, com a quantidade adequada e requerida de produtos, uma vez que, os clientes estão cada vez mais exigentes quanto a qualidade nos produtos ou serviços, qualidade no atendimento, rapidez na entrega, na sua confiabilidade e ao preço (PEREIRA et al., 2010).

A tecnologia da informação (TI) é hoje um dos alicerces da logística, por gerenciar as informações das centrais de distribuição de matéria prima e produto acabado. A TI conecta empresas e fornecedores com mais eficiência, além de proporcionar uma integração interna da empresa, que são os conhecidos sistemas ou programas de gestão (Junior, 2007).

Platt \& Klaes (2010) destacam que o avanço de tecnologias aplicadas à gestão da informação permite que as organizações incorporem sistemas informatizados no apoio às suas atividades nos mais diversos setores. Um dos avanços desses expoentes são os sistemas de informação empresariais, desenvolvidos para atender aos requisitos específicos das diversas áreas e departamentos de uma organização, de maneira que respeitem os procedimentos e fluxos de processos que cada empresa estrutura e trabalha.

Para analisar os benefícios da TI é necessário um levantamento de desempenho anterior a sua aplicação e evidenciar as mudanças ocorridas e o impacto nos processos e relacionamento entre empresa e mercado.

Deste modo o presente trabalho de conclusão de curso tem caráter qualitativo e o seu intuito é analisar o levantamento de Estratégias de Integração dos Processos e Serviços de um Atacado/Distribuidora e identificar os 
benefícios da implantação e inovação de um novo software para essa integração.

\subsection{FORMULAÇÃO DA SITUAÇÃO PROBLEMA}

Tendo em vista um mercado com uma elevada exigência por parte dos clientes, em vários nichos que compõem o mercado, a logística das empresas reformula 0 seu propósito e busca diminuir a distância existente entre produto e consumidor, de forma que o produto possa satisfazer $\mathrm{o}$ consumidor quanto as suas expectativas no que se refere à qualidade do mesmo, bem como, a distribuição com menor prazo de entrega, além de proporcionar um menor custo tanto para a empresa como para o consumidor.

Para isso é necessário que haja uma sequência lógica de processos executada para que não hajam atrasos na realização das atividades, compartilhamento automático de informações.

Assim os sistemas de informação passam a ganhar o mercado por proporcionar claras vantagens competitivas, tanto no setor público quanto privado, a maioria das organizações buscam cada vez mais utilizar sistemas que integrem os processos internos proporcionando uma melhor eficiência, com ações estratégicas, que gerem serviços e processos otimizados e de qualidade, pois o foco passou a ser o cliente.

São muitas as formas que os recursos e serviços de tecnologia podem assumir para potencializar a capacidade produtiva e impedir que ela não seja estrangulada pelo crescimento da demanda.

Contudo faz se necessárias alterações nos processos e a forma de se relacionar com o público interno e externo. Otimizar o processo de armazenagem, expedição e distribuição facilita o relacionamento interno e externo. A intenção deste estudo é então verificar o impacto da utilização dos conceitos e ferramentas proporcionados por um novo software de gestão de armazenagem no desempenho da estratégia focando nos aspectos da Inteligência Organizacional.

\subsection{OBJETIVO GERAL}

O Presente artigo busca compreender como sistemas desenvolvidos de acordo com as características e necessidades das empresas veem agregando e proporcionando valores financeiros e organizacionais.

Dessa forma pretende-se proporcionar subsídios para o aprimoramento do atacado/distribuidora, através de analises em diversos setores que possibilitem a identificação de pontos de grandes e baixos potenciais. Identificando assim ações e benefícios implementados no desenvolvimento das atividades, permitindo a comparação dos resultados obtidos com os resultados pretendidos pela empresa.

\subsection{METODOLOGIA}

Essa pesquisa tem caráter descritivo/explicativo, uma vez que foi utilizado observação do desenvolvimento de diversas atividades de armazenagens, vendas, emissão de pedidos, separação de pedidos, expedição e distribuição para a coleta de informações, de maneira a facilitar a identificação e classificação dos principais fatores que determinam ou contribuem para a ocorrência de problemas ocultos durante os processos, estabelecendo relações entre as variáveis envolvidas.

Foi utilizado também a forma de pesquisa caracterizada como exploratória com documentação indireta e qualitativa onde os dados, em vez de serem tabulados, de forma a apresentar um resultado preciso, são retratados por meio de relatórios, levando-se em conta aspectos tidos como relevantes, como as opiniões e comentários do público envolvido, assim é caracterizada pelo não emprego da quantificação, deixando de considerar prioritariamente as formas estatísticas como base do processo de análise.

A estruturação da análise teve em primeira instancia a observação e o levantamento de informações que pudessem fornecer subsídios que dessem base a análise. A informações foram coletadas através de observações e relatórios elaborados, sendo analisadas, agrupadas, possibilitando a maior previsibilidade dos processos.

\section{REVISÃO DA LITERATURA}

\subsection{ATACADOS E DISTRIBUIDORAS BRASILEIRAS}

Setor atacadista/distribuidor foi introduzido no Brasil em meados da década de 50, por 
portugueses imigrantes que aqui chegaram, e com o surgimento das grandes cidades caracterizadas como capitais e o crescimento do desenvolvimento econômico, surgiu o comercio atacadista distribuidor, que apesar de atuarem basicamente na forma de balcão, já possuíam vendedores cobrindo o interior do país, realizando negócios e enviando as mercadorias aos seus clientes por meio de transporte ferroviário, servindo como agente intermediário entre as indústrias e varejistas (SAFATLE \& PINHEIRO, 2011).

Nos últimos anos 0 comercio atacadista/distribuidor vem crescendo consideravelmente e demonstrando força na economia brasileira. Este crescimento constante proporciona uma barreira de entrada no mercado para novas e pequenas empresas, por acarretarem na necessidade de um alto investimento inicial, devido ao mercado altamente competitivo pelas grandes empresas já existente. Por isso a empresa, para se manter nesse mercado precisa ser eficiente na administração de materiais, canais de vendas e distribuição. E para atender as necessidades do mercado, as empresas atacadistas/distribuidoras, assim começaram a adotar novos e modernos procedimentos na compra e venda de mercadorias, investindo em tecnologias, valorizando informações para atender a evolução do mercado.

Para Kotler \& Armstrong (2008) este setor vem nos últimos anos enfrentando pressões competitivas cada vez maiores, com uma clientela cada vez mais exigente, o surgimento de novas tecnologias e um maior mix de programas de compras diretas. $O$ fato deste setor está se tornando cada vez mais competitivo, o que obriga as empresas a buscarem o aprimoramento de seus processos, reduções nos custos logísticos e estarem atentos as novas tendências mercadológicas.

Por se tratar de ser um segmento complexo e de diversos tipos de operações, as empresas atacadistas/distribuidoras buscam na maioria das vezes operacionalizar no mercado de forma integrada, e ter um modal devidamente estruturado, buscando métodos de roteirização que sejam mais eficientes, e atendam da melhor forma possível as necessidades de seus clientes, de maneira a proporcionar um diferencial competitivo para qualquer empresa que deseja destaque e se manter no mercado.

\subsection{LOGÍSTICA E GESTÃO DE ARMAZENAGEM}

Em tempos de acirrada competitividade empresarial, é notória a importância de se aumentar o grau de satisfação dos clientes e consumidores através de um efetivo gerenciamento da cadeia logística. Nesse contexto, é difícil imaginar clientes (internos e externos) satisfeitos, e, consequentemente, uma redução de custos em decorrência da otimização de processos, se as empresas não apresentarem uma eficiente logística interna, integrada a um também eficiente canal de suprimentos e distribuição (FREITAS et. al., 2006).

\subsubsection{LOGÍSTICA}

Com o decorrer dos anos a logística passou a ser considerada como uma abordagem gerencial, que trata de forma sistêmica e integrada todas as atividades relacionadas aos fluxos físicos, financeiros e de informações da organização (BARBOSA et.al., 2007).

A utilização da logística como fonte de vantagem competitiva pode ser feita a partir de sua gestão de forma integrada, passando a ser vista como um sistema, que compreende um conjunto de componentes interligados, que atuam de maneira coordenada visando um mesmo objetivo, um elo de ligação entre o mercado, que une a manufatura aos dois extremos que são fornecedores e clientes integrando estrategicamente a oferta e a procura (PINHEIRO, 2014).

\subsubsection{TECNOLOGIA DA INFORMAÇÃO E A LOGÍSTICA}

No ambiente atual, o fluxo de informação está se tornando um componente cada vez mais importante para a gestão da logística. Neste âmbito o uso da tecnologia de informação vem crescendo a cada ano, sendo explorada conforme o mercado vem demandando. Isso acarreta no desenvolvimento de novos sistemas para gerenciar toda uma cadeia ou apenas uma rede de setores subdivididos (RODRIGUES et. al., 2011).

Uma tecnologia de informação aplicada ao sistema logístico oferece apoio desde as decisões de planejamento estratégico até a 
programação e controle das atividades, de maneira integrada, auxiliando a coordenação de processos e o monitoramento de operações. As tecnologias de informações logísticas funcionam como elos que ligam as atividades logísticas em um processo integrado, combinando hardware e software para medir, controlar e gerenciar as operações logísticas. Estas operações tanto ocorrem dentro de uma empresa específica, bem como ao longo de toda cadeia de suprimentos (BRANSKI, 2008).

A implementação da TI na gestão da cadeia de suprimentos auxilia no relacionamento entre clientes internos, clientes externos e fornecedores, isso para se melhorar a qualidade no serviço logístico, gerenciando a informação para se obter, processar, gerenciar e transmitir informações, para uma tomada de decisão mais eficaz (BRANSKI, 2008).

\subsubsection{GESTÃO DE ARMAZENAGEM}

Para Lopes, Souza \& Moraes (2006) a armazenagem é uma das áreas mais tradicionais de suporte ao processo logístico, dando apoio ao desempenho das atividades primárias, propiciando às empresas maiores sucessos, mantendo e conquistando clientes com melhores atendimentos. Essas atividades envolvem a localização, dimensionamento, arranjo físico, equipamentos e pessoal especializado, controle de estoques, embalagens, manuseio, necessidade de recursos financeiros e humanos, entre outros, com o objetivo de atender às necessidades operacionais, sejam elas de consumo, de transformação ou de revenda.

A principal funcionalidade dos sistemas de gestão de armazenagem está voltada para o aumento do nível de serviço, aumento do controle dos estoques e a diminuição dos erros operacionais ao longo do canal logístico, utilizado assim para melhorar a eficiência do atacado e manter um inventário preciso das operações, ou seja, proporcionar um alto nível de controle, menos suscetível a falhas, sendo mais dinâmico no gerenciamento de informações recebidas de diversos setores da empresa, capaz de receber, estocar, separar e expedir mercadorias de forma eficaz (SHIAU \& LEE, 2010).

\subsection{GESTÃO ESTRATÉGICA DE OPERAÇÕES}

O termo Gestão Estratégica de operações consiste em definir de maneira clara, participativa e com base em um diagnóstico atual e futuro os ambientes interno e externo, a direção que se quer dar à organização, formulando missão, visão e valores, e ainda programar e controlar os objetivos, as estratégias e os planos de ações definidos, ou seja, a atividade de gerenciamento de recursos escassos e processos que produzem e entregam bens e serviços, visando atender à necessidade e/ou aos desejos de qualidade, tempo e custo de seus clientes (SILVA \& FERNANDES, 2009).

Todas a ações proporcionadas pela gestão estratégica, influenciam de forma direta e indireta no desempenho organizacional.

\subsection{MEDIDAS DE DESEMPENHO}

Atualmente existem várias técnicas utilizadas para o desenvolvimento de sistemas de desempenho que visam conceder as informações referentes ao comportamento da organização nas tarefas desenvolvidas e oferecidas, comparando o desempenho atual com o desempenho esperado, fornecendo assim subsídios que auxiliem nos processos de tomadas de decisões, ou seja, são indicadores capazes de identificar a situação presente da empresa e compará-la com a situação planejada, servindo como base de análise para os gestores (BARBOSA et al., 2007).

\subsection{MÉTODO DE ANÁLISE E SOLUÇÃO DE PROBLEMAS}

\subsubsection{CICLO PDCA}

O ciclo PDCA busca controle e melhoria dos processos de maneira continua através da localização de problemas, análise dos processos, padronização e estabelecimento de ações para o controle de tal forma que o problema não tenha mais probabilidade de ocorrer (NEVES, 2007).

Agostine (2014) afirma que o PDCA é composto por quatro fases:

$\checkmark \quad$ 10 Planejamento (Plan): nesta fase é determinada o métodos de avaliação do problema e como o mesmo será possivelmente solucionado, para isso, são definidos os objetivos/metas. Segundo Neves (2007) algumas ferramentas como Diagrama 
de Ishikawa, Gráfico de Pareto, brainstorming e 5W2H são muito úteis nesta fase, para fornecer alguns suportes às tomadas de decisões.

$\checkmark \quad 2^{\circ}$ Execução (Do): está relacionada à eficiência dos processos, onde a solução é implantada. Esta fase é realizada na maioria das vezes em duas etapas, sendo o treinamento e execução.

$\checkmark$ 3o Verificação (Check): verifica as ações executadas, de maneira comparativa entre os resultados obtidos e os estabelecidos na etapa de planejamento, e etapa 3 permite que se mensure a eficácia da solução escolhida, por isso está faze é considerada como a fase mais importante do ciclo. A partir dos dados levantados à organização deve efetuar as análises críticas das ações escolhidas, promovendo quando necessário as ações de correção ou melhoria, na solução adotada ou nos próprios processos.

$\checkmark \quad 4^{\circ}$ Ações corretivas (ACT): ações corretivas ou de melhorias que tenham sido constatadas como necessárias na fase anterior (verificação). Envolve a busca por melhoria contínua até se atingir os padrões estabelecidos. Aqui surgem as desejadas inovações que afetam toda a organização.

\subsubsection{ANÁLISE SWOT}

A matriz SWOT propõe que a empresa consiga ter uma visão clara e objetiva sobre quais são suas forças e fraquezas no ambiente interno, e suas oportunidades e ameaças no ambiente externo, ou seja, tratase de relacionar as oportunidades e ameaças presentes no ambiente externo com as forças e fraquezas mapeadas no ambiente interno da organização, dessa forma com essa análise os gerentes conseguem elaborar estratégias para obter vantagem competitiva e melhor o desempenho organizacional (RIBEIRO \& FERNANDES, 2007).

A análise SWOT utiliza de quatros elementos que são divididos em dois grupos de análises: analise do ambiente interno e análise do ambiente externo (VIEIRA, 2017).

\subsubsection{ANÁLISE DO AMBIENTE INTERNO}

A análise do ambiente interno é importante, pois através dessa análise que a empresa consegue verificar quais são suas forças e fraquezas, assim podendo obter vantagem competitiva, utilizando e potencializando suas forças para aumentar a sua participação de mercado, elaborando estratégias para minimizar ou até mesmo eliminar suas fraquezas (FARIAS, 2005).

$\checkmark \quad$ Forças (Strenghts): as forças estão relacionadas a pontos fortes da empresa que a diferencia das demais, the atribuindo vantagens competitivas, o que diferencia a organização de seus concorrentes (DORNELAS, 2015);

Fraquezas (Weakenesses): são as limitações, desvantagens e deficiências nas competências internas que dificultam 0 desenvolvimento de estratégias, ou seja, pontos fracos da empresa que a coloca em posição de desvantagem no mercado se comparada com outras no mesmo ramo (Dornelas, 2015).

Dantas \& Melo (2008) destacam que o ambiente interno pode ser controlado pelos dirigentes da empresa, uma vez que ele é resultado das estratégias de atuação definidas pelos próprios membros da organização.

\subsubsection{ANÁLISE DO AMBIENTE EXTERNO}

O ambiente externo está totalmente fora do controle da organização. Mas, apesar de não poder controlá-lo, a empresa deve conhecê-lo e monitorá-lo com frequência, de forma a aproveitar as oportunidades e evitar as ameaças (Dantas \& Melo, 2008).

$\checkmark \quad$ Oportunidades (Opportunities): são aspectos e condições favoráveis do produto/serviço da empresa em relação ao mercado onde está ou irá se inserir. Contudo é necessária sempre a verificação das condições e viabilidade da organização para utilizar tais oportunidades como estratégia competitiva (CHURCHILL \& PETTER, 2010);

$\checkmark \quad$ Ameaças (Threats): são as forças externas que podem impactar no sucesso da empresa, tal como a competição, a capacidade operacional e o custo de aumentos dos bens, pois são aspectos negativos do produto/serviço. Estão ligadas aos concorrentes e novos cenários, desafiando a atual estratégia do empreendimento. Para evita-las devem ser analisados seus graus de possibilidade de ocorrerem e níveis de gravidade (CHURCHILL \& PETTER, 2010). 
Segundo Dantas \& Melo (2008) após estabelecer estas quatro diretrizes da técnica SWOT, "é necessário cruzar as Oportunidades com as Forças e as Fragilidades com as Ameaças, buscando estabelecer estratégias que minimizem e monitorem os aspectos negativos e maximizem as potencialidades" de maneira a possibilitar a análise real da situação da empresa, e identificar possibilidades de implementações que proporcionem benefícios.

\subsubsection{MATRIZ GUT}

Para Martins (2006), matriz SWOT é a prática comum nas empresas voltadas para o pensamento estratégico e reforça que sua prática constante pode trazer uma melhor visão de negócios, devido aos cenários onde a empresa atua que estão sempre mudando. Contudo quanto às questões são analisadas de forma relativa à priorização, as pessoas envolvidas em buscar as melhorias nos processos, muitas vezes não possuem a capacidade, de discernimento entre quais providencias devem ser tomadas seguindo uma reta de prioridades conforme as reais necessidades e urgências da empresa.

Esta ferramenta responde racionalmente às questões de o que deve ser feito primeiro e por onde se deve começar. Para responder a tais questões a ferramenta GUT leva em consideração a Gravidade, Urgência e Tendência do fenômeno. Sendo que Gravidade é o impacto dos problemas sobre as coisas, pessoas, resultados, processos ou organizações e efeitos que surgirão em longo prazo, caso o problema não seja resolvido; Urgência é a relação com o tempo disponível ou necessário para resolver o problema; Tendência é a avaliação da tendência de crescimento, redução ou desaparecimento do problema (BEZERRA et. al., 2012).

O primeiro passo para montar a matriz GUT é fazer uma lista com os problemas que acontecem em seu departamento ou empresa. Em seguida, atribuir uma nota de 1 a 5, para cada problema listado em relação à sua Gravidade, Urgência e Tendência. As notas são dadas conforme os seguintes critérios: a nota maior, 5(cinco), vai para situações menos favoráveis, ou seja, a pior situação, e vai-se decrescendo até a nota 1 , que deve ser atribuída para situações mais favoráveis ou as situações leves, então ordena-se os problemas de forma decrescente, ou seja, da maior nota para a menor, para então elaborar um plano de ação. A Figura 1 apresenta uma ilustração dos critérios possíveis das pontuações em cada situação (VIEIRA, 2017).

Figura 1: Ilustração dos critérios possíveis das pontuações em matriz GUT

\begin{tabular}{|c|c|c|c|}
\hline Valor & $\begin{array}{c}\text { G - Gravidade } \\
\text { Os prejuizos ou dificuldades são: }\end{array}$ & $\begin{array}{c}U-\text { Urgência } \\
\text { É necessária uma ação: }\end{array}$ & $\begin{array}{c}\text { T-Tendência } \\
\text { Se nada for feito a situação irá: }\end{array}$ \\
\hline 5. & extremamente graves & Imediata & Piorar rapidamente. \\
\hline 4. & Muito grave & Com alguma urgência & Piorar em pouco tempo. \\
\hline 3. & Grave & O mais cedo possivel & Piorar a médio prazo \\
\hline 2. & Pouco grave & Pode esperar um pouco & Piorar a longo prazo \\
\hline 1. & Sem gravidade & Não tem pressa & Não vai piorar. \\
\hline
\end{tabular}

(Aguiar, 2004).

\section{ESTUDO DE CASO}

\subsection{A EMPRESA}

A empresa $Y$ iniciou suas atividades em 2008 e atua no ramo Atacadista e Distribuidor de produtos, atualmente não é líder no segmento em seu estado mais busca formas para atingir tais objetivos.

A empresa vem a cada dia consolidando seu nome no mercado atacadista e distribuidor.
Isto é feito graças à ampla gama de produtos que trabalha e sua qualidade na venda, no transporte e entrega de mercadorias. Presta serviços com agilidade e segurança, e conta com representantes comerciais autônomos para algumas regiões do País, equipados com catálogo de produtos, smartphones e sistemas

de informação gerando conectividade entre o "campo" e a empresa. 
Em seu portfólio, oferece mais de 700 tipos de produtos e seus clientes podem realizar compras fracionadas (unidades), desde que atinjam uma cota estabelecida de valor mínimo por pedido, recebendo os pedidos em até 5 dias dependendo da região. Sua operação é ancorada por um centro de distribuição de $550 \mathrm{~m}^{2}$. A empresa está vinculada a diversos fornecedores, além de contar com uma linha de fabricação própria, com itens diferenciados e exclusivos, que formam assim uma linha variada que possa atender cada vez mais as necessidades de cada lojista (cliente).

Com o crescimento do mercado e uma infraestrutura consolidada, os maiores desafios enfrentados pela empresa $\mathrm{Y}$, passaram a ser manter suas entregas dentro do prazo programado, com mínimo de erros na separação dos pedidos, ter sempre todos os itens solicitados pelos clientes disponíveis, à medida que a quantidade de clientes e número de pedidos foram aumentando, viu-se a necessidade do levantamento de estratégias de integração dos processos e serviços que pudesse possibilitar a empresa superar os desafios do crescimento.

Constantemente a empresa vem investido no aprimoramento de seus sistemas de informação e buscando otimizar seus processos com o intuito de qualificar o desenvolvimento de suas atividades, buscando crescer e se destacar perante seus concorrentes proporcionando o diferencial no mercado.

\subsection{ANÁLISE DO AMBIENTE}

A empresa trabalha com venda direta via catálogo, que é um sistema de comercialização de bens de consumo, realizado por meio de contato pessoal entre vendedor e o consumidor, fora da área de estocagem da empresa, em sua maioria dentro das lojas do clientes. Devido à grande complexidade de operações, a atuação da empresa necessita de investimentos em vendas, armazenagens e distribuição ou no investimento em terceirização desses serviços a operadores e empresas especializadas. Cabe ressaltar que os pedidos emitidos pelos revendedores são compostos por uma grande variedade de itens, de diversas linhas com apresentações, tamanhos e volumes variados.

O que acarreta numa necessidade de um centro de distribuição ágil, bem estruturado e integrado de forma direta e real com toda a estrutura logística, pois este tipo de empresa não possui lojas, sendo sua infraestrutura composta basicamente pelo centro de distribuição, onde são recebidas as mercadorias dos fornecedores e da própria indústria da empresa $Y$, armazenadas, separadas e enviadas aos clientes através de transportadoras, que devido ao grande fluxo de pedidos e expedições para diversas regiões do pais tornam complexas as operações envolvidas e controle da operação.

Neste contexto, através de uma análise a distribuidora/atacado $Y$ percebeu que em seu sistema operacional haviam necessidades de mudanças, pois não se utilizavam padrões na estocagem dos produtos, uma vez que não possuíam padrões de layout definidos e fixos para os produtos, o software de controle de armazenagem não era devidamente alimentado (atualizado) conforme as expedições eram realizadas, o que muitas vezes resultavam em informações inadequadas, que atrasavam $\mathrm{o}$ andamento dos pedidos, estendendo o seu tempo de entrega. A não disponibilidade de todos os Itens para entrega ocasionava insatisfação e negativação da empresa perante a alguns clientes.

\subsection{FORMULAÇÃO DA ESTRATÉGIA}

Como viu-se a necessidade de otimização e aprimoramento tanto nos fluxos de coordenação, quanto nos fluxos de operacionais, buscou-se o desenvolvimento e execução das ferramentas que melhores se enquadraram nos métodos utilizados pela empresa, dentre elas a formulação do método de análise SWOT e a Matriz GUT com o intuito de possibilitar a identificação das principais oportunidades e ameaças relacionadas ao ambiente externo, juntamente com as forças e fraquezas internas, onde os pontos negativos ou problemas pudessem ser priorizados conforme a gravidade, urgência e tendência respeitando o funcionamento dos processos e atividades. 
Tabela 1: Análise Swot.

\begin{tabular}{|c|c|c|}
\hline Análise Interna & $\begin{array}{l}\text { Forças } \\
\text { Marca; } \\
\text { Penetração no mercado } \\
\text { brasileiro; } \\
\text { Crescimento na aceitação } \\
\text { dos produtos; } \\
\quad \text { Fidelização potencial após } \\
\text { compra dos produtos. }\end{array}$ & $\begin{array}{l}\text { Fraquezas } \\
\text { Falta de controle do produto } \\
\text { comercializado; } \\
\quad \text { Necessidades constantes de } \\
\text { atualização de técnicas de controle de } \\
\text { mercadorias; } \\
\text { Canais de distribuição não otimizados; } \\
\text { Algumas irregularidades na } \\
\text { documentação dos clientes; } \\
\text { Pedidos reduzidos devido à falta de } \\
\text { produtos no estoque; } \\
\text { Falta de direção estratégica; } \\
\text { Falta de integração entre os } \\
\text { processos; } \\
\text { Variedades de produtos limitadas. }\end{array}$ \\
\hline Análise Externa & $\begin{array}{l}\text { Oportunidades } \\
\text { Crescimento do consumo de } \\
\text { produtos que a empresa trabalha; } \\
\text { Capacidade de expansão; } \\
\text { Demanda com crescimento } \\
\text { constante. }\end{array}$ & $\begin{array}{l}\text { Ameaças } \\
\text { Empresas de atacado/distribuição } \\
\text { consolidadas no mercado; } \\
\text { Surgimento de novos concorrentes; } \\
\text { Novas tecnologias de informação. }\end{array}$ \\
\hline
\end{tabular}

Após identificar as ameaças e fraquezas, as oportunidades e pontos fortes da empresa de atacado/distribuição $\mathrm{Y}$, gerou-se relatórios para análises de procedimentos de processos.

De acordo com os relatórios descritos após a análise SWOT, a empresa pode identificar não conformidades no sistema conforme se encontra listado na Tabela 2, sendo que essas falhas seriam priorizadas de acordo com o seu grau de importância e o impacto no desempenho. A partir da matriz GUT podese determinar o grau de importância de solução das falhas por meio da sua gravidade, da sua urgência e sua tendência em agravar outros problemas.

Tabela 2: Matriz GUT.

\begin{tabular}{|c|c|c|c|c|c|}
\hline \multicolumn{2}{|r|}{ Não Conformidades(Problemas) } & G & $\cup$ & $\mathrm{T}$ & \multirow{2}{*}{$\begin{array}{c}\text { Fator } \\
\text { GxUxT } \\
125\end{array}$} \\
\hline 1 & Pouco Controle Operacional; & 5 & 5 & 5 & \\
\hline 2 & Falta de Monitoramento dos processos; & 5 & 5 & 4 & 100 \\
\hline 3 & Sistema de informação antigo; & 5 & 5 & 5 & 125 \\
\hline 4 & Foco nas reclamações dos clientes; & 4 & 1 & 4 & 16 \\
\hline 5 & $\begin{array}{l}\text { Falta no Aprimoramento do setor de } \\
\text { separação e expedição; }\end{array}$ & 3 & 4 & 4 & 48 \\
\hline 6 & Falta no Controle de estoque; & 3 & 5 & 5 & 75 \\
\hline 7 & Falta na Atualização de estoque; & 3 & 5 & 5 & 75 \\
\hline 8 & Inter-relação das atividades logísticas; & 5 & 3 & 4 & 60 \\
\hline 9 & Comunicação interna defeituosa; & 5 & 5 & 4 & 100 \\
\hline 10 & Controle de registros não eficaz; & 3 & 5 & 4 & 60 \\
\hline 11 & Tempo de pedidos extensos; & 3 & 5 & 5 & 75 \\
\hline 12 & $\begin{array}{l}\text { Falta de Otimização da emissão e separação } \\
\text { dos pedidos; }\end{array}$ & 4 & 5 & 4 & 80 \\
\hline 13 & Banco de dados não atualizados; & 3 & 5 & 4 & 60 \\
\hline 14 & Qualidade no Atendimento ao cliente; & 3 & 1 & 4 & 12 \\
\hline 15 & Faltas de produtos para entrega; & 4 & 5 & 5 & 100 \\
\hline
\end{tabular}

Dentre as principais mudanças iniciais identificadas como sendo de prioridades estão:

- Aprimoramento do controle operacional;
- Redução do tempo pedidos com redundâncias de informações;

- Otimização do percurso da emissão e separação dos pedidos;

- $\quad$ Estocagem otimizada e padronizada; 
- Acesso atualizado dos bancos de dados;

Agilidade e eficiência no atendimento ao cliente;

- Informações precisas sobre o tempo de espera e a situação dos pedidos;

- $\quad$ Agilidade nas operações logísticas;

- Eliminação de erros e produtos em falta na entrega ao cliente;

- Maior acuracidade dos estoques;

- Inter-relações entre funções e atividades ao longo do canal logístico;

- Aprimoramento das expedições.

Essas mudanças trariam benefícios financeiros com o decorrer de seus aprimoramentos e acarretariam em mudanças no desenvolvimento das atividades.

\subsection{IMPLEMENTAÇÃO DA ESTRATÉGIA}

Identificou a necessidade da centralização das informações e um fluxo mais rápido e preciso, com o intuito de promover uma integração solida e construtiva dos processos, desde a compra, produção, o requerimento dos pedidos emitidos pelos vendedores até mesmo no processo de expedição e entrega dos produtos acabados. Consequentemente aprimorando assim os relacionamentos com seus clientes, por reduzir atrasos, aumentar a credibilidade da empresa, pois os sistemas de informações atuais segundo a empresa estavam defasados deixando a desejar em diversos destes aspectos.

Assim a empresa $Y$ em 2015 desenvolveu e estruturou um novo software personalizando-o conforme as suas necessidades e que atendesse e respeitasse suas condições operacionais. O novo software deveria realizar transações internas, armazenar dados e proporcionar ampla facilidade de compartilhamento de informações em tempo real entre os setores que fossem interligados, propiciando a melhoria nas habilidades de planejar e programar seus estoques, armazenagens, vendas, expedição e distribuição, buscando continuamente formas de se reduzir os erros que ocorriam constantemente. O programa foi então implantado e começou a ser utilizado e os resultados que o mesmo proporcionou passaram a ser analisados.

Os funcionários foram acompanhados na execução e utilização do software durante um tempo determinado, onde eram sempre avaliados segundos os desempenhos referentes a atividades designadas. Conforme o tempo de utilização observou-se que os funcionários iam aumentando seu desempenho e a eficiência individual, se adaptando e desenvolvendo cada vez melhor os processos.

\section{ANÁLISE DOS RESULTADOS}

Segundo a empresa os primeiros resultados surgiram rapidamente após a implantação do software e trouxe um grande número de benéficos nas funcionalidades, dentre os quais facilitadores para o lançamento de ordens de serviços, para o gerenciamento de estoque tanto de matéria prima para confecção de alguns produtos como de produtos acabados, na compra e consequentemente na contabilidade. Os dados e informações da indústria passaram a ser disponibilizados aos diversos setores do canal logístico (pontos de rede), agrupando a demanda real (os pedidos dos clientes) e a previsão de demanda para cada item estocado, usando períodos de planejamentos estabelecidos pela própria empresa.

O novo software auxilia no planejamento, na execução, no monitoramento e controle das atividades relativas à consolidação de carga, venda, pedidos, separação, expedição, emissão de documentos, entregas e coletas de produtos (devolução), rastreabilidade da frota e de produtos, auditoria de fretes, apoio à negociação, planejamento de rotas e modais, monitoramento de custos e nível de serviço, e planejamento e execução de manutenção da frota.

As principais funcionalidades do novo software podem ser classificadas como: planejamento e execução (apoio operacional e definição do padrão de serviços Logística); monitoramento, controle e apoio à negociação e auditoria de frete (comercial e venda) e gestão de contratos (controle dos serviços prestados). O módulo de planejamento e execução, além de focar na eficiência da atividade da empresa busca fazer com que suas ações sejam eficazes, pelo apoio à negociação e acompanhamento dos contratos e serviços oferecidos aos clientes. O uso do novo software permitiu definir a capacidade de realização do serviço, conforme padrões pré-definidos, e o controle de sua prestação. 
O software possibilitou uma rastreabilidade das operações, onde todos os recebimentos, separações e expedições são registrados em tempo real, podendo ser identificado de qual local o produto foi retirado, efetuando assim um histórico das operações realizadas.

A separação dos produtos, passou a ser através do sistema, que propiciou e estruturou a armazenagem das mercadorias de forma aleatória, podendo a área ser dividida em blocos, níveis, ruas ou colunas, conforme a importância e a demanda de saída de cada tipo de produto. Sendo assim, facilmente identificados no processo de separação.

A utilização da identificação automática ajuda a controlar o inventário, diminui a utilização de documentos em papel, reduzindo assim os custos do processo. O lote é controlado e classificado por série, permitindo a rastreabilidade das transações em referência aquele número de série. Assim o sistema interliga as informações de vários departamentos relacionados ao depósito e ao controle de estoques e distribuição.

Qualquer carência identificada no processo, o programa informa ao planejador da necessidade de emitir novas ordens podendo ser de compra, produção dentre outros. O programa foi desenvolvido com a capacidade de lidar e considerar restrições dependendo do produto, sendo uma delas a de possuir habilidade de calcular tempos de setup dependendo da sequência e dos múltiplos atributos de cada produto. A programação é flexível, podendo ser alterada a qualquer momento e ser ajustada as novas condições de execução dos processos, ou para a entrada de novos pedidos por exemplo.

Observou-se a redução dos custos de transporte e melhoria do nível de serviço ao cliente; maior produtividade no uso dos ativos; diminuição no tempo de planejamento da montagem da carga e da programação das entregas; disponibilidade de dados precisos de frete, por cliente, frota, viagem; suporte ao controle de desempenho. Para a empresa, os principais resultados da tecnologia são economia nos custos e aumento da funcionalidade para proporcionar prazos de entregas verossímeis.

O software também melhorou as condições do departamento comercial, facilitando o acompanhamento do andamento das ordens de pedidos, venda e expedição. E atualmente essa programação passou a ser considerada como uma função estratégica na empresa.
Através da pesquisa foi possível identificar o andamento e a eficiência das atividades realizadas com a utilização da nova tecnologia de informação, pode-se ainda diagnosticar que são necessárias mudanças nos processos organizacionais para que a tecnologia implantada traga efeitos positivos nos ambientes reestruturados.

\section{CONSIDERAÇÕES FINAIS}

Grande parte do sucesso empresarial está na capacidade de se adaptar as mudanças, reconhecer as ameaças externas, aproveitar as oportunidades, aprimorar seus processos de forma constante para se diferenciar perante o mercado. Assim as empresas procuram cada vez mais agilizar o fluxo de materiais, comprimindo o tempo entre recebimento e a entrega dos pedidos para reduzir os investimentos em estoque.

Para uma estruturação que traga benefícios impactantes e efetivos faz se necessárias ferramentas e técnicas e uma delas é a análise SWOT, que quando corretamente empregada, tem como resultado não só a organização dos dados e informações, mas também é especialmente eficaz no conhecimento dos ambientes e da própria empresa para descobrir vantagens competitivas. No presente trabalho, esta ferramenta de análise teve um papel fundamental como instrumento de avaliação para elaboração de um planejamento estratégico, propiciando muitos benefícios e vantagens. A forma como foi conduzida e direcionada a análise SWOT produziu benefícios diretos e visíveis dentro do processo de planejamento estratégico de mercado da empresa, reduzindo o desperdício de tempo e esforços depreendidos em sua utilização.

Através da matriz GUT, pode-se identificar qual o problema que deveria ser priorizado, e qual a real prioridade, o que possibilitou concentrar esforços iniciais no problema que realmente deveria ser corrigido, prioritariamente aos demais. A descrição do problema foi de fundamental importância, para possibilitar o conhecimento mais detalhado do mesmo, ou seja, quais as perdas, reincidências e quais as dificuldades implicava a medida que o tempo ia passando e o mesmo não era corrigido.

Chegando a causa raiz de cada problema, pode-se desenvolver um plano de ação de 
cada causa, de maneira a reduzir ou solucionar o problema, evitando a geração de reincidências, e a partir da conclusão destas ações, chegou-se a um resultado de se desenvolver um novo software onde o mesmo apresentou muitos ganhos para a empresa logo após o período de treinamento dos funcionários envolvidos.

Desta forma, o novo software implantado se mostrou bastante apropriado para a empresa, por auxiliar na comunicação e nas tomadas de decisões nos mais diversos setores, visto que estes eram os principais problemas para o aumento da eficiência e da eficácia nos

\section{REFERÊNCIAS}

[1] Agostine, F. S. A Utilização do Ciclo PDCA como Ferramenta para Solução de Problemas no Setor Logístico. Trabalho de conclusão de curso (Engenharia de Produção) - Universidade do Planalto Catarinense, Lajes (SC), p. 38 a 41, 2014.

[2] Barbosa, D. H.; Nunes, V. F.; Herrera, V. E.; Kurumoto, J. S.; Musetti, M. A. Desempenho Logístico no Setor Sucroalcooleiro: um estudo de caso exploratório. Gestão da Produção, Operações e Sistemas (GEPROS). Ano 2, Vol 5, p. 103 a 116, outubro/dezembro, 2007

[3] Bezerra, T. T. C.; Carvalho, M. V. P. S.; Carvalho, I. M.; Peres, W. O. M.; Barros, K. O. Aplicação das ferramentas da qualidade para diagnóstico de melhorias numa empresa de comercio de materiais elétricos. In: XXXII Encontro Nacional de Engenharia de Produção (ENEGEP), Bento Gonçalves (RS), outubro, 2012.

[4] Branski, R. M. O Papel da Tecnologia da Informação no Processo Logístico Estudos de Casos com Operadores Logístico. Tese (Doutorado em Engenharia) - Universidade de São Paulo (USP), São Paulo, p. 36 a 52, 2008.

[5] Choo; C. W. A organização do conhecimento: como as organizações usam a informação para criar significado, construir conhecimento e tomar decisões. São Paulo: Editora SENAC São Paulo, 2011.

[6] Chopra, S.; Meindl, P. Supply chain management: strategy, planning and operations.

[7] New York: Prentice Hall, 2003.

[8] Churchill, G. A; Petter, J. P. Marketing: Criando valor para os clientes. 2ed. São Paulo: Saraiva, 2010.

[9] Dantas, N. G. S.; Melo, R.S. O método de análise SWOT como ferramenta para promover o diagnóstico turístico de um local: o caso do município de Itabaiana / PB. In: Caderno Virtual de turismo, vol. 8 nำ1, 2008. processos. O software auxiliou na melhoria e veracidade das informações e do processo decisório, facilitando algumas mudanças organizacionais que resultaram em ganhos adicionais de produtividade.

Vale ressaltar ainda que a implantação de novas estruturas e métodos produtivos sem a devida análise de contexto pode não apresentar benefícios, e prejudicar o gerenciamento da cadeia produtiva da empresa, assim faz-se necessário o adequado delineamento de metas, objetivos e estratégias, bem como o treinamento dos funcionários.

[10] Dornelas, J. C. A. Empreendedorismo: Transformando ideias em negócios. 5ed. Rio de Janeiro: LTC, 2015.

[11] Farias, E. A. Elementos Essenciais à Montagem de Planos de Negócios em Serviços, Gestão de Negócios e Marketing. Material Acadêmico Complementar. Rio de Janeiro, 2005.

[12] Fernandes, A. P. L. M.; Correia, J. D. Processo de armazenagem e distribuição física dos produtos do gênero alimentício. In: VIII Congresso Nacional de Excelência em Gestão, junho de 2012.

[13] Freitas, F. F. T.; Nascimento, K. S. C.; Pelaes, T. S.; França, V. O. Otimização das operações de Movimentação e Armazenagem de materiais através de rearranjo físico: uma proposta de melhoria para um almoxarifado da esfera pública. In: XXVI Congresso Nacional de Engenharia de Produção (ENEGEP), Fortaleza (CE), 2006.

[14] Fresneda; P. S. V. Gonçalves, Sonia Maria Goulart Gonçalves. A experiência brasileira na formulação de uma proposta de política de gestão do conhecimento para a administração pública federal. Brasília: Câmara dos Deputados, Coordenação de Publicações, 2007.

[15] Júnior, A. M. Sistemas Integrados de Gestão: proposta para um processo de decisão multicritérios para a avaliação estratégica. 36f. Tese (Doutorado em Engenharia de Produção) USP, Universidade de São Paulo, São Paulo, 2007.

[16] Kotler, P.; Armstrong, G. Princípios de Marketing. Ed 12, São Paulo: Prentice Hall, 2008.

[17] Lopes, A. S.; Souza, E. R.; Moraes, M. L. Gestão Estratégica de Recursos Materiais: Um enfoque prático. Rio de Janeiro; Editora Pinto e Zincone, 2006.

[18] Martins, L. Marketing: Como se tornar um profissional de sucesso. 1. ed. São Paulo, 2006.

[19] Neves, T. F. Importância da Utilização do Ciclo PDCA para Garantia da Qualidade do Produto em uma Indústria Automobilística. 
Monografia (Engenharia de Produção) Universidade Federal de Juiz de Fora, p. 19 a 25, Juiz de Fora (MG), 2007.

[20] Pereira, S. R.; Toquetti, L. Z.; Ricci, D. T.; Duarte, J. M. Informática em Logística: Sistema WMS para Gestão de Armazéns. In: Periódico Eletrônico da Fatec- São Caetano do Sul, São Caetano do Sul, v.1, n. 3, Jul./Dez. 2010, p. 148 a 162.

[21] Pinheiro, P. A. Logística: Análise do Processo de Roteirização das Entregas de Cargas Fracionadas em uma Distribuidora Atacadista em Campina Grande - PB. Trabalho de Conclusão de Curso (Administração) - Universidade Estadual da Paraíba, p. 7 a 14, Campina Grande (PB), 2014.

[22] Platt, A. A.; Klaes, L. S. Utilizando o Sistema Integrado de Gestão (ERP) no apoio ao Ensino de Logística e Gestão da Cadeia de Suprimentos. Revista de Ciências da Administração. v. 12, n. 28, p. 224 a 241, set/dez 2010 .

[23] Ribeiro, M. M. A.; Fernandes, A. Análise Estratégica da Denominação de Origem Protegida Carne Mirandesa. Instituto Politécnico de Bragança, Escola Superior Agrária. Estudos regionais. 2007, p. 44 a 59.

[24] Rodrigues, E. F.; Fernandes, A. R.; Formigone, A.; Monteiro, R.; Campos, I. P. A. Logística Integrada Aplicada a um Centro de Distribuição: Comparativo do Desempenho do
Processo de Armazenagem Após a Implementação de um Sistema de Gerenciamento de Armazém (WMS). In: VIII Simpósio de Excelência em Gestão e Tecnologia (Seget), 2011.

[25] Safatle, F. P.; Pinheiro, T. C. Diagnóstico Funcional de Logística da Distribuidora Atacadista Rosa de Ouro. In: VII Congresso Nacional de Excelência em Gestão. Agosto de 2011.

[26] Silva, S. E.; Fernandes, F. C. F. Estratégia de Operações: um Estudo na Indústria Calçadista. In: SIMPOI, São Paulo, 2009.

[27] Shiau, J. Y.; Lee M. C. A warehouse management system with sequential picking for multi-container deliveries. Computers \& Industrial Engeneering. V. 58, n. 3, p. 382 a 392. Abril 2010.

[28] Soriano, F. F. Otimização e de redução de custos através da otimização do gerenciamento do fluxo físico de produtos e do fluxo de informações merecem cada vez mais a atenção das Empresas. Dissertação (Mestrado em Ciências) - Faculdade de Economia, Administração e Contabilidade de Ribeirão Preto da Universidade de São Paulo, Ribeirão Preto, p. 16 a 45, 2013.

[29] Vieira, L. G. D. Aplicação De Diagnóstico Organizacional: Um melhoramento do processo de produção de uma barbearia. Trabalho de Conclusão de Curso (Administração) Universidade Federal de Santa Catarina, p. 28 a 32, Florianópolis (SC), 2017. 


$$
\text { Alutary }
$$




\section{ALESSANDRA CRISTINA SANTOS AKKARI}

Bacharel em Ciência e Tecnologia (2011), pela Universidade Federal do ABC (UFABC); Engenheira de Produção (2014) premiada pelo Conselho Regional de Engenharia e Agronomia de São Paulo (CREA-SP) e Doutora em Nanotecnologia e Inovação (2015), no Laboratório de Prospecção e Caracterização de Bioativos da UFABC. Membro da Associação Brasileira de Engenharia de Produção - ABEPRO, avaliadora de cursos pelo Guia do Estudante e consultora na área de Educação e implementação de metodologias ativas de ensino em cursos de base tecnológica. Colaboradora voluntária no Programa de PósGraduação em Engenharia e Gestão da Inovação, da Universidade Federal do ABC. Atualmente, é professora pesquisadora do Centro de Ciência e Tecnologia da Universidade Presbiteriana Mackenzie e membro do núcleo de Empreendedorismo Mackenzie, sendo líder do Grupo de Pesquisa CNPq - Engenharia de Inovação, Materiais e Sustentabilidade com interesse nas áreas de Indústria 4.0, Gestão da Digitalização, Inovação e Empreendedorismo

\section{ALYNE MADEIRA KAUTNICK}

Mestranda do Programa de Pós-Graduação em Engenharia e Gestão do Conhecimento da Universidade Federal de Santa Catarina, com ênfase na área de Empreendedorismo e Inovação. Integra o Núcleo de Estudos em Inteligência, Gestão e Tecnologias para Inovação. Graduanda do curso de Gestão da Tecnologia da Informação do Instituto Federal de Santa Catarina. Pesquisadora no Instituto Superior de Engenharia do Porto (2017), em Portugal. Graduada em Língua e Literatura Italiana pela Universidade Federal de Santa Catarina (2014) e em Língua e Cultura Italiana pela Università per Stranieri di Siena (2012).

\section{ANA PAULA DUARTE}

Possui graduação em Bacharelado em Química - Ênfase Tecnológica pela Universidade de São Paulo - IQSC - USP, Licenciatura em Química pela UNIFRAN, MESTRADO e DOUTORADO em Ciências com ênfase em Química Analítica pelo Instituto de Química de São Carlos - IQSC - USP. Leciona no ensino superior há 16 anos e atualmente é docente na UEMG - Universidade Estadual de Minas Gerais e professora titular no UNIFEG. Tem experiência nas áreas de Gestão Ambiental, Produção mais Limpa, Química Analítica e Ambiental, atuando principalmente nos seguintes temas: Química Analítica e Ambiental, Gestão Ambiental, Produção mais limpa e Ecologia Industrial, Contaminação Química, Metais Pesados, Resíduos, Sensores Modificados Quimicamente, Eletroanalítica e espectroscopia atômica.

\section{BERNARDO ALMEIDA MUDJALIEB}

MBA em Gerenciamento de Projetos na Universidade Federal Fluminense, Graduado em Administração de Empresas pela Universidade Federal Rural do Rio de Janeiro e Life Coach pela Sociedade Brasileira de Coaching. Tem experiência na área de Consultoria Organizacional, Treinamentos e Coaching. Publicou artigos científicos na área de administração mercadológica, consumo e gestão de projetos. Trabalhou em projetos de apoio a gestão governamental e cooperação técnica internacional como planejamentos estratégicos, planos de capacitação, elaboração de manuais técnicos, mapeamento de processos, diagnóstico organizacional, entre outros.

\section{DARCIANE ALVES JUSTINO}

Graduada em Engenharia de Produção e Pós Graduada em Engenharia de Segurança do Trabalho. Gerente de contas e responsável pelo setor comercial e operacional na empresa Frete Rápido Desenvolvimento de Tecnologia Logística S/A. 


\section{DÉBORAH DANIEL FERREIRA COELHO SOARES}

Engenheira de Produção, formada pela Universidade Candido Mendes.

\section{DENISE TEREZINHA LISBOA BASSANI}

Possui Mestrado Profissionalizante em Sistemas de Gestão Universidade Federal Fluminense (2006). Atualmente é professora convidada da UFF em Gestão de Projetos, disciplinas de Gestão do Conhecimento e Estratégias de Operações para em Gerenciamento de Projetos. Tem experiência na área de Sistemas de Gestão da Qualidade, com ênfase em Gestão do Conhecimento e Garantia de Controle de Qualidade atuando no segmento do Petróleo e Petroquímico desde 2001.

\section{ÉDIS MAFRA LAPOLLI}

Doutora e mestre em Engenharia de Produção pela Universidade Federal de Santa Catarina (UFSC) com pós-doutorado em Sistemas de Informação pela Université de Montpellier IIFrance. Engenheira civil. Pesquisadora, Professora e Coordenadora da área de Gestão do Conhecimento do Programa de Pós-Graduação em Engenharia e Gestão do Conhecimento da UFSC. Líder do Grupo de Pesquisa Inovação em Ciência e Tecnologia - CoMovl (UFSC/CNPq). Consultora Organizacional nas áreas de Gestão de Pessoas, Desenvolvimento do Potencial Humano e Empreendedorismo. Coordenadora de projetos da Editora Pandion. Foi diretora da Escola de Novos Empreendedores (ENE) da UFSC. Orientou dezenas de mestres e doutores. É autora de livros, capítulos de livros, artigos em periódicos especializados e em anais de eventos nacionais e internacionais.

\section{GENIVAL JARDEL TRAJANO TEIXEIRA}

Graduado em Comércio Exterior pelo Instituto Federal de Educação, Ciência e Tecnologia do Rio Grande do Norte/IFRN (2017). Concluiu o Curso de Formação em Programação Básica pelo Instituto Metrópole Digital/UFRN (2014). Participou como pesquisador no Núcleo de Estudos de Tecnologia e Gestão na Indústria e Serviços (TGIS), no Instituto Federal de Ciência e Tecnologia do Rio Grande do Norte (IFRN), onde executou pesquisas sobre os determinantes do grau de dependência de fertilizantes para a balança comercial brasileira.

\section{IGOR POLEZI MUNHOZ}

Professor de Ensino Básico, Técnico e Tecnológico do Instituto Federal de Educação, Ciência e Tecnologia de São Paulo (IFSP) - Câmpus São Paulo Pirituba. Mestre em Engenharia Elétrica pela Universidade Federal do ABC (UFABC - 2014); Engenheiro de Produção pela UFABC - CREA-SP no 5069530784 (2014) e Bacharel em Ciência e Tecnologia pela UFABC (2012). Possui trabalho premiado na área de Dispositivos de Assistência Ventricular e Coração Artificial e outros dois prêmios acadêmicos durante a graduação. Atuou como monitor acadêmico por três períodos na disciplina Inovação Tecnológica e por dois anos como bolsista de iniciação científica, ambos na UFABC. Membro dos grupos de pesquisa: Engenharia de Inovação, Materiais e Sustentabilidade - Universidade Presbiteriana Mackenzie Campinas, sob coordenação da Profa. Dra. Alessandra Cristina Santos Akkari; Cultura, Valores, Desempenho e Governança nas Organizações - PUC-SP, sob a coordenação da Profa. Dra. Neusa M. B. F. dos Santos. Tem experiência na organização de eventos nacionais e internacionais e é filiado à ABEPRO (Associação Brasileira de Engenharia de Produção). 


\section{INARA ANTUNES VIEIRA WILLERDING}

Doutora e Mestre em Gestão do Conhecimento pela Universidade Federal de Santa Catarina - UFSC. Graduada em Administração. Professora, pesquisadora e líder do Grupo de Pesquisa de Inovação em Ciência e Tecnologia - UFSC/CNPq, organizadora de livros, autora de capítulos de livros e de artigos científicos especializados. Consultora empresarial com foco no desenvolvimento de pessoas voltado ao Empreendedorismo, Criatividade e Inovação, bem como na performance das organizações e do Potencial Humano com foco em resultados.

\section{INGRID JOHNSON}

Mestrado em Economia e Gestão Empresarial (2015) e Bacharel em Ciências Econômicas (1987), ambos pela Universidade Cândido Mendes (UCAM), Rio de Janeiro, Brasil. Experiência profissional em Planejamento Estratégico e Gestão; Planejamento de RH, Desenvolvimento de Pessoas e Mudança Organizacional; Gerenciamento de Processos e Projetos; e Planejamento Financeiro e Finanças. Tendo trabalhado principalmente nas empresas UTC Overseas Brasil Ltda., Infoglobo Comunicações S.A. e Allied Domecq Ltda..

\section{IURI PINHEIRO SANTOS}

Marketista. Bacharel em Marketing pela Universidade Estácio de Sá desde 2014 com CR 8,44. Profissional com atuação na área Administrativa no setor público nas Prefeituras Municipais de Saquarema e São Pedro da Aldeia; no setor privado, na área de Marketing como estagiário no Sebrae-RJ, na Fundação Mudes e na Injoy Blend. Atua em causas sociais para uma sociedade mais igualitária para todos, através de doação de sangue voluntária ao Hemorio e auxílio às causas do Grupo Francisco de Assis.

\section{JÉSSICA GALDINO DE FREITAS}

Doutoranda em Engenharia de Produção pela Universidade Federal Fluminense com graduação em Administração pela Universidade Federal Rural do Rio de Janeiro, MBA em Gestão pela Qualidade Total na Universidade Federal Fluminense e Mestrado em Engenharia de Produção pela Universidade Federal Fluminense. Especialista Green Belt em Lean Seis Sigma formada pela Werkema Consultores, com mais de 5 anos de experiência na área de Administração, com ênfase em Gestão, Engenharia de Produção, Qualidade, Gestão por processos, Estratégia e Gestão da produção. Possui experiência de trabalho com gestão de processos em empresas de grande porte como CSN, BRMalls e Lojas Americanas S.A.

\section{JESUS DOMECH MORE}

Possui graduação em Thermoenergetic Engineering - Moscow Power Engineering Institute (1987), mestrado em Ciências - Moscow Power Engineering Institute (1987) e doutorado em Programa em Engenharia Metalúrgica e de Materiais pela Universidade Federal de Rio de Janeiro (2004). Atualmente é professor Titular III do IBMEC (Instituto Brasileiro de Mercado de Capitais), professor Titular I na UNESA (Universidade Estácio de Sá), Pesquisador Visitante na Pontifícia Universidade Católica do Rio de Janeiro e pesquisador do Laboratório de Lógica Fuzzy na UFRJ. Tem experiência na área de Engenharia de Produção, com ênfase em Aplicação de Técnicas Inteligentes, atuando principalmente nos seguintes temas: conjuntos fuzzy, melhoria de processos, confiabilidade humana, aspectos cognitivos, erros humanos e em mineração de dados educacionais. Humanista. 


\section{JOÃO CALDEIRA LÉLIS}

Pós-graduado em Gestão Organizacional, em Engenharia de Produção e bacharel em Administração. Mais de 33 anos de experiência atuando em empresas de grande porte nos segmentos de mineração, fundição e siderurgia. Atuou como professor universitário na área de administração de recursos materiais e patrimoniais. Atualmente atua como Especialista de Planejamento e Controle em Projetos de CAPEX. Autor dos livros "Planejamento com Arte e Técnica", "Gestão de Projetos" e "Gestão de Materiais - Estoque não é o meu negócio", editados pela editora Brasport.

\section{JOÃO LUIZ RISSARDI}

Mestrado em Engenharia Civil pela Universidade Tecnológica Federal do Paraná com período sanduíche na Akdeniz University (Turquia), na linha de Materiais, Estruturas e Geotecnia. Especialização em Engenharia de Segurança do Trabalho e MBA em Gestão de Projetos pelo Centro Universitário Leonardo da Vinci. Graduação em Engenharia Civil pela Universidade Tecnológica Federal do Paraná com período sanduíche na University of Missouri-Kansas City (EUA).

\section{JOICELI ROSSONI LAPOLLI}

Pós-graduada MBA Executivo em Gestão Comercial - IPOG (2015). Graduada em Administração com ênfase em Marketing - Faculdades ASSESC - Florianópolis - Conclusão (2008). Trabalhou Clínica Médica IGM atuou como Gestora de Relacionamento. É aluna de disciplina isolada no Programa de Pós-Graduação em Engenharia e Gestão do Conhecimento da Universidade Federal de Santa Catarina (PPGEGC/UFSC). Membro do grupo de Pesquisa Inovação em Ciência e Tecnologia - CoMovl (UFSC/CNPq) Autora de capítulos de livros e artigos científicos.

\section{JORGE JULIO LANDEIRO DE VAZ}

Auditor de Defesa Nacional - Curso de Defesa Nacional 2010/2011. Instituto de Defesa Nacional.

1997 - Doutor Europeu - Grau atribuído pela Universidade de Sevilha, com parecer favorável do Prof. Doutor Rogério Fernandes Ferreira(ISEG/UTL) e do Prof. Doutor Mauricio Baravelli ( Director do Instituto di Economia degli Intermediari Financiari - Univ. de Messina e Prof. da Univ. Luigi Boconni de Milão). 1997 - Doutor em Ciências Económicas e Empresariais - Univ. de Sevilha, com equivalência ao grau de Doutor em Gestão e Organização de Empresas ISEG/UTL. 1995/93 - Programa de Doutoramento em Gestão e Organização de Empresas e Marketing da Faculdade de Ciências Económicas e Empresariais da Univ. de Sevilha. 1990 Pós - Graduação em Marketing Management. Universidade de Harvard - Boston, USA. 1988 - Mestre em Gestão e Organização de Empresas.- ISEG.- Univ. Técnica de Lisboa. Humanista.

\section{JOSE CARLOS BEKER}

Graduação em Administração / IM Bennett (1980), - Pós Latu / UFF / Estratégia, Pós Latu / FAP / CIÊNCIA POLITICA, Pós Latu / UFRJ/COPPE / ERP SAP, Pós Strictu/ UFF/ LATEC (2008) / Sistemas de Gestão. Experiencia Atual, Professor-Tutor / Professor Unesa / Administrador IFRJ. EXPERIENCIA como Tutor EaD, IFRJ / UNESA. Experiência anterior: Administrador na Prefeitura da Cidade RJ, Furnas Centrais Elétricas e outras grandes empresas brasileiras, e no exterior. Atividades nas áreas: Gestão Empresarial, Estratégica, Qualidade, Gestão de Processos de Negócios, Organização \& Métodos, Análise de Sistemas de Informação, TI / ERP - SAP, Módulo Distribuição e Logística, Orçamento, Auditoria, Gestão Pública, LAI, Dados Abertos. 


\section{KARINA MARIA COSTA BARDI}

Possui bacharelado em Engenharia de Produção e Qualidade pelo Centro Universitário da Fundação Educacional Guaxupé - UNIFEG. Há doze anos trabalha na área de confecções de moda íntima. Tem experiência com estudo de viabilidades de implantação de ferramentas de melhorias contínuas e gerenciamento de resíduos sólidos.

\section{LEANDRO COLOMBI RESENDO}

Possui graduação em Matemática pela Universidade Federal do Espírito Santo (2002), mestrado em Informática pela Universidade Federal do Espírito Santo (2004) e doutorado em engenharia elétrica pela Universidade Federal do Espirito Santo (2008). Tem experiência na área de Educação Matemática. Trabalhos publicados relacionados aos problemas de alocação linear e problema quadrático de alocação. A atual área de pesquisa está relacionada à redes ópticas WDM, problema de traffic grooming e programação linear inteira.

\section{LEANDRO MACIEL NASCIMENTO}

Mestrando no Programa de Pós-Graduação Engenharia e Gestão do Conhecimento. Bacharel em Design (UNIVALI-2011), com especialidade no MBA em Gestão Estratégica do Design (UNIVALI-2015). É designer e sócio proprietário da Lema Design de Negócios. Pesquisador em gestão do conhecimento, inovação e design no grupo COMOVI, Grupo de Pesquisa Inovação em Ciência e Tecnologia - UFSC/CNPq

\section{LEONARDO MANGIIA RODRIGUES}

Professor do curso de Engenharia de Produção da Universidade Cândido Mendes e da Escola Superior de Gestão e Tecnologia da Universidade Castelo Branco. Pesquisador do Laboratório de Sistemas Avançados de Gestão da Produção (SAGE) da COPPE/UFRJ e do Laboratório de Mobilidade e Logística Sustentável (MOBILOG) da POLI/DEI/UFRJ. Atuação em Produção Sustentável com foco em Avaliação Social do Ciclo de Vida e Logística Urbana. Doutorando em Engenharia de Produção, COPPE-UFRJ; Mestre em Engenharia de Produção pela COPPE-UFRJ, Engenheiro de Produção pelo CEFET-RJ;

\section{LOURENÇO COSTA}

Possui Graduação em Engenharia Mecânica pela Universidade Federal do Espírito Santo, Especialização e Mestrado em Engenharia de Produção pela Universidade Tecnológica Federal do Paraná e Doutorado em Engenharia de Produção pela Universidade Federal do Rio de Janeiro. É professor titular do Instituto Federal do Espírito Santo, com experiência de atuação nas áreas de Expressão Gráfica, Gestão de Processos de Negócio e Sustentabilidade Corporativa. É autor de diversos livros.

\section{LÚCIA DE FÁTIMA LÚCIO GOMES DA COSTA}

Professor of Administration at IFRN. Technology degree in Foreign Trade at Instituto Federal de Educação Ciência e Tecnologia - IFRN (2006). Bachelor in Administration from Universidade Federal do Rio Grande do Norte - UFRN (2011). Master in Administration from Universidade Federal do Rio Grande do Norte (2009). Doctor of Administration from the Universidade Federal do Rio Grande do Norte - UFRN (2014), works mainly in the following areas: International Business, Strategic Alliances, Foreign Trade and Business Strategy.

\section{MANUEL DUARTE PINHEIRO}

Doutorado em Engenharia do Ambiente pelo Instituto Superior Técnico da Universidade de Lisboa (2008). Especializações em Avaliações Ambientais (Estudos de Impactes Ambiental e Estudos de Avaliação Ambiental Estratégica), Análise Ciclo de Vida e Ecodesign, Sistemas de 
Gestão Ambiental, Sustentabilidade na Construção, Imobiliário e Turismo. Licenciatura em Engenharia do Ambiente pela Faculdade de Ciências e Tecnologia da Universidade Nova de Lisboa (1985). Docente no Instituto Superior Técnico desde 1999. Responsável pelo sistema LiderA de orientação e certificação da sustentabilidade na construção e Consultor na área de Impactes Ambientais, Sistemas de Gestão Ambiental, Construção Sustentável.

\section{MARCELA DUTRA TENORIO CAMPANY}

Graduada em Farmácia pela Unipli. MBA em gestão pela Qualidade Total pelo Latec/UFF. Mestranda em Metrologia e Qualidade pelo Inmetro

\section{MARIA CHRISTINA BARBOSA DA COSTA}

Doutora em Administração (UNR- Argentina), com especializações em Design for Sustainability (Gaia Education), Internet Technology (COPPE/UFRJ), Gerência de Sistemas (PUC-RJ) e Computação Gráfica (PUC-RJ) e Arquitetura (UFRJ). Com certificações como PMP - Project Management Professional (PMI - Project Management Institute) e em GRI Global Reporting Initiative. Professora da FGV nos MBAs de Gerenciamento de Projetos, Gestão Empresarial, de Pessoas, de Empreendedorismo e Inovação e conteudista da FGV On-line. Autora do Método "Modelo GES de Gestão Estratégica de Sustentabilidade". Coautora dos livros "PMO - Escritórios de Projetos, Programas e Portfólio na Prática" da Brasport e "Gerenciamento de Custos em Projetos" da FGV. Diretora Executiva da By Conn Consultoria e Treinamento em Gerenciamento de Sustentabilidade, Projetos, Programas e Portfólios, certificada como Empresa B, com projetos em empresas de pequeno, médio e grande porte. Em 15 anos como voluntária do PMI, foi membro dos boards globais do GAC Global Accreditation Center e do LIAG - Leadership Institute Advisory Group, além de VicePresidente de Comunicação e de Programas no Chapter Rio de Janeiro. Atualmente é membro da Comissão Brasileira para o Relato Integrado e do Lab60+.

\section{MÔNICA ALIMEIDA GAVILAN}

Graduada em Administração de Empresas pela Universidade de Brasília - UnB. Especialista em Gestão de Pessoas pela Universidade Castelo Branco e Mestra em Turismo pela Universidade Federal do Rio Grande do Norte.Professora da Universidade Potiguar-UNP e Professora formadora do curso de Especialização em Gestão Pública - IFRN.

\section{NELSON JOSÉ ROSAMILHA}

Possui mais de 25 anos de experiência internacional em projetos de tecnologia de informação, escritório de projetos e processos, ciclo de desenvolvimento, Serviços Gerenciados e Projetos de Transformação em diversos segmentos, atuando em cargos de direção e vice-presidência em empresas como IBM, Amdocs, Politec, INDRA, Ericsson e Netcracker ,nos últimos 3 anos tem atuado em projetos de transformação digital e de infraestrutura com foco nos pilares de Sucesso do Cliente, Ciclo de Vendas e aumento de receitas recorrentes. Sua experiencia em projetos de transformação de processos com foco em excelência operacional, redução de despesas (, melhoria da qualidade do serviço e redução nos prazos de entrega dos serviços foram realizados em empresas como Telefonica, Politec, Indra. Liderou a estruturação toda a área de delivery em linhas de negócio utilizandose de conceitos de ciclo de vendas, ciclo de vida de produto, customer success e práticas ágeis. É mestre em Administração de Empresas pela PUC-SP, MBA em Gestão de Projetos pela La Verne University e Amdocs Business School e MBA em Telecomunicações pela FAAP - Pen State University. Autor dos livros Prince 2 Foundation e Governança Corporativa e professor de pós-gradução em gerenciamento de projetos no Senac, Unibta e Saint Paul Escola de Negócios 


\section{NEUSA MARIA BASTOS FERNANDES DOS SANTOS}

Professora Titular da Pontifícia Universidade Católica de São Paulo. Faculty Research Program Fellow - McGill University, Canadá (1996) / Pós-Doutorado, Doutorado em Controladoria e Contabilidade pela USP (1992), Mestrado em Administração pela USP (1984) e Graduação em Administração de Empresas pela USP (1974). Em 1990 foi Fulbright Scholar (CIES/USA) na Business School of the University of Michigan, Ann Arbor (UMI). Entre $2003 \mathrm{e}$ 2009 foi bolsista do Governo Canadense pelo Programa International Council of Canadian Scholars (ICCS/Otawa). Professora Honoris Causa (Rede Paulista de Ensino Superior). Autora de livros, capítulos, trabalhos completos apresentados em congressos acadêmicos e artigos publicados em periódicos de âmbitos internacional e nacional. Coordenadora de Programa de Pós-Graduação Stricto-Sensu em Ciências Contábeis e Financeiras e Coordenadora de Programa de Pós-Graduação Stricto-Sensu em Administração. Consultora adhoc para agências de fomento (FAPESP, CAPES) e para órgãos públicos educacionais, como Conselho Estadual da Educação de São Paulo (CEE-SP) e INEP. Presidente do Conselho Diretor da Associação Brasileira de Editores Científicos (ABEC). Presidente do Conselho Científico da Sociedade Brasileira de Gestão do Conhecimento (SBGC). Membro da Mesa Diretora Nacional da Associação Brasileira de Estudos Canadenses (ABECAN) e Coordenadora de Núcleo de Estudos Canadenses / NEC/PUCSP. Membro da Comissão de Avaliação da Área de Administração e Contabilidade / CAPES. Membro do Júri Prêmio Franklin Delano Roosevelt / USA.

\section{PAULO CÉSAR LAPOLLI}

Doutorando em Engenharia e Gestão do Conhecimento, mestre em Engenharia de Produção (2003) e bacharel em Ciências da Computação (1984) pela Universidade Federal de Santa Catarina. Pós-graduado em Processamento de Dados (1991) pela Fundação Universitária da Região de Joinville. Trabalhou como analista de sistemas sênior nas empresas do grupo Brasmotor (Consul e Embraco). Atuou como Consultor de Implantação de Sistemas ERP para a RM Sistemas de Belo Horizonte. Trabalhou como analista de Sistemas para o Banco do Estado de Santa Catarina em Florianópolis. Atualmente atua como professor do curso de Análise e Desenvolvimento de Sistemas da Faculdade Senac e Coordenador do curso de Bacharelado em Sistemas de Informação da FEAN - Faculdade Energia de Administração e Negócios. Membro do Grupo de Pesquisa Inovação em Ciência e Tecnologia - UFSC/CNPq. lapolli@gmail.com.

\section{PAULO ROBERTO ROCHA AGUIAR}

Engenheiro Mecânico e de Automóveis, Graduado pelo Instituto Militar de Engenharia (IME), Mestre em Engenharia Mecânica pela Pontifícia Universidade Católica do Rio de Janeiro (PUC-Rio), em 1997 e Doutor em Engenharia Mecânica pela Pontifícia Universidade Católica do Rio de Janeiro, em 2002. Os interesses de pesquisa incluem Dinâmica dos Corpos Rígidos, Elásticos, e Plásticos, Estruturas e Projetos Mecânicos, com experiência nos temas: transporte, veículos automotores, conforto veicular, ergonomia veicular, blindagem, simulação numérica, elementos finitos, modelagem tridimensional parametrizada e gerenciamento de projetos.

\section{RAPHAEL ALVES SOARES}

Experiência em mais de 4 anos em planejamento e gestão estratégica de projetos no setor de serviços e eventos com equipes multiculturais, com foco em compartilhamento e transferência de conhecimento empresarial. Jovem com 25 anos, formado em Engenharia de Produção pela Universidade Candido Mendes. Trabalhou no Comitê Rio 2016, Grupo Editorial Record e hoje trabalha no Comitê Olímpico do Brasil. 


\section{REGINA RIANELLI DE BRITO}

Doutoranda pela Universidade Lusíada de Lisboa, Portugal. Mestre em Desenvolvimento Empresarial e Novos Negócios com habilitação em Medicamentos Genéricos; UNESA(CAPES 4). Graduação em Comunicação Social pela UFRJ. Professora Universitária na Universidade Estácio de Sá há 18 anos. Referee/ Parecerista para diversos periódicos. Voluntária em Homeopatia Social em Comunidades Carentes beneficiárias pela Oficina de Cáritas e Grupo Condessa Paula com Moradores de Rua, onde doa, graciosamente, as formulas homeopáticas para os beneficiários há dez anos, elementos estruturais dessa rede que visa à promoção de uma sociedade mais saudável, fraterna e igualitária para todos.

\section{RICHARDSON SILVEIRA ALMEIDA}

Possui graduação em Análise de Sistemas pela Universidade do Estado da Bahia, UNEB (2008), mestrado Profissional em Gestão de Políticas Públicas e Segurança Social pela Universidade Federal do Recôncavo da Bahia, UFRB (2018). Ingressou na Universidade Federal do Recôncavo da Bahia como Analista de Tecnologia da Informação em 2012 para atuar no desenvolvimento e manutenção de sistemas de informação. Tem experiência na área de engenharia de requisitos, análise e projeto orientado a objeto, padrões de projetos e desenvolvimento de sistemas na plataforma Java. Na pesquisa interessa-se, principalmente, pelos seguintes temas: governança e gestão de tecnologia da Informação.

\section{RICHELIEL ALBERT RODRIGUES SILVA}

Técnico em Agropecuária, Técnico em Comércio Exterior, Engenheiro Florestal e Mestre em Ciências Florestais (2007-2017) pela Universidade Federal do Rio Grande do Norte (UFRN), Doutorando em Ciências Florestais pela Universidade Estadual do Centro-Oeste (UNICENTRO). Desenvolve pesquisas de biologia reprodutiva, genética de populações e manejo de espécies florestais.

\section{RODRIGO MACKSSUEL SILVA DE MELO}

Bacharel em Administração Pública pela UFRN e Tecnólogo em Comércio Exterior pelo IFRN

\section{ROQUEMAR DE LIMA BALDAM}

Doutorado em Engenharia de Produção. Tem experiência prática na implantação em organizações Privadas e Públicas, nas áreas de Pesquisa, Processos, Projetos, Gerenciamento Eletrônico de Informação, Gestão do Conhecimento, Ferramentas para racionalização do trabalho. Certificado PMP (Project Management Professional), CBPP (Certified Business Process Professional) e CDIA+ (Certified Document Imaging Architect+). Gestor Regional da ABPMP Brasil.

\section{SONIA LOPES DA SILVA}

Doutora em Administração (UNR-Argentina), Mestre em Preservação do Patrimônio Histórico (UFRJ), Especialista em Gerenciamento de Projetos (FGV) e Arquitetura (UFRJ). Certificada como PMP - Project Management Professional (PMI) e como CSM - Certified ScrumMaster (Scrum Alliance). Professora nos MBAs de Gerenciamento de Projetos, Gestão de Empresas e Gestão de Escritórios de Arquitetura na FGV, MBAs de Gerenciamento de Projetos no LabCeo UFF, e conteudista nos cursos da FGV On-line. Autora dos Métodos: Método "Modelo GES de Gestão Estratégica de Sustentabilidade", "Modelo TIP de Gerenciamento de Projetos" e "Modelo TIP de Negociação", com técnicas Agile e Design Thinking. Coautora do livro "Negociação" (FGV - Série Cademp). Autora do livro "Métodos Ágeis para arquitetos e profissionais criativos" (Brasport). Diretora Executiva da By Conn - Consultoria e Treinamento em Gerenciamento de Sustentabilidade, Mudanças, Projetos, Programas e Portfólios, certificada como Empresa B, com projetos em empresas de pequeno, médio e grande porte. 


\section{TATIANE DE OLIVEIRA AMANCIO}

Estudante atualmente no oitavo semestre de Engenharia Civil na Pontifícia Universidade Católica de São Paulo. Atuou durante um ano como bolsista de iniciação científica no desenvolvimento do projeto "Telhado Verde: Um Estudo de Implantação na Faculdade de Ciências Exatas e Tecnologia da PUC-SP" e ministrou 2 monitorias (desenho técnico e mecânica dos fluídos). Recebeu o prêmio de Melhor Trabalho de Iniciação Científica Engenharia Civil na PUC-SP em Novembro de 2017. Estagiária na SiiLA Brasil desde Outubro de 2017.

\section{THALMO DE PAIVA COELHO JUNIOR}

Professor Titular do Instituto Federal de Educação, Ciência e Tecnologia do Espírito Santo (IFES) e docente permanente no Programa de Pós-Graduação em Gestão Pública da Universidade Federal do Espírito Santo (UFES), é Doutor em Engenharia de Produção pela COPPE/UFRJ2003 (Coordenação dos Programas de Pós-Graduação em Engenharia da Universidade Federal do Rio de Janeiro), Mestre em Engenharia Metalúrgica e de Materiais pela COPPE/ UFRJ 1997 e Especialista em Educação Tecnológica pela UFES'1997 (Universidade Federal do Espírito Santo), bem como Especialista em Didática e Pedagogia pela UFES'1993. Graduou-se em Engenharia Metalúrgica pela UFF 1988 (Universidade Federal Fluminense).

\section{VANESSA DO ROCIO NAHHAS SCANDELARI}

Possui doutorado em Administração pela Universidade Federal do Paraná, na linha de Administração de Tecnologia, Qualidade e Competitividade (2011), mestrado em Tecnologia pela Universidade Tecnológica Federal do Paraná (1998) e graduação em Engenharia Civil pela Universidade Federal do Paraná (1992). Atualmente é professora efetiva da Universidade Tecnológica Federal do Paraná. Tem experiência na área de Engenharia de Produção com ênfase em Garantia de Controle de Qualidade e Gestão de Projetos. Possui interesse nas linhas de pesquisa: Gestão da Qualidade, Gestão de Projetos, Gestão de Tecnologia e Inovação, Inovação e Sustentabilidade.

\section{WARLI ANJOS DE SOUZA}

Possui graduação em Engenharia Agronômica pela Universidade Federal de Lavras, UFLA (1981), mestrado em Administração pela Universidade Federal de Lavras, UFLA (1994) e doutorado em Economia Aplicada pela Universidade de São Paulo, USP (1999). Ingressou na Universidade Federal da Bahia, UFBA, na Escola de Agronomia, como professor de Economia em 1997, onde atuou em ensino, pesquisa e extensão até junho de 2005. Atualmente é professor da Universidade Federal do Recôncavo da Bahia, UFRB. Tem experiência em gestão pública, onde atuou como chefe de Departamento de Ciências Sociais Aplicadas à Agricultura da Escola de Agronomia da UFBA, entre 1999 e 2002; foi também coordenador do curso de graduação em Agronomia da UFBA no período de 2002 a 2004 , pró-reitor de graduação da UFRB no período de 2006 a 2007 e pró-reitor de planejamento da UFRB no período de 2007 a 2011. Atuou como membro do Conselho Universitário, do Conselho Acadêmico e do Conselho de Curadores da UFRB no período de 2006 a 2011. Atuou como vice-coordenador do Programa Gestão de Políticas Públicas e Segurança Social (Mestrado Profissional ) da UFRB no ano de 2012 e atualmente é coordenador Programa Gestão de Políticas Públicas e Segurança Social (Mestrado Profissional ) da UFRB. Tem experiência e atuação profissional na área de economia e gestão de finanças públicas, atuando principalmente nos seguintes temas: agronegócio, comercialização, derivativos, mercados futuros, bolsa de futuros, estratégias de hedging, avaliação e gerenciamento de projetos e gestão financeira e orçamentária de organizações públicas. 


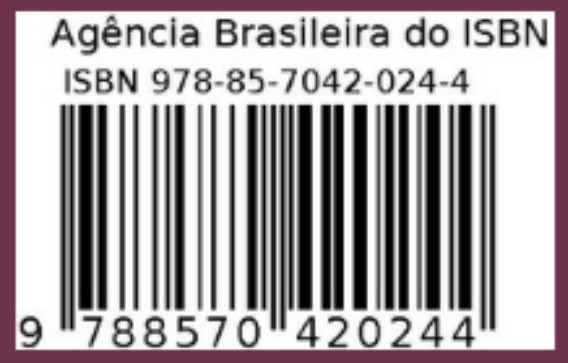

